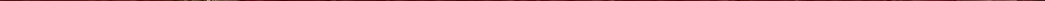




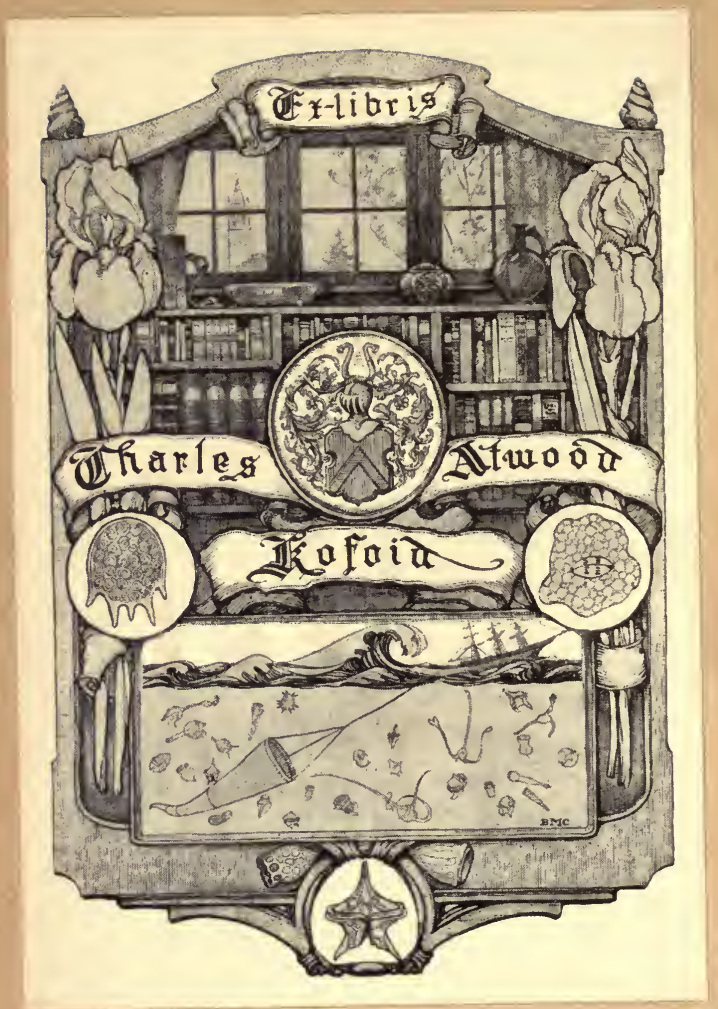




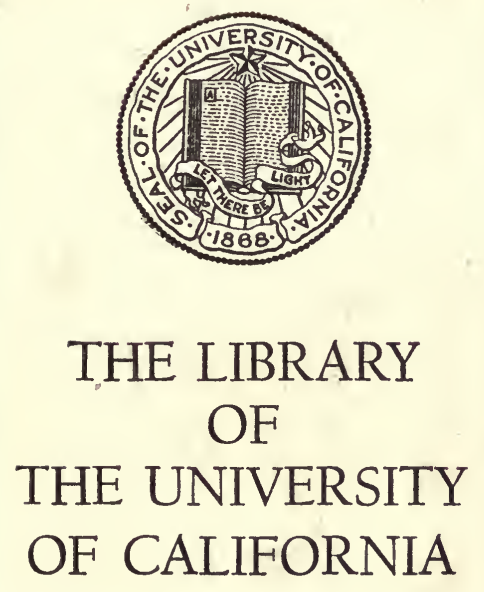

PRESENTED BY

PROF. CHARLES A. KOFOID AND MRS. PRUDENCE W. KOFOID 

FANCY PIGEONS. 

y.

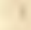

,

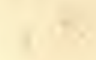

?

"

,

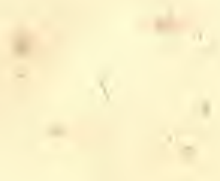

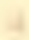

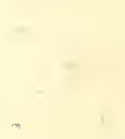




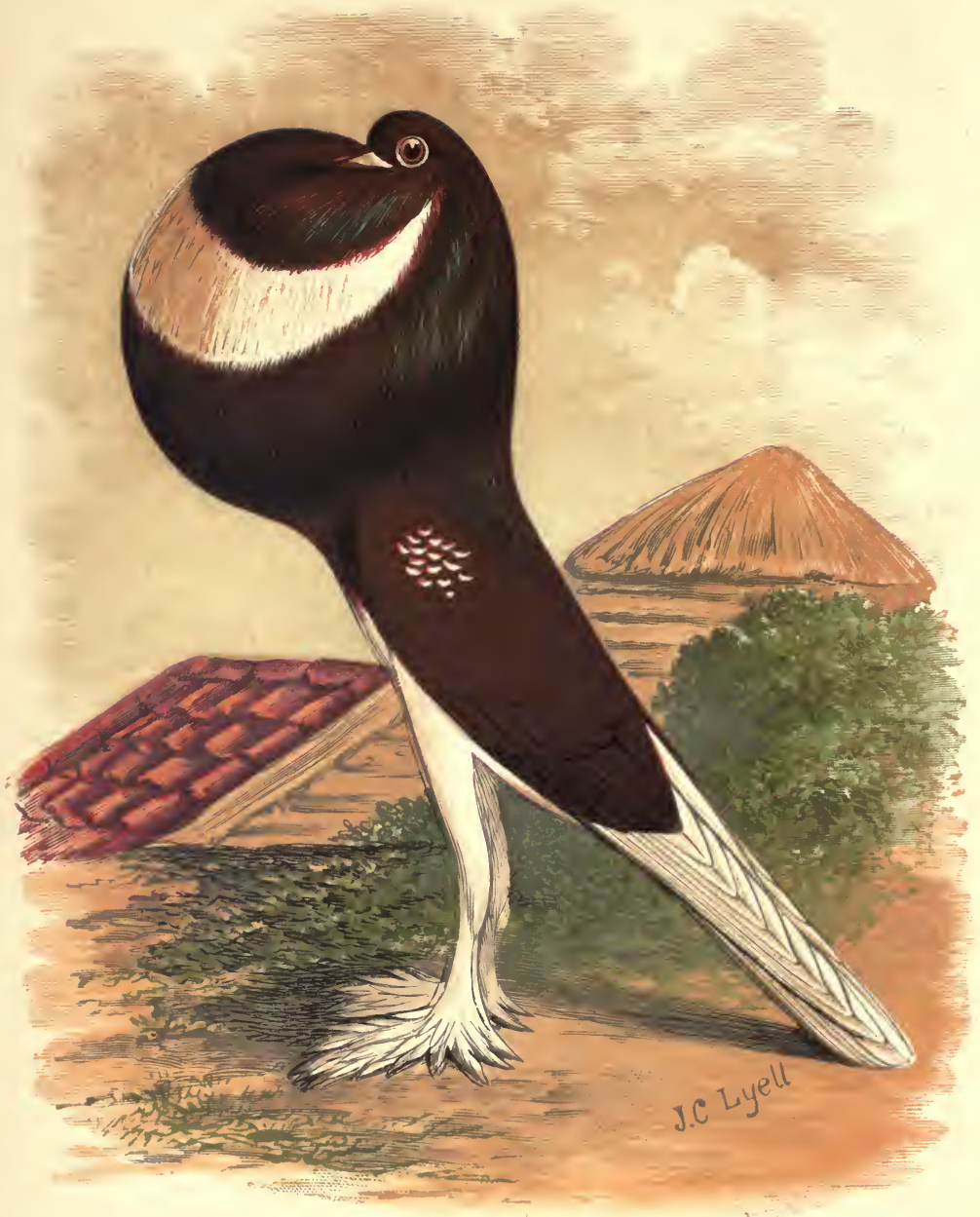

THE POU T E R. 


\section{FANCY PIGEONS:}

CONTAINING

FULL DIRECTIONS FOR THEIR BREEDING

AND MANAGEMENT,

WITH

DESCRIPTIONS OF EVERY KNOWN VARIETY,

AND

ALL OTHER INFORMATION OF INTEREST OR USE TO PIGEON FANCIERS.

Illustrated with Coloured Plates and Woodcuts.

BY JAMES C. LYELL。

THIRD EDITION.

LONDON :

L. UPCOTT GILL, 170 , STRAND, W.C. 
PRINTED BY A. BRADLEY, 170, STRAND, LONDON. 


\section{$L 9$ \\ 1887}

\section{PREFACE TO THE THIRD EDITION.}

$T^{\mathrm{HE}}$ previous editions of this book having met with a favourable reception, and being out of print, I have been induced to revise it. A considerable amount of new information has been added, as well as Coloured Illustrations of the principal varieties. The work being the result of the experience of a fancier who has studied domestic pigeons from his earliest years, the fancier as well as the naturalist, will find that it contains an exhaustive account of them. 



\section{CONTENTS.}

CHAP. PAGE

I.-Historical . . . . . . . . . . . . . . . . 1

II.-Origin of Fanct Pighons . . . . . . . . . . 8

III.-The Pigeon House, Loft, and Avraky . . . . 14

IV.-Selection of Stock . . . . . . . . . . . . . 26

V.-Feeding, Breeding, and Management . . . . 30

VI.-Colours of Fanct Pigeons . . . . . . . . . : 44

VII.-Exhibiting Prgeons . . . . . . . . . . . . . 50

VIII.-Diseases . . . . . . . . . . . . . . . . . 55

IX.-Varieties of Domestic Prgeons . . . . . . . 67

X.-Common Pigeons . . . . . . . . . . . . 70

XI.-Pigeons Distinguished Chiefit by their Colour or Marking . . . . . . . . . . . . 73

XII.-Pigeons of Peculiar Feathering . . . . . . . 103

XiII.-The Ringbeater . . . . . . . . . . . . . 111

XIV.-The Triganica . . . . . . . . . . . . . 115

XV.-Several Varieties of East Indian Prgeons - . 120

XVI.-Other Distinct Kinds of Asian Pigeons . . . 131

XVII.-The RUNT . . . . . . . . . . . . . . 133 
viii CONTENTS.

CHAP.

PAGE

XViII.-Pigeons of Peculiar Voice . . . . . . . . 144 XIX.-Pigeons with Short, Erect Talls. . . . . . . 157 XX.-The Fantail . . . . . . . . . . . . . 164 XXI.-ThE JАCOBIN . . . . . . . . . . . . . 175 XXII.-Short-Faced Frilled Pigeons . . . . . . . . 190 XXIII.-Pouting or Cropper Pigeons . . . . . . 223 XXIV.-Wattled Pigens _. . . . . . . . . . 276 XXV.-The TUMbler . . . . . . . . . . . . . . . 311

XXVI.-VARIeties originally TUMblers . . . . . . . . 330 XXVII.-The Short-Faced Tumbler . . . . . . . . . 335 XXVIII.-Homing Pigens . . . . . . . . . . . . . . 355 XXIX.-Turkestan Pigeons . . . . . . . . . . . 374 Appendix-Pigmon Literature . . . . . . . 381 Conchusion . . . . . . . . . . . . . 412

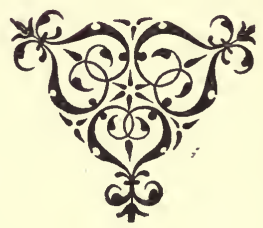




\section{\& FANCY . PIGEONS. \&}

\section{Chapter' I.}

$\propto$ HISTORICAL. $\varnothing$

Egyptian Records.

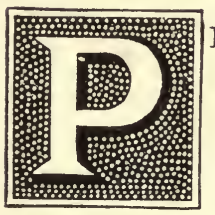

IGEONS must have been domesticated at a very early period. They figure on Egyptian monuments forty-six centuries old. Mr. H. Villiers Stuart, M.P., informs me he has seen pigeons represented on Egyptian bas-reliefs of the Fourth Dynasty, at least 2700 B.c., though some Egyptologists put it further back. He says they occur frequently in tombs of that and the following dynasties, being represented as borne in cages on the heads of slaves, or carried in their hands by the wings. $\mathrm{He}$ has also seen, on bas-reliefs of the Nineteenth Dynasty (about 1350 B.c.), pigeons being liberated in triumphal processions and flying away, possibly to convey intelligence of the event to the limits of the empire.

I find, in "Records of the Past" (1873), in the Annals of Thothmes III., of the Eighteenth Dynasty (about 1500 B.c.), 
mention made of " 258 pairs of pigeons and 5237 pigeons of another kind." It may be inferred that the former were of some special or choice description.

The Annals of 'Rameses III., of the Twentieth Dynasty (about 1200 B.c.). contained in the "Great Harris Papyrus," now in the British Museum, detail his donations to the temples of Thebes, Heliopolis, Memphis, and elsewhere. Plate 8, line 10, says: "Its barns had fatted geese, its poultry yards had fowls of heaven." The domestic fowl was then unknown in Europe and Africa. The pigeon was called by the Egyptians the bird or nestling of heaven. Again, on Plate 27, line 6: "I made to thee stables containing young oxen, apartments to bring up fowls (pigeons, or birds of heaven), with geese and ducks."

\section{Reference by Grecian Authors.}

Homer (about 950 B.c.) refers sometimes to "silver" doves, as in the line-

Messé's towers for silver doves renowned,

which may refer to albino or white pigeons, as found in almost every colony of semi-wild ones.

The carrier pigeon may have reached Greece from Egypt. Anacreon (563-478 B.c.), in his ode to it, so beautifully rendered by Thomas Moore, shows its early use there.

Socrates $(469-400$ B.C.) seems to refer to pigeons in his dialogue with Plato's brother Glaucon (Plato's "Republic," Book V., chap. viii.), when he says:

" 'Tell me this, Glaucon-for in your house I see both sporting dogs and a great number of well-bred birds-have you, by Zeus, ever attended to their pairing and bringing forth young?'

"Glaucon.- ' How?"

"Socrates.- First of all, among these, though all be wellbred, are not some of them far better than all the rest?"

"Glaucon.- - They are." 
"Socrates.- 'Do you breed, then, from all alike, $\omega$ are you careful to do so, as far as possible, from the best?'

"Glaucon.- "From the best." "

This passage, so pregnant with truth to the experienced breeder of all domestic animals, is the earliest record of what may be called scientific breeding, and shows the observation of one of the wisest of mankind. It refers, without any doubt, I think, to fancy pigeons; for what other birds, varying so much in excellence, would be kept indoors, in pairs, at that time?

Xenophon (455-355 B.c.) says, in the "Anabasis" (Book I., chap. vi.): "After these occurrences, Cyrus proceeded four days' march, a distance of twenty parasangs, to the river Chalus, which is a plethrum in breadth and full of tame fish, which the Syrians looked upon as gods, and allowed no one to hurt either them or the pigeons."

Aristotle (384-322 B.c.), in the many references he makes to pigeons in his "History of Animals," appears to have had a practical knowledge of them. He writes of them in a way that shows he had either carefully observed their habits, or got his information from an experienced fancier.

On account of its gentle nature, the pigeon has been protected in all ages. It is yet, as in Russia, and in most Mahomedan countries, considered a sacred bird. In this character, Tibullus (54-19 B.c.), the Roman poet, refers to it in his eighth Elegy: "Why need I tell how the sacred white pigeon flutters unmolested about the numerous cities of Syrian Palestine?" or, as an English poet renders it:

Why need I tell how sacred through the skies Of Syrian cities, the white pigeon flies?

which he doubtless learned from the works of Xenophor and others, who assert, as above, that the Syrians considered pigeons and doves sacred to their goddess Astarte, whom the Greeks identified with Aphrodite (Venus). 


\section{Reference by Latin Authors.}

The best evidence that the pigeon fancy existed in ancient times much as it does to-day, is found in the Natural History of Pliny (23-79 A.D.) (Book X., chap. lii.-liii.), where he says: "Many persons have quite a mania for pigeons, building houses for them on the tops of their roofs, and taking delight in relating the pedigree and noble origin of each. Of this there is an ancient instance that is very remarkable: L. Axius, a Roman of the Equestrian order, shortly before the civil war of Pompeius, sold a single pair for four hundred denarii (about $£ 13$ ), as we learn from the writings of M. Varro (114-26 B.c.). Countries, even, have gained renown for their pigeons; it is thought that those of Campania attain the largest size."

Columella, a contemporary of Pliny, also quotes from M. Varro as to the value of fancy pigeons, from which it appears that pairs were often sold at about $£ 8$, and occasionally for four times as much.

The use of domestic pigeons in time of war, to enable the inhabitants of besieged towns to communicate with their friends outside, was known at this period, as we learn from Pliny, who states that they were so employed at the siege of Modena (43 B.c.). Since then they have been often employed in like manner, as I shall mention hereafter.

Juvenal (3-83 A.D.), the Roman poet, refers to the keeping of pigeons in the garrets of Rome, just as they are kept to-day by fanciers in all large towns. Describing a fire in the city, he says:

For if the lowest floors already burn, Cocklofts and garrets soon will take their turn, Where thy tame pigeons next the tiles were bred, Which, in their nests unsafe, are timely fled.

From this period there is not much information available on the subject till about the year 1600 . Gibbon states that 
the Emperor Honorius (384-423 A.D.) amused himself with the rearing of "poultry;" and that Charlemagne (742-814) was careful to encourage this branch of rural economy, so ably carried out by the French to the present time. $\mathrm{He}$ says: "I touch with reverence the laws of Charlemagne, so highly applauded by a respectable judge. They compose not a system, but a series of occasional and minute edicts, for the correction of abuses, the reformation of manners, the economy of his farms, the care of his poultry, and even the sale of his eggs." Vataces John Ducas, Emperor of Constantinople, who reigned about the year 1250, presented a crown of diamonds and pearls to his empress, which, he informed her with a smile, had been purchased with the money derived from the sale of the eggs of his innumerable poultry. Perhaps something of more interest to the pigeon fancier than the above might be discovered from a perusal of the edicts - of Charlemagne. Gibbon relates that carrier pigeons were employed during the Crusades, at the sieges of Acre in Syria and Mansourah in Egypt.

\section{Early Pigeon Flying.}

The sport of pigeon flying is known to have been practised in Modena for a long time, as historical evidence carries it back to the year 1327 .

The Emperor Akbar (1542-1605) appears to have been a keen pigeon fancier. His prime minister, Abul Fazl, has made this apparent in the "Ain-i-Akbari" (Institutes of Akbar), where he devotes some pages to a description of the sport of pigeon flying as practised by his Majesty, and which is still in vogue in India, Persia, Turkey, and many parts of Europe.

The Nawab, M. Alaooddeen, of Loharoo, has written for me, at the request of my relative, Sir Charles U. Aitchison, Lieutenant-Governor of the Punjab, an essay comparing the sport, as presently carried on in Delhi, with Abul Fazl's account, 
from which it appears that it remains very much the same as it did in Akbar's time.

\section{In the Middle Ages.}

Ulyssis Aldrovandi, the naturalist, who began the publication. of his history in 1599, devotes considerable space to the pigeon, and gives figures of some varieties, but they are so bad as to be almost unrecognisable.

Francis Willoughby's “Ornithology," edited by John Ray, was published in London, in Latin, in 1676, and afterwards, in English, in 1678. He is the first English writer who gives a detailed list of fancy pigeons. $\mathrm{He}$ says he saw carriers in the aviary belonging to the King (Charles II.), in St. James's Park. He corresponded with Mr. Phillip Skippon (Cromwell's General?) on the subject of the barb, or Barbary pigeon, and derived information about croppers, carriers, and jacobins, from Mr. Cope, an embroiderer, living in Jewin Street. Skippon and Cope are the earliest English fanciers on record, so far as I have discovered.

\section{Recent History.}

John Moore, an apothecary in Abchurch-lane, London, published, in 1735, an octavo volume of $60 \mathrm{pp}$., entitled, "Columbarium; or, the Pigeon-House," which was the foundation of all English works on the subject published in the eighteenth century. Moore, who may be considered the father of the pigeon fancy in this country, was proprietor of a vermifuge, which is humorously referred to by Pope in some verses addressed to him. He is also referred to in the same character by Swift, in "A Letter from a Gentleman in the Country to his Friend in Town."

I have noticed some of the principal dealers in pigeons advertising that they have supplied birds to her Majesty Queen Victoria. Lady Bloomfield, in her recently-published book, "Reminiscences of Court and Diplomatic Life," speaks 
of visiting her Majesty's aviaries at Windsor, in the year 1843, where there was "a beautiful collection of pigeons of rare kinds."

The ancient pastime of pigeon breeding continues to flourish throughout Asia, North Africa, and Europe, as I know from experience, and from the works of many recent travellers. It is also spreading in America and in all English colonies. In this country choice pigeons have become greatly enhanced in value during the past twenty-five years, mostly on account of the numerous exhibitions, held somewhere almost daily, where prizes are offered which enable the best birds to win considerable sums of money in the course of a year; so that prices of from $£ 10$ to $£ 100$ are constantly being paid for good specimens, according to the standards of excellence well understood among breeders.

In the present work I shall give an account of how to keep pigeons in the way that experience has proved to be best; hnw to match up and breed them; how to treat them in health and disease; and describe every known variety. I shall also give, in an Appendix, a list of books on the subject, ancient and modern, with remarks thereon.

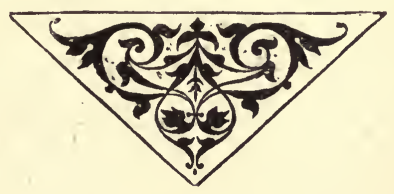




\section{Chapter II.}

\section{$\propto$ THE ORIGIN OF FANCY PIGEONS. $\varnothing$}

\section{Probable Progenitor.}

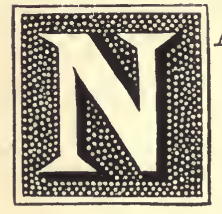

ATURALISTS look for the original stock of all tame pigeons in some wild variety, and for a long time the stock dove was regarded as their progenitor. This idea is now exploded, as the stock dove (Columba Qinas) is not a bird capable of domestication. The only wild pigeon now believed capable of being the originator of our domestic pigeons is the blue rock (Columba Livia), subvarieties of which are found in Europe, Asia, and Africa. The British blue rock inhabits the rocks and caves on our sea coasts, as well as precipitous inland rocks, and certainly the difference between this bird and a common blue flying tumbler is very little. Their colour is identical, their size almost so. The head, beak, and iris of the tumbler are somewhat different from those of the rock pigeon, and the pinions of the latter are longer and stronger, as must necessarily be the case from its mode of life. In the West of Scotland, where fanciers keep and show common pigeons, the wild blue rock domesticated is the bird so called. 
I think the best argument in favour of some common ancestor for the whole of our fancy pigeons is the fact that they all breed freely together, and that they are only kept up to their best forms by the guiding hands of experienced pigeon fanciers. They constantly throw back, to some remotè ancestor, stock that are unfit to go on with. The worst of these, if bred together, would no doubt breed young in some cases better than themselves, but also others still further removed from the desired type, and so the breed would soon become almost unrecognisable.

Supposing the more distinct varieties of pigeons to have been separate creations, then they must certainly have been so distributed in the world as not to come into contact with each other, or they would in a short time have got intermingled. And, again, if not from a common stock, then man must have, from time to time, captured the whole original stocks, or they must have died out, for I have never yet heard of anything like a fancy pigeon being found in a state of nature. In fact, if able to exist in a state of nature, and protect themselves from birds of prey, fancy pigeons must have been so modified in their fancy points, such as crops and fan-shaped tails, as to be but little removed from what we call common pigeons.

\section{Variations in Form, \&c.}

Some fanciers, who never in the course of their lives observed the least variation in the forms of their fancy pigeons, are of opinion that the more distinct kinds, such as pouters, carriers, jacobins, and fantails, were separate creations, and owe their origin to birds having, probably in a modified form, the peculiarities of these breeds. They have even offered silver cups or other rewards for the production of a new form of fancy pigeon other than a mere feather variety, in the belief that such could not be produced; but the life of a fancier who may have kept pigeons for even half a century, is but a 
little while compared to the time pigeons have been kept in the world as domestic birds; for we know they have been carefully bred for thousands of years. No other domestic animal I know of has branched out into such variety of form and colour, from which I infer. they have been long and extensively cherished by their admirers. Every leading feature of the bird seems to have been already played upon, so that one might almost be unable to suggest any new variation from what already exists; and yet, even lately, a quite new variety of pigeon appeared. This case occurred about thirty years ago, and is recorded in the pages of the Poultry Chronicle (1854-5). The bird in question was. a sport from common baldpate tumblers, and a reference to the illustration, which will be found in the Chronicle, will show what its peculiarity was. From the crown of its head rose a crest of rather long waving feathers, quite different and distinct from the peak or shell crest of many breeds. The account of the bird, as given at the time by its owner, Mr. W. Woodhouse, was as follows: "This curious pigeon is alive, and in my possession. It is a pure-bred baldpate, of which it has the properties-viz., clean cut, pearl-eyed, clean-thighed, and ten-a-side. It is the only one in the world, and is a cock bird. Several competent judges have seen it, and consider it a freak of Nature; but, whatever it is, it is a wonder. Several of my friends wish me to breed from it to get more, but of this I am doubtful." A few weeks after the above was published, Mr. Brent, the well-known authority on pigeons, wrote as follows in the Poultry Chronicle: "A month or two back, Mr. James Pryer, a. neighbour of mine, and a tolerable judge of pigeons, informed me he had seen something curious in that line at Sevenoaks. He described it as a common chequered dovehouse pigeon, with some rather long feathers growing from the head. Seeing Mr. Woodhouse's description of his crested baldpate, I showed him the cut, and he assured me that, so 
far as he could see, the pigeon in question was crested just the same. We have both made inquiries respecting the bird, but have not succeeded in discovering whence it came, or where it is gone. Mr. Woodhouse's pigeon is certainly a curiosity."

It will thus be seen that, twice within a short time, the said peculiarity was observed in separate breeds of pigeons. Unfortunately, Mr. Woodhouse's baldpate does not seem to have produced young like itself, or we should now be in possession of a variety quite distinct from anything that has come under my notice, either here or abroad. To such sports, coming unexpectedly, must, I think, be referred all the strange types of pigeons now existing on the globe. The whiskered owl, whose frill is so much developed that it divides at the top and runs quite round the neck in some birds, seems also a recent introduction-at least, I can find no notice of this type in any old book on the subject of fancy pigeons-but this can scarcely be called a new variety; it is rather an. extraordinary development of an old one.

Animals in domestication, and also in a wild state, are subject to variations. In the latter state, such variations are likely soon to disappear, but in domestication the guiding hand of man fixes them on account of their originality. By pairing any curious specimen of a breed with one of the common type, the young may not prove uncommon; but they, paired with their uncommon parent, are then likely occasionally to reproduce the desired peculiarity. In this way, I believe, every fancy pigeon, however now far removed from the blue rock, has been produced; and, judging from the following analogous case, it does not seem to take very long for Nature, guided by the reason of man, to produce the greatest differences in form.

\section{Effects of Domestication.}

It is well known that the canary bird was first introduced into Europe about 300 years ago. The difference between 
the Belgian or Lancashire coppy in form, and the lizard or cinnamon in feather, and the wild canary, as still yearly imported into this country, is as great as the difference between the pouter in form and colour and the blue rock pigeon.

Such results, in a comparatively short time, from canary breeding, have led me to suppose that, were bird fanciers to persevere with goldfinches, linnets, and siskins, all of which have been bred in confinement, we should ultimately see similar variations in them. Variety of colour constantly occurs among them in a wild state, and such has been noticed by naturalists for 200 years.

\section{Foreign Varieties.}

Besides the blue rock pigeon inhabiting our coasts, others differing from it slightly are known to exist in Asia and Africa. Any of these that may have been domesticated may have been progenitors of fancy pigeons. One of them, the Columba Leuconota, inhabiting the Himalayas, is marked on the head and tail like a nun, and, in addition, the wings are marked something like those of a swallow pigeon. But whether or not it is a true rock pigeon, capable of domestication, and able to produce young with a common blue rock or tame pigeon, themselves in turn fertile, is what I cannot say. This subject, however, is one more for naturalists than pigeon fanciers, who have generally their hands full with the work of keeping up, and possibly improving, the interesting forms of pigeon life handed down to them from of old.

Of late years we have received from abroad many kinds of pigeons of the highest excellence, showing such breeding that what we had before of the same types seemed but half-bred beside them. Still, no quite new or distinct forms have reached us, entirely different from what we knew of, though many distinct varieties of colour have appeared, as in the short-faced frilled varieties from Asia Minor. Since the first edition of this book was published, in 1881, a variety 
has been brought from China with an extraordinary development of gullet. I have named it the Chinese Dewlap pigeon. A recent Russian traveller writes of a mandarin in the interior of China, who kept his fancy pigeons with great care; it is possible we may still get from that country, or from the interior of Northern Africa, some variety hitherto unknown here.

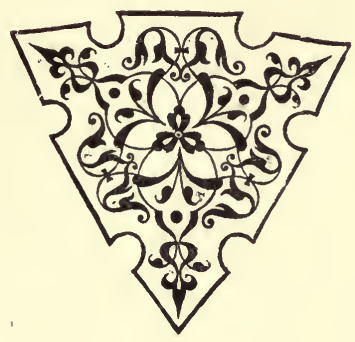




\section{Chapter III.}

$\propto$ THE PIGEON HOUSE, LOFT, AND AVIARY. $\varnothing$

Wall Boxes.

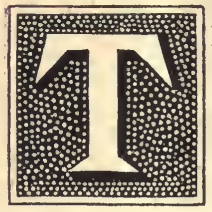

$\mathrm{HE}$ majority of pigeon fanciers, who commence their pursuit when young, begin by keeping a few common birds or flying tum. blers in boxes fixed to some wall, out of reach of cats or other enemies. This was the way I began the fancy, and some narrow escapes I had when up the ladder inspecting what was going on inside my pigeon locker; and I would advise all guardians of pigeon-keeping boys, who have no other means of housing their pets than in wall boxes, to see that these are not only properly secured-for I have known them to give way from improper fastening-but fixed at no great distance from the ground. Keeping really good pigeons in wall boxes is, however, almost out of the question, for little control over them ean be exercised, and, sooner or later, if the young fancier means advancement in his pursuit, he must find ways and means for the better housing of his birds.

When, however, no other means of keeping pigeons than in wall boxes is convenient, then such should be made of 
some kind of durable wood, and well jointed, so as to allow the wind no entrance except from the holes at which the birds go in and out; and they ought to be fixed in the most sheltered position available. The box space necessary for each pair of all small pigeons, such as tumblers and turbits, is about $12 \mathrm{in}$. by 12in., and 10in. high. This is the measurement inside, and, in addition, there is the landing board, which will project about 4in. Unless each pair is provided with two such apartments, there will be little peace in the colony, for pigeons do not like to lay in their last nest.

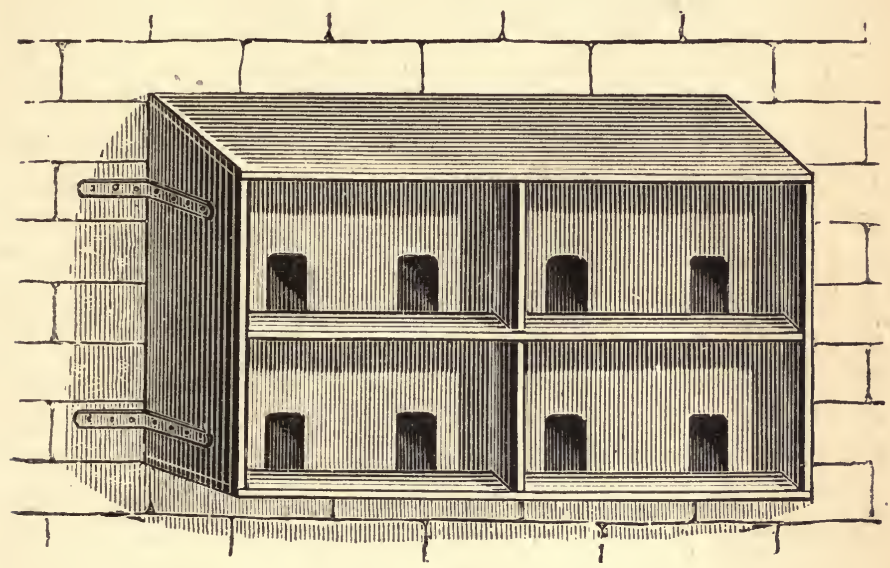

Fig. 1.-Pigeon House for Four Pairs.

They usually go to nest when their young ones are about three weeks old; they therefore require two nesting places.

Fig. 1 represents a wall dovecote suitable for four pairs, each pair having two apartments, in which they will nest alternately. The young ones will leave their nest when between three and four weeks old, but can easily be prevented going into the adjoining apartment and disturbing 
their sitting parent, by fixing a temporary division between the doorways.

No one, however, will continue to keep pigeons in wall lockers if he can by any means avoid it, and some vacant building, shed, or loft, will be appropriated for the purpose. Such a place a fancier ought, with the assistance of a few carpenter's tools, to be able to fit up himself. Cat and ratproof he must have it, and mouse-proof also, if possible; for, while the former will destroy the birds themselves, the latter spoils their food.

\section{Open-air Flights.}

The great majority of fancy pigeons may be allowed their liberty in the open air with safety to their lives and positive advantage to their health; but choice pouters, carriers, shortfaced tumblers, jacobins, or fantails, are not so able to take care of themselves. Still, it is surprising how wary even such varieties as these become, if flown when young. In granting them their liberty, however, which must only be occasional, according to the weather, the owner must be entirely guided by circumstances, such as the surroundings of his place and the special character of each bird. There must always be a certain amount of risk encountered, and it is for the owner to consider whether the advantages to be gained will outweigh it. Choice pigeons no doubt live a long time in close confinement when treated with reasonable and ordinary care, for many fanciers have no other means of keeping them. If occasional entire liberty cannot be given them, an open-air flight, inclosed by wire netting, will be of great advantage. This should always be roofed in, and only open to the less exposed aspects. The larger it can be made the better; but even a very small open-air flight will materially assist in keeping the birds in good health. When pigeons are kept in a room or loft with no outside liberty, an opening, covered with wire netting, for the admittance of light 
and air, should be provided. It should face the south, to admit the sunlight, and have a wide board adjoining, for the birds to rest on. The most domineering of them will monopolise this place as much as they can, but their domestic duties will prevent their being always there, so that all will have some advantage from it.

\section{Feeding Boards.}

Pigeons may be fed either from a flat board that has a marginal edge running round it, raised about an inch, to prevent the scattering of the grain, or from a self-supplying hopper. By the exercise of due care in not putting down more grain each time the birds are fed than they will eat, there need not be much waste of food. Giving them too much at a time, and then grudging to throw away any that becomes soiled, is but poor economy, and a likely cause of disease among them. If a flat board be used for their feeding on, it should be covered with sand or gravel to the depth of half an inch, which should be renewed weekly.

\section{Hoppers.}

In the breeding season, when a constant supply of food is more necessary, hoppers made of zinc or wood, such as shown in Fig. 2, will be useful. They can be made of any desired length. The lid, or lids, if they are intended to be divided inside, open with hinges, and should be at such an angle as will prevent the birds resting on them. A wire run along the ridge, raised an inch and a half, will keep them from settling there. As the food is eaten from the trough, the bulk inside will continue falling down, thus insuring a constant supply as long as it lasts. By an inside division, separating the hopper into two parts, two kinds or two separate mixtures of food may be supplied. Fig. 3 represents a very useful feeding box, which $I$ have used for some years. The inside wires are 2 in. apart, and prevent scattering of the 
grain. Hoppers of various designs may' be bought from manufacturers who make a speciality of them. One was brought out a few years ago in which the food is exposed

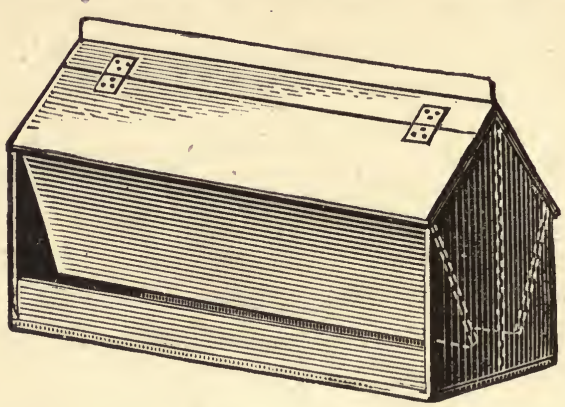

Fig. 2.-Grain Hopper.

by the pigeon stepping on the board in front of the box; this prevents waste from mice or sparrows, their weight being insufficient to open it.

\section{Water Fountains.}

Water fountains may be bought complete, of various patterns; but a good one may be improvised by carefully

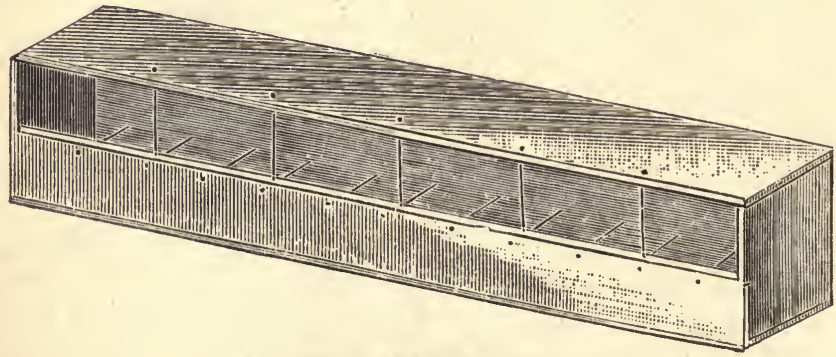

Fig. 3.-Feeding Box.

punching a hole in a two gallon stone jar, near the bottom, and hermetically sealing the mouth. This, placed in a flower-pot 
saucer, the edge of which is higher than the orifice made in the jar, will complete the fountain. But a better kind of jar, made in various sizes, is that shown in the illustration (Fig. 4), which, being without a bottom, can be better cleaned out. When the pigeon-house has an outside flight on the ground, or when the fancier has more than one such place, supplying the birds with drinking water can be better per-

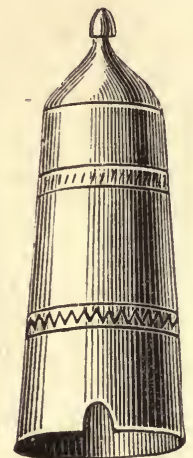

Fig. 4. - Water Bottle

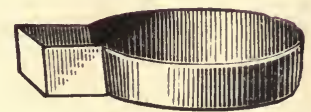

Fig. 5. - Water Dish.

formed from the outside. I made for myself a pattern in wood, like Fig. 5, from which I had several casts in iron taken, and then galvanised. These saucers are placed outside my flights, with the projecting part put through a hole cut in the wire netting. By this method, from the arrangements of my pigeonry, I can supply my birds with drinking water in half the time it would take to carry it inside.

\section{Small Pigeonry.}

As a specimen of a pigeonry extensive enough for one man to attend to who has to do everything connected with it himself, before and after business hours, I have prepared a plan of my own place (Fig. 6), which, though not perfect by any 
means-for almost every day brings forth some new wantis now tolerably complete. Its arrangement may be carried out on a greater or smaller scale by anyone either erecting a columbarium, or adapting some existing building. $\mathbf{P}$ is the entrance door to the court, which measures about $80 \mathrm{ft}$. by $60 \mathrm{ft}$., and is surrounded by high walls. The buildings are placed against the north wall, which is about $12 \mathrm{ft}$. high, and they slope down to about $7 \frac{1}{2} \mathrm{ft}$. in front. The roof is slated, but about one-third of the open-air flights,

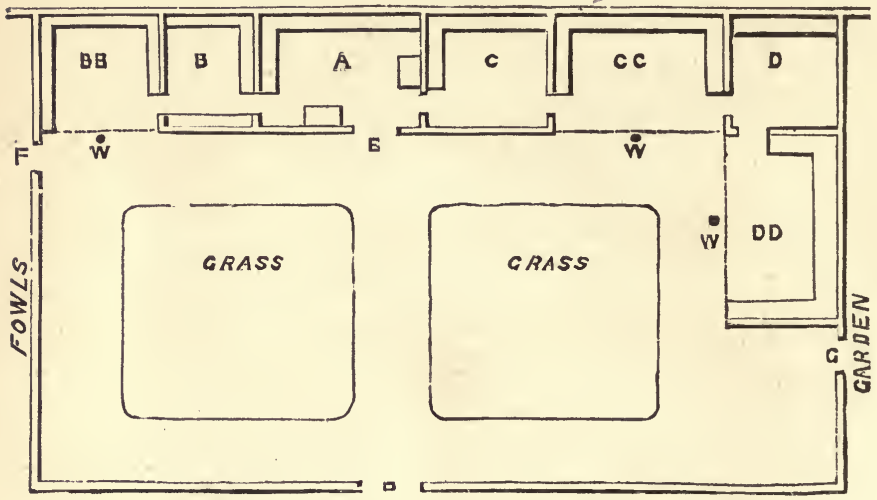

Fig. 6.-Plan of Small Pigeonry.

marked BB, CC, and DD, are roofed with glass, to admit light, and are wired in front. $\mathrm{E}$ is the entrance door to the whole; I adopted this plan from having often lost birds, in other places by the doors in the open-air flights being left open accidentally, being blown open by the wind, or by the birds dashing past me when entering; and it may happen that, not only may the birds themselves be lost in such cases, but any young ones they may have may die for want of a suitable change to another pair being handy at the time. The room $\mathrm{A}$ is about $16 \mathrm{ft}$. long by $12 \mathrm{ft}$. broad, 
and has a table running half round it, about $2 \mathrm{ft}$. broad, capable of holding ten bell-shaped wire show-pens for training pouters. Below this table are two tiers of matching.pens, each pair having a sliding wired frame dividing them, which, when withdrawn, enables the birds to go together. Two large corn chests for holding food are also shown, on the top of one of which are more matching pens; and the top of the

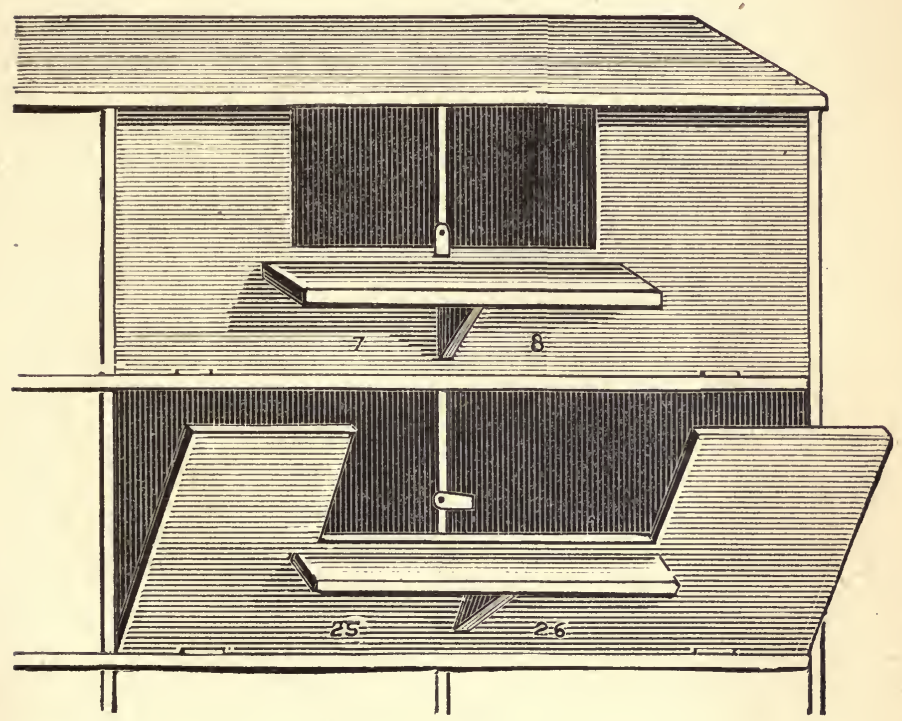

Fig. 7.-Nesting Boxes.

other is used as a carpenter's bench, quite a necessary in such a place, and never long out of use. The rooms $\mathrm{A}, \mathrm{B}, \mathrm{C}$, and $\mathrm{D}$ are lighted by roof lights, opening, when required, for ventilation. $B$ is a room about $9 \mathrm{ft}$. by $12 \mathrm{ft}$., for small pigeons, such as tumblers, turbits, owls, and jacobins, and is fitted with four tiers of nesting places, constructed on the principle shown in Fig. 7. 
Each nest box (Fig. 7) is about 14in. long by 12in. deep, and 1lin. high. A door, hinged at the bottom, covers two nests, which suffice for a pair of birds, and each nest is numbered for reference. About one-fourth of the door is cut away for entrance, and a landing board, supported by a small bracket, is fixed to it. A button screwed to the wood that divides each pair of nests keeps the door secure, and, if made so as to have no play, will never be accidentally forced up. The pair of nests numbered 7 and 8 are shown closed, and those marked 25 and 26 partly open. I find this style of nesting place answers very well for small pigeons, each pair of birds having all they require; they nest first in the one and then in the other, and by the time the young ones are able to come out they are strong enough to fly. The single landing boards have the advantage of keeping each pair entirely to themselves, and they are generally able to hold their own against all comers, as there is little room for fighting on them.

BB (Fig. 6) is the open-air flight of B, and has resting boards, $3 \frac{1}{2} \mathrm{ft}$. from the ground, 18in. wide, and close to the wall running round it. When there is a space between the board and the wall it is dangerous for pouters, fantails, and such pigeons. I like the broad resting boards, as they give plenty of room for the birds to pass each other. WW are the water fountains for the open-air flights, placed outside, with their saucers projecting through the wire. C is a room, $12 \mathrm{ft}$. by $12 \mathrm{ft}$., fitted up with three tiers of nests for pouters. The shelves are 18in. deep and 18in. high, divided into nesting places $3 \mathrm{ft}$. long, which, in the breeding season, are darkened at each end by boards, behind which the birds nest alternately. Like others I know, I could never be satisfied with so few birds as I could find accommodation for on the ground, so must run certain risks from the young ones falling from the higher nests, and be as careful in guarding against such mishaps as possible. D is 
another room, $10 \mathrm{ft}$. by $12 \mathrm{ft}$., fitted up with nesting places as in $\mathrm{C}$, and has a flight of $18 \mathrm{ft}$. long, marked DD.

There is a great advantage in having several compartments in a pigeonry, for without them it will sometimes be found almost impossible to unmatch certain pairs, when it is desirable to do so. Besides the buildings shown, I have several others for my birds, which, being outside the court, cannot be shown on the plan.

Earthenware or wood nest pans, of from 8in. to 10in. in diameter, are used by some fanciers, but they are not required in such nesting places as shown in Fig. 7. The method I adopt is to spread sawdust to the depth of half an inch, and place straw on it, which the birds form into a nest. There is a danger of young birds falling out of nest pans and dying of cold. In the breeding houses I have used sawdust over the floor, to the depth of 1in. or 2in., and have found it very suitable. This, if passed through a riddle of $\frac{1}{4}$ in. mesh once a week, will last for several weeks, but should be renewed oftener if the place be troubled with insects. Pine sawdust soon loses the pungent smell, which helps somewhat, though not entirely, to drive away vermin.

\section{Cleaning Pigeon Houses.}

Unless pigeon houses are often cleaned out, the smell arising from the dung soon becomes unpleasant. I clean out

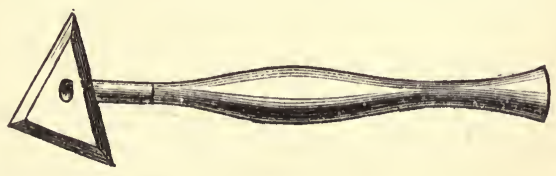

Fig. 8.-STEEL ScraPER.

my own places every morning, and as, from their extent, the time required for doing so is considerable, I have been obliged 
to find out the most suitable tools for the purpose. These are, a triangular steel scraper (Fig. 8), as used by shipwrights, and a steel hand shovel (Fig. 9). The former is good for all corner places, and the latter for broad surfaces, such as the floors and resting boards in the flights. When held at the proper angle, the shovel removes everything opposed to it as fast as one can walk along. It should be of the best steel, and kept sharp; those made of sheet iron wear but a short time. A stable broom set with stiff Brazil fibre is also neces-

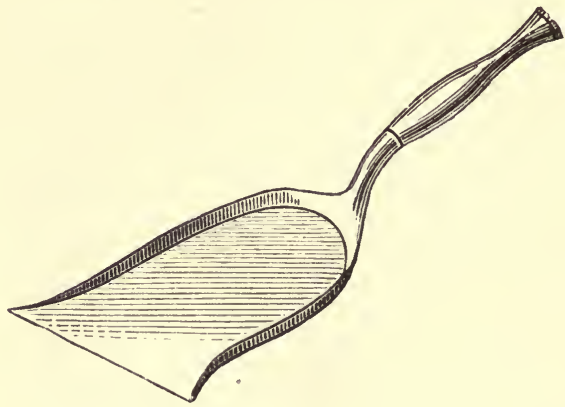

Fig. 9. - Steel Shovel.

sary for sweeping all up, when the scraper and shovel have done their part in freeing the dung from the wood. I have given up using sawdust on the floors for some time, not that I disapprove of it, but merely because I could not procure it conveniently. The labour in cleaning out the houses is as great when sawdust is used as when it is not, for the renewing and riddling of it takes up much time; if the floors are scraped daily the dung has no time to harden and adhere to the wood, when it become more difficult to remove.

\section{Covering for Floors of Flights.}

The best covering for the floors of outside flights is small 
gravel; such as can be got from sea beaches, mired to some extent with broken shells, is very useful, the birds using much of it to aid them in digesting their food. It should be raked together now and then, and renewed when it gets soiled by the droppings.

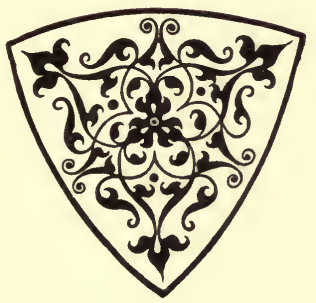




\section{Chapter IV.}

\section{$\propto$ SELECTION OF STOCK. $\varnothing$}

\section{Early Experience.}

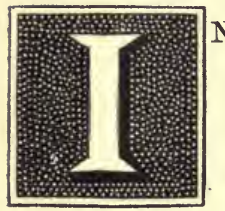

$\mathrm{N}$ the selection of stock the pigeon fancier has many varieties to choose from. Not only do the forms of pigeons vary much, but their plumage is diversified to an extraordinary degree, and the disposition or temper of the birds themselves varies greatly in different breeds. Most, if not all, who begin pigeon keeping early in life, commence with common kinds, with which they learn the rudiments of the fancy, and so gain the experience necessary to enable them to keep the more choice breeds with success. Of all who do so begin pigeon-keeping, however, but few follow it up in after life, either from want of the necessary accommodation in the places to which their destiny may lead them, or, more often, because the pursuit has no real hold on their minds. Whether the fancier begin early or late in life, it is necessary for him to spend some probationary time in mastering the rudiments of his pursuit, and to do so with expensive birds, the beauties of which he cannot, probably, realise, is a waste of money, unless he 
has some experienced friend often at hand to direct him in their management.

As a beginning, no better pigeons than common tumblers can be put into the hands of a young fancier. They are neat and tidy in appearance, of varied and beautiful colours, and their performances in the air are a constant source of pleasure to their owners. There are few fanciers, however select their pigeons may be, who, if they can find accommodation for them, fail to keep some pairs of these engaging birds. They breed freely, are very hardy, and are serviceable feeders for other pigeons.

\section{Characteristics of Breeds.}

The pigeons that look best on the wing are those of pronounced markings, suçh as baldheads, turbits, and nuns. As they wheel round in their flight, the contrast between the white and coloured part of their plumage is very striking. Pouters, of what might be called a second quality, for the choicest are scarcely to be trusted at large, Norwich croppers, pigmy pouters (such as Austrians and Isobels), and pouting horsemen, or half-bred pouters and carriers, are all capital flyers, and sail through the air in fine style.

The pigeons that become most familiar with their owners are pouters and fantails. It is necessary for the former to become very tame if intended for exhibition, as otherwise they lose much of their beauty and chance of success in competition. On the other hand, carriers look best wild and alarmed, familiarity on their part spoiling their fine shape and statuesque appearance.

Runts, though they look quiet and sedate in the loft, are often of a spiteful disposition, making the feathers fly by the dozen from birds that happen to encroach on their preserves.

Carriers, also, are very vicious, and play sad havoc with each other when they fall out.

Trumpeters, such as were in England before the so-called 
Russian ones were introduced, were noted for their quarrelsome disposition, and I have seen an unruly cock of this breed monopolise a whole loft to himself, preventing, till his removal, the least chance of success in breeding from the birds associated with him.

Owls, the Oriental frilled varieties, and turbits (the latter in a less degree), are shy and reserved in their demeanour, leaving their nests and young ones on the slightest alarm; but this will be of little consequence if the cause of their disquietude be soon removed, when they will generally return without delay to their nests.

If pigeons of varied and striking plumage be required, they may be found in archangels, almond tumblers, the Eastern frilled varieties, and in many of the German toys; contrasts of colour among nuns, magpies, swallows, and such kinds; while pouters, carriers, short-faced tumblers, barbs, jacobins, fantails, owls, turbits, and trumpeters, present abnormal conformation, and are denominated high-class pigeons, in distinction from those having little but curious colour and marking, because such conformation is more difficult to produce, and therefore thought more of, when obtained in a high degree, than mere feather.

\section{Keeping Several Varieties.}

But though a genuine pigeon fancier may have a preference for some particular variety, he will not be insensible to the beauties of others; and during an extended career in the fancy, he will most likely become possessed of specimens of every kind of fancy pigeon he can obtain. There is always a charm to the fancier in the acquisition of some new variety not previously possessed by him, which is taken up as a kind of extra thing, in addition to the variety on which his fancy is more permanently fixed, and as he tires of it some other novelty will take its place; for, as will be afterwards explained, it is not wise to keep many 
varieties at a time, if it is expected to breed any of them to perfection. Each distinct kind of pigeon is a study in itself; still, in addition to the favoured kind, and without detracting from the attention it may require, one or two other breeds may be introduced into the loft, when room can be afforded them, as a sort of by-play.

\section{Homing Pigeons.}

In addition to the breeds that are strictly fancy pigeons, there are those known as homing or racing pigeons, in the breeding and training of which many find great enjoyment. The dragoon, long-faced beard, and skinnum, were formerly used in England for this purpose, but of late the Antwerp carrier is almost exclusively employed for flying long matches. The flying fancy is a branch of the pigeon fancy by itself, and may be more properly denominated as racing, though in the management of the birds themselves there is no difference from that necessary for the generality of fancy pigeons.

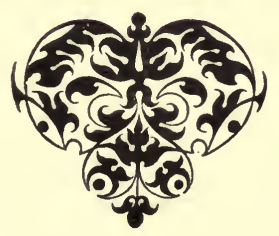




\section{Chapter V.}

\section{$\propto$ FEEDING, BREEDING, AND MANAGEMENT. $\varnothing$}

\section{Foods.}

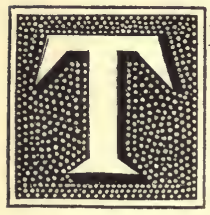

HE grain used for feeding fancy pigeons is wheat, barley, beans, peas, tares, and maize, besides some other kinds. All of these are good in their way, and may be mixed together. The fancier will find that some birds prefer one kind, and some another. The grain should neither be too new nor too old, for when used in the year it is grown it is inclined to be too relaxing, and apt to scour the birds; on the other hand, old grain, that has been ill kept, and become perforated by worms or weevils, will have lost most of its goodness, and a great part of it will be refused by the birds. Grain may be kept well for a considerable time if spread on a wooden floor to the depth of $6 \mathrm{in}$. or 9in., and turned over once a week or so. The place should be free from damp, or the grain will become musty. Well-conditioned grain keeps the birds in good health, and makes a great difference in the number of young ones reared, for any that has become too hard from age cannot be easily digested by them, and musty or worm-eaten stuff being distasteful to them, the young ones 
suffer in consequence. When floor space is not available for storage of grain, it should be changed from one bin to another as often as convenient, or, if kept in sacks, they should be shaken up now and then, with the object of destroying moths and other insects, which will assuredly find their way amongst it if it be left long undisturbed.

Wheat may be used more freely in the summer than in the winter. Pigeons are fond of it, and, when given them to the extent of one-fourth of their supply, it is beneficial during the breeding season.

Barley is good food for pigeons, and I use it to some extent all the year round; indeed, I have known of good results from pigeons fed on nothing else. It is generally the cheapest of all pigeon food, and cheapness is an object with many; but the birds are not very fond of it.

Maize, or Indian corn, is generally as cheap a grain as can be had, and, being highly nutritive, is in every respect suitable for pigeons. The small round kind, known as Hungarian, or Black Sea maize, is generally dearer than the flat American, but not more valuable as food; however, the flat kind is not so suitable for the smaller breeds of pigeons, being apt to stick in their throats and choke them.

Peas are of various kinds, such as white, blue, and mottled. The small white, or rather pale yellow, Canadian peas, are good food for pigeons. The dark brown mottled kind, known as partridge peas, are also very good; and the small Baltic feeding peas, which contain a mixture of white, blue, and mottled, are serviceable, and generally cheap.

Beans are of various kinds, such as the small tick bean and the medium-sized Egyptian-both good for pigeons. The larger varieties are not suitable, being apt to choke the birds.

Tares-either the small foreign or large Scotch-are suitable food, and may be mixed with the foregoing. 
A mixture of grain can always be had from dealers who make a specialty of supplying pigeon fanciers.

Other kinds of grain used by fanciers are buckwheat; dari, a white, tare-shaped grain from the Levant; rice; paddy, or rice in the husk; and mollah, a small East Indian blue-grey pea mottled with brown spots.

Pigeons are fond of all the seeds given to cage birds, such as millet, canary, and hemp, but they are too dear for general use, though they may be given as an occasional treat. Hemp seed is very stimulating, and should be seldom given to pigeons kept in close confinement.

As pigeons at liberty eat freely of lettuce and such green food, this may be supplied occasionally to those kept in confinement; but it is not an absolute necessity for them, and I never give them such in the winter time.

\section{Mode of Feeding.}

I have already referred to the way pigeons may be fed in lofts. When an outside flight, covered with gravel, is provided for them, the best way to feed them is to throw their food on the ground, always provided they can see to pick it up, which trumpeters, and certain heavily wattled pigeons cannot do. For such hoppers must be provided. Supposing a good many birds are kept, this will be the most expeditious mode of feeding. Hoppers, to supply perhaps a hundred birds, must be rather numerous, to prevent their constantly quarrelling over them. More food is destroyed by feeding from a flat board than from the ground, if it be kept constantly supplied with clean gravel a few inches in depth.

During the breeding season the birds should invariably be fed early in the morning, not later than eight o'clock. If food be left for them over night, they will go to it much before this hour in the summer time; but this is not absolutely necessary. Forgetting to feed them for half a day will cause the death of many young ones, not so much for 
want of food as from cold; for in such a case the old ones will not continue sitting on them, but will leave them and hang about waiting for their food. Young pigeons, from their birth till seven days old, cannot long survive the want of their parents' warm protection, even in the heat of summer.

\section{Water.}

The water vessels should be refilled daily, even if they hold more than a day's supply; for, if allowed to run dry, the same bad results follow as from want of food. They should be frequently cleaned out with boiling water, and such as have only a hole in them should have some sharp sand shaken up in them when being cleansed. If placed outside the flight, and exposed to the rays of the summer sun, they must either be protected from it by a box in very hot days, or be frequently refilled with cold water; for sun-heated water is prejudicial both to the old and young birds.

Bathing water may be allowed them twice a week, which is about as often as they will care to use it. If supplied in the loft, no vessel, however constructed, will prevent them dashing it about on the floor; but some sawdust, thrown upon the overflow, will absorb it in a few minutes, when it may be swept up. If the bath be made with sides inclining inwards, much less water will be scattered about than when they are upright or sloping outwards.

\section{Salt.}

Salt in some form is necessary for pigeons kept in confinement, as has been known from the time of Aristotle. It is required for keeping them in health, and for the successful rearing of their young. The old writers give recipes for what they termed the "salt-cat," which Moore refer's to as so called, he supposes, "from a certain fabulous oral Tradition of baking a Cat in the Time of her Salaciousness with Cummin-Seed 
as a Decoy for your Neighbours' Pigeons; this, tho' handed down by some Authors as the only Method for this Purpose, is generally laughed at by the Gentlemen of the Fancy, and never practis'd." I have an old book on Agriculture (1687), from which Moore has quoted when writing of the value of pigeons' dung, which gives a recipe for the preparation of the disgusting compound called salt-cat. The author also makes the following sensible remarks: "There is nothing that Pigeons more affect than Salt; therefore, do they usually give

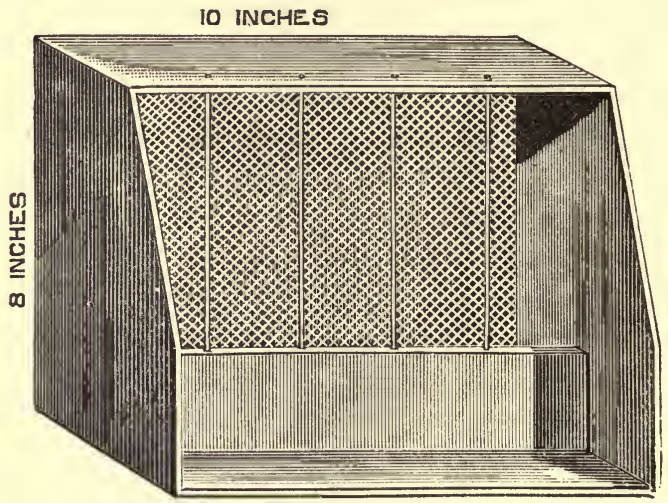

Fig. 10.-Salt Earth Box for Pigeons.

them, as oft as occasion requires, a Lump of Salt, which they usually call a Salt-Cat, made for that purpose at the Salterns, which makes the Pigeons much affect the place, and such as casually come there usually remain where they find such good entertainment." I have experimented regarding the necessity of salt for pigeons, and noted the experience of - others, and have ever found, when it has been long withheld from them, they suffered more from disease, and that a greater portion of their young died before maturity. One writer goes the length of saying, that it is necessary for the 
successful treatment of their complaints. The avidity with which they devour salt, when they get a supply after a long want of it, shows it to be very necessary; but, in such a case, both the old and young suffer from an overdose, as I have proved. I have noticed, when it was given in the form of rock salt, and when the lump had disappeared by melting, and by the birds eating it, that they greedily ate of the salt earth where it had lain till they made quite a depression in the ground.

As pigeons in confinement require lime, not only for the formation of the shells of their eggs, but for medicinal purposes, it is best to supply this in conjunction with salt and small gravel, the latter aiding in the digestion of their food. Let the fancier, then, proceed as follows in making up a mixture which will supply, along with sound grain, all his birds require for keeping them in as good health and condition as is possible, either in confinement or at liberty. Let him, when opportunity offers, procure and preserve in a box or barrel a supply of old lime from some building in course of demolition. Such rubbish is generally composed of one part of lime to about three or four of sand. Take of this lime rubbish, two parts; of small, gritty, pebbly sand, one part; of friable loam, of a clayey kind for choice, one part: beat all down, so that it will pass through a $\frac{1}{4}$ in. riddle, and mix well together. Then add coarse kitchen salt, to the extent of one-eighth part of the whole, and put the mixture in boxes, and, as Old Moore would have said, "You'll find your account in it." As the pigeons consume this, which they will do quickly, for every bird will visit the box daily, replenish the store all the year round. Fig. 10 represents a box, or hopper, suitable for holding the salt earth or gravel.

\section{Pairing.}

Supposing the pigeon fancier to have his loft and its arrangements completed, and to have selected his stock of 
birds, the first thing he will have to do will be to pair them together. In matching them up, with the object of breeding good young ones, the general rule may be laid down that, whatever faults one of the pair may possess, its mate should not possess the same. A pair of pigeons having between them the properties sufficient to constitute a perfect specimen, or something approaching to it, are likely to amalgamate, in some of their progeny, the good points they possess; and by this method are the most perfect specimens of fancy pigeons produced. But, besides the appearance of the birds themselves, that of their parents and more remote ancestors should be considered when it may be done, as pigeons, in common with other animals, throw back to their ancestral form as much, and often more, than to that of their own parents. It will therefore be seen that successful pigeon breeding requires considerable study, although good pigeons are not unfrequently produced from very ordinary stock; but such chance birds are not reliable for stock purposes. It is always better that a beginner should procure his stock birds from a breeder who has proved his ability to turn out good birds of any particular variety, than to buy those of whose pedigree he can learn nothing; for there is much virtue in a good strain, and much disappointment saved by procuring such. And yet the very best of pigeons will produce plenty of young ones quite unfit to go on breeding from, as all races living in a strictly artificial state must necessarily do; so a fair amount of quality should be looked for in birds intended to commence breeding from.

Pigeons are mated together by placing them in contiguous pens, where they can see each other. When in good health, they will generally show signs of becoming paired in a few days, but it is, of course, necessary to keep them from the sight of other birds, and especially of their last mates, or it will not be easy to match them up. When properly paired. it is always well, when practicable, to place them in a loft 
apart from their former mates, should they have had such, for even when these are themselves rematched, and with young ones, they will occasionally be inclined to go together again; but in this respect, and in many others, pigeons show the most various dispositions. Two or three lofts save much trouble to the fancier, and he can always work his birds about in them, so as to save time in his breeding operations. When a pair show signs of becoming matched up, they may be allowed to go together for a day, when the union between them will become more fixed than if turned into the loft at once. For this purpose, matching pens have generally a sliding wire division, withdrawable at pleasure. Once or twice in my experience $I$ have found it impossible to permanently match up a pair of pigeons. Though each would pair in the ordinary way with other birds, they invariably separated after being together a short time, seeming to have some antipathy to each other. In such a case, the only plan for keeping such a pair together, should there be some special reasons for doing so, will be to place them in a room by themselves.

\section{Nesting.}

When all goes well, the pair will soon begin building a nest, if provided with materials for doing so, and, usually in a week or ten days, the hen will lay her first egg, very near five o'clock in the evening. She will not sit on it through the following night, but stand over it; but next day the cock will generally be in such a hurry to begin the process of incubation, that it is always better to remove the egg when laid, substituting another, so as to insure the two hatching simultaneously, for when one is hatched a day before the other, the difference in size and strength of the young ones seems to get more marked day by day, and to increase rather than diminish. Many hens are apt to lose the power of their limbs when about to lay, and such must be carefully looked 
after. Others do so only at the beginning of the breeding season, when the weather proves unusually cold. Although there is no way of knowing an egg to be such as will produce a healthy young one, it may be told almost with certainty that eggs of a certain appearance will come to no good. Those that, instead of being smooth when laid, are very rough, or of a honeycombed appearance towards one end, are generally bad, and though they contain the germs of a living squab, it will generally die in the shell. Very small eggs have rarely a yolk in them, and very large ones have generally a double yolk. The latter almost invariably die during incubation, though instances have been known of two healthy young ones being hatched and reared from them. Good eggs have a smooth appearance, and a few hours after being laid a round air spot, usually at one end of them, will be observed on holding them up to the light. The hen lays her second egg forty-five hours after the first, or very nearly at two o'clock on the third day, and this is an almost invariable rule when all goes well. The first egg being replaced in the nest, incubation then commences, and in seventeen complete days, more or less, according to the weather, breed, and closeness of sitting, the young are hatched.

There is a great difference in the breeding powers of hen pigeons, and those that lay oftenest during their first season without any forcing, generally breed longer than such as lay only twice or thrice in their first year. When a hen lays single eggs to a nest, it is generally a sign that her procreative powers are drawing to a close, or that she is being unnaturally forced.

When the eggs have been sat on for three full days, it may be determined almost surely whether they are fertile or not. When held against a strong light, the heart, and blood ressels branching from it, of the embyro squab will be clearly seen in a good egg. When no such appearance is visible, the egg is bad, or, as happens occasionally, it has not 
been sat on closely, if fertile; but, in such a case, another day or two should determine whether it be good or bad. In a week a good egg is quite opaque when held against the light, and becomes of a blue colour.

Should a newly laid egg get chipped by the claw of the old bird, or by other accident, so long as the skin below the shell be not broken there is hope for it. A good thing to mend such a flaw is the marginal gummed paper round sheets of postage stamps, a piece of which the fancier should always keep in his pocket. Early in the season, thin-shelled eggs are often laid, and such generally get broken before being sat on many days. Should the fancier find his hen pigeons laying many eggs without shells, or with thin shells, it is time for him to attend to their supply of old lime and gravel. Sometimes a good egg will get very much indented a few days before it is due to hatch. So long as the skin below the shell be not broken, the indented shell may be carefully patched up with gummed paper, and the young one will often be successfully hatched.

\section{Young Pigeons.}

As a rule, young pigeons that require assistance from the egg are not worth the trouble in connection with them. Short-faced tumblers are an exception; but all other breeds, if possessed of the necessary strength to develop into healthy birds, should be allowed to hatch without any interference whatever.

Young pigeons when hatched are very helpless objects, but grow so fast when all goes well that a great increase in their size may be observed day by day. They are born blind, and covered with a yellow down, which, however, varies much, according to the colour they are to be. Silvers and yellows are hatched with scarcely any down on them, and this is a good indication of these colours. Yellows of the deepest and richest tint are, however, not hatched so thinly covered 
as those of a washed-out or mealy hue, such as is too often the case with many of our yellow pigeons, and attention to this will be no uncertain indication of the quality of colour that will be developed in due time in a newly hatched squab. When a week old, the young ones will be well stubbed over with feathers, which in another week will have begun to break, and give a good idea of colour and marking. If, during this time, a daily increase in size be not observed, or if one keeps getting behind the other, something is wrong; but unless the want is evidently from lack of food or warmth, nothing can be done with squabs so young. The bowels or digestive organs are out of order, and they seldom come right. The young of all small and hardy pigeons are as big as their parents at from four to five weeks old, when they will leave the nest and soon begin to feed themselves.

\section{Feeders.}

Feeders, such as common pigeons, Dragoons, Antwerps, and the strong and coarse specimens of fancy varieties, are used as nurses for the more choice breeds, and, although there is much misunderstanding as to the powers of even really good birds in their ability to successfully rear their own young, feeders may be advantageously made use of in many instances; but so long as good birds perform their natural functions, as the great majority are well able to do, it is but natural to allow them to do so.

When feeders are employed, the eggs of the good birds may be given to the feeders, if of the same age, or if one or two days older; but it is not safe to risk any greater difference in the age of the eggs, because, if hatched before their soft meat comes on them, the feeders will not feed them as a rule. In changing young ones, let them be a few days older than those they replace, and they will have so much additional care. When young birds are well feathered it is often unsafe to change them, as the feeders begin to 
know the difference in their appearance, and will occasionally either not feed them or drive them out of their nest. Some feeders are very valuable, from the care they bestow on any young ones given them, and a pair, of which the hen is barren, are often best of all in this respect. An egg placed in her nest will be taken to; after the interval of a day it may be removed, and a fresh pair of eggs from some choice pair of birds given to her, when she and her mate will treat them as their own, and rear them successfully in many instances. Barren bens have this advantage, that they can be made to wait till their owner has a use for them. The worst of feeders is, that they look so bad among good pigeons, and on this account they should always be kept in some separate loft if possible. A place for drafting young ones into is also a great convenience, for they soon become troublesome among breeding birds.

\section{Over Laying.}

Unless other eggs or young ones be given to pigeons who have been deprived of their own, they will often lay again much sooner than they would otherwise do, and when this is often repeated nothing but disaster can result. Such unnaturally forced eggs are often thin-shelled, unfertile, or, if they contain birds, they very often come to nothing. Rather than allow good hens to over lay themselves, if they cannot be supplied with substitutes in eggs or young ones, they should be penned up for a time, which will give their systems the needful rest.

\section{Sex of Young Pigeons.}

The usual pair of eggs laid by the hen pigeon generally result in a cock and hen, but so many instances occur of two cocks or two hens being produced in a nest that it is never safe to reckon on the sex of young ones. Certain indications of the sex of his young pigeons will soon present themselves 
to an experienced fancier; but, at the same time, where many young ones are bred, there will usually be one or two whose sex will puzzle the most experienced for a long time.

\section{Odd Birds.}

Odd birds in a loft, be they cocks or hens, are always very troublesome. Such should always be removed to a place by themselves, or common mates procured for them, when they may be used as feeders.

\section{Overcrowding.}

Pigeons are so productive that they often increase faster than accommodation can be provided; but nothing militates more against success in rearing young ones than overcrowded lofts, which are a fertile cause of disease, and when such does set in, the best seem to die first; at least, they are more missed than the worst, which is about the truth of it. When every result of an overcrowded loft is considered, such as extra expense for food, extra trouble in attendance, and the introduction of disease, it would be found to pay far better to use an unsparing hand in killing off faulty young ones, which seldom pay anything like their cost.

\section{Separating Sexes.}

Many fanciers separate the cocks from the hens during the winter season, and where there is every convenience for doing so it may be a good plan. When all nesting places are laid bare of their furnishings, there is but little inducement for the birds to breed during the short days of winter. It is at least unnatural for the sexes to lose the companionship of each other during several months of the year, and they have always seemed to me to thrive much better when left together. When all facilities for breeding are removed, as the birds begin to get deep in moult, and not replaced till the the beginning of spring, there will be no trouble experienced 
on this account, from pouters at least, though many of the small and hardy kinds of pigeons will not take advantage of such a long rest.

\section{Summary.}

The elements of success in breeding good fancy pigeons may be briefly summed up as follows:-Well-bred stock birds, properly paired in regard to their own and their ancestral form, supplied with good food and clean water, provided with proper breeding accommodation, not overcrowded, kept clean, and tended with all reasonable care by one who has their welfare and the love of them thoroughly at heart.

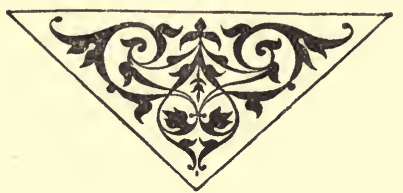




\section{Chapter VI.}

\section{$\propto$ COLOURS OF FANCY PIGEONS. $\varnothing$}

\section{The Wild Blue Rock.}

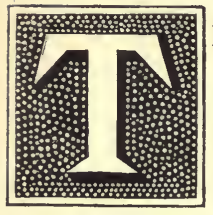

HE colour of the wild blue rock pigeon is found in nearly all domesticated fancy breeds of pigeons, and this is regarded as one of the proofs of their descent from it. The British blue rock pigeon differs from its congener in Asia in having a white rump, and this difference also exists in fancy pigeons of a blue colour, which are, however, always preferred to the blue rumped for the sake of uniformity. Many shades of the blue colour are found in tame pigeons, the one in most request being a rich even dark blue, neither running too dark and smoky in hue, nor too light and silvery in tone. The neck of a blue pigeon, of the best shade of colour, is dark, and sparkles with a metallic green and purple lustre. Two black bars cross the wings, and they should be deep black; but as the result of crossing of colours in breeding, many blue pigeons are faulty in this respect. The tail and flight feathers are much darker in shade than the shoulders, and the former are marked with black across their ends, forming, when the tail 
is outspread, a band of black. The outer tail feathers are margined with white on their outer edge as far as the black band.

The blue rock pigeon, when partially domesticated in field dovecotes, sometimes alters in colour, and the wing coverts assume a dappled appearance, being chequered on each feather with black. The dovehouse pigeon, as it is called, has been considered by some a distinct variety from the blue rock; but I have always found both the clear blue and blue chequered varieties living together in all the field dovecotes where I have observed these semi-wild pigeons. And not only in this country, but also in India, where semi-wild pigeons inhabit temples, mosques, and ruined buildings, both varieties may be found living together. The blue-chequered colour, like the blue, is found in most kinds of fancy pigeons, and may be considered to have originated all the curious spangling and chequering that exist in numerous kinds of pigeons.

\section{Changes in Colour.}

The first decided change in colour of the blue rock pigeon, after the chequered variety, is where the whole plumage alters to a red tint. This variation, also found in most kinds of tame pigeons, is known as mealy. The blue is replaced by a whitey-brown tint, and the neck and wing bars become dark red. When the mealy colour is improved by selection, it can be made into a very beautiful colour, as in the mealy show Antwerp. As the blue colour becomes chequered with black, so the mealy becomes chequered with red, and is called a red chequer.

These four colours, the blue, blue chequer, mealy, and red chequer, are, then, the most original colours in tame pigeons, and they are the foundation of all other colours found in them.

Besides the blue and mealy colours, there is what may be 
considered an offshoot of the former-the silver. In this colour the body tint assumes a dun hue, and the neck and wing bars become of a darker dun. There are two show shades of silvers, known as brown barred and black barred. They bear the same relation to each other as the wholecoloured duns, found in carriers and barbs. The carrier dun is soft and ruddy, while the barb dun is often very deep and merging into black. Although the dark-barred silver is called black barred, this is quite a misnomer, for real black bars on a dun-tinted body colour are, I believe, incompatible with nature. I have lately seen a silver cushat or ringdove which was shot in Fife, in January, 1885.

When the reddish tint of a mealy pigeon is changed to buff the neck and wing bars become yellow, and this colour is known in the fancy as yellow mealy, a soft and beautiful colour, found in many kinds of pigeons. Another barred colour found in pigeons is powdered blue, as in the Mahomet. The feathers of the head, neck, and shoulders of this bird are all tipped as if with hoar frost, the bars across its wings and tail remaining of an intense black. This colour has been engrafted on the blue owl pigeon, and a variation of it is known as powdered silver.

The barred colours of pigeons, therefore, include blue with black bars, silver with dun bars, mealy with red bars, and yellow mealy with yellow bars. As powdered silvers and powdered blues are found in owls, though not yet with such an intense powdering as in the Mahomet, powdered mealies and yellow mealies might, I think, be bred in time if wished for. Some of the mealy show Antwerps have already much powdering on their head and neck feathers. Through inter-breeding with other colours there are a great number of off-coloured barred pigeons, such as kite-barred blues, and reddish-barred blues; but all such are undesirable, each body colour being required pure of itself, and accompanied with sound bars to suit it, except in some varieties, such as the Triganica 
pigeon, of Modena, where many curious combinations of colour are found.

\section{Albinos and Melanoids.}

When colour fails altogether in animals, an albino, or white specimen is the result, and such are found among dovecote pigeons. Albinos, when bred with coloured pigeons often produce particoloured young, and this is the foundation of all white markings in fancy pigeons. A rarer freak of nature, however, than an albino, is when the normal colour of an animal becomes black, which is known as a melanoid. Melanoids occur in animals living in a state of nature, such as leopards, jackals, hares, and rabbits. I have not known of this natural change occurring in field dovecotes, but there can be little doubt that the black colour in tame pigeons is owing to this natural propensity, and that it is the foundation of all whole colours, such as red, yellow, and dun.

\section{Whole Colours.}

These colours, to he in perfection, should be uniform all over the bird, and not fall away to a lighter shade on the rump, wings, tail, belly, thighs, or vent. They advance in value according to the difficulty of producing them, blacks and duns being easy of acquisition, compared with reds and yellows, which latter are the choicest colours in fancy pigeons. To be seen in perfection, they must be seen on a whole feathered bird, or at least on a bird whose standard of marking does not require a white flight and tail, for the colour of these in a whole-feathered red or yellow is the crucial point in judging of their quality of colour. Black, red, and yellow of the choicest shades must be lustrous, with metallic sheen, the black being green, and the red greenish purple, in certain lights. Yellow has also an orange lustre, interspersed with' light green on the neck feathers, but there are few yellow 
pigeons that show such rich colour. Dun of the dark shade, as in barbs, also shows a greenish lustre; but the light or dull dun, so often seen in carriers, seldom carries any lustre beyond the neck feathers. This latter shade of dun colour, which is an off colour in all high-class fancy pigeons, except carriers, often fades with the advancing year, and when the bird is getting its new feathers at the moulting season it has sometimes a mottled appearance till they are all renewed; the same thing happens with many silver pigeons to a greater or less degree. There is a whole blue colour, without dark neck, flights, or tail, in which the black bars are wanting. It should be uniform in shade all over the bird, and may be seen in some Indian pigeons.

In some kinds of fancy pigeons the wing bars, both in barred and solid-coloured varieties, are changed to white, or are marked with white on the bar feathers.

\section{Spangled and Laced Birds.}

Many German and Oriental pigeons are spangled or laced. on the shoulders, such as hyacinths and blondinettes; but all such spangling or lacing is composed of a combination of the colours I have detailed as belonging to fancy pigeons, whether accompanied with white or not.

\section{Combinations of Colour.}

Some pigeons are clothed in two distinct colours, such as the archangel. I once bred a pigeon coloured in a way that has never before come under my observation-viz., a mealy, with black shoulders, a combination that I would not have believed possible, and it was nearly clean cut, like a good turbit. There is also the combined colour known as almond, or yellow spangled with black, besides many others, such as bronzed kite and golden dun. White markings on a coloured ground, and coloured markings on a white ground, are legion in fancy pigeons, the same constituting the claims of many 
to be considered as separate varieties, and each will be referred to in turn. The advance in colour from the normal blue may be traced as follows:-

Blue with black bars.

Blue chequered with black (blue chequer).

Whole black.

Silver with dun bars; a natural change from the blue.

Silver chequered with dun (silver chequer or dun chequer).

Whole dun.

Mealy with red bars; a natural change from the blue.

Mealy chequered with red (red chequer).

Whole red.

Buff with yellow bars; a natural change from the blue or mealy. Buff chequered with yellow (yellow chequer).

Whole yellow.

\section{General Remarks.}

All the barred, chequered, and solid colours are found in some varieties of fancy pigeons, while only some of them exist in others; but wherever blue, black, red and yellow exist, the other colours may be got if wanted, which they seldom are, being considered "off" colours, and of little value. The black, red, and yellow, when in the most lustrous perfection, have a beauty and richness that is not surpassed in the plumage of any bird; but it is seldom they are seen in perfection, and then only in some varieties of fancy pigeons. It must have taken long ages of careful breeding to bring the black, red, and yellow colours to perfection.

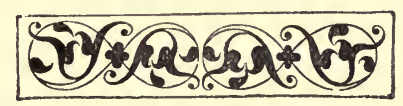




\section{Chapter VII.}

\section{$\propto$ EXHIBITING PIGEONS. $\infty$}

\section{Antiquity of Pigeon Shows.}

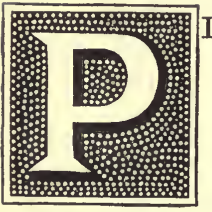

IGEON shows have probably been established in England for as long a period as any shows for the exhibition and comparison of fancy stock. The "Ordinances for Judging Almond Tumblers" date back to 1764, and it is likely that, long before then, the pigeon fanciers of the Metropolis had their meetings for the comparison of their pigeons. Before the days of railways, such meetings could only take place in some large centre, near to which there were resident many breeders, and an instance of this kind may be found in Lancashire, where shows for the exhibition of gold and silver mooney fowls have existed for time out of mind.

\section{Modern Show System.}

The show system of the present day has sprung up during the lifetime of the present generation, and some of the principal exhibitions draw together birds and their owners from all parts of the country. The chief of these meetings are 
the events of the year in the pigeon fancy, and determine who are the owners or breeders of the best specimens of each variety. Fanciers look forward to them as opportunities for meeting such as are like-minded with themselves; where they may compare their own stock with that of others, dispose of the good birds they have for sale, and purchase such as they may be in need of themselves. A visit to at least one of the chief shows in each season is beneficial to the fancier in many ways, and may either confirm him in his good opinion of his own birds, or enlighten him as to their demerits; for it is often the case, when one stays too much at home, that he insensibly contracts exaggerated ideas of his own birds, having no opportunity of seeing the progress made by others.

There are now a great number of pigeon shows held annually in this country, where valuable prizes are offered for the best specimens; and there can be no doubt that, owing to this fact, good birds have year by year increased in value, till the sum of $£ 100$ has been paid on more than one occasion for a choice specimen. Sums varying from $£ 25$ to $£ 50$ are by no means uncommon for really first-rate birds of the high-class varieties; and, indeed, it is only the very best birds that are worth buying for exhibition purposes, as they alone have any chance of repaying their cost.

\section{Show Boxes.}

Pigeons may be sent to shows in boxes or baskets. Boxes are liable to breakage, and when made extra strong and heavy are expensive in the way of carriage. Baskets are lighter, but, from their openness, are not so desirable in cold weather, unless lined with canvas. Both boxes and baskets, capable of holding from one to a dozen birds, are made in compartments. Fig. 11 illustrates a box, of a pattern long in use in Scotland, for holding two pouters. It measures 16in. long by $8 \mathrm{in}$. wide, and $8 \mathrm{in}$. deep inside. It is divided 
diagonally into two compartments, each having an inside lid, pierced with holes for ventilation. The birds are placed in it in opposite directions, and a couple of air holes should be made in the broad end of each compartment. The inside lids are lin. below the tops of the sides, which have notches cut in them, so that, when the outside lid is shut, a free current of air may pass through. The air holes represented in the figure are sufficient, and none should be made in the sides of the box, or in the narrow ends of the compartments. Boxes on the same principle as shown may be made with any number of divisions, but, for convenience

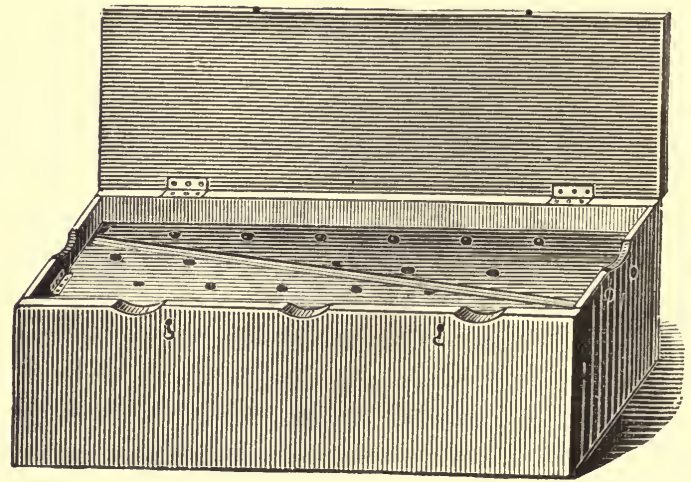

Fig. 11.-Travelling BoX for Pigeons.

in handling, six is usually the greatest number. The size of each compartment may vary, according to the breed they are to be used for; but they should always be made no larger than required, for when a bird has the least extra room, it is apt to turn, or attempt to turn, when its plumage will become disordered.

\section{Show Baskets.}

Baskets are made exactly on the same principle as the 
boxes described, and are, I think, on the whole preferable. When divided into compartments by wicker work or strong canvas, they form very good packages for pigeons. Good oblong baskets, measuring about 20in. by 12in., such as fruiterers sell cheaply, may be made into capital exhibition baskets, by dividing them into compartments with canvas, as shown in Fig. 12, which is a plan for a basket with eight

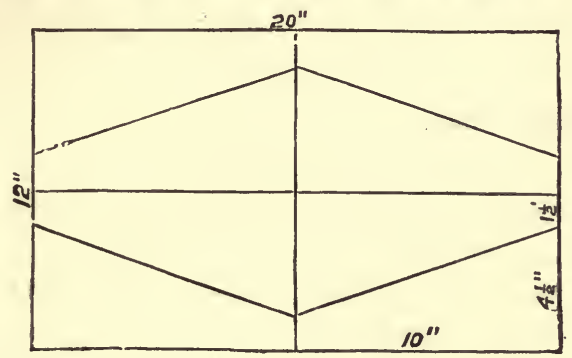

Fig. 12. - Plan for Dividing Pigeon Basket.

compartments, each $10 \mathrm{in}$. by $4 \frac{i}{2}$ in. at the wide, and $1 \frac{1}{2}$ in. at the narrow ends, and is suitable for such pigeons as turbits or owls. Jacobins are better sent in baskets having canvas instead of basket work divisions, and fantails should have large and lofty cloth-lined compartments, to save their tails from being broken or destroyed.

\section{Preparing Birds for Showing.}

The greater number of fancy pigeons may be sent to exhibitions without any preparation at home, except that, in cases where the birds are of an extra wild nature, some preliminary penning may be of advantage in rendering them to some extent at home in a show pen. Some, however, and especially pouters, really require a considerable training to enable them to be shown with advantage, and this will be referred to more particularly elsewhere. Pigeons should in all cases be shown in a clean state, as many judges lay considerable 
stress on this point; and although a good bird can never look very bad, though dirty, one equally good in spotless plumage looks very much better. A good deal may be done for dirty birds by careful washing with soap and soft water; but washed birds have never the finish of those that do not require it. A practice that cannot be too strongly deprecated is oiling or greasing the plumage to improve the colour. Birds so treated should never receive notice at the hands of a judge.

\section{Exhibition Pens.}

The best exhibition pens for pigeons are those of the beehive shape, made with galvanised wire; and a good thing for strewing them with is the husk of oats, though coarse pine sawdust is better than nothing. Each pen should have water and food tins, so placed that the birds can reach them without trouble. When thrown on the bottom of the pen, food soon gets soiled, and heavily wattled pigeons, accustomed to feed from hoppers, are unable to feed from the floor.

\section{Walking Pens.}

For judging pouters and fantails, a large walking pen should always be provided, as it is impossible to judge them properly otherwise; and, unless exhibitors see the process of adjudication for themselves, they should be sparing of criticism afterwards, as pouters, being pigeons chiefly of shape and carriage, look very different when standing on a block than when on their mettle in the show-pen.

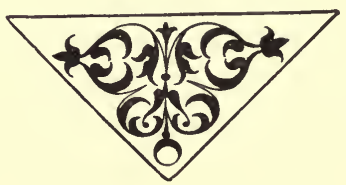




\section{Chapter VIII.}

\section{$\propto$ DISEASES OF PIGEONS. $\varnothing$}

\section{General Remarks.}

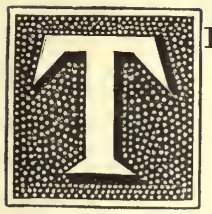

HE choicest kinds of fancy pigeons are subject to many diseases, no doubt arising in many instances from hereditary causes. Where a large stock is kept, the pens set apart for sick birds will seldom be altogether untenanted, for whether much doctoring be practised on them or not, ailing pigeons will have more chance of recovery when put in hospital than when left among the healthy birds, who often treat them very roughly. The eye of the experienced fancier soon detects a pigeon that is out of sorts; a disinclination for food or for the bath, a peculiarity in its flight or walk, and many other signs, may proclaim something wrong. As delay can only complicate matters, success in the treatment of a sick bird may often be attained by doing what may be done quickly. For my own part, I may say that I never had much success in treating pigeons with medicines, that I have found their action very uncertain, and that about the same number of sick ones recover, in certain illnesses, whether drugged or 
not. For better reference I shall treat of the principal diseases fancy pigeons are liable to in alphabetical order.

\section{Bowels, Inflammation of.}

The disease most fatal to fancy pigeons is inflammation of the bowels. Many have it at some period of their lives, and a large proportion before the completion of their first moult. It may almost be called the distemper of pigeons, and may be known by the huddled-up appearance of the bird. The disease is sometimes so rapid in its action that in a few days the bird is reduced to nothing but skin and bone. The power of flight is soon lost, and the bird retires into a corner. When first observed, the pigeon so affected should be secluded, and have access to old lime. The best remedy I have found for this disease, which is known in the fancy as "going light," is to give a strong purge of common salt, and, a day or two after, from six to ten drops of laudanum in a teaspoonful of water, for two or three days in succession. In many cases nothing seems to do the least good; but when the bird survives ten days of illness, there is always good hope of its ultimate recovery. When this disease attacks young pigeons in the nest, which it does in some cases, there is no hope of their recovery; but I have known them, when not attacked till six weeks old, come through very severe attacks of it. The most fatal time for them, when once able to fly and do for themselves, is during their first moult, and those that pass that period without having this distemper sometimes take it during their second year, and not unfrequently when feeding young ones. After this period they are comparatively safe, and their systems so hardened that, if they do take it, they are able more easily to throw it off, though there are exceptions. Many do not consider a bird safe till it has passed through this distemper in some form or other, and after safely passing through it many consider a 
bird about twice as valuable as it was before, so many having to succumb to its effects. Those that recover from very severe attacks may be reckoned on as good for several years. In the worst cases, it is astonishing how soon they recover when they once take the turn for the better; they seem to get heavy about as fast as they got light. In this disease it is better to feed sparingly for some days after seclusion. They have generally a great desire to eat; but when it is found that the food does not pass from the crop, it can only do harm, and hasten their death. I refer, of course, to the worst cases, each of which must be treated on its own merits, and by careful observation of the state of the crop each morning. When the dung, from an offensive green appearance, begins to change to a more healthy state, the recovery of the bird may be reckoned on. The best protection against this fatal disease is to keep the salt earth box constantly supplied with the mixture of old lime, gravel, and salt.

\section{Canker.}

This disease makes sad havoc in a loft of pigeons when it becomes established. I have generally found it make its appearance in overcrowded pigeonries; but it is undoubtedly most infectious, and may often be introduced by an infected bird, not necessarily suffering from it at the time of its introduction, but having in its system the seeds of the disease, which, by the time it shows itself, makes any measures for the protection of the other birds abortive. Although foul water may not be the cause of an outbreak of canker in a loft, the water from which they drink in common has much to do with the spread of it; but beyond separating the infected birds, and paying regard to cleanliness and ventilation, I cannot advise any method of retarding it when once thoroughly established in a loft, for it will run its course, and, when in a severe form, spoil a whole season's work in breeding, not disappearing till the advent 
of cold weather. When this disease has taken thorough hold in a loft, almost every young bird of choice breed will become infected with it at from two to four weeks old, even though the feeders do not themselves have it. Few recover from it, the strain on their systems when so young being too great. Canker would sometimes seem to be the direct result from foul drinking water and dirty food, as pigeons that are sent long distances by sea invariably become infected when not kept scrupulously clean. The best safeguards against an outbreak of canker are strict attention to cleanliness, no overcrowding in the loft, and great care in introducing fresh birds during the breeding season. I have never had a canker epidemic among my pigeons all through a breeding season, but more than once it has appeared in my pigeonry about the end of July, and almost every young one hatched thereafter has become affected with it. It takes various forms; first in the throat, in which case it appears, to a greater or lesser extent, as lumps of cheesy looking matter, which, if only small, and at the entrance of the throat, so as not to interfere with swallowing, may be often cured by touching with nitrate of silver or alum; but if of large extent, and deep down in the throat, so as to prevent swallowing, it causes death from choking or starvation. Canker sometimes forms in the head, below one eye, and it will then often grow so rapidly, that in a few days it will distort the head out of all proportion, and cause death. I have never been able to cure this form of it. Again, the upper or under mandible is often affected, and becomes swollen and distorted, preventing the squab from being fed. Painting the sores with tincture of perchloride of iron, or with glycerine and earbolic acid (six or eight parts of the former to one of the latter), has been advised by some; but nitrate of silver, or powdered alum, according to others, is more efficacious. Canker of the beak and eye wattles of carriers and barbs may be treated in the same 
way, and then covered with starch or plaster of Paris. Common salt is said to be a cure for the small tumours, called small pox, that sometimes appear on the wattles of carriers. I consider that attention to the salt earth mixture is the best protection against throat canker in young pigeons.

\section{Cold.}

Cold in pigeons may be known by a running at the nostrils and eyes. It becomes more or less severe according to its restriction to the upper or lower air passages. More or less deposit of cankerous looking matter will take place in severe cases, but warmth and an aperient will generally effect a cure. What is known as the "one-eyed cold" is a serious complaint. In this, only one of the bird's eyes is affected. The lid gets much swollen, and closes over the eye, from which, and from the nostrils and mouth as well, matter generally runs for a week or two. The inflammation is severe while it lasts, which is often for a fortnight or three weeks; but seclusion from draught, and bathing with warm water twice daily, will almost always result in cure, without the use of any medicine.

\section{Core, the.}

This is a tumour that grows in or near the vent, and is not of very common occurrence. When in the vent, the bird will be seen pecking at the part, and on examination there will be found what looks like a prolapsus of that organ, wet and bloody. After a few days this will harden and dry up, and when the scab comes away the core will come with it. The core was so called by the old writers on account of its resemblance to the core of an apple. When it comes on the belly, somewhere near the vent, its presence will be unsuspected till discovered by accident. A hard lump will be felt on handling the bird, and on remov- 
ing the feathers the skin will be found stretched over it like a net. On cutting the skin, the core, which is like a small shelled walnut, will come away easily, if ripe. I have not seen more than eight or ten cases of the core in thousands of pigeons.

\section{Diarrhœa.}

During the moulting season, some birds will for several weeks be affected with a more or less severe diarrhœa, and pass nothing but fluid matter. The best remedy for this is a plentiful supply of old lime, and they generally recover as they get through the moult. If a bird so affected loses flesh, a change to a more binding kind of food will be of service.

\section{Egg Bound.}

During a cold spring, or when matched up too early in the season, many hen pigeons become egg bound, and lose the power of their limbs. Such should be carefully watched, as they are liable to very rough treatment from their mates and other pigeons in the loft. If, when placed on their nests, they do not pass the egg at the time of day it should come, a teaspoonful of treacle will generally do good; but a few drops of sweet oil, passed into the vent with a feather, will also much assist them. Some delicate hens among shortfaced tumblers are constantly affected in this way, and the result in breeding from such is so little as to be not worth the trouble in connection with them. A hen that loses the power of her limbs from laying too early in the season, should be kept apart for a month or six weeks, to enable her to recruit her strength.

\section{Flesh Wen.}

This was a form of wing disease according to the old writers; but, apart from wens in connection with the joints, 
such tumours sometimes appear on the crown of the head and between the beak and eyes of pouters and other birds. They appear as small pea-shaped, movable lumps, and should be cut out before they attain large size. The skin may be slit with a sharp knife, when the tumour is easily pressed out, unless attached to the bone, which it sometimes is, when it must be cut away; but it is then likely to grow again.

\section{Gizzard Fallen.}

This was the old term for what is really a displacement of the bowels. Pouter hens are very subject to it after three or four years of age, and carriers and barbs also. There is no cure for it, though birds so affected will live a few months. I have never known a cock pouter with this disease, but have seen young ones affected with it in the nest, when it has always proved fatal in my experience.

\section{Gorging.}

This is an ailment of pouters, and more especially of such as have well-developed crops, the best birds in this respect having to be carefully watched. The old cure was to pass the bird through the leg of a stocking, and hang it up till the food passed off; but the same result may be attained by placing the bird in a narrow box, padded at one end to support the crop, so as to allow the food to pass into the stomach. Large cropped pouters, when allowed to feed their young, are very apt to gorge, some doing so invariably. When gorged from drinking too much water, this may be pressed out of them by gently squeezing the crop till they disgorge it, when they will be right again in a short time. When, however, the crop is so gorged as to contain nearly as much as the weight of the whole bird, it is a bad sign, and it will then be found that neither the stocking nor box 
remedy will be of any use, for the stomach has lost its power of action. The crop may then be cut open, cleaned out, and sewn up again, the inner and outer skins being carefully sewn separately. This operation is often successfully performed, but in many cases is of no use, as the powers of the stomach have become impaired, and as soon as the bird is at liberty it will speedily be gorged again, nothing that is eaten passing into the stomach. From this cause, many of the best pouter pigeons ever seen have died, and with those best developed in crop it will always be one of the complaints most to be feared. Besides cutting the crop open in bad cases of gorging, Moore says: "Others will tie that part of the crop in which the undigested meat lies tight round with a string, and let it rot off. This method never fails, though it spoils the shape of the crop." With a pouter considered valuable for stock, and past his best show days, a curtailment of crop is not any drawback, but rather the reverse. Charcoal capsules are useful for preventing the corruption of the food in the crop of a gorged pouter, and copaiba capsules are used to make them disgorge, generally proving effective. A pouter should be attended to on showing the least signs of becoming gorged; delay is dangerous.

\section{Insects.}

Pigeons are apt to be infested with several kinds of insects. The feather louse is harmless, as far as ever I saw, and seems to be common to all pigeons. It is found chiefly about the neck feathers, and requires the natural heat of the bird to keep it alive, for on the death of a bird they may be seen crowding up towards its head, in a sort of torpid state. The pigeon louse is "troublesome on all birds unable from a malformed beak to preen themselves, and when allowed to increase for want of a little blue ointment, renders their lives truly miserable. Short-faced tumblers are as liable as any to these lice, and should be examined frequently 
by blowing up the feathers about the vent. A little mercurial ointment rubbed about that part and under the wings will kill all that come in contact with it. Ticks, I think with $\mathrm{Mr}$. Brent,"proceed from a flat fly that may be sometimes seen running over young pigeons, and hiding among their feathers. This fly, which is difficult to catch, and difficult to kill when caught, for it is so tough that it can scarcely be squeezed to death between the finger and thumb, is not often seen. Ticks are the largest of the insects that infest pigeon houses, and are fortunately, at least in my experience, not very common. I have never been much troubled with mites, but have known others who were, in such countless thousands, that during a whole breeding season every successive nest of young ones was covered with them, causing the death of many. I suppose they are the same sort of vermin that trouble canary breeders. Fleas are the commonest kind of pests that infest pigeon houses, but they and all other insects may now be easily kept down by the use of the insecticide known as Dalmatian Insect Powder, which has lately come into universal use. It should be dusted over the nests occasionally, and it is the best friend of the pigeon fancier. Since I began using it, my pigeon houses have been quite free of fleas and other parasites.

\section{Leg Weakness.}

This is a complaint which generally attacks young pouter pigeons early or late in the season. A bird will, apparently, be going on well, and be nearly ready to quit the nest, when it will be observed to be unable to get on its legs. I have seldom known a bird so affected cured. Those that give promise of being extra long in limb and upstanding in carriage are most liable to it. Such weakness in the limbs, proceeding from some internal cause, must not, however, be mistaken for a fracture or sprain of the limb, an accident which sometimes happens through a bird falling over its 
nest mate. This is often curable by a few days of careful attention.

\section{Moulting.}

The majority of pigeons go through their annual moult without any trouble, but generally a few of them will fall into a diarrhœa during that time. When this becomes specially severe, the growth of the new feathers will sometimes suddenly stop. If the bird so affected recovers, the growth of its feathers will proceed, but many of the birds will be weak and unfurnished about the middle, showing where their growth was arrested; and instead of the feathers lying close to the bird's body, they will hang loosely, and flutter about with the wind. I have seen several cases of this, but it cannot be said to happen very often. Of course, the bird so affected cannot get into proper feather before another moult. When a pigeon casts its feathers in masses, as many do, so as to be quite bare on head and neck, it should get extra protection from cold and draught till the new feathers are well grown.

\section{Small Pox.}

Small Pox was well known to the old writers from their description of it, but I have never known a case of it in this country. In India, however, it is a common complaint of young pigeons in the nest, and I have known seasons there when every young bird bred by myself and others, to the number of hundreds, has been attacked with it. At about a fortnight old, pustules full of yellow matter would break out all over the bird, including its beak and feet. If let alone these would gradually dry up, and by the time the bird was able to fly, it would be nearly clear of them; but if broken they would bleed, and grow into big sores. I think this form of small pox is quite unknown in this country now: at least, I never heard any fancier say he had found it in his loft. 


\section{Spouts.}

These are fissures that form in the eye wattles of barbs and carriers, either naturally, from the skin growing into a fold, or from accident. They never heal of themselves, but must be cut out with sharp scissors, and the wound dressed with healing ointment; the hole soon fills up. The operation is no doubt a painful one, but is compensated for by the after comfort of the bird.

\section{Vertigo, or the Megrims.}

An affection of the brain, causing the bird to turn its head right round, and making it fall over and flutter about. Although not an uncommon disease, I have, fortunately, never been much troubled with it among my pigeons. I think it incurable, and, acting on that idea, have killed any birds so affected as soon as possible, to get them out of the way.

\section{Wing Disease.}

This disease is common to every variety of fancy pigeon. It can generally be detected before the bird loses all power of flight, by the one-sided way in which it flies. When so observed, a bird will be found to have a swelling on some of the joints of its wings. An almost certain cure at this stage of the disease is, not only to draw both primary and secondary flight feathers, but to strip the wing itself of all feathers except the small downy ones. The great flow of blood to the new feathers draws off the matter that would form in the swollen joint, and, by the time the wing is refurnished, all signs of the swelling will have disappeared, and the bird will fly as before. Having succeeded in this way in curing numerous pigeons, I can recommend it as the best thing to do. Formerly, the cure was to leech the swelling, or to wait till matter formed, and then lance it; but not one bird out of a dozen will fly again after 
being cut about the joint, as the tendons are apt to get severed. When the same disease attacks the thigh joint it is not so easily cured, but in my experience it seldom does so, as compared to the wing. The old writers divided this disease into the flesh wen and the bone wen, but the one is only an intensified form of the other. If taken in time, this disease may generally be cured by the method stated.

\section{Conclusion.}

There are certain strains of pigeons among all the highclass varieties which have become more healthy than others, on account of systematic weeding out of all diseased birds. The plan I adopt, and which I recommend to others, is to kill off or discard all birds that become affected with serious hereditary ailments, such as wing disease.

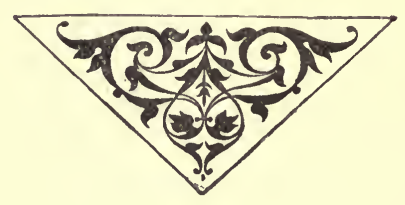




\section{Chapter IX.}

\section{$\propto$ VARIETIES OF DOMESTIC PIGEONS. $\varnothing$}

\section{Scheme of Description.}

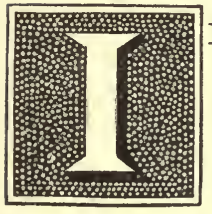

$\mathrm{N}$ describing the numerous varieties of domestic pigeons with which I am acquainted, I shall commence with those least removed from the original type, from which, as I believe, all varieties descend. Many of them are identical in conformation with the wild blue rock pigeon, and others have the addition of turned crowns, or feathered legs and feet. From them I shall proceed to the intermediate class, which will include varieties such as the runts, with their extraordinary size; the frizzled, frillback, and lace pigeons, with their curious plumage; and the ringbeater, lowtan, and tumbler, with their peculiar flight or movements. I shall then conclude with a description of what are called high-class pigeons, the favourites of the most exacting pigeon fanciers, the birds that come up but seldom to the standard of excellence laid down for them, because they have not only abnormal conformation, but carriage of body or style of movement, and beauty of feather as well, and so combine in themselves such a sum of excellence, when anything like 
perfect, that the successful breeding of them is the work of clever, thoughtful men.

\section{"Race" or "Original" Pigeons.}

These high-class birds, as well as the intermediate class, have been named by the Germans "race" or "original" pigeons; and while many have been able to assent to the blue rock theory of descent of the feather varieties, most of the others are so removed from them that some writers have considered them as separate creations. On this question, since writing the chapter on the "Origin of Fancy Pigeons," I have found, in the third edition (1876) of the work of Neumeister, the German writer, the following: "We shall not be very far removed from the truth in supposing that the first beginning in forming races took place by climatic influences, according to the same acting laws that produced species; but that these, by domestication, artificially conducted pairing, and continued breeding, in the course of thousands of years were raised to the highest expression of race types. Original races with perfect characteristics are not found in a free natural state; these only could be produced under the care and guardianship of man, who, as their protector, is rejoiced up to the present day by their fine and rare forms, pleasing manners, and symmetrical arrangement of colours. But that the supposition of their descent from one primitive race is justified, is proved by the facility with which all the races, the common field pigeon included, can pair and produce fruitful young ones, by the strikingly great resemblance of their nature, and the inclination constantly to return to the wild blue colour and shape of the field pigeon (Columba livia). The treacherous bluish colouring which so frequently springs up in black, red, and yellow, on certain parts (rump, vent, flights, and tail), is only too well known to every attentive breeder."

These ideas are quite in accordance with what I have ex- 
pressed here and elsewhere. I have already instanced the great differences existing in various races of canary birds from what we know was their progenitor, and as we can fix the time that it has taken to accomplish such results with comparative accuracy, the "thousands of years" supposed necessary by Neumeister for the perfecting of "race" pigeons may be somewhat modified, though I have no doubt that some of our varieties may have existed for some hundreds of centuries, when we remember what Pliny says about pedigree pigeons among the Romans.

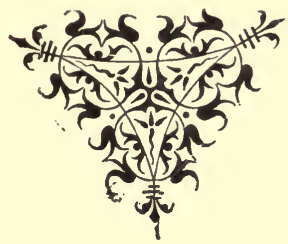




\section{Chapter X.}

\section{$\propto$ COMMON PIGEONS. $\nsim$}

\section{Rock Pigeons.}

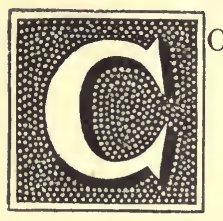

OMMON pigeons, strictly speaking, are rock or dovehouse pigeons, as found in a state of nature, or in a semi-wild state. I have already referred to them elsewhere, and have only to add that in the West of Scotland they are bred by pigeon fanciers, who have a class for their favourites at the annual show held in the town of Kilmarnock. Looking, as I have often done, at the class at this show, which generally includes over a dozen entries of blues and blue chequers, I have felt that I would rather not have the responsibility of awarding the prizes, the birds appear so very much alike. When a breed comes to be produced, as they, are, for size, good shape, and purity of colour and type, they must necessarily cease to be regarded as quite common, and would more truly be designated as fancy rock, or dovehouse pigeons.

\section{Common Pigeons.}

Common pigeons are generally understood to be those of 
mixed race, so interbred that it is often impossible to guess at their ancestry; and the same abound in almost every town and village in the kingdom. The old English name for them was runts, probably having the same meaning as when applied to common cattle, as Welsh runts, though a canary hen of three jears of age was also called a runt. Moore refers to common pigeons, after describing the fancy runts: "To these we may add common runts, which are kept purely for the dish, and generally in locker holes in inn yards or other places, and are well known to everybody; they are good feeders, and therefore good nurses for any of the more curious sorts of pigeons."

In France these common runts are known as Pigeons Mondains, and, according to Boitard and Corbie, who describe them as having no special characteristics, because they assume all forms and colours, what they lose in purity they gain in the way of fecundity. When extra feather-footed, such are known as Pigeons Patu, and the authors above-named describe and illustrate types of both denominations. Common runts, when selected for their gay and striking colours, are so far interesting that their young assume the most various, though uneven, markings; and for my own part, I would rather breed a motley lot of such, than confine myself to some single uninteresting, though undoubtedly distinct and pure race, such as the spot pigeon.

\section{Pigeons for the Market.}

In France a considerable trade is done in supplying the markets with hand-fed young pigeons, fattened in the following way: When the birds are about three weeks old they are placed in cages, each containing about thirty or forty, kept in a dark place, and fed five or six times a day, through a pipe, with a liquid paste of buckwheat flour mixed with whole maize. They become fat in five or six days, and "it is astonishing how much delicacy they assume in such a short time." 
I believe there is a limited trade for supplying the London markets with hand-fed or crammed pigeons, but the chief towns in this country are supplied almost exclusively direct from field dovecotes. Purchasers may know how to select young and tender birds by the presence of yellow down on their neck feathers.

When the value of the manure from a few pairs of common pigeons, kept in an aviary, is taken into account, this, in addition to the value of the young ones they produce, will pay for the food they consume. The manure may be kept in barrels, each layer, of an inch in depth, being covered with a similar layer of dry earth, siftings of ashes, or road scrapings, which will deodorise it, and make a very rich compost, worth several pounds a ton. I have seen capital crops from very poor soil, on which such a compost has been thrown, some three or four times as thickly as Peruvian guano is generally spread.

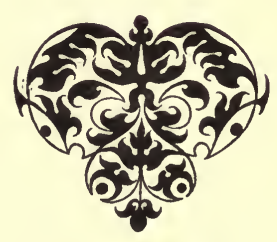





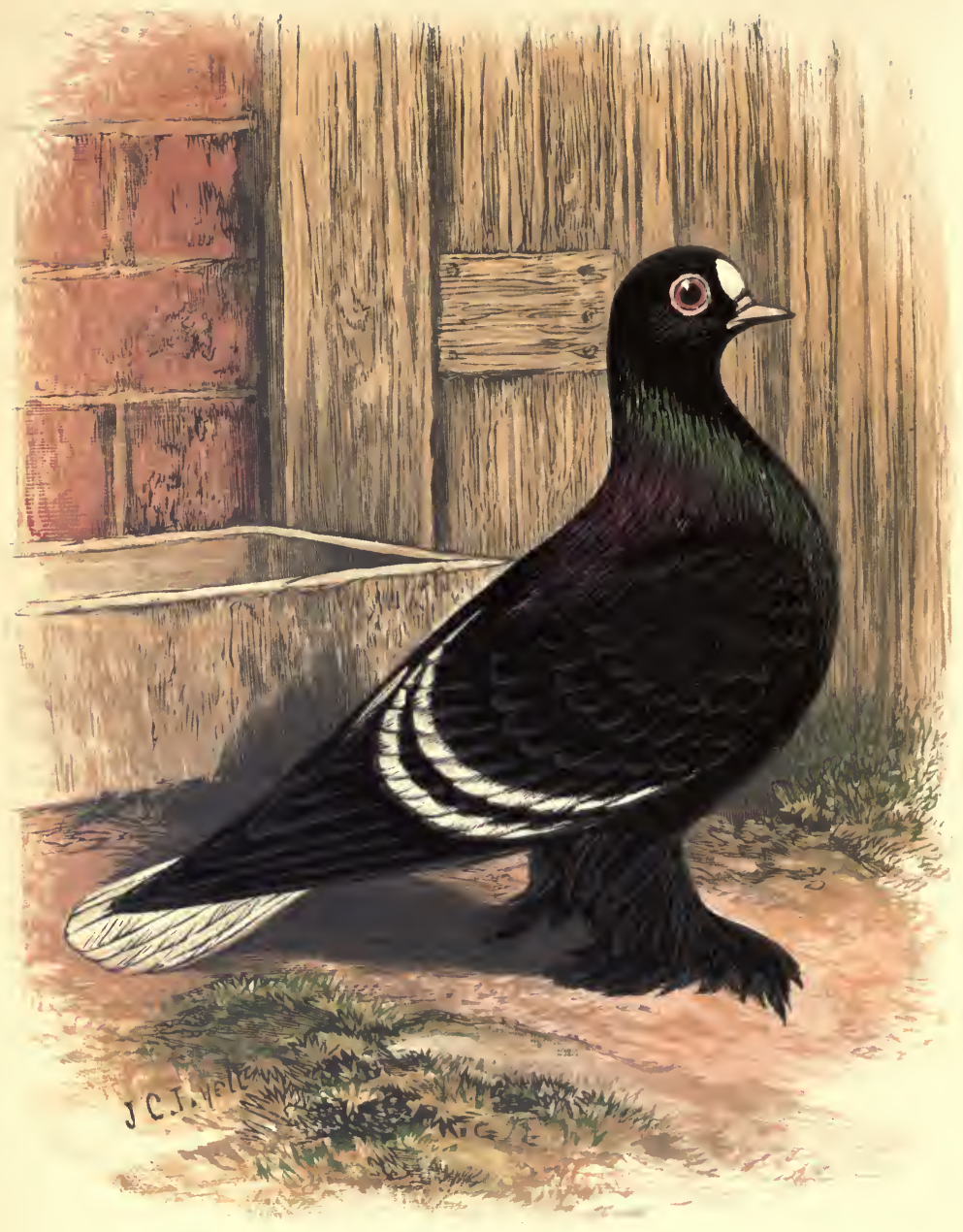

WHITE SPOT PIGEON. 


\section{Chapter XI.}

\section{PIGEONS DISTINGUISHED CHIEFLY BY THEIR COLOUR OR MARKING.}

\section{The Spot Pigeon.}

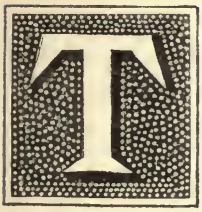

HE Spot has been described by every English writer, including Willughby, and is common on the Continent. The Germans call it the Maskentaube, and the French, Pigeon Heurté, or the Spot Pigeon. It is of the size and make of the common Field Pigeon, generally smooth-headed and clean-legged, and all white, except a spot of colour on the forehead, extending from the beak wattle to the middle of the brow-either blue, black, red, or yellow-and with a coloured tail and tail coverts to correspond. Some are peak-headed, and others shell-hooded, in which case the feet and legs are generally feathered as well. Boitard and Corbie refer to a variety with white tails, the spot being the only coloured portion of their feathers. These are classed with the Mondains, or common pigeons. The upper mandible of the Spot is coloured in accordance with its markings, the lower white. The iris of the eye is hazel-coloured. 


\section{The White-spot, or Blaze Face Pigeon.}

The White-spot Pigeon, generally known in England as the Blaze Face (die Weiszblössige Taube of Germany), is the reverse in marking of the common Spot. Its head is unhooded, the upper mandible white, the lower coloured in accordance with the plumage. The legs and feet are in some smooth, in others feathered. The heavier the leg-feathering in this breed the better they look; but it is not easy to procure them well-hocked and booted, the majority being only sparsely covered.

This pigeon is of the common Field type in formation of head and beak, and its chief value lies in the quality of its colouring and accuracy of its marking. The irides are yellow or red, following the body colour. The breed occurs in the following varieties:

The common White-spot, in all ground colours, with a white, regularly formed oval spot on the forehead. The tail, with its coverts, is also white.

The White-barred Spot is black or blue in colour, and has, in addition to the marks of the foregoing, white, or white edged with black, wing bars. White-barred reds and yellows, as in most other breeds, are rare.

The White-scaled Spot is black or blue. The Black, in addition to white spot and white tail, has the wing coverts scaled or chequered with white, the flights tipped or finched with white spots, and the bars either white, or spotted with white, like the flights; but the white in this variety is of a yellow or creamy cast. This pigeon has, probably, some connection with the spangled Suabian. The Blue, in addition to the white spot and tail, has the wing coverts chequered with white, and black bars across the wings.

The Copper-winged White-spot, or English Fire Pigeon, is the most beautiful of the Blaze Faces. It is thicker set, broader-breasted, and shorter than the preceding varieties. It has an orange iris, and must be heavily feathered on 


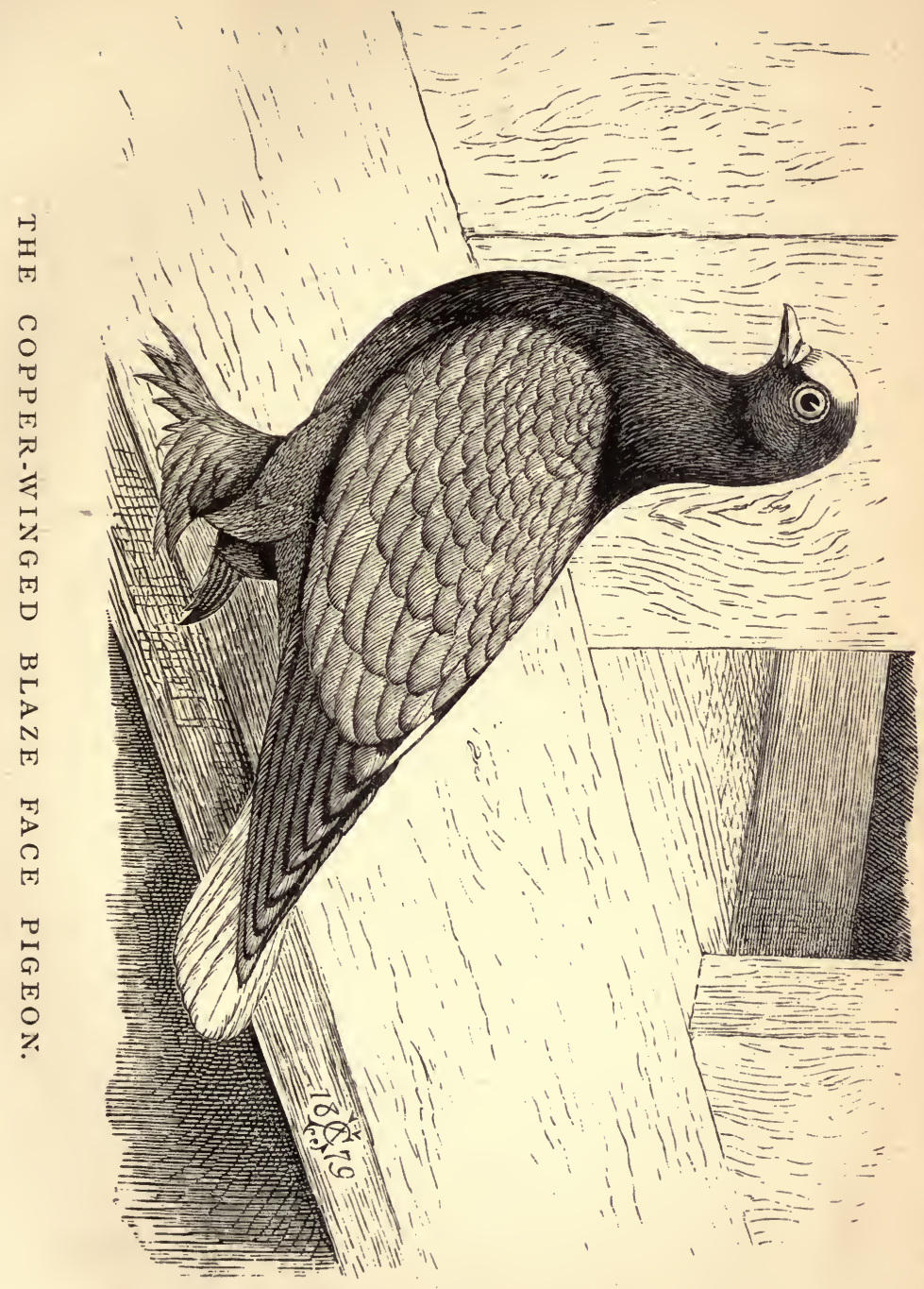



hocks, legs, and feet. The upper mandible, according to the German standard, should be white. This pigeon has the white forehead spot, white tail and tail coverts. The head, neck, and breast are dark blue-black, lustred with green and purple hues; the under body and leg-feathering should approach the same colouring as much as possible; and the flights are blueblack, with a bronzed kite colouring on their inner webs. The back and wing coverts, or shoulders, are of a burnished copper colour, but only after the first moult, the nestling feathers, as in other lustrous pigeons, being very dull compared with the matured plumage. Mr. Ludlow says the English Fire Pigeon is one of the varieties that show a sexual difference in their colouring, the hens having their copper feathers distinctly tipped with black, which the cocks do not. Whether this difference exists all through the breed, or only in one strain of it, I am not aware, but Neumeister makes no mention of it. It is a matter of taste which of the two appearances is the more pleasing. The Copper-wing is not found with white wing bars.

\section{The Saxon Pigeon.}

A variety of foreign Toy pigeon, called the Saxon, has been occasionally exhibited in this country lately. It is brilliant black in colour, with white wing bars. The head is unhooded, the eyes orange-coloured, and the legs and feet rather heavily feathered. I cannot find any reference to it among German authors. Such a variety might, no doubt, be produced by selection from the produce of the white-barred black Blaze Faces that happened to come foul-tailed and short of face marking. I believe it is not unusual for them to breed young ones entirely wanting the white brow spot.

\section{The Breast Pigeon.}

The Breast, Coloured Breasted, or Breaster Pigeon (die Brusttaube, Farbenbrïstige Taube, der Bruster), is a German 
Toy of peculiar marking belonging to the Field type of pigeons, but more slenderly built, and a good flyer and breeder. It is marked on the head, neck, and breast black, blue, red, or yellow, the colour being cut across, or evenly belted, before reaching the thighs. The back, wings, tail, and under parts are pure white, but only after the first moult, the nest feathers being tinged with colour. A variety of the yellow ones retain yellow wing bars; but these are rare. The beak is light, and the iris yellow. They are generally smooth-headed, but occasionally shellhooded, and smooth and feathered-legged specimens are found among them. The black variety generally retains some colour on the parts that should moult white, from which it derives the special name of Russtaube, or Soot Pigeon. I saw a pair of these birds lately. The head, neck, and breast were of a purple-black, and the wing coverts white, tinged with black, as if dirtied with much handling.

There are also Breast Pigeons having the said marking reversed, the head, neck, and breast being white, and the rest of the feathers coloured. Such are mentioned by the German author, Neumeister; but I have never seen any of them.

\section{The Ice Pigeon.}

This variety derives its name from its beautiful lavender blue colour, considered by the German fanciers to resemble blue ice; hence its name-die Eistaube. It is also known by the names Mehl and Lasurtaube, signifying Meal and Azure Blue Pigeon. There are several varieties of the Ice Pigeon, the simplest form being of a beautiful clear light blue, without wing bars, but with dark flights and barred tail. This form, which is probably the original of the others, is of the size of the common Field Pigeon, but more thickset, and broader chested, shorter necked and legged. It should be heavily feathered on the legs and feet. It has a dark beak 



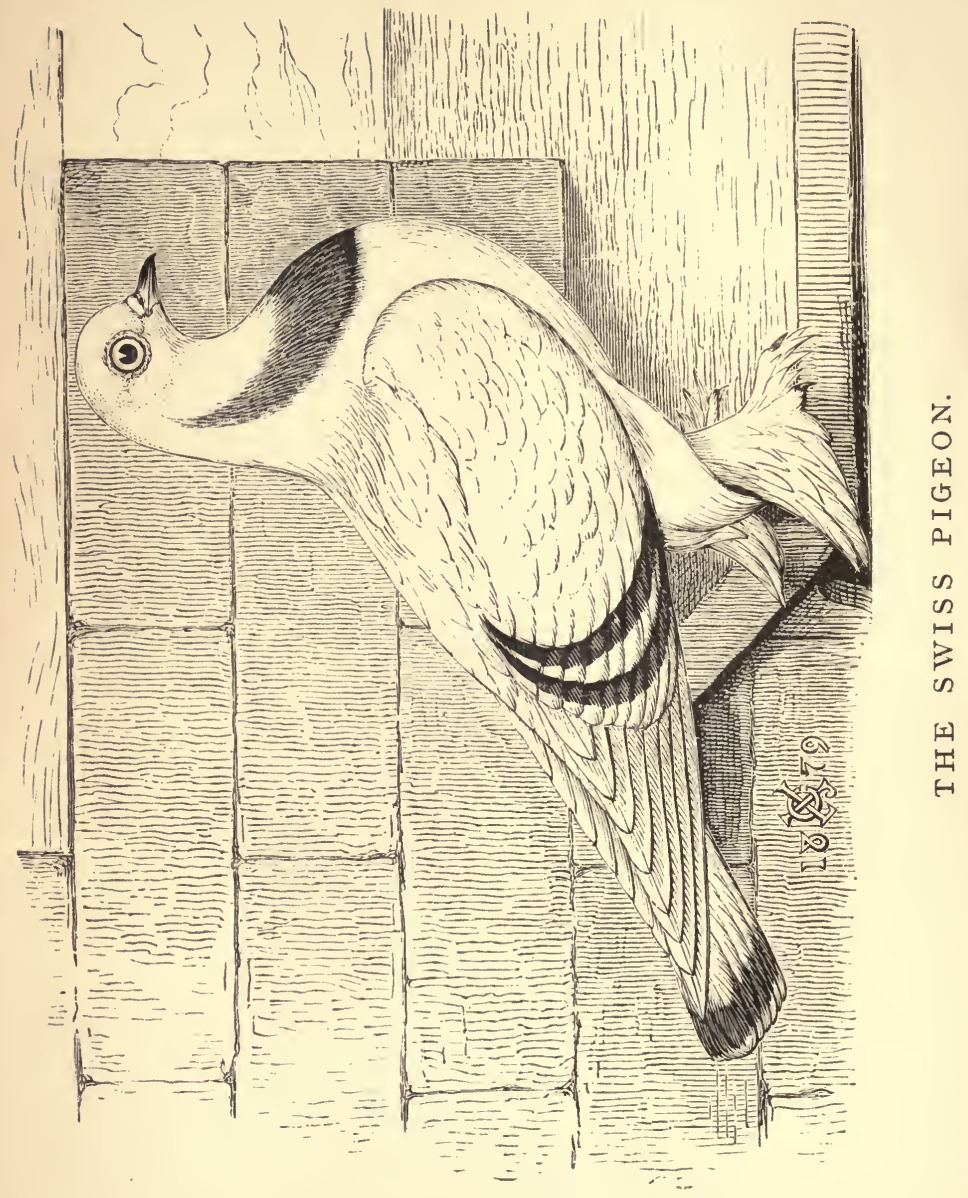


and nails, a reddish yellow iris, and is smooth-headed. The first remove from this form is that in which the colour is still more delicate and silvery, and in which the dark flights and tail bar almost disappear, and become nearly of the same tint as the body feathers. The next form, originally from Silesia, is of the same colouring as the preceding, but with white wing bars, beautifully edged with black, and with black tail bar. The newest and rarest form is known in Germany as the Porzelantaube, or Porcelain Pigeon, and, in addition to what the last-mentioned variety, the Silesian, shows, is chequered or spangled over the coverts of the wings, shoulders, upper and middle back, with narrow white spots fringed with black.

The make and shape of all these varieties are similar. They are found smooth, medium, and rough-legged, but are preferred heavily feathered. The smooth-legged chequered or spangled ones are known in this country as Ural Ice, while the rough-legged spangled birds are called Siberian Ice. In all varieties they range in colour from light to dark, but the powdered lavender ground tint, as uniform as possible, is the most desirable. The blacker the edging on white wing bars and spangling, the more inclined they are to run dark in the blue. The iris is always preferred to be yellow, but is often hazel in the lightest tinted birds. There are also Ice Pigeons whose ground tint is changed from lavender blue to a beautiful soft powdery silver. The various types should be distinct and well-marked, not halfway between, neither one thing nor another-that is, the spangled variety should be heavily spangled, and the merely white-barred should not show any incipient spangling.

\section{The Swiss Pigeon.}

In Boitard and Corbie's work this variety is called Pigeon Suisse. It is the Schweizertaube of Germany, where it also 
goes by the name of Moon, Crescent, and Badge of Honour Pigeon. It is of the common type in head, beak, and body, is smooth-headed, and should be heavily hocked, and feather-legged and footed. The irides are yellow or orange, and the beak and nails correspond with the colour of the markings. There are three principal colours in this breed-viz., the Red, Yellow, and Black-barred. The ground colour of all should be of a satiny white tint, shaded off into a very clear light mealy, buff, or blue, according to the colour of the marks; the first have red or rich brown wing bars and breastplate (which must be a clean-cut half-moon, as in the illustration); the second have similar yellow markings; and the third, a crescent of the colour of the neck of a blue pigeon, and black wing bars and tail bar. The red and yellow-marked ones correspond with the red and yellow mealy colours, which do not, of course, have a dark bar at the end of the tail. The crescent, or breastplate, should in all be well-lustred, and when its points meet at the back of the neck it is ring-necked, which is a great defect. Neumeister says: "The fledged young ones have no crescent marks on the breast; it only becomes visible after the first moulting. The more the ground colour approaches to pure white, and the darker and narrower at the same time the wing bars are, the more highly is the pigeon valued. It is quite a particular species, and loses all value by cross-breeding. In the South of Germany, and in Switzerland, it is often found without wing bars, with smooth feet and a yellowish crescent, although very heavily feathered feet seem to be peculiar to this race. Among the Swiss Pigeons the Starling Neck is sometimes reckoned, also the Whole-coloured Pigeon, with no crescent, but with white wing bars, which resembles it very much. The Red and Yellow Swiss Pigeons, with dark eyes and crescent, originating from suitable pairing with the Blue Starling Neck, although they occur very seldom, are a beautiful variety, which are paid large prices for by amateurs. The 
Swiss Pigeon is in general not common, and is only found in Saxony, Thuringia, and Silesia."

Boitard and Corbie, in their chapter on the Pigeons Suisses, include several varieties which appear to me to have no connection with them, such as the Pigeon Suisse bai Doré ou bis Doré. Their description and illustration of this variety make it out to be more like the Hyacinth: "Ce pigeon ressemble un peu au Maillé Feu," they say. Brent has reproduced the illustration of this pigeon on page 64 of his book (third edition), where it serves as a portrait of the Porcelain Pigeon, a sub-variety of the Hyacinth. I fancy that, after reading that it resembled the fire-coloured Pigeon Maillé, he thought it would do well to represent it.

\section{The Veiled Pigeon,}

Known in Germany as the Farbenköpfige Taube, or Colouredheaded Pigeon, and also as the Bärtige, or Bearded Pigeon, from its bib, is described by Neumeister as rather larger than the common Field Pigeon. It is found in all the chief colours, and the beak corresponds to the colour of the markings. The Black variety has the special name of the Mohrenkopf (Moor's Head), while others are Blue-head, Yellowhead, and so on. The head is broadly hooded, and the iris, Neumeister says, ought to be dark, but is generally yellow, just as, when a pearl eye is demanded, it often comes dark. The whole head is coloured, the shell hood included, though it is white in his illustration; and the colour runs down the breast, forming a bib. The tail, with its coverts, is coloured, and the rest of the bird white. The feet and legs are generally smooth, but sometimes feathered. Neumeister describes an unhooded variety, which must have a narrow white stripe dividing the coloured head at the nape, finishing at the back of the head.

Boitard and Corbie describe a similar variety to the above under the name of Pigeon Coquille Barbu; and still another 
(the Pigeon Coquille Tête de Morte, or Death's Head Shell pigeon), which has only the head and bib black, all the rest being pure white. It has clean legs and pearl eyes.

\section{The Latz Pigeon.}

The German Latz, signifying Bodice or Stomacher Pigeon, also called in Germany the Latz Shell Pigeon of Holland, and Helmet Pigeon, is of the size and type of the Field Pigeon, and a good flyer and breeder. Its head is adorned with a peculiar helmet, or large shell hood, not found so marked in any other species. From the back of its head to halfway down the back of its neck the feathers run up and to the side, forming an extensive hood. They do not lie closely and in a mass, but loosely and in disorder. The beak accords with the colour of the marking. Blues, Reds, and Yellows, according to Neumeister, seem to have died out, while the Blacks are frequently to be found under the name Wiener Latztauben (Vienna Bodice Pigeons). The head, front, and sides of the neck and breast, as shown in the illustration, are coloured, giving the appearance of a coloured bodice, from which the bird derives its name. The rest of the plumage, including all the shell feathers, is white. The eye is said to have a brownish-black iris, but is yellow in Neumeister's illustration. The feet and legs are generally stockinged, though sometimes heavily feathered and hocked, or trousered, as Neumeister calls it. The Latz is certainly a pretty pigeon, and would make a good addition to the aviaries of those who like birds of well-contrasted markings, and likely to breed very true to them.

\section{The Starling Pigeon.}

In Germany the Starling Pigeon goes by the name of der Staarenhals (the Starling Neck). It is a Continental variety. In size, shape, and in style of head and beak, it is similar to the common Field, or Dovecote Pigeon. The 


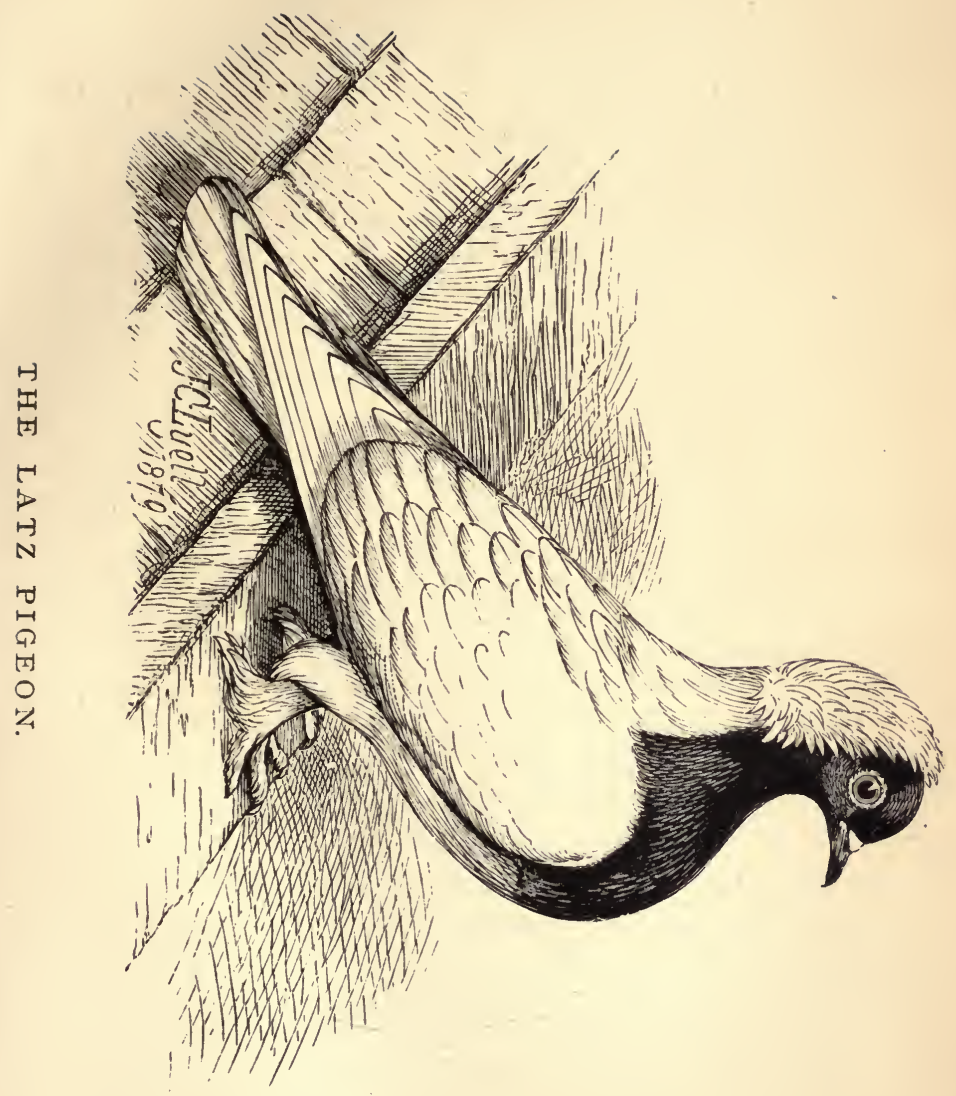



legs and feet are sometimes feathered, but in general are smooth; and the head, though usually uncrested, has sometimes a turn crown. The irides are red, and the beak and nails black. Although the Starling Pigeon is found in several colours, the Black variety is the one most esteemed, and it should be of a deep satin black, with a purple metallic lustre, and strongly pigeon-necked. On the breast there should be a crescent of white, and the evener this is cut the more the bird is valued. It is produced by the feathers forming it being tipped with white, and only comes to perfection on completion of the first moult. Two white bars cross the wings, which, with the crescent, are in the nest feathers usually of a rusty red, or kite colour. With age the Starling often loses its marking to a great extent, the crescent becoming large and shapeless, the ends of its flights becoming grizzled with white, and its head grey, or spotted with white. The white crescent and wing bars on the lustrous black ground being all the marking desired, such a standard is not easy to maintain in all the progeny, the birds being either too dark or too light. Blue and Red Starling Necks, though also obtainable in Germany, are not considered so beautiful. The crescent on the breast not being, as in the English Pouter, composed of white, but only of white-tipped dark feathers, I believe this kind of marking on a really sound Red is not easily attain: able, and that such a Red as can be got with these marks combined fails to look well.

Neumeister says of the Starling: "By reason of its particularly recommendable qualities for fielding, it is absolutely to be preferred to all other fancy pigeons that have to find most of their food. It has almost always at the same time young ones and eggs side by side, and seeks its food in any weather, summer or winter, so long as the ground is not covered with snow. For breeders of the finer species of pigeons it is highly valuable, inasmuch as it feeds almost 
all the young ones of other pairs running after it for food. It is the only kind that, during the so-called famine months, knows how to provide its young ones with the necessary food, and bring them up. It is particularly distinguished by its diligent roaming, possesses all the qualities of an excellent Field Pigeon, and generally serves as a guide to the others in the field."

The Starling Neck is also known in Germany as the Trauertaube, or Mourning Pigeon-a very appropriate name for the little fellow in his black coat and white bands.

The French Starling Pigeon described by Boitard and Corbie is stocking-legged and turn-crowned, and marked as the German. These authors only mention the Black variety, and, on account of its crest, place it among the Pigeons Coquilles; hence its name, Pigeon Coquille Étourneau.

Brent speaks of a Crested variety of the Starling that has, in addition to the ordinary marks of the breed, the upper mandible and head white, as in the Priest Pigeon. This may probably be the Starling-barred Priest; but Brent makes no mention of the white flights and tail.

\section{The Suabian Pigeon.}

The Suabian Pigeon, which is a German breed, is known also in France. Neumeister has classed it-not very correctly, I think-among the Priest Pigeons, under the name of die Gestaarte Silberschuppige Pfaffentaube (the Starling Silver-scaled Priest Pigeon), and says that it comes from Suabia. Boitard and Corbie class it among the Pigeons Coquilles, and call it the Pigeon Coquille Souabe. I think there can be little doubt that the Suabian was produced from the Starling Pigeon, by breeding together such as came too light in colour, till at length the desired marking was fixed. When in perfection, the Suabian is certainly one of the most beautifully feathered birds in creation, and a striking example of the ingenuity displayed by careful breeders of 
that most universally cherished bird, the domestic pigeon. In make of head and beak, and in shape of body, the Suabian, like the Starling, is of the common type, but is not considered such a good breeder, or so hardy. It is found both smooth and feather-legged, and both smooth-headed and turn-crowned; but the smooth-legged ones, with a good peak crest, are considered the originals, and look smartest. The ground colour of the Suabian should be of a good metallic black; but it is generally of a dull, dim black. On the head and neck the feathers should be all tipped with a creamy-white, interspersed with lustrous apple-green and red tints; and on the breast the white must be so intensified as to take the form of a crescent, or half moon, as in the Starling. The back and scapular feathers, and wing coverts, should be spangled or chequered with black on their creamy-white extremities, the pattern this spangling assumes being of different kinds. It may either be in a triangular form, or the feathers may be laced round with black, though I have never seen the latter form so perfect as in the illustration in Tegetmeier's Pigeon Book. But as the Eastern Blondinette Pigeons can be bred beautifully and regularly laced on the wing coverts, the same style of marking may yet be produced in the Suabian. The primaries, or flight feathers, should be black, with creamywhite oval spots near their extremities; and although it is rare to get specimens marked in a similar way on the principal tail feathers, no bird can be considered perfect without. The lower back, belly, vent and thighs, should also be as black as possible, and in theory these parts should show the Starling marking as well; but it will be found that this can only be attained by an excess of marking on the neck and wing coverts. To produce the happy medium in marking, and get birds with neither too little nor too much of it, is the difficult point to attain in the Suabian, and as its marking is of such a character, it is no easy matter to breed it true. It is only after the first moult that its beauties become 
apparent, the nestling being of a rusty red, as in the Starling; and not even then does it attain its full beauty, as the secondary flights are not all moulted in its first year, but in its second. With age it often becomes blotched and irregular in spangling, like other pigeons of variegated feather. The beak and toe nails should be black, and the irides orange or red. Brent mentions a sub-variety with white upper mandible and head, like the Priest, and Neumeister one with white flights and tail, both of which I consider rather out of keeping with the character of the breed.

Besides the Black-grounded Suabian, there is another form, in which the ground colour is of a ruddy brown or chocolate hue. These have been called Porcelains, which name has also been applied to a sub-variety of the Hyacinth; but it would be better to allow them to be known as Brownspangled Suabians. This sub-variety should possess the same characteristics as the other, and the more decided and pronounced it is in its ground colour the better. Many specimens are neither one thing nor another in their ground tint; and all such birds, unless possessing any special quality of spangling, which may be of value in breeding, are comparatively worthless in point of beauty and for exhibition purposes.

\section{The Shield Pigeon.}

Die Schild oder Deckeltaube (the Shield, or Cover Pigeon), a German breed, which takes its name from its marking, is of two kinds, one smooth-legged, the other heavily hocked, and feather-legged and footed. The latter, which is preferred, is the larger of the two, and is a low, broad-chested, thickset pigeon, of the Field type in head and beak. The eye is dark. The marking is that known as turbit, or shoulder marking, and to be right, they must neither have white wing butts nor foul thighs. Although pigeons of the Shield type are sometimes hooded, and even double-crested, 


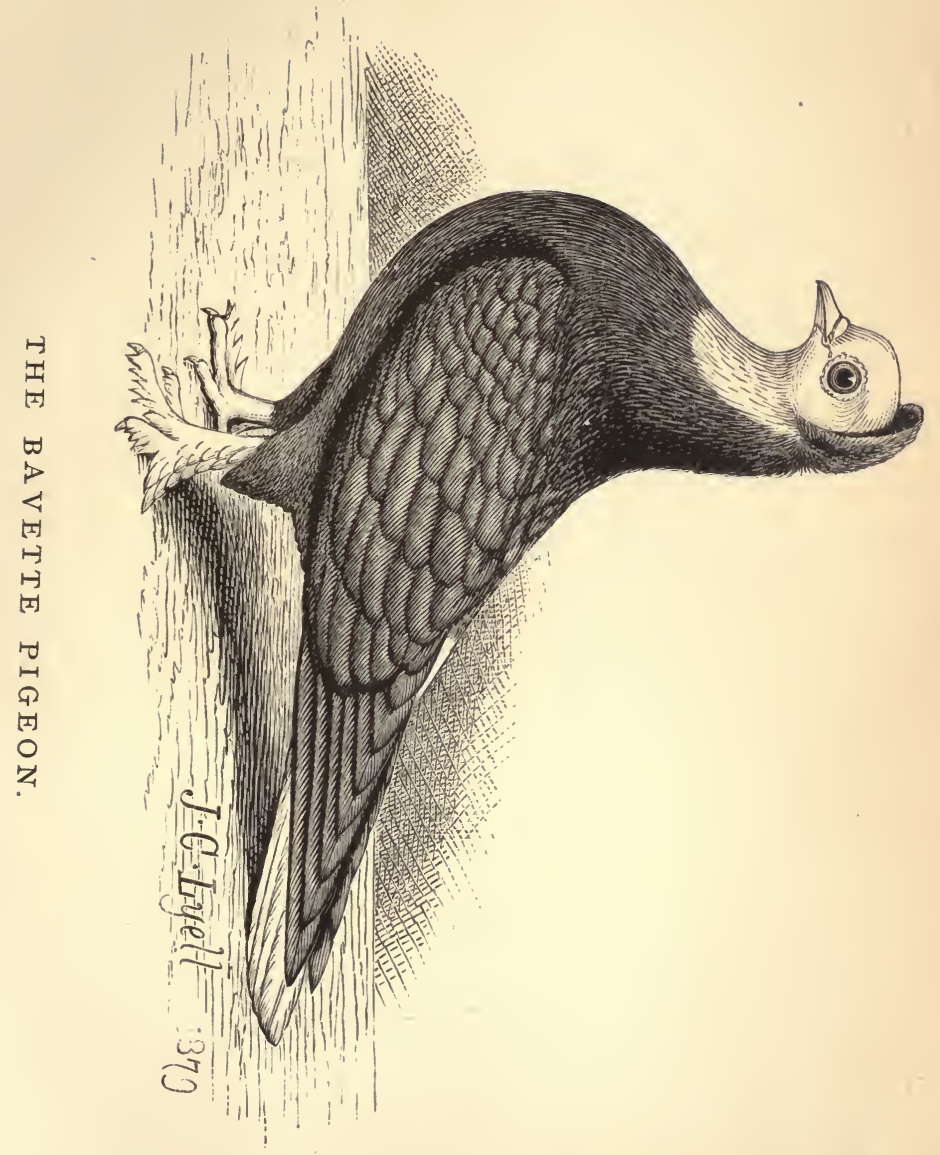




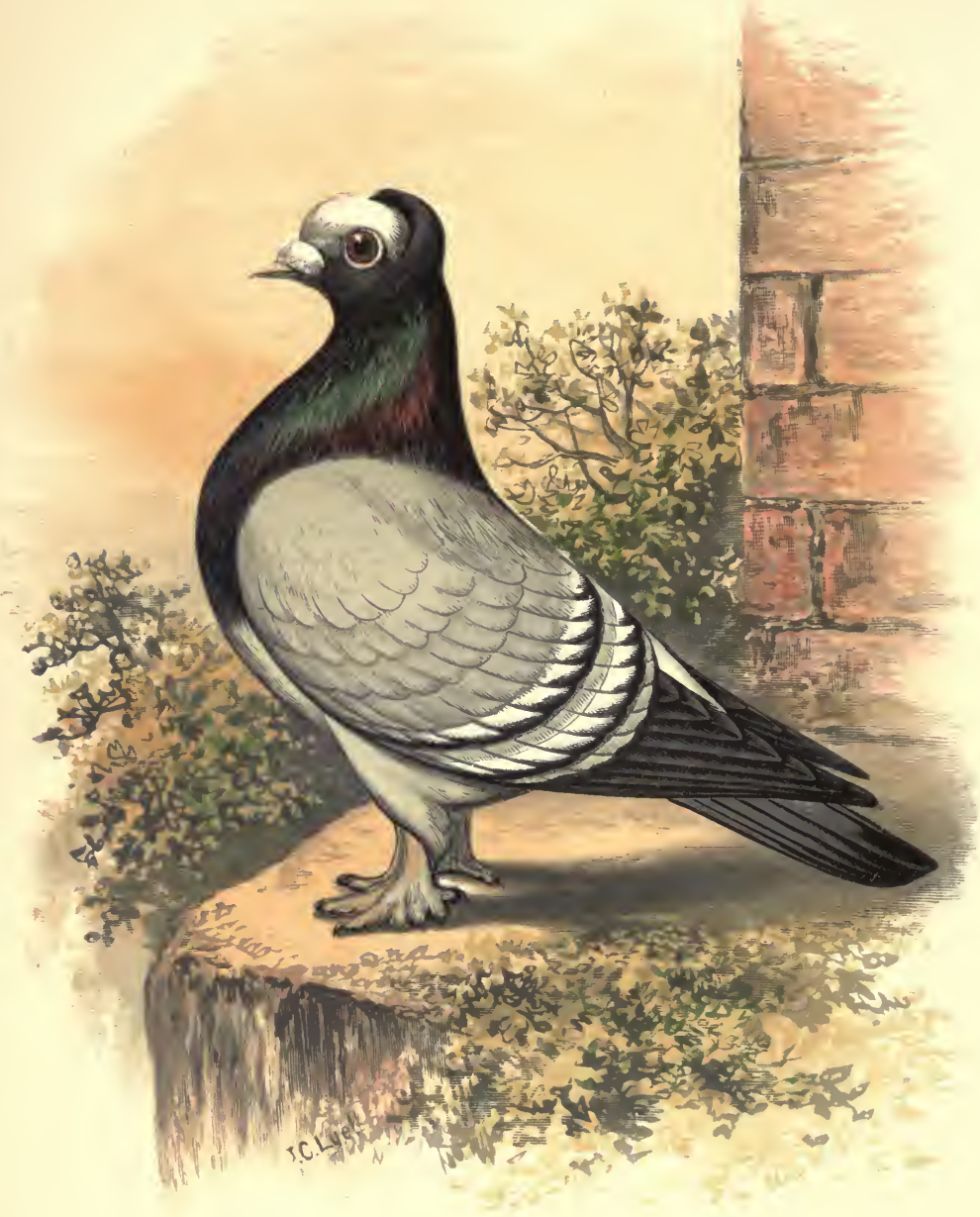

THE PRIEST PI( $\mathrm{E}$ EO 
these belong to a sub-variety of the Trumpeter, to be afterwards mentioned; the head of the true Shield is uncrested. In colour they are found black, red, yellow, blue, silver, and also in mixed colours, both plain and with white wing bars. Blues of the latter kind have a black edging on the bars. The rarest are Yellows, with white bars. In this breed some are spangled, marbled, or chequered on the shoulders with two or three colours, like some of the Eastern Frilled and Modena Pigeons. I have seen specimens of this breed exactly marked on the shoulders, and without a foul feather on under body, when lifted up by the wings.

\section{The Tyrolese Pigeon.}

Die Elstertaube, der Verkehrtflïgel (the Magpie, the Reversed Wing) is a German Toy marked like a Magpie Tumbler, except that the head is white from a line running below the eyes; but on the forehead a coloured spot, as in the Spot Pigeon, is indispensable. It is said to exist in all the chief colours, with a smooth head, and rather strongly feathered legs and feet. Neumeister (1876) says : "It is to be regretted that this really beautiful colour pigeon has been so much neglected that it threatens extinction; its beautiful delineation and shape adorns every dovecote." Herr Prütz calls it the Tyrolertaube in addition to its other names.

\section{The Priest Pigeon.}

The Priest Pigeon, the Pfaffentaube of Germany, where it is extensively bred, is now well-known in this country in several of its numerous varieties. The general form of the Priest is that of a stoutly-built, thickset pigeon, rather larger than the common Field Pigeon, with which it agrees in shape of head and beak. It is found in the following varieties:

The Common Priest, which is considered the original of the others, is found in black, blue, red, yellow, and in off colours, with a white upper mandible and head. The line of 
demarcation must run from the mouth across the eyes, and round the inside of the crest, which must be, if good, an extensive cupped shell, not lined with the white, but coloured. The colour of the eyes is sometimes yellow, but generally hazel. The legs and feet must be well covered with coloured feathers, of a medium length. The colours of the Common Priest are often excellent, and reds have been shown of late not inferior in colour to any red pigeons I have ever seen.

The Double-crested Priest is found in all colours, like the preceding. The second crest, or trumpeter's rose, on the forehead, falling over the nostrils, assumes various shapes, being either in the form of a flower, rayed from its centre, or a small twisted-up tuft of feathers. So long as it is symmetrical, and not all to one side, any form will do, as it is not expected to be developed as in the Trumpeter.

The White-stockinged Priest has, in addition, the feathers of the legs and feet white, but the thigh, belly, and vent feathers must remain coloured.

The White-barred Priest may have white or coloured stockings, with white wing bars, which, with the blue ground colour, are bordered with black. Reds and yellows so barred are rare, and cannot be got so fine in colour as in the original breed.

The White-flighted, White-barred Priest is like the preceding, but has the ten primaries white. The Blues have received the name of Blue Brunswicks in this country.

The White-flighted, Barred and Tailed Priest is like the preceding, with a white tail, and occurs almost always in black or blue.

The Starling-barred, White-flighted and Tailed Priest is said, by Neumeister, to be the most beautiful of the Priests. $\mathrm{He}$ says: "It is exceedingly rare, and only to be met with in the districts of Hohenzollern and the Upper Neckar, and only with a black plumage and unfeathered feet." I have never seen this kind, so cannot describe it more fully. 
There are also Priests which have mirrored or finched flights-i.e., with triangular or rounded white spots near the extremities of the flight feathers, like some Blondinettes. These spots appear after the first moult; and the bar feathers are similarly marked. There is also a variety of the priest with frontal tuft, but no crest at back of the head.

\section{The Whitehead, or Moulter Pigeon.}

This pigeon, which is referred to by Brent under the name of the Pilferer, as a sub-variety of the Priest, is known in Germany as die Weiszkopf oder die Mäusertaube. Mauser, besides meaning to filch or pilfer, also means to change feathers, or cast the skin. A German gentleman, to whom I referred the question, renders the above title, the Whitehead, or Moulter Pigeon, and the description of the breed is as follows: "The Whitehead is one of the rarest coloured pigeons, and is found only in a few places in Thuringia. Its head has a beautiful broad shell hood; the upper bill is white, the iris yellow, corresponding with the ground colour of the plumage. The legs and toes are feathered. The plumage has a metallic black, red, yellow, or dark bronze lustre, which forms the principal beauty of this pigeon. It has a broad breast and a low posture. The head and tail, with its coverts, are white. These marks are not, however, of any great fixity, the head being often marked unequally, sometimes only the upper part of it being white. The feathers on the feet are sometimes foul, and a part of the back is often white. In this variety, therefore, something always remains to be wished for. With black, red, or yellow ones, a belly changing somewhat into blue is a frequent fault which ought to be watched, and, by a suitable selection in breeding, avoided. But the Whitehead with perfect marks is a very fine pigeon. The black and red ones are often excellent, and particularly valued. The latter display, in fine specimens, a peculiarly burning red, even on the belly, 
under the wings, and as far as the points of the flight feathers, which is only very rarely found in other species. Sometimes this somewhat tender pigeon produces white-spotted young ones, which in moulting become quite white, but again breed correctly coloured and marked ones. The Moulter Pigeons prefer to remain by themselves, and rarely fly farther than the neighbouring roofs." I believe that the gorgeously coloured Red Priests shown of late in this country were of this variety, though they had coloured tails. They carried a metallic lustre to the very extremity of the tail-a rare thing in pigeons of a red colour.

Herr Prütz, in his new Book of Pigeons, represents the Whitehead in various forms-viz., red, with white head and tail, and shell crest; black, with shell crest, white head, tail, and wing bars; blue, with white head and tail, and with frontal tuft over the beak wattle, but no crest at the nape.

\section{The Monk Pigeon.}

The Monk Pigeon (Die Mönchtaube of Germany) is admitted to be a relative of the Priest, compared with which, however, it is larger and broader across the chest and back. It is found in all the chief colours, marked as follows: Both mandibles are white, the whole head is white, the line of demarcation running below the eyes, which should be hazel in colour. The flight feathers and the tail, with its coverts, are white, and the leg and feet feathers, from the knee downwards. The thighs and belly should be dark, but are often partly white, which is a fault in this breed. All colours are said to be found, both with and without white wing bars.

Herr Prütz represents the Monk as both plain-headed and shell-crested, marked as above. I saw a pair lately of a very beautiful blue chequer. These were uncrested.

\section{The Swallow Pigeon.}

The Swallow Pigeon, known in Germany in several varieties 



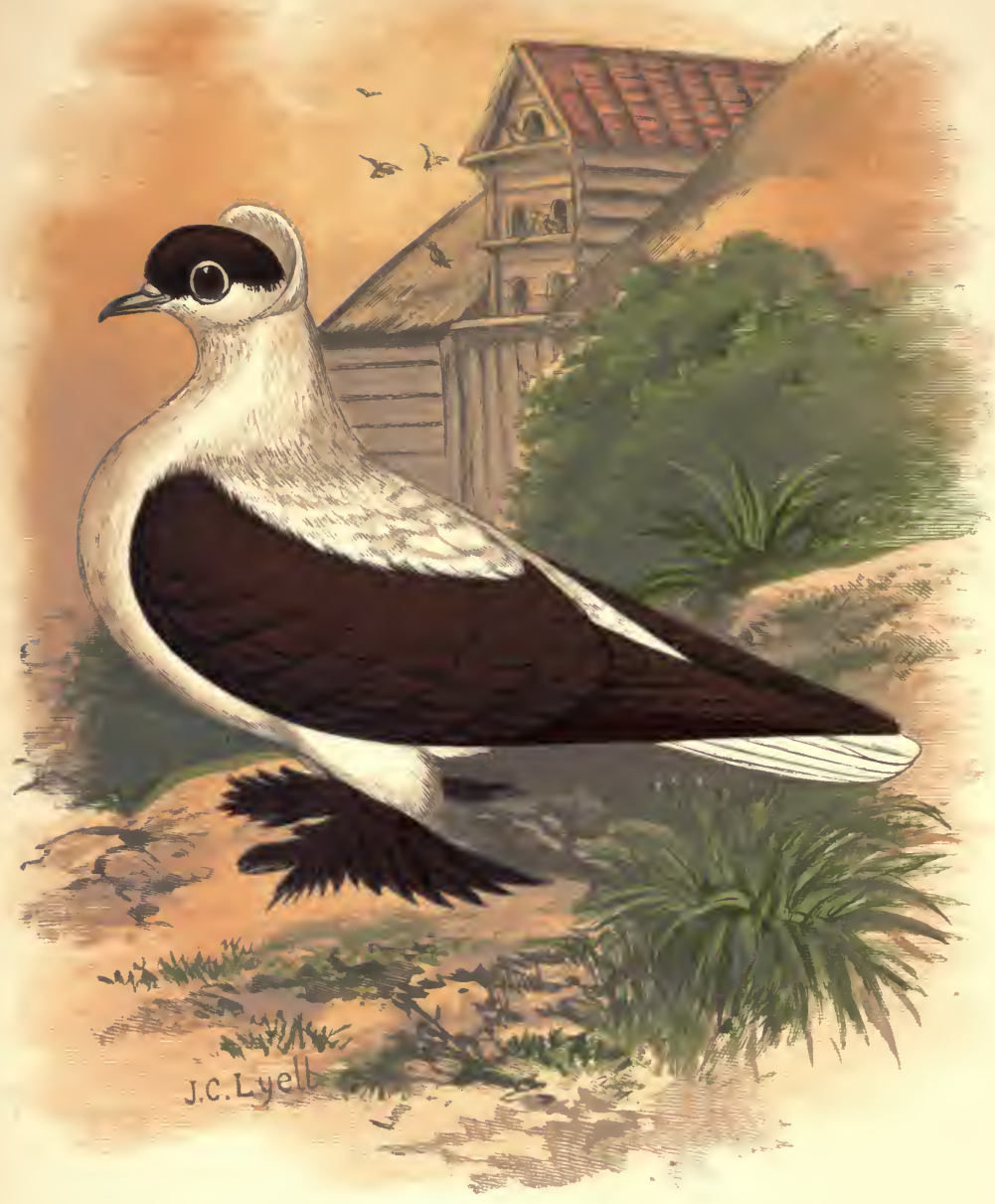

THE S W A L L O W. 
as the Schwalbentaube, and in France as the Hirondelle, has its name from its resemblance in marking to the tern, or sea swallow. The variety usually found in this country came originally from Germany, where it is known as the Nürnberg type, and is marked like the illustration. The Swallow has a long, slender beak, the upper mandible of which is coloured in accordance with the marking. The forehead rises rather abruptly, the head is flat, and coloured above an imaginary line running from the corners of the mouth through the eyes. The hood, which should be extensive and of a cupped shell form, should be all white, and not lined with coloured feathers, or the bird will lose in value. The eye has a dark hazel iris, and, when the markings are of rich colour, as they often are, the eye cere and corners of the mouth are bright red. The neck is slender and short, the breast broad, the body broad and flat, and the legs short. The wings and flights are coloured, but the scapular and back feathers must be all white, forming a heart-shaped figure on the back, the marking here being the reverse of the Magpie Pigeon. The legs and feet should be heavily hocked and booted, the heavier the better, as this adds to the appearance, and is in keeping with the shape of this variety. The hock feathers must be white, but all feathers below the hocks, on the legs and feet, must be coloured. The general appearance of the Swallow is that of a thickset, broad, low-standing pigeon. The common variety figured by Boitard and Corbie has no hood. The yellowmarked ones, according to them, are called Hirondelles Siam, while the Hirondelles Fauve Etincele, or Sparkling Fawncoloured Swallow, is described as follows: "This charming bird is extremely rare in France; it can hardly be got except in Germany, where it is not common; its mantle is fawn-coloured, agreeably scintillated with black or red." This would appear to be an almond-feathered variety. The colours of the Swallow are generally good, and sometimes 
very rich in quality. It is found in black, red, yellow, blue and silver, with dark bars and without bars, and in of colours.

The Saxon, or Bohemian Swallow Pigeon, according t Prütz, answers to the foregoing description, except that it $i$ marked on the head with only a frontal spot above the beak of the size of a pea; while another variety, known as th Silesian, has not even this mark, but is white-headed. Beside shell-crested and plain-headed ones, a variety exists double crested, or with a rose over the beak, like a Trumpeter 0 Priest.

The Nürnberg Swallow in its purity has been known according to Neumeister, from ancient times. In markin it is like the illustration, but the quality of its colours i exceedingly rich, owing to a certain fat or oil in its system which it has in common with certain Eastern pigeons. It plumage fits loosely, but, at the same time, is thick, soft and fatty to the touch. The colours are fiery and rich, th black deeper and more velvety than with all other (German species of pigeon; the white, on the other hand, looks as i oiled, for which reason this pigeon is called in Nürnber "the Greasy Fairy." All the feathers under the wings, abou the thighs, and round the vent, instead of shedding thei fibres in the usual way, remain merely cases filled witl yellow fat or wax, or, at most, only shed a small portior of their extremities. I have found the same peculiarity in other pigeons, and at one time considered it a disease, insteac of which I now believe it is this fat or grease in the systen which gives the extraordinary metallic lustre to the few varieties of domestic pigeons that possess it. The Black Nürnberg Swallow has most of these grease quills, and, from its beautiful green lustre, is called the "Velvet Fairy." Nex it comes the Red, while the Yellow and Blue have not so much of this peculiar feathering.

Swallows are said to be found in the following varieties: 
Black, red, and yellow, with white wing bars.

Blue, with white wing bars, edged with black.

Silver, corresponding to the blue.

Scaled-winged Swallows. On the ends of the coloured wing coverts are small white points, resembling the scales of a fish :

Black, red, and yellow, with white scales or chequers on the coverts, in addition to white wing bars.

Blue, with white scales, and white wing bars, edged with black.

Blue, with white black-edged scales, and white wing bars, edged with black.

Silvers, corresponding to the blues.

\section{The Carmelite Pigeon.}

The Carmelite described by Boitard and Corbie, whose description has been mostly copied by Brent in his book, is evidently a variety of the Swallow pigeon. M. Corbie, who had the breed under his care for nearly fifty years, considers M. Fournier, who was keeper of the aviaries of the Count de Clermont, mistaken in classing them as Swallows in his account of pigeons supplied to the naturalist, $M$. Buffon; but the only difference between the Common Swallow and Carmelite, as figured by Boitard and Corbie, is that the latter is smaller, has a crest, and more feet feathering than the former, which is smooth-headed. The markings are the same. In all probability, the Carmelite of Boitard and Corbie was the Nürnberg Swallow. Brent, whose illustrations are mostly copies from Boitard and Corbie, has the Carmelite similar in outline to them, but he has reversed the markings, showing it to be a magpie-coloured pigeon. How he fell into this error I cannot imagine, unless he understood the word manteau to refer to the scapular and back feathers, instead of to the wing coverts. In the descriptions of both Swallow and Carmelite, Boitard and Corbie apply the word 
manteau to the wing coverts, as reference to their letterpress and illustrations will show.

\section{The Stork Pigeon.}

Die Storch oder Schwingentaube (Stork, or Wing Pigeon of Germany) is in size and shape similar to the Spot Pigeon, with which it has in common the coloured spot on the brow-black, red, yellow, or blue. If the spot is small, the upper mandible may be white; but it is usually coloured if the spot is extensive. The head may be either smooth, peaked, or shell-crested. The eye is hazel-coloured. The legs and feet are preferred heavily hocked and feathered, and are coloured from the knee down, the thigh feathers themselves being white. The ten flight feathers in each wing should be coloured, and all the rest of the bird must be white, except the feathers of the spurious wing, and a few feathers about the wing butts. These coloured feathers give the bird its name, and, when the wing is closed, it has a coloured margin or framing at the butts of the wings, running round it, which must be regular, and not too broad. When well-marked, the Stork is considered one of the finest feather varieties in Germany.

\section{The Bavette Pigeon.}

The Bavette Pigeon, which I have so named from its white bib, has been introduced into this country within the last few years. As will be seen from the illustration, it is nearly the reverse of the Nun in marking, having a black shell crest, on which the white feathers of the head should not encroach. The bib should come well down on the breast, and be sharply cut. The beak is usually white, and the iris dark hazel. The tail, with its coverts, is white. The legs and feet are stockinged, and white from the hocks down. The position, size, and shape of the shell crest should be as in the Nun. The only colour I have seen in this variety is black. 



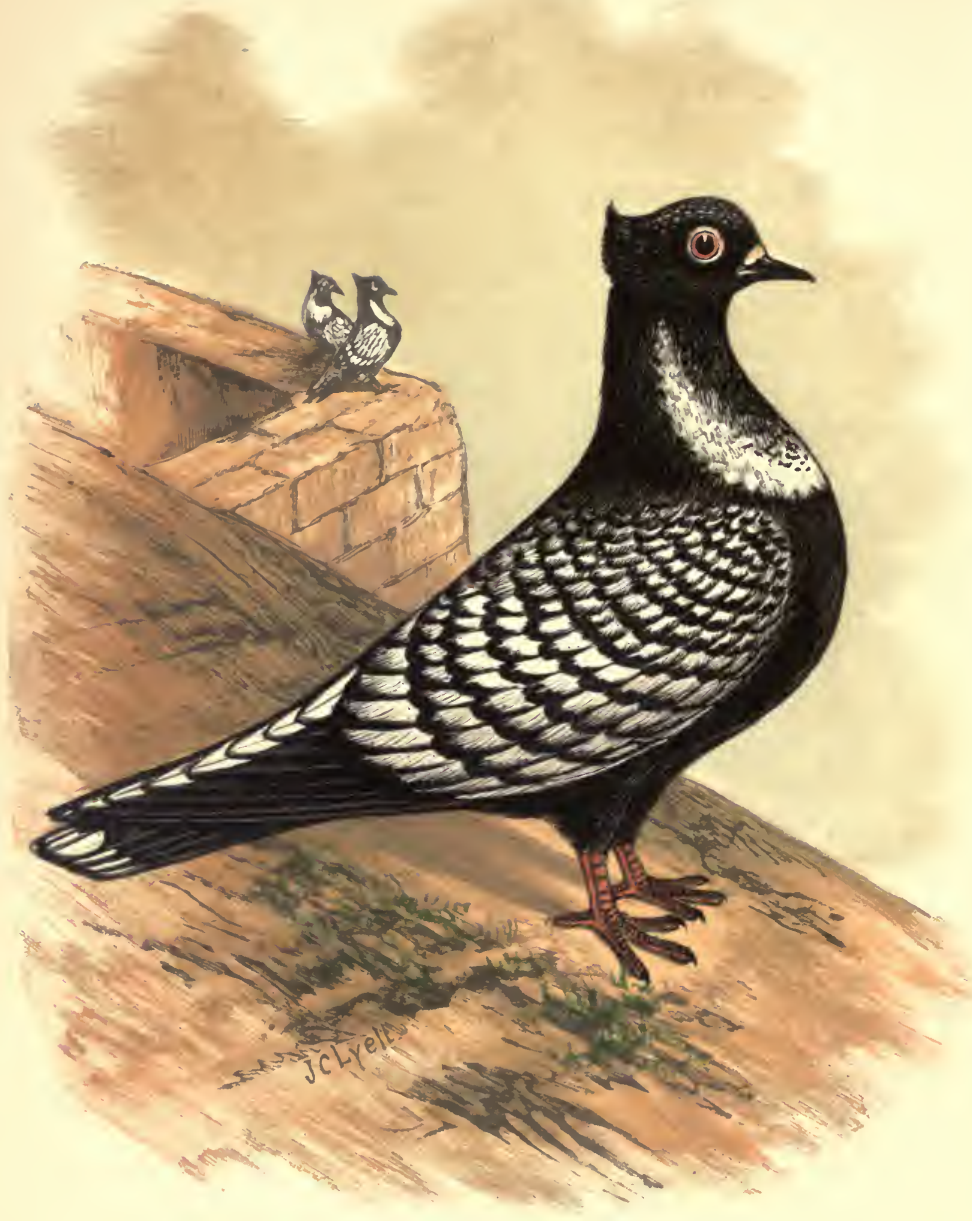

THE SUABIAN PIGEON. 
It is true that Dixon, in the "Dovecote and Aviary," quoting from Temminck, the ornithologist, mentions blackbodied Nuns with white heads, under the name of Nonnains Maurins; but this is not the variety I am describing. The Jacobin is called Nonnain, or Nun, in France, and the Nonnain Maurin is a variety of the Jacobin, fully described by Boitard and Corbie.

The Bavette is an exceedingly pretty pigeon, and entitled to rank high among the feather varieties. From the formation of its head and beak, it must be placed among what the Germans call colour pigeons. I have not yet found an account of it in any German work on pigeons, and $I$ am inclined to think it comes from Eastern Europe, or perhaps from Asia.

M. V. la Perre de Roo has given a full description of the Bavette (le Pigeon Moine à Bavette) in his lately published Book on Pigeons. At his request, I made a drawing of it for him on wood for that work, which differs from that in this book in having the flight feathers white. $\mathrm{He}$ informed me that he had some so marked, from which it appears there must be some variation in the breed. $\mathrm{He}$ says it is found in black, blue, red, and yellow, and that the iris is sometimes black, sometimes orange red. A black specimen I saw in London lately had orange eyes and a black beak, but the flight feathers were black, like my illustration.

\section{The Lark Pigeon.}

The Coburg Lerchentaube is a smooth-headed and legged bird, considerably larger than the common pigeon, and has become constant in the district from whence it is named. It derives its name of Lark Pigeon from its colour, which appears, from the plate in Herr Prütz's new book, to be that known here as silver or dun chequer. The breast, however, runs into a rich yellow. The beak and eye wattles are somewhat developed, 
and the beak is inclined to a flesh tint. It has the shape and style of a common pigeon. The yellow-breasted dun is a combination of colours found in various breeds, such as the Swift and Golden Dun Short-faced Tumbler.

The Nürnberg Lark Pigeon is another of the same family. In this variety the yellow colour extends from the breast to the neck and head. The wings and tail ought to be very light, approaching to white as nearly as can be got.

\section{The Fire Pigeon.}

Die Feuertaube, or the Fire Pigeon, is a variety I have never seen. It is mentioned by Friderich, the German ornithologist (1863), and by Neumeister (1876), whose description is as follows: "It reminds one very strikingly of a strong Tumbler, and is of the size of the medium Field Pigeon. The head is unhooded, the feet smooth, the colour of the whole plumage black, with an extremely bright copper red sheen. This metallic lustre is with the Fire Pigeon more intense than with any other species, and not only on the neck, but spread over the whole body, with the exception of the flights and tail. In the sunshine this pigeon reflects so splendidly that it actually irradiates, and then looks almost copper red. It is exceedingly rare, and seldom or never comes into the market."

As the Archangel itself is not excepted in the above description, the lustre on the Fire Pigeon must be a sight for a pigeon fancier to behold. If not extinct, this variety must be rather scarce and secluded, as it is never offered for sale in this country, or even mentioned in the reports of shows. It would make such a splendid addition to our feather varieties, that it would be worth the while of anyone having opportunities of acquiring the German Toys, to see if some specimens of the breed can still be got; but, as Herr Prütz does not, so far, refer to it in his new 



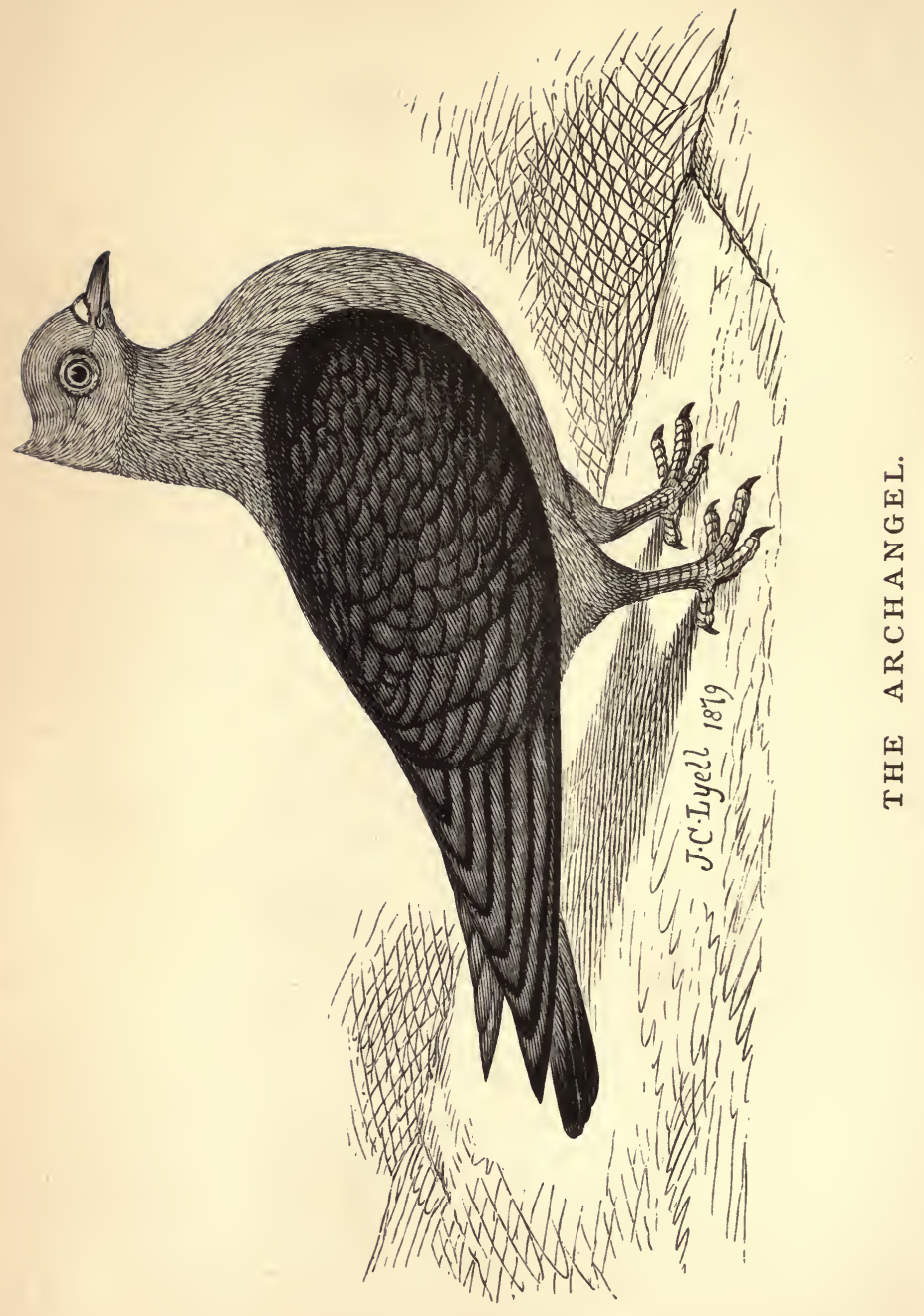


illustrated pigeon book, now publishing, I fear it has become lost.

\section{The Archangel Pigeon.}

The first mention of the Archangel Pigeon in English literature is in Dixon's "Dovecote and Aviary" (1851). An authentic account of its introduction into England is given, by $\mathrm{Mr}$. Betty, in Mr. Tegetmeier's work. The late Mr. Frank Redmond, being in Ghent in 1839, selecting some pigeons for Sir John Sebright, procured a pair of Archangels. Sir John bred them for some time, and at his death the greater number went to the aviaries of the Earl of Derby, at Knowsley, at whose death they were distributed. The English name is probably derived from the vivid metallic lustre the bird carries on the back and wing feathers, similar to what painters have shown on the wings of angels. At least, it does not derive its name from the town of Archangel. The German name is Gimpel, or, the Bullfinch Pigeon, considered as very appropriate by Neumeister, who says: "No other pigeon displays so decidedly its name by its colouring as does the Bullfinch, and thus it can be distinguished at a first glance." According to him, it has only been known in Germany for about fifty years, but whether this time is to be reckoned from the date of his first edition, or from the date of the copy from which I quote (1876), I am unable to say. Some authors, he says, call it a native of Southern Germany and the Tyrol, where it is common.

I find from C. Malmusi"s "Historical Notices of the Triganieri," or Pigeon Flyers of Modena (1851), that, besides the present breed, the Triganieri of Modena formerly trained three other kinds of pigeons for their aërial contests. "Pausing now," he writes, "in my description of the qualities of the Triganini, I will mention that three other distinct species, or races of pigeons were trained to flight by the Modenese Triganieri-that is to say, the Turchetti, Timpani, and 
Zinganini. The first is distinguished by its very short beak, eyes excessively large and prominent, surrounded by a red circle, and it came originally from Turkey." Evidently the Barb. "The second has the head and breast yellowish, and the wings and tail black; it is very much used in Austria, especially at Vienna, though originally coming also from Turkey." This can only apply to the Archangel, though not a quite correct description of it. Professor Bonizzi, in his work on the Triganini, after quoting the above, says: "The Timpani are no other than the Gimpel described by Neumeister." Malmusi continues: "The Zinganini are of one sole colour throughout, whatever it may be, and are distinguished by a white spot between the wings, which extends over the back, and sometimes even to the neck. This race ceased to exist in Modena some years ago, and there is a tradition that it was introduced by the gipsies of Hungary in the fifteenth century; thus, these birds were called Zingarini, or Zinganini."

Having now traced the Archangel as far as Turkey, we shall next find it in the Orient itself. When in Calcutta, in 1869, I heard of the arrival there of a pigeon fancier from the North-West provinces, with a large assortment of pigeons for sale. I found among them two pairs of Archangels, that were acquired by a friend of mine, in whose place I saw them often afterwards. This may not be conclusive evidence that they are an Indian breed, as they might have originated in Europe, and been carried East; but I am inclined to believe that the Archangel is an Asiatic variety, either Persian or Indian.

The Archangel is about the size of the common Field Pigeon, and of the same type in formation. Its beak should be of a dark flesh tint, brown at the tip, and free of hard blue or black colour, straight, and rather long. The head is long or snaky, and the eye should be of a vivid orange colour, surrounded by a narrow flesh-coloured cere or wattle. 
Though there are plain-headed and shell-crested, or, at least, partially shell-crested, birds among the breed, the correct style of head is the peak-crested; and so good in the peak are some Archangels, that they leave nothing to be desired in this respect. The feathers at the back of the head should all draw to a point, ending in a finely-pointed crest, and the higher this peak reaches, the better. I consider it immaterial whether there is a notch below the peak, dividing it from the back neck feathers, or a kind of hog mane, showing no break, so long as the peak itself is correct.

The head, neck, breast, belly, thighs, and vent feathers should be of a bronzed copper colour, burnished with metallic lustre, solid and even. But this appearance does not pervade these feathers down to the quills, as underneath they are of a dull black, which should not, however, assert itself to the eye, though it generally does about the thigh and vent feathers. The back, wings, and rump should be as black as possible, (though generally more or less bronzed), accompanied by metallic tints of green, blue, purple, and ruby colour, which show in any light, but which in a strong, or sun-light, when the bird is moving about, sparkle like coloured jewels of price. The flight feathers are bronzed black, or kite-coloured, and the tail is blue black, with a black bar at the end. I have heard of black-tailed Archangels, but have never seen any; nor do I consider that they should be other than dark blue-tailed, both on account of the greater variety in the plumage, and because, though blue-tailed, they show as much lustre on their feathers as any breed we have; at least, in Germany, from where we got them, the standard, according to Neumeister, is the blue-barred tail. The legs and feet should be unfeathered, and of a bright red, the nails dark.

Besides the above coloured Archangel pigeons, there are others whose whole plumage is more subdued. The copper 
is changed to yellow, the back and wings to a blue-black, and the tail to light blue, barred with black. This variety has but little Iustre compared to the other. It is a natural change that occurs in, and that has a value for, breeding. I have bred such from two birds of standard colouring; and they may be matched to the dark variety, when they will breed both colours, and others midway between.

The Archangel does not assume its full colour till after its second moult, for the four or five centre feathers of the secondary flights are not changed during the first. The breeder has, however, a good idea of what colour a bird will become when it leaves the nest.

There are so-called Archangels all white and all black, which may have originated from standard birds as natural sports, by way of albinism and melanism. The black variety, with its metallic lustre, is very pretty. German authors mention several other varieties, such as blues with black bars, blues without black bars, blues with white wing bars, blues and blacks with white flights, blues and blacks with white flights and heads. Blue Archangels are the yellow-breasted, bluewinged type.

\section{The Miroite Pigeon.}

This is a French variety, described by Boitard and Corbie, and mentioned by Brent. The French writers describe it thus: "It is inconceivable that none of the authors who have written about pigeons have mentioned this race, so remarkable for the beautiful colour of its plumage. Is it because they never heard of it? This cannot be, for, although not common, all amateurs know it, and some possess several varieties of it. Is it because they have not regarded it as a pure race? This cannot be the reason, for these pigeons are positively a pure race, since they cannot be crossed with any other variety, however much they resemble it, without being lost. Be this as it may, these birds have the general form 
of the Mondains (common Runts), and can scarcely be distinguished from them, except by the striking beauty of their plumage. They never have a cere round the eyes, and are generally yellow in the iris.

"Pigeon Miroité Rouge is the colour of the red blood of an ox, interrupted at two-thirds of an inch from the ends of the flight and tail feathers by a grey-white bar, half an inch broad. The ends of these feathers are of a red colour, a little clearer than the rest of the body; eye, yellow iris. This charming variety, of medium size, produces well, and merits, by all accounts, the care of amateurs.

"Pigeon Miroité Jaune.-This pretty bird only differs from the preceding by the ground of its plumage, which is yellow; moreover, it is miroité the same on the flight and tail feathers. It has the same fecundity.

"Pigeon Petit Miroité.-Similar to the preceding, but much smaller-about the size of the Rock Pigeon. This charming bird is a good breeder."

Brent says the word miroité is difficult to translate. He was informed that it meant, composed of three colours, of which two were blended in one. A French gentleman has informed me that miroité means flashing-e.g., the neck of the Blue Rock Pigeon is said to be miroité. The Miroité may therefore take its name from its great metallic lustre, or it may be a technical name, derived from the blending of the colours in its tail and flight feathers. The Miroité Pigeons may be had in Paris. I was recently offered some by the Parisian dealer, M. Vallée.

\section{The Hyacinth and its Sub-varieties.}

The Hyacinth Pigeon stands at the head of a French breed which is found in various colourings, and which are all included under the name of Pigeons Maillés (Mailed, Armoured, or Speckled Pigeons). They are large, smooth-headed, and clean-legged pigeons, and have been classed by French 
naturalists with the Pouters, as they have the power of slightly inflating their crops. I knew a fancier who bred them extensively, and his birds would have been correctly described as middle-sized Runts, with a slight dash of the Pouter. They are classed as follows:

Pigeon Maillé Jacinthe (Speckled Hyacinth Pigeon).-The shoulders as in a Turbit, or the Manteau in French, of clear blue, chequered or spangled in a particular pattern with white and black, or a black and blue bar on all the feathers, the outer side of the blue bar having a white spot, or spangle; the ten flight feathers of each wing pure white; the head, neck, breast, belly, and tail dark purpleblue; the tail barred with black.

Pigeon Maillé Jacinthe Plein is a little less in size than the preceding, but similar in colouring, except that it has dark blue, instead of white, flights.

The following varieties are said to be found both with white flights, and plein, or with dark flights.

Pigeon Maillé Couleur de Feu, red or flame-coloured, similar to the Hyacinth, but with red, instead of white, spangles.

Pigeon Maillé Noyer, coloured like walnut wood, or inclining to yellow in the spangles.

Pigeon Maillé Pécher, or peach-coloured in the spangles.

The Noyer is considered as a cross between the Jacinthe and Couleur de Feu; and the Pécher as a cross between the Jacinthe and Noyer. Each variety is, however, established. and breeds true, according to Boitard and Corbie.

All I have seen of these varieties were of the dark-flighted kinds. These pigeons have been promiscuously named Hyacinths, Victorias, and Porcelains in our pigeon literature; but the above description is that of undoubted authorities, the whitespangled ones alone being entitled to the name of Hyacinths. The white-flighted varieties appear to be larger than the plein, and to have more of the Pouter in them, and I think I can recognise them in Moore's "Columbarium" as follows : 
"The Parisian Powter.-This Pigeon was originally bred at Paris, and fiom thence brought to Brussels, whence it was transmitted to us; it has all the Nature of a Powter, but is generally long crop'd, and not very large; it is shortbodied, short-leg'd, and thick in the girt. What is chiefly admir'd in this Bird is its Feather, which is indeed very beautiful and peculiar only to it self, resembling a fine piece of Irish stitch, being chequer'd with various Colours in every Feather, except the flight, which is white; the more red it has intermix'd with the other Colours the more valuable it is. Some are Gravel ey'd, and some bull ey'd, but it is equally indifferent which eye it has." If for "every feather" we read the wing coverts-which are the only feathers, except the flights and tail, that can possibly be spangled in pigeons in the above way-Moore's description of the Parisian Pouter, (the Parazence Pouter of the treatise of 1765), agrees with that of the sub-varieties of the Pigeon Maille Jacinthe, or Hyacinth.

\section{The Polish Lynx Pigeon.}

This pigeon, according to Prütz, has only lately been introduced, by Professor J. B. Von Rozwadowsky, of Cracow, to the notice of German fanciers. It is described as a large, plain-headed and legged bird, measuring about 15in. from the beak to the end of the tail, strongly-built, low, and broadchested; a good forager at all seasons of the year, a free breeder, and especially good as a table bird. Its general appearance is that of a slightly inflated Pouter. The colours of the breed are black and blue; the same with white wing bars; also others with both white bars and white scales, or chequers, on the wing coverts. Sometimes the flight feathers are white. Reds and yellows are not known.

This is the description of the Polnische Luchstaube, as given by Prütz, and it seems to coincide in some respects 
with that of the Hyacinth of Boitard and Corbie (1824), the French authors.

\section{The Carp-scale Pigeon.}

This pigeon, known in Germany as the Karpfenschuppige Taube, is of the common type. It is smooth-headed, red or yellow-eyed, and has its legs covered with feathers of a medium length. Its colour is dark blue, with lustrous neck, except the mantle or shoulders, which are chequered as in the French Hyacinth and its sub-varieties. Some years ago, specimens were occasionally exhibited in this country under. the name of Hyacinths. I have bred a number of them, and found that they varied in colour in the same way as dark Blondinettes, which they resembled in colour very much, except in having no white marks on flight and tail feathers. The nestling feathers are of a dull, rusty hue, which disappears after the first moult, when some become laced, and others arrow-pointed on the wing coverts.

\section{The Annatalozia Pigeon.}

Such is the name of a pretty Toy Pigeon, which comes from Asia Minor. It is of the size of a common Tumbler; smoothheaded and grouse-legged; short-beaked, and yellow or orangeeyed; marked on the head like a Nun or Domino, either black, blue, red, or yellow, and with coloured primary flight feathers to correspond, the rest of the plumage being white.

\section{The Red Indian Pigeon}

Is another breed of Asia Minor, which has the make and shape of a common, clean-legged, large, flying Tumbler. Its colour is a glossy, burning, blood red, to the ends of the flight and tail feathers. It has been used as a cross to give colour to red and yellow Dragoons.

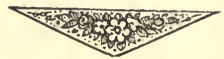





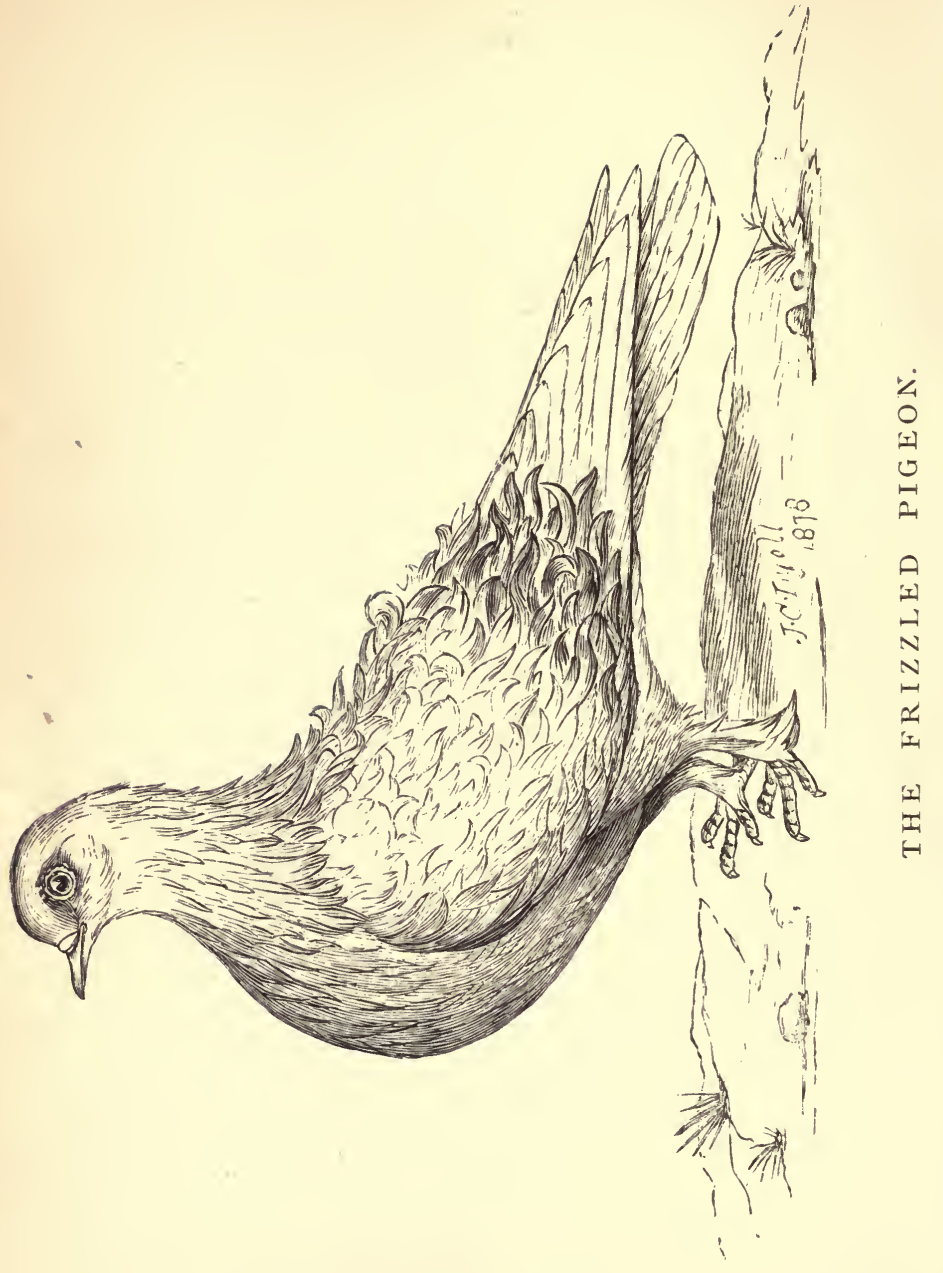




\section{Chapter XII.}

\section{$\propto$ PIGEONS OF PECULIAR FEATHERING. $\propto$}

\section{The Frizzled Pigeon.}

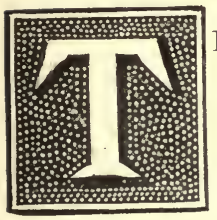

HE Frizzled Pigeon, or Friesland Runt, as it was formerly called, is not a Runt of the large kind, but a bird of the size and shape of a Common Pigeon. Moore writes of it as follows: "This pigeon comes from Friesland, and is one of the larger Sort of middle siz'd Runts; its feathers stand all reverted, and I can't see for what it can be admir'd, except for its Ugliness." So far Mr. Moore, whose successors, Mayor and Girton, follow on the same string, with variations, both adding that these pigeons were, in their time, very scarce in England. The Friesland Runtwhich name I merely use because it was formerly so called, and because it matters little what name it goes by, so long as it is not that of another pigeon-must have become extinct in England; but of late it has re-appeared from abroad. It is known as the Lockentaube in Germany, where it is said to be rare; and Neumeister says it comes from Hungary. It is usually smooth-headed, and stocking-legged, without much feathering on the toes. In colour it is gene- 
rally blue or mealy, but I have seen turbit-marked ones, with bronzed black shoulders. Its feathering is similar to that of the Frizzled Fowls, or Sebastopol Geese-that is, reverted, making it appear to have been out in a storm. This appearance is owing to the concave surface of the feathers, more especially those of the wing coverts and back, being outward instead of inward, or next the body, as in other pigeons. On its re-introduction into England, where it has been common for some years back, and where it has done some winning in the "Any other variety" classes, it was called by the name of another pigeon, one of an opposite character to it-the Frillback. This was the more inexcusable, as the Frillback was not extinct in England. This bird, being neither a Runt nor a Frillback, may be appropriately named the Frizzled Pigeon.

\section{The Frillback Pigeon.}

The first mention of this curious bird was in the "Treatise on Pigeons," dedicated to John Mayor, published in 1765. As the description is very good, concise, and clear, I reproduce it. "The Frillback is something less in size than a Dragoon, and in shape like the common Runt; their colour generally (if not always) white; and what is chiefly remarkable in them is the turn of their feathers, which appear as if every one distinctly had been raised at the extremity with a small round, pointed instrument, in such manner as to form a small cavity in each of them." The Frillback, which is the German Strupp oder Perltaube (Bristle, or Pearl Pigeon), is said to be a native of the Netherlands, and Brent met with it in Saxony. It is of the size of the common field pigeon, and is described as always pure white in colour, with an orange or gravelly red iris. I believe this variety is usually white, at least, I have never seen it of any other feather. They are turn-crowned, and generally smooth-legged; but I have seen specimens with well-feathered legs and feet. Their peculiar appearance is caused by the 
ends of their feathers, more especially those of the wing coverts and secondaries, being goffered or crimped, as if by a pair of curling tongs, as Brent describes it. This appearance is often seen in a less degree on hard-feathered pigeons, like Dragoons. As Brent says, the Frillback must not be confused with the Friesland Runt. Some fanciers, however, are of opinion that the Frizzled Pigeon must have been produced from the Frillback; but I think this is doubtful.

\section{The Lace Pigeon.}

The Lace Pigeon is another variety, distinguished, like the Frizzled and Frillback Pigeons, by the peculiar formation of its feathers. It has its prototype in the Silky Fowl of China and Japan, which early travellers called a fowl bearing hair or wool on its body instead of feathers. This pigeon was unknown to Moore, and was first described in our pigeon literature in the "Treatise" (1765), where a very good plate of it may be seen. It is described as white in colour, turncrowned, and as being valued on account of its scarcity, and the peculiarity of its feathers, "the fibres or web of which appear disunited from each other throughout their whole plumage, and not in the least connected, as in common with all other pigeons, where they form a smooth, close feather."

The Lace Pigeon, which is known in France as the Pigeon Soie (Silky Pigeon), and in Germany as the Seidenhaartaube (Silken-haired Pigeon), is of much the same size and bearing as the common field pigeon. It is almost always pure white in colour, and generally smooth-headed. The fibres of all its feathers are disunited, and appear as if every second one had been cut out. The wing coverts, and quill and tail feathers, with their long, fringed rays, have given it its English name of Lace Pigeon. It is not so hairy or woolly in appearance as the Silky Fowl, but more like the produce of that fowl when crossed with a common one. Its 
legs and feet are either quite smooth or slightly feathered; its irides are dark hazel. Being unable to fly, it must be kept in confinement, and under special conditions. However interesting as an object of curiosity, it presents little variation in its form or feather, and, consequently, will always be rather uncommon. It has the power of somewhat reproducing its peculiarity when crossed with other pigeons, and the French have a half-bred looking Fantail, called the Pigeon Trembleur Paon de Soie, from which the Scotch Lace Fantail, to be afterwards noticed, has been perfected.

The Frizzled, Frillback, and Lace Pigeons, are examples of natural sports perfected by selection. If lost, breeders could not recover them, but would have to wait till Nature provided them with a new beginning on which to work. As they exist, they can be kept up, in a fair degree of quality, with but little trouble as compared to many kinds that are called mere feather varieties, fine specimens of which are consequently much more valuable than they are. If fancy pigeons were separate creations, and not descended from a common origin, I wonder how the Lace Pigeon existed till taken in charge by pigeon fanciers.

\section{The Mane Pigeon.}

The Mane, or Curly Moor Head Pigeon (die Mähnentaube oder Krausige Mohrenköpf), is said by Neumeister to be probably the Latz Pigeon perfected by long breeding. From his description of it they appear to have much in common. It is rather larger than the field pigeon, broader-breasted, and more thickset in make. It is said to be found chiefly in Thuringia and the Saxon Erz mountains, and generally with black markings. "Its rather thick, strong beak, is polished black, its eye large, and brown in the iris. The thighs, legs, and feet are heavily feathered, the claws white. The ground colour is white, except, as in the Latz, the head, front, and sides of neck and breast, which are black; the tail, 
with its coverts, is, however, also black in this variety. Its characteristic is the white waving mane on the back neck, reaching upwards, downwards, and to the sides of the neck, parting the black of the bodice marking from the white. The mane consists of thinly sown, flaky feathers, hanging around the neck disorderly, and in the form of a mane, not by any means close, as in the Jacobin, but reaching as far down the neck as the coloured bodice does in front."

The chief difference between the Latz and Mane Pigeons seems to lie in the greater development of loose, disordered feathers at the back of the neck, the former having only a large hood, while these feathers in the latter take the form of a waving mane. The coloured tail and greater development of leg feather are also properties of the latter; but they are evidently near relatives.

The Mane Pigeon has been occasionally exhibited at the principal shows in this country during the last few years.

\section{The Egyptian Swift Pigeon.}

This pigeon, which is of Eastern origin, was first described in Fulton's Book of Pigeons, by Mr. Ludlow, who says that it is an Indian variety, but that it has been cultivated in Cairo and Alexandria, whence the best specimens have been imported into England; hence its name-the Egyptian Swift. I never met with it in Bengal, nor heard fanciers there speak of such a variety; but I believe there are many distinct breeds of pigeons existing in Hindostan, especially in the North-west, still unknown to us, and the Swift may be among them. This variety of the domestic pigeon has its name from the Swift, or Hawk Swallow, on account of its abnormally long flight feathers. Though a bird of ordinary size, it has the appearance of being larger than it is, from the fact of its feathers being long and loose. In this respect it resembles other kinds, such as the Trumpeter and Jacobin. The scapular feathers, on account of their length, 
incline downwards. Both the flight and tail feathers are excessively long, the former being carried crossed above the latter, and measuring as much as $32 \frac{1}{2}$ in. from tip to tip, when outstretched, according to Mr. Ludlow, who also says that the tail primaries measure $7 \frac{7}{8} \mathrm{in}$. between tips of quill and fibre. As a comparison, I measured an ordinary-sized flying Tumbler cock in the same way, and his outstretched wings covered 27in., while one of his tail primaries was $5 \frac{1}{2} \mathrm{in}$. The flights and tail of the Swift, therefore, extend $2 \frac{3}{4}$ in. beyond those of similar sized pigeons. To see how these measurements would compare with those of the Pouter, I measured a blue pied cock of $19 \frac{1}{2}$ in. in feather, and found that his outstretched wings covered 37in., and that one of his tail feathers was no less than $8 \frac{5}{16} \mathrm{in}$. in length. The Swift stands low, on unfeathered legs, is smooth-headed, and is represented by $\mathrm{Mr}$. Ludlow as an owl-headed, gulleted pigeon, with a narrow fleshcoloured eye cere and yellow iris. He says it is found in various colours, such as blue, blue-chequer, almondfeathered, and chocolate colour, heavily shot with yellow on the neck and wing coverts, which latter is the colour Mr. Ludlow has chosen for his illustration, and which might be called an exaggeration of the golden-dun found in Short-faced Tumblers. As represented by him, it is a very beautiful colour, and one not found so pronounced in any other variety I know of.

Instead of being an advantage to the Swift in flight, its long wings are an impediment to it, as the feathers are thin, and weak in texture. Like the Hawk Swallow, it rises from the ground with difficulty, but, unlike it, cannot make use of its long wings when once in the air. I once, when my age could be told by a single figure, caught a Swift Swallow in a garret, which I played with on the grass for some time, as it never attempted to fly away; but happening to throw it slightly from the ground, it went off like an arrow from a bow.

Mr. Ludlow says the Swift is hardy and long lived, one 
cock, an old one on his arrival in Birmingham, in 1864, having lived till 1875 .

Regarding the age of fancy pigeons generally, there was, some years ago, a notice in the Field newspaper, of the death of a White Trumpeter, belonging to Mr. Oates, formerly an exhibitor of this breed, at the age of twentytwo years, which is the same age as the pigeon Willughby (1676) refers to in the following passage : "Albertus sets the twentieth year for the term of a pigeon's life. As for tame pigeons (saith Aldrovandus), a certain man of good credit told me that he had heard from his father, who was much delighted in pigeons and other birds, that he had kept a pigeon two and twenty years, and that all that time it constantly bred, excepting the last six months, which time, having left its mate, it had chosen a single life." The oldest pigeon I ever had was a common flying Tumbler, red in colour, which was fifteen years old, and in good condition. I have known of a Pouter cock breeding well when twelve years old; but it would cheapen the price of fine pigeons if they usually lived so long.

\section{The Swallow-tail Pigeon.}

I have never seen the variety of domestic pigeon that has a forked tail, like the common House Swallow, and no pigeon fancier, either here or abroad, seems to have described it from actual observation. The existence of such a breed seems to depend on what has been said by Bechstein, the German naturalist, from whom Brent, who is the only fancier who mentions it, has gathered the following: "Die Taube mit Schwalbenschwanz.-Bechstein, in his 'Natural History of Germany' deseribes this variety as occasionally to be found among the collections of pigeon fanciers, and says they are blue, chequered, or black mottled, the outer feathers of the tail being much prolonged, or forked like that of the 
Chimney Swallow, from which circumstance they derive their name." And Brent adds: "A pigeon-fancying acquaintance informed me that he once had a pair of Swallow-tailed Baldheads, which he purchased in Manchester: so I conclude this variety is also to be met with in England, though I have not seen it. Some of the wild pigeons or doves of foreign countries have long, wedge-shaped tails, but such a formation of tail I have never seen or heard of among our domestic pigeons."

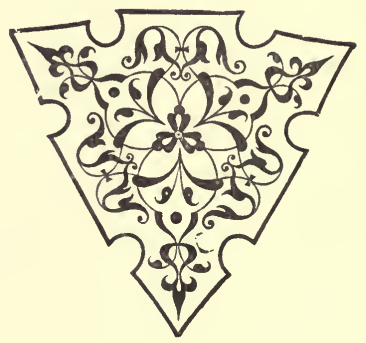




\section{Chapter XIII.}

\section{$\propto$ THE RINGBEATER PIGEON. $\varnothing$}

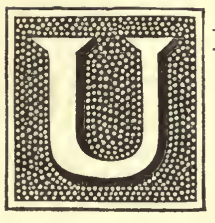

NDER the names of Smiter, Finnikin, and Turner, our former writers on pigeons have described varieties agreeing more or less with the French Pigeon Tournant, and German Ringschläger, or Ringbeater. Willughby says of Smiters: "These do not only shake their wings as they fly, but also, flying round about in a ring, especially over their females, clap them so strongly, that they make a greater sound than two battledores, or other boards, struck one against another, whence it comes to pass, that their quil-feathers are almost always broken and shattered; and sometimes so bad, that they cannot fly." He describes the Turner merely as "having a tuft hanging down backward from their head, parted like a horse's mane;" and the Finnikin, "like the precedent (the Turner), but less."

Moore describes no Smiter, but his Finnikin "is in Make and Shape very like a common Runt, and much about the same Size. The crown of its head is turned much after the manner of a snake's head; it is gravel-eyed, and has a tuft of feathers on the hinder part of the crown, which runs down 
its neck, not unlike a horse's mane; it is clean-footed and legged, and always black or blue pied. When it is salacious, it rises over its hen, and turns round three or four times, flapping its wings, then reverses, and turns as many the other way."

The Turner, he says, "is in many respects like the Finnikin, except that, when it is salacious, and plays to the female, it turns only one way, whereas the other turns both; it has no tuft on the hinder part of the head, neither is it snakeheaded."

Brent says he only saw one pair of Ringbeaters, which were at a pigeon dealer's in Coblentz. They were common-looking birds, with peaked crowns and red and white plumage. Their peculiar movement and circling flight were described to him, and he noticed that the vanes were beaten off the ends of their flight feathers.

Boitard and Corbie describe the Pigeons Tournants as stronger than Tumblers, stocking-legged, generally blue chequered, red, or pearl white in colour, marked with a pure white horseshoe mark on the back. "Whatever may be the space they are shut up in, they ascend to the ceiling, then descend, describing circles, first to right, then to left, absolutely like a bird of prey, which hovers, and then chases from high in the air." They say amateurs have discarded them on account of their quarrelsome and jealous disposition, which causes much mischief in the aviary.

The Pigeon Lillois Claquart, or Lille clapper, is a variety of the Lille Pouter, which Boitard and Corbie have confounded with the Turner. "It makes a noise with its wings when commencing to fly, like a clapper; hence its name." This is a usual thing with half-bred Pouters, and I have often seen such kept as decoys for stray pigeons.

Brent could find nothing in German books regarding the Ringbeater; but, in the last edition of Neumeister, I find a description of this curious breed, from which it appears 
they may now be got, not only with all their peculiarities of flight, but bred to feather as well. $\mathrm{He}$ says: "The excellent pigeon fancier, Führer, describes this pigeon, quite unknown in the North of Germany, in the following way: The Ringbeater is a pigeon only yet appearing on the Lower Rhine, and here and there in Westphalia, of stately size, strong figure, and good bearing. The head is covered with a pointed hood; the forehead of middle height, the beak light coloured, the irides according to the plumage, the eyelids bright flesh-coloured, the neck robust, breast and back proportionately broad, the legs and feet smooth." He describes a peculiarity in the primary wing feathers, which I understand to be, that the fifth from the outside is very much shorter than the fourth, so that, when the wing is extended, the four longest feathers seem to have grown away from the others, and are not in the usual gradation. "The plumage is close-fitting, and marked in all colours as follows: The whole head is white, the line of marking being the breadth of two straws below the eyes; the tail, with its covert and six flights a side, are white." I am not sure from the description whether this variety is white or coloured on belly and thighs. Their flight is described thus: "The characteristic of these pigeons is their flight; it is true they never fly farther than from roof to roof, but not for a single yard without flapping their wings together, so that it sounds afar; this is particularly done by the cock when courting his hen. A good beater must beat a ring round her from five to six times-i.e., flying around in a circle right and left, making a loud noise by beating his wings together. The hen beats likewise, but less strongly; both beat most in spring. In autumn their flights are so much beaten down that they cannot fly, and they easily meet with accidents. Their quite ragged pinions are then sometimes pulled out, which does not hurt them when done only once in a year. Those birds are most valuable which flap much, and yet pre. 
serve their pinions well. The young ones begin to flap as soon as fledged. The Ringbeater is a healthy, very lively, and quarrelsome bird, causing much disturbance in the loft, and unfitted to live with other pigeons. It is also very prolific, and it is a matter of wonder that it is not more spread. Besides good ringbeating, we require in this pigeon a considerable size of body, fine bright colours, and pure markings. The price of purely marked black and yellow ones is several marks a pair; the red, mostly bad in colour, are cheaper."

The Ringbeater is a pigeon that would be valued by many in this country, where, as appears from the pigeon books of the last century, it was formerly not uncommon. It is the same bird that Willughby wrote of as the Smiter, and which Moore calls the Finnikin, though evidently now bred for colour and marking as well as ringbeating. It was no doubt produced by selection from such as had its peculiar flight in a modified degree. In a loft of Tumblers some lively cock will often be found having a good deal of the above description in his flight.

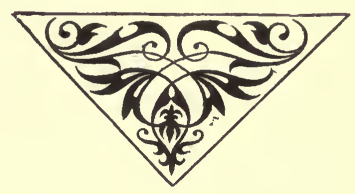





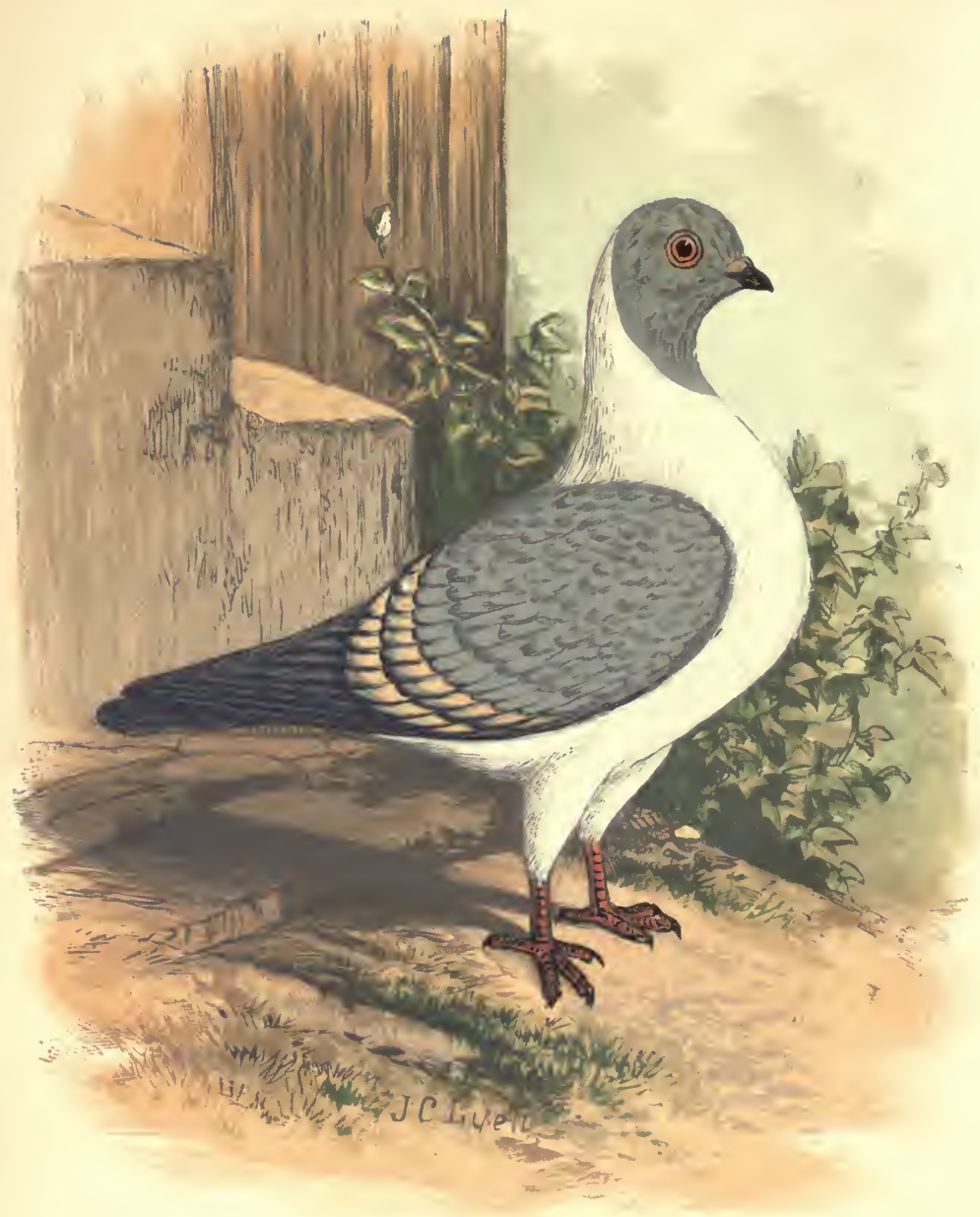

THE TRIGANICA, OR MODENA PIGEON. 


\section{Chapter XIV.}

\section{$\propto$ THE TRIGANICA PIGEON. $\infty$}

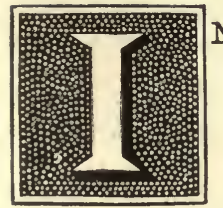

$\mathrm{N}$ the city of Modena the sport of pigeonflying has been in vogue from time immemorial. Those who are devoted to this sport are called Triganieri, and the bird they employ is known as the Triganica, or Triganina Pigeon. Historical evidence carries the sport back to the year 1327, the date of the Modenese Statute, $D e$ Columbis non Capiendis nec Trappola Tenenda. In the same Statute, reformed in 1547, the word Triganieros, used only in Modena, is first found. In the Latin poem, De Aucupio Coternicum, by the Modenese, Seraphino Salvarani, published in 1678 , there is a fine description of the method in which the Triganieri carry on their aërial warfare. Tassoni has alluded to them as

... A company of loose livers,

Given up to gaming and making pigeons fly,

Which were called Triganieri,

Natural enemies to the Bacchettoni,

the latter being "certain people who go about by day kiss- 
ing little pictures painted on boards, and in the evening assemble together to use the scourge on their bare backs." About the time that Moore wrote his "Columbarium," Dr. Domenico Vandelli was writing a description of the sport carried on with pigeons by the Triganieri, which differs but little from that in vogue at the present day. The dovecotes of the Modenese fanciers are on the roofs of the houses, and they are surrounded by stepped platforms, on which the Triganieri stand, directing the flight of their pigeons by the waving of a little flag at the end of a pole. The flag, some grain of which the birds are fond, and the shrill whistle of the owner (instead of which a cornet was used in olden times), are all the means used for directing them. The object of the sport is the pleasure of making them fly as required, and the capture of birds belonging to enemies. Some of the phrases used will illustrate the methods employed.

Guastare, is to let loose for flight one or more pigeons for the first time.

Sparare, is to let loose for flight, and to send round in circles, the pigeons already trained.

Mischiare, is to join together, and confuse in one single band, the various flying bands which belong to several Triganieri, taught to do this by a signal given them by their respective masters.

Strappare, is the sudden division and separation of the united bands, at the whistle of any Triganiere, who thus calls back his band to his own roof, when they are all united together.

Scavezzare, is the signal which the Triganiere makes with his flag to his band, when he observes, mingled with his own birds, one or more strange pigeons, which they can more easily surround, and bring to his dovecote.

Avvujare, is to induce a band, into which some strange pigeons have been brought, to fly backwards and forwards in long-continued flights around the dovecote, in order to seize a favourable opportunity of making them descend all together. 


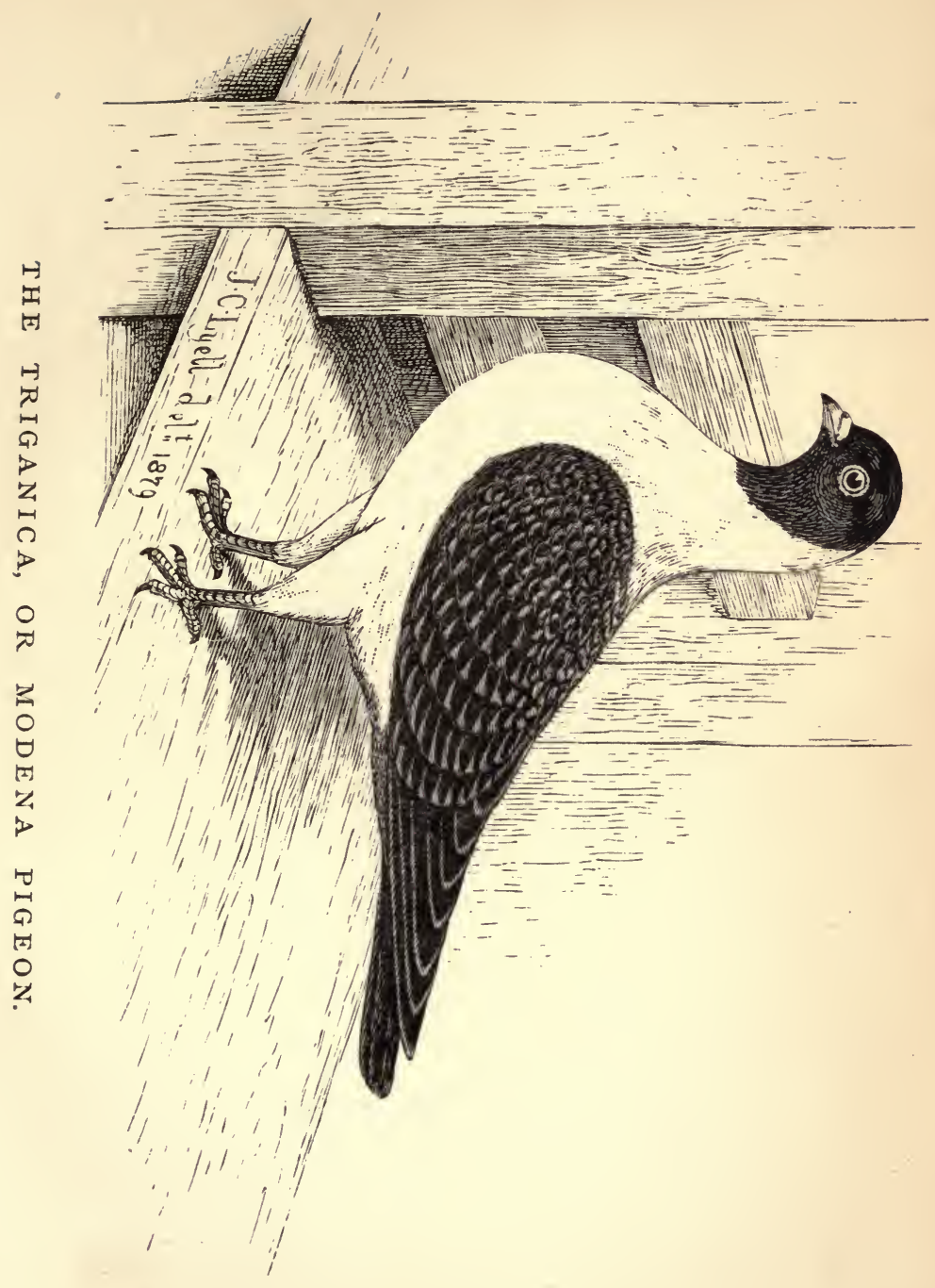



Trattare, or Gustare, is the giving of grain to the pigeons when they have descended, as a reward for having been obedient in their flight to the signals of the Triganiere.

Tirar giì niente, is the recalling of the flock of pigeons by their master when they do not obey his signals, without giving them food, the better to incite them to obedience.

Andare indietro spalla, is to feign to send the pigeons to mingle with others, and, when they have almost mingled, to call them back suddenly, with the probability of some of the pigeons of the other bands returning with them.

Dare la mano, is the act of taking up the strange pigeons which have perched on the platform with the pigeons of the Triganiere.

When Vandelli wrote, the sport was carried on in four ways. First, on the terms of good friendship, in which a reciprocal restitution of captives was made without compensation. Second, on the terms of fair battle, by the redemption of the captives at a price agreed upon by the combatants. Third, on declared war, when the pigeons were taken with impunity, and with no obligation on the part of the captor to restore them. And, fourth, on war to the last drop of blood, when the captive was immediately hung from the platform in full sight of the dovecote of the adversary; or there was attached to its tail a little bottle of gunpowder, in which a fuse was placed, and then, when the enemy sent out his pigeons, the captive was let loose, after the fuse had been fired, so that, when it arrived in the midst of the flight, the bottle burst, and many of the pigeons near were killed or wounded.

In the present day, however, such cruel reprisals are not practised, and the sport is generally carried on $\grave{a}$ lira, or on the terms of the redemption of captives at the rate of a Modenese lira.

I am indebted to the Italian books to be mentioned in the Appendix for the foregoing information on the Triganieri, and chiefly to Malmusi’s “Dei Triganieri,” 1851. 
The Triganica Pigeon, which is of comparatively modern origin-other varieties, as described under the Archangel pigeon, having been previously used for the sport-is said by Neumeister to be a variety of the Hühnertauben, under which classification he describes it. The marking is certainly very similar to that of the Florentiner, but the Triganica Pigeon is now only a medium-sized bird, and, though many of them carry their tails somewhat erect, they ought to carry them horizontally. This variety certainly shows some relationship to the Hühnertauben, or Fowl-like Pigeons, in being high on the legs, short in the flights and tail, and in being marked much the same as the Florentiner; but its shape is in every respect modified, and other elements have, without doubt, entered into its composition.

There are no less than 152 colours in this variety, all of which have received names from the Triganieri, and these may be found in Professor Bonizzi's "I Colombi di Modena." Seventy-six of these are what are called schietti, or pure colours-that is, the pigeons are all coloured, without any entirely white feathers, and the other seventy-six are the corresponding gazzi, or magpies of these colours-that is, pied with white, like the illustration. Some of the most beautiful colours are-black, with the wing coverts chequered with red, which I have attempted to show in the woodcut illustration. Black, with the wing coverts heavily tipped with red, so that the whole shoulder, as in a Turbit, is red, the head, flights, and tail being black. The same, with yellow-chequered or whole yellow shoulders. Dun head, flights, and tail, the shoulders buff, but tipped with bright yellow. The same with solid yellow shoulders. Blue magpies, with red or yellow wing bars, black-barred blues being of no value. Light blue, of a uniform tint, without any wing bars. Black and white grizzles, in which every coloured feather should show black and white. Blue and white grizzles. Three-coloured birds, in which every feather should show 
black, red, and white. Oddities, having one wing of one colour, and the other of another colour. I had lately some good Triganica Pigeons, light blue in colour, marbled on the shoulders with dark blue, and with yellow wing bars, like the coloured illustration.

These pigeons are bred by many fanciers who have neither time nor inclination for the sport as practised by the Triganieri proper. Some of the colours are rare, and only in the hands of their producers, who are so jealous of parting with them that they would rather destroy their surplus stock than let the breed out of their hands. The magpies present the same difficulties in breeding as other pied pigeons, coloured feathers in the parts that should be white, and vice versî, troubling the breeders in Modena as much as they do us in our pied varieties; so that a perfectly marked pigeon is a rarity, and is, consequently, valuable.

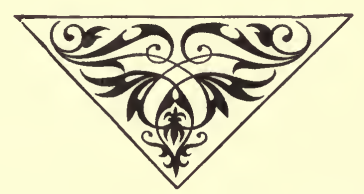




\section{Chapter XV.}

\section{$\propto$ SEVERAL VARIETIES OF EAST INDIAN PIGEONS. $\infty$}

\section{The Sherajee Pigeon.}

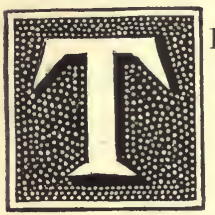

HE Sherajee, so named in Bengal, but called Sherazie in Northern India, is a favourite pigeon throughout Hindostan. The name is, no doubt, derived from the city of Sheraz, in Persia, where it might possiby have originated. This pigeon is, in shape and size, very similar to the tight-feathered Trumpeters common in this country before the so-called Russians were introduced. The head and beak of the Sherajee are of the common type, the latter neither short, nor long and thin; and birds of good colour always have a reddish tinge on the eye ceres, beak wattles, and the edges of the mouth. The irides are dark hazel colour, the head is unhooded, and the legs and feet are feathered. Long toe feathers, spreading out on each side, are much admired. The marking of the Sherajee is peculiar to itself, nothing similar to it being found in any other variety that I know of. The upper mandible is coloured, except with those colours that are generally accompanied by a. flesh. 



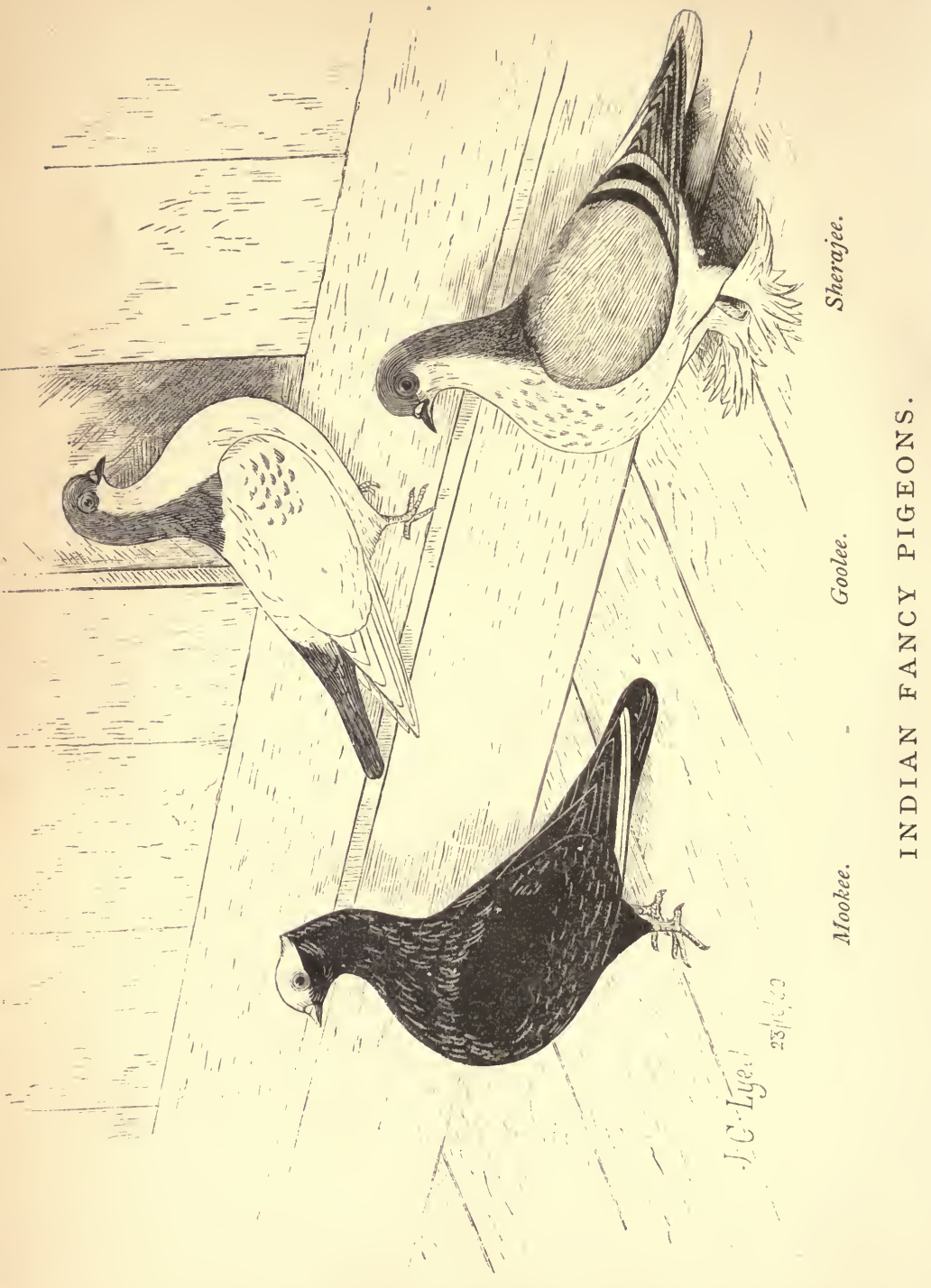


coloured beak; and the marking, commencing at the beak wattle, runs over the head and down the back of the neck, till it meets the back and wings. Looked at in profile, the marking should show a clean division down the side of the neck; from behind, the neck appears all coloured, and from before, all white. The back, wings, and flight feathers are also coloured, the rest of the plumage being pure white.

A rarer variety of the Sherajee is that known as the Mottled. The breast of this variety must be well-mottled with single feathers, no two of which ought to touch each other. This is a kind of mottling peculiar to Indian fancy pigeons, being the reverse of what is required in this country, where standard mottling is always composed of single white feathers on a coloured ground. The Mottled Sherajee, when anything like perfect, becomes a very valuable pigeon, and is often sold at so much the mottle; I was told, on good and satisfactory authority, that as much as 1000 rupees had been paid for a fine bird of this breed. While a few coloured feathers on the breast of the Sherajee only spoil what might otherwise be a good plain-breasted bird, when the number reaches to about thirty single, well-separated mottles, the value is reckoned something in the same way as that of the diamond, by squaring the number of feathers, and multiplying by a price. After all, 1000 rupees, formerly equal to about $£ 100$ sterling, is no more than has been paid in this country for a Carrier, and Indian potentates are known to be as keen in acquiring the objects of their fancy as people of any other country.

The Sherajee can only be seen good in the collections of experienced pigeon fanciers, though no bird is more common in the places in Calcutta where pigeon shops abound. I have seen them in black, red, yellow, and dun, also in blue and silver, both barred and barless, and in many off colours. Those found for sale in the bazaars are generally of black 
marking, and often either bare or only half-feathered on the legs.

Some five or six hundred large vessels leave Calcutta for Great Britain every year, and few of them without some live stock on board as pets, for sailors are very fond of a monkey, parrot, or pair of birds to amuse themselves with on the long voyage. In this way, many black Sherajee Pigeons, such as can be bought for $2 \mathrm{~s}$. or $3 \mathrm{~s}$. a pair, have reached this country, and probably they have been coming for the last 200 years or more; but the earliest mention of this breed I know of in our literature, is in the Poultry Chronicle, vol. iii., page 443, in the report of Prescot Show, in Lancashire, on the 4th July, 1855, as follows: "The pigeons seemed to be the subject of universal interest. Among these were two pens, quite new (and distinct as to variety), and which, we believe. have never hitherto been shown at any public competition, We allude to birds entered as 'Tailors.' Why so called we know not, but are informed the original parent birds were imported from the Canadas (under that name), at an immense expense, by the late Earl of Derby, for the Knowsley aviary." And then follows the description of them, agreeing with what I have given of the Sherajee, except as to mottled breast and feathered feet, which shows them to have been merely sailors' pigeons, though called "Tailors"; and no doubt they were bought in Liverpool out of some East India vessel, the Canadas not having any such stock to part with. Again, at page 491 of the same volume, they are referred to by Mr. Brent as follows: "I beg to second Mr. Eaton's appeal to pigeon fanciers, and hope they will support the Anerley Show; and trust to see some of the rare varieties there, such as Laughers, Silk Fantails, Taylors, and others."

In Brent's Pigeon Book, and in Eaton's 1858 Treatise, the name of "Tailor" is dropped, and that of "Lahore," or "Martin," substituted, the former being given because Brent had found they came from that city, and the latter on account of their 
resemblance in marking to the Martin, or Window Swallow (Hirundo urbica).

\section{The Mookee Pigeon.}

This is another Indian pigeon, of pure and distinct race, that has not been unknown in British seaports having a connection with the East Indies, during the past twenty or thirty years; but which was not recognised until I pointed it out some years ago, as the Narrow-tailed Shaker of Willughby's "Ornithology," published in London in 1676. Willughby says of this kind: "Narrow or Close-tailed Shaking PigeonsAnglicè, Narrow-tailed Shakers. These agree with the precedent (the Broad-tailed Shakers) in shaking, but differ in the narrowness of their tails, as the name imports. They are said also to vary in colour. This kind we have not as yet seen, nor have we more to sày of it." Willughby had this information, without doubt, from some pigeon fancier who knew the breed, though he does not name his authority, as he elsewhere names $\mathrm{Mr}$. Cope, of Jewin-street.

When Moore wrote his "Columbarium," about sixty years later, he described the Narrow-tailed Shaker, the last kind mentioned in his book, as follows: "This Pigeon is reckon'd by some a distinct Species, tho' I am apt to believe it is only a bastard breed between the foregoing (the Broad-tail'd Shaker) and some other Bird. Its neck is shorter and thicker, its back longer, the Feathers of its Tail are not so much spread out, but fall as it were double, lying over one another, and the Tail generally lops very much." And thus, from Moore onwards, every writer described the Narrow-tailed Shaker as a crossbred Fantail, as no doubt the bird above described was, Moore never having seen the true breed. But it will be observed that Moore says: "This Pigeon is reckon'd by some a distinct species." No pigeon fancier would reckon a crossbred Fantail as a distinct species, so there were, even in Moore's time, some who either knew, or had been 
told, about the true Narrow-tailed Shaker, which is the Indian Mookee, a pigeon having the tremulous shaking neck of the Fantail, and a close, narrow tail, with the normal number of twelve feathers.

The head of the Mookee is flat, showing no stop, and its beak rather longer than that of a common flying Tumbler; it is also generally peak-headed. The irides are dark hazel in colour. The upper mandible is white, and the lower follows the plumage. The whole head is white above a line running across the eyes. The two longest flight feathers should be white, and all the rest of the bird coloured. The head often comes foul or unequally cut, and the flights often foul. Three, or even four a side, are better than unequal flights, but two a side are considered the standard. The curious thing about the Mookee is the tremulous shaking of the neck, which is never absent, and which is most constant when the bird is salacious. It is singular to see the cock driving the hen to nest; his head and neck shake continually backward and forward, but he never loses his balance. The tail is carried horizontally and close, as in most pigeons.

I have seen all colours in this breed, as in the Sherajee, but the great majority are black. Blues with black bars, barless blues, and duns, are next in order of number, while reds and yellows are comparatively scarce, though they were to be seen in the possession of several Calcutta fanciers ten years ago.

Putting aside the curious markings, it is obvious that the Mookee is not a bastard Fantail, for, united to a close tail of twelve feathers, it has all the shaking of ordinary Fantails; and it is known that, in crossing the Fantail, its tremulous neck motion is lost long before the tail is reduced to twelve feathers. It is as probable that extra tail feathers in the Mookee resulted in the Broad-tailed Shaker as that it was bred down from the Fantail. No one can say now how either variety was produced, and to experiment on the subject would 
be wasting time that might be better employed, as we have both varieties ready made to our hands.

The Mookee is a good breeder and feeder. It is a longlived pigeon. One dun cock that I sent to Dundee from Calcutta, old when he left, lived for ten years afterwards.

\section{The Goolee Pigeon.}

The Goolee is a small pigeon, not much larger than the Short-faced Tumbler. It was in the possession of a $\mathrm{Mr}$. Wood, one of four brothers, all pigeon fanciers in Calcutta, that I first saw a good collection of Goolees, and what at once struck me, was their close resemblance in shape and carriage to our Short-faced Tumblers. The Goolee has a spindle beak, like that of our small, clean-legged, flying Tumblers, and an abruptly rising forehead, showing a decided stop. Were the best of them to be subjected to treatment from the skull improvers that are said to be used in this country for shaping the heads of Short-faced Tumblers, the result would be birds differing little from these pigeons, except in colour. Indian fanciers, however, do not use such instruments, for they only value properties that can be bred in their pigeons.

The upper mandible of the Goolee is coloured, the lower white; but reds and yellows have generally light beaks. The marking of the head and neck is the same as in the Sherajee. The irides are usually dark. The tail, with its coverts, is coloured. This marking is found in all solid colours, and, when the colours are rich and lustrous, as they often are, the eye ceres and corners of the mouth are of a decidedly reddish hue. The rest of the plumage is white, except in a rarer variety, known as the Mottled Goolee. The mottled variety, to be right, must have a rose pinion of coloured feather's on the wing coverts; when this rose pinion is composed of well-separated feathers the effect is very pleasing. Some of the Mottled Goolees are of three colours, 
such as dark dun on head, neck, and tail, yellow mottled shoulders, and white ground. I have seen them of this rare combination of colours, and I believe other three coloured varieties exist, such as black marked ones with red mottled shoulders. The Goolee is clean-legged, walks on tip-toe when proud, trails its wings, and has the carriage of a good Almond Tumbler. There are in Bengal as many degrees in quality in this variety as there are here between the best Short-faces and Common Flying Tumblers. The choicest birds can only be seen in the possession of experienced breeders, and are never offered for sale in the bazaars. The Goolee shares with the Sherajee the position of chief favourite among Calcutta pigeon fanciers, some preferring the former, others the latter. Fine specimens of both kinds fetch long prices.

\section{The Lowtan Pigeon.}

The Lowtan is indeed a curiosity among Pigeons. It is a native of India, and was quite unknown among fanciers in Britain until some letters regarding it, from Indian correspondents, were published in the Field newspaper. These may be found in Tegetmeier's book, and give a good account of it. I knew the Lowtan very well in Bengal, and have seen many of them. In size they were the same as the common Field Pigeon. and all I have seen were pure white, with a turn crown. Their eyes were dark hazel, their legs and feet unfeathered, and in general appearance they were quite common-looking pigeons. To make the Lowtan perform, it is laid hold of across the back, held horizontally, and shaken smartly from side to side three or four times. This seems to put it into a fit, for, on being placed on the ground, it immediately turns head over tail till exhausted; but it is generally picked up after fluttering about for a short time, as there is a belief that it would die if left alone, though this is not the case. Whether the Lowtan suffers pain or not when made to roll about I cannot say, but 
if it does it soon recovers, for on being taken up during its fluttering fit it becomes quiet, and when let fly it will at once play up to its mate, if a cock, or commence to eat as if nothing had happened. There is no variety in its exhibition, which is rather unpleasing after being seen once or twice, and those who keep Lowtans seldom put them through their manœuvres.

One of the correspondents referred to, writing from Madras, mentions two varieties of the Lowtan, one being the Kulmee, or high caste kind, that would roll about on being merely touched on the head or peak; while the other kind, the Sadhee, or Common Lowtan, required to be shaken as I have described before it would perform.

The other correspondent, writing from Rohilcund, had kept the Common Lowtans for two years, and on inquiring for the high caste, or Choteen Lowtans-so called because they were - said to roll on the chotee, or turn crown, being touched-he procured four specimens, all of which rolled on being struck on the back of the head with the forefinger. One of them was similar to his Common Lowtans; another similar in appearance, but Turbit marked, being white with dark shoulders; and the other two had "great long legs, feathered to the toes."

I never saw any of the kind that performed on being merely touched, nor other than pure white ones.

I saw a pair of White Lowtans two years ago, in one of the pens, at a meeting of the National Peristeronic Society, in London. No one knew what they were until I put them through their peculiar performance, to the amusement of the spectators.

The breed is mentioned in the "Ain-i-Akbari," or "Institutes of Akbar," written about the year 1600 .

\section{East Indian Flying Pigeons.}

When passing through the streets of large cities in Northern India, from an hour before sunset till dark, an observer may 
see many people on the flat roofs of the houses, directing the flight of large flocks of pigeons by means of flags attached to long bamboo poles. This sport is carried on with great energy in the city of Delhi, where I have seen immense numbers of pigeons flown in this way. In Calcutta also, anyone who may be passing through the native parts of the city, near sunset, will see the same sport carried on by numerous pigeon flyers. Garden Reach (the southern suburb of Calcutta) was formerly the residence of many of the principal merchants and civil servants, whose palatial houses, standing in their compounds of from two to twenty acres of ground, are now (1878) chiefly owned by the exking of Oude, a State prisoner there, who has gradually bought up a great many of them, and surrounded them by a high wall. When passing up the Hooghly river, I often saw flights of pigeons that seemed to number thousands, flying, to all appearance, under command, over the King's grounds; but, as it seemed impossible to gain admittance to the place, I could never get a closer inspection of them, till, observing in the newspapers one day that certain people would be admitted, I hastened to avail myself of the opportunity. The ex-king of Oude has what is said to be the largest private collection of rare birds and animals in the world, on which he has spent an immense sum of money, and of which he is very fond. It would be out of place here to describe the beautifully laid out grounds, the lovely plants, the rare animals, the marble-margined tanks or ponds, surrounded by gilded railings, and full of rare aquatic birds, and the houses fitted up as aviaries, and full of the most gorgeously feathered birds; so I shall confine myself to a description of the four great flights of pigeons, which are kept in four of the houses in the King's grounds. These flights are said to number about a thousand in each, and are composed of only one breed, the native name of which I forget. This variety is a medium-sized, very hard- 
feathered, smooth-headed, bare-legged, boldly upstanding, rather long-faced pigeon, not unlike the cross between a Dragoon and Tumbler. It is invariably pied in colour, the head and neck, as far as in Triganica, or Nun Pigeons, being usually coloured. The rest of the plumage is white, on which irregular patches of colour, differing in different individuals, may be found. It is difficult to find any two birds exactly alike in marking. The four large flocks are of four colours, one being black pied, and the others red, yellow, and blue pied. The houses these flocks are kept in were formerly dwelling houses, in the upper rooms of which I was told the pigeons were bred. The keeper of each flight has a long bamboo, to which is attached a small flag, and a jar of seed, something like millet in appearance. $\mathrm{He}$ must also be an adept in uttering a shrill whistle, produced by placing his first and second fingers between his lips. It will, therefore, be seen that the modus operandi of directing the pigeons is exactly the same as that in use in Modena. The flight I observed first was composed of blue pieds, whose keeper drove them out of the lower hall of the house in which they were with his bamboo. They all settled on a large rack, such as is fitted up in greenhouses for placing the pots on, which stood in front of the house. He then gave his shrill whistle, waved his flag, and the whole flock rose into the air. The other flights were up at. the same time, and it was a fine sight to see them intermingling, separating, and wheeling round in their flight, the dense masses casting shadows on the ground like passing clouds, and the whizzing of their many wings being pleasant to hear. After they had flown for some time, I asked the keeper to bring them down, and I could then see how quick they were, for, the moment he dropped his flag, and put his hand into the seed jar, they stopped in their flight, hung in the air for a moment, and then came down to the ground at my feet with a rush. The keeper went in amongst 
them, and picked up one, which he shook from side to side, and then tossed into the air. It was a yellow pied, from one of the other flights.

It is probable that pigeon flying carried on in this way has travelled westward from Asia. The Italian books make mention of a similar practice being common in Moscow. It is well-known that the Taj Mahal, at Agra, and other fine buildings that are the glory of the East, were designed by Italian architects, and nothing is more likely than that some of the Italians, who were in India from two to three hundred years ago, may have been pigeon fanciers, and taken the sport home with them. There is even some resemblance in the respective breeds used for the sport in Italy and India. The Modenese Statutes of 1327 and 1547 prohibit the snaring of pigeons by nets or strings, but they do not prove conclusively that this sport was in use then. Some of the Venetians may have originated the sport in the fifteenth century. The Venetians had intimate business relations with India 400 years ago, and their coins are still plentiful there. I have bought old Venetian ducats in India, where they are valued for their purity, and hoarded up with the gold Mohurs of Akbar. The sport of pigeon-flying may have reached Italy from Turkey or the Levant, for I have no doubt it is carried on in Persia, Turkish Arabia, and Asia Minor, in very much the same manner as in Hindostan.

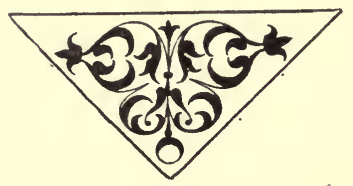





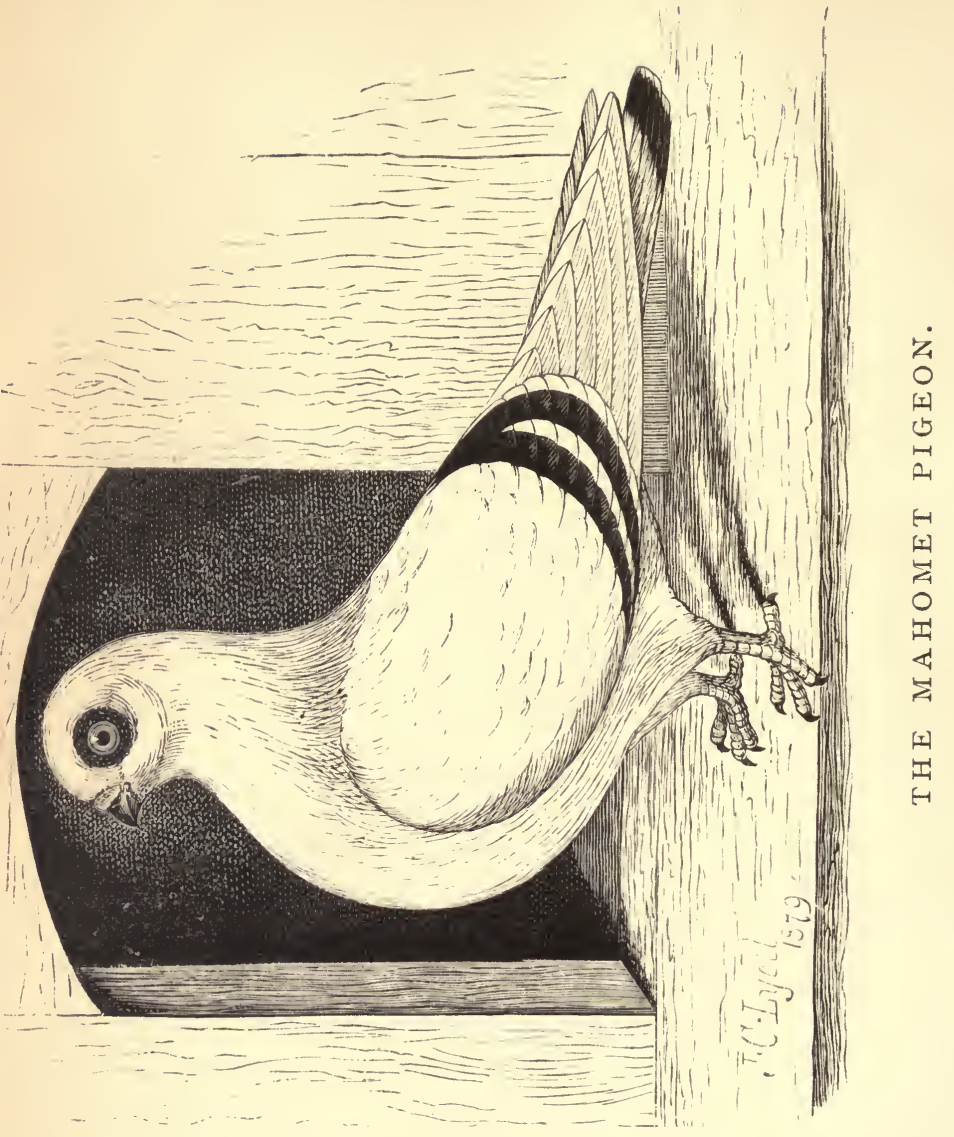




\section{Chapter XVI.}

\section{OTHER DISTINCT KINDS OF ASIAN PIGEONS.}

\section{The Mahomet Pigeon.}

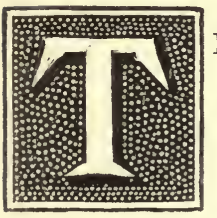

HE Mahomet, formerly known in England as the Mawmet, was first described by Willughby, in 1676, who says: "Mawmets, called (as I take it) from Mahomet, perchance because brought out of Turkey, notable for their great black eyes, else like to the Barbaries." Willughby must either have seen such pigeons, or had his description of them from others. When Moore wrote his book, some sixty years later, he knew of no pigeons "notable for their great black eyes," but he describes the Mahomet as "no more in Reality than a white Barb, which makes the red tuberous Flesh round the Eyes look very beautiful." In the preface to the "Treatise on Pigeons" (1765), the author admits that his book is "on the plan of Mr. Moore," but says that he has corrected some of his errors, and made many additions. After mentioning Moore's description of the Mahomet, he proceeds: "so far Mr. Moore; but it is the opinion of many fanciers, that the Bird called a mahomet is nearly of a cream colour, with bars cross the wings as 
black as ebony, the feathers very particular, being of two colours: the upper part, or surface of them, appearing of a cream, and underneath a kind of sooty colour, nearly approaching to black; as are likewise the flue feathers, and even the skin, which I never observed in any other Pigeons but these: its size much like that of a Turbit, with a fine gullet, and in lieu of a frill; the feathers rather appear like a seam; the head is short, and inclined to be thick; hath an orange-eye, and a small naked circle of black flesh round the same; and a beak something resembling that of a bullfinch, with a small black wattle on it."

In the pages of the Poultry Chronicle (1854-55) will be found a discussion on the Mahomet Pigeon. Mr. W. Woodhouse, who had been breeding and also showing crested, three-quarter bred white Barbs, as Mahomets, informed fanciers in his letter to that journal, on 13th December, 1854, how he bred them. Brent would not accept these birds as Mahomets, for he had shortly before, when writing of them, quoted the above description of the true breed from the Treatise, and had actually seen a pair in London. He says: "This is one of the varieties of fancy pigeons with which I have but a very slight acquaintance, having only once seen a pair at a London dealer's, and their appearance gave me the idea of a cross between an Owl and a Barb Pigeon; nevertheless, their seam and black wattle, cere, and skin, I consider sufficient distinctive peculiarities to give them a place among fancy pigeons as a separate variety."

About the year 1868, Mr. Boyd, of Edinburgh, brought home with him, from Constantinople, a pair of Mahomets. They became the property of Mr. James Wallace, of Glasgow, who showed them there, in 1869 , as Damascenes. The hen lived but a short time, and the cock came into my possession in 1878; but he was then past breeding, and shortly afterwards met his death from an accident. In 1883, several pairs 
were brought to this country from Asia Minor, some of which came into my possession.

In shape and size of body, the Mahomet is not unlike the Barb, and, were it not that its beak and eye wattles are nearly black, instead of red, it might naturally be supposed to be of the Barb race. The head is full and round, the beak short and thick, but not hooked; the irides are bright orange or deep yellow, and the beak and eye wattles, though almost black, are covered, when in health, with a powder that makes them of a beautiful blue colour. In colour, this pigeon is of the most lovely light blue, frosted all over as if with powder, except on the wing bars, flights, and tail. The bars should remain, as in the old description, as black as ebony. The flights are of a medium tint, darker than shown in the illustration, as is the tail, except that it has the jet black bar at its extremity. The lower part of the neck is lustrous with hues of very light green and purple. The beak and nails are black, the feet and legs bright red, sometimes stockinged, but I much prefer them smooth. Although of such a beautiful light blue, or what is called a French white, tint on the surface, the neck and body feathers are dark bluish-black underneath when exposed; but this must not assert itself when the bird is at liberty. This beautiful colouring is not confined entirely to the Mahomet, as the same feather, or nearly so, may be found among the Ice Pigeons; but what makes the former of such an original type is the dark eye wattles. It would almost seem to be related to the $\mathrm{Owl}$ race of pigeons as well, as it has a very pronounced gullet and seam, or division down the breast, though no actual frill.

This distinction, and the shape of its head, make it a likely cross with the Blue Owl, which I know has been tried with success in more than one instance.

It is a pity that the Mahomet is so scarce, for, although it has not in its composition what would make it, even though 
plentiful, only to be seen of high quality now and then, as the Pouter or Turbit, it would be a beautiful and telling variety in an aviary of different kinds, and likely to breed very true to its characteristics. I know those I had were often picked out by strangers as the most beautiful pigeons in my aviary.

The Mahomet shows the powdered blue colour in the very highest degree, and has the power of reproducing its colour to a great extent when crossed with a blue or silver pigeon.

\section{The Capuchin Pigeon.}

A pigeon under this name was described by Moore, who says that it is in shape and make very like the Jacobin, but something larger in body, longer in beak, with a tolerable hood, but no chain, though in feather and other properties the same. He says: "Some will assert it to be a distinct Species, but I am more inclinable to imagine it is only a bastard breed from a Jacobin and another Pigeon; however, thus far I am sure, that a Jack and another will breed a Bird so like it, as will puzzle the Authors of this Assertion to distinguish it from what they call their separate Species."

Remembering what Moore has said of the Mahomet and Narrow-tailed Shaker, I doubt if his half-bred Jacobin was really what some fanciers asserted to be the true Capuchin. Moore evidently knew the motto, viam aut inveniam aut faciam, and it puzzles me to hear of any fancier asserting a half-bred Jacobin to be a distinct species; however, if there was a pure race, as described, known as the Capuchin then, we do not know it now, for its description cannot apply to the bird we now class under that name.

The Capuchin was first imported into England, and first described in Fulton's book, by my friend, Mr. H. P. Caridia, of Birmingham. It is, he says, a native of one locality of Asia Minor; and those I have seen are certainly of pure and 
distinct race. The head is round and full in front, the beak short and fine, the iris pure white, surrounded by a thin purple-black cere, and the beak and toe nails black. The plumage is a rich metallic black, sparkling with lustre, the tail, with its coverts, alone being white. Mr. Caridia says there are also similarly marked blues and whole-coloured whites. The Capuchin gets its name from an extensive closefitting hood on the back of its head, which comes down a very short distance on each side of its neck. It carries the flights low, generally below the tail. It is thin-necked, broad-chested, and has much of the shape and carriage of the Short-faced Tumbler. It is said to be a good flyer, breeder, and feeder.

I have heard some say that this pigeon is the original of our Jacobins, which I consider an hallucination. Its black eye cere alone points to a separate origin, but I believe the third or fourth cross from it and the Jacobin has resulted in very fair specimens of the latter breed, which I can easily imagine would be the case. I could fancy it to have originated from the Jacobin and the Mahomet, but this is mere speculation. The breed as it stands may be many centuries old.

\section{The Coral-eyed Pigeon.}

The Coral-eye is a variety of the domestic pigeon well known in Bengal. I have seen these birds in the possession of different fanciers in Calcutta, among whom they went by the above name; and I believe their Hindostanee designation has the same meaning. In size and shape the Coral-eye resembles a strong English Owl Pigeon, but its head and beak are more of the common type, the latter not long and spindly, but of moderate length and thickness. It is neither turn-crowned nor feather-legged, and always, as far as I have seen, whole-coloured blue, with the usual black wing bars. What constitutes this pigeon of pure 
and distinct race is the colour of its irides, which are large in size, and bolting, like the choice African Owl; in colour they are of a vivid ruby red, of the hue known among jewel merchants as "pigeon's blood." I have seen nothing nearly approaching them in any other breed of pigeon, for they are like big beads of living fire sparkling in the head of the bird, and so noticeable that they tell at the distance of several yards. This pigeon breeds true, but loses all value if crossed with another variety. It is an instance of the manifold variations that exist in that universal favourite, the domestic pigeon. I described this pigeon in the Journal of Horticulture some years ago, before which I am not aware that it was ever mentioned in this country.

\section{The Chinese Dewlap Pigeon.}

Some specimens of this very distinct variety of the domestic pigeon first made their appearance in Europe within the last five years. Three pairs of them were brought from China by M. Vallois, an officer in the French navy, for his brother in Paris, an enthusiastic fancier. One pair of them was given to M. Victor la Perre de Roo, who sent me some photographs of them, taken from life. In size and shape they are similar to a large Homing Antwerp Pigeon. The head is of the Owl type, round and down-faced, the beak thick and short. Their greatest peculiarity is the enormous gullet, filling up the hollow of the throat, from the jew wattle to far down the neck, described as, and seeming to be, from the photographs, over half an inch broad. In colour they are blue, but marked in a very original way with a large white spot on the forehead, white upper mandible, a white oval spot on each side of the neck, and with white flights, as shown in the illustration. The best gullet yet seen on any of our Frill-breasted Owl type of pigeons can only be called rudimentary when compared with that of this wonderful bird.

The Dewlap Pigeons had brass bangles on their legs when 
昰

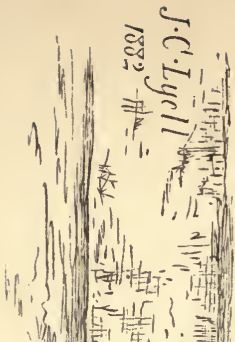

量

I' Af

艰

D

式

侊

式

1) $12-$ है $=51 \mathrm{~L}$.

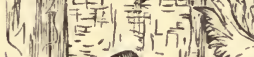

1. If

$=11 y$

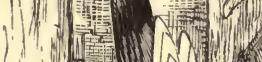

iN IN N N

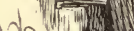

Nond

i. (1)

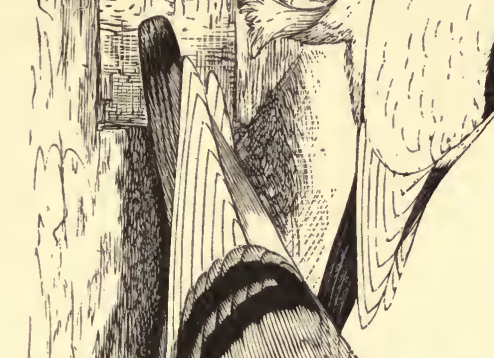

1)
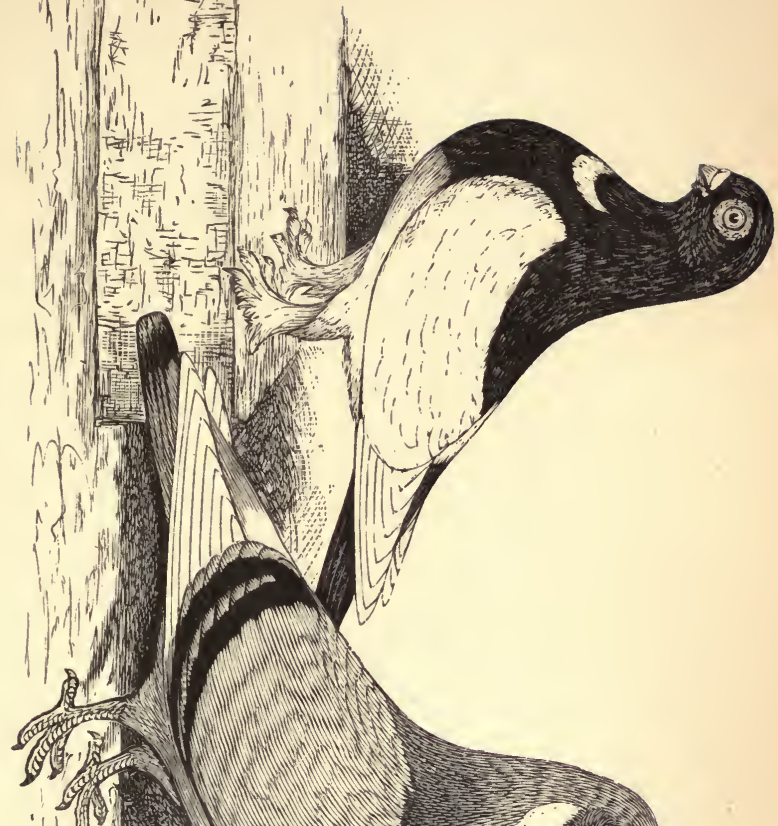

113 is

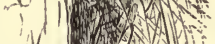

$\checkmark$ P

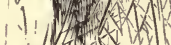

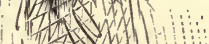



they arrived in France, showing that they had been favourites of someone. It is a general custom in Hindostan for fanciers to ornament their pigeons in this way.

M. la Perre de Roo, in his Monograph on Domestic Pigeons, published in Paris, in 1883, names this variety Le Pigeon Voyageur de Beyrouth, being under the impression, when he wrote his account of them, that they came from Syria; but since then has informed me he had discovered they came from Pekin, in the way I have mentioned. I think it likely that other curious breeds of pigeons may still reach us from the same source.

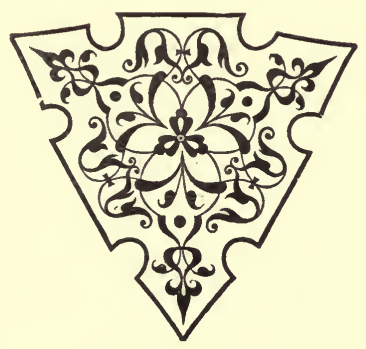




\section{Chapter XVII.}

\section{$\propto$ THE RUNT PIGEON. $\varnothing$}

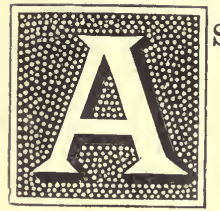

S explained before, the name of Runt was formerly applied generally to all common pigeons in England, and is, no doubt, often still so used; but pigeon fanciers now use the name to designate the variety of gigantic pigeons which Moore and subsequent authors wrote of as the Spanish Runt. I should suppose that the name was given on account of the breed having so little to distinguish it, in general conformation, from the common pigeon, that they were looked upon, when first introduced into England, as the common pigeons of the place they came from, and that the name is not, as supposed by Willughby, a corruption of the Italian Tronfo, or of anything else. The Runt would appear to be of an ancient race. Dixon says:- "But the point respecting Runts which most deserves the notice of speculative naturalists is their extreme antiquity. The notices of them in Pliny and other nearly contemporary writers are but modern records, for Dr. Buckland enumerates the bones of the pigeon among the remains in the cave at Kirkdale, and figures a bone which, he says, approaches closely to the Spanish Runt, which is 



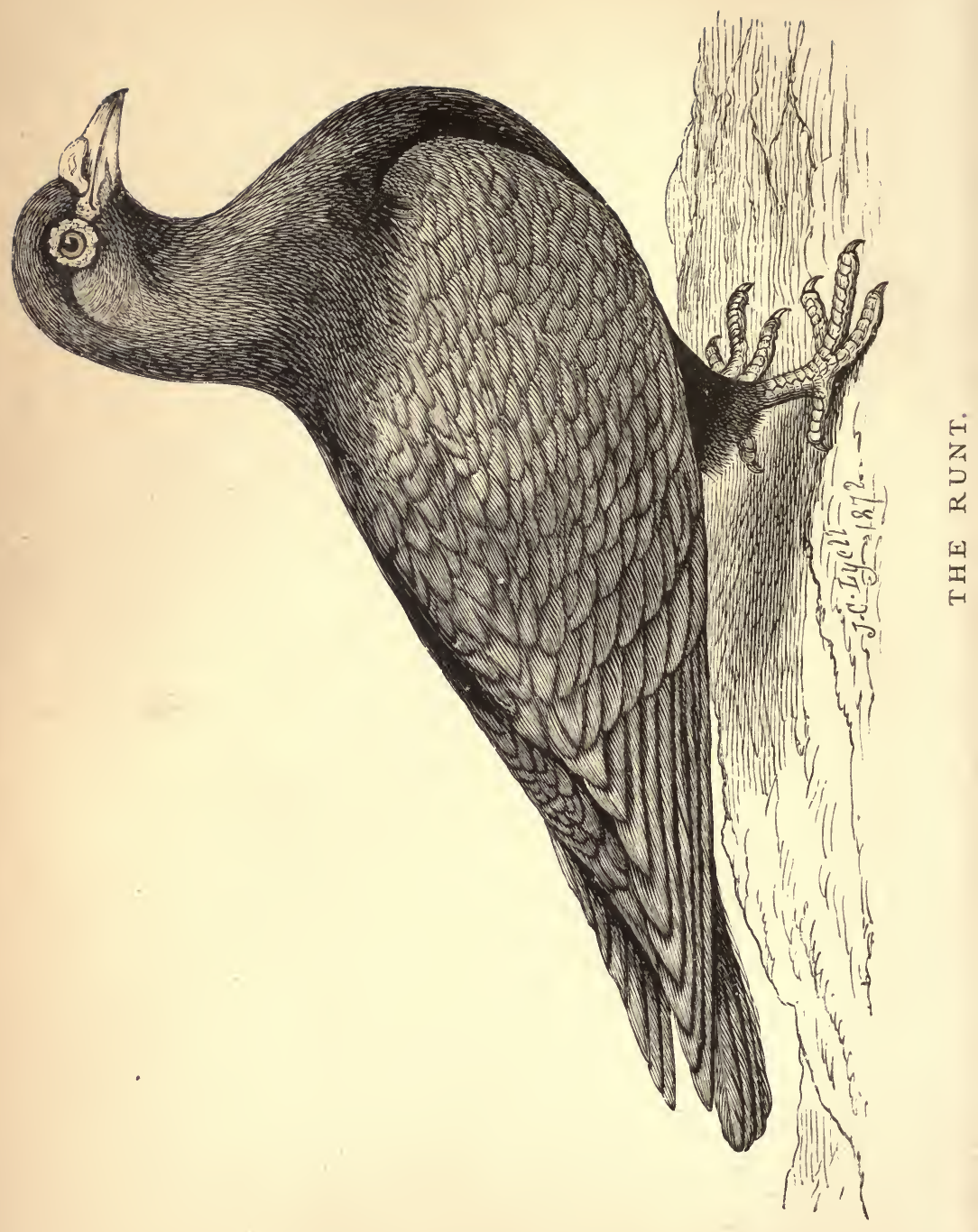


one of the largest of the pigeon tribe. Ever since the classic period, these birds have been celebrated among the poultry produce of the shores of the Mediterranean."

The Runt would, therefore, appear to have been distributed throughout Europe from Italy, and the name it bears in France, from where we get the best, is Pigeon Romain, which points to a like origin for the breed.

\section{Blue and Silver Runts.}

The general colours of the Runt are blue and silver; but there are many others, some of which can claim a high position as fancy pigeons. The Blue and Silver have, perhaps, reached the greatest weights, and are probably the original colours. In appearance Runts are like huge common pigeons, smooth-headed and smooth-legged, but having a rather heavy eye and beak wattle as they get old. The irides are generally orange in the Blues and lighter in the Silvers, and the eyes lie deep in the head, which, when viewed from before, appears narrow and pinched, considering the size of the bird. As to size, a matured pair of birds (cock and hen) weighing less than 4lb. are considered small, and 5lb. may be considered the maximum, although I have not heard of any being quite so heavy. From 4lb. 12oz. to $4 \mathrm{lb}$. 15oz. has been often reached by show birds.

\section{Fancy Runts.}

The illustration given is from the cock of a pair of Red Runts I got from Messrs. Baily and Son, who imported them from France. Although in general shape and carriage of body they resembled the Blue variety, they at once proclaimed themselves of a different race. The irides are pure white, and form a very striking feature in their appearance. The eye wattle is heavy in front and pinched behind, and, with the beak wattle, is of as bright a red as in the Barb. The under mandible is much broader than the upper, even when shrunk, 
as in matured birds; while with young ones in the nest this point is so developed that it gives them a very strange appearance. In colour they are of a rich, deep, burning red, glossy with metallic lustre, and within very little of the best red I have ever seen in any domestic pigeons. I have also had Yellow Runts of the same race as these Reds, and as good for their colour, but they were mottled in the way the Short-faced Mottled Tumbler ought to be marked, that is, rose pinioned on each wing, and handkerchief backed. The marking was just about as accurate as it could be painted in a picture. I am astonished, therefore, that, considering all these fine properties of colour, marking, real pearl eyes, and large size, anyone should write of the Runt as having only the one point of size. In France, these Fancy Runts are to be had in black, red, and yellow, both self-coloured and mottled. Pure whites with pearl eyes are, I believe, the rarest. They are all very bad fliers, and, although good breeders, the young are somewhat delicate, and difficult to rear. The fancy coloured ones do not reach the great size of the Blues and Silvers, and from 4lb. to $4 \frac{1}{2} 1 \mathrm{lb}$. a pair is a good weight for them. Being powerful pigeons, Runts should not be kept with small varieties. When to great strength a spiteful disposition is joined, as it often is with them, they become rather dangerous to other pigeons.

Boitard and Corbie mention several varieties of the Pigeons Romains distinct in colour and marking, some of the most beautiful being described as follows:

Pigeon Romain Mantelé.-All red except the wing coverts and under body, which are white. Brent mentions these under the name of Tigre Rouge. The white mantle probably appears only after the first moult.

Pigeon Romain Marcanu.-Always black or dun (minime), the head having a mixture of white feathers, giving it a grey appearance; irides pearl.

Pigeon Romain Gris Piqueté-One of the largest of the 
race; irides yellow; plumage grey, chequered with black over the body, à piquetures plus rapprochées sur la gorge; feet lightly stockinged.

Pigeon Romain Minime Caillouté.-Its colour is dun or tan, with the edge of the feathers of the mantle and throat of a pale hue, drawing to a clear fire colour; smooth legs and feet; pearl eyes. It is very productive.

Pigeon Romain Soupe-de-lait.-The smallest of the race. It has a thickish membrane on the nostrils, a cere round the eyes, and yellow irides. Its feet are bare; its plumage is the colour of café-au-lait, with two bars of a deeper colour on the wings. This very pretty pigeon has also the essential quality of being tolerably productive.

Pigeon Romain Argenté.-Head fond white, mixed with a clear slate colour; neck and throat bluish-black, reflecting green and metallic; the mantle of a bluish-grey tinted with white, each feather darker at the base, with a light white border. Flights of a blackish grey, barred with clear grey; tail slate colour, with a black bar; pearl eyes. This superb bird is generally very productive.

\section{The Montauban Pigeon.}

The Montauban Pigeon is a variety of the Runt, but not so heavy, though a large bird. It is chiefly black or white, but sometimes blue, brown, and mottled. It has a large shell crest, which should extend from ear to ear, and the legs are sometimes feathered.

\section{The Norwegian Pigeon.}

Brent says that the largest pigeons he ever saw were some white ones, with long feathers on the feet, that came from Belgium, and were called Norwegians. He says: "As I cannot give their exact size and weight, I forbear to state my ideas."

\section{The Roman Pigeon.}

Moore says: "There are other Sorts of Runts, as the Roman 
Runt, which is so big and heavy it can hardly fly; and the Smyrna Runt, which is middle-siz'd and feather-footed." These words are repeated by Mayor and Girton. I think it probable that the title "Roman" was merely the retention of the French name for some importations of Pigeons Romains. There is nothing in the "Columbarium" to indicate that the Roman Runt was of the Leghorn type.

\section{Runts as Table Pigeons.}

Eaton says of Runts: "I knew a pair sold for £25." They were likely something out of the common. At present they are not in great request, and it is a mistake to imagine that, because they are large, they are worth keeping from an agricultural point of view. Three pairs of common Tumblers, or two pairs of large Homing Antwerps, would weigh about the same as a pair of large Runts, and certainly not consume more food. I think either the Tumblers or the Antwerps would produce twice or thrice the weight of young ones in a year that the Runts would do in this country. Although Eaton's note regarding Runts is printed under Moore's account of the Leghorn Runt, the information he gives regarding them refers to the Spanish Runt (Pigeon Romain), not to the Cock-tailed, or Leghorn Runt.

\section{The Almond and Blue Grizzled Runt Pigeons.}

I have seen some very fine Runts in India, in the possession of the ex-King of Oude. He had almond-feathered and blue grizzled ones of great size, the latter the Pigeon Romain Argenté, I fancy, and I understand they were procured for him, from France, by Mr. Jamrach, who took many of them to Calcutta about the year 1870 .

\section{The Black-backed Gull Pigeon.}

I have never seen this variety, which has only been described by Brent, so far as I can find. He says: "Of this variety I 
have seen a few specimens in London, called also the great China Gull; but as to their origin I know nothing. In appearance they were much larger than the common kinds, approaching in form that of the Spanish Runts, smooth-headed and clean-footed. The scapular feathers, and the wings, with the exception of the extreme or the marginal pinion feathers, were black, the marginal flight feathers and the rest of the plumage being white, thus bearing a marked resemblance to the large Black-backed Gulls (Larus Marinus) so common on our coasts. I believe there are also some stuffed specimens of this variety in the British Museum."

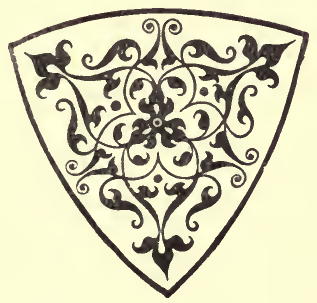




\section{Chapter XVIII.}

\section{$\propto$ PIGEONS OF PECULIAR VOICE. $\varnothing$}

\section{The Trumpeter PIgeon.}

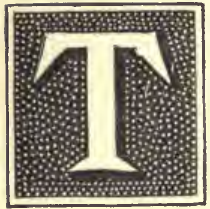

HE Trumpeter Pigeon has been known in this country since Moore's time, and is common on the Continent of Europe. In France it is called the Pigeon Tambour Glou-glou, and in Germany, the Trommeltaube, or Drummer. Its various names are, therefore, all derived from its voice, which, not being reckoned of any consequence in the show-pen, may be left unnoticed till I describe the form and feather of this wonderful pigeon. Until soon after the year 1865, when some very high-class Trumpeters were imported into this country, the breed appears to have remained almost stationary since Moore described it. The earliest picture of a Trumpeter I know of is that in the Treatise of 1765, which represents a very poor Black Mottle, with black fights and tail, and white body, over which is sprinkled about thirty-five black feathers. It has black thighs and leg-feathering, but is bare toed. The author of that book, who copied his description of the breed from Moore, says "they are generally pearl-eyed, black mottled, very feather-footed and legged, turn crowned like the Nun, and 



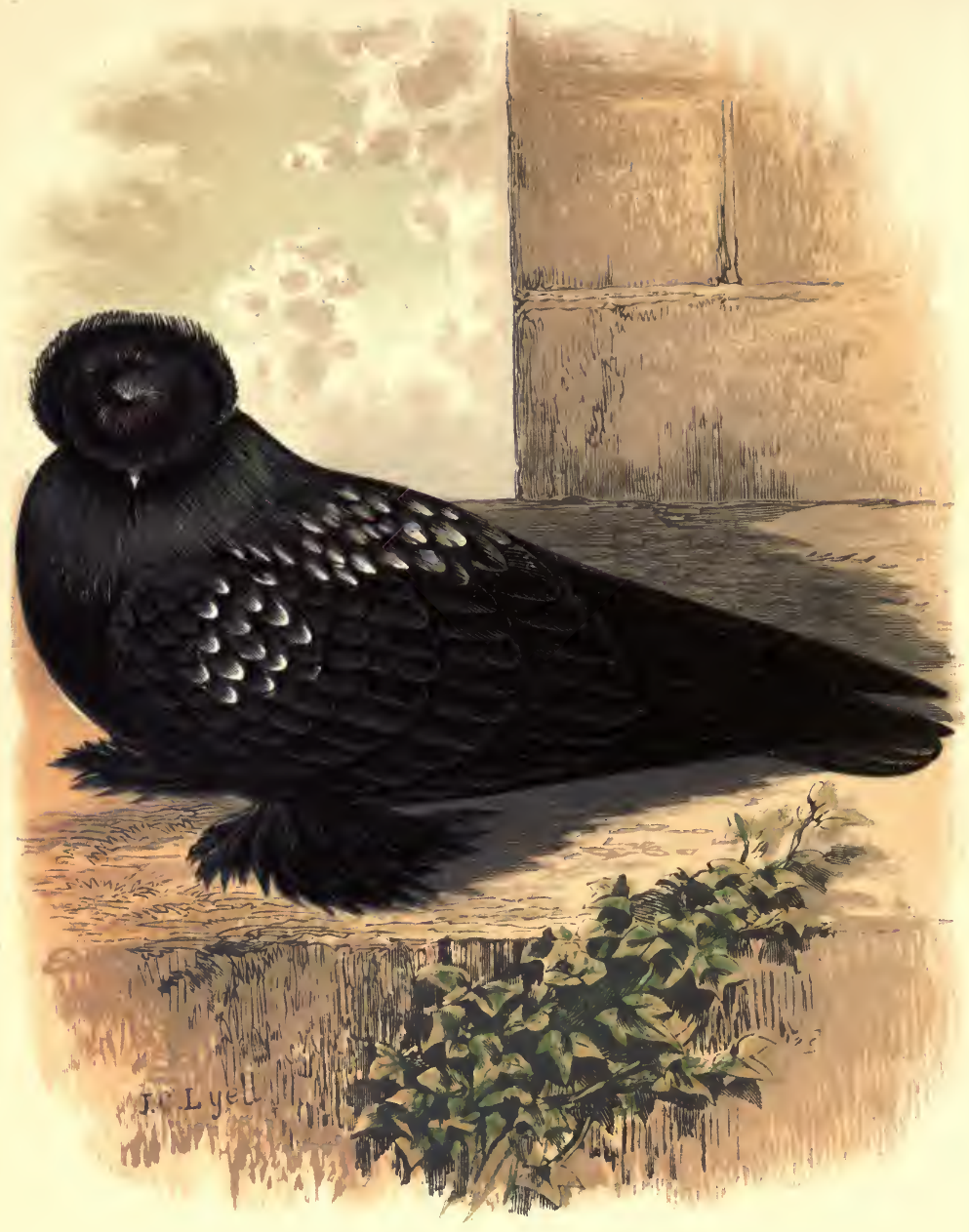

THE TRUM PETER. 
sometimes like a Finnikin, but much larger, which are reckoned the better sort, as being more melodious."

\section{The Bokhara Trumpeter Pigeon.}

It would be of no advantage to minutely describe the Trumpeter as we had it before 1865 , because the Central Asian breed, which was imported shortly after that date, put it entirely into the shade. The best we used to have were Blacks, Black Mottles, and Whites, though Duns, Reds, and Yellows were occasionally to be met with; and I once bred a very good Blue Mottle. The new breed, coming here viâ Russia, received the name of Russian Trumpeter, which is what the Germans call such birds as we formerly had, because they are said to be found in their greatest beauty in the neighbourhood of Moscow. It is not, however, a native of Russia, but of Bokhara, in Central Asia, and its appearance in Europe was, no doubt, the effect of the Russian conquests in the East during late years. At the same time, choice Trumpeters may have existed for a long while in the interior of Russia; but if they have, I doubt not they originally came from Asia. Finding these choice birds described by Neumeister and Prütz as Bucharische Trommeltauben, I inquired of several German gentlemen the meaning of the name-whether it signified Bucharest or Bokhara-but no one could decide. Afterwards, however, in the course of a correspondence with Mr. Charles Jamrach, of London, regarding some of these pigeons brought here by a Russian, he informed me that the man actually brought them all the way from Bokhara, with other live stock. So I think it is conclusive that they are a Central Asian breed, which has only lately reached us in its purity, all previous importations of Trumpeters having either been inferior, or allowed by Europeans to decline in quality; while, on the other hand, it is possible that, when European fanciers did nothing to raise the character of what they had, the 
Bokharians may have improved theirs from stock similar to what we had before.

The Trumpeter is certainly a very high-class, original pigeon, but, for some reason, not a general favourite, though no one will deny that it has many beautiful properties. The reason that it is not more generally fancied and bred, is, doubtless, the fact that it has nothing in its conformation very abnormal-like the Pouter, Carrier, or Turbit, all of which birds present great difficulty in breeding towards an ideal standard-while its peculiarities are almost entirely those of feathering, of such a fixed type, that it presents little scope for competition. Were as many fanciers to employ their time in breeding Trumpeters as Pouters, there would be twenty of the former for one of the latter approaching perfection. Fanciers know this, and therefore the Trumpeter is left in a few hands, regarded more as a curiosity than as a fancier's pigeon. Supposing, with all its fine properties, the Short-faced Mottled Tumbler's standard of feather were to be fixed for the Trumpeter, it would then present difficulties which any fancier might be proud in overcoming; but this standard is not only full of difficulties, but is a standard open, above all others, to fraud. The Germans have for a long time bred Trumpeters to Turbit and other markings, though in doing so they have lost quality in the more important parts of the breed. Brent and others have written of the difficulty there is in preserving the voice and rose of the Trumpeter when it is crossed; but though it doubtless takes a long time to recover either, it can be done, as in the case of the Altenburg Trumpeter, which I shall afterwards describe, and which is not inferior in voice to the pure breed itself. Could all the peculiarities of the breed be well-retained, in addition to well-defined specific markings-such as white, with coloured shoulders-the Trumpeter would rank higher in the fancy than at present, when many care not how badly their birds may be mottled, or even splashed, so long as they are good in rose and other points. 
The fancy points of the Trumpeter are rose, crest, eye, leg and foot feather, colour and marking, quality of feather, size, shape, and voice.

The Rose is the first property of the Trumpeter, and is what makes it distinct from all other pigeons. The Priest, and other varieties which possess it, do so only in a modified degree, and are supposed to have derived it from this pigeon. The rose is formed by the feathers on the crown of the head growing out from a centre in regular form. In a good bird it will be large enough to form a complete covering to the head, hiding the eyes, reaching nearly to the shell crest, and covering the beak wattle, but not the point of the beak. All the feathers forming the rose should lie well down, without any irregularity, and the more circular and even the rose is at its edges the better.

ThE CREST is an extensive shell hood, reaching round the back of the head, almost from eye to eye, and finishing off at its extremities with an ornamental turn, of the same formation as the rose. The crest ought to be of a cupped form, reaching over the head; but though wanted as firm and compact as possible, it is always more or less loose in texture, from the nature of the bird's feather. The feathers forming the crest, and those supporting it, can be moved by the bird at will, and the crest is, therefore, seen more loose at some times than at others.

The Exe.-Though described by the old writers as pearleyed, the Trumpeter was generally red or orange-coloured in the irides immediately before the introduction of the Bokhara breed. The latter have generally pearl eyes, regarding which a German author says: "The fine pearl eyes betray the noble race which exacts admiration from every fancier."

Leg and Foot Feather.-The legs and feet should be heavily hocked and feathered. In this property the former birds excelled the first importations of the Asian race; but the latter, from the silkiness of their feather, were more liable 
to have their long toe feathers broken, which partly accounted for the want of them. Their toe feathers want the strength of those of the old tight-plumaged birds, and seldom reach their natural length without damage. I have noticed, that birds bred from good imported ones, when inclined to closeness of plumage, which is faulty, grow stronger toe feathers. It is almost impossible to preserve these feathers unbroken for any length of time after the moult. An examination of the feet will always show what strength of feather the bird is there naturally furnished with, though the feathers may be broken off short.

Colour and Marking. - The Bokhara Trumpeters are chiefly Blacks, and Blacks mottled or splashed in some way with white, though both Duns and Dun Mottles have been imported. The beak is almost always white, and is a pleasing feature in the breed, as it looks well just appearing from under the rose. The bird I sketched my illustration from was a very fine Dun Mottle, with a strong red cast through its dun feathers. It was not marked as I have drawn it, but was almost half white, with dark flights and tail. As a standard to breed from, I think the marking shown in the coloured illustration, which is the same as is wanted in the Short-faced Mottled Tumbler, is preferable to any gayer marking; but so long as the white is disposed in single feathers, a bird mottled on the head and neck, as well as on the wing coverts and back, looks very well if the tail, flights, under parts, and leg and foot feather, remain black. Many Trumpeters are nearly white, and of late some have been bred entirely free of coloured feathers.

Some are all black except the head and upper neck, which sometimes remain nearly white; and if the rose alone could be got white, or even lightly grizzled, the rest of the bird remaining black, it would look very well, and such marking might in time become fixed if bred for. I understand from Mr. T. B. C. Williams, who was lately travelling on 
the Continent, that Blood Red Trumpeters of high quality are in existence. He informed me that he saw a pair of them in Paris. Some idea of their rarity and value may be learned from the fact that the price asked for them was 3,000 francs; and he learned afterwards that they had been sold at this price. He described them as fine in colour, and well-lustred. I have no doubt that there must be Yellows as well. I have never bred any of the new Trumpeters, but my experience with the former kind, both here and in India, with English ones, showed me, that they alter very much in feather during their first moult, after which I always found them to moult without further change. A bird which moulted into a fair mottle, always came out of the nest entirely black, or with only a few grizzled feathers on the wing coverts. If there was much white on a nestling, it generally got very gay, and some would become half white when almost black in the nest. I never saw a bird get darker during its first moult.

Quality of Feather.-The choice Trumpeter should be long and loose in feather, the flights should reach beyond the tail, and all the feathers should be soft and silky in texture.

Size.-The size of the Trumpeter should be above the average of fancy pigeons; the larger it is the better, for, if rose, \&c., are in proportion, large size adds to its appearance.

SHAPE. - The appearance of a good bird is that of a very low standing, broad-set, short-necked pigeon, almost close to the ground, unable to see about it, except in a downward direction; it gropes about from place to place, and is fond of retiring into corners, where it drums to its mate.

VoICE.-One of the chief pleasures in keeping Trumpeters is to hear their pleasant notes. They are, with their subvarieties, and the Laughers, the musicians of the Columbarium. I would think little of a bird, however good in fancy points, if quite deficient in voice; and, although it cannot be taken into account in judging at a show, it should 
be carefully cultivated in the loft. Many of the old breed were capital drummers, and kept up a constant concert in their lofts; but some of the new ones are very deficient in vocal powers, which is, perhaps, the reason they left their native place. The Trumpeter's voice does not seem to have been cultivated so well in this country as in Germany. From Neumeister and Prütz I gather what constitutes a good drummer there-" Excited by anger or love, its voice falls directly, or from the usual cooing-which, however, must rarely be heard in a good drum pigeon-suddenly into that rolling, quivering, deep hollow drumming; at the same time -mostly sitting still-moving the beak, puffing up its crop a little-the less the better-moving to and fro the front part of its body, and trembling with its wings. For correct drumming, there are required a good beginning, a distinctly marked delivery, alternate rising and falling of the sound, shaking, and sustaining. The more frequently, and especially the more sustainedly, without stopping, it drums in good style, the more valuable is the pigeon. There are cocks which, with quite short interruptions, drum away for ten minutes, and make themselves heard the whole day, especially in spring, or if they get a good supply of hemp seed. Even when eating they drum away, and by a number of good ones a dunning noise is produced. The principal sounds come rolling out of the mouth like the beating of a drum, the lower mandible at the same time moving up and down. The sounds become by turns stronger and weaker, and die off till they can scarcely be heard. The more subdued sounds form a monotone rolling, which is produced in the interior without movement of the beak, and thus appearing to come from another bird altogether. There is no difference in the sounds whether the crop be full or empty. The hen also drums, less frequently, however, and with less force and perseverance."

It is usual, during the breeding season, to clip the Trum- 



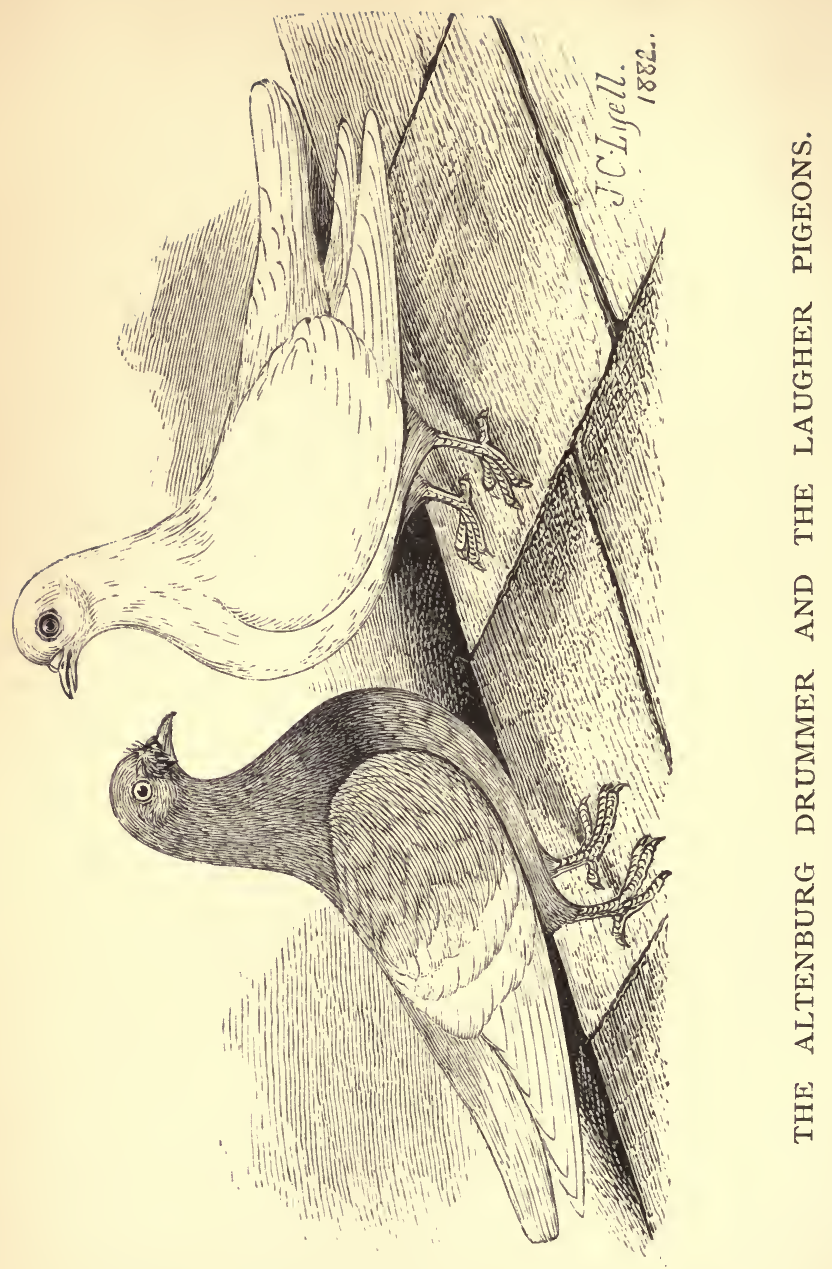


peter's rose, not only that it may see better, but because it gets clogged with food when feeding its young ones.

\section{Sub-Varieties of Trumpeter Pigeon.}

In Germany there is a sub-variety of the Trumpeter, marked like the Shield Pigeon, or exactly as a Turbit ought to be marked-all white, with coloured shoulders. Neumeister figures them on plate 10 of his book, under the name of Bastard Trommeltauben. They are represented, on the same plate, with well-feathered feet, but with smaller rose and crest than the pure Trumpeters. The Black and Blue have white wing bars, the Red and Yellow are solid shouldered. In Tegetmeier's book there is a picture of a pair of these pigeons with red shoulders and white wing bars, called Letz Pigeons, under which name the author says they had been exhibited at English shows. There was probably some mistake in the naming of them-perhaps the Latz was meantat least, I cannot find the name in any German book. Brent says, in the Poultry Chronicle, that "lats-chige"-rough slippered-is a German provincial name for the Trumpeter.

Neumeister also figures another sub-variety, the reverse in marking of the preceding, viz., all red and yellow with white shoulders. These probably come out of the nest self-coloured, and moult white-sided, like Tumblers and Runts. Boitard and Corbie describe some varieties of the Trumpeter which $\mathbf{M}$. Corbie brought from Germany, the breed having become scarce in France at the time they wrote. These are the above Red and Yellow White-sides, Whole Blacks with White Wing Bars, Grey-headed Blacks, Blues with white heads, flights, and tails, and similar Blues, with the addition of yellowish wing bars. Some of these were probably Priest Pigeons.

\section{The Altenburg Trumpeter Pigeon.}

This variety of the Trumpeter, deriving its name from the district of Altenburg, is distinguished by its melodious vocal 
powers. There are two, apparently distinct, varieties of these birds, the Buff and the Lavender Altenburgers.

In colour, the Buff Altenburger is what is known in this country as yellow-mealy, being buff-coloured on the wing coverts, with yellow neck and wing bars. The legs and feet are covered with feathers of a medium length; the beak is rather long and slender; the iris yellow, or pearl-coloured; the head is smooth at the nape, but has a frontal tuft on the brow, which ought to be twisted up in the form of a peak; and this, when well formed, gives the bird an original appearance. The voice of the Buff Altenburger resembles that of the Common Trumpeter.

The Lavender Altenburger breed, which I kept for some time, appears to me to be quite distinct from the Buff. It is rather smaller, and more slenderly made, being about the size of a common flying Tumbler, which bird it resembles in form, except that its beak is somewhat longer. The eye is pearl-coloured; the legs and feet are sometimes smooth, and sometimes slightly feathered. A peculiarity with most of those I have had, though not altogether unknown in other pigeons, was an inclination to webbed feet, the middle and inner front toes of nearly all the young ones I bred being joined together throughout their whole length; but I am not aware if this is general in the variety. The head is unhooded at the nape, and the nasal tuft, instead of being single, and peaked, as in the Buff variety, assumes a double form. On each side of the brow, between beak and eye, there is a small tuft of feathers growing from a centre. In some specimens the tufts are quite distinctly separated from each other by the smooth upward-growing feathers of the forehead. The colour in this kind is a light lavender tinted blue, somewhat uniform throughout, except on the breast, when it merges into a bright yellow; and the wing bars are nearly white. There is also a Silver variety, which bears exactly the same relation to the 
Lavender that a silver pigeon does to a blue one. The voice of this pigeon, in both sexes, is melodious, is quite peculiar to the breed, and differs from that of the Trumpeter and Laugher. It commences by a very highly pitched, prolonged coo-roo; then, with the head down, and with shaking wings, the bird breaks off into a long-sustained roo-roo-rooroo-wach-wach-wach-roo-oo, which is broken now and again by sighs, as if it were short of breath. The hen's voice is much lower in tone than the cock's, and is especially sweet as she goes to her nest, when she purrs like a cat for about half a minute.

\section{The Laugher Pigeon.}

The Laugher is a breed of pigeon that has been known in this country, off and on, since Moore's time. It seems to have died out and been re-imported several times. Brent mentions two stocks of these birds he knew of. The first closely resembled blue chequered dovehouse pigeons, but were rather smaller, and had very slightly feathered legs, the only difference he could notice being a slight fulness at the back of the neck, behind the head, and the edge of the eyelids being inclined to red. The cock of a pair he had was dark chequered, the hen the same, but pied with white. The other stock, which, he was told, was imported from India, and which were taken thence by Mohammedans who had been on a pilgrimage to Mecca, were of the same dovehouse form, but with narrow, peaked crowns, and in colour of a light haggle, or something between a grizzle and a gay mottle.

Moore says of the Laugher: "It is red mottled; and some tell me they have seen blues. They are said to come from the holy Land, near Jerusalem." It seems, therefore, that the breed is of different colours, sometimes peaked, and sometimes slightly feathered on the legs. Their peculiar voice is what makes them a distinct breed, and Moore describes it 
thus: "When the Cock plays to his Hen, he has a hoarse Coo, not unlike the Guggling of a Bottle of Water, when pour'd out, and then makes a Noise, which very much imitates a soft Laughter, and from thence this Bird has its Name."

These pigeons are known in France as Pigeons Chanteurs $d u$ Soudan, Les Rieurs du Soudan, or as Chanteurs de la Mecque; and in Germany, as Mekkatauben. The holy city of Mecca appears to be the head-quarters of the breed, whence pilgrims take them to Mahomedan countries. They have probably been taken to Hindostan for centuries, as Akbar's Kokah Pigeon, whose voice resembles the call to prayer, would seem to have been of this breed. In size and shape they resemble common flying Tumblers. The beak is slender, and rather longer than that of the common cleanlegged Tumbler. They usually carry the wings low, especially when laughing.

The first of this breed I possessed was a Blue hen, that appears to have been brought to Dundee in a vessel from Calcutta. I was told that, in a certain shop, there was a pigeon with a very strange voice, but differing from that of the Trumpeter. On going to see it, I learned it was sold, but recognised it from the description as a Laugher. I found where it had gone to, and I bought it. This bird was barren, but she had a perfect voice. I next got two Blues from M. la Perre de Roo. They came from Marseilles, and were both hens, so I was unable to get any young ones. As the colour of all these birds was peculiar, I will describe it. Their wing coverts were of a smoky, leaden blue, their wing bars not very distinct, and their neck feathers were glossed with a reddish purple tint. Shortly afterwards I found, in a different shop in Dundee, a cock bird of this breed, which also came from India. $\mathrm{He}$ was blue chequered, with a few white feathers on the head and rump. From him and one of the Blue hens I bred 
several young ones, resembling their mother in colour, and all very good in voice. I afterwards got a fine pair of pure Whites, and some more Blues, from M. la Perre de Roo, who tells me that they are not as yet very common in France. One of the Whites was entirely clean-legged, the other had short feathers on the shanks, but none on the toes. I had a Blue well-feathered both on legs and feet; most of them, however, were entirely clean-legged, but on the middle and outer toes had feathers about half an inch in length, which style seems confined to this breed, at least, I do not at present remember any other variety so feathered on the feet, though bare-legged. Some of the Blues had a yellow iris, and some were hazel-eyed. The eye wattle, which is generally very narrow, and the corners of the mouth were reddish, and the beak light.

The voice of the Laugher varies considerably, so much so, that I could tell each bird from its voice. They vary in the tone and length of their notes. Their ordinary coo is louder and more modulated than with pigeons generally. It is after cooing that, with the head bent down, and with the wings hanging and trembling, as with other "voice" pigeons, they break away into a prolonged hua-hua-hua-hua; all who have heard the Laugher in my pigeonry for the first time have been quite struck by its voice, inquiring with astonishment, "What's that; what kind of pigeon is that?" and wishing to hear it repeated. In fact, one never tires of hearing it, especially when several birds, all differing somewhat in tone, are laughing in concert. The hens are nearly as musical as the cocks. A Black Pied Pouter cock paired with one of my odd Blue Laugher hens. She laid, and, her mate having been sold, sat on the eggs alone, and hatched and brought up a young one. This half-bred resembled an Austrian Pouter in shape, and was blue chequered in colour, without any white. I kept it to see if its voice would differ from that of an ordinary pigeon. When 
moulted off, I found he (for it proved to be a cock bird) possessed a very strong, sonorous coo, but had great difficulty in breaking off into the laugh. Only twice did I hear him laugh, and that in a crude style compared to the pure birds; but I have little doubt that his young ones by a pure hen would have had very good voices had I kept, and bred from him. As this breed hails from Mecca, the holiest of Mussulman cities, I would expect to hear that it is there regarded as the descendant of Mahomet's pigeon.

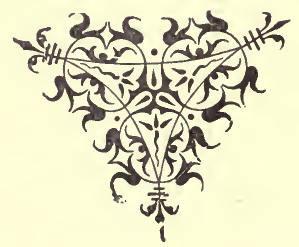





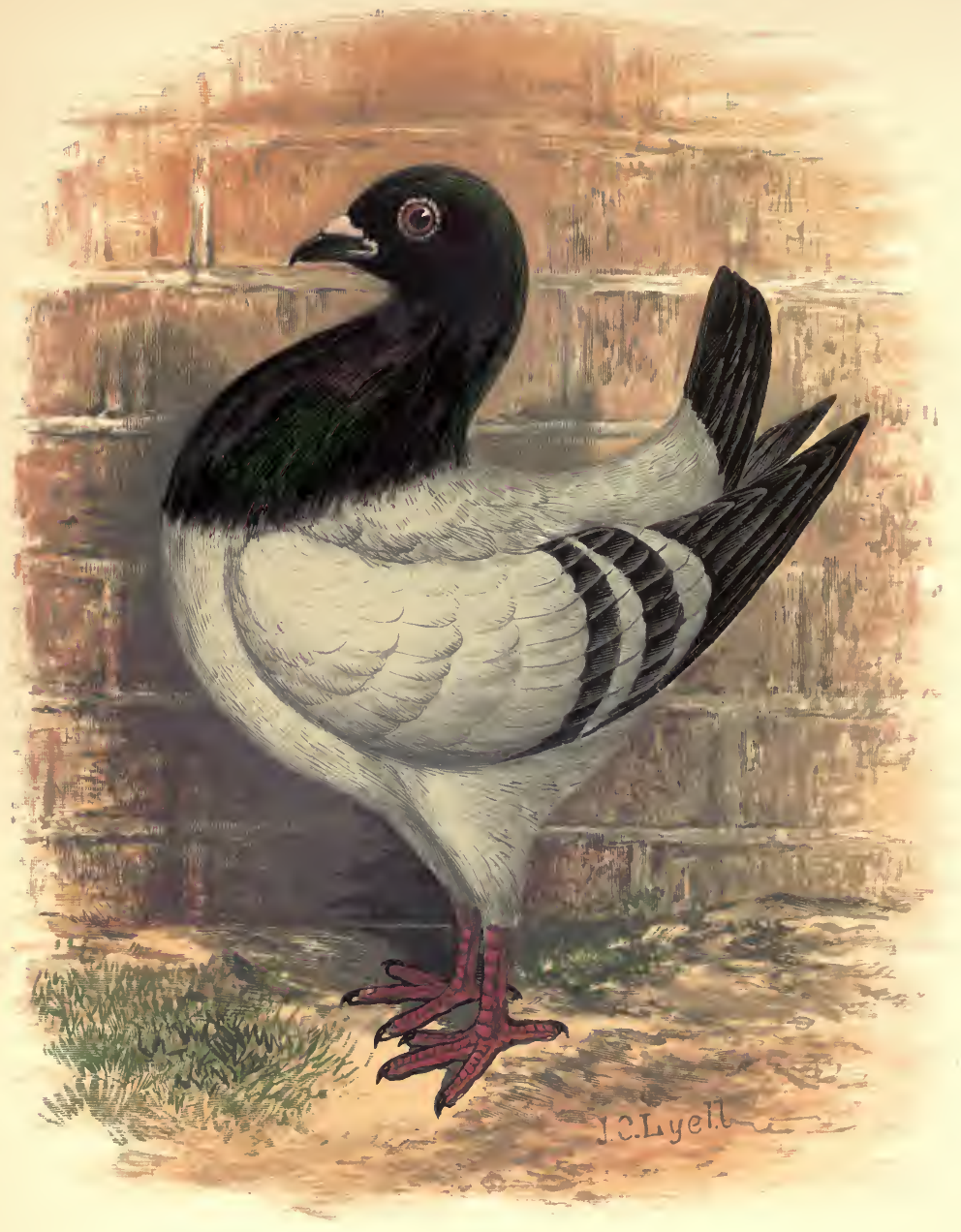

THE LEGHORN R U NT. 


\section{Chapter XIX.}

\section{PIGEONS WITH SHORT, ERECT TAILS.}

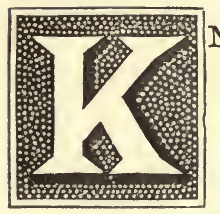

NOWN in Germany as Hühnertauben, or Fowllike Pigeons, and existing in numerous varieties, these birds are not now valued in this country, as they appear formerly to have been. The peculiarities of this race are, to stand high, on long, unfeathered legs, to be short in the back, broad in the breast and body, to have a short, erectly-carried tail, and a long, swan-shaped, tremulous neck.

\section{The Leghorn Runt Pigeon.}

Moore, in his "Columbarium" (1735), describes this variety as follows: "The Leghorn Runt is a stately, large Pigeon, Seven inches or better in Legs, close feather'd, and fast Flesht, extremely broad chested, and very short in the back; he carries his Tail, when he walks, somewhat turned up, like a Duck, but when he plays, he tucks it down; his neck is longer than any other Pigeon, which he carries bending like a Goose or a Swan. He is goose headed, and his Eye lies hollow in his Head, with a thin Skin round it, much like the Dutch Tumbler, but broader; his Beak is very short for so large 
a Bird, with a small Wattle on it, and the upper chap a little bending over the under.

"They are a very tender Bird, and great care ought to be taken with their young ones. I was offered Seventeen Shillings for a single Cock, and Sir Dolbey Thomas would have given me a Guinea and a half for the same Bird. There are very few true original ones of this breed in England; and if matcht to a Spanish Runt, they will breed a very large Pigeon, closer in Flesh and Feather than the Spanish Runt, and will breed much faster; I have kill'd of their young ones which, when on the Spit, were full as large as middling spring Fowls. I here note that these and all other Runts encrease in their bulk till they are three or four Years old.

"As to their Feather, they are various, but the best that I have seen were either black or red mottled.

"There is a vast difference in these Birds, and I have seen very bad ones, that have been brought from Leghorn, little better than a common Runt; however, this is the genuine true Description of the Leghorn Runt, which is more valued than any other sort of Runts."

The author of the "Treatise on Pigeons" (1765) quotes the foregoing, and adds: "Mr. Moore says they are a very tender Bird; but I must beg leave to dissent from that opinion of them, having kept them several winters in a little shed or room, one side of which was entirely open, and exposed to the easterly winds, with no other fence but a net which kept them confined. I have known four guineas given for a pair of these Birds. I have had a hen of the Leghorn breed which weighed two pounds two ounces avoirdupois weight."

The illustration of this breed in the Treatise of 1765 represents a large, heavy-looking bird, with sunken eyes and halferect tail, but not nearly so pronounced in type as my illustration, which is taken from the Black or Black Mottled variety of the race, often shown of late in this country as 



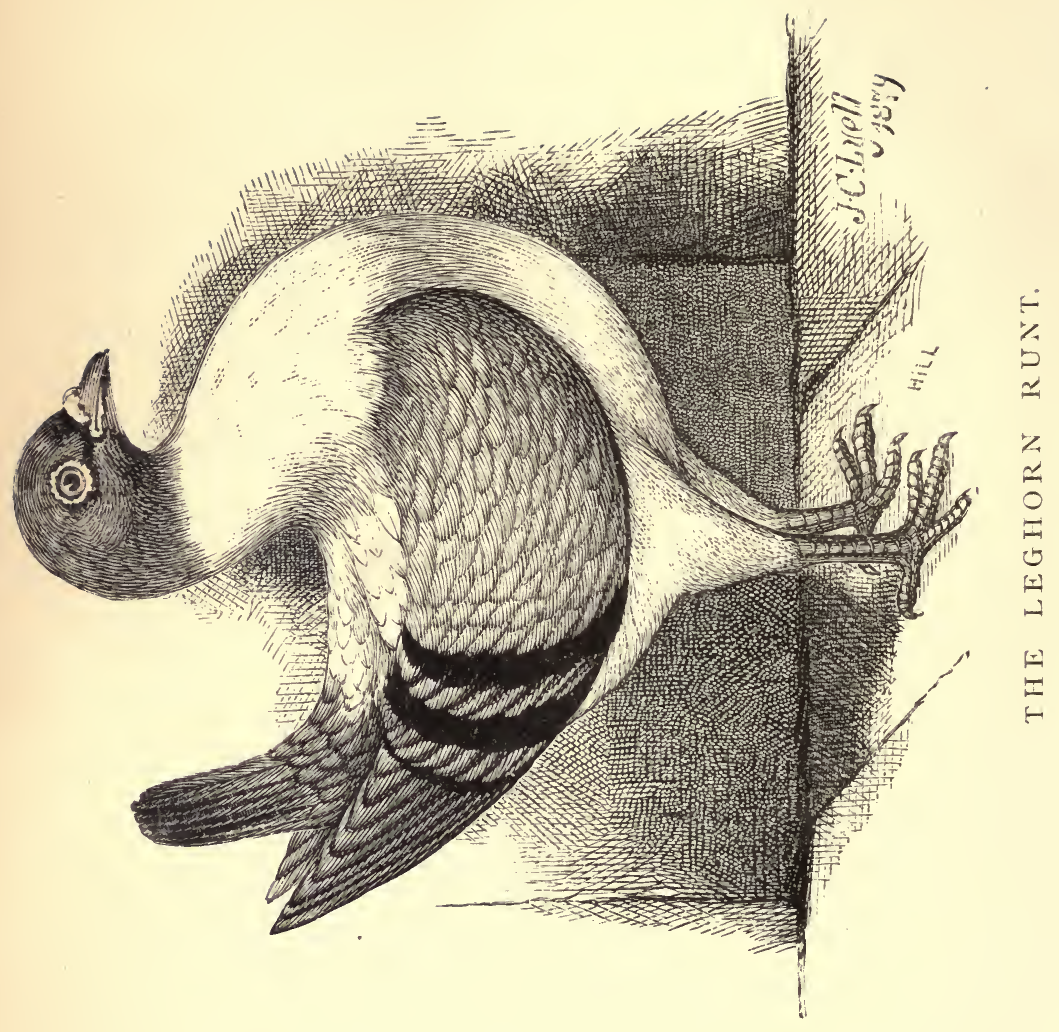


the Burmese. It seems to me, after consideration, that Moore's Leghorn Runt was either the breed known on the Continent as the great Maltese Pigeon, or the species described by Neumeister as the Monteneur, said to be formerly common in Stralsund and Griefswald in Pomerania. As I shall afterwards show, when treating of the Pomeranian Pouter, there appears to have been some connection between the fanciers of London and Pomerania during the early part of last century, and my idea is, that Moore's Leghorn Runt, though apparently of the type of the great Maltese Pigeon, was so large that it must have been' more like the Monteneur.

A very exhaustive treatise on the Hühvertauben has lately appeared in G. Prütz's "Mustertaubenbuch," now publishing, in parts, in Germany. Mr. O. Neef informs me it is from the pen of the Baron Von Washington.

\section{The Burmese Pigeon.}

This variety, called in Germany der Epaulettenscheck, Hühntaube, or, as we would say, Shoulder-mottled Hen, or Fowl-shaped Pigeon, is certainly the most pronounced in type of the race. It stands high on the legs, with a short, erect tail, below which the flight feathers ought to meet at the points, though sometimes they are carried above the tail; but this is not correct. The long, swan-shaped, tremulous neck, suggests a remote connection with the Fantail Pigeon; and, indeed, a fan-shaped tail on a good specimen of the Burmese would transform it into a long-legged Fantail. The tail feathers, however, in this bird, are as abnormally short as they are unusually long in a good Fantail; so that, when held in the hand, the feet ought to extend beyond them. Whether or not the Burmese came to Europe from Burmah or India I am not aware, but I never saw anything like it during my residence in the East. The idea has struck me that either this pigeon, or the Mookee, might have been the Narrow-tailed Shaker of Willughby. In size, Burmese Pigeons 
come midway between common pigeons and large Runts, being from $2 \frac{1}{2} l b$. to $31 b$. a pair.

The following varieties of the Hühnertauben, or Fowl-shaped Pigeons, are described by German writers:

\section{The Maltese Pigeon.}

Die Malthesertaube (the Maltese) is of the size of a small English Bantam fowl, with a smooth head, somewhat long and tapering; a truncate beak, strong nasal skin, deep set eyes; fleshy, red eyelids; a somewhat projecting crop, broad back; round, arched breast; small, short wings; strong, smooth, red legs and feet; and a very short tail, standing up straight over the pinions of the wings, and seeming as if cut off short with scissors. The lower part of the body behind is, as with the domestic fowl, thickly provided with down. The whole form is globular, almost as broad as it is long, and very highlegged. The Gallinaceous Pigeon has a turned-up rump, like the Fantail Pigeon. It takes long steps, and its bearing, gait, and the movements of its head, are like the common fowl. It propagates well, and brings up young ones all the year round, except during the moulting season. The plumage is, with the pure original race, self-coloured white; next to it comes the whole-coloured blue. With other coloured ones, as black and brown, its characteristics are weakened. These birds are chiefly found in the neighbourhood of Linz.

Judging from Neumeister's illustration, these birds would appear to weigh something like 3lb. per pair. He figures a variety called the Kleine Maltheser, or Little Maltese, which appears little bigger than a common Tumbler.

\section{The Florentine Pigeon.}

Die Florentiner oder Piemontesertaube (the Florentine, or Piedmont Pigeon) is a peculiarly marked variety. The head and neck, the shoulders, and the tail are coloured. This marking is also found in other pigeons, such as the Modena 
Flying Pigeon. The Florentine is described as being about the size of an English Bantam hen, similar in characteristics to the Maltese, and generally with blue markings. German writers class the Modena Flying Pigeon as a variety of the Hïhnertauben, and it may have been produced from the Florentine; but although the Modenese Pigeon sometimes carries the tail raised, it ought to be horizontal.

\section{The Speckled Hen Pigeon.}

Die Hühnerschecke Taube (the Speckled Hen Pigeon) resembles the Maltese in its general points, but is seldom so round in build. Its head is fine; its wax-coloured, somewhat strong beak is of the usual length; its neck and legs are somewhat shorter than the Maltese, and it seldom carries its tail so upright. It has often fourteen feathers in the tail; the inner side of the leg is sometimes provided with short feathers; the ground colour is white, with black, red, yellow, and blue speckles of a very intense colour.

\section{The Hungarian Pigeon.}

Ungar'sche Taube (the Hungarian Pigeon) is described as follows: By perseverance and chance, there has risen from the Florentine the so much liked, beautifully marked, and expensive Hungarian Pigeon. It is found mostly in Austrian Hungary. The nearer it approaches the Maltese in form, the better. The colouring of its plumage is beautiful; the black deep and velvety, with metallic sheen; the red and yellow fiery and sated; the blue clear. Its distinguishing mark is the so-called "band" mark, which is peculiar to this pigeon. This white band, or stripe, begins at the nostrils, about the breadth of a straw, widens as it goes back, dividing the colouring of the head, and disappears at the nape of the neck, which is white down to the shoulders. The colour, therefore, runs over each eye, turns down by the ears, and forms a deep, pear-shaped bib on 
the breast. Viewed in profile, the front of the neck is coloured, the back of it white. The whole of the wing coverts and scapular feathers, the flights, the tail and its coverts, are coloured.

The foregoing descriptions of the Hühnerschecke and Ungar'sche Tauben are from Prütz's Die Arten der Hanstaube, and the third edition of Neumeister's work, edited by Prütz; but the latter, in his new work on pigeons, presently publishing in Hamburg, describes the Hïhnerschecke at great length, and gives illustrations of its head and neck, from which it appears to answer the above description of the Hungarian Pigeon, a breed he no longer notices. There seems to have been more than one name for the same breed, but, until I see the various sub-varieties of the race, I shall not be able to give a more intelligible account of them. It is a pity that taste among fanciers in this country does not tend more in the direction of the numerous beautiful varieties existing abroad; we might then see, at the large shows, more variation in form and feather than we have been accustomed to, and the long lines of Homing Antwerps, which are not really exhibition pigeons, would be replaced by something worth looking at.

\section{The Monteneur Pigeon.}

The Monteneur Pigeon is the last of this race mentioned by Neumeister, and I think it is the most likely of any to be the Leghorn Runt of Moore, as it is said to excel both the Romain and Montauban in size. Its description is as follows: "A formerly pretty well known, but for long very rare, pigeon, which, by its gigantic size, more resembles a hen than a pigeon. Body and breast strong, provided with a rather short tail. It proves somewhat clumsy in flight, while it moves easily on the ground with its unfeathered, rather high, legs. The long neck is, with the cocks, very strong, and the crop, when cooing, a little more inflated 
than with common pigeons. In size, the Monteneur excels both the Roman and Montauban Pigeons, has shorter wings and tail than these, and reminds one more of a domestic fowl than a pigeon. The colour is generally blue, dappled, or red. In the North of Germany, these pigeons were formerly much bred in Griefswald, Stralsund, and Colberg, but seem to have become quite extinct there."

\section{The Strasser Pigeon.}

This pigeon is classed by Prütz among the feather pigeons, but said to be a cross product of the Florentine Hühntaube, which it resembles in marking. It is said to resemble the Polish Lynx Pigeon in its extraordinary fecundity, and to be one of the best for table purposes, or as a nurse for more delicate breeds.

\section{Other Fowl-Shaped Varieties.}

Prütz mentions self-coloured reds, yellows, and Whiteshielded Fowl Pigeons, the latter being marked the reverse way of a Turbit-marked pigeon.

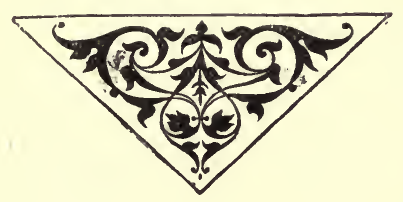




\section{Chapter XX.}

\section{$\propto$ THE FANTAIL PIGEON. $\infty$}

\section{History and Literature.}

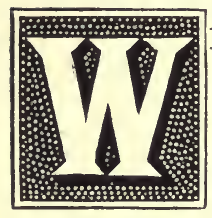

RITERS on pigeons, both British and foreign, agree that Hindostan was the birthplace of the Fantail Pigeon. It is certainly there where it is found in the greatest numbers. That such a curious and beautiful domestic bird would be early taken by traders, from where it originated, into distant lands, there can be no doubt; but it is impossible to fix any time for its arrival in Europe. The Romans, in all probability, would have it from India, if it existed there 2,000 years ago. I sometimes think there must be old manuscripts existing that would be of great interest to pigeon fanciers, and, some day or other, old lore on the subject of our domestic pigeons may come to light when least expected. In Calcutta, the Fantail is the commonest variety found for sale, and I think I am well within the mark in saying that from 200 to 300 pairs of them annually leave that city, in vessels bound to the different ports connected with it by trade. Fantails have existed for at least two centuries in England, as we find from Willughby, who refers to them as "Broad tail'd Shakers-called Shakers 

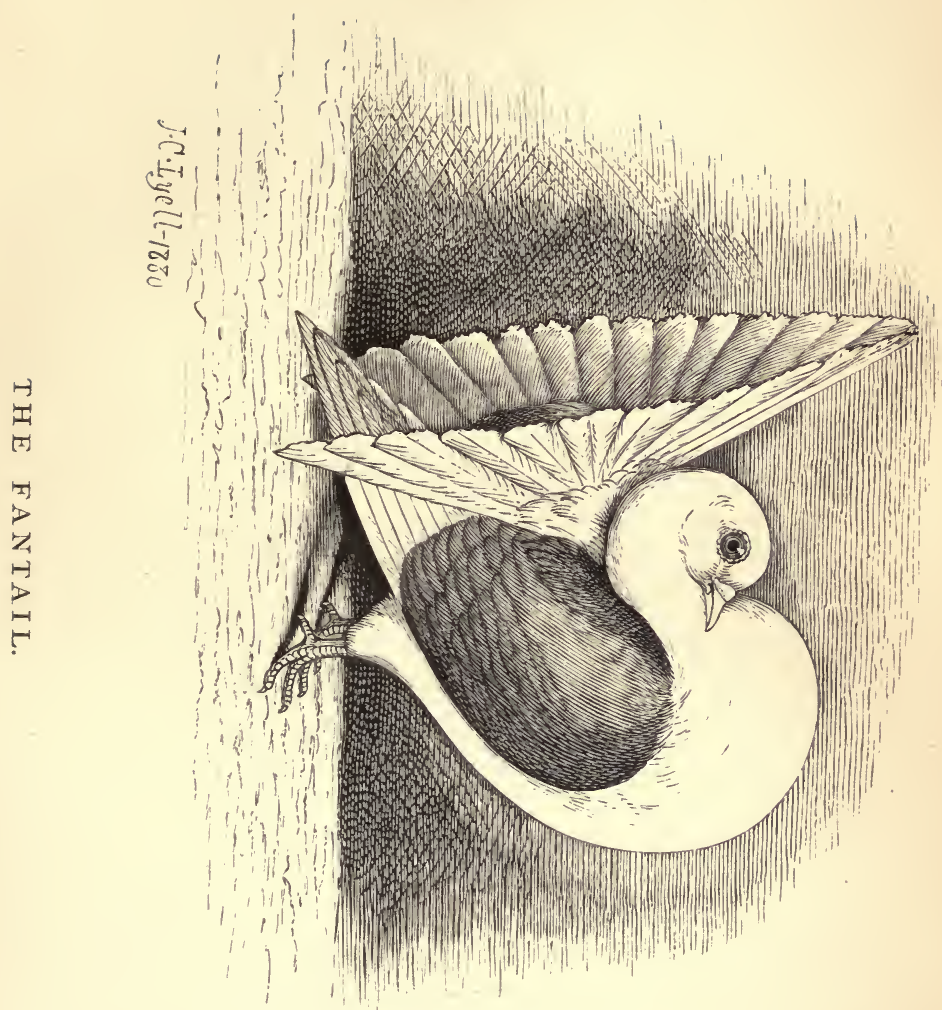
$$
\text { - }
$$ 
because they do almost constantly shake or wag their heads and necks up and down. Broad tailed, from the great number of feathers they have in their tails; they say not fewer than twenty-six. When they walk up and down, they do for the most part hold their tails erect, like a hen or Turkey Cock. These also vary much in Colour." It is also necessary, for the better understanding of what I shall have to say, to quote Moore's description, who also terms the bird the Broadtailed Shaker. "This Pigeon has a beautiful long thin Neck, which bends like the Neck of a Swan, leaning towards the Back; it has a frequent tremulous Motion, or shaking in the Neck, especially when salacious, which is the Reason they are called Shakers. It has a full Breast, a very short Back, and a Tail consisting of a great Number of Feathers, seldom less than four-and-twenty, which it spreads in a very elegant Manner, like the Tail of a Turkey Cock, and throws it up so much that the Head and Tail frequently meet. They are called by some Fan-Tails, and I once saw one that had six-and-thirty Feathers in its Tail; but when they have so many Feathers, it is apt to make them lop their Tails, and not let it meet with their Head, which is a very great Fault. They are most commonly all white, tho' I have seen both black, blue, red, and yellow Pieds, but the white ones have generally the best Carriage in their Tail and Head: There are two Sorts of these Broad tail'd Shakers, the one having a Neck much longer and more slender than the other; but the longest Neck is the most beautiful and the most esteem'd."

If the chief varieties of fancy pigeons, excepting the English Pouter and Carrier, did exist in anything like perfection in Moore's time, they must have declined in quality during the following century; for it is during the lifetime of the present generation that the Barb, Trumpeter, Fantail, Jacobin, Owl, and Turbit have been improved, and in every case by the introduction of foreign blood; so that our day may be well termed the "renaissance" of the fancy. Moore 
mentions two varieties of the Fantail, but the long-necked, tremulous, short-backed variety, seems to have died out in England, along with good quality in the rest of the abovementioned kinds.

\section{The Indian Fantail.}

Indian Fantails, as found in Calcutta, are usually entirely white, with large, well-spread tails, long backs, and without much tremulous motion in the neck. It is rare to get them both smooth-headed and free of leg feather, most of them having peak-crested heads, or grouse-feathered legs, while some have both. Indian fanciers are fond of putting small brass bangles on the legs of Fantails. This is done before the birds leave the nest, so that, when full grown, the ornaments cannot fall off. The bangles are hollow, and open at the edges, and have small metal balls put into them; their edges are then brought close together, and, as the birds walk about, a tinkling sound is produced. In India, the tail feathers of Fantails are sometimes cut off short, and the ends of Peacocks' tail feathers introduced into the hollow stumps. If well done, this has a pretty effect. After the entirely white Fantails, whole blues, and ash-coloured, or barless blues, are the commonest. The latter are nearly even in colour all over. I knew a fancier in Calcutta who had a breed of glossy green lustred blacks, with peaked heads and feathered legs. I knew of whole reds and yellows in India, but never saw any. They belonged to a doctor in the Government service at Dinapore, and at his death were advertised for sale, but before I could secure them, as I intended doing, they were bought by a native gentleman. I heard that fine coloured reds and yellows could be got in the North-west provinces of India.

\section{Dundee Fantails.}

Moore mentions having seen black, blue, red, and yellow pieds. Three old paintings in my possession, that appear 
to be about 150 year's old, represent Fantails. The best is a completely Turbit-marked, or Saddle-backed yellow, while the other two are almond-feathered. The latter have lowcut white heads and bibs, and are partly white in the tail. The author of the treatise mentions an almond Narrow-tailed Shaker, which was purchased by a certain nobleman. My two paintings of almonds represent more than Narrow-tailed Shakers, but they do not come up to the yellow Saddle-back, which is a very good Fantail. The red and yellow pieds must have become extinct in England, but black and blue pieds still exist, I believe. They also existed in Scotland fifty years ago, and were found in Dundee and its neighbourhood. From forty to fifty years ago, there was imported into Dundee-from where is not certain, though a fancier there, Mr. David M'Intosh, who remembers the bird well, asserts that it came from India-a well-marked black Saddleback Shaker hen, of high quality, which was the originator of the breed known as Dundee Saddle-backed Fantails. This hen, crossed with the then existing breed of black and blue pieds, produced a race of pied Broad-tailed Shakers of the greatest excellence, which have, unfortunately, become very scarce. A fancier named Mudie, who was lame, and went by the name of "Cripple Mudie," had the strain about forty years ago, and he bred many excellent specimens of red and black-sided ones. He possessed the original hen, which, when mated with a black splashed cock, produced one or more red pieds, which were the progenitors of the Redmarked ones, now nearly extinct. From recent inquiries I have made, I believe this to be the true account of the origin of these birds. The original black-saddled hen was first secured by a Mr. Alexander Dow, who told me, in 1880, that he sold her to the said Mudie. One of the first pigeons I ever possessed was a red Saddle-backed Fantail. This was thirty-five years ago, and about ten years afterwards I had another red-sided cock of extraordinary style. The 
latter could never breed while I had it, but when it became three or four years of age it began to breed. It was then in the possession of a fancier named Mure, or Muir, in Glasgow, to whom I sold it, and I believe its descendants are still to the fore in the West of Scotland. The reason the coloured-sided birds became so scarce about Dundee was, that pure white ones became the fashion. To obtain these, crossing with whites was resorted to, but splashed and saddle-marked ones long continued, and still continue, to come, even when breeding whites together, on account of the coloured strain there is in them. As far as I ever saw, the Dundee Saddle-backs were seldom marked quite so accurately as a Turbit, but had generally more or less coloured feathers in the head, neck, and breast, and sometimes in the tail. The few good ones still in existence are marked more or less in the same way, though they do not appear so at shows. Careful breeding would, however, do much to rectify this, if even only a few persevering fanciers were to turn their thoughts to the breed. I know one or two who are directing their attention to Saddle-backs, and hope they will be successful.

There is no doubt in my mind that the bird or birds which originated the Dundee breed of Fantails came from India, because I had one of the same style in Calcutta. It was a red Saddle-back cock, the exact counterpart of the one I sold to the Glasgow fancier some twenty-five years ago. I bought it in the Tiretta Bazaar, Calcutta, about 1870, and it was the only one of the wonderful Shaking breed I ever saw there. Not following up its history at the time, I never learned where it came from; but, on my return to this country, I wrote to a friend in India, who could procure me similar birds if they were to be got, and he told me they were very scarce, but that he knew of them. He died shortly afterwards, however, and I have not been able to learn more about them. The bird in question lived but a short time. 
It was not clean cut, but had a mottled neck and breast, like the old Dundee birds.

\section{English Fantails.}

Twenty-five years ago, when shows began to get common in this country, white Fantails of a large size, with little action, loose in feather, and with immense tails, which were sometimes carried right over their backs, entirely concealing the latter, were often exhibited. Scotch fanciers, whose ideas of a Fantail were all towards high style of carriage, could not endure these non-shakers, which, though called English Fantails, were, I believe, if the truth were told, nothing but imported Calcutta birds, or their immediate descendants. The battle for precedence between the two breeds-for they are distinct breeds-then commenced, and it has ended in a compromise. English Fantail fanciers have crossed their large, motionless birds with the small Scotch shaking breed, and Scotch fanciers have bred for tail, so that both can now meet on the show bench with more equality than formerly. For my own part, I like the old breed of small, round, compact, close-feathered, dancing birds, which I never tire of admiring, as they are ever on the move. At the same time, they are seldom seen with the tails necessary for show birds, to breed which is the difficulty. They breed very true, although they have often been crossed to make them en: tirely white; and, except for the size, shape, and carriage of tail, they can so easily be bred good, that they present little scope for competition.

\section{Fancy Points.}

The properties of the Fantail are as follows:-

Size.-Other things being equal, I prefer the Fantail as small as possible. I weighed a cock and hen, matured birds, of the Dundee shaking breed, and they were $12 \mathrm{oz}$. and 10oz. respectively. The hen was extra small, the cock of an average size. 
Make ANd Shape.-Although differing much in size, all the Fantails I have ever seen, excepting one pair, were of the same formation in head and beak, viz., the common type. Cocks are rather coarser in head than hens. The head is long, narrow, and flat, the beak long and slender. The beak wattle should be small, and there should be very little eye wattle. Smooth legs are necessary in the show Fantail, and nearly all fanciers prefer smooth heads. When the head is crested, the crest is generally a neat peak, and I never saw a shell-crested one. I do not dislike a peak crest on a good Fantail, though it necessarily takes from the rounded outline of the head and neck. I once saw a pair of white Fantails with rather round heads, and shorter and thicker beaks than usual, but they were not good birds otherwise. I believe they were imported from the Continent. Except for the flights, tail, and legs, the shape of the Fantail should be as round, compact, and close-feathered as possible. It should look like a pigeon pressed into the shape of a ball. A peculiarity generally found in the best Shakers is the split breast, an indentation running up the middle of it, which is most apparent in birds of good carriage. The legs should be moderately long. They are seldom too long, but often too short.

CARRIAGE.-The carriage of a first-class shaking Fantail is something wonderful to behold. The head is thrown back till it rests at the root of the tail, the crown of the head being far below the level of the breast. The head sometimes goes through the tail, which is a great fault. Some birds have an up and down motion in their necks, the head leaving its position against the tail, and returning to it by a succession of strokes. I dislike this style, and prefer the head to remain fixed in position, while the whole body of the bird is in a constant state of agitation. A good one is unable to walk forward while in action, but has to turn its tail in the direction it wishes to go, when it backs with a dancing style of movement. It will occasionally make three or four complete turns 
round, as on a pivot. There seems to be some invisible influence trying to drag it off the ground, to counteract which requires all the power of gravitation. Resting only on the tips of its front toes, the hind ones are quite off the ground. The shoulders are carried close to the body, and the flights are often to be seen dragging on the ground. When a good one wants to fly, it turns its tail in the direction of the place it wishes to reach, when, after several feints, it makes a dash, turning rapidly in its flight. With all their extraordinary carriage, these birds are not bad fliers. Unlike other pigeons, they contract instead of spreading their tails in flight.

TAIL.-The tail feathers of the Fantail ought to be both longer and broader than in other pigeons of similar size. These feathers do not generally shed their fibres freely when growing, and, unless some attention is paid to this, by carefully scraping off the husk or skin as they grow, they will often reach their entire length without opening out, and become rotten. A little care will obviate this. Malformed tail feathers are common in Fantails. These are usually two separate, incomplete feathers, growing from one quill, often at right angles to each other, spoiling the appearance of the tail. The tail feathers ought to be frizzed at their ends and edges for about half their length from their extremities; not, however, like the feathers of the Lace Pigeon, but ten or twelve of the fibres may adhere together, and be divided from another set. Fantails with as many as forty-two tail feathers have been noticed. I never counted more than thirty-six. The number is not of so much consequence as the shape of the tail. It ought to form as complete a circle as possible, the opening at the bottom being something like a fourth part of the circle, or even less. Through this opening the flights should project, and not cross at their points. The perfect tail is quite flat, and, when viewed in profile, perpendicular. It ought not to incline forward, which is worse than being a little arched or 
inclining backward. I have never seen the perfect tail on a really first-class Shaker, though I have seen it on a bird of no merit otherwise. The difficulty is to produce carriage and tail combined, and the nearest to it is, of course, the best. While some persons even prefer an arched tail on a Shaker, they have not indicated how much or how little arch they want. Surely the perfectly flat, fan-shaped tail is what is wanted, and what has been seen, though not with all else perfect. My own illustration is not that of a quite flat-tailed bird, and is, so far, not that of a perfect specimen.

Feather. - I have referred to whole-feathered Fantails, such as white, black, blue, silver, red, and yellow, and to Turbitmarked, or Saddle-backed ones. The latter ought to have the wings, including the scapular feathers, coloured, the flight feathers and all else white. They have been seen very correctly marked, though generally mottled on the head and neck, and otherwise foul, and such have often red or yellow irides. The eyes may be either hazel or gravel-coloured in a Saddleback, but not broken. Yellow eyes would be difficult to breed, and would be so far an additional property. Whole-feathered yellow Fantails come from Germany, I understand, but are not of good quality. The Germans have, also, coloured birds with white tails, and reversely marked ones, as well as Saddlebacks, which are all described and illustrated by Neumeister. At a show held in Copenhagen, early in 1885, Saddle-backed Fantails, of various colours, were exhibited. I think much of my old paintings of almonds and a yellow Saddle-back, evidently portraits, as they show me that such birds formerly existed.

Boitard and Corbie, in writing of the Fantail, say : "It is all white, or white with the head and tail black; they are also found with the shoulders (manteau) and tail affected with all the colours common to pigeons." Saddle-backs are preferred with only coloured wings; but I have seen them with the tail 
coloured as well. The German and French names for the Fantail are Pfautaube, and Pigeon Trembleur Paon, both signifying Peacock Pigeon.

\section{The Fantail Club.}

The Fantail Club was established in the year 1885, chiefly for the purpose of endeavouring to put down the dishonest practice, so common of late, of manipulating Fantails, so that very ordinary birds are manufactured into the semblance of good ones. The adepts at this art have for years succeeded in carrying off the principal prizes, and sold numerous goodlooking birds, which, after moulting in their purchasers' possession, have turned out ordinary spoon-tailed specimens; but they have kept the secret of their art so well, that no one can say what methods they employ. Pasteboard, or wire frames, for fixing to the tail during its growth, at the annual moult, is said to be one of the means employed; while extra feathers, fixed into the quills of the natural ones, have actually been discovered in the tails of prize birds. Loading the lower tail feathers with lead, so as to form as complete a circle as possible, is also in vogue. When such frauds are constantly practised, honest men get disgusted, and go into some other variety, declining to compete with those who artificially improve their birds.

\section{The Lace Fantail.}

Lace Fantails, so called from their feathering being similar to that of the Lace Pigeon already referred to, are known in Germany as Seiden Pfautauben, and in France as Pigeons Trembleur Paon de Soie, names signifying Silken Fantails. I believe they are generally white, and were probably produced from the Fantail and Lace Pigeon. The Lace-feathered Fantails that have reached us from abroad could only be described as narrow-tailed; but from them, and good specimens of ordinary close-feathered Fantails, Scotch fanciers have pro- 
duced the modern Laced birds, which, in some late instances, have been bred so good as to be able to compete successfully in classes of any variety of the breed. The Laced and common kinds, when bred together, produce young of both types, and the close-feathered ones so bred may be depended on, when bred back to a Laced bird, to produce a large proportion of the Lace-feathered variety. This peculiar feathering is, therefore, not only maintained without difficulty, but easily transmitted to other pigeons. The only colour yet seen in Laced Fantails is pure white, but I think blacks and blues might be produced without much trouble.

After describing this pigeon, Boitard and Corbie have the following: "Pigeon Trembleur de la Guyane.-This superb variety has the tail large, and displayed like the Peacock, and has been brought from Guiana, from which it takes its name. The ground of its plumage is of a dull white; the wings are blue, shaded with a sort of bright eyes, and rays of black bars. All the races of small pigeons crossed with the Lace Fantail produced laced pigeons of all forms and colours; but, especially if the latter is bred with a pigeon with black-barred wings, their young will have fringed bars of various colours, imitating tapering fringes, and producing a very agreeable effect." This would appear to be a coloured-winged Lace Fantail, with a fancifully derived name, just as they name certain colours in other varieties "Siam." It seems unlikely that any special variety should hail from Guiana.

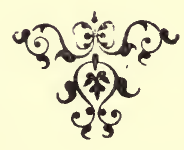




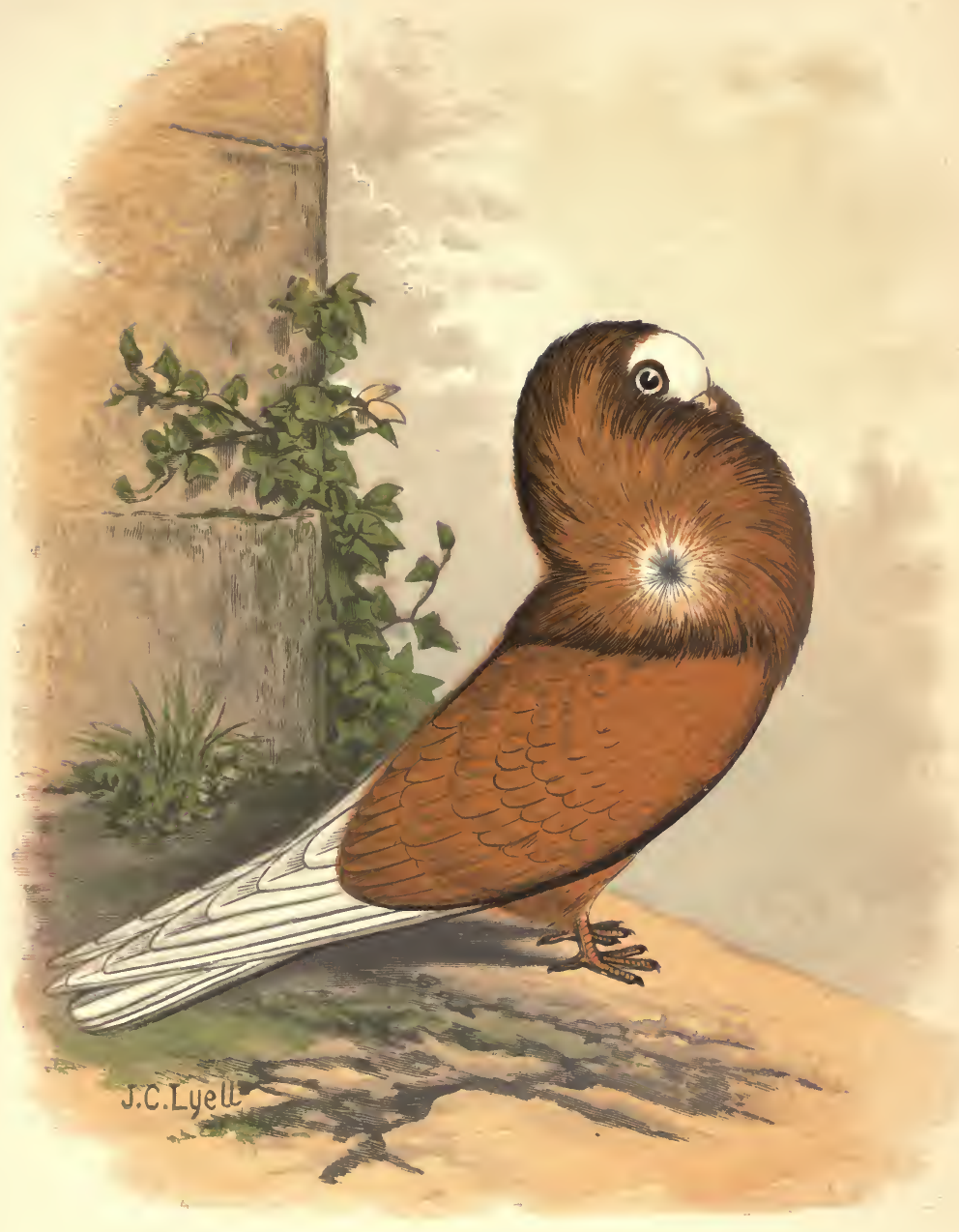

THE JACOBIN PIGEON. 


\section{Chapter XXI.}

\section{$\propto$ THE JACOBIN PIGEON. $\varnothing$}

\section{History and Literature.}

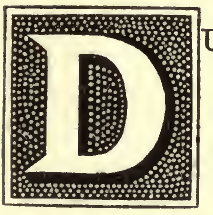

URING the past few years, there has been considerable controversy over this variety, which is one of the choicest in the whole fancy. Such controversy was nothing new, for, although it turned on a fresh question regarding what constitutes the true breed, our first writer of note on pigeonsJohn Moore, himself-clearly indicates that there were differences of opinion in his day about this pigeon. Subsequent writers, mostly imitators of Moore, continued denouncing the Jacobins of their time as not the true breed, and there has been no rest for its breeders, as first one, and then another writer, felt called on to declaim in no measured terms against the generally accepted standard of the breed. I will give my ideas on the questions forming the chief differences of opinion later on, and commence with an account of what is known of the Jacobin from books. It is mentioned by Aldrovandus, in his "Ornithology," as the Columba Cypria Cucullata. Willughby, who was indebted to Aldrovandus for a good deal of what he wrote on pigeons, says: "Jacobines, called by the Low 
Dutch, Cappers, because, on the hinder part of the head, or nape of the neck, certain feathers reflected upward encompass the head behind, almost after the fashion of a monk's hood when he puts it back to uncover his head. These are called Cyprus Pigeons by Aldrovand, and there are of them roughfooted. Aldrovandus has set forth three or four, either species or accidental varieties of this kind. Their bill is short, the irides of their eyes of a pearl colour, and the head (as Mr. Cope told us) in all white." It is to be noted, that there were Bald-headed Jacobins before 1676, according to what Mr. Cope, the Pouter fancier of Jewin-street, told Willughby.

Moore, of course, gives a good account of the Jacobin, which was then, as now, called the Jack, for shortness. It was then, "if true, the smallest of all Pigeons, and the smaller still the better"; and he adds: "there are but very few now to be found in England compleat." I think it unlikely that Moore ever saw such good Jacobins as are in existence at the present time, after reading that "the Feathers of this Chain ought to be long and close, so that, if you strain the Neck a little, by taking hold of the Bill, the two sides will lap over each other in some of the best." The very best, in his time, therefore, required the above treatment before their chains would cross in front. Nowadays, many Jacobins exist whose chains lap over naturally, not only without straining the neck by "taking hold of the Bill," but without cutting out a piece of the skin of the throat, as "Mayor" (1765) says was practised for the same purpose. Moore describes a pigeon known as a Ruff, "larger than the true original Jacobine, tho' in shape and make much the same. It has a longer Beak, the Irides of the Eyes in some are of a Pearl Colour, in others of a Gravel Colour, the Feathers of its Hood and Chain are much longer, tho' the Chain does not come down so low to the Shoulders of the Wings, neither are they so close and compact as the others, but are apt to blow about by every blast of Wind, fall more backward off the Head, and lie in a rough 
confus'd Manner, whence the Pigeon has its Name. The Strain of Jacobines has been much vitiated by matching them to this Pigeon, in Order to improve their Chain by the Length of the Ruff's Feathers, but instead of this, the Jack is bred larger, longer-beakt, looser in its Hood and Chain, and in short worsted in all its original Properties."

The account of the Jacobin in the Treatise of 1765 contains very little in addition to that of Moore, whose ideas are retained, though his language is altered. The ruff is also described, and its use in Jacobin-breeding condemned. Yellow Jacobins had the preference over the other colours. The portrait or illustration in that book representing the breed is, however, very good, considering all things, and is the earliest fancier's picture of a Jacobin I know of, Willughby's, of 1676, and another in Albin's "History of Birds" (1734), not being worth consideration. The following passage from the Treatise (page 117) points to another picture of a Jacobin as existing, but I have not yet met with it: "The following being in itself so uncommon, and a fact, I cannot help taking notice of it: a person the other day passing through Fleet-street, seeing a print of this Bird" (the Jacobin) "at a shop window, stopped to make his observations thereon, and having well viewed it, he went in and purchased it, declaring to the seller, that he never saw a stronger likeness in his life; and as for the wig, it was exactly the same he always wore. For he imagined it altogether a caricatura of one of his intimate acquaintance; and the person of whom he bought it, did not think it necessary at that time to undeceive him."

The picture of a Jacobin in the Treatise represents a very round-headed, short-beaked, rather down-faced, apparently highcut bird, with the broad eye wattle of a good Jacobin. It is entirely dark-thighed and vented, and full-flighted as far as seen. The chain feathers are long, but do not meet in front, as they ought to do. The mane is clearly brought out, but is not so even at its ridge as many modern birds have it. 
We know that the Short-faced Tumbler had not reached a high degree of quality when the author wrote, and, as he says, "the true Jack is a very small Bird, very little bigger than a tumbler;" we know that, whatever its size was when Moore wrote, it was by no means the smallest of pigeons thirty years afterwards. The fact is, all the small varieties of pigeons produce extra small stock occasionally, and although small size is admired in many varieties, quality in the properties that go to make them excellent ought not to be, and is not, sacrificed for size.

One of a set of eight oil paintings of pigeons in my possession, evidently about 150 years old, is a self-coloured Jacobin, with feathered legs and bare feet. It is a gravel-eyed, short and open-chained, large bird, not worth consideration from a fancier's point of view. Although I was able to rub off the varnish from the other seven pictures, I could make nothing of this one; but from what I can make out, it represents a blue with black bars.

There is not much difference in modern opinion regarding what a Jacobin Pigeon ought to be, excepting on the property called the mane. Some say the mane is wrong, and that a breed existed having a clean division of the feathers all round the back of the neck, which was the true breed. If this is correct, I have never seen it, and, moreover, do not believe it is natural for the feathers of the Jacobin to grow in this way. I have formed this opinion from observation of great numbers of the breed, both British and foreign-not poor, half-bred looking things, known in country places, and by mere keepers of pigeons, as Ruffs, but what were fairly good Jacobins. The feathers at the back of the neck in the Jacobin, Trumpeter, and some other varieties, can be moved by them at will, so that they assume different positions at different times. The Jacobin in the Treatise is certainly a maned bird; and Brent wrote, in the Poultry Chronicle of 20th September, 1854, when describing the Jacobin: "At the lower part of the 
chain the feathers turn out all round, and expose a centre spot of white down." Exactly so; the rose is the centre of chain, tippet, and mane. The following is what the German ornithologist, Friderich, says in his "Natural History of Birds" (second edition, 1863), where he treats of pigeons at great length: "The feathery ruff runs along the sides of the neck, down over the angles of the wings, reaches upwards over a part of the crown, like a cowl, forming the mane (mähne) towards the back part of the neck. This feathery ruff is parted along the sides of the neck towards the front, the back, and the top." Mr. P. H. Jones had Jacobins with manes before 1840, and Mr. Esquilant before 1850, according to their published statements. From all the foregoing, nothing could be more clear, than that the mane is not a modern property of the Jacobin. I am inclined to believe, that the mere assertion that it was modern has been the cause of most of the late disturbance, some fanciers being so conservative that they oppose, on principle, all new ideas.

Another hallucination regarding the Jacobin is, that its head and beak, or its marking, were derived from the Bald-headed Tumbler. It was a short-faced bird before the Short-faced Tumbler was in existence. It would be something like a hundred years after Willughby described it before a Short. faced Baldhead was produced. The Baldhead is first described in 1765, among common Tumblers. Is it for its marking that it is a relative of the Tumbler? Then why not choose the German Monk, Priest, Ringbeater, or even the old Bald-headed German Pouter, for its ancestor-not to mention the Indian Mookee, and plenty more? To say that it derived its marking from the Tumbler, is about on a par with what a "judge" once said to me at a show, when I asked him why he had entirely passed some very good Baldheads in a class of Flying Tumblers. "Give a prize to these things," said he; "why, they're bred from Jacobins." I could not reply to this, for I quite lost the power of speech. In comparing the pictures of the Jacobin 
and Almond Tumbler in the Treatise, the former is all we want in head and beak, the latter a mere Long-faced common Tumbler. Nothing could be more erroneous than to say, as Brent and others have said, that a Short-faced Baldhead with a Jacobin's hood and chain would be the perfect Jacobin. It might be a pretty pigeon, but it would be the very opposite of a Jacobin in many ways.

\section{Jacobin Properties.}

The properties of the Jacobin are size, shape, carriage, head, beak, eye, legs and feet, quality of feather, hood, chain, tippet, rose, mane, colour, and marking. It must not be inferred that I consider them valuable in the order named. I shall merely describe what I consider a perfect bird, and no bird can be considered very good which is not fairly well up in all points. The same remarks must be held to apply to my descriptions of all other varieties.

Size.-There is considerable difference in size among Jacobins. When other things are equal, the smaller pigeon is to be preferred. By equal, I mean equal in proportion to size.

SHAPE.-The neck ought to be long. This is a grand property, the effect of which can easily be seen by comparing long-necked and short-necked birds together. The body ought to be long, and narrow in girth. A well-bred Jacobin, which weighs the same, or even rather more, than a pigeon of another variety, will easily force its way through the bars of a cage which will effectually confine the latter. I have seen this illustrated in the case of a very small African Owl and a Jacobin, the latter being much the heavier pigeon of the two, which gives a good idea of the difference in shape between the two varieties.

CARRIAGE.-A Jacobin of the best type, whose head is wellsmothered in hood and chain, is unable to see well about it. Such birds have a groping way of going about, and endeavour, 
by stretching their necks, to see over those chain feathers which obscure their vision. Some of the longest-chained birds are, consequently, all the better for being clipped about the eyes during the breeding season, like the best Trumpeters. The real carriage of the Jacobin is seen when the cock is driving the hen to nest. The head is carried well up, and the chain will then lap over in front, if it ever will.

HEAD. - The head should be broad across the crown, and well rounded off over the eyes. There should be a little tuft of feathers projecting over each eye, like two small horns; but this is only seen in broad-skulled, short-faced birds, and not always in them. These tufts are quite a peculiarity of the breed. The forehead must be broad and prominent, well rounded in profile, from the crown to the beak wattle, and not showing a stop, as in the Short-faced Tumbler. A narrow skull, and runout, or mousey head, is a great fault.

BEAK.-This should be short, and rather thick at its base, but coming to a fine point, with a downward inclination. The true beak is differently formed from that of the Owl tribe, not being so blunt and thick at the tip; the beak wattle should be fine and smooth. Any gullet is faulty, though it is sometimes found in good birds.

ExE.-The irides should be of a pearly white colour, but often have a reddish tinge round their outer circles. Clouded or dusky pearl, yellow, red, broken, and entirely dark, or bull eyes, are all found in Jacobins, and are all to be avoided. Bad as a bull eye looks, it can often be bred out easier than a yellow one, if it has not existed to any great extent in the strain. The eye wattle ought to be broad, and of a bright red colour. I have seen the wattle almost, if not quite, a quarter of an inch in breadth. In richness of colour it follows the quality of colour in the feather. Bad blacks, reds, or yellows, do not have a deep red eye wattle, though a strawberry bred from a rich black and red may; and such a wattle on a strawberry would indicate that it was of a good coloured 
strain. I look on the broad bright red eye wattle as a great attraction in an otherwise good bird.

LEGS AND FEeT.-Although the Jacobin may be got with feathered legs, such a variety having existed for centuries, being mentioned by Aldrovandus, Willughby, and Moore, our standard permits only smooth legs and feet, which should be small, neat, and bright red in colour.

Quality of Feather.-The feathers should be soft and silky, of great length, making the bird appear larger and heavier than it would prove to be on being handled. The flights should extend considerably beyond the tail, as much as an inch when the bird is in the hand, though usually not to such an extent when it is at liberty; but the longer they are the better.

HooD.-The hood is the property of utmost consequence in the Jacobin. It is formed by the feathers round the back of the head and upper neck all growing forward. The feathers of the head do not, in a good bird, turn up where they meet the forward growing hood, and so fall into the sweep of it, as they would prevent it lying close; but the hood forces itself through these feathers in a succession of regular steps, and every feather forming the hood should grow towards the beak. Sometimes the feathers on one side will grow towards the other, and so form a twisted hood, more or less faulty. The head feathers will often prove too strong for the hood, and cause it to stick up, which spoils the bird; and there are altogether so many difficulties in getting a perfectly formed hood, that to obtain one naturally perfect, and which requires no faking whatever, is half the battle in producing a good pigeon of this variety. Supposing the formation of the hood to be right, its position is next to be considered. Some commence low down on the nape, and cannot, in consequence, come far enough forward. Such a hood, often plastered down at the back of the head, is not what is wanted; it ought to grow well forward at the back of the head, and it will then, in a long- 
feathered bird, get as far as the middle of the head, over the eyes. It should lie close, but not as if pasted to the head, a slight space between it and the crown being well liked. It ought also to be regular in its outline, and not split or divided in its centre, as many are, but compact, well filled up, and look like a feathered cap reaching over the head to protect it.

Charn.-The chain, or frill, is the continuation of the forward-growing hood feathers down each side of the neck. The first difficulty with a good chain is the cheek feathers, or whiskers, growing out against it, and causing irregularity in its shape, to obviate which they are often weeded out. The chain should come down on each side of the neck as far as possible, and, without "taking hold of the Bill," should at least meet in front, hiding the beak; so that, in a first-rate bird, the crown of its head is alone visible, both beak and eyes being hidden in feathers. An exposed throat is faulty according to its extent. In birds whose chains lap over, this is not caused by one side lying right over the other, but by the two sides meeting, and forcing their way through each other, which, of course, causes a certain irregularity that cannot be avoided. Otherwise, the whole outline of hood and chain ought to be as even as possible. The feathers forming the hood and chain should present a smooth surface, each one lying in order; this is the difficulty with very long-feathered birds, the shorter-feathered ones, with half an inch or more of exposed throat, being much easier to produce good in this respect.

It will now be seen how a long neck adds to the appearance of the Jacobin, and how it gives room for a display of chain. Let a short-necked one be ever so good in hood and chain, it looks mean beside an equally well-furnished long-necked one. The ends of the chain must turn beautifully round at the bottom.

TIPPET.-This is formed by the feathers growing backwards 
over the shoulders and back. It ought to be full, and convex in shape all round; and the longer and fuller in feather a bird is, the better it will be in this property.

Rose.-Opposed to the theory that the perfect Jacobin should have a clean division of the feathers at the back of its neck, part growing forward, to form the hood and chain, and part backward, to form the tippet, is the fact, that on each side of the neck the feathers grow out all round from a centre, as on the head of the Trumpeter. The formation of the rose may be well seen in a young bird as it gradually feathers in the nest. When about three weeks old, the young one which will become good when matured has a perfectly formed rose on each side of its neck, the feathers at the top of which become the mane. At maturity, the rose should appear as an oval-shaped spot of white down, hollow in the centre; in those colours which have a white under down to the feather, as red and yellow. In blacks, the downy part of the feather is not white, but of a medium tint; but, although the black cannot, therefore, have such a contrast in colour between the chain and rose, the formation of the latter should be correct. The formation of hood, chain, tippet, and mane, may be all very good, and yet the rose may be faulty from an awkward feather or two standing up in the centre of it, the removal of which would cause all to look well.

MANE.-The feathers forming the mane have no connection with those of the hood, but grow from low down on each side of the neck, being those which take an upward direction from the centre, known as the rose. They ought to fall in with the sweep of the hood and tippet, filling up the cavity which, but for them, would exist. A good mane is difficult to get, as, instead of its ridge being sharp and even, one of the sides forming it often presses down the other, causing a twisted mane; or each side may force itself through the other at some part, and so spoil the hogged appearance it 
ought to have. The feathers forming the mane are also movable by the bird at will, so that, what may be a good mane at one time, is at another only a mass of rough feathers. The outline of the hood and mane should form part of a circle, and the deeper in feather a Jacobin is from ridge of mane to bottom of chain, and the broader from front of chain to tippet, the better, for all of which a long neck is of the greatest consequence. The great difficulty is to get the whole formation even in its outline, and firm in texture as well, for, the feathers being long, soft, and silky, they are generally inclined to be loose.

Colour.-The chief colours of the Jacobin are red, yellow, and black, and, for the most part, they are of good quality. Before the introduction of certain foreign pigeons, Jacobins were, indeed, regarded as sometimes perfect in colour; but I have never seen any with the same lustre and fatty quills about the under body that I have referred to when writing of the Swallow, and which the Smyrna Turbiteens have in perfection. The red, yellow, and black are, however, generally good, and sometimes very good in colour, though not absolutely perfect when compared with Turbiteens. The thigh and vent feathers ought to be as lustrous as the wing coverts, though they often fall away in reds and yellows to a half tint, and sometimes to a mere grey, which is an indication of bad colour elsewhere. The nearer the thigh and vent feathers approach the colour of the wing coverts, the better will be the colour throughout. There are Blue and Silver Jacobins, but, so far, they do not approach the red, yellow, and black in quality. Mottles also exist, and they are an old variety, being mentioned by Moore. Mottles are chiefly reds, and, while retaining the white head, flights, and tail, should be marked as much as possible with single coloured feathers over a white ground. Pure whites are favourites, and present a difficulty in regard to pearl eyes, being inclined, like other pure white pigeons, 
to be hazel, or broken, in the irides. When whites have a coloured feather or two in the hood or chain, the pearl eye generally accompanies them; and as it is impossible to detect the removal of a few feathers, what appear to be White Jacobins at shows are not always so in reality. In off colours, the chief are the strawberry, or sandy, of various shades; kites; duns; red and yellow chequers; an occasional red or yellow mealy, with distinct wing bars; and the very dark chequer, or bad black, which, while often of a fair black on the wing coverts, is of blue grey on the thighs and vent. These are all the result of crossing the black, red, and yellow, or the produce of sound colours and such as themselves. The first cross of black and red in all varieties of pigeons, even in those of superlative colour, often results in a strawberry, which is, accordingly, useful in breeding back to these colours, especially to the black. It altogether depends, however, on how the strawberry itself may have been breed, whether or not it may be a good match for some of the solid colours, its indiscriminate use being calculated to spoil good colours. I have known a pair of Red Jacobins produce red, yellow, black, and dun young ones in one season. This was on account of the way they were bred, the cock being from a red and black, and the hen from a red and a yellow.

Marking. - The Jacobin, in common with many other varieties of fancy pigeons-none of which have any connection with it, except that, as I believe, they all descended originally from a common origin-is marked in the way called bald-headed. It has been so for at least two hundred years: Many instances occur to me of bald-headed pigeons being produced from a self-coloured bird when mated with a pure white. The first pair of pigeons I ever possessed, which I bought for sixpence, while they were still unhatched, and which I saw in the nest day by day as they feathered, were a pair of Baldheads-a blue and a red-and were bred from 
a whole-coloured red cock and white hen. They were common pigeons of mixed race, and certainly may have had Baldhead Tumbler blood in them, but I think it unlikely. The young ones had very low-cut, slobbered necks, and I merely mention them to show that a coloured bird, mated to a pure white, often breeds coloured young ones with white points. I had lately a similar instance in my pigeon house. A pure white, peak-headed, cock common pigeon, with an appearance of Fantail blood, mated with a whole dun Tumbler hen, used as feeders, reared a pair of their own young ones, their eggs not having been changed. One was a blue Baldhead, and the other a dun Baldhead-such another pair as those I began the fancy with, thirty-five years ago, when aged seven. Again, when passing through Leadenhall Market one summer, I saw a cage containing two or three dozens of blue and blue-chequered dovehouse pigeons, among which was one with clean white head and flights. I looked at it particularly, and felt certain it was of the same race as the rest. It was, most likely, the produce of a blue and a white, or albino, such as may be found in almost any field dovecote. In fact, a coloured body with white points may be found in many domestic animals, such as horses, dogs, and rabbits, and was doubtless originally produced from the cross of self-colours with albinos. I merely mention all this, because some people refer the marking of the Jacobin to the Baldheaded Tumbler, while nothing is more certain than that it could have been produced without any admixture of alien blood.

The head of the Jacobin ought to be white above a line running from the mouth across the eyes. Both mandibles are white in rich-coloured reds and yellows; but a high-cut black has often the lower mandible coloured, or partly so. There is a natural line between the eyes and mouth, which serves as a guide for marking; at the same time, a few of the short feathers below this line are generally white, or, if not, a few 
of those above it are sometimes coloured, for it is difficult to get the marking quite exact. When the white comes below the eyes, or any way down the throat, the bird is low-cutcertainly no great eyesore in a first-class bird, which will never show it unless its chain be opened out; but the high-cut marking is what is desired. The flight feathers should be white to the turn, and the tail, with its coverts, also white. All else should, be coloured, though, even in the darkest thighed and vented birds, there is generally some white where the thigh feathers finish off at the hocks. When this can only be detected by handling it is no great fault. It was for some time a very difficult matter to get full-flighted, high-cut, dark-thighed birds, because so many were low-cut and whitethighed; but during the last few years immense progress has been made in the desired marking. I have seen Jacobins imported from the Continent beautifully marked, though not to be compared with our own in the more important points of the breed; at the same time, I believe foreign blood has been used here, during the past twenty years, in bringing the Jacobin to its present high quality.

Formerly the Carrier, Pouter, and Short-faced Tumbler were the only varieties regarded in this country as high-class pigeons. The Jacobin, Turbit, \&c., were Toys. Ideas have changed, and the Jacobin is now regarded as a very high-class pigeon. Not only is it full of properties difficult to breed, but it is one of the most beautiful pigeons known, and a general favourite. I dislike placing the different varieties of pigeons in any order of merit, and will only say that, in my opinion, it ranks among the first four, leaving other fanciers to please themselves.

\section{Foreign Jacobins.}

The Jacobin is known in France as the Pigeon Nonnain, or Pigeon Nonnain Capucin. A variety mentioned by Boitard and Corbie as the Nonnain Maurin is described as follows: 
"It is black, with the head, tail, and flight white. It is of a size above the ordinary Nuns" (Nonnains, i.e., Jacobins), " approaching to that of Pouters. It has, like the latter, the habit of inflating its throat a little. It has an elegant form, and the ruff of feathers raised gracefully, but it is not very productive." Dixon, in his "Dovecote and Aviary," quoting from Temminck, mistakes this variety for a Nun, the name having misled him. In France, Nuns are styled Pigeons Coquilles-shell-headed pigeons.

In Germany, the Jacobin is chiefly known as the Perückentaube, or Wig Pigeon, of which there are several subvarieties. I have seen self-coloured blacks, all colours of bald-headed with feathered legs, also most of the baldhead colours with both feathered legs and rose on the forehead, like a Priest Pigeon. There are also blues and blacks with white wing bars.

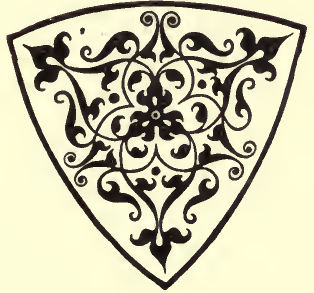




\section{Chapter XXII.}

\section{$\propto$ SHORT-FACED FRILLED PIGEONS. $\nsim$}

\section{Historical.}

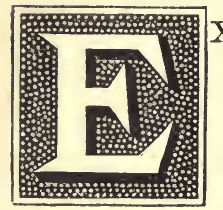

XTENSIVELY spread throughout Europe, Asia, and North Africa, the Short-faced Frillbreasted varieties include many of the most charming types of pigeon beauty. Some of the countries bordering on the Mediterranean Sea would seem to be the bome of this race, as those we had in this country, or from France and Germany, before the introduction of Tunis Owls and Turkish Frilled Pigeons, were very much inferior in many respects. There is only a meagre account of them in our early literature. Willughby says: "Turbits, of the meaning and original of which name I must confess myself to be ignorant. They have a very short thick Bill, like that of a Bullfinch; the crown of their head is flat and depressed; the feathers on the Breast reflected both ways. They are about the bigness of the Jacobines, or a little bigger. I take these to be the Candy or Indian doves of Aldrovand, tom. 2, pp. 477-478, the Low Dutch Cortbeke." A naturalist describing the Turbit at the present time might give a similar description, the head being "flat and depressed" 



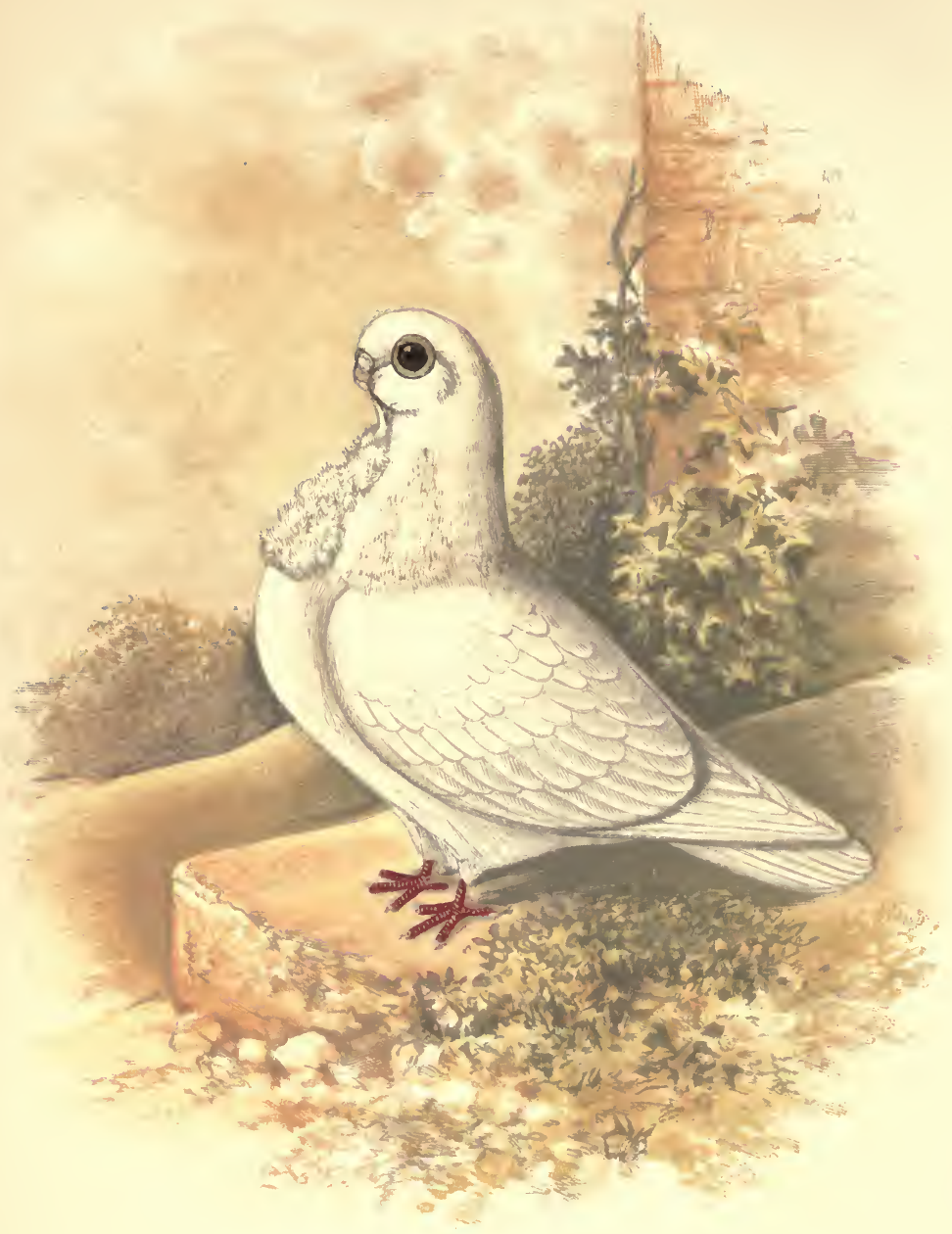

T H E A R I A N O W L. 
in the great majority. From the following account of the Turbit and Owl, by Moore (the description of the latter being the first notice by name there is of it), it will be seen how much he was indebted to Willughby, who wrote about sixty years before him:

“The Turbit.-The Reason, why this Pigeon is so nam'd by the English, I cannot by any Means account for; the low Dutch call it Cort-beke or Short-bill upon the Account of the Shortness of its Beak. It is a small Pigeon very little bigger than a Jacobine, its Beak is very short like a Partridge, and the shorter the better; it has a round button Head, and the Feathers on the Breast open and reflect both Ways, standing out almost like a Fringe or the Frill of a modern Shirt; this is call'd the Purle, and the more of it the Bird has, the more it is admir'd. As for the Feather, their Tail and Back of the Wings ought to be of one entire Colour, as blue, black, red, yellow, dun and sometimes chequer'd; the flight Feathers and all the rest of the Body shou'd be white. They are a very pretty light Pigeon, and if us'd to fly when young, some of them make very good flyers. I have seen a Flight of them kept by one Girton that wou'd mount almost high as Tumblers. There are of this Sort all white, black, and blue, which by a Mistake are often call'd and taken for Owls."

"The Owl.-This Pigeon is in make and Shape like the former, except that the upper Chap of its Beak is hookt over like an Owl's from whence it has its Name. Its Plumage is always entirely white, blue, or black."

Moore also mentions, when writing of the disease called the vertigo: "I once had a Turbit, of the Owl Kind, taken with it in a violent Manner."

There is no mention of the gullet or crest in this description; the head, however, is said to be round, and it was not the shoulder marking alone that constituted a Turbit, as it might be self-coloured. The difference between the Turbit and Owl seemed to be only in the beak. 
On reading the descriptions of the Turbit and Owl in the Treatise of 1765 , which are very much more extensive than Moore's, it would appear that either some recent importations of finer Owls had been made, or that breeders had effected great improvements on the old stock. The illustrations accompanying the descriptions differ very little in their outlines: both are plain-headed; exactly alike in beak, that of the Owl not being hooked; the chief difference lying in the Turbit's head being very round, while the $\mathrm{Owl}$ is rather flat-crowned. The author says: "The owl is, according to Mr. Moore, a small Pigeon, very little larger than a jacobine, which might be their size in his time; but at present they are brought to such perfection, that they are hardly, if anything, larger than a very small tumbler. . . Its plumage is always of one entire colour, as white, a fine sky-blue, black, and yellow, \&c., except some that are chequered. The blue ones should have black bars cross the wings; and the lighter they are in colour, particularly in the hackle, the more they are valued." $\mathrm{He}$ mentions the gullet, "reaching down from the beak to the frill," both in the Owl and Turbit; and that the latter, when red and yellow, had white, not coloured, tails. For about a hundred years after the preceding was written, or till about 1860 , there seems to have been no improvement made in pigeons of the Owl tribe in England; I rather think they must have lost quality from neglect. Mr. Jayne says the African Owl was used as part of the composition of the Shortfaced Tumbler, but the record of how and when is lost. Mr. Fulton says, in his book, that a Dundee fancier had African Owls in 1838, and that they were brought to this country by his brother. From what I was told by the said fancier years ago, I could never believe the pigeons in question were African Owls. In 1838 he would be about twenty years of age, and his elder brother, who was not a seafaring man, having occasion to make a voyage to the Baltic, brought home with him some coloured-tailed White Owls, which were, doubtless, the 


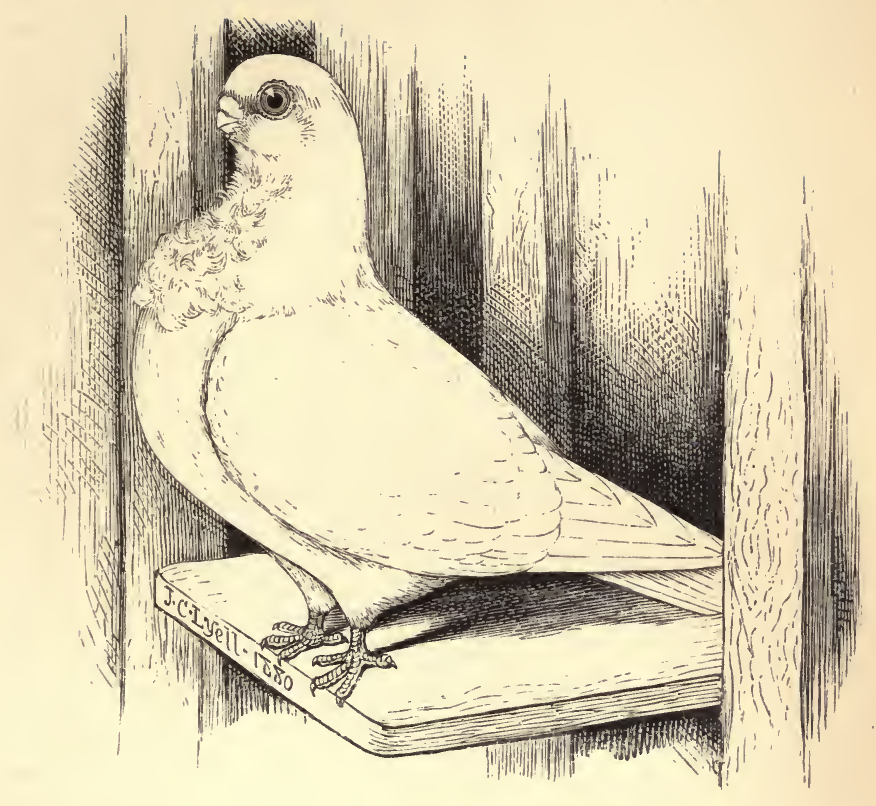

THE AFRICAN OWL. 
- 
Danish or North German pigeons known here as Meeves (Mövchen), which bear about the same relation to African Owls that Skinnums do to Carriers.

\section{The African Owl Pigeon.}

It was about the year 1858 that the first pair of African Owl Pigeons known to the present generation of British pigeon fanciers was imported into this country. They were exhibited at the Crystal Palace Show, by their importer, Mr. E. V. Harcourt, and the description of them in The Field newspaper of 22nd January, 1858, is as follows: " Owls (all colours) well represented; but the best pair of Owls in the Show was certainly a pair of whites, in the class for other varieties, under the name of 'Booz' Pigeons from Tunis." Since then thousands of these beautiful pigeons have been imported from the North of Africa, chiefly, I believe, from Tunis. The late Mr. John Baily, jun., who, with his father, did a large business in exporting and importing fancy pigeons, informed me that these beautiful birds were bred, he understood, about the mosques in Tunis, and allowed to pair together as they liked. If this is so, they must certainly be the only variety there, or the breed could not be kept pure. As far as I know, no experienced fancier has yet visited Tunis, so we have but little information regarding these birds, and can only judge of them as they appear. How they originated, or came to. be located in Tunis, is a mystery. The great proportion of those brought to this country are quite worthless in comparison with the select few in each shipment; so that Mr. Baily told me that latterly it did not pay to import them, as, when the one or two good ones had been picked out, the rest were unsaleable. From the careless treatment they generally get on the voyage, as well as from the fact that a great proportion of them arrive in their nest feathers, canker, and other diseases of the head and throat, are very prevalent among those that come to this country, so that I have known only some ten or fifteen per 
cent. of a lot survive the first month of their residence here. They are very delicate pigeons, but, when acclimatised, are fairly hardy, and good breeders. I have bred them in this country, as well as in India, where they do very well.

In detailing the properties of the African, or Tunisian Owl, I may say, that the nearer all the frill-breasted, gulleted pigeons approach the ideal standard of conformation, the better they are. Some fanciers agree with me, others do not. Under each variety I shall describe the various differences of feather, size, \&c.,-which constitute them separate breeds.

Size.-The African $\mathrm{Owl}$ is the smallest domestic pigeon known. A good pair will weigh about 1lb., and hens are sometimes found under 7oz. in weight. The smaller they are the more they are valued, if good in the various properties which fanciers admire.

SHAPE.-Short in neck, broad-chested, short in flights and tail, the legs long enough to make the thighs visible in profile, the back rather hollow, and the rump rather full.

CARriage, very erect, the head carried well up, and the chest full and prominent.

HEAD, as round as possible, both from the nape to the beak wattle, and from eye to eye. The prevailing fault in the head is more or less flatness on the crown, and there is often a prominence at the back, which is undesirable. The forehead sery broad and prominent; the cheeks full.

BEAK, short and thick, the upper mandible as much as possible in the same curve as the head, so that, from the nape to the point of the beak, a half-circle should be described. The under mandible should approach the upper in consistency as much as possible, and fit closely to it; or, in the language of pigeon fanciers, the beak should be "boxed." The only difference between the $\mathrm{Owl}$ and Turbit, according to Moore, was in the beak, the upper mandible of the former being " hookt over like an owl's, from whence it has its name." The upper mandible in all pigeons is inclined to overlap the under 
more or less, and in the race under review it sometimes does so very considerably, from the formation of the head and beak; but I have found that, when it does, it is generally owing to a weak under mandible; while I have also found, that birds so formed are much troubled with vermin, being unable to keep themselves free from them, like Short-faced Tumblers whose beaks have been distorted in the process of head-shaping. The upper mandible of a pigeon has no independent motion, and is not jointed like that of a parrot, which can move its upper beak at will, so that, though much hooked, it can lay hold of anything small. The best under mandibled African Owls I have seen were not much hooked in the upper beak. The picture of an Owl in the Treatise of 1765 does not represent a bird with a hooked beak; nor has Mr. Ludlow, in Mr. Fulton's book, represented any of this family of pigeons so. The mandibles may never be completely boxed, but, in my opinion, the nearer they are so the better. The mouth should be.wide, and deep in the head.

Exe should be large, prominent or bolting, and placed in the centre of the head. The irides are hazel or "bull" in whites, and orange or yellow in coloured birds.

BeAK ANd Exe Wattues vary considerably in birds of the same family, A moderate amount is natural, and therefore allowable. The beak wattle thickens with age, and, so long as it does not stand out much beyond the curve of the skull, cannot be objected to. Neither the beak nor eye wattles should be rough and lumpy, otherwise they give coarseness to 0 wls and their varieties.

GULLET is a thin, transparent skin filling up the hollow of the throat, commencing on the under mandible, as far forward as the feathers grow, and reaching, in a good bird, to the top of the frill. This property can be seen, whenever a bird is hatched, if the beak be gently raised. The gullet is about the last part of a bird to be covered with feathers; and I may say here, that pigeons of the $\mathrm{O}_{\mathrm{wl}}$ tribe feather differently from 
all others, the sides of the breast feathering before the frill makes its appearance, and the centre of the breast remaining bare for about three weeks from the date of birth. The longer and deeper the gullet is the better, and, if it is not present in a bird when hatched, it never comes later. With age it generally thickens at its junction with the lower mandible, forming there a little lump, which is, in fact, a jew-wattle. This gives a fulness to a bird's appearance; but it cannot be got on a young one. Gullet, to a more or less extent, is seen sometimes in various kinds of pigeons; but the $\mathrm{O}_{\text {wl }}$ tribe (in which the Chinese Dewlap Pigeon may be included) and the Mahomet are the only races in which it is regarded as necessary. In them it is a beautiful property, giving that breadth across the neck in profile which adds so much to their appearance, and without which they fail to look well.

FrILL is the property in which the African Owl is most deficient. Great numbers of these birds have been imported entirely wanting in this necessary adornment, while the most have far too little of it. Such frills as those on the wonderful Whiskered $O$ wls are never seen on African Owls. The frill ought to spread out on each side of the breast, the more of which it covers the better, and is formed by the feathers composing it growing out in all directions. It ought not to lie in any particular position, but stand out from the breast roughly, as I have attempted to show in my drawing. The more confusedly the feathers forming it grow, the better it looks. Where it joins the gullet it ought to divide, and spread to right and left, and so form the figure of a cross. Hence this race is sometimes called "Cross" Pigeon in Germany (Kreuz Taube). None of the Owl tribe, with the exception of the Whiskered $\mathrm{Owl}$-to be afterwards described -are yet complete in this beautiful property, and when they will be it is impossible even to guess, for their standard of perfection is one so complex, and difficult of attainment, that to have all of it fairly good is as hard a task as the 
whole fancy presents, excepting the standard of no variety whatever.

LEGS AND FEET, small and neat, bright red in colour, and free of feathers, from the hocks down.

CoLour.-Self-coloured, white, blue, and black. It will be noticed that Moore has mentioned these colours as those of the Owl, and that other colours were not mentioned till thirty years later. The majority of African Owls, as imported, are whites, and black and blue pieds, whole blues and blacks being, however, not uncommon. The number of splashed birds that come would favour the idea, from their appearance, that no regard is paid to the matching of them for colour. The only apparent regular marking is white, with black or blue tail; but nothing comes oftener from a pure white and whole blue or black than such marking. From the fact of my having bred pure white, whole blue, and black and blue splashes, from a black-tailed white cock and blue-tailed white hen, I think that, if Mr. Baily was not well informed when he told me how these pigeons are bred in Tunis, very little regard to colour must be given in matching them. No reds or yellows have been brought here, so far as I know, nor even mealies, the origin of these colours; but I would expect to find an occasional mealy were I to visit the native place of these pigeons, as such a natural variation is very likely to have been produced. I once had a blue hen, an imported bird, from Messrs. Baily, with most of the frill white. I consider this marking a very suitable one for the coloured Owl, and I am inclined to think that the bird I had was not a mere chance production, for I find notice of the same marking in Neumeister's book among the Frilled Pigeons, all of which, whether self-coloured or Turbit-marked, go by the name of Mövchen (seagulls) in Germany, so that the blue-shouldered variety seems to have given the name to the entire family. The blue Tunis Owl is often of a good deep sound colour, with jet black bars, and is also frequently of a smoky tint, the evident result of having 
been crossed with the black. The black is generally of a dull colour, showing bars of a darker hue, and is never of such intensity, nor accompanied with such lustre, as is seen in other varieties. I should imagine there are blue chequers among these pigeons, but I have not seen any. The colours of the African $\mathrm{Owl}$, as far as known here, are, therefore, the original blue, and albinos and melanoids, as found in most, if not all, domestic animals, and black and blue splashes. But although the artificial colours, the result of extended breeding on the part of fanciers, are unknown in this breed, form is sometimes found in such perfection, that, with the exception of more frill, this bird may be said to be as complete a pigeon as we know of.

Small size being a desideratum in the Tunis Owl, and the hen in all kinds of pigeons being less than the cock, the former generally comes nearer perfection than the latter for this reason; but what gives a better idea than anything else, of the high state of breeding found in this variety is, that the hens are equal to the cocks in all that goes to make a perfect bird, a most rare thing to find in other varieties of frilled and gulleted pigeons. I have an idea that red and yellow African Owls may yet appear, for the interior of Tunis is not as yet much known to Europeans; and I cannot but believe that if, as Mr. Baily told me, exporters have to employ a man about the mosques to catch such fine birds as we have already received, others, showing still more of the breeder's skill, must be in existence in the hands of fanciers.

\section{The English Owl Pigeon.}

The English Owl, as it existed at the time the African variety was introduced, could not be found so good in $\mathrm{Owl}$ properties as at present, so that the difference between the two varieties was then more marked than it is now. The improvement has been effected by crossing with the Tunis breed. There are not two standards for Owls as regards shape of head and beak, gullet, 



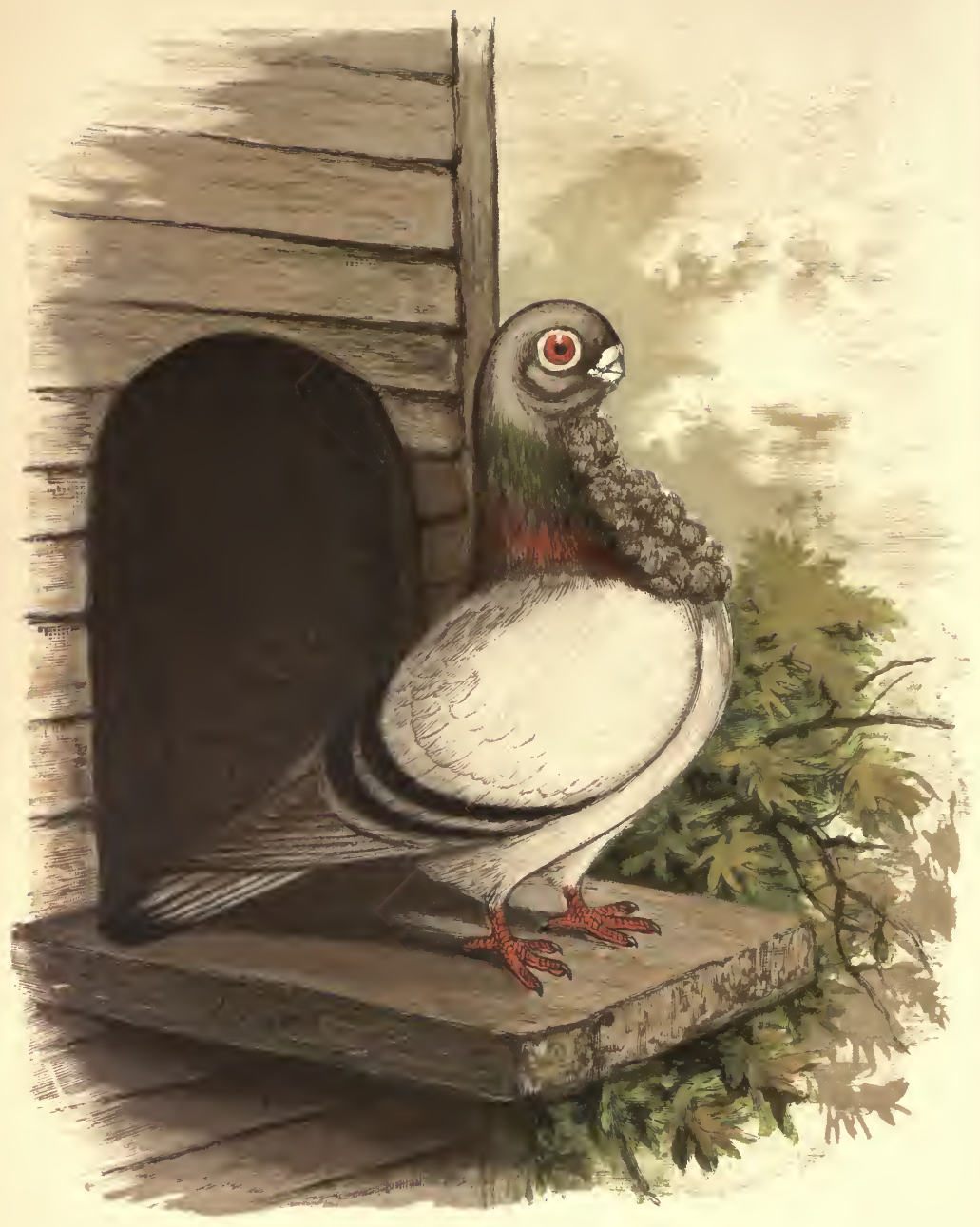

THE ENGLISH O WL. 
frill, \&c. The difference between the two varieties consists only in size, and greater variety of colour.

Size. - The English Owl is wanted as large as possible, so that it may present a contrast with the African, as the Pouter does with the Pigmy Pouter. To gain size, it is said that crossing with the Short-faced Antwerp, which is of Owl descent, has been resorted to, and that the Barb has been used to give breadth of skull.

CoLour. -The English Owl is self-coloured, and exists in white, black, red, yellow, dun, blue, silver, and in various off colours, as mealies and chequers. Splashed Owls are not regarded, except it may be locally, or as stock birds. The blues and silvers are chiefly fancied and bred, and the best English Owls are of these colours. The blues should be of a deep, sound, rich colour, even in tone, with broad black wing and tail bars, and dark hackle, lustrous with green and purple hues. The silvers should be of a light creamy dun body colour, with very dark dun wing and tail bars, merging into black, and with lustrous dun hackle. White rumps in both are faulty, but cannot be regarded in blue and silver pigeons as blemishes of the same degree of magnitude as when occurring in blacks, reds, or yellows. The chief defects are indistinctness and bad colour of wing bars, ticked or slightly chequered wing coverts, sometimes showing indications of a third bar, and too light body colour and hackle, through crossing with the powdered blues and silvers; these latter, as varieties of the blues and silvers, require special mention, as they have a history of their own.

As the author of the "Treatise on Pigeons" (1765) says, regarding blue Owls, "The lighter they are in colour, particularly in the hackle, the more they are valued," a distinction not recorded by Moore thirty years previously, and as the true Mahomet Pigeon, unknown to Moore, was welldescribed by the author of the above quotation, I have thought that it had been made use of in his time to produce the colour known as powdered blue, as it certainly has of late years. 
The powdered blue and silver English Owls of our day were, however, bred in London about the year 1855, according to a letter from Mr. Harrison Weir, appearing in the Live Stock Journal of 1878 , who states therein that they were produced by himself and the late Matthew Wicking. When requested by me, in the same publication, to state how they were bred, if it was no secret, Mr. Weir made no sign. I have considered that the appearance in London of a pair of true Mahomets, about the year 1850, as mentioned by Brent, had some connection with the powdered Owls which appeared soon afterwards. That they sported from common blues is very unlikely; but from the long, mousey faces, and freedom from gullet, of those I have seen, they might have been bred from the German Ice Pigeon, which has much of the same colouring as the Mahomet. The late Mr. James Wallace, of Glasgow, with the Mahomet Pigeon already mentioned by me, and a blue English Owl, bred beautifully powdered birds, wanting the frill, which he recovered by the next cross of these half-breds with blue Owls, though at the expense of some colour. These quarter-bred Mahomets were equal in powder, and better Owls, than any of Mr. Weir's breed I ever saw. Some mystery seemed to be made out of the production of the powdered Owl in London; but there is really no mystery in the matter, for, even if it was not produced as I say, similar coloured and better Owls can be so produced. That the same kind of Owl existed in the last century seems likely; and, in the year 1824, Boitard and Corbie published the following in Paris: "Pigeon Cravate Anglais ; Columba Turbita Anglica ; En Anglais, Turbit Pigeon:.... plumage entirely amethyst blue, with black bars on the wings. This pretty variety is very pure, for it cannot be crossed with another variety without entirely losing its colour." Like the German writers, Boitard and Corbie do not distinguish between Owls and Turbits-all are Pigeons à Cravate. The above, though called the Turbit, cannot read as referring to a Turbit-marked pigeon; such 
marking, with blue and other coloured manteaux, they also describe. I understand it to mean a self-coloured, very light blue pigeon, that could not bear crossing without losing its peculiar colour, which is the characteristic of the English powdered Owl. It may be, that the French had, in 1824, such pigeons as are described in our Treatise of 1765, which they called Cravate Anglais, and that from them were descended the London powdered Owls of late years.

So long as the powdered Owl was considered of an original colour it was worth while preserving; but as it is, at its best, only half-powdered, in comparison with the Mahomet, I see no reason why any special value should be put on it, more especially as it is inferior in Owl properties to the best blues and silvers. The colour, in perfection, should be the same as that of the Mahomet in the blue, and the silver should bear the relation to it that the common silver does to the common blue, the same as in the Ice Pigeons. As for red and yellow English Owls, they are inferior to the blues and silvers, probably on account of no African Owls of these colours ever having reached us with which to improve them. I have seen and had red and yellow Owls of good colour, however, and they probably represented the breed as it existed in England when the Treatise of 1765 was written. Between twenty and thirty years ago I had one pair of yellow mottled Owls, marked nearly as exactly as the show mottled Tumbler ought to be. I received them from Glasgow, but they were imported from the Continent, I believe. Whole-coloured Owls, excepting the wing bars, which are white, are mentioned by the German writers; also white ones with coloured tails, and coloured ones with white tails.

The standard of the Owl requires a smooth head, as a crest, and especially a peak crest, from its formation, takes much from the roundness of the head. Still, peak-crested Owls are not uncommon, and I have known very good ones bred from the best blue English Owls. Self-coloured, peak-crested, black, 
red, and yellow $\mathrm{Owls}$ are sometimes called whole-coloured, or solid Turbits; but the name Turbit is usually, and ought only, to be applied to white Frilled Pigeons with coloured shoulders.

The English Owl being wanted large, the hen generally fails in this respect from looking so well as the cock, for the same reason as in the African breed she often excels him; but in conformation also, she is generally, as in all other frilled races, except the African, much inferior, so that good hens are rare.

The English Owl is a variety which is now widely spread and greatly fancied, so that choice specimens are very valuable. There is little doubt that it owes all its quality to the African breed, which began to be imported into this country about thirty years ago, as already mentioned. There were no such English Owls as exist now twenty years ago, and much still remains to be done with them; for, until both cocks and hens that will bear comparison with the little foreigners in all but size are produced, they cannot be said to have reached their best state.

Hitherto the supply of African Owls from Tunis has not failed; but, should it do so, it is a question if they would continue to exist in this country for any length of time, on account of the delicacy of the breed. If they could not be kept up here, unless by constant importations, it is an additional reason why the large English Owl should be cultivated.

During the past few years, since the first edition of this book was published, great progress has been made in breeding powdered English Owls, chiefly by Mr. Stephen Salter, who informed me that he had used a half-bred Damascene, or Mahomet, to improve the colour. There are now in existence some powdered blue Owls nearly up to the standard of the common blues and silvers, and greatly superior to the breed that existed thirty years ago, regarding which, Mr. H. Weir has lately said that $I$ was mistaken in supposing that he 
bred his from the Damascene cross; but he still refused to say how they were bred. Those who take any interest in the question, should procure a copy of the new German illustrated pigeon work, "Mustertaubenbuch," and study the coloured illustration of Italian Owls therein, which are very well drawn.

\section{The Italian OwI Pigeon.}

Herr Prütz, in his "Mustertaubenbuch," now publishing, describes this variety, and gives both woodcut and coloured illustrations of it. The former represents plain-headed, frillbreasted, white birds, with coloured shoulders, flights, and tails, the latter carried high, and suggesting some connection with the Modenese Triganica Pigeons. The coloured plate represents two beautiful pigeons, one of which is blue, with blackish shoulders, the feathers of which are laced with white; the other is of the colour of a Mahomet. Both are plainheaded, with good gullets and frills. From Italy, then, the English powdered Owls of thirty years ago may have come; certainly, Herr Prütz's illustration has a remarkable likeness to those that used to be seen here.

\section{The Whiskered Owl Pigeon.}

This beautiful variety is of a medium size between the African and English Owls. Those I have seen were either white or blue in colour, with the usual black wing and tail bars. In head, beak, gullet, and general $\mathrm{Owl}$ properties, they could only be called passable, and could not be compared with the African variety. In frill, however, they were extraordinary, their breasts being covered with it from butt to butt of wings. The frill also reached up to the throat, and, dividing to right and left, was continued almost round the neck. I understand that in some of them it actually goes quite round the neck. These pigeons are called Chinese Gulls in Germany (Chinesiche Mövchen), and the only account of them I have found is by Neumeister and Prütz, as follows : 
"The Chinese Gull is somewhat larger than, but not so finely built as, the Egyptian Gull (Tunis Owl). The beautifully arched head is smooth, and not so angular, but rounder; the strong bill, somewhat crooked in front, is a little longer, in the form of a Parrot's beak, with which bird this pigeon has much resemblance in many respects-as, namely, in bearing, neck, and eyes. The eye is large, the iris orangecoloured, and very lively; the breast is full, the neck short and powerful; the pinions reach to 12 millimètres from the end of the tail; feet and toes are short and smooth. The jabôt (frill) on the breast and neck is the most peculiar thing about this pigeon. When it stretches its neck the crop is invisible, as it is hidden behind the so-called cravatte. This cravatte is formed by several rows of feathers, which stand upwards, on the under side of the neck, lying closely to each other from one side to the other. Proceeding from this, the jabôt goes downwards to the middle of the breast, forming a rosette. The feathers from this point radiate to all sides, reaching almost over the breast, and offering a beautiful sight. This pigeon became known in Germany only a few years ago, and therefore the price for a pair is still rather high. It is found in blue, with black bars, black, yellow, silver-grey, and sometimes white.

"J. Destriveaux, a fancier in Paris, who accidentally came into possession of a pair, originated the name Chinese Gulls. There exists a certain obscurity about the descent of these pigeons; however, they probably owe their origin and propagation to chance. Some ships laden with sugar, returning from the East Indies, brought, shortly after 1850, a large number of Chinese Gulls to Tilsit and Memel, and that in so excellent a plumage as nowadays is no more to be seen. From thence, these pigeons came into the South of Germany, and disappeared from the market for a long time, until, later, they re-appeared in Paris, from which place the distinguished fencing-master, A. Prosche, in Dresden, got possession of some, 



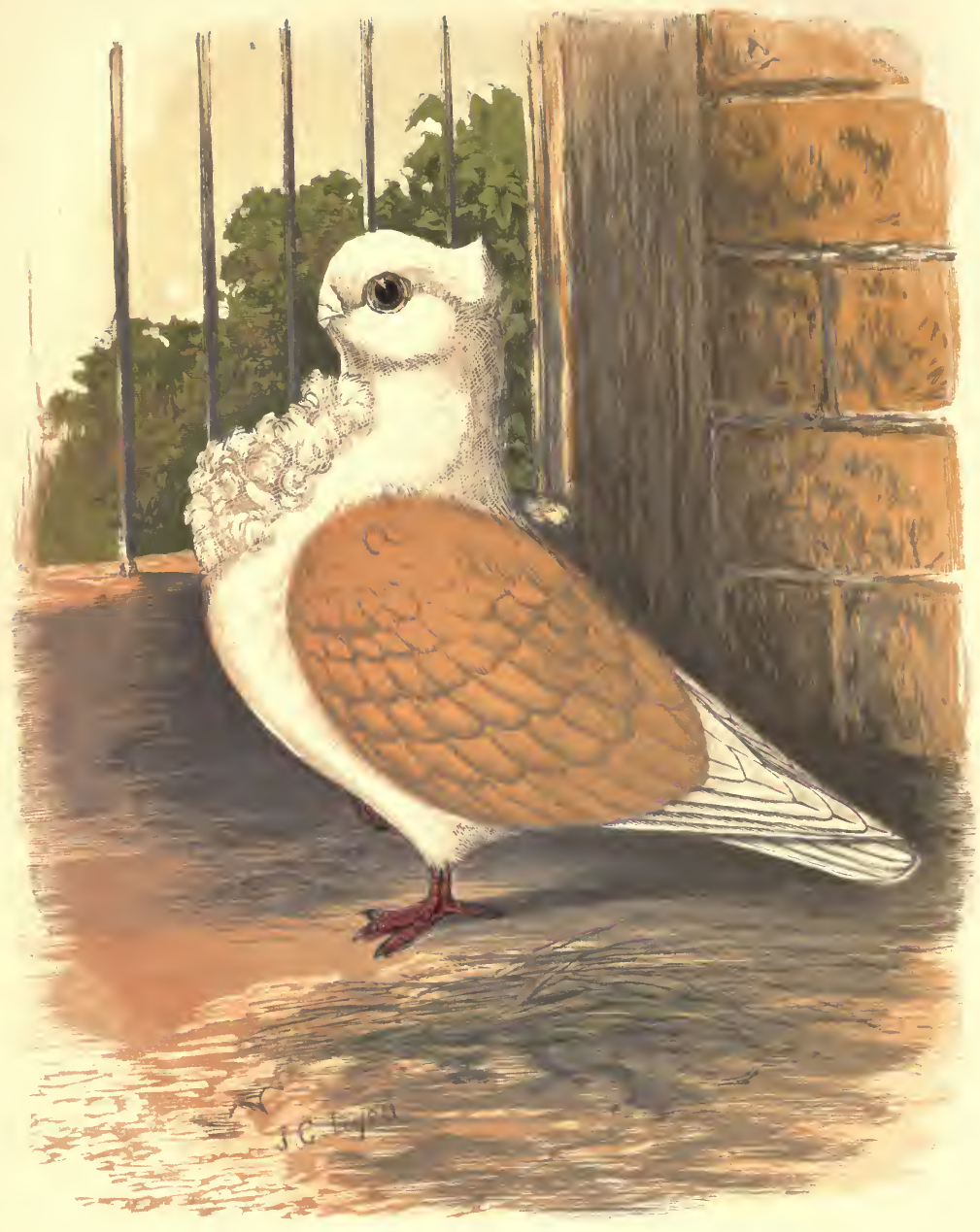

THE Y ELLOW T T R T T. 
and has bred them successfully for years, as well as the Egyptian (Tunis) Owl."

From the above, it seems that the Whiskered Owl cannot now be found in such perfection as when first imported. The interesting account of the breed makes one wish to know more about it, and especially from whence it came. I have seen many varieties and types of fancy pigeons in India, but none of the frilled race, except such as were imported from Europe. There is nothing to connect the re-appearance of the Whiskered Owl in Paris with the Tilsit and Memel birds. The Paris birds may have been a fresh importation, and the name given them-Chinese Pigeons-may not be a mere fanciful one. However good the first arrivals were-and, if better than such as I have seen, they must have been very choice birds-there doubtless exists, in the hands of fanciers somewhere, a race of most extraordinary pigeons, compared to which all other races we know of are much inferior in jabôt, or frill.

\section{The Turbit Pigeon.}

The origin of the name Turbit seems to have puzzled our old writers on pigeons. It is evidently derived from the Latin, as was first pointed out in the eleventh, and last edition, of "Moubray's Book on Poultry," edited by Méall and Horner, and published in 1854. That the Turbit alone, among all the varieties of fancy pigeons known in England 200 years ago, should have had a Latin name, has caused me to think that a frill-breasted pigeon of some kind may have been introduced into this country by the Romans as the Columba Turbata. Willughby appears to have been the first writer to use the word, and though Turbat would have been the more correct form, any vowel would have rendered the sound of the name. The name Turbit, therefore, signifies a frilled pigeon of any colour, though we now use it only for those that are white, with coloured shoulders.

There are differences of opinion regarding the formation of 
the head of the Turbit. I have shown what the old writers say about it, and that Moore particularly says it should be round; while the earliest picture of a Turbit I know of-that in the Treatise of 1765-shows a pigeon rather rounder in head than the $\mathrm{O}_{\mathrm{wl}}$ in the same book. It is a fault too often found in frilled pigeons-the choice African Owl included-to be flat on the crown; but, although there is no difference specified in any old book between the Owl and Turbit head, some modern writers have held that the latter should be frog-headed. When or how this idea originated I cannot trace, unless it was derived from what was published in Paris, by Boitard and Corbie, in 1824. They say, in their introductory notice of the Frilled Pigeons: "Their beak is short, and head toad-shapedthat is, in the prettiest varieties; the eyes are extremely projecting in the upper part of the skull, where they form two well-marked protuberances, as also the bone behind the head, which forms a third, which gives their head a sort of resemblance to that of a toad."

I have seen the frog or toad head even more marked in some birds than this description, the head having a decided hollow between the two rising eyebrows, and this was in the case of some birds bred from a Turbit and African Owl. I dislike this style of head, and hold, with many fanciers, such as Fulton and Caridia, that, the nearer the head of a Turbit approaches that of the ideal Owl, the better it is. The Owl type is that most difficult to obtain, for it can seldom be got very good; it is the result of careful breeding, and never comes by chance.

The ideal standard of a Turbit-in my opinion, and in that of many more who are devoted to this beautiful pigeon-is, therefore, exactly the same as that of the African Owl, except as to colour and crest.

Size.-The Turbit, as it exists, is, even in small specimens, very much larger than the African Owl. I prefer it small, but would not have it so at the sacrifice of any of its properties. 
Generally speaking, it is as large as the clean-legged flying Tumbler. To reduce it materially in size can only be accomplished by crossing with the African Owl, its undoubted relative. I have been doing this for several seasons, with much greater success than I had hoped to anticipate, and I believe others are now adopting the same method. Such experiments, however, take long to complete; and as all the Frilled Pigeons are with me more delicate, and apt to succumb under that dread disease, inflammation of the bowels, than any other race of pigeons, I have several times been thrown back after making a decided advance. In crossing with the African Owl, my object has been, both to reduce size, and improve the Turbit in head and beak; in fact, to have a peak-headed, colouredshouldered, African Owl, which would be, in my opinion, the perfect Turbit.

Many Turbits are neither peak nor shell-crested, but something between the two. Some of these are merely the faulty produce from pure bred birds of either variety; but crossing the two kinds is apt to result in badly-crested birds. They ought, therefore, to be kept distinct, for the mane is diffcult to maintain in perfection.

Colovr. - The Turbit should be entirely white, with coloured shoulders. The wings, including the scapular feathers, with the exception of the primary flight feathers, ought to be coloured. Nothing is easier to get fairly good, and yet nothing is more difficult to breed to a feather, than this beautiful marking. The flight feathers, generally ten a side, though occasionally only nine, may often be got right; but to have freedom from foul thighs, vent feathers, or underbody, on the one hand, and no white feathers on the wings, except the flights, on the other, is the great difficulty. I consider that a bird quite clean below, with white wing butts, looks worse than one free of white on the wings and a little foul below, because bishoped wings are very glaring. With a full set of white flights we almost invariably find 
the short feathers covering the spurious wing white, thus giving a white edging to the margin of the wing when closed. To get the spurious wing coloured, which prevents white butts when the wing is closed, is a very difficult matter, if the bird is quite clean below. Formerly black and blue Turbits had coloured tails, and they often breed young ones with the tail partly so; but the coloured tail is no longer considered desirable. Reds and yellows do likewise; but, in that case, the tail feathers are usually only of a weak half tint. It is only lately, owing to keen competition at the numerous shows, that great attention has been paid to proper marking. Not only in this country, but in others where Turbit-marked frilled pigeons are fancied, foul thighs and vents have been very prevalent, simply because these natural faults have not been considered of grave account. It is no easy matter to eradicate such mismarking when breeding from the strains that have it; but, once this is got rid of, it is comparatively easy to maintain clean thighs and vents in many of the produce.

The Triganica Pigeon, in addition to coloured wings, has the head, tail, and flights coloured; and although it is common enough to find this variety foul below, like the majority of Turbits, I found it easy enough to breed many quite cleanthighed and vented birds of this breed, by commencing with such as were free from these faults.

I have stated that I have crossed the African $O$ wl and Turbit, and have mentioned my reasons for doing so. I commenced by matching a very fine green-glossed black Turbiteen cock to a pure white African Owl hen, and from their young ones I selected a very round-headed, white cock, with about half of one shoulder black, which was as much colour as any of the produce possessed, some being pure white. I mated this bird, which was smooth-headed, like both his parents, to a good peak-headed black Turbit hen of Mr. Roper's breed. She was not quite clean below, being 


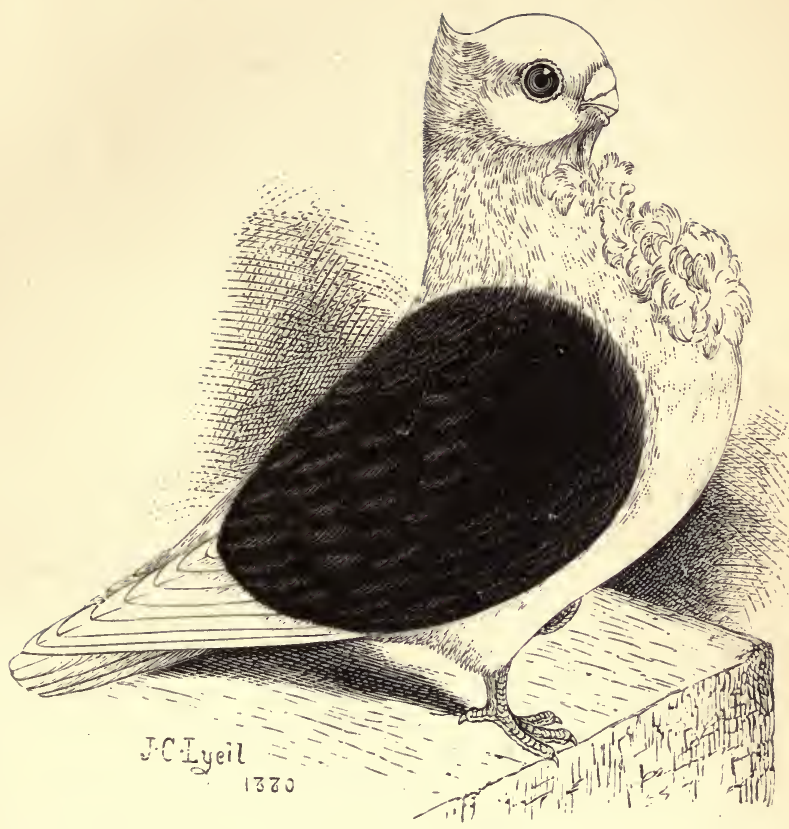

THE BLACK TURBIT. 
foul-vented. The best of the young ones from this pair was a smooth-headed, almost completely Turbit-marked cock, of small size, and good properties all over. I matched him to his mother, and they bred several very small, peak-headed birds of first rate quality, so well marked that, when lifted up by the wings, some of them did not show one foul feather below. The black Turbit hen mentioned above was descended from the hen of the first pair of black Turbiteens imported about 1872, which were probably superior to any since brought to this country. I went on breeding this strain of birds, and again crossed them with a hen I got from Mr. Roper, till, in 1883, I succeeded in winning the cup, at the Crystal Palace Show, for the best young Turbit of all colours, with a very glossy black cock. Since then, these birds and their offspring, in different hands, have won many prizes at all the principal shows.

The Turbit is found in all the twelve barred, chequered, and solid colours, mentioned on page 49, but of these only five-the black, red, yellow, blue, and silver-are chiefly bred and shown.

The black colour, when in perfection, is strongly glossed with a green metallic lustre. Even when decidedly bad in colour, a black Turbit shows any foul feathers on thighs or vent so glaringly, that they tell strongly against it in competition with others, such as blues and silvers; and I have often seen specimens of the latter colours, which were no. better than blacks opposed to them, preferred because they appeared cleaner-thighed and vented, whereas they were in reality very much fouler.

Red and yellow Turbits were, at the best, only fair in colour. before the introduction of red and yellow Turbiteens from Smyrna. A great improvement has been effected by crossing with these beautifully-coloured pigeons, and though their feathered legs, head markings, and plain heads, take much careful breeding to eradicate, it has been done. So much has 
crossing with the Turbiteen been resorted to during the past few years, that I imagine few fanciers could say for certain that their red and yellow Turbits, if fit to hold their own in strong competition, were of pure English blood. Reds and yellows, when anything like right in colour, show any foulness on their under body very distinctly; when poor in colour, foul thighs hardly show on them; hence, I have known them called clean-thighed and vented when so hopelessly foul on these parts that, had their colour been even fair, they would have been unfit to put into a pen. Black, red, and yellow Turbits, especially black, when of rich colour, have their eye wattles of a reddish tint.

The blue Turbit has also been crossed with foreign blood, but not to any great extent. The best birds of this colour generally show a sexual difference in colouring, the hens being of a duller and more smoky tint than the cocks. The colour in cocks is sometimes very clear and delicate; so much so, that white will hardly show on it, and this light blue is even preferred by some. It is a matter of taste, but I prefer a darker and more vivid blue, like the colour of the wild Rock Pigeon. The delicate blue is too near an approach to silver, and I think the more pronounced the colours, the better they look from an artistic point of view. Such a beautiful rich blue as I have had in Triganica Pigeons would only require to be seen to have its superiority allowed. The wing bars of the blue should be of a deep black, broad and distinct.

The silver Turbit should be of a creamy dun, with bars of the darkest glossy đun, merging into black. To have really black bars on the silver ground is, perhaps, not an impossibility, but I have never seen them. When I consider that bright red and yellow bars can be seen on rich blue Triganica Pigeons, black bars on a silver ground may not be incompatible with Nature. So very light in colour are foul thigh and vent feathers on silvers and the light blues, that it is scarcely possible to distinguish them, and so they often 
pass undetected. I consider that the silver colour ought to have bright golden dun wing bars, with neck and tail to match. In a Turbit, this colour, confined to the shoulders, is ineffective, being so light. Darker wing coverts, and bars merging into black, are, therefore, more effective for a Turbit.

Red and yellow barred-winged Turbits, as well as duns, strawberries, and the various chequers, are usually called off-colours, and are not cultivated. The barred colours are, however, very pretty, and if bred for, could be improved by selection. To each of the solid colours, black, red, yellow, and dun, there is a corresponding barred and chequered colour, as referred to in the Chapter on "Colours." It is, doubtless, by the judicious blending of all of them, that so many variations are found in the colours of foreign pigeons. But however intricate and effective are chequering, spangling, and breaking up of colour, as in the Smyrna Satinettes and Triganica Pigeons, they do not fill the eye like black, red, and yellow, when these are in perfection.

There are also pure white Turbits, inasmuch as such are occasionally produced, by way of albinism, from colouredshouldered birds. They might as well be called Crested Owls, unless they are of the decided frog-headed formation, which no Owl ought to be. It is a manifest mistake, however, to allow them to compete with coloured-shouldered birds, whether frog or Owl-headed. The best so-called white Turbits I have ever seen were very thick-headed, down-faced ones, of the Owl type, with broad shell crests.

The Peaked Turbit.-This variety should have a long mane running up the back of its neck, quite unbroken, and ending in a finely-pointed peak crest. There is much to contend with in getting the right peak and mane. The peak ought to reach higher than the crown of the head, but it is rarely more than level with it, and often set so low down in the neck, that the bird would look better if altogether smoothheaded. As the peak crest is formed by the feathers on the 
nape, and those on each side of it, all drawing to a fine point, the bird cannot look so round-headed as the Smoothheaded Owl. A very good peak is sometimes seen with no mane on the back of the neck, and this form has generally a deep notch below the peak. Many of the Turkish Frilled Pigeons are of this style, which is considered very faulty in the English Turbit. The peak must not incline to either side of the neck, but rise straight from the middle of the nape.

The Shell-CRested TURBIT.-This variety, according to Neumeister, is bred largely in the North of Germany. It is not uncommon in this country, but is not so generally fancied and bred as the Peaked. The shell ought to extend quite round the back of the head, and be of the cupped form, as in the Swallow Pigeon: The more extensive, even in outline, and firm in texture it is, the better. There ought to be no mane on the Shell-crested Turbit.

\section{Turkish Frilled Pigeons.}

Mr. H. P. Caridia, of Birmingham, was the first to import the various kinds of Eastern short-faced Frilled Pigeons into this country. This was, perhaps, about twenty years ago. For a long time, however, there was not much known about them, as he only kept them for his own pleasure, and parted with very few of them. They became better known after he wrote the account of them in Fulton's Book of Pigeons; but, for many years after that, they were not much kept by breeders here, notwithstanding their great merits as fancy pigeons. During the past few years, however, a change has taken place, and they seem at last to have taken hold of the British fancier, as very large classes of them have lately been exhibited at the principal shows.

The varieties are the Satinette, Blondinette, Domino, Vizor, and Turbiteen. The first and third appear to be old breeds; the others, more recently established. I am not aware who gave the first three their names; but $\mathrm{Mr}$. Ludlow, of Bir- 


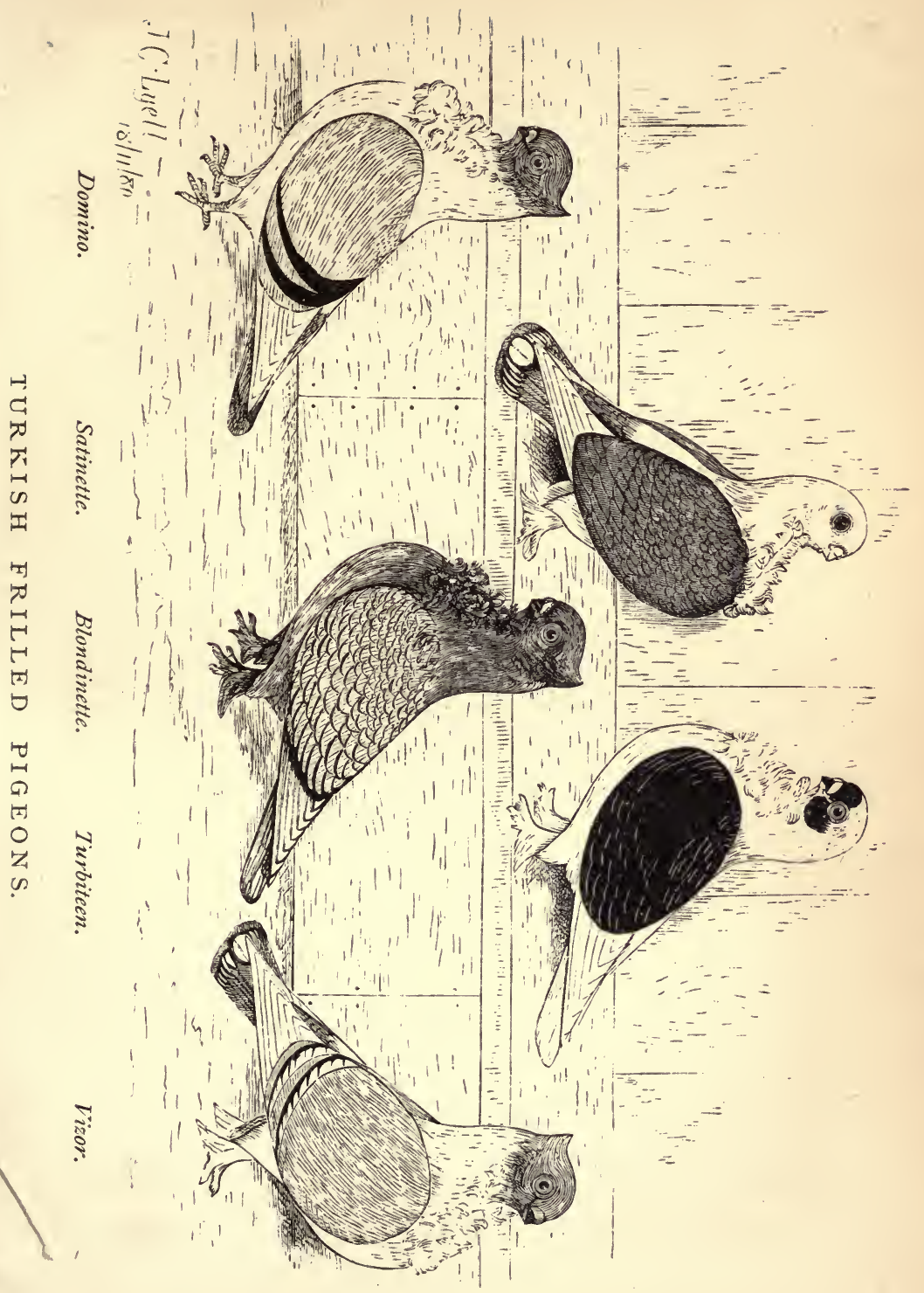


mingham, has said he named the last two. The differences between the five kinds consist in colour and marking, in plain or crested heads, and in smooth or feathered legs and feet. They vary a little in size, but, for the most part, are larger than British Turbits. They are generally excellent in carriage, sometimes very round in head, full in gullet, and short and thick in beak, which is generally well-boxed, and not overlapping at the point. From a side view, their heads are sometimes well-arched; but they are often deficient in great breadth of skull and forehead, and, leaving size out of the question, are seldom or never up to the standard of the best Tunisian Owls in head properties. When crested, the correct standard for all the varieties is a needle-pointed peak, standing as high as possible; not springing from a mane, as in the Turbit, however, but divided from the feathers at the back of the neck by a notch. The peak is sometimes seen very good on these pigeons, though lopsided and half shell crests are common enough. Mr. H. P. Caridia considers that "no maned bird can possess a close-fitting, well-pointed crest," in which opinion $I$ think he is mistaken. When feathered on the legs, the correct style is what is sometimes called grouse-legged, or stocking-legged-that is, with legs and feet completely covered with rather short feathers, so as to show no bare skin. The feathers on the legs should be long. enough to stand out somewhat at the sides of the feet, but the toes ought to be covered with very short ones.

The great majority of the coloured-shouldered, white-bodied varieties are very foul on thighs and under body. It appears, from what Mr. Caridia has written, that no attention is paid to this in the East, and that they are allowed to be foulthighed. I have never, however, seen him point out definitely how the colour must be disposed on the under body, nor can I believe, were competition to arise in Turkey, as it exists here, that foul under body would be any longer recognised there. With a standard of only seven white flight feathers, 
and foul thighs allowed, as he says is the case in Turkey, foul wing butts are no difficulty whatever. The Triganica Magpie has coloured flights, in addition to all the marking of the Vizor and Domino. Foul under body is not allowed in Triganicas, according to the Italian writers, and I have both seen and bred them without a foul feather underneath. I think, therefore, that it only requires the attention of Turkish breeders, to enable them to eradicate foul under body in their pigeons, and they certainly require it.

The irides in coloured-headed Turkish Frilled Pigeons should be orange; in white-headed ones they should be dark hazel, as in our Turbits. Turbiteens, when heavily head marked, have sometimes orange eyes, which look very well. Many, however, have broken irides, which are decidedly faulty.

As regards the frill on the breast, the Turkish varieties are about on a par with our Turbits and Owls. They are certainly not, on an average, better than them. In this beautiful and distinctive property much, therefore, remains to be done for them, if we are to take the frill of the Whiskered $O$ wl as our standard.

\section{The Satinette Pigeon.}

This beautiful variety is grouse-legged, and usually smoothheaded, though a few have lately been imported with peaked crests. It is coloured-shouldered and tailed, and the rest of its plumage ought to be white. As for its wing marking, it ought to be similar to that of the Turbit, and foul under body, coloured primary flights, white secondaries, and white wing butts, are all as faulty in it as in the Turbit. In addition to the colour of the Satinette proper, there are several others found in the breed, some of which have received special names, while it wouid have been less confusing to have retained the generic name for all, prefixing a word to distinguish them, as, for instance, Blue Satinette, instead of Bluette.

The Satinette is an old breed, according to $\mathrm{Mr}$. Caridia, 
who says he has traced it back for 120 years, through three generations of fanciers. When he wrote the account of it in Mr. Fulton's book, about 1874, he said that an aged Presbyter in Smyrna, then upwards of eighty years of age, had bred them all his life, and that his father and grandfather had done so before him.

The ground colour of the shoulders of this pigeon, after it has cast its nest feathers, should be of clear pink-brown, or nearly of a flesh colour, each feather being laced round with lustrous purple-black; or the same with an inner lacing of reddish brown, making the plumage tricoloured. This is what $I$ consider the most beautiful marking; but it is not the only one. Some of them are chequered, at the extremity of each shoulder feather, with a triangular, or arrow-pointed mark, which often runs too large, and which, when blue in colour, as it very often is, considerably spoils the appearance of a bird. Small triangular chequers of purple-black are very pleasing on the fleshcoloured ground, and even small blue markings are pretty; but when the general appearance is more blue than fleshcoloured, the effect is spoiled. The tail and its coverts should be as in a blue chequered pigeon, and on the black bar, at the extremity of each primary tail feather, there ought to be a large round white spot, which gives a fine effect when the tail is outspread. The shaft of the tail feather should be dark throughout, and this has also a nice effect, running through the white spot.

The BRUNETTE bears the same relation to the Satinette as a silver does to a blue pigeon. Its ground colour should be of a silvery dun tint, each feather being laced or chequered with dark dun. Its tail is much the same colour as that of a silver pigeon, and the bar at its extremity should show the same large round white spot as in the Satinette. Its more correct name would be Dun-laced, or Spangled Satinette, according to the style of its marking. 
The Bluette, or Blue Satinetre, is of an even, clear blue on the shoulders, with white wing bars, which ought to be laced with intense black, and also have an inner lacing of a red or dark flesh colour. The tail is the same as in the Satinette, or a shade lighter.

The Silverette, or Silver Satinetre, should be of an even clear silvery dun on the shoulders, with white wing bars, laced round with dark dun; and if there is an inner lacing of buff or yellow, so much the better. This pigeon bears the same relation to the Bluette as the Brunette does to the Satinette. The tail is of the same colour and marking as in the latter, or a shade lighter.

These four varieties may be interbred occasionally; but, if it be intended to follow after the laced marking in the Satinette, the Bluette and Silverette cannot assist it. So many shades of colour appear in the breeding of Satinettes, that care must be exercised in the selection of stock. A bird with excessive lacing or spangling must be paired with one too lightly marked. This plan is, however, less likely to produce a large proportion of well-coloured young ones, than by pairing two birds which are themselves nearly of the desired colour. I think, if the breeding of Satinettes were to extend in this country, that either the clear flesh tint, evenly laced with black, or, in addition, an inner lacing of red or brown, making three colours in each feather, would come to be regarded as the only standard colour. Besides the foregoing varieties, there are also Blacklaced Satinettes, whose shoulders are white, each feather being laced with black. Towards the wing butts they appear more black than white. The principal tail feathers and their coverts should also be white, laced round with black.

\section{The Blondinette Pigeon.}

The Blondinette has been produced in recent years, according to Mr. Caridia, who has recorded its history. The Blondinettes bear the same relation to the Satinettes, in their several varie- 
ties, as the Schietti, or whole-coloured Triganicas, do to the Gazzi, or pied ones. I am not aware if every variety of colour in the Blondinette is represented in the Satinette, not having seen so many; but the same natural laws of variation of colour must affect both in course of time.

The SAtin Blondinetre is marked on the shoulders and tail exactly the same as the Satinette, and, where the latter is white, the former is of a dark blue; but its primary flights should have large oval spots on their extremities, making them, when closed, to appear laced. The colour which has gained most acceptance in this country is the clear pinky flesh ground, evenly laced with black, the flight feathers of which, when opened out, are also generally laced all round their edges, but with, usually, a strong brownish cast on their inner webs. There is, however, an immense variety of colour among Satin Blondinettes, many being heavily marked on the wing coverts with arrow-pointed blue chequers; but the inferiority of these, in appearance, is at once seen when they are placed alongside the laced kind. The nest plumage of the different kinds of Blondinettes is dull and heavy, the intricate markings and clear ground colour only appearing after the first autumnal moult. The bronzy flesh colour of the wing coverts often reaches up the back of the neck, which ought to be dark blue. The Blondinettes are grouse-legged, and generally peakcrested.

Brown AND SUlPHUR BLondinetTes.-Very pretty varieties are the red and yellow laced or spangled ones. The former is reddish-brown, and the latter sulphur-yellow, where the Satin variety is dark blue, and their shoulders are of the same colours, merging into white, each feather being laced, spangled, or chequered at the edge with reddishbrown or clear yellow. These varieties fall away in colour in tail and flights. I have not seen similarly shouldered Satinettes, but should suppose they could be bred.

Black Laced Blondinettes.-There are black and white 
laced Blondinettes, in which the head, neck, and under body are black, the wings, flights, and tail being white, strongly laced with black, dark towards the wing butts, and gradually lighter towards the tail, according to the size of the feathers.

The Blue Blondinette is of the colour of a blue pigeon, with tricoloured wing bars and white-spotted tail, the same as in the blue Satinette. Its primary flights ought also to have white oval spots on their extremities.

The Silder Blondinetre differs from the blue, exactly the same as these colours differ from each other in the Satinettes. There are also whole dark dun Blondinettes, with white wing bars, and spotted tail and flight feathers.

\section{The Domino Pigeon.}

The Domino is peak-headed, smooth-legged, coloured on shoulders and tail, and is marked on the head like a Nun. The colour of the head includes the peak crest, and comes low down in front, forming a bib. I have only seen one specimen of this variety, and I believe it is the only one of the pure original race which has appeared in this country. Its marking resembled that of my drawing of the Triganica Pigeon, except the flight feathers, which were white. It was imported by $\mathrm{Mr}$. Caridia, and was shown very successfully by Mr. Yardley, of Birmingham. It was blue in colour, with the usual black wing and tail bars. In a letter published in 1879, Mr. Caridia stated that the Dominoes, "though very scarce now, were in colours, blacks, blues, silvers with bars, duns without bars, and chequers of all these colours. There were also a few without the crest, and I possessed there [in Smyrna] some of these which were perfection." The bird I have referred to was of grand $\mathrm{Owl}$ properties, and its colour and marking were so good, that I venture to think, were such birds to be imported, they would take the fancy of pigeon breeders in this country before any of the other Turkish frilled pigeons. They 
appear, however, to be almost extinct, and it seems to me that it does not say much for those in whose care they were that such is the case. A prettier, and, at the same time, higher-class pigeon, than the solitary blue Domino, shown so often during the last few years, never presented itself to my eyesight. I cannot say how it was as regards clean thighs and under body; but its general appearance was very fine. Minor defects would only be regarded if the breed were plentiful.

\section{The Vizor Pigeon.}

This variety was produced by crossing the Domino with the Satinette tribe, the object being to have coloured-headed Satinettes. This has been partially accomplished, and I have seen some fairly marked satin and blue Vizors. The best of them were, however, somewhat peppered with white about the head, so that much still requires to be done in perfecting them. The Vizor should be completely grouse-legged, like the Satinette. It may be smooth-headed or peak-crested-the latter or choice, as it is an additional property. The colour of its head will, of course, be in accordance with that of its shoulders, viz., light blue in the Bluette-marked, and dark purple blue in the satin. Black-headed Vizors, with black laced shoulders and tail, would look very well, and will, no doubt, be produced if the Eastern fanciers are successful with the blues and satins.

\section{The Turbiteen Pigeon.}

According to Mr. Caridia, it is now between thirty and forty years since this much-admired variety was produced. He says it is a composition of the Domino, white Owl, and Oriental Turbit; but I cannot exactly understand the method of breeding which was adopted. I understand from his account, that the Oriental Turbit was marked as the British kind; and to employ a white $\mathrm{Owl}$ " to counteract and balance the colour of the black tail" in the Domino, appears a very roundabout process, when the Turbit of Smyrna was itself white-tailed. However, it seems a misfortune that Smyrna 
Turbits, marked according to our standard, with peak crest and clean legs, and with the blazing colour and grand $\mathrm{Owl}$ properties of some of the Turbiteens, should have been allowed to disappear in the desire for something new. Such pigeons would now be very valuable.

The Turbiteen is generally smooth-headed, but a few peakcrested ones have been brought to this country. It is grouselegged, and white in colour, marked as follows: The shoulders should be coloured exactly the same as in the British Turbit. The head markings are by no means well fixed in the breed, but are occasionally to be seen very good, according to the standard agreed on by fanciers, viz., a round, coloured spot on the forehead, commencing at the beak wattle, and of about the size of a shilling, and a similar spot on each cheek. There ought to be a distinct white line between the forehead and cheek spots, and the throat should be white, dividing the cheek marks. The whole face and throat is sometimes coloured in a heavily-marked bird, which is faulty.

The eyes should be orange for choice; they are often broken in colour, which is worse than being dark-eyed.

The Turbiteen is exceedingly foul-thighed in general, the only clean-thighed ones I ever saw being a few blacks that I bred myself; but they had white wing butts, which looked very bad. I have seen them with the feathers on the outside of the thighs coloured, and still white-vented, and white between the thighs. This approached to a specific marking, and may be what is wished for in Smyrna; but I have stated my ideas on this point already. I have seen a few black Turbiteens with black tails in addition to the usual marking.

The colour found in some of these birds is superb, and, though I have seen it equalled in other pigeons, I have never seen it surpassed. The black, red, and yellow leave nothing to be desired. There are also duns of various tints, some of them being of a lovely lavender shade; but this colour is apt to fade, and becomes dappled at the moulting season, till 
all the feathers are renewed. There are blues, silvers, chequers, strawberries, and bar-winged reds and yellows as well, according to Mr. Caridia. Most of these I have seen and bred, but they are of little beauty alongside the glossy blacks, reds, and yellows. The latter are full of the fatty quills about the root of the tail and vent referred to in the description of the Nurnberg Swallows. These feathers only shed, at most, the tips of their fibres, and many of them never break at all.

The standard of the Turbiteen, therefore, comprises all that is requisite in a Turbit, with the addition of feathered legs and face markings. The feathered legs give little difficulty, but they occasionally come with too little or too much leg and foot covering. The face markings cause much trouble, as they are comparatively new. Out of several scores of these pigeons which I have bred, when I kept them some years ago, only four were about right in face markings. They may be bred with small cheek marks, about equal on each side; but nothing less than the size of a shilling to that of a florin looks well. The black, red, and yellow may be interbred; but the first, with either of the last two, often produces a sandy, or strawberry, which, however, frequently throws back to good colour when matched with either a black, red, or yellow. It must not be supposed, however, that it requires no care to keep up colour in this breed. Many of them are bad in that respect when compared with the best; but even the second and third degrees of colour in Turbiteens would be highly valued in many varieties of pigeons, which shows how good they are in this feature. I never possessed an imported bird of this breed with a crest, but I bred a peak-headed one from a pair of smooth-heads. I consider the peak crest a fine property, and difficult to breed right, therefore valuable.

The upper mandible is generally coloured in Turbiteens, or at least tipped, according to the feather, white or flesh-coloured beaks being exceptional. There ought to be no hard blue, however, in the beaks of blacks, reds, and yellows; the black 
should have a black beak, the red a ruddy brown one, and the yellow, just enough colour in the beak to make it show.

\section{The Turkish Turbit Pigeon.}

Some Turkish Turbits of very superior quality have occasionally been brought to this country of late. I have seen some blues and blacks with broader and better filled up foreheads than any of the other Eastern frilled varieties. These have all been smooth-headed birds, some with feathered, and others with clean, legs. In all cases their tails were coloured, but none were face-marked in any way.

\section{Turkish Nomenclature.}

The following list of the Turkish names of the various Frilled Pigeons was published lately by Mr. C. E. Duckworth, of Liverpool, who procured it from the East:

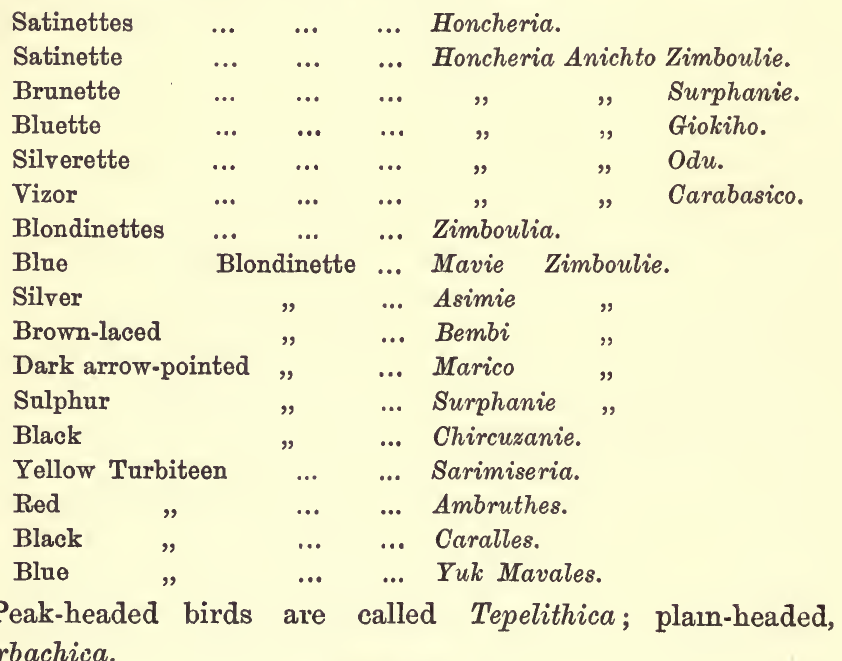
Carbachica. 


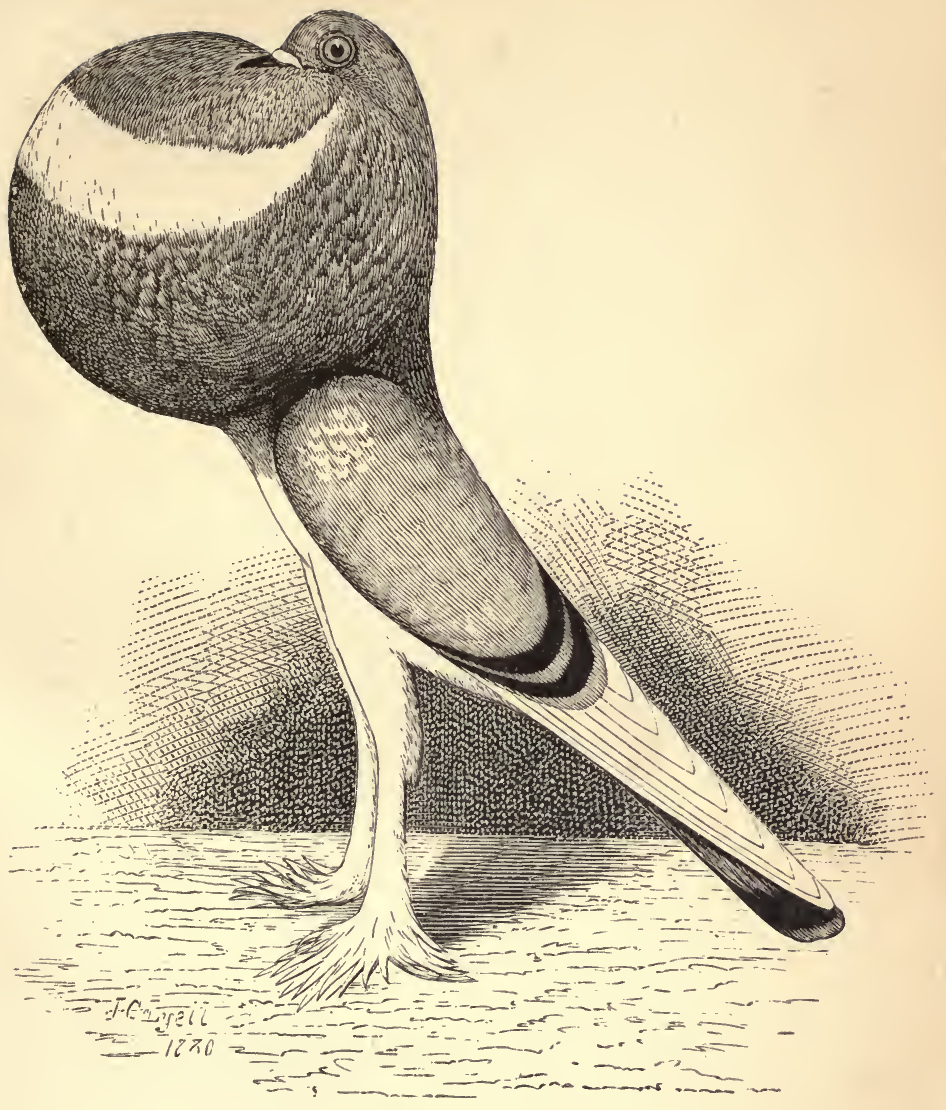

THE BLUE POUTER. 



\section{Chapter XXIII.}

\section{POUTING OR CROPPER PIGEONS.}

\section{The English Pouter Pigeon.}

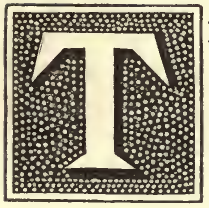

HIS noble pigeon has always been considered one of the finest varieties, sharing, with the Carrier, the premier position in the fancy since the time when we have any records on the subject. It is referred to by Willughby as follows: "Croppers, so called because they can, and usually do, by attracting the air, blow up their crops to that strange bigness that they exceed the bulk of the whole body beside. A certain Hollander informed Aldrovandus that these Kroppers Duve, as they call them, are twice as big as the common Domestic Pigeons, which, as they fly, and while they make that murmuring noise, swell their throats to a great bigness, and the bigger the better and more generous they are esteemed. Those that I saw at Mr. Cope's, a citizen of London, living in Jewin Street, seemed to me nothing bigger, but rather less than Runts, and somewhat more slender and long-bodied. These differ no less one from another in colour than the precedent" (i.e., Runts).

Meagre though this description be, we can learn from it 
that, 200 years ago, the London Pouters were large pigeons, long and slender in body, and with great crops. Sixty years later, however, we have Moore's succinct account of the origin of the English Pouter; but whether it was merely a traditionary account, or a narrative of facts within his own knowledge, cannot now, I fancy, be determined. First of all, he describes the Dutch Cropper as follows: "This Pigeon seems to be originally Dutch, being naturally thick, and its Name is derived from a large Bag, or crop of Wind, which they carry under their Beak, and can at Pleasure either raise or depress; they are thick bodied and short, their Legs are likewise thick, short, and feather'd down to their Feet; their Crop is large, but always hangs low; the Feathers on their Thighs hang loose, whereby they are said to be flagthigh'd; their Legs stand wide, and they seldom play upright; they are gravel Ey'd, and generally very bad Feeders; therefore, as soon as they have fed off their soft Meat, it is proper to put their young ones under a pair of small Runts, Dragoons, or Powting-horsemen, which may be kept as Nurses for that Purpose. There are of all Sorts of Feathers in this Pigeon, and the Dutch in breeding it take a very great care; for as soon as they have fed off their soft Meat, they put the young ones under others to nurse, and then separate the old ones, placing them in different Coops, and feeding them high with Hemp or Rape Seed for a Month, then turning them together; and by being very hearty and salacious, they breed Pigeons with very good Properties: from whence we may observe, that wou'd Mankind be like abstemious, their Progeny might be more compleat both in Body and Mind. These are the Pigeons that are most apt to gorge, if not kept constantly supplied with Meat and Water."

Moore commences his description of the English Pouter thus: "This Pigeon, which was first bred in England, and is therefore call'd the English Powter, is originally a mixt breed between 
a Horseman and a Cropper, and by matching their young ones over and over to the Cropper, Experience teaches us, it will add a wonderful Beauty to this Bird, and raise in it the five following Properties." Though Moore does not say what kind of Cropper was used for breeding the English Pouter, the inference is that he referred to the aforesaid Dutch variety, which is, in fact, the only Cropper he describes. His description of what constituted a good English Pouter in 1735, is, indeed, excellent, so far as it goes; and though he does not go minutely into the appearance of the bird, his account of it, had nothing been added by the author of the Treatise of 1765, would give those who read his work to-day the idea that our Pouter is identical with the one he describes. During the thirty years following the publication of Moore's work, however, a considerable advance appears to have been made in the breeding of fancy pigeons, as I learn from the following, taken from the preface of the Treatise of 1765, page xiv.: "It is to be observed that the species in general, and the Almond Tumbler in particular, are, from great care and expence in breeding them, arrived to so great a perfection, and so different from what they were twenty or thirty years past, that if a person who had been a fancier at that period, and had quitted the fancy, and not been conversant therein during the intermediate time; was to give his opinion now, he would be apt to condemn them, for no other reason than because they are not like what used to be thought good when he was in the fancy before; for instance, the Powter was formerly bred with thin legs, and void of feathers on them, which by the present fanciers are in no esteem, and called by them naked and wire-legg'd, who now endeavour to breed them with strong substantial limbs, and well feathered."

One of the set of eight old oil paintings of fancy pigeons which I am fortunate in having acquired, and which I have before referred to (see page 178), represents a magnificent. black-pied Pouter cock of the kind stated by the above- 
mentioned writer to have been fancied in Moore's time. As this picture shows a bird quite bare in limb, with the exception of a few very short feathers down the outside of the leg, and with none whatever on the toes, I think it, as well as the others, must have been painted about the time Moore wrote his book, for they are all uniform, and evidently the work of the same artist. The pictures representing the other pigeons being life-size, I suppose that of the black-pied cock to be the same; and although I have occasionally seen a bird in life standing as high as he does, it has been but seldom. He is $14 \frac{1}{4}$ in. from the crown of his head to the soles of his feet, and must have measured about $20 \mathrm{in}$. in feather. He is short of bib, and his rose pinion -might have been dressed, had the artist meant to depict a well-marked pigeon. I think, for this reason, the picture is a portrait. I can scarcely believe that such a pigeon could have been produced, in the way Moore says, in a short period of time, for the immense crop and intricate marking would take long to fix after a cross with the Horseman; and then, Willughby's description of the Pouter, such as it is, written about sixty years before Moore's, is extant. At the same time, when a drawing of a model Pouter is made, quite devoid of crop, there can be seen in it much of the shape of the thoroughbred Carrier, as anyone may prove for himself; so that it is extremely likely that the union of such a bird as Moore's Dutch Cropper and the Carrier would result, after a long, careful breeding, in such a bird as the English Pouter. We find that, with age, certain Pouters develop a good deal of beak and eye wattle, though birds of the same family vary greatly in this respect. If this be not derived from a remote cross of the Carrier, either direct or through some of the long Runts which likewise possess it, it must have-developed itself in the Pouter race in the same way as in that of the Carrier. There has arisen lately, in Germany, a theory that the English Pouter might have been derived from the Pomeranian Cropper, 
the appearance of which I shall describe, and the arguments connected with which I shall discuss, when I come to write about it. In the meantime, I shall describe what constitutes a perfect English Pouter, which, even on the Continent, where many varieties of the family exist, stands confessedly at the head of them all, and by many in this country is considered the finest, noblest, and most beautiful of all pigeons.

As will be shown, the great run on the Almond Tumbler, about the middle of last century, was the cause of the Pouter being to a great extent neglected in London; and the fancy for it appears to have languished from that time, till at last the breed nearly disappeared thence. About the year $\mathbf{1 8 3 0}$ Scotch fanciers began to breed this pigeon, and ultimately got it almost entirely into their own hands. At that time, some of the linen manufacturers of Dundee brought home with them from London-which place they were in the habit of visiting annually by way of trade-many fine Pouters, which have been described to me, by those who remember them, as stylish birds, good in colour and marking. At the same time, or soon afterwards, fanciers in the West of Scotland also began breeding Pouters, and from 1860 to 1870 the fancy for them may be said to have reached its zenith in Scotland. Soon after the Glasgow pigeon shows were established, or about 1860, English fanciers went into Pouter-breeding, but for some time were obliged to draw their supplies of stock birds from Scotland, the breed being next to extinct south of the Border. As records will show, this was so much the case, that the Pouter was for years often quite unrepresented at the annual exhibitions of Metropolitan pigeon societies, the members of which confined themselves to the Carrier, Short-faced Tumbler, Dragoon, \&c. At the present time, Scotland and England may be said to divide between them the breeding of Pouters; but in London, the very home of this variety, and where it was undoubtedly produced, so far as I know, there are still few who keep them, with the exception of the large dealers. Irish 
fanciers have, to some extent, bred these noble pigeons for several years past, and they have succeeded in producing many fine ones, as is well known. Some of the best I have bred myself I can trace back to birds I bought from the late Mr. Montgomery, of Belfast, whose stock was founded chiefly on Scotch blood.

It has been usual to write of the English Pouter as having five properties-viz., crop, length of limb, length of feather, slenderness of girth, and feather. Authorities are divided on the respective value of these properties, and also as to which is the most valuable. It is no use, however, to argue over this, as a Pouter must be fairly well up in all points to have any chance of winning at a good show, the bird which fails conspicuously in any one of them having little chance in keen competition. In describing the Pouter, I shall restrict its properties to four-viz., size, shape, carriage, and feather.

SizE.-The Pouter must be a very large pigeon, very tall and upstanding, the larger the better. It will be found in breeding, that the great difficulty is to get it of gigantic proportions, combined with quality in shape, feather, and carriage. Under-sized Pouters, otherwise very good, are common enough; but, as soon as a certain size is reached, there is not only a very great difficulty in rearing a bird, but it almost invariably fails in shape and carriage. When size and shape are got, the difficulty of producing good colour and the intricate marking at once decimates the number fit for exhibition. Those whose experience in breeding pigeons has been confined to self-coloured varieties, such as Carriers and Barbs, know nothing of the difficulty there is in producing colour and marking, combined with size and shape, in the Pouter. I believe the Pouter was formerly the most valuable variety. Moore says: "I have known eight guineas refused for a single Pigeon of this breed"; and the author of the Treatise of 1765 quotes a sale of Pouters by auction, at which two pairs realised $£ 13$ 6s. and $£ 16$ 16s. respectively. He says that 
two pairs from the same sale were afterwards sold for thirtysix guineas by private contract. I believe $£ 60$ is the highest price which has been paid in late years for a Pouter.

SHAPE.-My drawing of a Pouter represents the shape or outline of a good bird in position. The head and beak do not constitute fancy points, because, generally, there is nothing abnormal about them. As I have said, beak and eye wattle are sometimes developed to an abnormal extent, but generally when the bird is past being fit for exhibition. Allowing for size, the head and beak of the Pouter may be said to be of the common type.

The chief and most important part in the shape of a Pouter is the crop, towards the setting off of which to the greatest advantage all its other parts are designed. By the time a young bird has moulted its nest feathers, the breeder will have an idea if it is likely to be well-developed in this respect. The cocks are generally better in crop than the hens, though, in young birds, the latter generally show it sooner. The crop ought to be very large, and as round as possible from every point of view. It ought to be carried with freedom, and fully expanded when the bird is in show.

Slenderness of girth, or smallness in waist, shows off a good crop to the greatest advantage, and is one of the principal points contributing to fine shape in a Pouter. While most Pouters thicken in body after two years of age, I have known some retain their slender girth for six years, and never be shown without winning. Fanciers should strive to obtain birds of the latter type, the only one which a breeder who has passed through his novitiate has any pleasure in keeping.

Next to a good crop, the limbs are the most important points about the shape of the Pouter. They ought to be long, properly placed in the body, well-shaped, and rightly feathered. Limb is measured from the joint of the thigh, first above the hock, to the point of the nail of the middle toe. A limb measuring in this way 7in. is extra long. Some years ago, I 
visited the lofts of more than thirty Scotch and English Pouter breeders, and all the really 7in.-limbed Pouters I saw on my journey could be counted on the fingers of one hand. Since then, however, a great improvement has been made in this respect, and birds measuring $7 \frac{1}{4}$ in., and even $7 \frac{3}{8}$ in. in limb, have been bred. It is usual, either intentionally, or from ignorance of how to measure, to overstate the length of limb in Pouters about a quarter of an inch; but this extra quarter sometimes makes a great difference in the value of a bird. A fancier once wrote me that he required his cock Pouters to be 7in. in limb, and his hens $6 \frac{3}{4}$ in.; but when I visited him, he could not show me a bird out of thirty measuring so much. Some birds wear down their toe nails very much; in others, living under the same conditions, the nails grow out extra long. Neither form is fairly to be taken into account in measuring the limb; the length of an average toe nail may only be included; but neither form affects the height of a pigeon. The difference in length of limb between the cock and hen Pouter is about $\frac{1}{4}$ in., so that $6 \frac{3}{4} \mathrm{in}$. in a hen is as good as 7in. in a cock. I measure the limb of a Pouter on a marked board projecting from the wall, placing the nail of the index finger of my left hand in the joint of the left thigh of the bird, and bringing it exactly to the corner of the board; then, stretching out the limb with my right hand, I can find the exact length to $\frac{1}{16}$ th of an inch. Others who measure without assistance, hold the pigeon by the back in the left hand, place the point of the index finger of the right hand on the joint of the thigh, and then, bringing the limb down the palm of the hand, ascertain the length from the natural marks on their palm. This is a true way to measure if one remembers what signifies such and such lengths on his hand, but not otherwise, as I have often found. Of more importance, however, than actual measurement of limbs, is their position in the body, and their shape. They ought to be placed far back, so that there remains a good length of body between 
them and the crop. It is only birds so formed that can be very tall. The limbs ought also to be placed closely together, and, when viewed from the front, continue to approach each other down as far as the hocks; then, gradually separating, the feet ought to be as far apart as the thighs are at their junction with the body. The hocks must closely approach, but not touch, each other, otherwise the pigeon cannot walk gracefully. In profile view, the limbs must form a very obtuse angle at the hocks; on this depends very much the height of a bird. I have shown in my drawing, as nearly as I can, the correct shape of the limbs from this point of view.

While pigeons generally are in-toed, the Pouter must turn his feet decidedly out. It is quite unnecessary to describe all the faults in shape of limb usually seen in Pouters, every other form from that described being faulty. Limbs too straight and stiff, or too much bent and crouching, are frequent faults, as also are those set too far forward in the body, or widely placed, the latter often appearing quite bowed at the thigh from a front view. A Pouter should show all his limbs as far as the thigh joint; but many have this joint concealed in the feathers of the body, their thighs lying close to their body, like a runt's, instead of standing well out. Finally, there is the way the limbs ought to be feathered. The correct style is known as stocking-limbed, or with the legs entirely covered with short, soft, downy feathers. These feathers may overhang at the hocks as much as shown in the illustration. The feathers on the toes must, however, be very long, spreading out from each foot for $3 \mathrm{in}$. or $4 \mathrm{in}$. For a short time after the annual moult these toe feathers remain perfect in some birds, if care has been exercised; but they never remain perfect throughout the season, and usually get broken before they are full grown. They give such birds as have them a very fine appearance, but very few are naturally furnished with them in perfection, if the limbs themselves are just completely stockinged, and not over-feathered. Pouters proper 
as apart from small Croppers, are not now found entirely barelegged, the least amount of leg covering seen showing about half the leg bare, or with short feathers on the outsides of the limbs and on the toes. This is how the portrait of a Pouter is represented in the Treatise of 1765, which shows the gradual improvement in this respect from Moore's time. Pouters are now found from half leg-feathered to rough-limbed, some of the latter having coarse hock feathers reaching to the ground, and toe feathers over 6in. long. Such leg-feathering quite impedes graceful movement; but as it often comes in birds otherwise excellent, these are bred with others under-feathered in limb. In matching stocking-legged birds together, the produce is rather inclined to come barelegged, and it is annoying to find what are otherwise the best young birds so. Rough limbs have, and, it is likely, always will have, a place in every loft. As a matter of individual taste I dislike them very much, and greatly prefer thin-limbed birds, as they are much handsomer, more graceful, and have greater freedom in movement. It will be seen what a heavy tax on the Pouter breeder this matter of legfeathering is of itself. All else may be about right, but it is three to one against the limbs being properly feathered.

Length of feather, or, the length from the point of the beak to the end of the tail, is next to be considered in the shape of the Pouter. This is ascertained by holding the bird in the left hand; then, by placing the index finger of the right hand under his beak, and the thumb at the back of his head, he can be stretched out to his natural length, and measured against a marked board as before. In this way some birds measure 20in., which is a good length. I once saw one $21 \mathrm{in}$. full, but he had one feather in his tail an inch longer than the others, and which was, consequently, of no value, but rather a fault. I have often measured two Pouters and found them the same length, though the flights and tail of one were a full inch longer than those of the other. The birds 
were differently formed, one making up in neck what he lost in feather. I think this may be some slight proof of the Carrier cross, the greater length of neck enabling the bird to stand higher, and giving room for greater development of crop. Short-necked birds, whose length depends on flights and tail, have little style, and can never have fine carriage. Mere length from beak to tail should never have been made a property in the breed. Pouters may be too long as well as too short. What they ought to be depends entirely on the set and apparent length of their limbs. There are, at present, three too long for every one too short. A Pouter which has 7in. limbs, of the proper shape, and rightly placed, and which has a good long neck, can afford to measure 19in. from point of beak to tip of tail, and no more. A bird measuring 20in., however long in neck, requires limbs $7 \frac{1}{4}$ in. long, and of the very best description, to enable him to stand properly.

The next excellence in shape of a Pouter, supposing him to be standing in position in a show-pen, or on the ground, is to be hollow-backed, the opposite of which-being hog-backedis a most serious defect. His wings must be carried close to his body, and well up, so as to show his breast and belly in profile. Drooping wings, which conceal this outline, are very faulty, and generally hereditary. His flights must always be carried over his tail, and reach nearly to the end of it; they ought to be broad, and not narrow. The tail should be carried very near the ground, but not touching it; it ought never to be carried high, which is a great, though common, fault. Many of the best Pouters I have seen were split-tailed, having their tails in two equal divisions, this being more noticeable when the birds were in the hand than when at liberty. I bave heard old fanciers say that the split-tail is a mark of high breeding, and also that long hairs on the breast of a Pouter were proof of good blood. What is known as a fish-tail, or one split in two, and diverging at the points, is, however, very undesirable. Pouters often have extra tail feathers, as many as fifteen 
primaries being common. Several strains have also an extra primary flight, and I have had many with eleven flights a side.

CARRIAGE.-Having stated what constitutes good shape in a Pouter when seen standing still in a show-pen, or on the floor of his loft, I now proceed to describe the way he ought to carry himself when in motion. Regarding carriage, Moore expresses himself as follows: "Besides the five Properties before mention'd, there is another, which tho' not generally allow'd, will be found to be one of the best, I mean the Carriage." A Pouter which is not formed on good lines, and is not well-proportioned, can never look well, however he may carry himself; but, however well he may be shaped, it does not follow that his carriage will be right. Shape and carriage are, therefore, separate properties, as Moore states. The crop being well filled, the bird may, as he plays up to his hen, begin to "bufle," as Moore describes it, or to choke with wind by overfilling his crop. He then sets up the feathers at the back of his neck, and struggles from side to side, endeavouring to free himself from the encumbrance. Some birds are much addicted to this fault, and will, unless caught up and relieved, by their beaks being opened, and the air pressed out of their crops, remain in such a state for half-an-hour at a time. Some birds, though naturally possessed of capacious crops, never fill them, but allow them to hang down like an empty bag. These are said to be slack-winded, and, as Moore says, "appear not much better than an ill-shap'd Runt." A Pouter as he plays must keep himself perfectly upright, so that his head is perpendicular with his feet; he must on no account jump off the ground as he plays, but walk in a very dignified way, with his tail slightly spread out. A grave fault in carriage is jumping off the ground as he plays, which is generally accompanied by rumping, or setting up the feathers of his back and rump, the tail at the same time being tucked under him, and dragged along the ground. All these faults are 
often seen in birds which look well enough when standing still. Pouters ought, therefore, to be always judged in a large show-pen, to allow their carriage to be seen, and this is now generally done at important shows.

Feather.-The standard colours of the Pouter are yellow, red, black, and blue pied, valuable, both of old and at the present time, in the order named, when the birds are equal in all else. Pure white comes next, and then the other colours, pied according to the standard. The way in which a Pouter must be pied, or marked with white, is as follows: On his ground colour he must have a crescent or half-moon mark of white on the front of his crop, as shown in the illustration. This half-moon mark looks best when about 2 in. wide at its deepest part. It must finish off with fine points a little below the ears, and be set low enough on the crop to leave a large bib of colour between it and the beak. When this bib is wanting the bird is swallow-throated, and then, of course, there is no properly defined crescent at all. The ends of the crescent often reach to the eyes, finishing off too widely, and this is apt to result in broken or bull eyes. All pied Pouters should have clear yellow or orange irides, and beaks coloured according to their feather, though it may be mentioned that a flesh-coloured beak is not only allowed, but admired by some, in reds and yellows. Serious defects in marking are a blaze of white or snip on the forehead; and a ring neck, which is caused by the crop marking going right round the neck. On the shoulders, and well away from the butts of the wings, there should be a mottling of single white feathers, forming what is known as the rosepinion, which ought to be round, and cover a space $1 \frac{1}{2}$ in. in diameter. It is but seldom this beautiful mark is seen welldefined; the white feathers forming it are generally more or less in patches; and it is often represented by a single patch of white, which, when it reaches the edge of the wing, makes the bird bishop-winged, bishoped, or lawn-sleeved, which is more faulty than being entirely solid winged. The primary 
flight feather's must be white to the turn of the wing, or a bird will be foul-flighted; and if the outer flight feather alone is foul - a common enough fault-he will be sword-flighted. Next, if a Pouter be lifted up by the wings, he ought to be entirely white on the lower back, sides, belly, thighs, and legs. The tail, with its coverts, upper and under, must be coloured, being cut sharply off, the same as in the Nun; and the line of demarcation between the belly and breast must be sharply cut, or, as it is called, evenly-belted, as shown in the drawing.

In treating of the various colours found in Pouters, the yellow comes first, as being the most valuable when all else is equal. Cocks of this colour, really good in properties, are, and always have been, scarce, but good yellow hens are common enough. In reds, on the other hand, good cocks are plentiful, and really fine hens rather scarce. These colours have a great natural affinity, and are to a great extent interbred in all varieties of fancy pigeons. The colour of yellow Pouters is often pleasing enough, but is not, in reality, any nearer perfection than the majority of reds. The latter were formerly sometimes to be found of a glossy blood-red, but they became very scarce. Of late years, attention having been directed to them, much has been done in resuscitating the colour: but although I have seen, in my experience, many very good coloured reds, I never saw any that could compare, in general Pouter properties, with such as were only of a second or third degree of colour. There is a beauty and richness in the best degree of the red colour, as seen in many foreign pigeons, which makes it universally admired. The best coloured red Pouter I ever saw was a cock, bred in London, I believe, which was in the possession of Mr. Fulton, about 1870, and from which are descended some of the best coloured reds now in existence. This bird had not a white beak, which many consider essential in a red Pouter; his beak was of a dark ruddy hue. His tail was heavily stained with red, and his rump, or upper tail coverts, was as red as his wing coverts. I have always considered that 
it is owing to the poverty of colour in reds and yellows generally that they are unable to carry colour in the tail; but however white the tail may appear to be, an examination will always show that the feathers are not really white, like those in the tail of an all white Pouter, the shafts of the primaries being usually dark, and the under coverts grey, in the lightest tailed birds. When fine coloured red Jacobins, Turbiteens, or other red pigeons with white extremities, breed young ones with a foul tail feather or two, as they frequently do, these feathers are invariably weak in colour compared with their body feathers. The old breeders, finding it impossible to breed red and yellow Pouters with tails as dark as their wing coverts, probably tried to breed them with tails as white as possible, for it cannot be denied that a halfcoloured or stained tail does not look well. But then, if the white tail were imperative, it would be necessary to keep reds and yellows entirely distinct from blacks, for how could the black-tailed black, when crossed with the red, be expected to breed reds with pure white tails, and blacks with black tails? As a matter of fact, the best coloured reds and yellows are usually the most heavily stained in tail; therefore, finding that it is natural for them to be so, it should not prejudice them. I do not suppose any intelligent breeder would prefer a brick-red, with an apparently white tail, to a blood red with a dark rump and stained tail. There is no trouble with the tails of black Pouters; however bad their colour, they can always carry it to the end of the tail. In crossing black with blue Pouters, smoky blacks, showing wing bars of a darker hue, are a common result. This can be bred out in a series of crosses; but it ruins colour in reds and yellows to breed any such blue-bred blacks with them. The first cross between black and red, in all varieties of pigeons, however good in colour, often results in strawberry or sandy. These are of various shades, from such as are very light, looking as if sanded over, to such as are of a reddish strawberry, many of which are ticked with black. It is well known that some of the best black pieds have been bred 
from a sandy and a black. Blue-pied Pouters have always been favourites, and their colour being the most natural one, is easiest to breed good. Through crossing with artificial colours, blues have certain inherent faults, which must be carefully guarded against. Their wing bars ought to be jet black, but frequently come brown, when they are called kite-barred. Their wing coverts ought to be of a sound dark blue, neither smoky nor dusky, nor so light and silvery that the white rose pinions are with difficulty distinguished on them. White Pouters ought to have flesh-coloured beaks, and almost invariably have bull or hazel eyes. It may almost be taken for certain that a white Pouter, with its beak even slightly stained, has some coloured feathers about its head. A white Pouter with a dark, or partly dark beak, cannot rightly be shown in a class for whites, if the strict letter of the law be enforced; but such a bird is in much the same position as a white-vented black Carrier in a class for blacks. The difference between them is, that the Carrier's fault is hidden, while the Pouter's is very glaring. There was once a strain of orange-eyed white Pouters, but whether they were free of foul feathers I know not. Pure whites with orange eyes would look very well, and I see no reason why they should not, if ever shown, be allowed to compete with whites, for they would really have an additional property over bull-eyed birds, and one difficult to keep up, as in white Jacobins and white Tumblers. There would always, however, be a suspicion that they were foulfeathered somewhere; but so there is with other pearl or yelloweyed white pigeons.

The colours of Pouters other than yellow, red, black, and blue-pied and pure white, are generally called off-colours, and are not so valuable, neither are they generally bred for. This would not, however, long continue to be the case if the Pouter fancy were to extend greatly over the country, because increasing competition would cause breeders to cultivate some of the so-called off-colours, many of which are very beautiful. Dun, which is a standard colour in Carriers, was, till lately, 
very scarce in Pouters. I do not admire it myself, but it could be vastly improved if bred for. Duns are usually hens, but I have seen a dun cock. I have seen blue, red, yellow, and dun chequers. Of these, the blue is the only one which can be said to be common, and that not so much so as formerly. Such chequers as come in crossing the solid with the barred colours do not represent what could be made of them were they to be systematically bred for; but in the present state of the Pouter fancy I do not think there is room for them. The blue chequer is of two kinds-the light, and the dark, sometimes called black chequer. The light blue chequer is useful for improving colour of wing coverts and bars in blues, but it must be used with care, and with due regard as to how it was itself produced. This colour has always existed in the breed. The black chequer is sometimes so dark that it is apparently black on the wing coverts; but its tail is dark blue, with the usual black bar, and any foul feathers on its under body are greyish blue. This colour is often thrown by a pair of reds which have had a recent cross of black. It is a very good cross for black, and some of the most lustrous black pieds have been so produced.

The mealy Pouter has always been a favourite in Scotland, because many of the best birds ever seen have been so coloured. It is of various shades, the correct colour being the same as in the best show Antwerps. The neck and wing bars ought to be lustrous red, and the wing coverts of a clear light tint, but still decided enough to show up the rose pinion. The tail should be so light as to appear nearly white. Mealy has been continually bred with blue, and, consequently, most mealies are of a bluish tint, with a hard blue-black beak, instead of a soft-coloured, ruddy one. The mealy could be greatly improved by cultivation, which it is well worth, as are the other barwinged colours, the silver and yellow-mealy. Silvers are occasionally bred from blues, and are almost invariably, in my experience, hens. It is many years since I heard of a silver 
cock. The wing bars and neck of a silver ought to be of a clear bright golden dun, and not as black as possible, which would be a departure from the correct colour, and too near an approach to blue. The wing coverts should be of a creamy dun, and only dark enough to show up the rose pinion. The tail is of a medium shade of dun, barred with the same colour as that of the wing bars. The yellow-mealy ought to have bright yellow neck and wing bars; but the wing coverts in this colour are never so decided in colour as to show the rose pinion without the closest examination. The tail is so light as to appear white. Yellow-mealies are usually hens. The four solid colours-black, dun, red, and yellow-have, therefore, their corresponding barred colours, all of which are very beautiful when good; but in the present state of the fancy, I question if there is a sufficiency of breeders to give them the attention they require. In crossing the barred with the solid colours, chequers are produced, which are of service in breeding back to the barred, but detrimental to the solid, colours, which they tend to spoil, as is well known to those who understand breeding for colour.

To give a Pouter every chance in competition at a show, it must be carefully tamed and rendered familiar by systematic training. The difficulties which beset the Pouter fancier on this account are very graphically described by Eaton, in a note where he compares the ever-merry Norwich Cropper with the frequently-sulky and phlegmatic Pouter. Temper and disposition are very variable in Pouters, many of the best birds, when penned up, obstinately refusing to show off what good shape they possess. To send the average Pouter direct to a show from his loft or aviary, where he has been so far at liberty, without preliminary training, is to lose half the chance he may have of winning. The greater portion of the lives of some birds, even in the breeding season, is spent closely penned up; but most fanciers have neither accommodation nor inclination to keep their birds in this way, and only commence to train 



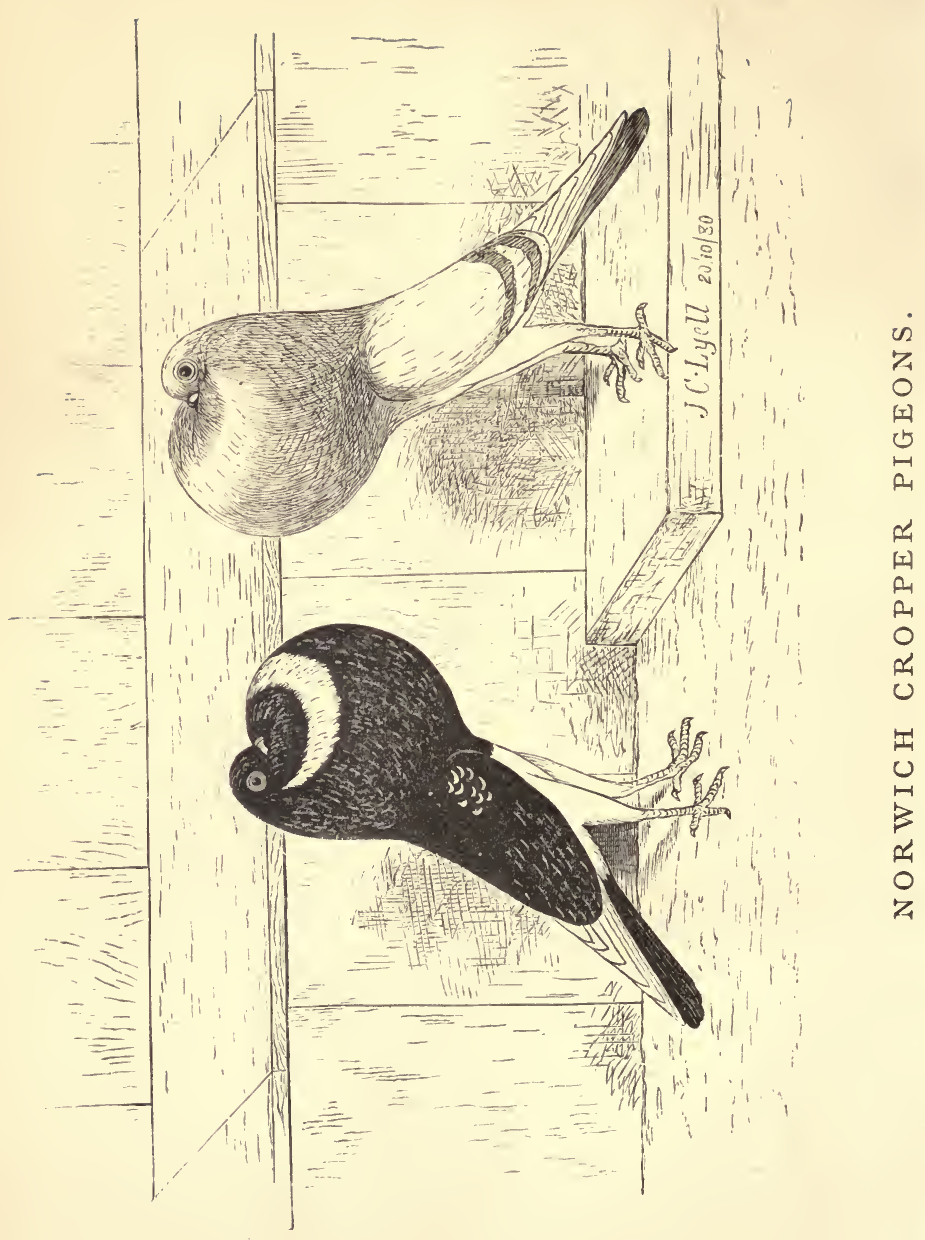


them after the breeding time. Every bird intended to be shown must, therefore, be penned up separately, the cocks being placed out of sight of the hens; and by often talking to them, using such expressions as "hip, hip, hoo-a, hoo-a," and at the same time snapping the fingers, a good-tempered pigeon soon becomes very tame, and shows up whenever called upon. A proud hen, that will stand quietly on the hand, may also be carried round before the cocks, which soon puts them on their mettle; and it is well to allow all penned-up birds out occasionally, so that they may stretch their wings. It is a bad practice to put one's hands in the pens and allow the birds to peck at them; this gets them into the habit of always jumping off their blocks, and coming to the front of their pens, on the approach of anyone. Pouters are naturally familiar birds, few of them refusing to become very tame if any trouble is taken with them; but perseverance and judicious treatment must be exercised, and kindness accorded to such as keep long shy and stubborn, for they will not be driven into showing. The late Mr. Montgomery, of Belfast, said: "Pigeons, like other animals, have got tempers; a sulky, bad-tempered bird will never be a winner in a show-pen, and I question the propriety of breeding from such birds, as they transmit this peculiarity as well as others." As to breeding from such, everyone will, of course, be guided by circumstances. I fear good Pouters will never be plentiful enough to allow any hardand-fast line to be drawn against breeding from one possessing a particular fault, if good otherwise.

\section{The Norwich Cropper.}

The Norwich Cropper is a pigeon which is found in its purity in the counties of Norfolk, Suffolk, and Essex. It has hitherto been undescribed by name in any book treating of English pigeons, though quite distinct from the large Pouter; but some allusions are made to it by Eaton, who was evidently sensible of its great beauty and fine style. The Uploper and 
Pouting Horseman are two varieties of Croppers described by Moore, at pages 37 and 38 of his "Columbarium." Of the former he says: "The Uploper is a Pigeon bred originally in Holland, its Make and Shape grees in every respect with the English Powter, only it is smaller in every Property. Its Crop is very round, in which it generally buries its Bill; its Legs are very small and slender, and its toes are short and close together, on which it treads so nicely, that when moving, you may put anything under the Ball of its Foot; it is close thigh'd, plays very upright, and when it approaches the Hen, generally leaps to her, with its tail spread, which is the reason the Name is given to it, from the Dutch Word Uplopen, which signifies to leap up. These Pigeons are generally all blue, white, or black, tho' I will not assert that there are no Pieds of this Species. There are but very few of them in England, and I have been inform'd that in Holland they have ask'd five and twenty Guineas for a single Pair of them."

Moore then describes the "Powting Horseman" as follows : "This Pigeon is a bastard Strain between the Cropper and the Horseman, and according to the Number of Times that their young ones are bred over from the Cropper, they are call'd first, second, or third bred; and the oftner they are bred over, the larger their Crop proves. The Reason of breeding these Pigeons is to improve the Strain of the Powters, by making them close thigh'd, tho' it is apt to make them rump, from the Horseman's Blood: They are a very merry Pigeon upon a House, and by often dashing off are good to pitch stray Pigeons, that are at a Loss to find their own Home; they breed often and are good Nurses, generally feeding their young ones well. I have known these Pigeons to be six Inches and six and a half in Legs; they are a hearty Pigeon and, give 'em but Meat and Water, need very little other Attendance. Some of them will home ten or twenty Miles." 
There is certainly much in the description of the Uploper which agrees with that of the Norwich Cropper, and, if Moore had said that it was marked like the Pouter, I should consider the breeds identical. The Uploper was, however, a self-coloured Cropper, and Moore could not say positively that there were pieds among the breed. While the shape, carriage, and general characteristics of the Norwich Cropper are well described by Moore in his account of the Uploper, its merry disposition and peculiar flight is, to a slight extent, mentioned in his description of the Pouting Horseman; but I cannot consider the latter to be the same variety, for it was evidently much nearer the Pouter in size, nothing like 6in. to $6 \frac{1}{2}$ in. in limb being found in pure Croppers. Nor have Croppers the slightest indication of ever having been crossed with the Horseman, their heads and beaks being of a pure Blue Rock Pigeon formation. That the Norwich Cropper, as it exists, is a much older and more constant breed of pigeon than the English Pouter I am well satisfied of, but I have no means of knowing how long it has existed, or how it was originally produced. Its marking, like the Pouter's, is found in several Continental breeds of Croppers, and the probability is, that both our Pouter and Cropper were gradually bred up from Continental varieties, perhaps brought here by immigrants in the Middle Ages. Gonzales, in his account of Britain (1730), says of Norwich: "The worsted manufacture, for which this city has long been famous, was first brought hither by the Flemings, in the reign of Edward III., and afterwards improved to great perfection by the Dutch, who fled from the Duke d'Alva's bloody persecutions."

The properties of the Norwich Cropper are size, shape, carriage, feather, and flight. Flight is, indeed, the chief point with many, who, though they may admire all the other points, consider them as of little consequence if a bird cannot perform well in the air. The German writers, Neumeister and Prütz, mention certain peculiarities in the flight of some 
of the Continental Pigmy Pouters; but that similar peculiarities are shared by a pure English variety, the fanciers of which have an old, though unwritten, code of rules to guide them, is not generally known. I learned much of what I know of these rules from Mr. Boreham, of Colchester, who graduated under an old Cropper fancier, the late Mr. Perry, of Great Yarmouth, who, I believe, died, at an advanced age, somewhere about 1871 . He was a Cropper fancier all his life, always kept up a stock of good birds, and was always willing to buy a good one. I had one old cock which belonged to him, from which the best I ever possessed descended.

Size.-I admire smallness of size in a Cropper, though not at any sacrifice of what goes to make up general good shape. Mr. Boreham, and others with whom I have exchanged ideas on the subject, agree with me in this, while many pay no regard to size if a bird flies well. The best Croppers I have seen were of a medium size; but there little difference in size between the largest and smallest birds of the pure breed.

ShaPe.-While it would take the best parts of several first-class English Pouters to make up such a pigeon as my drawing represents, I have seen many Croppers quite equal in outline to my illustration. The crop in these pigeons is, for the most part, far better developed than in Pouters, their respective sizes considered; indeed, many of these beautiful little pigeons have crops that would be considered good in a large Pouter. The crop, or bladder, as it is called in Norwich, is often as round as a ball, even filling out behind the neck, so that a perfectly spherical shape is sometimes attained; and in it, as Moore says of the Uploper, the bird "generally buries its Bill." The legs should be entirely free of feathers; but about half the number of Croppers I have seen or possessed have had some short feathers down the outsides of the legs and on the middle toes, which I consider so far faulty, the barelegged birds 
being very much smarter in appearance. However, as some of the best birds are slightly feather-legged, they are not to be discarded on this account. Flight being considered allin-all by many Cropper fanciers, feathered legs are of little consequence; at the same time, bare legs are allowed to be correct. I have not seen any pure Croppers completely stocking-legged, and the more they are so the worse they look. No doubt the Pouter is vastly improved by completely feathered stocking limbs; but, as I have shown, it was barelegged in Moore's time. The little Cropper having, however, quite a different carriage from the Pouter, feathered legs give it a clumsy appearance, and this is a settled question among many of those who keep them. The legs ought to be placed in the body as in the Pouter, compared with which the Cropper is straighter in limb, not inclining so much at the hocks. Slenderness of girth, or of waist as it is termed, is, of course, an admirable property in the Cropper, and is best seen in young birds, for they naturally thicken as they increase in age.

Regarding length of limb and feather in Croppers, I give the following measurements of birds I have possessed, some of which were bred in Norfolk and the adjoining counties, and some by myself. Ten cocks averaged $5 \frac{5}{16} \mathrm{in}$. in limb, and $15 \mathrm{in}$. in feather; they varied from $5 \frac{3}{16} \mathrm{in}$. to $5 \frac{1}{2} \mathrm{in}$. in $\operatorname{limb}$, and from $14 \frac{1}{2}$ in to $15 \frac{1}{4} \mathrm{in}$. in feather. Nine hens averaged $5 \frac{3}{16} \mathrm{in}$. in limb, and $14 \frac{1}{2} \mathrm{in}$. in feather; they varied from $5 \mathrm{in}$. to $5 \frac{3}{8} \mathrm{in}$. in limb, and from 14in. to 15in. in feather. There is, therefore, nothing like the variation in length of limb and feather among them that there is among Pouters. Their average length of limb, in proportion to their average length of feather, is also equal to what is only rarely attained in Pouters, which proves them to be more easily bred good in shape than Pouters. This is, indeed, the case, and many perfect models in shape may be found among them, which, of course, makes them very much less valuable. Good Croppers should feel no heavier in the 
hand than average-sized common flying Tumblers. They vary a little in size, like every other variety.

CARRIAGE.-Croppers have the most upright carriage of any variety of pouting pigeons I know of. They occasionally overcharge their crop with wind when young, but generally soon grow out of this habit. Slack-winded birds are almost unknown among them. So long as they keep in health they remain in show, and in this respect present the greatest contrast to large Pouters. For the most part they walk perfectly upright, their wings being carried tightly to their sides, and their flights never crossed at the points. They are, however, inclined to carry their wings rather low, thereby not showing so much of their belly and thighs in profile as is desirable. The flights ought not to reach to the end of the tail by nearly an inch, long-flighted birds being bad fliers. It is noticeable that the best flying varieties of pigeons, such as Blue Rocks, Tumblers, Dragoons, Antwerps, Triganicas, and Croppers, are all rather short in flights, long wings being impedimental to pigeons in their flight, whatever they may be to some other kinds of birds. The tail of the Cropper is carried as shown in the drawing, and seldom any higher. In stretching itself to its utmost height, it often walks on its front toes only, the back ones being off the ground, or just touching it, resembling in this respect the Uploper, regarding which Moore says, "that when moving you may put anything under the Ball of its Foot." Its style of movement so far resembles the Pouter's; but it is allowable for the Cropper to spring off the ground when playing to another pigeon, and this it often does in leaps of $3 \mathrm{ft}$. or $4 \mathrm{ft}$. across the floor, opening its wings on its way, and quickly closing them as it alights. This leaping, which is so ungainly in the Pouter, is executed with such expertness by the Cropper that it is pleasant to see them perform it.

Feather. - The Cropper is found in eight principal pied colours, all of which are admired, because they are all beautiful. Four of these are solid colours, and the others are their 
corresponding barred colours. Some of them being known, in the Cropper fancy, by different names from what is usual, I here give the Norwich and general nomenclatures:

\begin{tabular}{llll} 
English Podter. & & \multicolumn{2}{c}{ Norwich Cropper. } \\
Black & $\ldots$ & $\ldots$ & Black. \\
Red & $\ldots$ & $\ldots$ & Cinnamon. \\
Yellow & $\ldots$ & $\ldots$ & Yellow. \\
Dun & $\ldots$ & $\ldots$ & Mouse. \\
Blue & $\ldots$ & $\ldots$ & Blue. \\
Mealy & $\ldots$ & $\ldots$ & Dun. \\
Yellow-Mealy & $\ldots$ & $\ldots$ & Cream. \\
Silver & $\ldots$ & $\ldots$ & Cloth.
\end{tabular}

Black, owing to the practice of breeding the best flying birds together, regardless of their colour, is seldom seen very glossy in Croppers. Some of the best shaped and marked birds I have seen were of this colour. Black pieds are often quite free of objectionable leg feathering, and generally very good fliers. Cinnamons (reds) and yellows are scarce, and difficult to get. I have seen and had well-marked and fairlycoloured birds of both these colours. They are generally somewhat feather-legged, which makes them valuable to breeders of stocking-legged pied Pigmy Pouters. Mousecoloured Croppers (i.e., dun, as in Carriers) are not common. I was told that the late Mr. Perry, of Yarmouth, had a good bird of this colour, and as I bred one myself from a bird which formerly belonged to him, it may have been a descendant of the one he had.

The great proportion of Croppers are of the bar-winged colours, blue and dun (i.e., mealy) being the commonest. The blue ought, of course, to have black bars, but kite-barred blues are very common. The dun, like all mealy pigeons, has a light tail. Its neck and wing bars ought to be bright red, and its wing coverts of a clear light mealy, when it is called a miller dun. A red dun has the wing coverts of a reddish tinge. Between the miller dun and cinnamon there are many 
degrees of colour, according to the amount of red in the plumage. Cloth (i.e., silver) is one of the prettiest colours, and is of many shades. The neck and wing bars of a Cropper of this colour vary from a light dove-coloured to a hard blackish dun, a beautiful golden chestnut dun being the most pleasing tint. The wing coverts ought to be of a soft creamy dun, only dark enough to show up the rose pinion. This colour pigeon has, of course, a dun tail, barred to match the neck and wings. Cloths are mostly hens, a really good cloth cock being rather a scarce pigeon. Creams (i.e., yellow-mealies) are also usually hens, and very rare. They have, of course, light tails, and their colour is so delicate that a rose pinion is scarcely distinguishable on their wings. Their necks and wing bars ought to be rich yellow. The barred colours are very much interbred, the result being left to chance; in fact, it is usual to breed two good birds together, no matter what colour they are; hence, unless when breeding from a pair of the same colour-and not always then-it is impossible to predict what the young ones will be like. To improve blacks, yellows, and cinnamons, they ought, of course, to be kept distinct from the barred colours. As all the solid and primary barred colours are found in Croppers, the intermediate or chequered also exist in a great variety of shades, but are not generally liked or bred for. Pure white birds are occasionally seen, and whites with coloured tails are an old and favourite variety. There are three colours of them-viz., black, blue, and clothtailed. To be properly marked they ought to be entirely white, with the exception of the tail and its upper and under coverts. Some coloured feathers on the head are often found in them, as well as a white feather or two in the tail, or among the under tail coverts, which does not look well when the birds are flying. Their tail primaries ought to be sound in colour, but are frequently very much grizzled with white. The Cropper is very often mis-marked in having an excess of white, though 
I have had a few of them very well marked to the Pouter standard. A deficiency, or total want of bib, causing the ugly swallow throat, is very common; so is the blaze face, or snip on the forehead. A flesh-coloured beak usually accompanies a large snip; the bird is then said to be pink-nosed. The whole front of the crop is often white, and ring-necks are sometimes found. The rose pinion is occasionally seen beautifully defined, but a wing free of any white is more seldom seen than a bishop wing. A good flying bird, however ill marked, is bred from, because perfect flight is not easily got-and so bad marking is perpetuated.

Flight.-The Cropper is the merriest and liveliest, and can be made the tamest and most familiar, of all pigeons. In the loft, or out of it, he is always on the move, and, so long as he remains in health he keeps in show. The rules for good flying are as follow: A good bird should spring up from his trap like an acrobat from a spring-board, and go off in a circle, loudly clapping his wings, so that he can be heard from afar. His tail must be carried spread out like a fan, but depressed in the middle, so that it has the shape of a scoop. A well-spread scoop tail is valuable, because rare to get. Extra tail feathers are often found in Croppers, some having fourteen or more; a well-carried tail is all the better to have these extra feathers. Like other breeds in which more than twelve tail primaries are often seen, Croppers generally want the oil gland on the rump. A good Cropper should have a rocking action in his flight, his head and tail going up and down like the movement of a rocking horse. Then, as soon as he gets enough way on his flight, he must stop using his wings, and, raising them, so that they nearly touch at the points, sail motionless through the air, and the longer he can so sail, the more valuable he is. A good bird will sail along for 50yds., gradually lowering as he goes; then, again using his wings, with loud claps, he will rise as much as he has fallen, and go on alternately in this way 
till he pitches. A Cropper ought not to fly far nor long at a time. He may go twice or thrice round his house in a wide circle, then pitch, play up to his hen, and fly off again. The period during which they fly best is the week or ten days before the hen lays, when their courting is going on; but, even when sitting or feeding young ones, each will fly well alone, though not in such good style as during the time mentioned. A good way to gain the flight of Croppers is to let out a lot of odd cocks and one proud hen, when good sport may be had.

There is certainly nothing in the whole pigeon fancy from which greater pleasure can be derived than a flight of welltrained Norwich Croppers. Beautiful in shape and feather, grand fliers, ever dashing about with spirit, both in the loft and out of it, in them the owner possesses a source of inexhaustible amusement. I have always kept the noble and majestic Pouter, which everyone will allow is one of the choicest pigeons in the fancy; but he generally wants the spirit and life of the active, merry Cropper. The Pouter can certainly fly, after a fashion, and if flown from his squeakerhood is fairly able to take care of himself when allowed liberty; but the choicest large birds cannot be said to be at home in the air, which the Cropper is, to a much greater extent than most pigeons.

The remarks on Pouters by Dixon, in his "Dovecote and Aviary," apply solely to the Norwich Cropper, as can be seen from his allusions to its flight, colour, \&c. His illustration of it represents a barelegged blue Cropper, and is, perhaps, the best and most life-like picture of a pigeon in his book. I observe from the preface, that he was living at Norwich when the work was issued. He says, at page 122: "The flight, also, of the Cropper is stately and dignified in its way. The inflated crop is not generally collapsed by the exertion, but is seen to move slowly forward through the air, like a large permanent soap-bubble with a body and wings attached to it. The bird is fond of clapping his wings loudly at first 
starting to take his few lazy rounds in the air, for he is too much of a fine gentleman to condescend to violent exertion. Other pigeons will indulge in the same action in a less degree, but Croppers are the claquers par excellence; and hence we believe the Smiters of Willughby to be only a synonym of the present kind." This description is very true to Nature; but, as I have shown, the Smiter of Willughby is the bird known in Germany as the Ringbeater.

Eaton could appreciate the excellence of the Cropper, which he writes of as the Pouting Horseman as follows: "I have seen some of these light-bodied Pouting Horsemen that appeared to me to fly as light as Tumblers, and, when flying with the Tumblers, their round, globular crops, well filled and up, have a very pleasing effect, owing to the contrast of the Tumblers. With regard to dashing off, they are not only a merry but a spirited pigeon; not only spirited, but graceful in the extreme; I would rather see an elegant shape, small or narrow-girt Pouting Horseman, 6 $\frac{1}{2}$ in. in the leg (think of this, Gentlemen of the Pouting Fancy!) than an English Pouter, even if it would measure 7in. A large English Pouter, with thick girt, and hog-backed. Style is a grand thing, and the Pouting Horseman is the English Pouter in miniature, retaining all its properties." As I have explained, Croppers are nothing like $6 \frac{1}{2} \mathrm{in}$. in limb; but Eaton, if he ever measured any, was probably unwilling to write what, at the time, would have been regarded as something very heterodox. How well he goes on to describe what may be seen at any show of Pouters: "How often it happens, at a grand show of these remarkable, fine, large, English Pouters, after having been previously prepared for showing, that is separating each cock and hen, and not allowing them to see a pigeon, show well in their own pens; but when put into the show pen, a male bird, expecting it will show, it stretches forth its head and neck, apparently taking a sight of all the Fanciers in the room, almost as much as to say to some of them-you owe 
me something; some may show to a certain extent. It is very disheartening to Gentlemen Fanciers of the English Pouter when this takes place, after forwarding their birds miles, \&c., to give their brother Fanciers a treat, as it was supposed; it does not always turn out to be so, owing to their not showing, as it is called. Nevertheless, it often proves a treat to see what length of body and shape, length in leg, and beautiful in feather. It is otherwise with the light (not heavy) merry spirited Pouting Horseman cock, when put into the show pen, always up and ready for his work, not long in stripping himself, putting himself in attitude, and suiting the action to the word, display that fine action of showing which is well understood by the Gentlemen of the Fancy; giving infinite satisfaction with regard to being a merry pigeon, \&c. ... I have this week bought two pretty little Pouting Horseman cocks; I am informed they come from Norwich. I am given to understand they fly tremendously, with very large crops. . . The Gentlemen Fanciers of the English Pouter may assume that $I$ admire the small Pouting Horseman more than the large English Pouter. The contrary is the fact; I never have, and never shall, advise the young and inexperienced Fancier to attempt to breed a second-rate bird, while he has the opportunity to breed a first-rate bird, therefore I shall not advise him to breed the Pouting Horseman while he has the opportunity to attempt to breed the English Pouter, any more than I shall advise him to breed a Skinnum, Dragon, or Horseman, while he has the opportunity to attempt to breed a Carrier, for degeneracy will do that, in spite of the efforts of the most experienced Fanciers; but I am desirous you should breed the English Pouter with more style and grace, with a hollow back, smaller in the girt, stout legs, but not like mill-posts, soft downy or snow-like feather legs; but not rushed and sprouted with feathers that almost prevent the bird from walking."

All the foregoing is in a long note to Moore's description 
of the "Powting Horseman," which I have already quoted. Eaton took it for granted that the Norwich Cropper was identical with the Horseman, and evidently could not see, though he had had birds direct from Norwich, that they were a pure and distinct breed, baving nothing to do with it. His remarks on their fine style, in comparison with that of the Pouter, are, however, well weighed, and very conclusive.

It is about six years since the foregoing account of the Norwich Cropper was published in the first edition of this work; and, in the interval, the taste for this engaging pigeon has spread widely, and it is now kept in districts where it was previously unknown. Some shows have lately given classes for them, which have been well filled; and I expect that, with the steady increase of the pigeon fancy in general, and keen competition in most of the better known varieties, the Norwich Cropper will gradually take a prominent place in the principal exhibitions, which it is well entitled to.

That well-known fancier and writer, the Rev. Alex. Headley, of Chippenham ("Wiltshire Rector"), some time ago described, in enthusiastic terms, a flight of these lovely birds which he had got together since reading my account of them. Others, also, who like pigeons of beautiful appearance, merry ways, and great power of flight, have found all this in the Norwich Cropper, regarding which $I$ once wrote :

He springs from his trap, he sails through the air,

Loud clapping his wings as he goes,

Now he's down on the roof, playing up to his hen,

See how neatly he trips on his toes!

They're off now together, and as they wheel round

You may hear the wind sigh through their wings,

Like the zephyrs so sweet through Elolus his harp

As they murmur their song through the strings.

\section{The Pigmy Pouter Pigeon.}

The English pied Pigmy Pouter is a modern breed, which ought to agree in every respect, except size, with the large 
Pouter. Captain Norman Hill has been working at this variety for about twenty years, and to his skill and perseverance we are indebted for many of the best specimens that have been exhibited. A noted specimen, bred by him, was a black pied hen, first exhibited in 1879. Afterwards he produced a very curious one, which was black pied on one side, and blue pied on the other. This bird, which was very small, was well marked according to the Pouter standard. At the Crystal Palace Show of 1885 he showed some very well-marked, glossy-coloured black pieds.

The following correspondence with Captain Hill, in the year 1880, will show how he produced his now well-known breed of Pigmies. He wrote to me as follows: "Some time ago I saw a letter of yours, in the Fancier's Chronicle, on the Norwich Cropper, which in itself was good, and correctly written; but therein you ventured a remark which I must take exception to, and which, at the time, I fully intended putting you right on, as far as my strain of pied Pigmies are concerned. Your opinion then was, as far as I can recollect, that my good Pigmy that had been produced lately was a cross between the Norwich Cropper and the foreigner. Until I went to Colchester I had never seen a Cropper worth looking at; then I saw one or two, in Mr. Boreham's collection, with fair markings and more character than I had before seen. The thought then struck me, had I possessed one of them at the time I began, I might have saved years in the manufacture of my Pigmies; but this may be doubtful. However, I never had one in my possession until this season, when I bought three from Mr. Boreham, after he had supplied you with the best specimens he got at Norwich or Yarmouth. I am now giving them up, having no opportunity of witnessing their flying powers, and I cannot agree with you in admiring their other properties in preference to the Pigmy.

"In reply to your inquiry, how I bred my much-admired black pied Pigmy, I may state, briefly, by in-breeding and 
selection of the most diminutive and Pouter-like birds for the last fourteen years. Its genealogical family tree, as far as I can trace it, starts from a whole-coloured blue Austrian Pouter cock I bought, in 1866, from the late Mr. Evans, of the Borough, at that time a good Pouter fancier. This bird was quite bare on shanks, and nearly so on toes, but very small, and of fine form. I mated him to a blue Pouter hen, a weed, small, gay in marking, and well-feathered on limbs and toes, determined to try to breed dwarf Pouters on the same principle as Game Bantams were produced. I in-bred for five years, and then obtained a whole-coloured, mealy-chequered cock, with good limbs and toe feathering, finding it more difficult to obtain the latter points than correct markings. I mated him to my best pied hen, and from them got whole-coloured and foul-marked dun, mealy, satinette, and other nondescript colours. Inbreeding then for some years with the blue pieds, they produced some black and blue splashes-some dark, others nearly white. From two black splashed cocks, mated to a silver and a blue pied hen, in one season was produced two blacks-a cock and hen-which are the parents of the little black pied wonder.

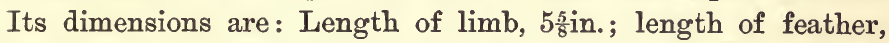
13: $\mathrm{in}$. There are bred from it, this season, two black pieds, two blue pieds, two black and one blue splashes, all small and. stylish, but none equal to the parent in markings or combination of Pouter properties; still, I do not despair of producing other equally perfect specimens of the miniature Pouter of the period."

With reference to the above, not having seen the bird described, I could not make any comparison between it and a good Cropper; all I could say was, that I preferred such Croppers as I had to any foreign Pigmy Pouters I have seen. Knowing that a Pouter with 7in. limbs, properly shaped, and rightly placed in the body, can afford to measure 19⿺辶n. in feather, if such length is made up in a certain way, as described, I at once saw that Captain Hill's Pigmy was quite out of this 
proportion. But even taking 7in. limbs to $18 \frac{3}{4}$ in. in feather, this Pigmy, being $5 \frac{5}{8}$ in. in limbs, ought to measure 15in. in feather, if formed on the same lines. I pointed this out to Captain Hill, and had the following reply: "In order to satisfy you and myself, I have re-measured my little gem, and find length of feather $13 \frac{1}{4} \mathrm{in}$. in full, or at the outside $\frac{1}{8} \mathrm{in}$. more; limb, 55in. These are the same measurements as were taken by Fulton and a crowd of admirers at the Palace, when the bird was first shown there (not for competition) in November, 1879. It appeared there again, two months afterwards, at the Peristeronic Show. Although the above measurements appear out of proportion to those you quote, and are so, according to the old rule for the Pouter, still, no one who has seen this little bird has made the remark that it was not symmetrical; on the contrary, either on or off the block it is considered graceful in form, and walks well, without rumping or jumping. In my opinion, a slender Pouter, with 7in. limbs, well-formed and placed, is much more pleasing to the eye, if under 19in., than one over that length; but such birds are rare. The limbs of this Pigmy are not spindly, but well-set and stockinged, with the proper curves, not too straight, neither bent, and with perfectly spread toe-feathering. Markings very perfect, goodsized bib, crop and both pinions correct, no approach to bishoping, and a true line at belt; but, like the majority of its large. brethren of same colour, it has a few foul feathers at thigh joints. Flights ample, and well-carried; colour a deep black; dark orange eye; pout a good size, and well-shaped; but, as you intend making mention of it, you ought to know, what was a great surprise to me and to others-viz., the discovery, when it was about nine months old, that it had deceived us in its sex, as it turned out to be a hen after being matched up to another hen. It is again keeping close company with a large Pouter hen. I have known other instances of a similar kind, but never one whose action, voice, and coo, were so like to a cock. 
"I have given you all these particulars as I find I cannot bring my mind to risk the journey to-and-fro of my wee pet, much as I would like you to see it at the present time. The mealy-chequer is the only new blood introduced into my strain, with the exception of a yellow Austrian hen, whose young have never lived. The mealy is most unlike the Norwich Cropper, being heavily covered on limb and toes, and the blue cock, wire-legged, is now the oldest bird I bred, and longer in limb than any Cropper."

Eaton, at page 72 of his 1858 book, says: "At the sale of Bantams, pigeons, \&c., belonging to the late celebrated and spirited fancier, Sir John Sebright, I was astonished to see the English Pouters in miniature possessing the five properties of the English Pouter." Some have supposed these were stockinglegged birds; but no proof of this can be adduced. The above is contained in a note on the Pouting Horseman, much of which I have already quoted; and my own impression is, that they were selected Norwich Croppers, such as I have had myself.

There is still room for improvement in the pied Pigmy Pouter, its prevailing faults being wide set limbs, round or hog back, and too little crop; but as several persons are now directing their attention to it, we may expect to see great improvement as time goes on. The colours of the breed at present are mostly black, blue, and silver pieds : red and yellow pieds are scarce. A few have been bred coloured like the laced Blondinettes, but wanting the white spots on the tail feathers. These seem to have been produced from crossing blues, blacks, and strawberries.

\section{French Pouters.}

According to Boitard and Corbie, there are several varieties of Pouters bred in France. The writings of these authors evince a personal acquaintance with most of the varieties; but their descriptions are so meagre, and their technical words so impossible to translate-just as the terms used only by pigeon 
fanciers here would be into any foreign language-that, were it not for the illustrations in their book, it would be quite impossible to form any correct idea of the appearance of the birds described by them as follows :

The largest French Pouters are known as Pigeons Grosses-gorges, or Pigeons Boulans, and are represented as large, thick-bodied, short and barelegged, clumsy, Runtishlooking birds. They appear to be both self-coloured and pied. The latter have white flights, and are white in front of the crop, so far approximating in the disposition of their marking to the English Pouter and Norwich Cropper, which, doubtless, have some remote connection with them. The crop is well-developed.

Boitard and Corbie allow that the English Pouter attains a greater size than the French. I made an attempt, some time ago, to obtain from France some blood-red Pouters of this variety, but my correspondent searched for them in vain. The Grosse-gorge Bleu, with white crop and flights, is, it is said, much spread over Picardy, where it is greatly esteemed. Every separate colour seems to constitute a distinct variety with these writers, hence, nearly twenty kinds are classified; but, except that some are entirely barelegged, while others are somewhat feather-legged, I can find no mention of any difference in form between the various breeds. On page 28 of Brent's pigeon book is an exact copy of Boitard and Corbie's Pigeon Grosse-gorge Maurin à Bavette, but entitled by him the "Old German Pouter."

Lille Pouters (Pigeons Lillois) are thus described: "This race of superb pigeons belongs to the Pouter division, since, like the preceding, they have the power of inflating the throat, but in a lesser degree. The crop in the Boulans is always of a spherical form, instead of which these have it in the form of a long pear, of which the thinnest part is below, and the largest part under the beak. These pigeons take their name from the town of Lille, where they are much bred and esteemed. 
Their head is small, beak long and slender, and they are not subject to the crop diseases of the large Pouters."

The Pigeon Lillois Elégant is portrayed as a short-legged, thick-bodied, very upright-standing bird, with a small oval crop, which is white in front, as are the flights. Boitard and Corbie say: "It is very well made, of an elegant and graceful form, body placed almost vertically on the legs, in such manner that the head is on the same line as the feet; small head, no cere round the eyes, stockinged legs, only the middle toes covered with feathers-a trait which is only met with in this variety-wings long and crossed. This bird is of light flight, is of great productiveness, and is greatly to be recommended to amateurs who wish to unite the useful with the agreeable."

This pigeon seems to bear some resemblance to the Norwich Cropper, and, from what I can make out, its colours are like those of the bar-winged Croppers; but to a British Pouter fancier, nothing more inelegant than the shape of it, as pictured, can be imagined, so that I can scarcely believe it to correctly represent the breed.

The next variety mentioned by the same writers has evidently a resemblance to our Cropper in flight.

Pigeon Lillois Claquart.-“"This pigeon, which Buffon has confounded with the Tournant" (Smiter, or Ringbeater), "makes a noise with its wings when commencing to fly, like a claquette; hence its name. It inflates its throat, has long wings, crossed over the tail, a cere round the eyes, and stocking legs. Its plumage is white or chamois, or blue shouldered with whitethat is, having the upper part of the wing white. It produces well, which makes it much sought after."

For my own part, I have never seen long-flighted pigeons fly so well as the short-flighted.

The Cavalier Pouter (Pigeon Cavalier) is recommended for its beauty and productiveness. "This race appears to be extracted from Runts (Romains) and Pouters, of which they have the general form, as also the power of inflating the 
throat, more or less according to the variety. Some have thick nostrils, membranous and fleshy, or even a little mushroomed, but rarely; they have a red cere round the eyes." The Pigeon Cavalier Faraud is pictured as a tall, upstanding, shell-crested, long-cropped, and barelegged Pouter. It is said to be a cross between the common Cavalier and the Bagadais Mondain à l'œil.

\section{German Pouters.}

Neumeister and Prütz describe several varieties of German Croppers (Kropftauben), and say, regarding the whole race: "This universally known and favourite kind of pigeon is distinguished from all others by its ability of puffing up its throat to the highest degree, so that it often becomes as large as the remaining body. This is done by drawing in air into the throat, by means of the bill, somewhat opened, the throat valve closing; which closing is brought about in a manner which has not yet been thoroughly investigated, but it is likely by a co-operation of the neck muscles. As to the beauty of Croppers, it is essential that the neck be long, so that the head does not stick between the shoulders, which gives them an unshapely appearance. Their flight is mostly good, though somewhat heavy; they flap much with their wings, and frequently make playful gyrations, with their wings held high. Their propagation is but middling, but they are much liked on account of their cheerful ways and the above-described remarkable blowing up of their crops, which gives them peculiarly graceful attitudes and movements. They should never be kept with other pigeons, especially large kinds, as they are helpless when blowing, and unable to withdraw from, or defend themselves against, the attacks of others. The crop loses its feathers by blows from the beak, is even sometimes pierced; when feeding with other nimble kinds they often come short; their pairing is also interfered with, which is telling on the offspring. They are variously marked, of 
quite different forms, and therefore divided into the following varieties :"

The Old German Pouter (Der Deutsche Kurz und Glattfüszige Kröpfer) " is one of the largest Croppers, of considerable height. Its length 55 centimètres" ( $21 \frac{2}{3} \mathrm{in} ., 36 \mathrm{in} .=91 \frac{1}{3}$ centimètres), "and breadth of outspread wings, 105 centimètres. It passes for the original race of all the remaining Cropper kinds. The round head is mostly smooth, sometimes with a pointed hood, brow high, bill proportionately short, neck very long, and, along with the crop, strongly hung with hair; breast and back broad, the latter somewhat hollow. The crop always puffed up, hanging somewhat forward, has a diameter of $12 \frac{1}{2}-15$ centimètres, and a circumference up to $42 \frac{1}{2}$ centimètres. The short, strong legs, are unfeathered; the wings, carelessly hanging down, overreach the tail end by 5 centimètres. This is the characteristic mark of the German Cropper, and is not found in any of the following varieties. The usual colour is either white, or blue with white head or tips, yellow with a white tail and head, or black. It is very much to be lamented that this pigeon, in its pure state, seems almost to have disappeared, as it is never represented at the exhibitions. The propagation is extremely poor. The main cause of its disappearance is likely owing to change of fashion, in consequence of which breeders have turned more to the slender, high-legged kinds."

This breed is represented, on Plate XI. of Neumeister's "Das Ganze der Taubenzucht," in four colours-white, yellow, red and blue; the two last have turn crowns. The coloured birds have white heads, flights, and tails, but are dark thighed. They are short, and bare in limb.

The Breslau Pouter (Der Breslauer Kröpfer) "comęs nearest to the preceding, is of stately size, generally speaking is one of the largest Croppers, yet not long in body, nor do the pinions reach beyond the tail, so the dimensions are much less. It occurs one-coloured and marked, in the latter case 
with a white upper head, the yellow marked frequently with white flights and tail."

The Pomeranian Pouter (Die Pommersche Kröpftaube) "has a great resemblance to the English Pouter, with which it is unmistakably connected. It is found in perfect beauty at Stralsund and Greifswald." And then follows a detailed description of it, taken from an article by Dr. Bodinus, published in the year 1858.

Herr Prütz, in the third edition of "Die Arten der Haustaube," published in 1878, states that the Pomeranian Cropper " is said to have been imported from England many years ago; but it is, without doubt, much handsomer than all similar Croppers which have lately been brought from England that I have seen. The late Herr Wermann, of Altenburg, an authority on pigeons, was quite delighted when he first saw a pair which I had sent to Herr von Beust." From his description of this variety, it would appear to resemble the English Pouter in all respects, except that any white pinion on the wing, which, when rightly defined, is so valuable in our breed, is a fault in it. It would also appear that the Pomeranian must have much rougher limbs than our Pouter.

The principal breeder of Pomeranian Croppers, Herr Wilhelm Hevernick, in a lecture entitled "The Pomeranian Cropper, and its Relation to the English one," delivered in the Ornithological Club of Stralsund, and published in Columbia of February 15th, 1879, a copy of which was very kindly sent to me by its editor, Herr Prütz, says as follows: "If I try in the following paper to establish the relationship of the Pomeranian and English Croppers, as well as their descent, to point to the value of a rational breed of Pomeranian Croppers, and to warn against crossing with the English, I must preface the plan of my work with this my view, without claiming infallibility, that this subject, so far as I know, has not been handled by anyone before me, excepting Dr. Bodinus. He first described the Pomeranian Cropper about twenty-five years ago, and drew 
the attention of pigeon-lovers to this beautiful bird, at that time not known anywhere beyond Fore-Pomerania. I must remark, that only my great love for this race of pigeons induced me to undertake investigations into its descent, development, and relations, and to communicate the result here, in the hope of giving others breeders a motive, through my views, to consider this circumstance, to make known their views, and to treat this subject further in our club, in order that we may be in a position to breed our beautiful Cropper in such quantity and quality that it may equal the English and French breed in beauty. I am persuaded that this is very easily practicable, provided we have the understanding and will necessary for it. To perfect the first, and to aim at the latter, is the plan of my lecture."

He then goes on to describe the peculiarity of all CropperPigeons, and argues that the distension of their crops must haveproceeded from long, careful, selective breeding in domesticity, because such pigeons could not naturally exist, as they could. never hold their own in a state of Nature. Assuming that. Croppers, as well as all other races, are derived from the Blue Rock Pigeon, he does not think that all the kinds of Croppers are necessarily derived from one original race, but. that they might have originated from parallel running lines; or, in other words, that the distension of crop in pigeons may have been noticed in different countries and times, and independent races established from them. He does not, however, mean to try to prove which races may be considered originals, but only to express his opinion on the relationship and origin. of the Pomeranian and English breeds, as the clearing up of this relationship is necessary for the rational breeding of the former. He evidently did not know that it is on record how our English Pouter was produced, which would have materially assisted him in his investigations. He proceeds:

"As I suppose that, to all who are interested in our Cropper, the marks of both races are known, I will omit an exact 
description of them, yet it appears necessary for my plan to illustrate more nearly the striking peculiarities, as well as the resemblances, of both. The English Cropper is very large, and very much of the same size as the Pomeranian. The inflated crop is round, and must be intersected by an incision on the breast, so that this incision forms a regular shape; the rump is proportionately thin, the tail long and slender, the legs are very long, possibly equally feathered with downy feathers, only the toes must have standing out feathers so that they quite hide the toes, but at the same time form no shoes, which is a decided defect in the English Cropper."

What is meant by "shoes" I do not exactly know, but I learn further on that the Pomeranian breed is much rougherlimbed than ours, which, though considered a beauty in them, is a grievous defect in ours.

"The Pomeranian Cropper is almost, or quite, of the same size as the English; but its rump is thicker, its crop not inflated so like a ball, on account of which the shape is lost; the tail is shorter, and is carried a little more spread out. The legs with good birds are almost as long as with the English. Yet from a distance they do not appear so long, because they are provided with pretty large feathers, which form stockings below the hocks and shoes at the feet. The colours and marks are the same as with the English; pure whites also occur, though they have become rare; and there are whites with black and blue tails. The last mark often occurs, and I have hitherto believed that whites with black tails existed in no other race, especially in the English, for Fulton does not mention them, although he treats his subject very minutely and fully. It is striking that among the Pomeranian Croppers there are no whites with red or yellow tails."

I have seen many blue and black-tailed white English Pouters, and they can easily be bred by pairing a black or blue pied with a white. The first cross often results in such marking, as I have observed elsewhere, and it can easily be fixed, as 
in the Norwich Croppers. Red and yellow-tailed whites are however, impossible, or next to it, because, as Herr Hevernick truly observes, the coloured tail is not found in red and yellow pied Pouters; at least, not dark enough to match the body colour.

"On beard and heart" (i.e., bib and half-moon), "as it is called, we place the same conditions with Pomeranian as with English Croppers; but white feathers on the wings, which with the English are more and more highly prized according to their form, are in all circumstances a defect with the Pomeranian, and a sign of careless breeding, or of a bad origin. In consequence of this, these feathers are cut off with a pair of scissors by many breeders. On this occasion I cannot refrain from blaming this proceeding most decidedly, for there can be no interest, in my opinion, in examining the pigeons of a breeder of whom we know that he indulges in such rectifications; however, on the other hand, it may perhaps be represented that someone may say he sells no pigeons, and removes their feathers in order that his pigeons may please him better, no matter to him whether other breeders allow this proceeding or not. But, if anyone sends pigeons to an exhibition, all the same whether for sale or not, I can find no point from which such manipulations can be defended, for they have only impure motives, such as bragging or base dishonesty. The bearing of the Pomeranian must be high and upright, though not so high as with the English. But if, as Prütz says in his noteworthy book, 'Die Arten der Haustaube,' the back must be arched a little convexly, be is mistaken; at least, I have heard this hog's back, as the English call it, always very expressively blamed.

"Now, if we compare the two races with each other, we find that size and marking are nearly the same; but with the English the crop is somewhat more inflated, the shape somewhat thinner, the tail more slender, and longer, the legs somewhat longer, but less strongly feathered, and the bearing more 
upright than with the Pomeranian. With both races white feathers occur on the wings; yet this is considered a defect in the Pomeranian, while with the English this mark is highly valued. But this mark is only the result of a careful choice in breeding, continued for years, and is very difficult to fix; it occurs in England in the wished-for perfection very seldom, and is only known to me by description and pictures from English prize birds; while I have never met with this mark, in specimens shown in Continental exhibitions, in anything like such perfection. If we place an English and a Pomeranian pattern bird together, the first must positively please us most, not on account of its beauty, but on account of its peculiarity, which consists therein that the bird, with its great length, and upright bearing, shows a very voluminous upper body, and a high, thin, under body, both of which are only joined by the slender figure. Dr. Bodinus says: 'The English Cropper gives the impression of a large, beautiful statue placed on a small pedestal,' and I find this very striking. The Pomeranian Cropper, on the other hand, appears very compact, firm, and powerful, yet shows in the parts of its body, and in its whole appearance, such great harmony as I have never seen in any other race of Croppers, with the exception of the striped Hollanders" (whole-coloured Croppers with white, long bars). "If we examine more closely the whole impression of both races, we find that in both the character of the nation is exactly expressed. The Englishman likes the unusual and peculiar, and the Pomeranian (especially the New Fore-Pomeranian) likes the less striking, but compact and strong; and from these motives in the breeding both races have evidently arisen. After having seen that the total impression with each race is quite different, we find that the differences in the single parts of the body are not important. This circumstance lets us know that both races are nearly related; therefore, there remains only the question whether one race descends from the other, and which has been the 
original, or whether both have arisen from some common stock. In my opinion, we find the answer to this question very easily if we look practically into the way and manner of degeneration in both races. That both easily degenerate with careless breeding lets us know that both races are not yet very old; but in this respect we must not think of the generations of man, for, no doubt, both races have existed 200-300 years. If we now examine the degeneracies of English Pouters, the shorter legs and less upright carriage show their ancestors must have had these faults. With the degeneration of Pomeranian Croppers we find lower and less-feathered legs, white spots on the wings, and white snips on the forehead, which leads us to suppose that they proceed from a race which had bare legs and white heads. Only the old German Croppers are so marked, and I therefore take them to be the original of our Croppers."

From the foregoing it is evident that there is enough resemblance between the English and Pomeranian Croppers to establish a connection between them. Sailors speak of every northern European who is not a Frenchman as a Dutchman. Moore's Dutch Cropper was evidently a bird with much resemblance to the Pomeranian, so it is not unlikely that this pigeon, "flag thigh'd," as Moore says, was the ancestor of our Pouter. The Horseman cross would take the feathers from its legs at first, evidence of which I have adduced from the Treatise of 1765, and from the description of my old painting of the time of Moore; but leg feathering to suit the taste of fanciers was quickly recovered. As to solid shoulders being infinitely preferable to bishoped wings there is no doubt; but the Pomeranian breed itself is evidently not altogether free of white "daubs" on the wing, as they are called. As to deducing both varieties from the old bald-headed, long-bodied German Cropper, already referred to, I can see nothing in the argument at all. The correct crop marking of the English Pouter, and similarly marked breeds, must necessarily vary very con. 
siderably in breeding, there being no certainty in the production of a white mark which has no structural conformation in the bird to guide it, such as a white head, wings, or tail. The rose pinion, for the same reason, is a difficult mark to breed. Hence, Pouters come, and must always come, more or less close or open marked. The crop is sometimes seen solid, or free of white, and sometimes the bib is wanting; the bird is then swallow-throated, and a white blaze on the forehead often appears. The same may appear on a bird correctly marked on the crop. No one would adduce a white blaze on the forehead of a short-faced mottled Tumbler from Baldhead blood. The little Norwich Cropper, from careless breeding, is very subject to the blaze face. I have seen Runts, imported from abroad, some of which I had, marked exactly as the Pouter ought to be marked, except that they had no white feathers on the shoulders. They weighed over 3lb. per pair. It is something for one who admires his own breed so much as Herr Hevernick does, to allow that a pattern English Pouter "must positively please" a fancier more than a pattern Pomeranian. It is unlikely that many English Pouters of the first quality have been seen in Germany, because they easily sell here for several times the price foreigners will give for them. Were English fanciers to breed for solid shoulders they could very easily accomplish their desire; but they consider the rose pinion such a set-off to a bird that they will not abandon it; and, although it is rare to see it well-defined, it is now and then seen.

Herr Hevernick says that it was Dr. Bodinus who named the Pomeranian Cropper, that it was sometimes known before as the Hollander, and that he has seen some that were brought. from Holland very like it. These might have been taken from England, or they might have been of a Dutch breed. He saw some in the market of Rotterdam which were not English, but which resembled the Pomeranian, though not so good. $\mathrm{He}$ says the breed has lost quality in late years; that it was better 
twenty-five years ago, but that, about that time, offers of tempting prices induced breeders to part with their best birds, which were scattered to all places, and soon lost sight of. $\mathrm{He}$ concludes his lecture by giving much valuable information on the breeding of the Pomeranian Cropper, observing, that of late a great increase in breeding had taken place, and warning breeders against crossing with English blood, which he had found did not improve this variety. From all I can learn from his lecture, I do not think this variety, though evidently allied to ours, can be of any service to Pouter fanciers here, because it seems smaller, and rather inferior in all its points of shape in comparison with our best birds; however, if I were to see a collection of good Pomeranians, which I may do when I can spare the necessary time, I could at once form an opinion on the subject more to the point than can be gathered from any amount of descriptive writing.

The Saxon Pouter (Die Sächsische Kropftaube) "is not so large as the German, far quicker and lighter in flight, and of a slimmer shape. The wings lie close to the body, and reach to the end of the tail, on which the wing-points cross. The beak is longer and thinner than with the German Cropper; legs and thighs are high, and feathered. It is of a weakly constitution, and propagates poorly. The plumage, generally, is one-coloured blue, black, red, or yellow; frequently, however, pay-coloured, with white wing-bars."

The Dutch Pouten (Die Holländische Kropftaube).-I understand that the following description applies to a Cropper bred in Germany, and known by this name: "The Dutch Cropper is distinguished from the Prague Cropper by a somewhat larger body, and by a crop more of the shape of a cylinder than a ball. Its legs are high, covered with trousers and feathers. It is always one-coloured, often with white wing bars. The bay-coloured" (Isabel-coloured) "among them are most cultivated, and no other colour is found in the same perfection. In Holland, where this breed is original, it like- 
wise occur's only one-coloured, yet there it has thin legs, less feathered, and short toes, standing close together. The gait of the cock is tripping, and he leaps towards the hen. It is of a very erect bearing, slimly made, and high-legged, because it carries its thighs outside the plumage of the belly. It inflates its crop very well, and it assumes an oval, cylindrical form. The wings do not reach the end of the tail, are narrowly drawn together, and their points cross over the tail. The Dutch Cropper, in its erect posture, when strongly feathered on the legs, resembles a falcon at rest. It is a very cheerful pigeon, fond of flying, of flapping its wings, and especially of swooping along, floating with high held wings. It is a pretty good breeder."

The Austrian KLatcher (Der Oesterreichische Klätscher) "is between the Dutch and German Croppers in size, and a powerful pigeon. Compared with the Dutch, it is broader built, heavier, has shorter, unfeathered legs and feet, does not stand so erect, has longer wings, and inflates its crop in the same way as the German. One might take it for a cross-breed between the German and Dutch Croppers; but such is not the case. Its plumage is distinguished by being glossy and glittering; it is entirely self-coloured, and never shows white pinions, or any white on the head, which would be the case if it were a descendant of the German Cropper. It is a very good breeder, very lively, and when flying the shortest distance it flaps its wings, so that it is heard from afar, like the Ringbeater. It occurs in Switzerland blue, yellow, and white."

The Prague Magpie Pouter (Die Prager Elster-Kropftaube).- "This Cropper, which has become very rare, is of a structure between the German and Dutch breeds, standing higher than the latter, and having well-feathered legs and feet. It is a good pigeon for breeding, very lively, and has the manner of the Dutch Cropper." The illustration of this Cropper represents an upstanding, rough-legged, Magpie-marked back. The marking is exactly the same as that of the Magpie 
Pigeon, except that the head is white. There seems, from what Neumeister says, to have been formerly a similarly marked German Cropper. The Prague Magpie Cropper, though shown with a white head on his coloured plate, has evidently not a pure white head, as he says that, from the beak to the middle of the head, it is of a "coloured paleness," probably meaning that the head is of a powdered colour.

This concludes the account of the large Continental Croppers as gathered from the French and German writers named.

Tegetmeier says, at page 71 of his Book on Pigeons, regarding foreign Croppers: "Many of these birds are very prettily marked; a pair, a short time since, came into our possession of a very bright yellow, with pure white wings and flight feathers, and well-defined white rings round the necks." This marking nearly resembles that of the Prague Magpie Cropper, already described, to which race they probably belonged.

\section{The Bengal Pouter Pigeon.}

I have seen in Bengal several Croppers of a breed which I believe is peculiar to that country. They were of a size between the English Pouter and Norwich Cropper, feathered on the legs, but not roughly, and by no means very gracefullooking pigeons. They were called by a name which signifies swell neck. Such as I saw were either self-coloured blue, or blue grizzled in colour. They were evidently bred for crop alone, being short in limb and feather. Considering their size, some of them had very large crops. They seem to me to have no connection with English Pouters, several imported specimens of which I have seen in Bengal from time to time. There are probably several other varieties of Croppers throughout India and adjacent countries.

\section{Foreign Pigmy Pouters.}

Several varieties of Continental Pigmy Croppers have been known in this country for a good many years. The 
first that were introduced, so far as I know, were self-coloured blacks, reds, blues, \&c., which went by the name of Austrians. Self colours with white wing bars are also known, the most beantiful being the delicate cream or light dove-coloured ones called Isabels. The smallest of these Pigmies are now generally known by their German name of Brünners. So far as I can learn from the description of these varieties by Neumeister and Prïtz, they ought to have clean legs. I have had them with feathers on the outsides of the legs and middle toes, precisely the same as in many of our Norwich Croppers, but I prefer bare legs. Tegetmeier figures a pair of pigeons called Isabels, very tall and rough-legged, but entirely devoid of crop, and with none of the shape of a Cropper. He also figures a pair of red Austrians, which well represent such as I have seen, except that their limbs are well covered with downy feathers, and their colour is too bright. Such Isabels as I have had were miniature Pouters with hardly any leg feathering, more delicate in colour than those Mr. Tegetmeier represents in his book, Uplopers in carriage, only medium-sized in crop, and carried their wings crossed at the tips. They were splendid fliers, floating lightly in the air, with wings upheld, for great distances, but did not clap so loudly as Norwich Croppers, nor carry their tails so fan-like. They had the ability, mentioned by Neumeister, of bending their hock joints forward when stretched to their utmost height; but they were not nearly so small as he speaks of, being very little less than average-sized Norwich Croppers. Mr. Tegetmeier, who bred foreign Pigmy Pouters extensively, and produced them with stocking limbs like English Pouters, gives the following weights and measurements of birds he possessed:

$\begin{array}{lllllll}\text { White cock } & \ldots & \ldots & 13 \frac{1}{4} \text { in. by } 5 \frac{1}{4} \text { in. } & \ldots & \ldots & \text { Weight } 8 \text { oz. }\end{array}$

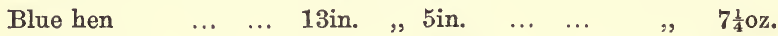

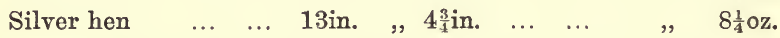

Neumeister and Prütz describe these miniature Croppers as follows : 
The BrüNN Pouter (Die Brünner Kropftaube), according to Neumeister, "is found particularly beautiful in Prague and Vienna, where it is known by the false name of the 'Dutch Cropper.' It is the most elegant and finest of all the Croppers. Having been first imported to us from Brünn, it was named Brünner Cropper, and it is mostly known by that name. It has the smallest body of all the house pigeons, its whole length amounting to $27 \frac{1}{2}$ centimètres (11in.). Legs very long, the thighs being outside the plumage of the belly, and being so stretched during the act of inflating the crop that they almost form a perpendicular line. The leg measures 14 centimètres ( $5 \frac{1}{2}$ in.); the full-grown pigeon weighs 200-266 $\frac{2}{3}$ grm. (7 to $9 \frac{2}{5} \mathrm{oz}$.). When not inflated, it is very little bigger than a Blackbird, and so slim that you can draw it through your thumb and forefinger. When affected, it presses its thighs outwards, to such a degree that they look like knees "which can be moved forward, as it stands almost perpendicularly on the points of its toes. Its smooth, finely-shaped head, is oval; brow high, neck long; the globular crop is $7 \frac{1}{2}$ centimètres (3in.) in diameter, but without hair. The bill is thin, the waist delicate. The wings, fitting closely to the body, reach within an inch of the end of the tail. The tips are strongly drawn together, narrow and long, and much crossed over the rump. Feet and toes are weakly and smooth. On the whole, the pigeon has a loose plumage, but, notwithstanding, flies well and perseveringly. The Brünn Cropper is mostly coloured like the Saxon. The black with white wing bars, blue, red, and yellow, are the most common. The delicate bay with white wing bars are the rarest. In this colouring the whole plumage, without exception, must be equally, as it were, breathed upon with the most delicate and aërial bay, not so light but that the pure white wing bars can be distinctly seen on it. In connection with this is an un. spotted, delicate, flesh-coloured beak, toe nails, and eye wattle. The iris is light yellow, with an orange border. A dark 
beak is a chief defect. The Brünn Croppers are cheerful and lively, are fond of flying rapidly, and of flapping, but do not like to go near strange dovecotes. It is a worthy parallel to the fine English Almond Tumbler, and as neat, elegant, and cheerful in its way. Nothing prettier can be imagined than a loftful of these lively, neat, and amorous pigeons, among whom there is no end of courting and caressing. The loving cock drives the hen before him, all the while inflating his crop and cooing, while she walks forward in proud decorum. It flies lightly, quickly, and with flapping wings, and is very persevering in its flight; in this the inflated crop helps, for it happens that the Brünn Cropper can float for from fifty to sixty steps in the air, holding its spread wings high over its back without moving them. No other pigeon is able to do so for so long a distance. Generally speaking, its flight differs from that of other pigeons. If a swarm of these Croppers fly, it is clearly seen how fond they are of it. It is for them a pleasure to fly in wide circles around their house for half an hour. The Brünn Cropper, when affected, runs on high legs, as if on stilts, standing even on its toes, and inflating its round crop so full that it reaches a diameter of $7 \frac{1}{2}$ centimètres" (3in.).

The length of the Brünn Cropper (1lin.) seems out of all proportion to its limb, and I think, considering the weight of the bird, it is mis-stated. Compared with our Norwich Cropper, the Brünner is, doubtless, a smaller and more slender pigeon; but those I have had were very little less than my best Croppers, which attained a diameter in crop up to 5in., $4 \frac{1}{2}$ in. being commonly seen. The Brün Cropper is certainly smaller in girth, and shows its thighs more than our Cropper, but its habit of crossing its wings is a bad fault, in my opinion. I had one Isabel-coloured Brünner hen which did not have this fault, and some who saw her considered her one of the best shaped little Pouters they had seen. She was $5 \frac{1}{4}$ in. in limb, and

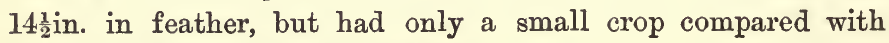
that of a good Norwich Cropper. 
The Prague Pigmx Pouter (Die Prager Kropftaube), "also called the Stork Cropper, is not much larger than the Brünner; the legs are of the same height, and, along with the toes, somewhat feathered. It is either one-coloured, with white wing-bars, or, like a stork, white with mottled, mostly reddishbrown breast, flights, and tail. It comes from Bohemia, and frequently very strong blowers are found among them."

This pigeon, of which Neumeister gives a coloured portrait, is represented as a barelegged, very upstanding Cropper, with red crop, flights, and tail. The head and upper neck are light, the colour gradually deepening towards the lower neck.

The Dutch Balloon Pouter (Die Holländische Ballonkropftaube) "is, in the first place, distinguished from all other Croppers by its peculiarly short, round form, and bent back neck. Its length is $32 \frac{1}{2}$ centimètres (13in.), the length of its leg 14 centimètres $\left(5 \frac{1}{2} \mathrm{in}.\right)$, the weight of the body up to

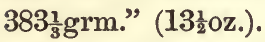

"The head is smooth, the nape very powerful, the neck bent back as with the Fantail, even when not blowing, and this is the first characteristic mark of the Balloon Cropper. The breast is correspondingly protruding and broad. The crop

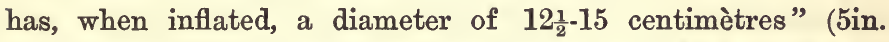
to $6 \mathrm{in}$.$) . "The flights do not reach the end of the tail, and$ are somewhat crossed. The leg is shortly feathered, and the colour and markings vary. It stands with stiff legs, and rather low, and walks with dignity, nodding very much. In flying, it holds its head and crop upright, which lends to the pigeon the appearance of a balloon; hence its name. All other pigeons stretch their necks out horizontally when flying, and this deviation from the rule is its second characteristic mark. It propagates badly. In Holland, much care is spent on its production; in Germany less, as, on the whole, this pigeon does not make a very fine impression." 


\section{Chapter XXIV.}

$\propto$ WATTLED PIGEONS.

The Barb Pigeon.

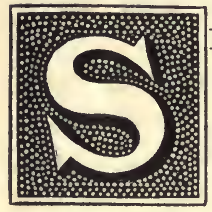

HAKESPEARE'S reference to the Barbary Pigeon makes it the earliest noticed variety that I know of in our literature. As Willughby gives a recognisable description of the Barb, under the same name (Barbary Pigeon), within a hundred years of Shakespeare's allusion to it, there can be no reasonable doubt that this breed has been cultivated for at least three centuries in our country. Willughby describes it as having a bill like that of a Bullfinch, with a circle of naked, tuberous, white flesh, round its eyes, as in the Carriers, and with white irides; and adds: "My worthy friend, Mr. Phillip Skippon, in a letter to me concerning tame pigeons, writes that the eyes of this kind are red."

I think it likely enough that Willughby's "worthy friend" was Major General Phillip Skippon, who was so much associated with Oliver Cromwell in the Civil War; and if so, he is the earliest English pigeon fancier of whom we know anything. The part he took in the troubled times in which he lived may be learned from Carlyle's "Letters of Cromwell." He was 


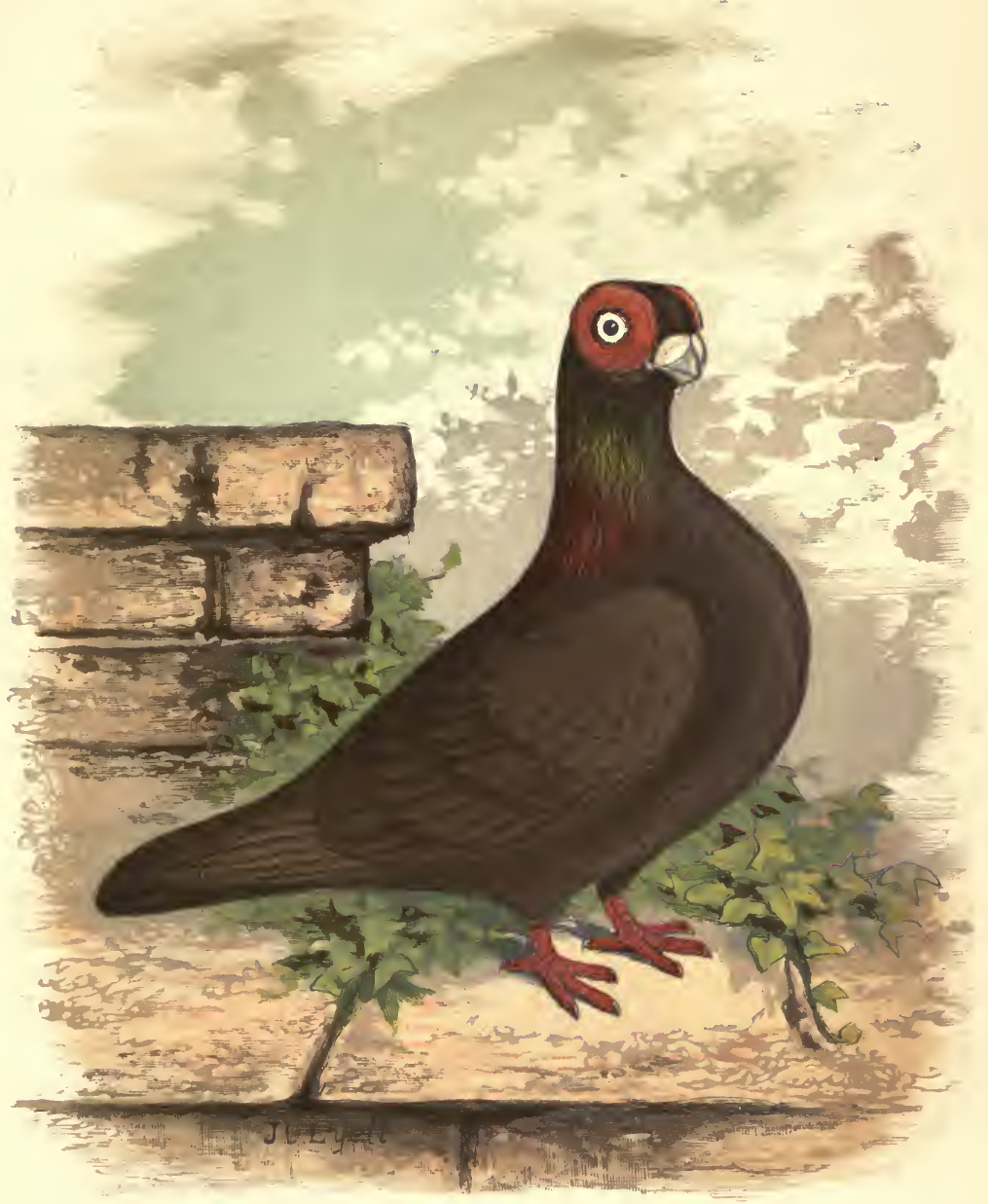

TH F $\mathrm{B}$ A R B. 
the author of the following religious books: "A Salve for every Sore" (1643), "Truth's Triumphs" (1648), and "A Pearle of Price" (1649). When Field Marshal in the army, he was deputed by the Parliament, in conjunction with Cromwell and another, to go to Saffron Walden to allay some discontent that had broken out among the soldiers. He is thus alluded to in an old ballad:

Some citizens they say will ride,

To buy knacks for their wives;

Let Skippon skip-on as their guide,

He may protect their lives.

Perhaps Willughby's correspondence is extant.. Skippon's letter about tame pigeons would be interesting to read.

It is owing to some importations of Baibs from the South of France, made by Messrs. John Baily and Son, about thirty

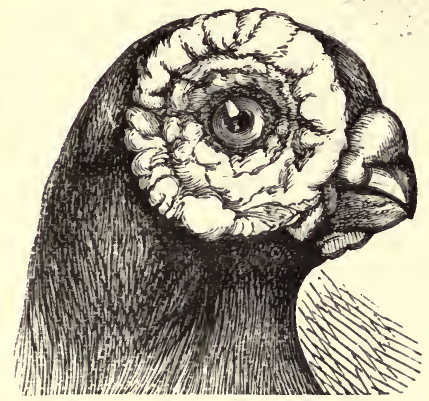

Fig. 13.-HEAd OF a Barb.

years ago, that this pigeon exists in our country in its present excellence. Its French name is the Polish Pigeon (Pigeon Polonais); and though it is now known in Germany as the Barbary Pigeon, from its English name, it is also called the Indian Pigeon (Indianische-taube). Neumeister says : "There is no explanation of the origin of the name 'Indian,' and the French designation, "Polish." From what we know 
of moderm nomenclature, as applied to new varieties of pigeons and poultry, it would never do to depend on the names of old varieties as being indications of their origin. It is certain that the Barbs which came from the South of France were far superior to what were here previously; and though the name of this bird in French literature is Pigeon Polonais, it may have another in the South. It is evidently an ancient variety, and more nearly allied to the highest type of the Owl tribe than any other. Both may be from the same stem, and both may have existed from pre-historic times. I have seen a few Barbs in Bengal, but was informed that they were the produce of some that had been imported from - Europe.

The Barb should be smooth-headed and clean-legged; at the same time, a crested variety has existed for long, and is mentioned in our old pigeon books. The legs are occasionally slightly feathered, which is so far faulty. A sub-variety is bred in Germany with frilled breast like an Owl.

SIzE.-There is a certain difference of opinion regarding size, some liking a small bird, and others a large one. I think that, when the head properties in two birds are equal in proportion to their respective sizes, the larger bird is to be preferred, as being bolder in all its points.

SHAPE.-The neck short and thin, the breast very broad, the legs short, and the flights rather long, and carried neither high nor low, but lying on each side of the tail, is, I think, the correct style for this pigeon, and it is that described by Continental writers. Any gullet or fulness of throat takes from the wished-for appearance of a massive head set on a thin stem, which most, though not all, look for in a Barb. A gullet, filling up the hollow of the throat, and making a bird broad across the neck in profile, is a grand property in the Owl tribe, with their sprightly carriage; but the Barb has little carriage, properly so called, and looks much better with a hollow, clean run throat. 
SkULL.-This should be very broad, and is, consequently, rather flat, and generally with a fulness at the back. It should be as much as possible of an equal breadth, and not wedgeshaped. The forehead should be very broad, prominent, and well-filled out, and form a curve from the crown to the beak wattle, a straight-lined forehead in profile being a bad fault very often seen. The forehead must be well-ribbed up, with an indented line on each side of it, as if carved out, which gives this pigeon a very nice modelled appearance in head, not so marked in any other variety, though seen, in a less degree, in the Owl tribe.

BEAK, very short, thick, well-boxed, and wide in the gape: the upper mandible in the same curve as the forehead, and the under mandible approaching the upper in massiveness as much as possible, which is hard to get, but which, when got, gives a bird a grand appearance. The beak should be flesh-coloured, or no more than tipped with colour.

EYE, as pure white or pearl coloured as possible, though the nearest approach to this is usually a white iris, rather red at its outer edge. Many good Barbs have yellow irides, which ought not to disqualify, but be duly allowed for in competition. White.Barbs have been seen with pearl eyes, but generally have bull or hazel eyes.

Bвак WAтtLE.-At maturity the beak wattle ought to have filled up all inequality in the curve of the forehead and upper mandible, and it may stand out a little in addition; but it ought to be as free as possible from rough wartiness, and show a clean division in the middle, appearing like a small bean split open and laid across the beak. The jew wattle on the under mandible should not be excessive, but of course grows to a certain extent in such a pigeon as the Barb. It should appear as three small warts, one in the middle of the lower mandible, where the feathers finish off, and the others on each side, below the opening of the mouth. The beak wattle in a healthy bird is nearly white, 
the jew wattle and corners of the mouth being of a reddish flesh colour.

Eye Wattle.-This is one of the chief properties of the Barb. It continues growing till the bird is from three to four years of age, when it ought to be at its best. It should be of an equal breadth all round, and, consistent with roundness, the larger in diameter the better. It ought to be thickest at its outer edge, and of a concave form, or shaped like the outside of a cart wheel, the eye being represented by the nave, which stands out in the centre. The more prominent or less sunken in the head the eye is, the better. The colour of the eye wattle ought to be bright red; with age it often becomes light, sometimes turning almost white.

The hen is generally less developed in all head properties than the cock, though hens have been seen good enough to be mistaken for cocks when exhibited. Before a hen can reach such quality she is generally past breeding, Looked at in front, the Barb's head ought to be very square and blunt, the tops of the eye wattles reaching higher than the skull, and standing away from it. When they incline towards each other by rolling over the skull, the head appears contracted, which is the opposite of what is wanted.

CoLour.-The Barb is a self-coloured pigeon, and is found in black, red, yellow, dun, and white. Blue is rare, but is occasionally seen on the Continent. I think the red eye wattle would harmonise very well with the blue colour. The black is the most usual colour, and it can often be found good, being the easiest of the artificial colours to breed; at the same time, it is not found with such vivid green, metallic lustre, as in some other varieties. Black may look very well, and yet be far from the best possible tint. What the best Barb black is in reality may be seen by looking at the reds and yellows of the same relationship. The latter colours are not found very good in Barbs, the red usually falling off very much in colour towards the rump, flights, tail, and under body. 
The yellow may sometimes be seen fairly good, it being a colour which does not look so bad, when a little thin, as the red. Red, well lustred to the ends of the flights and tail, is undoubtedly the most difficult colour to breed and to maintain in fancy pigeons. Where it exists, black and yellow will be found good. Dun in Barbs is usually of a deep, dark colour, often merging into black. Pure white Barbs are scarce; they appear from time to time as albinos bred from coloured birds. To breed whites with coloured ones would certainly result in a pied produce to some extent, but such are not wished for. By this method, however, some specific marking would be obtainable in time, if wanted. Black, red, yellow, and dun Barbs, are so much crossed that, when any two of them are breeding together, there is great uncertainty as to the colour of the produce. Mr. P. H. Jones, in his description of this pigeon in Mr. Fulton's book, mentions having bred from a pair, in one season, black, red, yellow, dun, and white young ones. He has given the following measurements of the Barb in the same work: "Weight, 13oz. to 1lb.; length, beak to tip of tail, $12 \frac{1}{2} \mathrm{in}$. to 14in.; inner edge of eye to tip of beak, $\frac{7}{8} \mathrm{in}$.; width of skull, a full inch to $1 \frac{1}{8}$ in., measured between, not over, the eye wattles; diameter of eye wattle, $1 \frac{1}{8} \mathrm{in}$.; length of limb, measured as Pouters, $4 \frac{1}{2}$ in. to $4 \frac{3}{4}$ in. These dimensions would apply to cocks, and would be a little modified for hens, more especially in width of skull." He considers these measurements a fair standard, though a few birds might be found to exceed them.

Formerly the native breeds of the Pouter, Carrier, and Shortfaced Tumbler, were regarded as the only high-class pigeons, the Jacobin, Fantail, Owl, Turbit, Barb, and Trumpeter coming lower in the scale, and being regarded as "Toys." Lately, Mr. Fulton, in his book, has removed the Barb from the "Toy" division, and added it to the "high "class" or inner circle, making four varieties of the latter. For my part, I regard the Jacobin and all the Owl family as much choicer pigeons 
than the Barb; but I dislike placing the various breeds in any order of merit, as they are all very high-class pigeons.

\section{The English Carrier Pigeon.}

"This Bird is esteem'd, by the Gentlemen of the Fancy, as: the King of Pigeons, on the Account of its Beauty, and great. Sagacity." So writes old Moore regarding the English Carrier; and I believe, were a vote of English fanciers to be taken today, the English Carrier would still be found to be considered. the "king of pigeons;" while the great majority of Scotchmen would vote for the Pouter. Moore says: "The original of these Pigeons came from Bazora, in Persia, being sometimes brought by shipping, and sometimes in the Carravans; hence by some ignorant People they are call'd Bussories. . . . The Dutch call this Pigeon Bagadat, I suppose from a Corruption of the Name of the City Bagdat, which was formerly old Babylon, which Nimrod built, because they judge this Pigeon in its Way from Bazora to be brought thro' that City." I have not met with this account of the origin of the English Carrier in any book older than the "Columbarium"; it is not to be found in Willughby's "Ornithology," from which Moore has drawn so largely; and as the breed was well established in England, according to Willughby, sixty years before Moore wrote, it is probably a traditionary account. I have satisfied myself, however, that Moore's account is a true one, having had many opportunities of seeing the Carrier Pigeons of Bagdad. In Calcutta, some years since, resided Mr. David J. Ezra, a native of Bagdad, whose business connections extended over all the south of Asia. He had been a Carrier fancier in Bagdad in his youth, and, at the time referred to, the ships that were consigned to him from Bussora-the Bazora of Moore-often brought him Carriers to add to the stock of those birds which he had kept for many years in Calcutta. I shall describe the appearance of these later on. They were kept in an aviary, in the inner courtyard of his house, and 



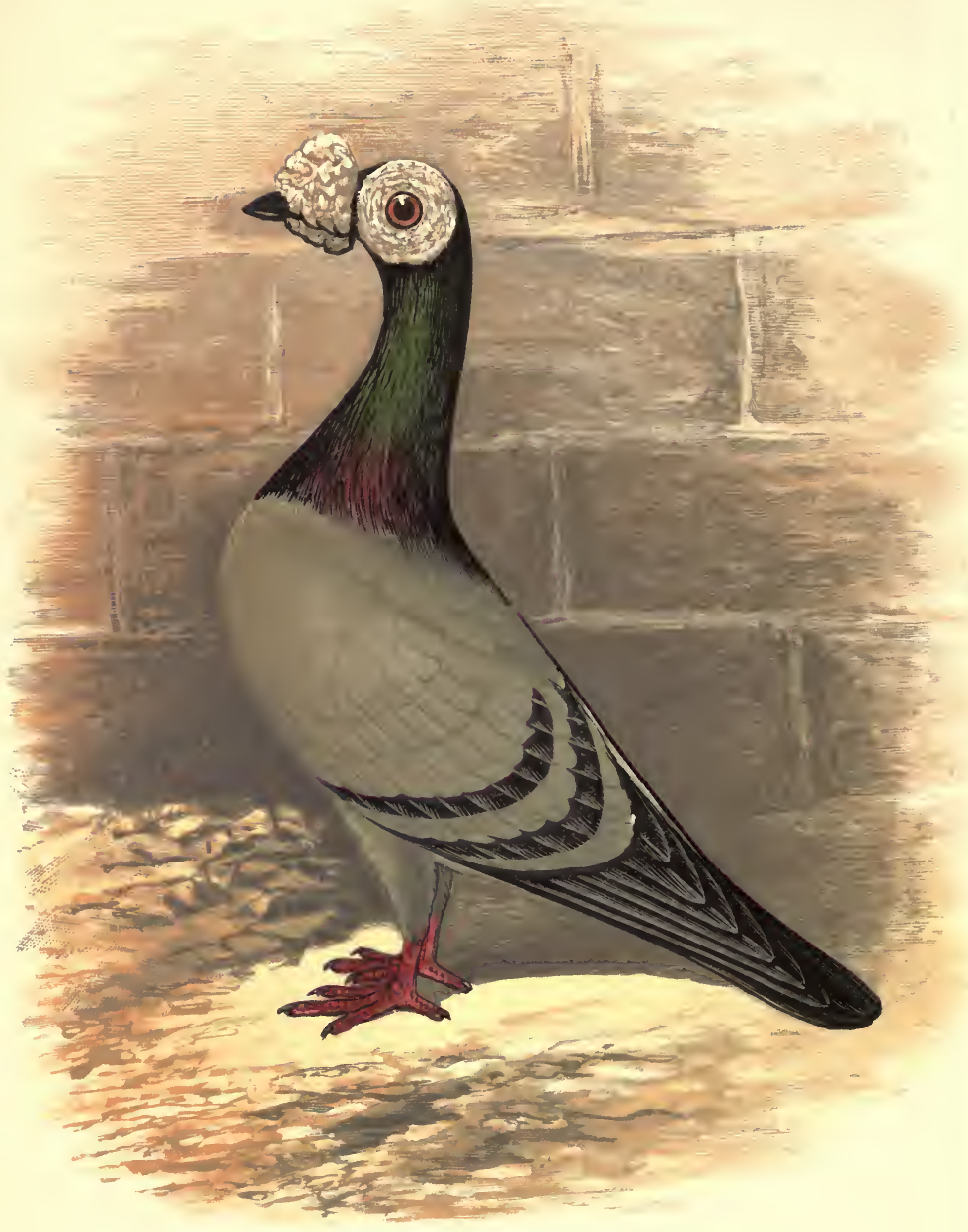

TH E C A R I E R. 
shared, with some Arabian gazelles, the care and attention of their owner.

The earliest description of the English Carrier known to me is Willughby's. He describes these birds as "of equal bigness with common pigeons, or somewhat less, of a dark blue or blackish colour; their eyes are compassed about with a broad circle of naked, tuberous, white, furfuraceous skin; the upper chap of the bill is covered above half way from the head with a double crust of the like fungous skin." The beak is described as black in colour, and not short, but of a moderate length. "Of this kind," he says, "we saw in the King's aviary in St. James's Park, and at Mr. Cope's, an embroiderer in Jewin Street, London." Mr. Cope would seem, from the repeated mention of him by Willughby, to have been a very prominent fancier in London then; and King Charles II., in addition to his fondness for the breed of spaniels which now bears his name, was evidently a Carrier fancier. "Charles was also extremely fond of sauntering in St. James's Park, where he would feed the birds, with which it was well stocked, with his own hands, and on these occasions very much preferred being attended by only one or two of his personal friends rather than by a retinue." This may be found in the short account of the King's personal history in Bohn's edition of Count Grammont's "Memoirs of the Court of Charles II."

It seems strange that, among the many admirers of the Carrier, no one should have written a treatise on it, which might well have been done, considering how much there is in connection with it worth writing about. Some enthusiastic fancier may yet do as much for this pigeon as Windus and Eaton have done for the Almond Tumbler. What might have become a monograph on the English Carrier was begun, in a serial way, in the pages of The Pigeon, by its editor, Mr. Thomas M. Denne, of London, but was never completed, on account of the cessation of that journal through the ill-health of that gentleman. 
The Carrier takes three years and upwards to come to maturity. At some of the principal exhibitions classes are provided for birds bred during the preceding season; but, generally, Carrier classes are only available for old birds. This pigeon looks particularly well during two periods of its existence-viz., when under a year old, when its noble shape and carriage are at their best; and then, again, when its head properties are fully developed. A careful study of all that our old books on pigeons contain regarding it, proves that it has steadily advanced in excellence since Moore's time. Like other varieties which take long to mature, good specimens are very valuable, and I believe the sum of $£ 100$ has been paid, on at least three occasions, for a fine specimen of this breed. Its name is, without doubt, derived from the use made of it when first introduced into this country, the same having been retained when it became strictly a fancier's pigeon. Its sub-varieties, the Horseman and Dragoon-names which also clearly show their origin-were the birds mostly used in Moore's time as homing pigeons, but it was merely because Carriers were too valuable "to risque their being lost upon every trifling wager," as he plainly says, and not that they were incapable of homing a good distance; for, says he, "such is the admirable Cunning, or Sagacity of this Bird, that tho' you carry 'em Hood-winkt, twenty or thirty Miles, nay I have known 'em to be carried three-score or a hundred, and there turn'd loose, they will immediately hasten to the Place where they were bred." When Moore has written this regarding the pure Carriers of his day, we must come to the conclusion that they were not so developed in fancy points as they now are, or that such as could fly sixty to a hundred miles were either comparatively young ones, or old ones which had never made up much in beak and eye wattle. There can be no reasonable doubt that the Carrier is descended from the same stock that has been used for many ages in the East as messenger pigeons, and that, whatever it might be capable of doing now, its relative, the homing Antwerp Carrier, is the variety capable, above all 
others, of homing from great distances. We have no means: of knowing when the originals of our fancy Carriers were first brought into England. It may have been about the time of the Crusades; but, from Moore's succinct account, it is probable that the breed was of no long standing in London when he wrote, and that his words, already quoted, may have been handed down through only a few generations of fanciers. From the fact of pigeons having been used as messengers by the ancient Egyptians and Greeks, and from the fact of a long-faced, heavily beak and eye-wattled, Asiatic breed, being the foundation of the highest developed type of homing pigeon, we may assume that such a breed has existed for a long time in the world.

The points of excellence in the fancy Carrier are the following :-

Size.-The Carrier should be a large pigeon, and the larger the better. From the point of the beak to the end of the tail, as: fanciers measure a pigeon, it should be from 16in. upwards. I once measured a blue hen, and found her 173in., and a young. blue cock of the same strain was $17 \frac{1}{2}$ in. This hen owed her length as much to neck as to feather, and was not badly proportioned in any way. I should say, then, that a full-sized cock Carrier should measure 18in. in feather, without having an unduly long tail. Blues are, however, admitted to be very stylish. and handsome birds, though not generally up to blacks and duns in head properties. For the latter, 17in., at present, is a good measurement.

Shape and Carriage. - In Moore's description of the Carrier, the following sentence occurs: "Their Flesh is naturally firm, and their Feathers close, when they stand erect upon their Legs, their Necks being usually long, there appears in them a wonderful Symmetry of Shape beyond other Pigeons, which are generally crowded on Heaps." This is so well put that I cannot help quoting it. It will be seen from the illustration, that the bird stands very erect, and firmly on its legs, with a long, out- 
stretched neck, and with its beak at right angles to the same. The neck ought to be long and thin, with a clean run under the jaw, showing no gullet or thickness, and with a beautifully arched or rounded-off shape at the back of the head. The neck ought to be, as much as possible, slender all the way down, till it runs into the body; but this appearance is only seen in young birds. As they mature they naturally get thicker at the junction of neck and body. The wing butts should be well forward, and level with the front of the breast, which ought to be broad. The Carrier is naturally shy and wild, and this is of advantage to its shape and carriage in the show pen, as any tameness or familiarity is quite at variance with a statuesque appearance. The inflation of the crop and spreading of the tail, which add to the beauty of a good Pouter, when seen in a Carrier only spoil its fine shape.

The Beak.-This ought to be long, straight, and thick. Moore says: "As to its Length, an Inch and a half is reckon'd a long Beak, tho' there are very good Carriers that are found not to exceed an Inch and a Quarter." The arguments that have been founded on this statement have evidently been based on the assumption that Moore's measurement was the same as that still known as London measure-viz., from the point of the beak to the inner edge of the eye. I cannot believe that Moore measured as far as the eye, considering the length he gives. He evidently measured from the point of the beak to where the feathers begin to grow, behind the mouth. I think the fairest way to measure is from the point of the beak to the centre of the eye, which is the method now generally adopted and best understood. Measured in this way, therefore, the Carrier should be as long as possible; but mere length is of little consequence compared to the style and set of the beak. It ought to be thick, and especially so at the point; and the under mandible ought to approach the upper in consistency as much as possible, fitting closely to it. This is known as a box beak, which is one of the 
greatest beauties of the Carrier. The beak ought next to be straight, and not inclining downwards, or the bird is downfaced, which takes considerably from its appearance. The division between the mandibles should be exactly straight, and, when the bird is in position, level, or at a right angle with the neck. As to the length of the beak, measured to the centre of the eye, 2in. is about the extreme length ever seen in a box-beaked bird. Thin spindle beaks, and those in which the upper mandible has been allowed to grow out past the under, have been seen exceeding this measurement considerably, but such are of no intrinsic value, a blunt box beak being what is desired.

BeaK Wattle.-This being one of the hardest points to breed good, is, accordingly, a valuable one when anything like perfect. A bird has seldom enough of it, to enable it to be shown with success, till it has moulted several times, and it sometimes continues to grow for five or six years. Many kinds of pigeons get rough in beak and eye wattle with age, but the Carrier has an extraordinary development of these parts. This abnormal growth of wattle round the eyes and on the beak constitutes its chief fancy value, all its other properties being merely adjuncts thereto, calculated to set off these wattle points to the greatest advantage. A good beak wattle must be broad across the beak when seen from the front, short in profile view, so as to show as much of the point of the beak as possible, and rise high above the beak with a forward inclination at its summit, which is called being well tilted. The growth of the beak wattle has been compared to that of the cauliflower, which is a good illustration. It ought to rise in three distinct portions as shown, and be as equal as possible in formation on each of its sides, so as to have their indentations, or crevices, corresponding. The wattle on the under mandible is called the "jew wattle," a term not in use in the old pigeon books, and the origin of which is obscure. Some have considered jewed to be a corruption of jawed; but as 
it was customary for the Jews, during the last century, to wear their beards when the English did not do so, the word may be no corruption or technicality, but mean, literally, bearded. The Carrier seems to have had little jew wattle in Moore's time; he refers to the beak wattle as being "sometimes join'd by two small Excrescences of the same kind on each Side of the under Chap." The picture of a Carrier in the Treatise of 1765, however, represents a bird well jewed. The jew wattle ought to be similarly formed to that on the upper mandible, though less in degree; so that, when all is fairly well formed, the beak with its wattles, upper and under, has the shape of a peg top. Sometimes the jew wattle grows very much forward, and is heaviest towards the point of the beak; and this, though not the correct form, is generally found on what are very stout birds. A form of beak wattle called the "walnut wattle" has the three portions on the upper mandible very much in one mass, and not so prominently defined as in the peg-top style. This form, when large and well-shaped, is also valuable. A full-sized beak wattle should measure 4in. in circumference.

The Head ought to be long, narrow, and flat on the top. Length is necessary for the growth of eye wattle, and to prevent the crowding together of the beak and eye wattles. Length of head assists what is called the distance, or space, dividing the eye wattle from that of the beak, and this is also improved by the tilting of the latter. However, Moore very truly says, when writing of the distance: "But I cannot allow this to be a Property, because when a Carrier comes to be three or four years old, if the Eye is broad, and the Wattle large, they must of Necessity meet." This is no doubt true; at the same time, a clear dividing space or distance between the wattles is admired, and, the greater the length of head, the more distance there will be. The head ought to be narrow, and, as much as possible, equally broad over its length; it ought also to be flat across, and is sometimes depressed on 
the crown, which is not considered any fault. There is often a protuberance at the back of the skull, but the less of this the better, as it takes from the graceful curve of the head and neck. If the head be arched from side to side, it is barrelheaded, which is a serious defect. In profile view, however, the head ought to be rather rounded from back to forehead, or there will be no room for a large eye wattle to spread upwards, in which case it must either grow over the crown, or, if thick and heavy, fall downwards over the eye, which is called being beetle-browed.

Exe.-The eye should be large and prominent-bolting, or staring, as it is called by fanciers. When looked at from above, the pupils should be seen standing quite outside of the eye wattles. The bolt eye always tells well in competition, as it gives an otherwise good bird a fine appearance. The irides of black and blue Carriers ought to be, and usually are, of a fiery red; they are lighter in duns, and hazel in whites.

Eye Wattle.-This ought to be as large as is consistent with perfect roundness, and, consequently, the diameter of a perfect eye wattle is limited to an inch or a little more. I have seen a crown piece laid on the eye of a Carrier and not cover the wattle. Such enormous eye wattles are generally accompanied by rather small beak wattles, and are of no intrinsic value, because in their growth they must depart from the true circular shape. The eye wattle ought to be thin rather than thick in substance, soft yet firm in flesh, of an equal breadth all round the eye, and evenly laced. This is known as a "rose eye," is the most difficult to obtain, and the most esteemed. When the inner edge of the eye wattle takes an angular shape, instead of being round, it is known as a diamond eye; but though many admire this, it is not a form of such true beauty as the rose eye. The eye wattle is a property which is subsidiary to the beak wattle, the latter being the most difficult point to get both large and wellshaped. Given a good beak wattle, then a distance is neces- 
sary between it and the eye wattle to set off both, and, consequently, there is only room for a really round eye wattle of a certain diameter. An eye wattle perfectly circular, and more than an inch in diameter, must encroach on the beak wattle, and decrease the distance.

Colour.-The Carrier ought to be self-coloured, and is found black, dun, blue, silver, chequered, and white. Moore says: "Its Feather is chiefly black or dun, tho' there are likewise blues, whites, and pieds of each Feather, but the black and dun answer best the foregoing Properties; yet the blues, and blue pieds are generally esteem'd for their Scarcity, tho' they will not usually come up to the Properties of the foregoing Feathers." This statement remains generally true after a lapse of a century and a half. The black ought to be deep and glossy, showing no dulness on the wing coverts, or with wing bars of a darker colour, as is often the case. A white beak, or the same with a black tip to the upper mandible, is admired, as often accompanying lustrous colour; but though a white or flesh-coloured beak in a black Carrier is admired, it is not a sine quâa non. Strictly speaking, a black pigeon ought to have the beak and toenails black, just as a white pigeon must have them white. A white Pouter without a coloured feather on it would lose all chance in competition if dark beaked; a white beak in a black Pouter would be a serious fault; and a black-headed Nun with a white beak would have no chance in competition whatever, however good otherwise. How, then, does it come that black pigeons, such as Carriers and Barbs, are allowed to have white beaks, and are admired with such? The reason is, that in breeding the different self colours together in Barbs, and the black and light-beaked dun in Carriers, the fleshcoloured beak often remains in the best coloured blacks, so that it has come to be considered by many as correct.

Regarding the colour of the wattles in the Carrier, Moore says: "This Flesh is in some Carriers more inclinable to a 
blackish Colour, which is generally the more valued." At the present time, the whiter they are in the colour of the wattles the better they are liked. Pigeons of brilliant colour are generally inclined to run reddish in the flesh round the eyes, and Carriers are occasionally seen so marked in this respect that very good ones have been distinguished as "red eyed." Many have decidedly reddish flesh-coloured wattles.

The usual method in breeding Carriers is to freely cross the black and dun colours. By this means the black is more easily kept good than by constantly breeding blacks together. The dun, which is generally considered an off-colour in most fancy pigeons, though not in Carriers, is mostly of a soft tint, inclined to fade near the end of the season, and presenting a very dappled appearance during the moult, till all the feathers are renewed. Neither the bright lavender dun seen in some foreign pigeons, nor the deep glossy dun of the Barb, are common in Carriers.

Blue Carriers are still inferior in average quality of head points to the blacks and duns, but in size and shape they are sometimes excellent. They fail, however, for the most part, in colour, being often of a dull or dusky blue on the wing coverts, with indistinct or half-obliterated wing-bars. Blues have of late years risen in favour among fanciers, and some superior ones are occasionally to be seen. Considerable attention is being paid to them, and they will, no doubt, continue to improve.

Silvers are sometimes produced from blues, and have usually the same failing in colour. They are generally hens. The bad colour in blue Carriers is often attributed to crossing with blacks, which is sometimes done to obtain stoutness in head points; but I am of opinion that this bad colour is inherent in the breed, and has always existed since it was introduced, as I have observed the same bad blue colour among the Carriers of Bagdad, the undoubted originals of our Carriers. Black being occasionally bred with blue, and 
all blacks being full of dun blood, the silver colour, which is the original of the dun, is bred from the black-crossed blue as a natural consequence.

As the blue and black, and the silver and dun colours, exist in the breed, their intermediate, or connecting colours, the blue and silver chequers (dun chequers in fanciers' language) are sometimes produced. These colours are not cultivated, however, though birds having them might, if otherwise good, be valuable enough as stock birds. Such blue and dun chequers as are produced in crossing the solid with the barred colours do not illustrate what might be accomplished were they to be bred for as varieties. A correctly-marked chequer must not only be properly dappled on the wing coverts, but show the marking down the rump and on its under body. To get such marking distinct is a very difficult matter indeed. Red and yellow, the choicest colours in domestic pigeons, do not exist in Carriers. I have been told that Mr. Corker, the wellknown fancier, made considerable progress at one time in breeding yellow Carriers, but that he did not persevere in his attempt. There is no doubt that reds and yellows could be produced, but the time and expense requisite for the work would necessarily be very great. Were several breeders to attempt it simultaneously, it is not unlikely that in time both reds and yellows might be bred.

White Carriers existed from Moore's time down to about 1860, when the best collection of them belonged to $\mathrm{Mr}$. Potter, a London breeder. His stock was stolen, and it is believed they were destroyed, as none of them were ever recovered. Since then attempts have been made to resuscitate this variety, and some very good specimens have been bred lately, by General Hassard and others who have been working with them for years. Although there is no sure way of breeding albinos from coloured pigeons, we know that they are occasionally so produced, and I know of several instances. It is not unlikely, therefore, that some one of the many 
Carrier breeders may be fortunate enough to breed a pure white young one from his best black or dun birds, and such would be valuble to a breeder of whites. When an albino is bred from a pair of coloured pigeons, they ought to be kept breeding together if albinos are desired, as they are likely to do the same again, the cause of lack of colour in their produce remaining with them. Ordinary white pigeons are well-covered with yellow down when hatched, but an albino from coloured parents is hatched devoid of down, like the majority of pigeons which afterwards prove to be of a poor yellow; for richly-coloured yellows have a good covering of down when hatched, though not so much as reds and blacks.

Pied Carriers are mentioned by Moore, but how they ought to be pied neither he nor any subsequent writer has set forth. I do not think there is any understanding among fanciers on the question. During the late scarcity of whites, and in the attempts to breed them, parti-coloured birds have been produced, and classes have occasionally been made for "whites or pieds." There is enough in the standard of the Carrier, as a self-coloured bird, to require the utmost attention of its breeders, without adding specific white marking, which would have to be done if pieds were to be recognised. There is no doubt the Carrier looks best as a whole-coloured pigeon. Blacks and duns have often white vents, and occasionally white feathers, or white crutches, as they are called, at their hocks, as well. These faults, in the eyes of some judges, preclude their being shown as self-coloured birds, which, with such pigeons as Carriers, is carrying the letter of the law too far. A white-crutched bird should doubtless lose a point or two in competition, but not be disqualified altogether, unless the white about it is extensive. A merely white-vented bird, which does not show it unless when handled, should only lose to an equally good bird free of white. Many good strains of Carriers have these small faults, which have not been 
considered a disqualification hitherto; but the question is one for breeders to settle among themselves.

When the beak wattle of a Carrier grows unequally, or when its eye wattles become overhanging, causing it to be beetle-browed, cutting and carving them into shape is sometimes practised. Pigeons made up in this way ought, of course, to be disqualified if exhibited, the object of all shows of fancy stock, such as pigeons, poultry, or dogs, being to encourage natural, not artificial, excellence. Carriers cut in the eye wattles for spouts are, however, on a different footing. They have undergone a necessary operation, which should not disqualify them in competition. But as it is an object to breed the true rose eye which will not spout, one cut for that fault ought to be heavily handicapped in competition, as being a bird likely to perpetuate spouting eyes in its produce, and, therefore, not of a desirable type.

\section{The Bagdad Carrier Pigeon.}

My acquaintance with the Carrier Pigeons of Bagdad has been confined to such as were brought to Bengal by Arab ships from Bussora, during my residence in Calcutta. The best I have seen were those I mentioned as belonging to the Jewish merchant, Mr. D. J. Ezra. I occasionally saw an odd pair or two elsewhere, but they were always inferior to his, and would be more correctly described as heavy Dragoons than Carriers. They went by the name of Bagdadees, from their native place. Mr. Ezra, from his position and influence, would be able to obtain the best birds, and I have no doubt that those in his aviary fairly represented the breed. He had about six or seven pairs, some of which were matured pigeons. They were all blues with black bars, most of them rather dusky in colour. I could see no difference between them and English Carriers as regards size and general characteristics. The old cocks had heavy beak wattles and fair eye wattles. Their faults were those of forty-nine out of every 


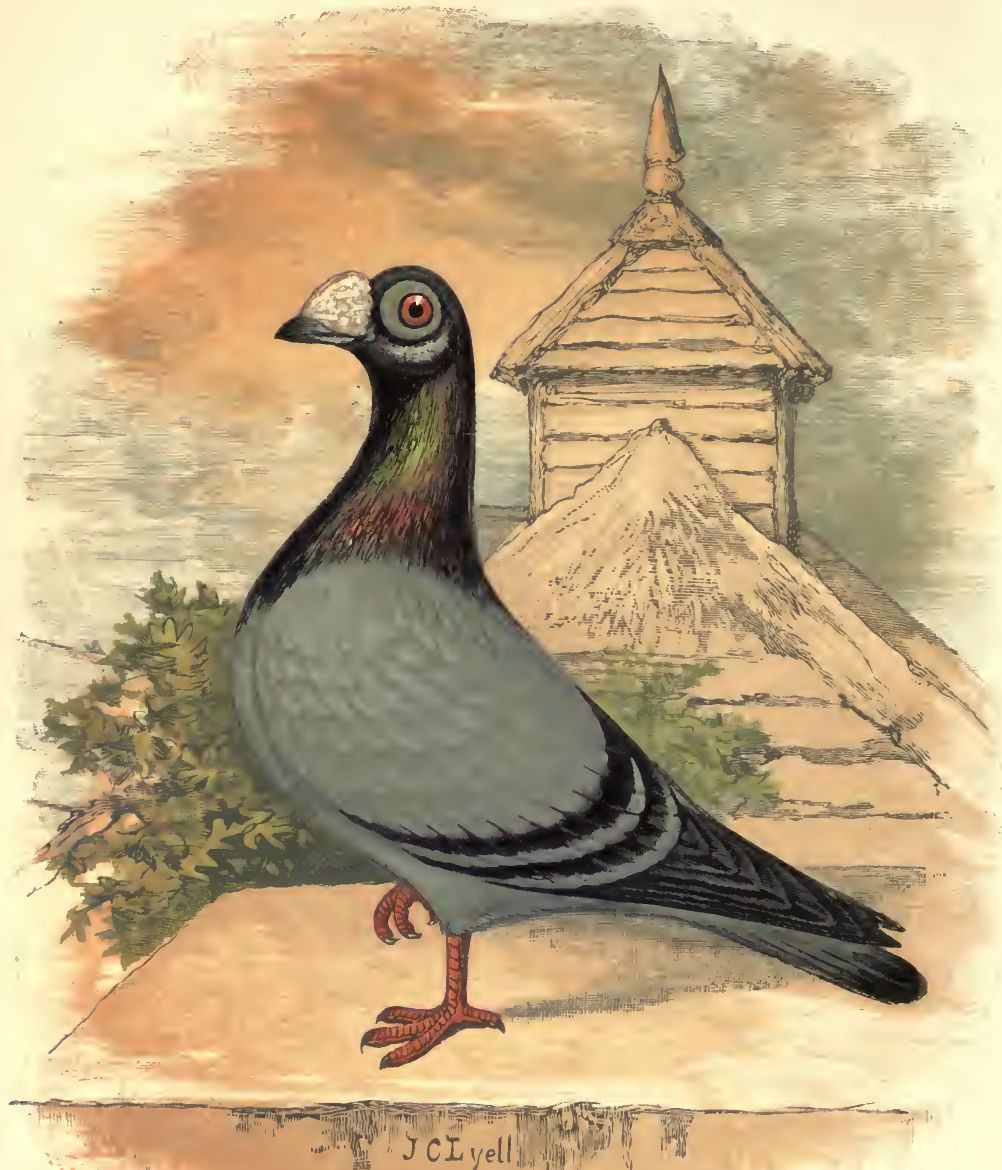

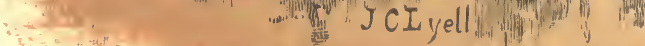

THE DRAGOON. 
fifty English Carriers, an inclination to be broad-skulled and rather down-faced, or Roman-nosed. I consider them, not only from Moore's account, but from their appearance, as the undoubted originals of our Carriers, which have been brought to their present condition by generations of persevering fanciers. And, after all, how many Carriers out of the hundreds bred annually in England are fit to be penned at a first class-show? The best birds we have produce plenty not nearly so stout as the best of those I have seen from Bagdad. Were any good Carrier breeder to visit that city, I believe he might find birds which he would consider well worth bringing home with him, but whether of other colours than blue I am unable to say.

\section{The Dragoon Pigeon.}

Before touching on the Dragoon, it is necessary to say something about the pigeon which our old writers called the Horseman, a bird holding a position somewhere between the Carrier and Dragoon. Although no longer recognised in the fancy, the Horseman was distinguished from the Carrier in being found in greater variety of colour. It was evidently, when Moore wrote, the pigeon capable of flying the longest distances, and it had then a distinct place in the fancy, as will be seen from the following passage in Moore's work: "This Pigeon in Shape and Make very much resembles the Carrier, only it is smaller in all its Properties, viz. Somewhat less in Body, shorter neck'd, the protuberant Flesh upon the Beak Smaller, as likewise that round the Eye, so that there remains a larger Space or Distance between the Wattle and the Eye, in this Pigeon than in the Carrier. They are generally more inclin'd to be barrel-headed, and their Eye somewhat pinch'd.

"It is to this Day a Matter of Dispute, whether this be an original Pigeon: or whether it be not a bastard strain, bred between a Carrier and a Tumbler, or a Carrier and a Powter, and so bred over again from a Carrier, and the oft'ner it is thus bred, the stouter the Horseman becomes. 
"The only thing that seems inclinable to favour the Opinion, that they are original, is a strain of this kind brought over from Scanderoon, which will fly very great Lengths and very swift; but still the Answer readily occurs, that they may be bred originally the same way at Scanderoon, and so transmitted to us, however, non nostrum est inter vos tantas componere lites, that is, we shan't take upon us to determine such Controversies as these.

"There are of this kind, of all Manners of Feathers; but the Blue and Blue-pieds are most noted to be genuine and good, and if flown are very good breeders.

"These are one of the sorts of Pigeons that are chiefly made Use of in England, for the carriage of Letters, or flying of Wagers; because those that are possess'd of the true original Carriers, which are at present very scarce here, pay too dear, and have too great a Value for them, to risque their being lost upon every trifling wager.

“These Pigeons when regularly flown, twice on a Day, that is, turn'd out alone and put upon wing without any others, will fly very large Circumferences, so that after they have made a Tour or two round your own House, they will fly four or five Miles out at Length and so maintain the Circuit for an Hour or two: This the Fancyers call going an End, and is what Daniel Moggs, who was one of the oldest Fancyers, meant, when he jocularly us'd to bid his Pigeons maintain their Length.

"This Practice is of admirable Service to 'em, when they come to be train'd for the homing Part."

And the following is the whole of what Moore says about the Dragoon :

"This Pigeon is absolutely and without dispute a bastard Strain, being bred originally between a Horseman and a Tumbler, and by matching their breed often to the Horseman, they will obtain a tolerable Degree of Stoutness.

"This Pigeon is a very good breeder, and as they are 
somewhat less than a Horseman, are reckon'd lighter, and more expeditious in their Flight, for ten or twenty Miles, but the Horseman if good, will generally out-do them at a greater Length; they ought to be flown and train'd like the foregoing."

During the last few years the Dragoon has been extensively bred and shown, and its popularity has been so great that, even at first-class shows, it has been encouraged with a classification and an amount of prize money out of all proportion to its merits. This pandering to false taste in pigeon breeding culminated at the Oxford Show of 1876, where Dragoons had eighteen classes, against sixteen for Carriers, Pouters, Tumblers, and Barbs combined. Wearisome discussions have also gone on for years over the standard of a Dragoon, and I am not aware if those who have a place in their hearts for fancy pigeons which the Dragoon is capable of filling have settled the matter amongst themselves yet. Some time ago the National Peristeronic Society of London appointed a committee of its members to consider the question, and, on the 6th January, 1880, this committee, after taking the subject to avizandum, handed in the following report, which it was hoped would have been accepted as the conclusion of the whole matter; but it merely opened up some fresh discussions, so that their deliverance can only be called an interlocutor after all.

"Gentlemen,-Your Committee, appointed to consider and note the points of the Dragon, have the satisfaction of presenting in their Report the following enumeration of properties which, subject to your approval, will constitute the Standard of the Dragon as recognised by the Members of the National Peristeronic Society.

"The Skull wedge-shaped and broad, yet proportionate to the stoutness and length of the beak, slightly curved when viewed from the side or front, thus showing no angle or extended flat surface. 
"The Beak thick at its base, and so continuing for about half its length, thence gradually lessening in calibre. Measurement from the termination of the beak horn to the anterior corner of the eye, not less than $1 \frac{1}{2} \mathrm{in}$. The lower mandible, stout and straight; the upper, also thick, and terminating in a slight curve.

"The Beak-wattle peg-shaped-i.e., broad and perpendicular" at its base, narrowing with even sides and longitudinal furrows towards the point of the upper mandible, but not intruding on the lower.

"The Eye-wattle small, not fleshy, nearly circular, slightly pinched at the back.

"The Eye prominent and watchful. In blues, silvers, chequers, and grizzles, the irides of a deep rich red colour. In other varieties, an approximation to this colour, except in whites, in which the iris is dark coloured.

"The Neck of medium length, neither thin nor gulleted at the head, and widening boldly at the shoulders.

"The Breast broad, the Shoulders prominently defined.

"The Back nearly straight, neither hollow nor hogged.

"The Wings strong, the Flights carried slightly above the tail.

"The Tail running in a line with the back, carried clear of the ground, and extending quite half-an-inch beyond the tips of the wings.

"Measurement of the Leg, from the hock to the foot, about 1 $\frac{1}{2}$ in. The Thigh stout and muscular. The whole length of the Dragon, from the point of the beak to the extremity of the tail, about $15 \mathrm{in}$.

"Colour in Blues.-The Neck dark and lustrous; the Body, Rump, and Thighs, a leaden blue of uniform shade. MarkingsA broad black bar across the end of the tail. Two black bars, about $\frac{3}{8}$ of an inch wide, even and distinct, running transversely from top to bottom of each wing, in the form of the letter $\mathrm{V}$ inverted. Colour of beak, black. Colour of eyewattle, a deep blue-grey. 
"Silvers.-An uniform and bright creamy tint. Neck of a deeper shade. Bars as black as possible. Beak of a dark shade.

"Grizzles and Chequers.-Each feather distinctly grizzled or chequered. The Markings, colour of Beaks, and Eye-wattles, same as in blues.

"Yellows and Reds.-Colour uniform and bright. Beak of an even flesh colour."

The foregoing scale of points nearly agrees with what was formerly known as the "London style," opposed to which, the "Birmingham School" upheld a more Skinnumy kind of Dragoon. Both kinds are fully described by their partisans in Mr. Fulton's book, where coloured plates of each are given. I think no one can carefully read Moore's descriptions of the Horseman and Dragoon without coming to the conclusion that the latter was, in his day, a different bird from the modern London one, which closely approximates to his description of the Horseman, with its barrel head, pinched eye, and various colours, of which "the blues and blue-pieds are most noted to be genuine and good." I think that, in the course of time, Moore's Horseman and Dragoon have gradually amalgamated in the present London Dragoon, which has become of a somewhat fixed type in the hands of London pigeon keepers, though probably without much design on their part; and now, in these days of pigeon shows, when, in the course of a year, a typical bird, according to the foregoing standard, can win quite a large sum of money in prizes, it is no wonder that what was, before show days, a pigeon worth only a few shillings, is now very valuable indeed.

On comparing the standards of the Carrier and Dragoon, it will be seen that much which is faulty in the former becomes positively excellent in the latter. From this it might be supposed that a very bad Carrier would make a very good Dragoon, which is by no means the case, for, in practice, it is found no easy matter to breed the latter good according to the 
standard. About the time of the Oxford Show, in 1876, already referred to, Mr. Denne, editor of the Pigeon, published an article in that paper on "Exhibiting and Breeding Dragoons," from which I copy the following: "It matters not what interested parties may say, the real value of Dragoons is about four or five shillings a pair. Of course, temporary causes, such as this sudden run upon them for exhibition, may cause the price of them to rise to much more than this, but the price we name is the true one, as experienced men know, and we have bought scores of pairs as good as ever have been seen, and could have bought thousands at the price. We have even bought them as late as the early part of this year, and end of last, at an average price of seven shillings a pair, as good as need be wished for, and, in some cases, good enough to win prizes. The highest price we ever paid for a Dragoon, in the whole of our experience, we paid this year, viz., seven and sixpence for a blue hen, and, at the time we did so, thought we must have been slightly 'touched' to pay such a price. From these birds we purchased we could, had we been disposed to have gone in for Dragoon breeding, have bred as good blues, chequers, and grizzles, in the course of one, or, at the most, two seasons, as the 'next man,' and so can anyone who has a very slight knowledge of breeding, by following the instructions we will give."

Before the days of pigeon shows, a pair of choice Pouters, Carriers, or Almond Tumblers, were worth as many sovereigns as the best Dragoons were worth shillings. How is it, then, that now a good Dragoon is worth, roundly speaking, about as much as a good pigeon of these varieties? Merely because it pays well enough to give as much for a bird as it can win in a season. The Dragoon formerly held the present position of the homing Antwerp Carrier, and, like it, may have been occasionally worth a large sum for flying purposes. It now holds the same position as the Short-faced exhibition Antwerp, and is just about equal to it as a fancy pigeon. Both would go down to their former price of a few shillings a pair but for show encourage- 
ment. Real fancy pigeons have undoubtedly risen in value since shows were established; but they were highly valued before, and they would continue to be highly valued were pigeon shows abolished. To establish a breed of exhibition pigeons from the faulty produce of Barbs, taking as their standard of perfection a narrow skull, a small pinched eye wattle, and a run-out face of a certain length, would be an analogous case to what has been done with the Dragoon since pigeon shows were established. Before then the breed had no fancy value whatever, and it has no fancy value now out of England, and only there within a limited circle.

The first thing to be observed in the National Peristeronic Society's standard of the Dragoon is the name they give it-the "Dragon." The analogy between the names Carrier, Horseman, and Dragoon, is clear, but at some time before the oldest living fanciers were born it became usual to call the Dragoon the Dragon, This is noticed in Moubray's Poultry Book, first. published in 1815, and which went through five editions in ten years. The author says: "Dragoons (commonly called Dragons)." The name would easily become corrupted, and more easily pronounceable among illiterate pigeon keepers, who were, doubtless, formerly the chief breeders of Dragoons; and, when gentlemen went to buy feeders for their Carriers and Pouters, they would hear them spoken of by shopkeepers, and others, as Dragons, and so gradually come to speak of them by that. name among themselves. I have known a similar alteration of the name in my own experience. I can remember when there were very few Dragoons, Skinnums, or Antwerps in Dundee, nothing but flying Tumblers being fancied by the poorer class of pigeon keepers. When homing pigeons became in request, everything with the least beak or eye wattle more than a Tumbler was known, in their language, as a "Draigon." This was afterwards shortened into "Draig," and now the word is "Drake." I was once rather surprised to hear a gentleman's son tell me he had some fine "Drake" pigeons. I have written 
Dragon before now for Dragoon, but I admit there is no defence for this. However the word may be pronounced in conversation, it ought to be written as of old, because its meaning is clear, and not obscure. There is a quaint note by Eaton, on page 59 of his 1858 book, on this question: "Why do authors on pigeons spell the Dragon with two ' $o$ 's', making the word Dragoon, a kind of soldier, \&c. (Walker)? In society we never call it the Dragoon, but the Dragon-Drag-un, a winged serpent (Walker), from which it derives its name. I hope no author who follows me will be guilty of doing it." This is amusing, and very Eatonesque.

I must next say something about the beak and eye wattles of the Dragoon. What they ought to be in a show bird is clearly stated; but it is quite usual for the best birds, while still in the very prime of life, to put on, with advancing age, more wattle than is allowable for the show-pen, or to become "more than a Dragon," as it is called. This bird, therefore, occupies a quite unique position among exhibition pigeons. A Fantail can never become more than a Fantail, nor a Jacobin more than a Jacobin. I have seen Dragoons that could win prizes at from two to three years of age become, when five or six, great coarse-wattled, pinch-eyed Horsemen. They are then only fit for stock birds.

The colours of Dragoons mentioned in the Peristeronic Society's Report do not include black and dun. This is wisdom itself. It would scarcely do, for reasons good, to have show Dragoons of these colours. There was once an inquiry in The Bazaar newspaper on this very subject, and the answer given was this: "They would have no chance in competition whatever." But why not? I would have thought that, the more variety of colour in a breed, the better. It will be seen from the Report, that the said Society advocates a silver with dark beak and eyes, and with bars as black as possible. There can be no harm in fancying such a colour, but why should the real silver be ignored, and not even be mentioned? As I have said 
before, what may be called the four primary barred colours of pigeons include the silver with dun bars. There are many variations in the colours of wing bars in pigeons, one of whichthe body colour of the silver with the black bar of the blue, or as near it as possible-is what many consider a silver ought to be; but I know this is a mistake. The golden dun barred Dragoon, generally called brown barred, is a well-known variety, which ought to be recognised. It has a yellow iris and light beak.

A well-known breeder of blue Carriers told me that, having an odd blue Carrier cock matched to an Antwerp hen as feeders, he bred a young one from them which so took the fancy of a Dragoon breeder that he gave him $£ 7$ for it.

The following is from the "Treatise on Pigeons," 1765, page 89 : "They are very good breeders, and good nurses; and are chiefly kept as feeders for raising of Powters, Leghorn Runts, \&c.

"The following may be depended upon as fact, notwithstanding the appearance of incredibility, as several gentlemen now living can affirm the same if requisite:

"A gentleman of my acquaintance, having a small wager depending, sent a Dragoon by the stage coach to his friend at St. Edmond's Bury, together with a note, desiring the Pigeon, two days after his arrival there, might be thrown up precisely when the town clock struck nine in the morning, which was accordingly executed, and the Pigeon arrived in London, and flew to the sign of the Bull Inn, in Bishopsgate Street, into the loft, and was there shewn at half-an-hour past eleven o'clock the same morning on which he had been thrown up at St. Edmond's Bury, having flown seventy-two miles in two hours and a half; the wager was confirmed by a letter sent by the next post from the person at St. Edmond's Bury.

"I could relate several more exploits of this nature performed by Dragoons; particularly of their being thrown up and returning home by moonlight, \&c." 
In Eaton's 1858 book, page 59, there is also the following note by Mr. John Boys: "Thirty-six years ago, when my collection of Dragons (about thirty) every morning brought me from London, in slips, the leading article of the Morning Post newspaper, tied round the leg"-regarding which, Eaton adds : "From London to Margate, seventy-two miles; a decent fly, and proves Dragons can do work."

Blue and blue chequered Dragoons ought to have a dark eye wattle, something like that of the Mahomet Pigeon. It appears to get lighter in colour with age, and, if report can be believed, is often produced artificially.

\section{Foreign Wattled Pigeons.}

French Bagdads.-There are various kinds of beak and eye-wattled pigeons described by Continental writers, all of which are called Bagdads, or Turks, which serves to show they are considered to be of Eastern origin. Such as seem of distinct breed from our Carriers, though undoubtedly belonging to the same family, are described as follows by Boitard and Corbie, whose work on pigeons, it must be remembered, was published in Paris in 1824. Whether or not the varieties mentioned are still in existence is more than I can say.

Great Wattled, or Mushroomed Bagdad (Pigeon Bagadais ¿े Grande Morille).- "A mushroom, or large fleshy excrescence on the beak; large ribbon round the eyes, forming, when the bird is old, a second eyelid, fleshy and reddish, which falls over the eyes and prevents it from seeing. These ribbons (eye wattles) are sometimes so large that they join at the top of the head. Beak curved and crooked; eye black. This bird is thick, high on the legs, large, and short in the body, the neck fine and long, wings short, legs bare. Its backmost part is always of an inflamed red. There are several sub-varieties, with plumage black, red, black and white, dun, \&c. They all produce little, and with difficulty; they have also become very rare, and are scarcely preserved, except as a curiosity." 
Batavian Bagdad (Pigeon Bagadais Batave).--"Some authors call it Grand Batavian, because the first of them were brought from Batavia; they think also that it, and not the Blue Rock Pigeon, ought to be regarded as the primitive stock of the Bagdads. Larger than the Great Mushroomed Bagdad, though with less beak and eye wattle; pearled eyes; very long beak, attaining up to dix-huit lignes de longeur; neck extremely long; body large, short, and very high on the legs; feet. and legs of the colour of blood, often long enough to get a good finger length beyond the tail when stretched out. Its walk is heavy. and its flight laborious, on account of its short wings, which, besides, are sparsely covered with feathers, and the prominent bones of the shoulders appear nearly bare. It produces little, and is not now much sought after by amateurs, who formerly did not grudge to pay up to ten louis a pair for them. This is no doubt owing to the little grace of their form, and the destruction they make in the aviary in plucking and killing the young of others with their formidable beaks. This bird is the largest of all pigeons. M. Corbie has one large enough to drink out of an ordinary bucket without the least trouble. There has been seen, with a fancier coming from Germany, a bird called a Hen Pigeon" (Leghorn Runt, or Hühnertaube), " in all respects like the Batavian, except having no beak and eye wattle."

Boitard and Corbie's illustration of this curious pigeon has been copied by Brent, on page 21 of his book, and called the Scanderoon, or Great Horseman. It has much in common with my drawing of the Leghorn Runt, but its very short tail is carried below its flights. I can scarcely believe that its original home was in Batavia, though brought thence to France. There has for centuries been a trade between Batavia and the Persian Gulf. This is said to be the largest. of all pigeons, not excepting the Runt, or Pigeon Romain. It is also described by Neumeister-who gives a drawing of it, coloured red (Plate XVII. of his book)-as the 
Französische Bagdette. He speaks of it in similar terms to the foregoing, adding that the tail is sometimes carried upright, but must not be like a swallow's tail-probably meaning that it must be close, and not split. He says the plumage is close, fitting the body so tightly that all its parts are sharply prominent, especially the shoulders and the breast bone, the bare skin being often visible on these parts, which is a peculiarity, more or less, of all the Carrier race. Brent says : "I have met with very fine specimens in France, by the name of Swan-necked Egyptians. They are very large pigeons, almost as large as the best Runts. They are thinly covered with feathers, and these lie very close to the body; neither are the tail and pinion feathers remarkable for length. Their beaks are very long, and somewhat bent, and they have a moderate wattle, of a whitish colour, and the cere round the eyes is broad and red. The head is flat; the neck long, thin, and much bent; the shoulders are broad; the legs long and large, and they are the most powerful of all pigeons I have met with. They are heavy, clumsy birds, and appear to have great difficulty in rising; but I have found the young, if kept in exercise, and not allowed to get too fat, to be very swift, and excellent homing birds. In the air they remind me of wild ducks, owing to their scanty plumage and angular form. Many points of the body are left bare, as the front of the neck and the shoulders of the wings, exposing a red skin. Mine were very good breeders, though they are not generally considered so. Their plumage is usually white, black, blue, or pied." It is worth notice that Brent found these pigeons excellent homing birds.

The Little Batavian Bagdad (Pigeon Bagadais petit Batave) "resembles in general form the Great Batavian, but differs in its size, being much less. It produces advantageously."

The Lace-feathered Batavian Bagdad (Pigeon Bagadais Batave Soie).- "A new variety, quite as rare as singular. It resembles the preceding (petit Batave) in size and general form, but the fibres of its feathers are long and silky, and 



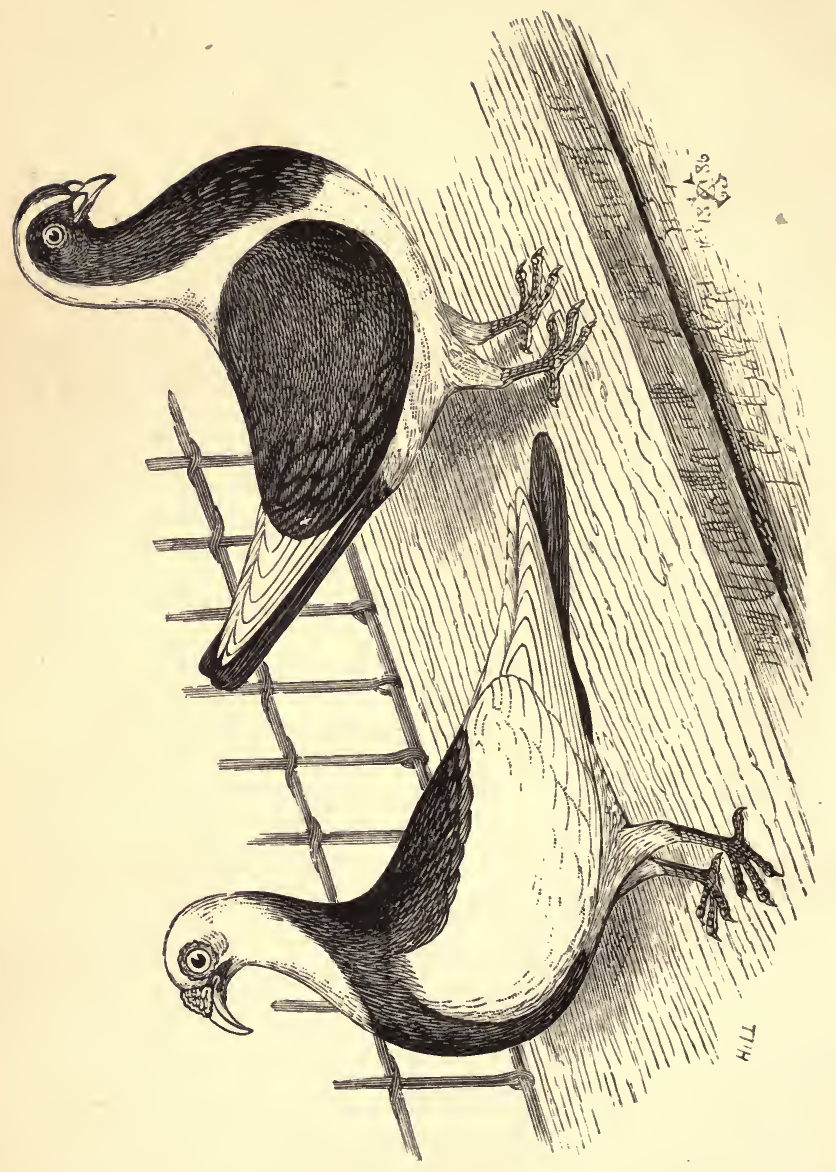

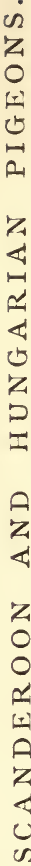


do not adhere together, which prevents it from flying. This bird, which is not in commerce, no doubt only multiplies in the hands of amateurs, who only consider it an object of curiosity."

I am not aware if this variety still exists, but the fact of a Lace-feathered Bagdad having existed shows that such a natural variation in feathering might occur in any breed.

TuRKish BAgDads (Pigeons Turcs).- " These superb birds make the natural link between the Bagdads and Runts. They have, like the first, a large beak and eye wattle, the latter red in colour, and are of large size; but they come nearer to the Runts by their thighs, legs, and neck, being shorter, and by their long wings." They are described as of various colours, and both crested and plain-headed. I believe most of the fancy Runts, such as the one I made my drawing from, have the blood of these Turcs, as they have more beak and eye wattle than the common blue and silver Runts. Brent has reproduced the portrait of a Pigeon Turc on page 20 of his book.

German Bagdads.-We come next to the German varieties of the Carrier family, as described by Neumeister, which are as follows :

The Short-faced Turkish Bagdad (Die Kurzschnäbelige Bagdette, or Türlischetaube).-This variety is illustrated on Plate XIV. of his work on pigeons, and is represented as both crested and plain-headed, self-coloured black, red, and yellow, rather short in beak, and looking very like short-faced English Dragoon Pigeons.

The Nürnberg Bagdad (Die Deutsche Krummschnäbelige Bag. dette, or Nürnberger Bagdette). -The crooked-beaked Bagdad is already well known in England as the Scanderoon, and is well portrayed, by Mr. Ludlow, in Mr. Fulton's book. The German fancier, Führer, has thus described, in Neumeister's work, the history and standard of excellence of this bird: "This exceedingly interesting pigeon, resembling more a fierce bird of prey than a peaceful, granivorous bird, had its home 
in the Orient, and was probably first brought into commerce from Bagdad. In Germany, it is chiefly at Nürnberg that it is beautifully bred, a town which, hundreds of years ago, was in a lively commercial intercourse with the Levant, and has the merit of having introduced, and first bred, this stately bird, where it is said to be still the favourite pigeon. The beak must be beautifully bent, long, thick, blunt, and light coloured; the beak wattle must sit deeply below on the brow, rather flat than high, heart-shaped, and not too broad; the head must be long and narrow, and, seen from the side, must form a semicircle from the nape to the point of the beak; the eye wattle, or rose, must be large, flat, and regular, bright red in early age, later in life rather white; the neck long and thin, and the chin adorned with a beard; the body must show a broad back and breast; the ridge of the breast bone must spring forth sharply; the pinions must be narrow and short, the tail short, and legs high.

"If the brow and beak form an angle, if the crown has a depression, if the upper mandible is longer than the under, or if they do not fit close, these are faults which are opposed to the beauty of the race."

The only thing obscure in the above is the chin being adorned with a beard, which word is used in Germany to designate various properties in pigeons. If, in this instance, it means the slight jew wattle inseparable from all abnormally wattled pigeons, the less of it the better. I should say that a clean-cut, hollow curve, from the point of the lower mandible, down the throat, would look best... It is said that, in whole colours, this pigeon is only found of the highest type all white. The pied ones are the most valued, and on the regularity of their markings fanciers set a high value. The chief marking is that shown in Mr. Ludlow's drawing, and may be described as exactly the same as that of the Magpie Pigeon, except that the head and upper neck are white. From low down on the nape, the white runs down the sides of the neck, 
to a point on the breast, forming a pointed bib. There ought to be a spot of colour on each side of the face, at the gape of the mouth, and this is shown in the illustration of the breed in Herr Prütz's new book. There are also others coloured, in addition, on lower body, from breast to tail, including the thighs, the head and bib, wing coverts and flights, remaining white. The back must always remain coloured, as in the Magpie, and form the figure of a heart, and is known as "the heart." Others, again, are all coloured except the head, upper neck and bib, flight feathers, and butts of the wings, as in the Stork Pigeon. The quality of colour in this variety is sometimes superb.

"Its flight is powerful, quick, and more stormy than dexterous; its voice abrupt and deep. Towards smaller pigeons it is violent, and therefore not suited to live with them, and best kept alone. It shows mistrust to men, and only gradually becomes accustomed to its feeder." This wild nature is common to all the Carrier race and their descendants.

The Himalayan Carrier.-When writing about Indian pigeons, I mentioned some gentlemen named Wood, whom I knew in Calcutta as enthusiastic pigeon fanciers. There were four brothers of them who bred choice pigeons, and their father had done so before them. The eldest brother had the largest and best collection I knew of in Calcutta, with the exception of that belonging to the ex-King of Oude. It was in Mr. Wood's aviaries I first saw this variety, which I have named as above; the native name $I$ have forgotten, if $I$ ever heard it. This pigeon is about the size of an average Dragoon. It is very hard and close-feathered, upright in carriage, thin in neck, moderately long in neck and limbs, and inclined to be short in flights and tail. It is short in face, measuring about 13in. from centre of eye. The beak is stout and thick at the base, sharp rather than blunt at the point, and straight. The head is angular, or wedge-shaped, the brow forming an angle with the crown and beak. It has a smooth beak wattle, of 
moderate amount, which never grows quite so large as that considered necessary for a show Dragoon. The striking point about this pigeon is its staring or bolting eyes, which stand further out of its head than I have ever seen in other pigeons; these are mostly hazel-coloured, large, bright, and surrounded by a thin, smooth wattle, of about $\frac{5}{8}$ in. diameter in matured birds. The colours of those birds I.saw were black or blue pied, the white predominating, and some being nearly all white. The black and blue patches were disposed without any regularity, no two birds being exactly alike. This pigeon, though a sub-variety of the Carrier, has assumed a distinct type of its own, and bears a highly-bred look. I was told that the breed had been brought from some of the countries north of the Himalayan mountains.

The only specimen of the Himalayan Carrier I have seen in this country is at present in my possession. Going on board an East Indiaman in Dundee Docks last March (1886), I saw the bird walking about the quarter-deck. The captain gave it to me; it is all white, with dark horn-coloured beak, and orange eyes. The eye wattle, which resembles that of a show Dragoon in its prime, is of a reddish purple hue; but the greatest peculiarity of the bird is its bolting eyes, and the great space between the irides and the eye wattles.

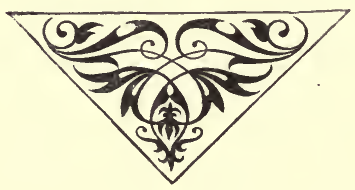




\section{Chapter XXV.}

\section{$\propto$ THE TUMBLER PIGEON. $\varnothing$}

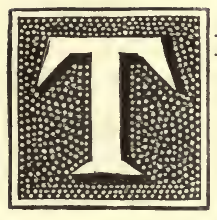

HE above heading causes the almost forgotten past to be remembered. Visions of bygone celebrities, that were known by such names as the Red Mottle, the Blue Hen, and the Red Breaster, crowd up from the days of the springtime of life. I recall the feat of my little blue Tumbler, which, when heading against a strong wind, and neither making nor losing any headway, turned clean over forty times within the minute, in the same aërial space. The pennies that ought to have been spent on biscuits to appease the mid-day appetite, were hoarded up till such a sum was accumulated as would cause some well-known performer to change ownership; and then there was joy in fetching it home, the basket being opened many times on the way for " another look." I should think there are more Tumbler pigeons kept in this country than there are of all other fancy kinds put together, and that the accumulation of genuine pleasure derived by their owners from them exceeds that from all other kinds. Many a fancier has begun with Tumblers, and but few refuse to provide a place for their 
first favourites, into whatever other channels their fancy may roam.

The Tumbler derives its name from its inherited propensity of turning over backwards in its flight. What causes it to tumble over in this way is not known, though many theories have been propounded to account for it. Some wellbred birds never attain to it, while others carry it to such an excess that they cannot rise from the ground a couple of feet. The latter kind, known as Ground Tumblers, often resume flying and tumbling in the air, and again become Grounders. House Tumblers are such as can rise from the ground, but often tumble in their flight across a room; they do not, however, always perform when required to do so. Air Tumblers sometimes become so proficient and systematic in their performances that they change hands for 10s. each and upwards among poor men. Such birds will sometimes go off tumbling, and fall in value to the normal price of a shilling, and, after remaining very ordinary ones for a year or two, suddenly become good ones again, and rise in value in proportion. Many a good Tumbler has never given a turn till two or three years old, and some can never get more than half over in their attempts to turn. I certainly think that, in the case of ordinary Tumblers, tumbling is a real pleasure to them, and that they do it voluntarily; but the habit grows on some birds to such an extent, that they either cannot rise from the ground, or, when in mid air, lose command of themselves, and, striking against some projection, destroy themselves.

There are many styles of tumbling, and the one most generally admired is that in which the bird turns over once at a time, and often, but without losing way in its flight. At the same time, those that rise and fall in the air by alternate soaring and rolling-each roll being composed of several backward turns-are also liked by many people. Some birds make the most extraordinary motions in the air, 
turning at right angles in their flight, and throwing themselves about so rapidly that the eye can scarcely follow their turns. High-flying Tumblers generally tumble only when ascending or descending; but they sometimes go so high-in fact, quite out of sight-that it is impossible to follow them in their movements. I have watched them, on a clear day, till they seemed no bigger than mites, and then lost them altogether. Some remaining on the housetops are seen by those in the air, and this tends to bring them down sooner than they might otherwise come. Tumblers, when allowed unlimited freedom, become lazy, and unwilling to fly, and seldom fly in concert.

Great care and much trouble are necessary in getting up a good flight of Tumblers; birds that will not rise must be weeded out. To insure success, the birds must be flown only at stated times. The morning is the best time, before they are fed; and after they return to their loft they should be confined till late in the afternoon, or till next morning, according to the wishes of their owner. To fly Tumblers systematically is, indeed, a separate branch of the pigeon fancy, which is only excelled in by such as lay themselves out for it. I have known fanciers, including myself, buy the best soaring birds that could be got, and I have seen them gradually deteriorate for want of the necessary attention. Tumblers require special training for flying time matches. Dried peas, and other grain, are considered the best foods for them, as such take long to digest, and assist in keeping up their strength during the time they keep on the wing. Without such special foods they would be unable to fly so long as they do.

Mr. G. Smith, a breeder of high-flying Tumblers and Tipplers in Nottingham, has lately published a little book giving information, derived from experience, on this fancy. 
The following Tippler handicap was flown Tuesday, 30th March, 1886, at Leicester :

NAMES.

TIME.

START.

W. Warner $\quad \ldots \quad \ldots \quad 11 \mathrm{hr}$. 9min. $\quad \ldots \quad \ldots \quad$ Scratch.

W. Holland $\ldots \begin{array}{lllllll} & \ldots & 11 & 4 & \ldots & \ldots & \text { Scratch. }\end{array}$

$\begin{array}{lllllllll}\text { W. Allen } & \ldots & \ldots & 10 & 45 & \ldots & \ldots & \text { Scratch. }\end{array}$

$\begin{array}{lllllllll}\text { R. Collins } & \ldots & \ldots & 4 & 7 & \ldots & \ldots & 30 \mathrm{~min} .\end{array}$

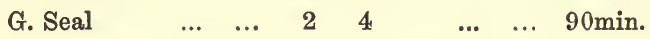

The birds were started at 8.0 a.m.

Mr. W. Holland, of 15, New Walk, Leicester, made a match to fly his birds for twelve hours. The birds were started on Monday, 12th April, at 6 a.m., and had to be dropped at night. Time, $13 \mathrm{hrs}$. $45 \mathrm{~min}$. - the best on record with Tipplers.

\section{Common Tumblers.}

The Tumbler is spread in great variety throughout Europe and Asia. It has long been known in this country, and is described by Willughby (1678). He says: "These are small, and of divers colours. They have strange motions, turning themselves backwards over their heads, and show like footballs in the air." The ordinary Tumbler of this country is a small pigeon, thin in the neck, full in the breast, of medium length in flights and tail, short-legged, and free of leg and foot feather. The head is rounded, and free from sharp angles, and the forehead of middle height. The beak should be short and thin, or what is known as a spindle beak. The beak wattle and eye wattle should not be greatly developed. The eye should be white or pearl-coloured in the iris, but is usually of a red pearl, not nearly so white as in the Continental Cumulet. There are, however, many yellow, red, and hazel-eyed birds as good performers as ever flew; but I am describing the Tumbler as it ought to be when shown, and as it is in many lofts where kept only to be flown, for goodlooking birds that are good performers as well, may be got 
by selection from the immense numbers kept in every large town. I have seen good clean-legged Tumblers with shell crests, and also peak-headed ones. I once bred several peaked yellow whole feathers from a pair of smooth-headed ones. I could only account for this variation as a natural sport.

The Tumbler is found in all the principal colours, such as whole blue, silver, black, red, yellow, dun, and white; and in such infinite variety of Mottles, Grizzles, and Splashes, that it would be no difficult matter to put up a hundred matched pairs, any one of which might easily be distinguished from the rest. Birds are matched together for their excellence in tumbling, no matter what colour they are, and therefore produce a great variety of curiously-coloured and marked offspring. It is generally from Tumblers so matched up for their powers of tumbling that the House and Ground Tumblers are produced, and, accordingly, many of them have little in their appearance, from a fancy point of view, to recommend them in the way of feather. Such are out of place in the show-pen, however, for which the colours must be pure and good to enable them to compete successfully.

Among those races of Tumblers of the best quality, as regards performances in the air, which have been kept to feather to a certain extent, I may mention the red Mottles, not marked so exactly as show Mottles ought to be, but mottled over the whole wing coverts, and often with white feathers on the head and neck; black and yellow Mottles of the same character; blacks with white flight feathers, white beaks, and reddish eye wattle; whites ticked on the neck with red; and, lastly, almond-feathered ones. I have known fanciers confine themselves to some of these breeds, and, by careful selection of such as were good flyers and performers, establish flights which would breed very true to feather.

\section{Exhibition Tumblers.}

Show Tumblers are sub-divided into Self-colours, Mottles, 
Baldheads, and Beards. I am of opinion that foreign elements have been, in some cases, introduced into the breeding of the self colours and Mottles, to give colour, and that few of the pretty birds to be seen at shows would be of much account in a flight; but there is this to be said of showing Tumblers, that, independently of performance in the air, they are worth show recognition from a fancy point of view. The show Tumbler should have, in the first place, all the character in shape of head, beak, and body, of the best type of the real performing Tumbler, and on no account have about the head even a suspicion of any cross with the Short-faced Tumbler. Many people erroneously think, or used to think, that the half or quarterbred Short-face, being neater in head, is better for the showpen; but this idea is on the wane, if it be not altogether eradicated. There is a medium between shortness and too great length of face, and between too thick and too thin a beak for the show Tumbler. I have known a quarter-bred Barb win all through a season as a common black Tumbler. The Barb cross gave colour, pearl eyes, and a white beak; but the latter was too thick, and there was too much beak and eye wattle to deceive me. The reddish tinge on beak and eye wattles was no conclusive proof of the cross, because this accompanies fine colour in black, red, and yellow, and I have had the very best performers so coloured in the eye wattles. The black, red, and yellow colours ought to be as sound, and accompanied with as much metallic lustre, as possible. Glossy blacks may be seen, but I have never seen reds and yellows within many shades of the colour to be seen in many foreign pigeons. These colours not being in the breed, therefore, in their best possible tints, any crosses with other varieties which do possess them must result in the loss of the tumbling propensity, however much the appearance of the pure Tumbler may be retained; but as the tumbling propensity is of no account, and cannot be tested in the show- 
pen, shape and feather are all that are looked for in the Tumbler as a show pigeon.

\section{Macclesfield Tipplers.}

A well-known variety of the flying Tumbler is known as the Macclesfield Tippler, which must only make single turns in its flight. Some of these birds are very fine flyers, and so rapid in their tumbling that the eye can scarcely follow them. I believe the Tippler is of various colours, but there is one especial marking which I have seen many of - that is, white, with dark head, flights, and tail. The colour is generally Kity-black, the flight feathers showing sometimes black, brown, and white. The marking of the head is not cut off sharply, like that of the Nun, but gradually disappears in mottling, and there are sometimes grizzled feathers on the neck, breast, and body. This variety breeds true to these characteristics, but with some variation in colour of points, and is known locally, I believe, as the Printed Tippler.

\section{Birmingham Rollers.}

In addition to such Tumblers as I have described, Moore mentions the Dutch Tumbler, as "much of the same make, but larger, often feather-leg'd, and more jowlter-headed with a thin Flesh or Skin round the Eye, not unlike a very sheer Dragoon; some People don't esteem them upon this Account, tho' I have known very good ones of the Dutch breed, not any Ways inferior to what they call the English. Others have remarked that they are apt to tumble too much, and to lose Ground, that is, sink beneath the rest of the Flight, which is a very great Fault, but I have observ'd the same by the English, and am apt to believe that most of the extraordinary Feathers have been produc'd by mixing with the Dutch breed; for it is generally observ'd that the English Tumblers are chiefly black, blue, or white." This is a good description of what are now known as Birmingham Rollers, 
many of which are much larger and coarser pigeons than the neat, trim, clean-legged Tumblers.

Rollers are of many colours, such as whole-feathers; mottles; saddles, marked exactly the same as the Magpie; white sides, or with white wing coverts and under body when through the moult, but self-coloured as nestlings; badges, which are all coloured, except with some white sprinkling about the head, white flights, and white leg-feathering from the hocks down; grizzles, of various shades, and oddities of all kinds of uneven markings. Rollers may be smooth or feather-legged. Many are heavily hocked, with feathers on the feet 3in. to 4in. long. They are much fancied in Birmingham and the Midland counties, where great numbers of them are kept, and, when bred for good shape, colour, and markings, they realise considerable prices for show purposes. I have seen Tumblers imported from the Continent with much of the character of these pigeons.

\section{The Mottled Tumbler Pigeon.}

Mottled flying Tumblers for the show-pen are either black, red, or yellow, though I have occasionally seen duns. The mottling of these birds should either be a rose pinion on the shoulders, composed of single white feathers, no two of which should be in contact, or run together, or the same marking accompanied by what is known as a "handkerchief back," which is a V-shaped figure on the back, between the shoulders, also composed, when right, of single, separated white feathers; while the mottling of the rose pinion is on the wing coverts, the handkerchief back is on the scapular feathers. Some admire the rose wing alone, others the compound marking. The chief defect in Mottles is an excess of white feathers, and, when these are not absolutely in patches, weeding can transform a bird nearly right into perfection. Removing a few superfluous white feathers is not so difficult as supplying some to a wing rather undermarked; but there are men who 
will stick at nothing to win somehow, and $I$ have known of a self-coloured bird transformed into a perfect Mottle, the white feathers being pasted in. There can be no doubt that no pigeon has its toilet made to a greater extent than the show Mottle, and that, if absolute perfection has been seen, it has been but rarely.

In breeding Mottles, the best plan is to ascertain how the pigeons to be mated have been bred for as many generations back as can be found out. If they should have descended through some generations of nearly perfectly marked birds, they ought to breed many such themselves; but as the general plan is to mate a self-coloured bird, bred in most cases from a Mottle and a self-colour, to a Mottle bred in the same way, self-colours and Mottles are produced from such mating. Self-colours, therefore, are part of the Mottle breeder's stock, and represent more than they appear to do. To put a self-coloured to a gay bird is not the plan that experience has taught as most likely to produce the right marking, for the produce is ever inclined to run too gay. And yet, if the self-colour and Mottle matching results in an undue proportion of undermarked birds, one rather overmarked must be thrown in occasionally. To attain success in Mottle breeding, a fancier cannot know too much of the pedigree of his stock birds, and, the longer he has the strain, the better he should be able to produce good ones.

The young Mottle does not leave the nest as it appears after its first moult, but entirely self-coloured. If a bird has even a few grizzled feathers about it as a nestling, it often becomes too white after moulting. It is during its first autumnal moult, therefore, that its beauties become apparent, and that is the time when eager eyes are on the watch for a coming wonder. Many flying Tumblers which are selfcoloured as nestlings become more than half white during their first moult. The mottled flying Tumbler is not nearly so difficult to breed good as the Short-faced Mottle; but yet it 
is difficult enough to breed, and, if the majority of birds seen at shows were penned unweeded, they would be found very mismarked. Foul feathers in the neck and breast are very prevalent; but as it is easy to remove many such without the possibility of detection, many fanciers who admire the Mottle prefer rather to spend their time over pigeons not so easily manufactured for the show-pen.

\section{The Baldhead Tumbler Pigeon.}

When Moore, in his description of the Tumbler, said, "This Pigeon affords a very great Variety of Colours in its Plumage, as blacks, blues, whites, reds, yellows, Duns, Silvers, and, in short, a pleasant mixture of all these Colours with the white," it is probable that he included Baldheads and Beards as "pleasant mixtures." We are, however, indebted to the author of the Treatise of 1765 for the first account of these favourite varieties of the Tumbler, and his description of them, which is one of the original pieces in his book, is as follows: "The Bald-pated Tumblers, which are of various colours in their body, as blacks, blues, \&c., with a clean white head, a pearl eye, white flight, and white tail, are esteemed good flyers, and are very pretty, even when flying in the air, for the contrast of the feather appears at that distance when the weather is clear and fine; but the blue ones are reputed to rise higher than any other colour. There are also some called blue or black-bearded-that is, either of those colours having a long white spot from the under jaw and cheek, a little way down the throat, and regularly shaped, which has a pretty effect as an ornament; and if they run clean in the flight and tail, as before mentioned in the Bald-pated ones, they are accounted handsome."

Baldheads are found in black, blue, silver, red, and yellow, and in off colours, as chequers and mealies. The correct marking is as follows: Both mandibles should be white; and the whole head, above a line running about $\frac{1}{8}$ in. under 
the eyes, should also be white. The line should be cut straight and sharp. This marking is known as "high cut," in opposition to that in which the white extends farther down the neck, which is called "low cut"; and if the line of demarcation is uneven, or if the white in any case dips down in patches, the bird is said to be "slobbered." The Baldhead ought to have pearl eyes, but many otherwise good ones are spoilt by having one or both eyes bull, or dark hazel, in colour. This, however, in a flying Baldhead, is an intolerable fault for the show-pen. The primary flights should be white; and, as they almost invariably number ten in each wing, the correct marking in the Baldhead is spoken of as "ten-a-side." White to the turn of the flight would be the more correct standard, as Tumblers sometimes have only nine primary flight feathers. Next, if the bird be lifted up by its wings, it should be all white below them, including the rump and tail, with its upper and under coverts. If it has any coloured feathers on thighs or vent, it is foul-thighed or vented-both very great faults. If the colour of the breast does not finish off in a straight, sharp line, about an inch before the thighs-evenly belted, as it is called-it is faulty. In shape of head, beak, and body, and in size and carriage, the Baldhead is similar to the small, clean-legged, flying Tumbler. I have never seen any with feathered legs, and I am not aware if such exist.

The Baldhead is a good flyer, and a favourite pigeon with many, on account of its beauty, both when seen close or in the air. It is sometimes a good tumbler, though not so generally as the common Tumblers first described, for, having in many cases been bred for feather, or for high flying alone, the tumbling propensity has not been so carefully cultivated; at the same time, I have had and seen many really first-class. tumbling Baldheads.

I have never seen any almond-feathered common Baldheads, but they might be produced in time by crossing with the common Almond Tumbler. I have seen yellows with a few 
black ticks through the hackle, but I think fanciers are agreed that the almond feather is not suitable in any pigeon with white markings, such as the Baldhead or Pouter, and that, however well it might look in its early beauty, it would not compare with black, red, and yellow, in their best tints, when it began to darken with age.

\section{The Beard Tumbler Pigeon.}

The Beard Tumbler, like the Baldhead, is found in black, blue, silver, red, and yellow. The ordinary variety of flying, tumbling Beard, is similar in size, \&c., to the common Baldhead and other Tumblers. It is always clean-legged, as far as I have noticed, and ought to be marked in the following manner: The upper mandible should be coloured, though reds and yellows may have it white; and the lower, in all cases, white. The beard, from which the bird has its name, is a dash of white, extending from eye to eye, across the throat. Commencing below the eye as a point, it widens to about half-an-inch below the beak, and it should be exactly alike on each cheek. This is the marking as described in the Treatise before-mentioned; but another style of Beard, known as the Pepper-faced, or Peppered Beard, has this dash of white sprinkled with coloured feathers. I think this is an undesirable marking, though it was liked by many in days gone by. There are also Beards with a coloured line down the throat, dividing the white into two parts. In addition to the white beard, the flights should be white to the turn, and the tail, with its coverts, upper and under, should be white; all else should be coloured. I am aware that it is not easy to get Beards, entirely dark-thighed, with ten white flights a side; but that is no reason why the standard should be reduced. Such birds have been seen, and are all the more valuable because scarce. It is considered that seven or eighta-side is good enough for a dark-thighed bird; but I have had a strain of Tumblers with far less white about them than 


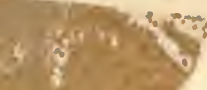




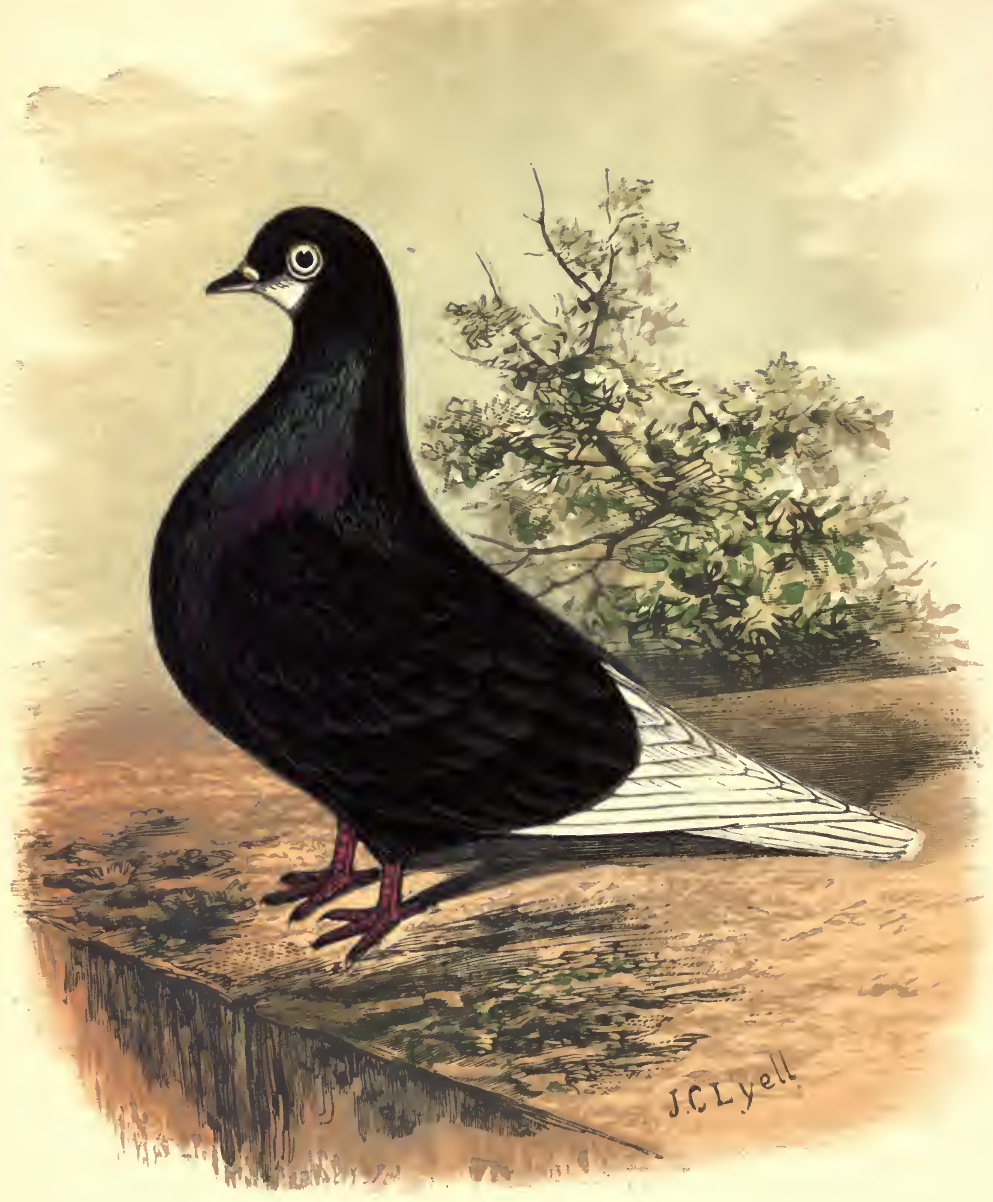

THE BEARD T $\mathrm{C}^{*} \mathrm{M} \mathrm{BER}$. 
the Beard-viz., blacks, all coloured except the primary flights, which were white-and they bred true. And when Beards are once got full-flighted and dark-thighed, they will breed true after a time, though it may be difficult to fix such marking without trouble. Standards of excellence in pigeons should be standards difficult of attainment, and they should also be artistically beautiful to entitle them to support. Although the Beard ought to be entirely dark-thighed, there is always some white where the feathers finish off at the hocks; but the less of this the better. The Beard ought to have pearl eyes, and, as the whole head above the eyes is coloured, this is not a difficult point to maintain.

Among blue Beards, the hens were formerly always smoky in colour, and I have never seen any of a good bright blue. This fault appears to be in the breed, as it is in some other breeds of blue-marked pigeons. It might possibly be eradicated by crossing blue Beard cocks with good coloured all blue hens; but as such experiments take years to complete, and the result is so remote, and the reward so uncertain, who will be at the trouble of it, neglecting what might truly be reckoned more important work in the fancy? Black, blue, and silver Beards, of the common flying Tumbler type, were, when I kept them in my boyhood, capital flyers and tumblers.

A flight of Balds and Beards, assorted in colour, is a pretty sight; in clear weather the white markings tell well against the coloured body at a considerable height in the air. To make them fly high, and well together, however, they require all the attention necessary in raising a flight of Tumblers, and must not be allowed continual liberty, otherwise they will give little satisfaction as high flyers.

For those who employ feeders for all small, highclass pigeons, they answer every requirement, being careful nurses and breeders the year through, except in the depth of winter; and, when kept for this purpose alone, 
they are all the better for unlimited freedom, as in country places they gather much green food, and other things serviceable in the rearing of young birds, which they could not procure if kept confined.

\section{Foreign Tumblers.}

Numerous varieties of the Tumbler exist throughout India, Persia, and Asia Minor, according to recent writers who have referred to pigeons in their works. In 1885, some commonlooking Tumblers, undistinguished by specific marking, but which could not rise a yard from the ground without tumbling, were brought to Dundee in a vessel from Calcutta. When I resided in Calcutta (from 1865 to 1872) I knew many fanciers who kept large numbers of Tumblers, which no doubt are, in their numerous varieties, the most universally fancied of all pigeons. There is a breed of blue Tumblers in Calcutta, similar in size and shape to the common British Tumbler, but with the eye wattle-which is very narrow-of a dark blue, like that of a Mahomet Pigeon; they have clear white irides.

The Turkish Roller.-These Tumblers were introduced from Smyrna by Mr. H. P. Caridia, and first described, in 1874, by Mr. Ludlow, of Birmingham. They are longer in head and beak than our Tumblers, the head being flatter, and wanting the high forehead, and the beak thicker and stronger. The neck is rather short, as are the legs. The back is hollow, and the tail is carried rather elevated, and over the flights. The tail is peculiar, being long, and composed of from fourteen to twenty-two feathers, the average being about sixteen; these feathers have no approach or resemblance to a fan tail, but lie one over the other, in two divisions, showing a slight parting, or split, between them. As is common with other varieties having an abnormal number of tail feathers, a double feather growing from one quill is often seen in this breed. The oil gland above 



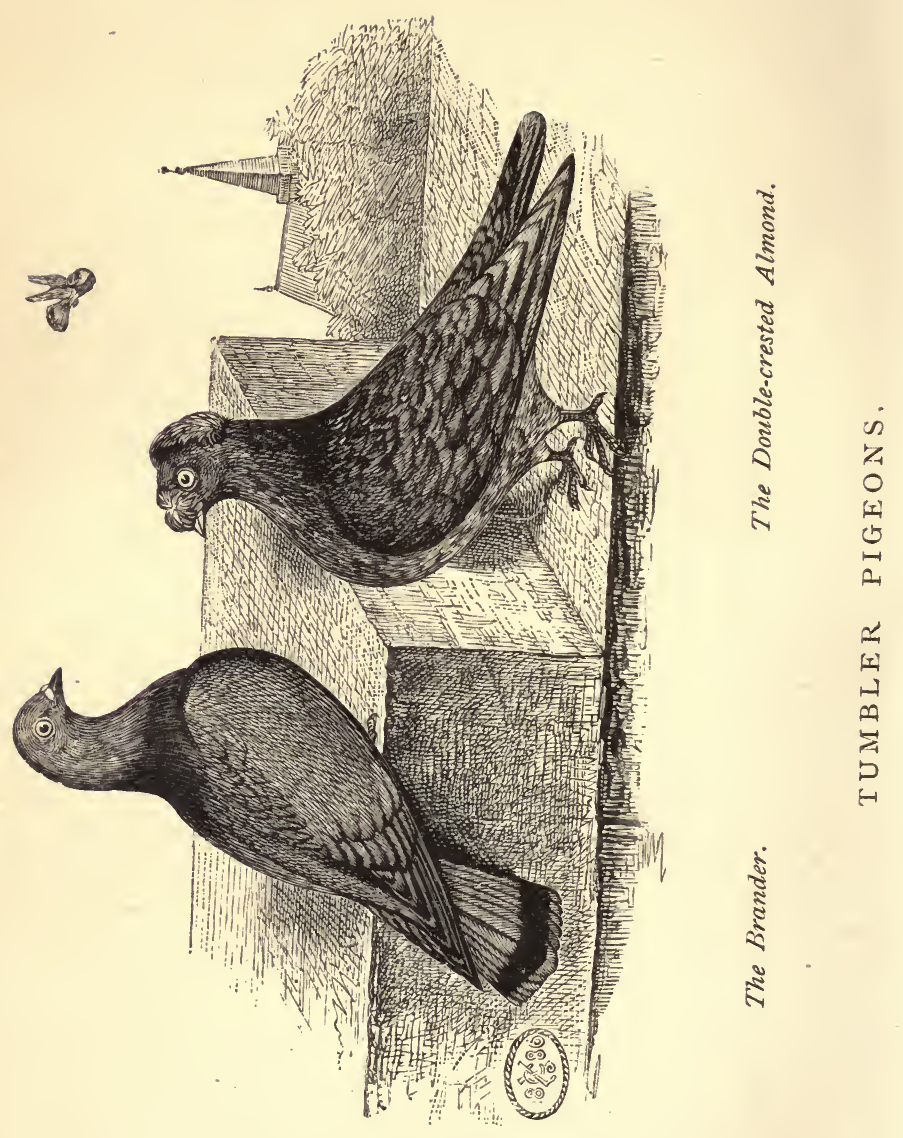


the tail is also wanting. Turkish Rollers are of many colours, such as black, white, dun, and almond splash, the blacks being well-lustred, and with white, black-tipped beaks-as is usual with good-coloured blacks, among British Tumblers. I have not had any of these birds myself, but $\mathrm{Mr}$. Ludlow, from whose description I have gathered the above, asserts that they are capital performers and flyers.

The Double-Crested Tumbler.-The first of this interesting variety, comprising a pair each of Almonds and Blacks-or, probably, Kites-were brought to Liverpool, from some Mediterranean port (probably Smyrna), in the spring of 1886. The Almonds were purchased by me, and their description is as follows: The cock is rather dark, of a mahogany ground colour, and well spangled with black: the hen light buff in ground, and showing very little black spangling, except in neck. In size and shape they resemble the best type of flying Tumbler, having extremely good carriage, with head thrown back, and full, prominent breast. The flights are generally carried low. In head, beak, and eye, they are similar to our common Tumblers, and their legs and feet are unfeathered. They have a broad shell crest on the nape, and a rose on the forehead similar in formation to that of the Trumpeter, but smaller. I was told they were guaranteed to tumble well; but I have not tested their powers, being afraid of losing them before I had bred some young ones from them. Their first three nests produced three pairs of almonds, all with the head feathering of the parents. Their fourth nest contained one almond and a white, or albino, both double-crested.

The Russian Frontal-Crested Tumbler.-Herr Prütz, in his new book on pigeons, illustrates this curious variety, which may be described as a Tumbler of the common smoothlegged type, with a frontal tuft on the forehead, but uncrested on the nape, thereby resembling the Altenburg Drummer. These pigeons are represented of a dark reddish 
strawberry colour, with a few black spots, or ink marks, interspersed.

The Riga TUMbler.-In my youthful days, and probably still, though I never now watch the arrival of Baltic traders, as I then did, vessels from Russia often brought to Dundee what we used to call Riga Tumblers. They were self-coloured blacks, reds, and yellows, of large size, with heavily feathered legs and feet (the quills on the latter often 4in. in length), and a large shell crest. They were very similar in shape and size to the Trumpeter as we then had it, except as to the tuft of feathers over the beak. They were very good flyers and tumblers.

German Tumblers.-Numerous varieties of the Tumbler are spread over Germany and Austria, many of which are, no doubt, bred chiefly for their marking. They vary greatly in type, some being long and flat headed, while others are short and thick beaked, with a high forehead. The principal varieties, some of them now well-known in this country, are the following :

The White-Tailed Tumbler.-These birds, with clean legs and pearl eyes, are similar in size and style to our common Tumblers. Some have a shell crest. They are of various ground colours, with a pure white tail and tail coverts. There is another pure breed, similar in all respects to these, except that their primary flight feathers also are white.

The Coloured-Tailed Tumbler.-Birds of this variety are all white, with coloured tails. They have clear pearl eyes, and some have shell crests.

The Königsberg Moorhead.-These pigeons have large shell crests, pearl eyes, coloured tails, and heavily feathered legs and feet, and are marked on the head like a Nun. I believe they are either black or blue marked.

The Brunswick Beard is now well-known in this country. It is rather long in face, and flat in bead, with pearl eyes and clean legs, though I believe a variety with feathered 
ones also exists. These birds are found of very good and glossy colours, in black, red, and yellow. The beard in this variety ought not to extend to the eyes, but should appear as a round white spot under the lower mandible, which ought also to be white in all colours. The flight feathers are white, the rest of the plumage being coloured.

The White-barred Prague Tumbler is short and thick in beak, with a high forehead, pearl eyes, and smooth legs. In colour these pigeons resemble Brünner Pigmy Pouters, being either light blue or light fawn, with white wing bars.

The Hungarian Magpie Tumbler resembles, in marking, our common Magpie Pigeon, except that the head is white above a line running through the eyes. It is shell-crested.

The Brander is a Copenhagen Tumbler, of a black ground colour, but strongly glossed with reddish bronze. A good bird should appear all over of the same colour as that on the breast of the bronzed Archangel Pigeon, except that the points of the primary and secondary flights, as well as a bar across the end of the tail, should be black. The Brander is smooth-headed and legged, and is, doubtless, the breed referred to by Neumeister as the Fire Pigeon. The hen of a pair in my possession answers the above description; the cock is darker, showing less bronze over the black ground colour.

The Shaking Tumbler.-All the specimens of this breed I have seen came from Germany, and were yellow whole-feathers, with grouse-muffed legs. They resembled our common Tumblers in general appearance, but had a trembling neck, similar, though less in degree, to what the Indian Mookee displays. I was informed that they exist in various colours, both selfcoloured and Magpie marked, and that the Magpies ought to have a small white crescent on the breast.

The German Ancient.-The Altstämmer, or Ancient, bears somewhat the same relation to the Shaking Tumbler as our Shortfaced do to our Common Tumblers. Its appearance betokens Barb descent, it having a rather pronounced red eye wattle, a 
thick, short beak, and a broad skull; otherwise, in colour, markings, and grouse-feathered legs, it resembles the Shaker; but I believe the trembling neck is seldom found in them.

Mr. O. Neef, of the German Consulate in London, who introduced this beautiful variety into England, being desirous of making known its merits, has requested me to publish the following:

"The Ancient Pigeon (Altstämmer), though German, is not a Toy Pigeon like the Feldtaube, such as the Swallow, Ice, and others, which have long, thin beaks, and heavily-built bodies, as characteristics of their type, but is one of the few German varieties with the distinguishing features of a short beak, round head, and elegantly-shaped body.

"It is, moreover, a special Berlin variety, reared almost exclusively there, but also largely represented in Stettin; in other parts of Germany it is seldom met with.

"Really good specimens are very rare, and command a high price. Thus, for instance, at a late exhibition at Königsberg, an offer of 1000 marks (about £50) was declined for a single pair of them. The sum of $£ 25$ was also offered at the Berlin Exhibition, in 1882, by a Birmingham dealer, for a pair, and likewise refused.

"The Ancient Pigeon, as the name implies, is a very old variety, the origin of which is unknown, and all explanations hitherto advanced concerning it are mere suppositions, devoid of any positive proof. This much, however, is fact: If the Ancient be crossed with another variety, its characteristics are at once lost.

"Friends at Berlin have lately elected a body of breeders of this variety for the express purpose of ascertaining its origin and age; but as yet their efforts have been fruitless. From investigation of special and other literature on pigeons, it appears that the Ancient was known as early as 1779, but nothing has been discovered regarding its origin, or where it came from. 
"The Ancient is found in black, red, and yellow colours, with white-i.e., marked like the Magpie-with the additional white mark on the breast, like the English Pouter. In blue they are very scarce, and never particularly good. It is a remarkable fact that these pigeons produce self-coloured specimens in all these colours, as well as pure whites. If a pure white Ancient be paired to a whole black, red, or yellow, the coloured one ought always to have six or eight white flight feathers in each wing; they then often produce the best specimens of Magpie colour. This is a singular characteristic of the breed, and is probably peculiar to it alone.

"There are also extant some with long beaks-viz., the Flugtaube-in all the four prime colours, both self-coloured and Magpie-marked. The difference between these and the former kind is about the same as that between the Short and Long-faced Tumblers."

The Vienna Gansel.-This breed, as represented by Prütz, greatly resembles the Ancient in style of head and beak, appearing, from its broad, ribbed-up forehead, thick beak, and rather broad, red wattle, to be descended from the Barb. It is smooth-legged and Magpie-marked; but the head and upper neck are white, the white coming down in front, and forming a deep bib. The Gansel exists in black, red, jellow, blue, and silver.

The foregoing descriptions do not exhaust the Continental breeds of Tumblers. There are an immense number of local varieties spread over middle Europe. It is the custom in some places to castrate these birds, probably with the intention of making them better flyers, for the purpose of training the young birds in their flight. 


\section{Chapter XXVI.}

\section{$\propto$ VARIETIES ORIGINALLY TUMBLERS. $\varnothing$}

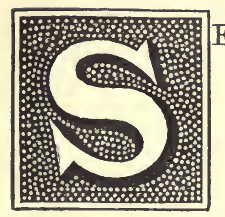

EVERAL varieties, long bred for colour and marking, in which the tumbling propensity no longer remains, are considered, from their formation of head and beak, size, and shape, to have been derived from the common Tumbler. The Nun, Magpie, and Helmet Pigeons, may be included in this category.

\section{The Nun Pigeon.}

This beautiful breed, from its striking contrast of colours, has always held a high place among fancy pigeons. It is supposed to derive its name from the arrangement of its marking, but in France it is the Jacobin, with its coloured body and white head, that is called a Nun (Nonnain). The French call the Nun, Pigeon Coquille Hollondais, or Dutch Shell Pigeon, from its shell crown; and the Germans, Das Nönnchen, or little Nun, to distinguish it from a somewhat similarly marked variety. Neumeister says that, although hitherto considered as belonging to the field, or dovehouse, type of pigeons, the Nun is an undoubted Tumbler in formation, and in this I agree with him. Having been bred so long, 



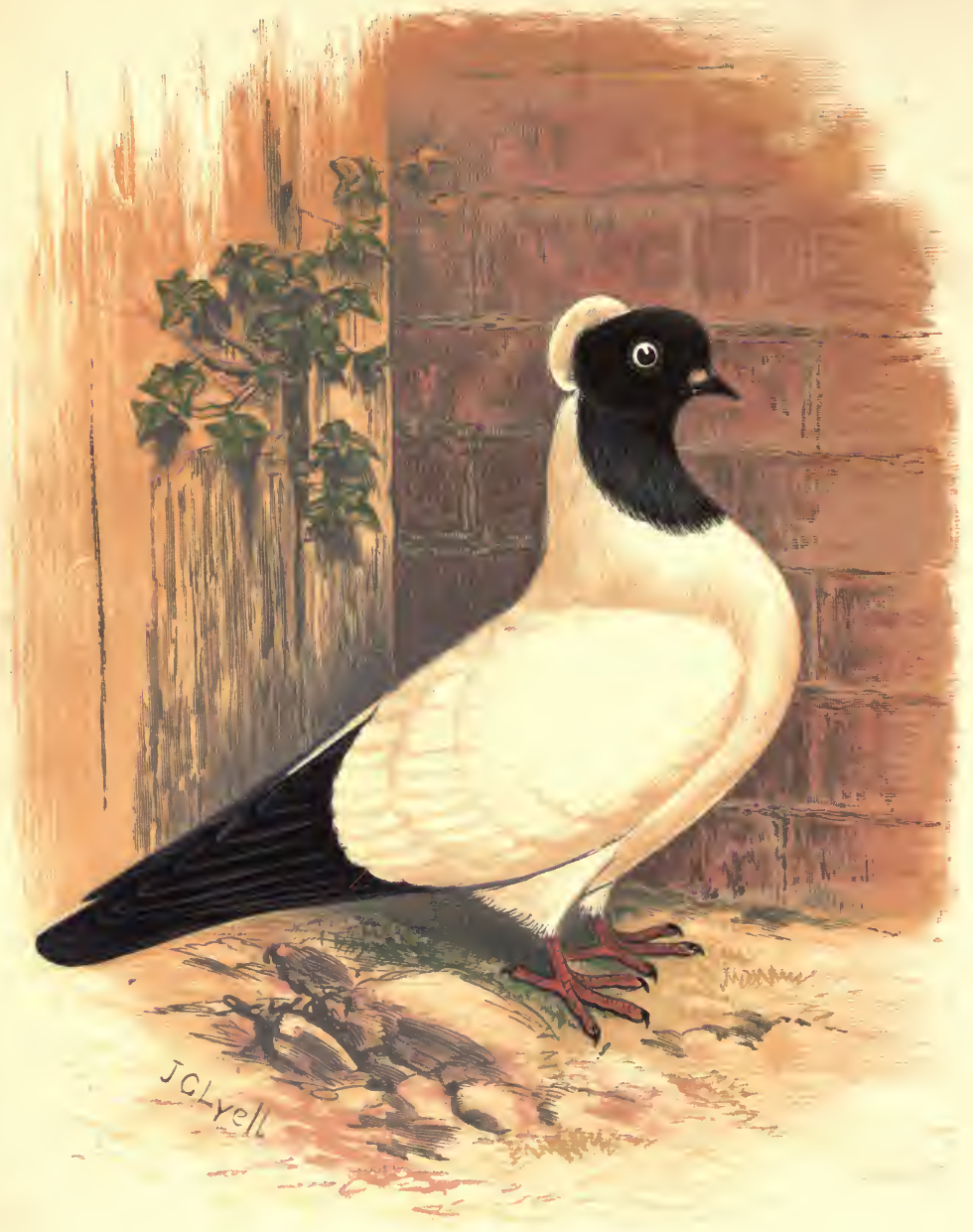

THE NUN PIGEON. 
however-it is described by Willughby under the name of Helmet-for mere markings, it has lost the tumbling propensity.

The Nun is a compact, trimly-built pigeon, of upright carriage, with a Tumbler's head, beak, and pearl eye, which latter, in the black variety, is surrounded with a narrow blackish cere. The shell, which is sometimes miscalled a hood, should be very extensive, and resemble a cockle shell filled with plaster of Paris, stuck, as it were, on the back of the bird's head. It should on no account take a cupped form, but, when viewed in profile, be perpendicular, and so extensive that, when seen from before, it should describe three-quarters of a circle. The more even its edge, so as to form an unbroken line, the better, and although but few have it so large, it should come down below the level of the eyes; and the more it stands out from the head the better, when it resembles the halo around the head of a mediæval saint.

The Nun is found of several colours, such as black, blue, dun, red, and yellow-headed. I shall take the black first in my description, and, although it is comparatively easy to breed this colour good, yet many Nuns are to be found very offcoloured in their black.

The black Nun, however good in colour, must not have a light beak like other black-headed pigeons, such as Barbs, which are preferred white-beaked, but its beak should be as black as possible; and, I may say, it never is white-beaked as far as I have noticed. The head, as far back as the shell, which should stand up, and be purely white, must be black. As the shell feathers grow with a forward inclination, and those of the crown of the head backward, the latter, where they meet the shell feathers, take an upward turn, and form the support of the shell. If all the backward-growing feathers of the crown are black, the shell will, therefore, have a black lining, which, being unwished for, causes the dodging exhibitor to cut or pluck them, and so show a clean white shell.

When the young Nun is about twelve days old, the head 
feathers will, in a good one, be black only a little way behind the middle of the crown, and those feathers which adjoin the rising shell will be white. By the time the feathers are full grown the black will reach the shell, but not rise against it. The black marking of the head should run round the corners of the shell, so that, when the bird is viewed from behind, two black, pointed patches, are seen, and the colour should run down the sides of the neck to the breast, with a wide sweep, forming the bib, which ought to be evenly cut.

The flight feathers, or ten primaries, should be black. Moore only speaks of six coloured flights in the Nun, but no bird with less than ten-a-side can be reckoned a standard one now. Eight. a-side certainly looks a full flight when the wing is closed, but not when the bird is flying; however, eight-a-side, with quite clean butts of the wings, is preferable to more black flights with the spurious wing and adjacent feathers coloured, a very common fault with all Nuns, especially with fullflighted ones. Here, again, plucking is often resorted to; but an examination of the open wing will enable the searcher to detect it, if at all extensive. The twelve tail feathers, with their upper and under coverts, must also be black, and cut sharply across. There should be no black feathers over the rest of the body, nor white ones among the black markings; but a prevailing foul marking is at the knees, or hocks, where the thigh feathers finish off.

The feet and legs of the black Nun, when in the nest, are either quite black or heavily patched with black, but this generally wears away afterwards, though some birds retain it partly, especially those of a very rich colour. The black Nun looks much better, however, with bright vermilion-coloured legs and feet. The nails of the toes should be quite black, though many a good bird has a small fault in having some of them light.

Probably on account of the less contrast in colour, red and yellow-headed Nuns have not been so much fancied by breeders as blacks; at least, they do not exist in such per- 



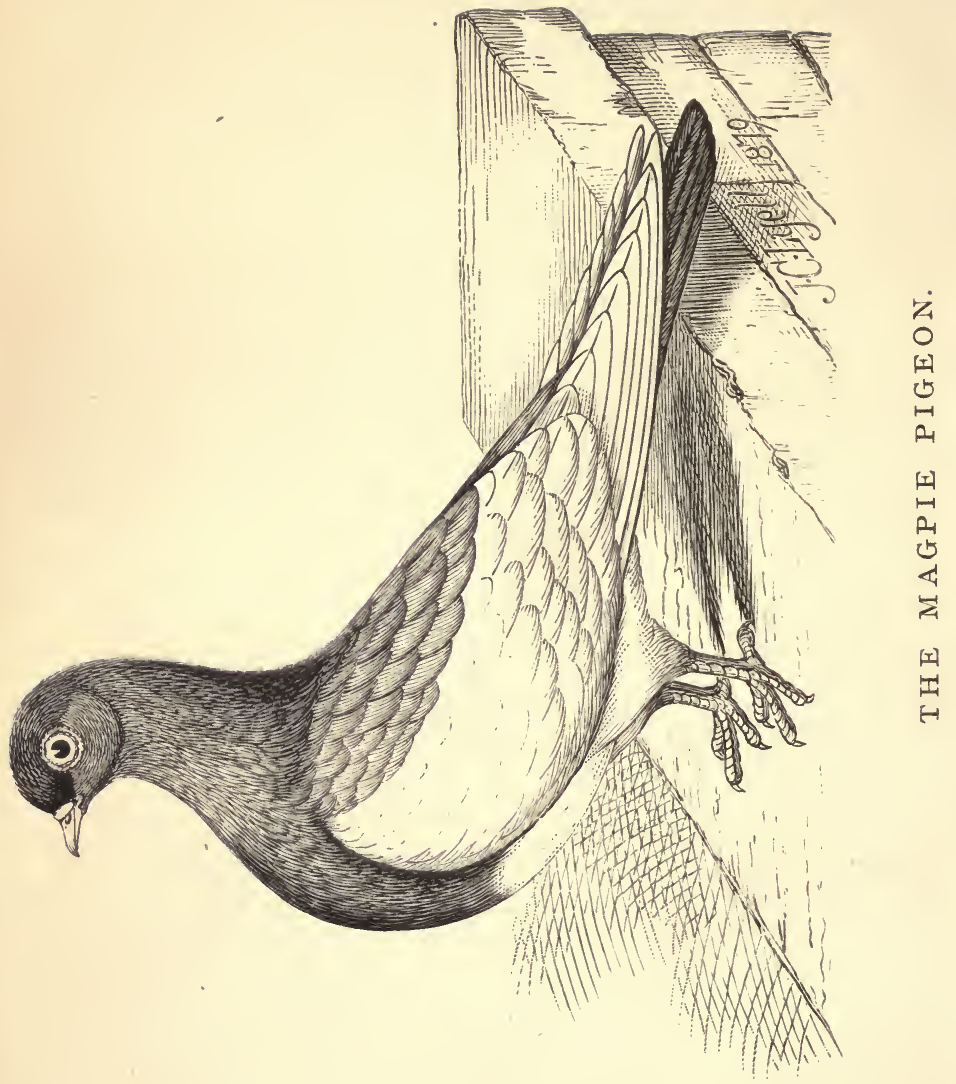


fection, being, as a rule, very deficient both in shell and quality of colour; and it so happens, that the marking of the Nun encroaches on those parts of the bird which present the very greatest difficulty to the breeder of red and yellow pigeons-the tail and flights. Could red and yellow Nuns be produced of such rich and lustrous colour as some kinds of pigeons display, I would consider them very much finer examples of the breeder's skill than blacks, though, at the same time, they would lack the contrast; the red, however, would not be much behind even there. Red and yellow Nuns have light beaks and toe nails.

\section{The Magpie Pigeon.}

This beautiful variety of the Tumbler, known in Germany as the Elstertïmmler, is now extensively fancied in this country. During late years competition has been strong among its admirers, who have drawn up a standard of its points, and formed a club for its encouragement. Although few of the pretty birds to be seen at shows would be able to tumble in the air, as they are bred mostly for appearance, the tumbling propensity is not entirely eradicated, as I have seen some of them perform creditably when flown. What is wanted at present in a show Magpie is a very small, slenderly-built pigeon, with a flattish head and long, slender beak, a thin neck, and short flights and tail. The iris should be as pearly white as possible, and the legs and feet free of feathers. The colours are black, red, yellow, dun, blue, and silver, marked as follows: The head, neck, and breast, are coloured to a line running between the butts of the wings; the scapular feathers are coloured so as to form the saddle, or heart-shaped figure, on the back; the back and tail, with its upper and under coverts, are coloured; the rest of the feathers ought to be white. This marking is so fixed, that the Magpie breeds very true to it. Absolute perfection, however, is so rare, that, to make the lines of 
demarcation between the white and coloured portions of the plumage exact, the bird is understood to be as subject to having its show toilet made as the Nun, or Mottle Tumbler. The beak in blacks, reds, and yellows-the chief show colours -is preferred to be flesh-coloured, but in the black is often tipped with Vandyke brown. Varieties of the Magpie with peak and shell crests exist on the Continent, but such are in no request here at present. The colours of the Magpie are, for the most part, rich and lustrous, reds being at present the most deficient in this respect, but they have lately shown signs of improvement.

\section{The Helmet Pigeon.}

The pigeon known at present as the Helmet is a German Tumbler. Neumeister describes it under the name of Der Farbenplättige Tümmler oder die Calottentaube (Colouredheaded Tumbler, or Calotte Pigeon), and says that it has long been bred in the greatest perfection in Hamburg. The Helmet is of the size of our ordinary flying Tumblers, and is similarly formed in head, beak, and body. The upper mandible is coloured, the lower white; the head is black, blue, red, or yellow, the tail, with its coverts, matching the same. The line of demarcation of the helmet, or coloured cap, should run through the eye, as it were, and dip somewhat at the back of the head. The iris should be pearly white in colour. The Helmet is generally smooth-headed and clean-legged, but Brent mentions a variety with feathered legs and feet, coloured, he says, from the hocks down, to match the head and tail. Neumeister says that some Helmets are hooded, and that such are more valued, having an additional beauty to commend them to the breeder.

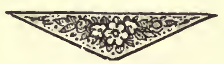




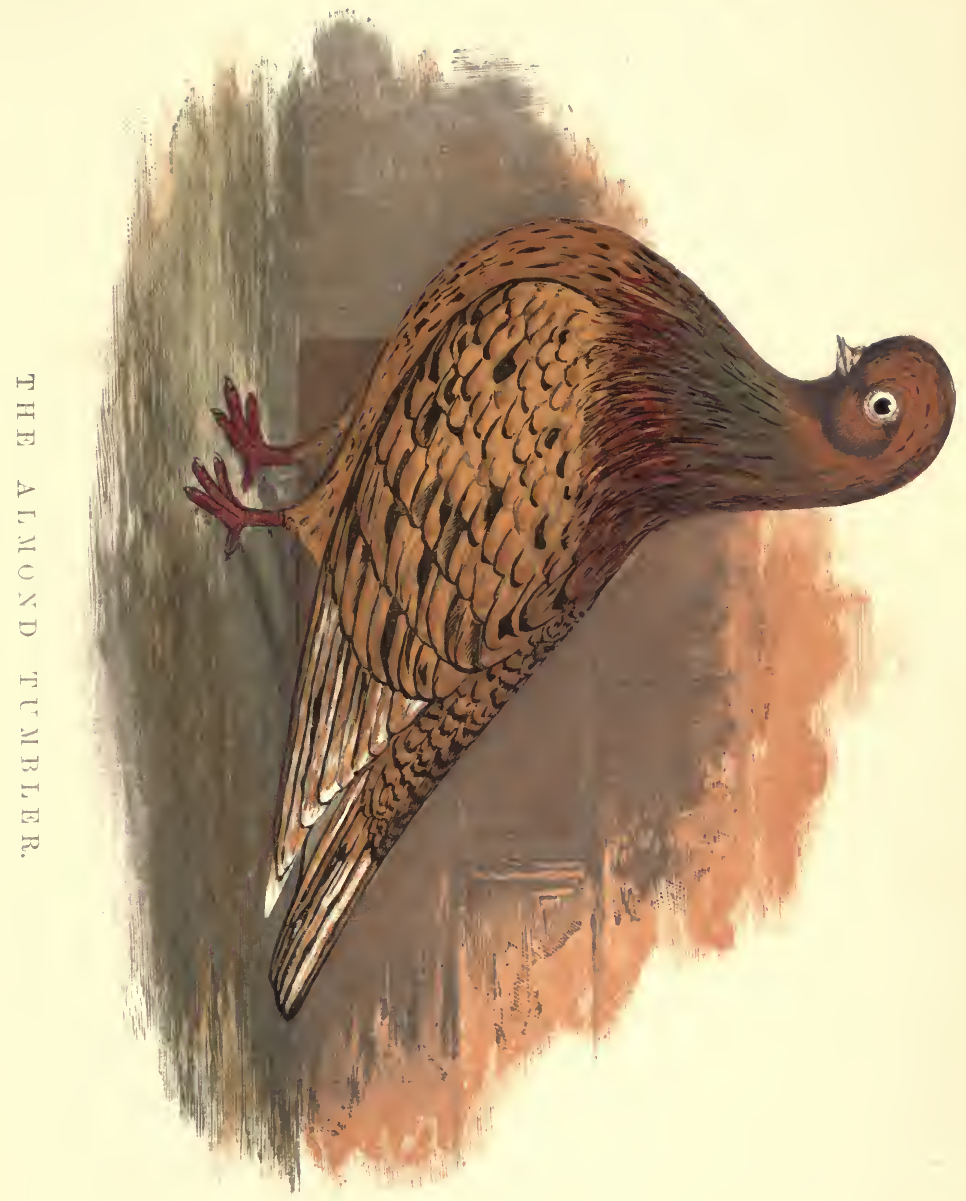





\section{Chapter XXVII.}

$\propto$ THE SHORT-FACED TUMBLER PIGEON. $\varnothing$

The Almond.

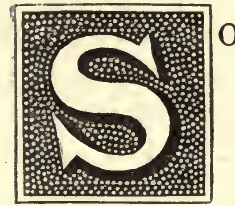

OON after the death of Moore, a variety of Tumbler called the Almond became in great estimation in London, and supplanted the Pouter and Carrier in the lofts of many breeders. We are enabled to trace its history with some degree of accuracy. There is no doubt that its cultivation began before Moore wrote, as will be seen from the following passage from his book. He says, in writing of Tumblers : "But amongst all, there is Mixture of three Colours, vulgarly call'd an Almond, perhaps from the quantity of Almond colour'd Feathers that are found in the Hackle: Others call it an Ermine, I suppose from the black Spots that are generally in it; however I am sensible the Name is not compatible to the Term so call'd in Heraldry, which is only white spotted with black; yet as the Gentlemen of the Fancy have assign'd this Name to this mottley Colour, I shan't quarrel with them about a Term: if the three Colours run thro' the Feathers of the Flight and Tail, it is reckon'd a very good Almond, or Ermine, and is much valued. 
"N.B.-An ermine Tumbler never comes to the full Beauty of its Feather, till it has twice molted off, and when it. grows very old will decline, till it runs away to a down-right. Mottle or other Colour."

The Almond Tumbler was, therefore, very much valued when the three colours ran through the flights and tail, as. early as 1735; and a standard had by that time been established for it in regard to feather. But it seems unlikely, if it was then anything else than an almond-feathered common Tumbler, that Moore would have omitted to describe its peculiarities of head, beak, and carriage. It seems probable, therefore, that at this date it had not altered much in size and shape from the common Tumbler, seeing that Moore describes it as a variety of that breed.

Thirty years afterwards the Almond Tumbler had made great progress in London, for it is described by the author of the Treatise of 1765 at length, and as then distinct in character from the common Tumblers. It was then "a very small Pigeon, with a short body, short legs, a full chest, a thin neck, a very short and spindle beak, and a round button head, and the iris of the eye a bright pearl colour." But the illustration which accompanies this description is disappointing, as it represents a pigeon of a much commoner type, compared to the modern Short-faced Tumbler, than some of the author's other illustrations are, compared to their modern representatives. The author had, however, become enamoured of the Almond, and considered that the title of the King of Pigeons, conferred by former fanciers on the Carrier, might, with greater propriety, be conferred on the new favourite. Some of the reasons he gives for this opinion are its exceeding beauty and diversity of plumage, its increasing value-twenty guineas having been paid for five pairs, and those not of the best-and the ease with which it could be bred, compared with the Pouter and Carrier. Then, after dilating, through four pages of his work, on the difficulties of 
Pouter breeding, he adds: "The above, and many other inconveniences too tedious to mention attending the Pouter, and no trouble at all (comparatively speaking) attending the other, easily accounts for the preference given to the Almond Tumbler," which requires "no attendance while breeding, provided you supply them with meat and water, and throw them a little straw." Considering that he himself quotes a sale of Pouters by auction, where the prices realised were as high as sixteen guineas a pair, and that Moore had known eight guineas refused for a single Pouter, the price of the Almond Tumblers-two guineas each-was nothing great; but then he says they were not the best; and probably some of the lot of five pairs were worth much more than the average price of the whole.

The fancy for the Almond Tumbler was now established, and, the year before (1764), a standard had been published setting forth the perfections and imperfections of the bird. This was entitled "Ordinances Established by the Columbarian Society," and was headed by a picture of an Almond, "elegantly engraved on copperplate." The Almond went on increasing in popularity after this, and its name, at least, became so widely known that people who would not have recognised the bird had they seen it, had heard of it. The Sporting Magazine, some years after its commencement, in 1792, had a portrait of a choice specimen; and, in 1802, a monograph on the breed was published in London, by "An Old Fancier." The author was Mr. W. P. Windus, a solicitor, a member, and afterwards the president, of the Columbarian Society. An engraved circular, dated 1813, signed by him, and headed by a picture of an Almond, calling a meeting of the society, is in my possession. His treatise was the first book ever published on any single variety of fancy pigeon, and it goes thoroughly into its subject. We learn from it, that though it had been necessary to limit the length of face, from the point of the beak to the iris, or 
inner circle of the eye, to $\frac{7}{8} \mathrm{in}$., it was usual, when he wrote, to see birds scarcely $\frac{6}{8} \mathrm{in}$. in face, so that a great improvement had been made.

In 1851, Mr. Eaton, an enthusiastic fancier of the Almond Tumbler, published another monograph on the breed; so that this pigeon has been twice honoured above all other fancy varieties. Mr. Eaton's book is an unacknowledged reprint of the 1802 one, with additions describing the Almond as it was in his day; and this brings us down to modern times.

Although it is expressly stated by the author of the Treatise of 1765 that "this beautiful and very valuable species were originally produced from the common Tumblers, being properly matched so as to intermix the feather, viz., blacks, black-grisles, black-splash'd, yellows, whites, duns, \&c., and are always attainable if you are endowed with patience sufficient for the tedious process, which requires a length of time," I have to submit that, as regards the almond feather alone, it is not confined to the Tumbler. The author of the Treatise (1765) mentions an Almond Barb, and an Almond Narrow-tailed Shaker, which were purchased by a certain nobleman, and I have seen Almond Runts and almond-feathered pigeons in India, besides a very good commencement for this colour in a yellow ground, broken to some extent with black, in Turbits and Jacobins. The Oriental Roller and Double-crested Oriental Tumbler also exist almond coloured. The Short-faced Tumbler, however, independent of colour, is a different matter, and how it was produced is a question worth some attention. Not to admit the possibility of its origin from the common Tumbler alone would be a denial of all I have advanced when writing of the origin of fancy pigeons; but certain facts having presented themselves to me in my experience and observation of pigeons, I have acquired the belief that the Short-faced Tumbler is a composite breed, and derived from the com. mon Tumbler and some other varieties. When in India, the love of pigeons, which has possessed me from my child- 
hood, caused me to associate with pigeon fanciers there; and when I saw a race of birds (the Goolees) having all the shape and carriage of Short-faced Tumblers, of much the same size, and of the same style of head, it struck me that, as the Mookee had been described by Willughby in 1676, the Goolee might also have been in England at that time, and have helped to found the breed of Short-faces.

About the year 1878, being in London, I met the late Mr. Jayne, of Croydon, one of the principal breeders of Almond Tumblers, and as he invited me to see his stud of birds, I gladly availed myself of the opportunity. After seeing his stock, I asked him if he believed that the Short-faced Tumbler had been bred from the common Tumbler and nothing else. He replied that it was the result of crosses between the Tumbler and other varieties, that the African Owl had been used in producing it, and that his friend, the late Mr. Morey, was the only man he ever knew who could give its true history. Eaton in his 1858 book, at page 187, says: "The late Mr. Harry Edward Morey, chairman of the City Columbarian Society, and an excellent old fancier, used to say, however low his stud of birds was reduced, he had never been without pigeons for the last sixty years." The combined evidence of $\mathrm{Mr}$. Jayne and $\mathrm{Mr}$. Morey, therefore, goes back to the last century, and it is probable enough that Mr. Morey had spoken in his youth to men who had been pigeon fanciers before the Treatise of 1765 was ever designed, and that was about the time the Almond Tumbler became of consequence in the fancy. Since speaking with Mr. Jayne on this subject, I found in the Field newspaper of 19th Oct., 1872, a report of an address he delivered to the members of the National Peristeronic Society when he was president. His subject was "The Almond Tumbler," and I quote the following sentences: "You are aware my only hobby has been a Short-faced pigeon, and, of all the varieties, none can equal, in my idea, the Almond Tumbler; if for no other 
reason, I should admire it as a purely English-manufactured pigeon. How often and how deeply have I lamented that I allowed to escape the knowledge of this beautiful bird possessed by my esteemed companion, the late Mr. Morey. He was the only person that I ever heard give a description of the thirty-two crosses by which this Almond Tumbler was produced."

Without having seen Mr. Jayne and conversed with him on the subject, I should not have known what to understand by the thirty-two crosses he refers to-whether they were merely crosses of different-coloured Tumblers to produce the almond feather, or of other breeds of fancy pigeons as well, to produce the Short-faced Tumbler. The latter is what he meant, and as the knowledge Mr. Morey possessed is lost, all I can say is that there is good evidence for my belief that the Short-face has something more in its composition than the common Tumbler.

The pictures of the Almond Tumbler in the Treatises of 1765, 1802, and 1851, show the gradual improvements made in eighty-six years. I do not put much stress on the wings being carried over the tail in the 1765 and 1802 pictures, as they might have been so represented on account of trailing wings being considered faulty. Windus says, regarding carriage: "The bird should stand low, with a fine, prominent, and full, or, as the Fanciers term it, a square chest, which is thrown up considerably by the bird's elevating himself on tiptoe, and thereby depressing his tail, so that the point of it touches the flooring of the area, penn, or whatever place he stands upon."

As interesting to the fancier of Short-faces, on account of the light it throws on the materials used about eighty years ago for breeding Almonds, I here give a copy of a little handbill in my possession, which is probably unique. I found it, with the circular signed by Windus, in a copy of the 1802 Treatise which has the autograph of Thos. Garle, 
jun., 7th Feb., 1809. The reward offered would imply that the pigeons were valuable. Though the bill is undated, the type shows it to have been issued not later than 1810 .

Fifteen Guineas

REWARD.

WHEREAS the DOVE-HOUSE of Mr. PARR, of Bethnal-Green, was on FrIdAY Night, the 13th inst., BROKE OPEN, and the following

\section{TWELVE TUMBLER PIGEONS}

Stole therein :

A very fine Feathered ALMOND COCK, small Size, remarkable bright Pearl Eyes, fine Beak, the end of upper Bill rather Brown, owing to the Canker when young.

A Rich ALMOND COCK, large size, a little White on the Back of his Neck, no Yellow in his Tail except a little in the middle of one Feather, a Brown mark on one side of his Neck in front.

A Rich ALMOND COCK, small short Body, good Shape, Pearl Eyes, and fine Beak.

A Broad-Chested SPLASH COCK, stands low, bold Head, Pearl Eyes, fine Beak which droops at the Point, stocking Leg'd.

Another SPLASH COCK, small round Head, Pearl Eyes, short straight Beak.

A Soft Ground HEN, round Head, good Shape, a few rich Dun Feathers about her Neck and Flights, stocking Leg'd, a little broken Eyed.

A DUN HEN, fine Pearl Eyes, straight Beak, rather thin Face.

An ALMOND HEN, strong Ground, a few Kite Feathers in her Left Flight, bright Pearl Eyes, and fine straight Beak.

A remarkable clear BLACK SPLASH COCK, Pearl Eyes, round Head, a little coarse in Beak \& Wattle.

A large dark SPLASH COCK, lofty round Head, broken Eyes, short down Beak.

A soft ground ALMOND COCK, dull pearl Eyes.

Also a RED COCK, his right Wing only two thirds grown.

Whoever will discover the Offender or Offenders, shall on Recovery of the said Pigeons, receive FIVE GUINEAS, and in Proportion for 
any Part thereof; and on Conviction, a further Reward of TEN GUINEAS to be paid by Mr. PARR, No. 103, Holborn-Hill.

Or if any Person will give Mr. PARR a Hint respecting the said Robbery, his Name shall be kept secret, and fully satisfied for such Information.

It will have been noticed that Mr. Jayne mentioned the African $\mathrm{Owl}$ as a progenitor of the Short-faced Tumbler. The first pair of these beautiful pigeons known to the present generation was exhibited in 1858; but that they were known in this country in the last century I quite believe, and Mr. Jayne had, no doubt, vel'y good reasons for his statement, Mr. Morey probably having mentioned such birds as part of the composition of the Short-face.

Having dealt with the history of the Short-faced Tumbler, so far as I have been able to trace it, at some length, I now come to a consideration of the bird as it exists. The almond-feathered Short-face first demands attention, both because it has always been considered the representative of its race, and because it best answers the standard of perfection laid down. It has always been a matter of speculation, from Moore downwards, why this pigeon got the name of Almond Tumbler, and it has generally been supposed that it was so called from the almond nut-coloured feathers which compose its ground tint. The nut itself, as well as the shell, both inside and outside, in all stages from ripe to rotten, have been fixed on by authorities as "the reason why." I could never see why only one of the colours in this bird should give it its name, and think that a whole-feathered yellow pigeon would be more appropriately called an Almond. I incline to the belief that the name is not derived from either the nut or its shell, but that, as suggested by Brent, the word almond is a corruption of Allemand, the French word signifying German, and that almond-feathered pigeons of some sort, brought from France under the name of Allemand Pigeons, originated the name. Such coloured 
French Tumbler Pigeons were described by Boitard and Corbie, in 1824, as Pigeons Culbutant Savoyard.

Taking the Almond as the representative of all the Short-faced Tumblers, it may be described as a very small pigeon, only larger than the African $\mathrm{Owl}$, and generally said to have five properties-Feather, carriage, head, beak, and eye.

Feather.-A standard Almond is one having its twelve primary tail feathers, and its primary flights, whether nine or ten-a-side, composed of the three colours-black, red, and yellow. A bird with nine-a-side, all standard feathers, is preferable, in my opinion, to one with ten-a-side having only nine in each wing standard feathers, because it is full flighted; but if the bird with ten-a-side had ouly the shortest flight in each wing out in colour, it would be much nearer perfection than if any of its other flight feathers were wrong in colour. There are, however, so many other properties in the Almond, that it is unlikely such close competition will often arise; but where it is a case of showing standard birds only, the whole of the flight feathers, whether nine or ten-a-side, must show the three colours. The ground colour of the Almond should be of as deep and rich a yellow as can be got; but it is generally either mealy and spotty in colour, or of a reddish colour which can neither be called red nor yellow-like unpolished mahogany wood. As the most difficult thing to produce is the bright yellow ground-which, indeed, has been seen but seldom-this is the point of most consequence; in fact, however good in head and beak a bird may be, it is not a real Almond if it has not the ground colour. If the bird does not come out of the nest of a good ground colour on back, wings, and rump, it can never attain to it later in life. The ground colour being right, it must be pencilled over with black of as intense a deepness as possible, not in any particular pattern, but to show well as a whole. This pencilling ought to increase with the autumnal moults 
till the bird is from two to three years of age, when it comes to its best, after which it gets annually darker, till it becomes more black than yellow, and the tail and flights lose their standard character through absence of white. Even then the bird is beautiful, though past its best from a standard point of view. In the Treatise of 1765 the author says, at page 57: "I have had some in my collection that have had few feathers in them but what have contained the three colours that constitute the Almond, or Ermine-viz., black, white, and yellow, variously and richly interspersed." This has been often quoted as to mean that the three colours should run through all the feathers of the Almond; but no white must appear elsewhere than in flights and tail at any period of the bird's existence. When the ground colour is only a yellow tinged with white, it is called an Almond Splash, and to breed from such for colour is to go backwards, and is like breeding from bad coloured pigeons of any sort. The Almond Tumbler is one of the varieties which show a sexual difference in colouring, the hens, for the most part, being weaker in their ground colour than the cocks, and wanting the black pencilling evenly distributed over the body. There is generally less break in the feather, and the black is seldom of so deep a tint. A really good hen takes longer to come to perfection than a cock, and consequently remains longer in feather. There is no such thing as a standard-feathered hen in flights and tail, or, at least, such is of the greatest rarity.

CARRIAGE.-The shape and carriage of the Almond is the next property to be mentioned. The breast ought to be broad and prominent, the neck short and thin, the back hollow, the rump rather full, and the tail carried above the flights, which should touch the ground, but not drag on it. The head should be thrown back, and the bird should walk on tiptoe, on short, unfeathered legs. Nothing is more attractive in an Almond than excellent carriage, and it is a sign of good blood; for, however fine a bird may be in its other pro- 
perties, it never can look well without good carriage. Shape and carriage have been called one and the same thing; but a bird may have all the necessary conformation, and yet lack that spirit and vivaciousness which enable it to carry itself properly. The Almond shows best when salacious, and when driving his hen to nest.

BEAK.-Two distinct forms of beak are seen in Short-faces, and that which is most generally admired, and which I admire, is what is known as the "goldfinch beak," which is formed like that of the well-known song bird. The goldfinch beak, from its shape, is generally longer, and more inclined to keep growing at the point, than the other form, which more resembles a grain of barley, dipping a little at the end. The goldfinch form is, however, so distinct from the beak of any other variety of pigeon, that, in my opinion, it is the most worthy of encouragement; but whichever style of beak a Short-face may have, it must be straight out from its head, with neither an upward nor downward inclination, and as short and fine as possible. The beak wattle should be small, and delicate in appearance, any coarseness being considered a great fault.

HEAD.-The head ought to be very lofty, broad, and overhanging the beak, if it can be got so. Though the skull itself may not do so, the feathers growing out from the forehead sometimes give it that appearance in a fine bird, which then has a deep stop, or indentation, at the root of the beak. The head itself ought to be round from all points of view; and, when the cheek feathers are puffed out, or muffed, as it is called, it adds wonderfully to the natty appearance of the Short-face.

Exe.-The iris ought to be white or pearl coloured, and surrounded by a fine and narrow eye wattle, of which the less there is the better. A full and prominent eye adds greatly to the appearance. The faults of eye are a reddish pearl, a dusky or clouded iris, and a broken iris, which looks very bad, and spoils the appearance of any bird. 
As the Almond feather is a composite one, made up of various colours, it is preserved by the judicious crossing of its various sub-varieties, such as Kites, Duns, Agates, and Whole-feathers. Kites are of various shades, from such as are almost black, with only the primaries bronzed with yellow, to such as have the yellow cast on their feathers more or less all over them, especially on the breast. Duns also show the yellow on their neck and breast feathers when rich in colour, and are then called Golden Duns. Duns are almost invariably hens, and, when bred from two well-grounded Almonds, are useful for matching with a rich Almond. Agates are such as are red or yellow, splashed or mottled with white. They are of various markings, some showing a preponderance of colour, and others of white. Whole-feathers are either red or yellow, and when sound in colour through flights and tail (which is sometimes seen in reds, and very rarely in yellows), they are both valuable for Almond breeding and for themselves, as they are the choicest of the sub-varieties of the Almond. Black Splashes, or what might be called black Agates, appear to have been formerly used in Almond breeding; but this colour seems to have been bred entirely out of our modern birds, which is, perhaps, the cause of the black pencilling in our Almonds being usually of a kitey or dun black, and, on this account, a cross of a good black mottle, or mottle-bred black, might be of advantage. Even the darkest Kites always show a smoky tail, barred at the end with darker colour; and, however much such birds may assist in breaking the feather in Almond breeding, they cannot impart the desired velvety black colour. Red and yellow Whole-feathers, grizzled with white in flights and tail, or Agate Whole-feathers, as they have been called, are merely unsound reds and yellows, weak in strength of colour. All these subvarieties of the Almond are used in Almond breeding, and are matched with Almonds according to the way they are themselves bred. Although it is not unusual to breed 
Almonds together occasionally, such breeding from richlygrounded ones often results in young ones entirely or almost white, with what are called "bladder" eyes, and almost or quite blind. When such a result happens, the pair must be dismatched at once, and some of the off colours used. I have seen a pair of Almonds produce all the colours I have mentioned except blacks and black Splashes; so it will easily be seen that there is much uncertainty in the production of this beautiful pigeon, and that it is a study in itself. When I was young in the fancy I thought the Almond Tumbler the finest and the most beautiful of all pigeons, and I was never weary of admiring my first pair, which were Spitalfieldsbred birds and cost me a sum of $£ 5$. It is over twentyfive years ago since then, but I well remember that I bred five birds from them during their first season (two Almond cocks, an Almond hen, and two Golden Dun hens), which realised me $£ 12$, and pigeons were cheaper in those days than of late years.

Since the secret, so well kept for so long, and which was in reality a trade secret, of manufacturing the heads of Shortfaced Tumblers, was given to the world in Fulton's "Book of Pigeons," the Almond fancy has declined; but after a time it will rise again, when the importance attached to the head of the bird gives way to its other beautiful properties. There is enough in the natural Short-faced Tumbler, in all its varieties, to entitle it to the position of a very high-class pigeon. The shaping of the skull, which is begun when the squab is a few days old, and continued during its growth in the nest, is done by pressing with a wooden instrument shaped for the purpose, or with the thumb nail, at the root of its beak, and so forcing the bone back into the head, which gives breadth, height, and a deep stop. This is a cruel process, which kills many in the doing, and which renders the lives of those that survive it, for the most part, miserable. No pigeon is so much troubled with vermin as the Short-face, as it is unable, 
with its tiny beak, to free itself entirely from them; and, when the beak is distorted in the shaping of the skull, as it often is, the bird is quite unfit to keep itself free from parasites. The signs to know a made-faced bird are when it is up-faced, which is never natural; and if the lower mandible protrudes beyond the upper at the point, it may be taken as certain that the operator has been at work. Wry beaks are, no doubt, often produced naturally in Short-faces, but there is something about a natural wry beak different from one which is the effect of shaping the skull. The natural wry beak, though crossing at the point, generally fits closely farther back, which is not the case with the artificial one. As I have seen many Short-faces of high quality which I know were never tampered with when young, I would not condemn the whole race, as some do, because manipulated birds may sometimes get away undetected; but I would hold for absolute disqualification of all birds which clearly showed they had been tampered with, because the whole system of making heads is a swindle, and only done to obtain money under false pretences.

Many a man has gone into the Short-faced fancy, and finding he could never produce birds anything like so good as those he began with, for the simple reason that they were unnatural, has given it up in bewilderment; or, learning how the thing was done, he has become a modeller himself, and then cheated others as he was cheated himself. The decline in this fancy is principally on account of the unsatisfactoriness of merely producing quality in pigeons by hand. Honest men wish to breed quality, not to make it with a wooden spoon. I think it may be safely said that when a bird does not show that something has been done to it, there has been so little done that it may be allowed to pass as natural; but when the skull has been forced in, the upper mandible is always displaced to a certain extent, and a bird showing this should invariably be passed over. The under mandible may be turned up, but it cannot be forced back. I think 
that it depends on the judges whether the Short-faced fancy is to decline still further, or whether it is to rise again. The Short-face is naturally a charming pigeon, beautiful in all its colourings, and original in many ways.

One of my set of eight life-size, very old, oil paintings of fancy pigeons, is an Almond Tumbler. From a careful study of these paintings, I conclude they are the work of a faithful and conscientious artist, and if not older than Moore's "Columbarium," they are at least older than the Treatise of 1765 . The Almond represents a common Tumbler in shape and general style, carrying its wings over its tail. It is a richfeathered bird, showing white in its flight feathers. The pictures are evidently portraits, as many little faults are represented which would have been left out had the artist. meant to depict perfect birds.

\section{The Mottle Short-faced Tumbler.}

As already pointed out from the Treatise on pigeons of 1765 , and from the old handbill, black Splashes and black Grizzles were formerly sub-varieties of the Short-faced Almond Tumbler. These gradually settled down into a separate variety, and are referred to at page 64 of that book as follows: "There was also a prize last season for black Mottled Tumblers, whose properties should agree with those of the Almond Tumbler, except the feather, which should be a black ground, the body mottled with white, with a black tail and flight; and, when they are in perfection, they are an excessively pretty fancy, and very valuable. There is also another very pretty fancy, equal at least, if not superior, to the black Mottled, viz., the yellow Mottled Tumbler, whose properties likewise agree with the Almond Tumbler, except the feather, which should be a yellow ground, the body mottled with white, and a yellow flight and tail. Either of these two last-mentioned fancies are extremely useful (provided they answer in their other properties) to intermix occa- 
sionally with the Almond." The illustration of the Mottle accompanying these remarks represents a long-legged, commonlooking type of Tumbler, with a black flight and tail, and white body, over which are dotted about thirty-four wellseparated black feathers. I scarcely think it represents the author's intentions, as he expressly says, "a black ground, the body mottled with white." The Mottle may, however, be said to have been then in its infancy, and a standard more difficult of attainment would soon be aimed at. The present standard is the same as that mentioned for the Mottled flying Tumbler, viz., a self-coloured pigeon with a rose pinion of single, well-separated white feathers on the shoulder, either with or without the $\mathrm{V}$-shaped handkerchief back, but with it for choice. This standard of feather, accompanying good Shortface properties of head, beak, eye, and carriage, makes up one of the most difficult standards in fancy pigeons to breed at all good. When a fancier with such experience of Shortfaced Tumblers as Mr. Fulton, has said that he has only seen a few pairs of Mottles that could even be trimmed into something like perfection, and that the nearest approach to a perfect bird he ever knew of had to be weeded on both breast and shoulders, it will be seen how much remains to be done for the Short-faced Mottle. Whoever follows after this fancy, then, has not only to contend against made heads, as in the Almond, but also against trimming; and so he sets himself a difficult task. Perhaps there have been but few Long-faced Mottles ever produced perfectly marked; but there are certain inherent faults of marking in the Short-faced Mottle, as it exists, which make it harder to produce than the Long-faced. There still exists, however, what may be called the remnants of a good strain of black Mottles, in which the ground colour is good, but which are much inclined to a blaze of white on the forehead, and to orange instead of white eyes. Both are great faults, and a white-eyed bird has only to be seen by the side of a yellow or orange-eyed 
one to show how very much better it looks. From the amount of colour in the Mottle there is but little to contend with in the way of broken eyes, as in the Almond. In head and beak they are, though sometimes passable, never so broad nor so lofty as the best Almonds, while in carriage they are sometimes very good indeed, which is a great setoff to their appearance. In breeding black Mottles, the blaze face should be avoided, however good they may otherwise be, and it might be eradicated in time, as in black pied Pouters, which nearly always had it many years ago.

About the year 1872, I bought two pairs of black Mottles from the late Mr. James Ford, of London, who then had a good strain of them. Two of them were very fairly marked, and the others were Mottle-bred black Whole-feathers of the same strain. As the Mottles were quite free of blaze on the forehead, I managed to keep it out of the great proportion of the produce; but the orange eye, which one of the Whole-feathers had, was difficult to alter, the best marked young ones generally coming with it. I found that a bird which had any white on it as a nestling became too gay when it moulted off, and that when a bird moulted something like what a Mottle ought to be, it came out of the nest all black. There was, therefore, no distinguishing between what were to become fair Mottles or remain Wholefeathers till after the first moult. Dun Mottles are occasionally bred from blacks, and they are useful for breeding back to blacks, but dun being an off-colour, few care for them.

Red and yellow Mottles would each be more difficult to keep good in colour than blacks, but I am not aware that any long-standing strain of either is in existence. In Almond breeding, both red and yellow Agates are often produced well marked to the Mottle standard. These, however, have generally a weak, washed-out colour in flight and tail feathers, and white rumps as well; but it is from the judicious 
breeding of such with red and yellow Whole-feathers and Agate Whole-feathers that a strain of red and yellow Mottles might be produced. Such red and yellow Mottles as were in existence when the fancy for them was at its best were doubtless produced in this way.

Considering the difficulty there is in producing Short-faced Mottles, and remembering the fact that none have ever been seen naturally perfect in marking, it is a question if the standard of feather for them is not too high. A standard that would allow of white feathers on the head, neck, breast, wings, and back, but retaining the entirely dark flights, tail, rump, and under body, would be a pleasing one. There would also be great difficulty in keeping the white feathers separate, as they are always inclined to run together.

\section{The Blue Short-faced Tumbler.}

There is another whole-feathered Short-faced Tumbler, now seldom seen, viz., the Blue. It was formerly bred to great perfection in London. Eaton, who has a picture of one in his Treatise of 1858, says: "I cannot by any possibility let the opportunity pass without noticing the observations and great admiration the venerable and much-respected old Fanciers bestow upon the amazingly pretty little compact Sky or Powder Blue Whole-feather, with its black bars, black as ebony, the Short-faced head and beak, with its other properties-the pretty little Blue Tumbler. Whenever they have the opportunity to see one, I have almost fancied they would have gone into fits in observing a good one with its five splendid properties-head, beak, eye, carriage or shape, and feather. It appeared to me almost to make them boys again; it has as great or greater an effect upon them as going to the mill to be ground young again. Unfortunately, it is seldom you have the opportunity to see one; they are very scarce at this time (1858)."

It was soon after this time (in 1862) that I saw in the 
possession of Mr. Fulton, who then lived in Deptford, a very fine pair of Short-faced Blue Tumblers; I have often spoken to him about them since. I believe such good birds as they were are not now in existence. Though probably made-faced, they were broad and lofty in skull, with good colour and fine carriage.

\section{Baldheads and Beards.}

Short-faced Baldheads of good quality are now extremely scarce. They have always been rare, but formerly there were at least some very fair ones in blacks, blues, and silvers. Blacks are scarcest at the present time, and it is now about twenty years since I saw a good pair of that colour. During the past twenty years Short-faced Balds have been represented chiefly by the strain of Mr. Woodhouse, who has shown blues and silvers, with which he has carried off many prizes at the principal shows where classes were given for Balds. Red and yellow Balds have lately been shown of very fair colour and quality, and I understand they were produced from a cross with the Almond and its sub-varieties. They were bred by Mr. Burchett, a London fancier, who sold off some years ago, when they were distributed among the breeders of this very beautiful and interesting variety. The standard of feather for the Short-faced is the same as for the Long-faced Bald; but there are very few, if any, really wellmarked ones in existence which combine good Short-faced properties of head, beak, eye, and carriage. Compared to the best Almonds they are far behind, and all I have seen, which I knew to be untampered with about the head, could only be called pleasant faced at the best. I have, however, seen of late several of each colour-excepting the blacks, which seem nowhere at present-manufactured into very passable ones. I say manufactured, because it was plain from their appearance that they had been tampered with, and the young ones they produced showed it clearly. Beards are even of 
lower quality, as judged by the Short-faced standard, than Balds, and the only colours in existence at all good are the blues and silvers. Mr. Woodhouse has bred some of the best. As for black, red, and yellow really Short-faced Beards, I have never seen any. Beards ought to be marked exactly the same as the flying ones.

All Short-faced Tumblers of high quality have a difficulty in shedding their flight and tail feathers during the moult. The feathers will grow to their complete length without bursting from their sheaths, and, if allowed to do so, their fibres will rot. The upper skin of the feather should be scraped off with the thumb nail as it continues to grow, and the inside core of the feather carefully removed. By this means the feathers may be preserved good.

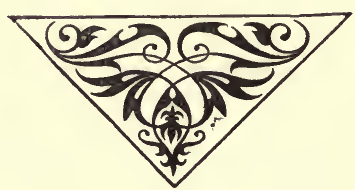




\section{Chapter XXVIII.}

\section{$\propto$ HOMING PIGEONS. $\infty$}

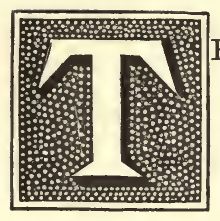

HE well-known love of pigeons generally for their homes has been taken advantage of, from the earliest ages, by making use of them as messengers. The flying fancier can point to Anacreon's "Ode to the Carrier Pigeon," written twenty-five centuries ago, as a proof of the existence of his fancy in early times:-

"Tell me why, my sweetest dove, Thus your humid pinions move?"

"Cnrious stranger! I belong To the bard of Teian song; With his mandate now I fly To the nymph of azure eye."

Throughout history there are records of the use of Carrier Pigeons as messengers to and from beleaguered cities: from the amphitheatre, to tell the results of the sports or combats; and from caravans, to announce their setting out or arrival Many passages from mediæval writers have recently been brought to light regarding their employment; and if, in modern 
times, the telegraph has superseded them in Europe as swift carriers of news, railways have afforded such facile means of training them, that probably at no other period of the world's history have such immense numbers of these birds been kept, by sweepstakes and others fliers, as at the present time.

The pigeons formerly used in this country as messengers were mainly of Carrier descent, such as Horsemen, Dragoons, Skinnums, and Long-faced Beards. All such have been for long known amongst us as Homing Pigeons, and are so referred to by Moore in his "Columbarium," where, at page 5 , in describing the construction of the "Trap, or Airy," he says: "Others build them very wide and lofty, designing them to give Room and Air to Pigeons of the homing Sort." Again, at page 32, under the Horseman: "This Practice is of admirable Service to 'em, when they come to be train'd for the homing Part"; and elsewhere, when writing of the "Powting Horseman."

\section{The Skinnum Pigeon.}

The Horseman and Dragoon have been already described, and the Skinnum, probably named from the somewhat skinny appearance of its eye wattles, is merely some mixture of the Dragoon and Tumbler varieties. For short distances the Skinnum is capable of quick work.

\section{The London Beard Pigeon.}

The Long-faced, or London Beard, is a pigeon of respectable homing powers, having in recent years done as much as 100 miles, when carefully trained. These bold, intelligentlooking pigeons, are found chiefly in black, blue, silver, and dun, as well as in chequers of these colours. They ought to be marked exactly the same as the English Beard Tumbler. They vary in type, some having a considerable amount of eye wattle, denoting Dragoon blood; but the correct type is 
that of the flying Tumbler on a large scale. Although some birds have measured more, $1 \frac{5}{8} \mathrm{in}$. in face, from the point of the beak to the centre of the eye, may be considered the standard for a cock of the Tumbler type, hens being about $\frac{x}{16}$ in. less.

\section{The Antwerp Carrier Pigeon.}

On the Continent, the pigeon now chiefly used for match flying is the Antwerp Carrier, or Belgian Voyageur, which has been bred from a judicious mixture of several long and high-flying varieties. The first of these-a pigeon that can itself do long distances-is the Smerle of Liege, which is quoted in Mr. Tegetmeier's book as capable, when matured, of doing 500 miles in twelve hours, in fine weather. The Smerle is the opposite in appearance of the Dragoon type, being arched and broad in skull, with a short, thick beak, and with evident appearance of Owl descent, some of them even showing the frilled breast. The next mixture is the Continental Cumulet, a pigeon noted for the length of time it can keep on the wing. I have seen it mentioned that these pigeons have flown as long as thirteen hours at a stretch, the distance covered during that time being probably several hundred miles. They are of various colours, but blacks and reds, with white tails or white flights, or with both, are known as varieties, while pure whites, ticked with red on the head and neck, are also a well-known race, distinguished in France as Pigeons Volant cou-Rouge. The Cumulet is much alike in size and shape to the common clean-legged flying Tumbler, but is rather longer in beak. It has a pure white iris, which is larger than usual in pigeons, the pupil being small and contracted. The third ingredient of the composite bird now known as the Antwerp Carrier is the English Dragoon, known in Belgium as the Bec-Anglais. The fusion of these three varieties has taken place during the present century, and a race of pigeons has been established remarkable for 
their power of flying long distances in quick time. The cross of the Dragoon with the Smerle, or the Cumulet, is called a Demi-bec, and the cross of the Dragoon-Smerle with the Cumulet, or Dragoon-Cumulet with the Smerle, a Quart-bec. The Quart-bec, bred over again to the Smerle, or the Cumulet, takes after its progenitors; so that among the best pigeons there are various types of skull, some being after the $\mathrm{Owl}$ strain, while others are more run out in head and beak. The chief colours found in the Antwerp are blue, blue chequer, mealy, and red chequer, and these colours pied to some extent with white. These colours are the most natural, being what are found among semi-wild pigeons, and in process of time have doubtless asserted themselves as the hardiest and fittest for the severe work they have to perform.

Coming now to the consideration of the wonderful performances of Antwerps in returning distances of 500 miles and more, there is no doubt that training has much to do with it, that great numbers of them are lost in the severe training they get, and that the percentage of birds that would return from a first toss of 400 miles would be but small. Still, they have been known to return to their domicile from such a distance without any previous training, and therefore there remains something. still unexplained in connection with them, which may never be satisfactorily elucidated. Dogs, cats, and other animals, have been known to return immense distances when taken from home; they have been sent by sea, and have returned by land. But then we hear of such incidents when they happen, and of those who do not so distinguish themselves we never hear.

Some years ago Mr. James Huie, of Glasgow, the wellknown Pouter fancier, a writer whose diction and style of composition have caused many to wish that he had written otherwise than only fugitively on fancy pigeons, contributed the following article on the Antwerp Carrier to the Journal of Horticulture : 


\section{"POWER OF WING AND COMPASS.}

"I hear a voice you cannot hear,

Which bids me not to stay;

I see a hand you cannot see,

Which beckons me away.

"There has been much interesting writing on the powers of the Carrier Pigeon, the length and rapidity of their flights, and modes of training, along with speculations as to their guide for their homeward course. The latter points to the theory of this bird flying by sight alone. I find that the Rev. E. S. Dixon, in his very interesting work, 'The Dovecote and Aviary,' takes this same view; and though I always hesitate to place my opinion against that of such men of letters as Mr. Dixon, still on this point (the guide of the Carrier on the wing) I beg most respectfully to differ. It is pretty well known that I am not an Antwerp Carrier fancier, and do not encourage the Antwerp as a bird that ought to be in the fancy, for several reasons which I shall not discuss at present. But Antwerps I keep for two purposes: First, as feeders for my young Pouters; and second, for table use. For both these purposes I find them most suitable. First, then, as to the power of wing possessed by this bird. I do not think this point is yet fully developed in this country; but, so far as my personal experience goes, I shall give it. The plain narrative, I think, may answer the purpose best. It may be interesting, and I hope will not weary readers.

"Several years ago, when in Manchester, I called on Mr. W. Millward, bird dealer, from whom I had all my Belgian Canaries. He had lately arrived from the Continent, and brought with him a stock of Antwerp Carriers, which he then found to be most unprofitable. Not having before seen such birds which I could be sure of having been imported, I purchased three pairs. The stock consisted of mostly blues, some mealies, and some nameless colours; but all were self- 
coloured, and all showing a cross of the Owl-a slight division of the feathers on the breast. Some of them had the breast feathers slightly turned, indicating the frill. They were wild as newly-caught hawks, and strong enough to carry before them a pane of window glass, as one of them did when in my possession. After much care and caution I found them to be hardy birds, breeders almost the year round-indeed, I am never without some few young ones. During the season, when early light, they take two flights per day, the cocks and unoccupied hens at about 7 a.m., the hens and unoccupied cocks about 1 p.m. The flock invariably fly southward, and are away for about an hour and a half each time. I have seen them fully ten miles south still holding in that direction. When first noticed on their return they are always at a very great height; but should it be blowing hard (the weather seems of little consequence to them), they often return from the northward, having, no doubt, been carried to the east or west, beyond their home. Three years passed, when a friend came on a visit from Ledbury, Herefordshire. This friend saw my Antwerps, and expressed a wish for a pair or two to breed for table use. After his leaving for home I caught three pairs, all bred in my loft (Antwerp loft, for with them I have nothing else). They were put into a box (not a basket or cage), and addressed to a mutual friend in Manchester, as they could not reach Ledbury in one day from Glasgow. They reached Manchester in the evening, were re-booked for Ledbury next morning, and reached their destination that evening, but until then were not taken out of the box in which I had placed them. Before sending the birds away I pulled the flight feathers out of the right wing of each bird, and my instructions were: 'Keep them confined, with such a netting as will let them see the locality, till they have each a nest of young ones, and are sitting upon their second eggs.' Those instructions were rigidly adhered to. One night the 
netting was removed according to instructions, and the birds were at liberty next morning. A man was set to watch. The cocks took sundry short flights, and by-and-by relieved their mates occupied in incubation; the hens came out, and at once took wing. The date now I cannot give preciselylet me call it the 18th of July. On the morning of the 20th I had a letter from my friend, dated the day before (the 19th), saying: "The birds were yesterday morning let out, but two of them have not returned. I am afraid they are lost.' While in the act of reading my friend's letter, my man who attends to those birds came into my office, saying: 'I think two of Mr. —-'s birds are back.' Scarcely believing him, I went out into the yard, and there certainly were two of the hens I had sent to Ledbury.

"Now I can tell to a mile the distance between Glasgow and Ledbury, Herefordshire, by railway; but I will let our readers measure the distance as the crow flies, and decide whether or not this is a very long flight. Mark, first, those birds had never been trained; second, they had never been in the hands of anyone till caught by me, when I pulled the flight feathers from one wing of each bird. These birds would leave their cote at Ledbury about 10 or 11 a.m. on the 18th, and, as I did not know what day or week they were to be set at liberty, of course I did not expect them, and at all events I certainly did not expect they would at any time return to Glasgow on the wing. For all I know, they may have reached on the evening of the 18th, or during the day of the 19th. Two months after this I gave a pair to a friend in Paisley - a pair of young ones. They had only been two days outside the loft, and never had left it beyond a hundred yards. They were taken away squeakers, and confined, with a netting in front, for three weeks. When let out, they were at their birthplace in ten or twelve minutes. It is only seven miles to Paisley by road. Those birds had never been flown." 
The following was published in the Fanciers' Chronicle of 20th August, 1880, and was noticed also in the Field and other papers: "Wonderful performance of a Homer.-In February last year I bought from Mr. Mills, Brussels, some homing pigeons. On Sunday, the 8th instant, I gave one of these birds its liberty, and it disappeared. I thought no more of it, but on Thursday last I was surprised to receive from Mr. Mills a letter, saying that the bird reached his loft on Wednesday morning. I send you this information, as I consider this a most marvellous performance, the bird having been in confinement many months, and had to travel over about four hundred miles of country which it had never seen. The pigeon in question is a three-year-old blue chequer hen, and will be again in my possession to-night or to-morrow morning, Mr. Mills having sent it off yesterday.-JAMES P. TaYlor, Moss Croft, Gateshead-on-Tyne."

This is a record of a truly wonderful performance, one similar to that which was accomplished by the birds of $\mathrm{Mr}$. Huie, of Glasgow. Training brings out the natural homing powers of these pigeons, but that they do not fly by sight alone the above proves. And in training for the long Continental matches the final stages often exceed a hundred miles, over which the best birds fly straight home. What guides them on their way?

That some pigeons, especially certain breeds, both from a strong natural and inherited love of home, will return from long distances without any previous training, is therefore an established fact. But at the same time, little dependence could be placed on even the best bred flying pigeons without training. They must, therefore be flown first from a short distance, and gradually by increased stages, till perfect at their work, during which process of training many of them will of course be lost. It has been recommended by writers on this subject, that birds in their first year should not be flown above a hundred miles from home, and not 
over two hundred miles in their second year, as they are not fully matured till over two years of age.

It is an established fact that pedigree in homing birds is of the first consequence, so that those entering on pigeon flying should by all means endeavour to procure stock from fliers of repute. If the best Homers could be selected by appearance there would be no need to go further; but it is well known that some of the best have had little in their looks to recommend them.

The most absurd stories regarding Carrier pigeons are often circulated in the newspapers, such as the return of some sent to the Arctic regions to their home in Ayrshire, the flight of others across the Atlantic Ocean, and the capture of others at sea with stamps on their wings showing them to have been employed during the Siege of Paris, which happened seven or eight years before their capture, and since which event their flight feathers must have been renewed annually. It seems impossible to kill these fables, and they crop up at regular intervals. One or more Carriers were captured at sea during the Siege of Paris, and were shown at exhibitions of pigeons as objects of interest. Since then the story has been repeatedly re-published as a late event, and it will probably continue to be published in time to come, as it comes under the observation of those who do not understand the way in which pigeons are used as messengers.

On the Continent the flying fancy is much followed. In Belgium there are hundreds of clubs or societies for the cultivation of the Voyageur Pigeon, whilst they also abound in France and Germany. In this country the fancy is increasing, and rising in public estimation, many gentlemen and respectable people being devoted to it. The use of the Voyageur for war purposes has been recognised on the Continent, and Government studs of them have been established in France, Germany, and other countries. The principal foreign flying matches take place in July, and extend over distances of from 200 to 
500 miles. Twice have races been organised from Rome to Belgium, a distance of some 900 miles, but with so little success, both as to time and the percentage of returns, that it is now recognised that this long fly can only be attained at too great a sacrifice.

The following interesting account of the origin of the Belgian Homing Pigeons was sent to me, in 1880, by M. Victor La Perre de Roo, so well known on the Continent for his researches into the subject, and as the adviser of nearly all the Continental Governments as to the adoption of these pigeons for war purposes.

"As regards the Belgian Homing Pigeons, they are very much like our street dogs (chiens de rue); they are the result of numerous crossings between the Carrier and the different varieties of pigeons which existed in Belgium about a century ago. In other words, they are degenerated Carriers, as the wattle on the upper mandible of the beak and round the eye shows clearly. Some have thick, short beaks; but as a rule they have thin beaks, like those sent you by $M$. Géré.

"There are some birds with round heads, very short beaks, and frills like Owls; but they are very small birds, and are not so much liked in Belgium as the large Antwerp birds, their wings not being so powerful. These birds have undoubtedly been obtained by crossing the degenerated Carrier with the Owl.

"The Carrier was brought to Belgium by Dutch sailors, got neglected, and soon degenerated.

"There are also birds with white eyes, and these are supposed to be a cross between the degenerated Carrier and the Pigeon Volant, or Highflier (the Cumulet).

"But all these birds have been crossed, as I state in my book, dans nos fermes et nos basses cours, with the Pigeon $B$ iset (the Blüe Rock Pigeon) and all the other varieties of pigeons which existed in Belgium a century ago, as is generally the case with pigeons which are kept only for table purposes. 
"My father died twenty years ago, at the age of seventy-six, and he often told me that the birds he had when he was a boy had more wattle on the beak and round the eye than the birds I kept about thirty years ago; but at that time a pigeon which had flown a distance of twenty-five miles was looked upon as a very good bird, and the very few birds which had been sent to be thrown from Paris-that is, about a hundred and fifty miles from Brussels-were considered to be most wonderful and exceptional birds.

"Since then you know what regular training has done. During the season, about 100,000 to 150,000 pigeons are sent every Saturday from all parts of Belgium, to be thrown from all parts of France, and Auch, Bordeaux, Bayonne, Biarritz, and St. Sebastien (Spain), are now the stations they are generally sent to.

"There are now upwards of 1000 pigeon societies in Belgium."

M. La Perre de Roo sent me several lots of Antwerp Carriers, all of which were descended from the birds presented to the French Government, after the war of 1870, by MM. D'Hanis and Gits. I have kept the strain pure, and supplied numerous fanciers with their produce, many of which have flown long distances. They are easily trained up to 100 miles during their first season.

As feeders for my Pouters these Antwerps are the best birds I ever employed. They are larger than the Homers usually seen, and such prolific breeders that I am never without fat squabs for the table.

\section{Exhibition Antwerp Pigeons.}

Although a Homing Antwerp Carrier of the highest type has little in its appearance to distinguish it from birds which could not possibly home a moderate distance with certainty, it has been usual for some years to exhibit the Homer for prizes in the show-pen. This method has been of great use 
in one respect, as the immense classes of these so-called Homers have proved serviceable in providing funds for the encouragement of real fancy pigeons which might not otherwise have been provided with classes. No doubt many really good flying birds are of good colour and style; while others as good, or better, have nothing in their appearance to recommend them; so that showing the Homer is a mere lottery as far as being able to pick out the best flying bird is concerned.

Where prizes for homing pigeons are offered at shows, the following remarks on judging them, by Mr. W. B. Tegetmeier, who is an authority on the subject, will be found of value. He says:

"The classes for Homing Antwerps which are now common at many shows offer considerable difficulty to those who have to award the prizes, unless, indeed, as not very often happens, they are practically acquainted with the breed.

"When the judge is not in this position the birds selected are usually of the short-faced Birmingham type; and I have seen, at Bingley Hall and elsewhere, prizes given to a set of bad show birds, the best of which would have been lost at twenty or thirty miles, even if they could have been trained that distance. It should be borne in mind, that the properties of a homing pigeon lie in the wing more than in the head, and a judge who simply looks at a pen and decides the prizes upon the appearance of the birds proves that he knows nothing whatever about the subject on which he undertakes to decide.

"At the exhibition of the birds that won in the late (1876) race to Brussels from the Alexandra Palace several distinct types were recognisable. Some of the birds were rather light, and fine in the head, whilst others were heavy, thicker in head, and stouter in body. Although the lighter birds are generally regarded as flying well in fine weather, and for short distances, the stouter are usually regarded as the standard type. 
"Of the three engravings which accompany this article, the first (Fig. 14) represents, life size, a head which may be regarded as that of a very handsome Belgian Voyageur cock. It may be taken as that of the bird which Mons. Ch. Mills and Mr. C. L. Sutherland-both practical men-gave me the first prize for at the Alexandra Poultry Show, 1875; but it was not drawn from that bird, but from a cock I obtained of Mons. Ch. Mills. The bird has all the properties that I desire to

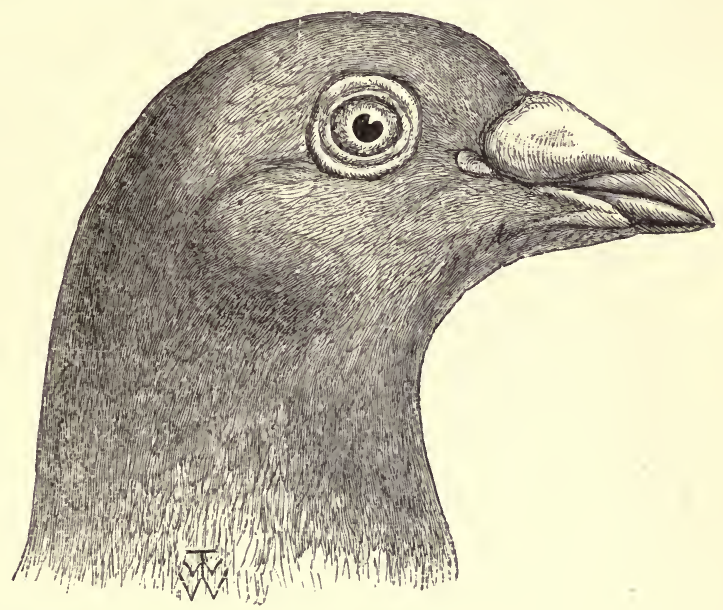

FIG. 14.

see in the head of a flying pigeon-a full-developed brain ease, showing a large brain, and such a structure of head as indicates strength and endurance-and he is without any tendency to the absurd exaggeration of any fancy point. Of course, no really practical judge would give a prize in a homing class, even to such a bird, unless he were in first-rate condition, with his plumage hard and firm, the flight feathers broad and overlapping, and the bones of the wing well clothed with power- 
ful muscles. To prove that this bird is as good as he looks, I may give his history. He was hatched, early in 1874, from a bird of Mons. Ch. Mills' that was one of the first winners in the great annual national match from Marseilles, in the south of France, to Belgium-a 500 miles race. The same year, as a young bird, he flew from St. Quentin and Creil (abcut 200 miles), and in 1875 he again flew from St. Quentin, taking first prize; also from Paris, Orleans, and was a winner in the race from London-200 miles.

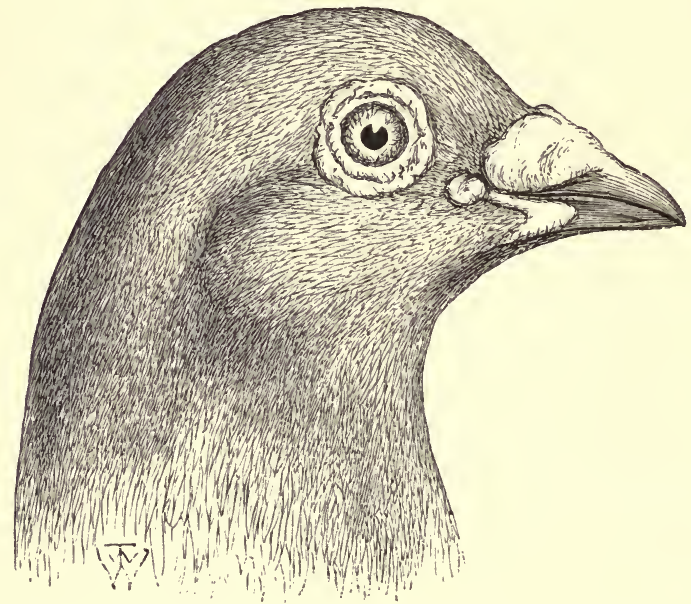

F1G. 15.

"At my request Mons. Ch. Mills sent him over to show at the Alexandra Poultry Show, 19th Oct., 1875, and I induced him-very reluctantly, I am afraid-to part with him. The bird was, necessarily, useless to me to fly, for on liberation he would doubtless have returned to Brussels, as I have had birds do after two years' confinement in England; but I kept him to breed from, and his early progeny are very good indeed. 
"So good is the bird in appearance, that I have repeatedly refused the offer of $£ 5$ for him merely as a stock bird.

"Fig. 15 represents a Homing Antwerp belonging to me to which the judges gave the silver cup at the Crystal Palace Poultry Show in 1875. The bird was certainly a handsome one, but not, in my opinion, equal to the former, even in looks; he was purely Belgian bred, and was a good Homer, having flown about 100 miles in previous years. In 1876, I entered him in a private race from Brussels, but-the truth must be told-I have never seen him since he was let off in that pleasant city on the morning of the 20th July, and was lost, although his companion in the race, not half as good looking, is walking about before my eyes.

"I have now shown what is regarded as the most esteemed

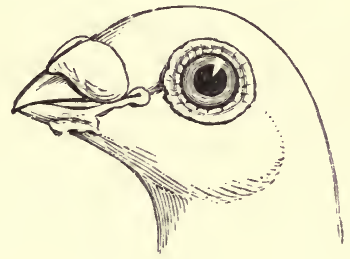

FIG. 16.

type of Belgian birds-viz., as regards cocks, for the hens are generally less stout in the head and beak; and I may state, that the sketches are executed with the most extreme accuracy, not only as regards the form, but also as to the expression of the birds. Mr. T. W. Wood, one of the most accurate of natural history draughtsmen, devoted very great care to their delineation, and I may state that the drawings are not altered to suit my views of what a good Homer should be, but show the birds exactly as they are.

"I now wish to show what is not an uncommon view of a homing bird amongst some amateurs. The outline sketch (Fig. 16) is traced with the closest accuracy from one of the drawings 
of Mr. Ludlow, of Birmingham, published in the New York Pet Stock and Poultry Bulletin. The drawing represented, with all Mr. Ludlow's skill, an indifferent Birmingham show Antwerp, with pert, upright carriage, short, stubby beak, large eyes, small head and brain, and is no more like a Belgian Voyageur than I to Hercules. Such a bird could not fly fifty miles, and would not fly five.

"I have visited over and over again the lofts of the Belgian amateurs ; I have owned, and still own, hundreds of these birds; I have had thousands pass through my hands; but in all Belgium I never saw a bird approaching the form that is apparently regarded by $\mathrm{Mr}$. Ludlow and the Birmingham fanciers as that of a Belgian Voyageur.

"The exhibition of the right sort of birds is very much promoted by their liberation after being judged in the pens, the prizes being withheld if the birds are not returned at a given time. It is true some of the birds may live close to the show, and have their flying powers very slightly tested, but really good flyers are certain to be sent for the selection of the judge, and the Short-faced show birds will be kept at home.

"The liberation clause should always be qualified with the stipulation, 'weather permitting,' for it would be a serious matter if, during the worst flying months of the year, a flight of really good birds should be liberated in a fog, or in hazy weather, when they could not see their way home. For, in spite of all the nonsense written about flying by instinct, all practical men know that a bird flies by sight. I have lost some of the best birds I ever possessed from trying to fly them across London on a foggy day."

\section{The Short-faced Antwerp Pigeon.}

This pigeon has been produced principally from the Smerle of Liege, one of the varieties from which the Belgian Voyageur descends, as mentioned already. According to Fulton, who ought to know, some breeders have made use of 
the Barb in breeding it. Its chief properties lie in its bead, which must be capacious, and present in profile an unbroken curve from the nape to the point of the beak. The beak itself ought to be thick and short, the under mandible approaching the upper in consistency as much as possible, and fitting close to it, or, as fanciers say, boxed. Any gullet is objectionable, and detracts from the appearance and value of this variety in the opinion of its admirers. Viewed in front, the head ought also to be round from eye to eye. The irides should be orange or blood red in colour, light or pearl eyes being faulty. The eyes must be prominent, or bolting, and be surrounded with a fair but not excessive amount of wattle. Like other pigeons of this type of head, the beak wattle thickens with age; it should be of considerable substance, lying well spread on each side, and by the time the bird arrives at maturity-some three or four years-it should have filled up all inequalities in the curve of the head, and even if it stands out a little beyond the curve it is not considered any fault in a good bird. Mere shortness of face, therefore, is no desideratum in this bird, but rather the reverse, for room is required for the forehead behind the beak wattle to fill out, and this is the point which gives a finish to a good bird, and makes it massive in skull.

The Short-faced Antwerp should be a large pigeon, bold in appearance, upstanding, and tight-feathered. The choicest colour is the mealy, almost always now called silver dun, which is a good sounding name; but there is certainly no silver in this colour, neither is there any dun. The mealy colour may be said to have been bred to perfection in this pigeon. The cocks are sometimes finely powdered on the head and upper neck, while the lower neck, breast, and wing bars, are of a rich brown or red; but it is difficult to get the same colour in the hens, which are generally dark-headed. Next comes the red chequer, both dark and light; the blue chequer, also of various shades; and the black-barred blue, the original colour of wild pigeons. 
These are the chief colours, valued, I believe, in the order named. Then come silvers, preferred with bars of as dark a dun as possible; dun chequers, called silver chequers; yellow mealies, called creamies; and lastly blacks, which are sooty or blue black, showing bars of a deeper black.

My opinion of the Short-faced Antwerp is in accordance with that of a great many men who are the mainstays of the pigeon fancy. I cannot admit that it has one original point in its composition entitling it to be called an original variety, and all the diagrams and illustrations published of it only confirm this opinion. The chief difference between it and the $\mathrm{Owl}$ is said to be that the latter is essentially a short-faced pigeon, which the Antwerp ought not to be. No doubt all the Owl tribe are known as Short-faced Frilled Pigeons; but they would quite as correctly be called blunt-faced, for mere shortness of face is not any desideratum in them, as it takes away room for the filling up of the forehead behind the beak wattle. This when well-developed gives them, above all else, a look of quality, just as it does the Antwerp.

The Short-faced Antwerp may be difficult to breed good according to the standard laid down for it; but, when bred as good as can be, it is no more than a pigeon with some Owl points in its head, and, for the most part, clothed in the mere off colours of fancy pigeons. I think the encouragement it gets tends to foster low art in pigeon breeding, wastes time and trouble that might be much better employed, and that there is no result, from an artistic point of view, in its production. Many fanciers, whose judgment of pigeons is acknowledged to be sound, agree with me in this opinion.

\section{The Long-faced Antwerp Pigeon.}

During the past few years this variety, bred for the show-pen, has come into considerable prominence. Those birds I have seen were very large pigeons, mealy and red chequer in colour, with enormous, long, arched heads, and a considerable amount of 
beak and eye wattle. A great winner was a mealy one, called "Goose," who with his son, known as "Young Goose," swept the boards for a long time. They were aptly named, having, with their small, sunken eyes, the look of being descended from the Runt, which as Moore says is Goose-headed.

\section{The Medium-faced Antwerp Pigeon.}

There is still another show Antwerp, known as the Mediumfaced, and there are frequent disputes over prize birds, difference of opinion existing as to what type they really belong.

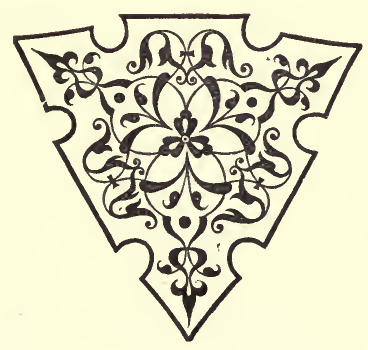




\section{Chapter XXIX.}

\section{$\propto$ TURKESTAN PIGEONS. $\varnothing$}

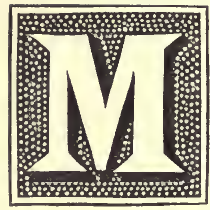

R. T. B. COOMBE WILLIAMS, M.A., has lately described, and illustrated with woodcuts, in the periodical Poultry (July 3Oct. 30,1885$)$, a series of skins of fancy pigeons belonging to the Zoological Department of the British Museum, South Kensington. They were collected by Dr. Scully, a member of an expedition that visited Turkestan in 1875, and were procured in the city of Yarkand. The following is part of a note written by Dr. Scully regarding them :-

"In the spring and summer of 1875 I purchased all the varieties of domestic pigeons that I could find in the place. When I found that my stay in the country would be limited to a short time, I thought it might be worth while to prepare skins of all the varieties to which the natives give distinct names. In this way I found that there were about twenty-six named varieties, of which the accompanying skins are specimens.

"These varieties are said by the Yarkandis to breed true, and the fanciers select and match the different kinds. The 
natives of Eastern Turkestan assert that the differences which are found among the pigeons are due to the direct interposition of Providence, but they know that the varieties can only be regularly perpetuated by interbreeding. They also add, that by crossing different varieties they could predict almost exactly what the resulting progeny would be like; in short, they seemed to think that pigeons could be bred to a feather.

"The people were well aware of the great fondness domestic pigeons have for salt. A Yarkandi fancier advised me to give my birds plenty of salt. He said the result of this would be that my pigeons would attract those of other people to the place where the salt was to be found, and that I should thus greatly increase my stock of pigeons at a very trifling cost.

"The domestic pigeons of Kashgaria are very fond of perching. In almost every house where pigeons are kept, a pole is placed across the open courtyard, from wall to wall, for them to perch on, and several other plans are resorted to for the same object. In the house where I kept my pigeons, I had sticks placed across in various directions, and I found that they preferred perching on them to standing on the ground. Great fights often took place among the birds to secure favourite places.

"In Eastern Turkestan I never saw any of the dovecotes tenanted by semi-domesticated pigeons in nearly the same livery as the wild stock which are commonly met with about the villages in Egypt.

"I have given all the native names first in the Persi Arabic character, as written by the Yarkandis, then a translation of the words into Roman character, and, wherever it is known to me, I have added the meaning in English. It will be noticed that many of the names (Damdar, Palang, Zagh, \&c.) are Persian, and that others have reference to China.

"All the measurements were made in the flesh, before skinning. The length is from the tip of the beak to the tip of 
the longest tail feathers; the wing, from the point of the carpal joint to the end of the longest primary; the tail, from the vent to the end of the longest tail feather; and the bill, straight from the angle of the gape to the tip of the upper mandible. The measurements are in English inches and decimals of inches; the weight, in ounces and decimals of ounces avoirdupois."

Mr. Williams has added the length of face from centre of eye to point of beak; but these measurements, being taken from the skins, can only be regarded as approximately correct. The varieties he has made drawings of are the five following:-Ak Bash Zagh, Char Bash, Kara Tokum Damdar, Sidam Rakhshi, and Sidam Borghul.

The following is Mr. Williams' description of these Yarkand pigeons. I give the weight, but not all the measurementsonly the length of face and feather.

KashKa KoK.-Male. Beak, black; eyes, orange-yellow; head and neck, silvery, with much green lustre; breast, vinous; shoulders, silver, with dark bars; flights, bluish dun; tail, silvery blue, with dark bar. Face, 1.35 ; length, 13.5. Weight, 11 oz.

Sidam Kок.-Male. Beak, greyish black; eyes, bright red; general colour, light blue, with black wing bars; neck and breast, darker, and lustred; belly, light; flights, slightly grizzled with white; tail, blue, with Kity tinge and black bars. A few white feathers at back of skull. Face, 1.5; length, 13.5. Weight, $12 \cdot 2 \mathrm{oz}$.

Aк BАSн Кок (White-headed Blue).-Male. Upper mandible, flesh-coloured, with dark stripe; lower, black; eyes, reddishbrown; head, white above eyes; body, blue; neck and breast, darker, and lustred; belly, dark; grizzled black wing bars; rump, white; tail, blue, with black bar. Face, 1.32; length, 13. Weight, $10 \cdot 3 \mathrm{oz}$.

Gora BAJINI (Bajini $=$ Chinese).-Male, very short-faced. Beak, livid, horny ; eyes, dark straw ; general colour, white, with 
vinous tint, the quill of nearly every feather being red; top of head, dark red; a few black feathers on neck; quills of flights, ruddy; tail feathers, some white, others with ruddy quills; legs slightly feathered. Face $\cdot 82$; length, 12:3. Weight, 9.7oz.

AK BASH ZAGH (White-headed Crow); also called Siah Palang (Black Leopard).-Male. Beak, light, horny; eyes, reddish brown; colour, white, with blackish cheek markings like a Turbiteen, rusty black shoulders like a Turbit, and coloured breast and belly within lines drawn across breast and vent. Face, 125; length, 13.2. Weight, 9.6oz.

Khutani (from Khotan, a town in Turkestan).-Male. Closely resembles the foregoing in marking; colour, bluish chequer, with red bronze wing bars. Face, 1.33; length, 13. Weight, 8.7oz.

KIzIL BASH (Red Head).-Female. Beak, livid, horny; eyes, orange; head, white, with reddish tinge, which becomes darker on neck and breast; shoulders and flights, white; tail, white, with a little bluish red in it. Face, 1·12; length, 13.8. Weight, 12·25oz.

Kок BaSH (Grey or Blue Head).-Male. Upper mandible, dark; lower, light; both with great substance. Eyes, orangered; head and neck, silvery blue, lustred with green and red. The colour is cut off across the breast like a low-cut Magpie, and the remainder of the bird should, probably, be white, but it has some foul feathers on body. Face, 1.07; length, 14:5. Weight, 12:25oz.

Char Bash.-Male. Beak, light; eyes, orange. Very peculiar pigeon, black in colour, except shoulders as in a Turbit, and under body from breast to vent, which are white; beak, short and thick. Is crested up the forehead, from beak wattle to crown of head, in shape like that of a rose-combed fowl; the feathers rise up over each eye, and meet together in the centre, a form of head crest not known in Europe. Face, 1.08; length, 13.9. Weight, $11 \cdot 6 \mathrm{oz}$.

KarA Bash (Black Head).-Male. Marked like the preceding, 
and with the peculiar frontal tuft, but rather smaller. Face, 1.07 ; length, 13.5. Weight, 10.3oz.

Aldi Popshar Ala Kargha (Frontal Top-knot Variegated Crow).-Female. Beak, very short and thick; eyes, golden yellow; marked like the Char Bash; frontal tuft wonderfully developed. Face, 82 ; length, 12:1. Weight, 8.25oz. Some of the short-faced Yarkand pigeons tumble in the air, but not to any great extent.

Sidam Rakhshi.-Male. A very curious bird. Beak, light; eyes, yellow; colour, black; head, white above eyes; white stripe down the gullet, about an inch long; white flight feathers; shoulders, as in a Turbit, whitish, but showing black through the white, the quills and under down being dark. Face, $1 \cdot 07$; length, $12 \cdot 7$. Weight, $9 \cdot 5 \mathrm{oz}$.

DAMDAR (Blower, or Trumpeter).-Male. Beak, light, red flesh-colour at base; eye ceres, orange; eyes, dark brown; peak, crested; legs, feathered; a few toe feathers; colour, pure white. Face, 1.37 ; length, $12 \cdot 7$. Weight, $10.50 \mathrm{z}$.

Kizin Tokum Damdar (Red Blower).-Male. Beak, light; eyes, dark brown; shell crest; stocking legs; colour, white, with ashy-red shoulders; breast, mottled, with about twenty feathers, well separated. Face, 1·25; length, 13 . Weight, $9 \cdot 4 \mathrm{oz}$.

Kara Tokum Damdar (Black Blower).-Female. Beak, light; eyes, dark brown; shell crest; legs unfeathered; Kity black shoulders; mottled breast. Face, 1.24; length, 13.2. Weight, 7·25oz.

Kaghazi (Kaghaz means Paper).-Female. All white Dovelike pigeon; eyes, dark brown. Face, 1.25; length, 12.3. Weight, $8 \cdot 9 \mathrm{oz}$.

Pelang (Leopard, or Mottled).-Female. Upper mandible, light; lower, dark; eyes, bright red; head and neck with Turbiteen cheek markings; shoulders, Kity black; rest of body plumage white, flecked with black; some flights white, others black; tail, rusty black. Face, 1.25; length, 12.5. Weight, $8 \cdot 250 \mathrm{z}$. 
Sidam ZaGH (Zagh, Persian for Crow).-Female. Beak, brownish black; eyes, orange-yellow; plumage, black throughout. Face, $1 \cdot 25$; length, 13 . Weight, $10.5 \mathrm{oz}$.

Sidam Arghuni.-Male. Beak brown; eyes, light pink; general colour, Kity black; breast, all bronze lustre, which turns to green towards thighs; rump, ashy black. Face, 1.1; length, 12. Weight, 7oz.

Sidam ArghonI.-Male. Beak, ;black; eyes, orange-yellow; plumage, black, grizzled with blue, and exceedingly lustrous. Face, $1 \cdot 12$; length, $12 \cdot 9$. Weight, $10 \cdot 75 \mathrm{oz}$.

Migizi (Brain (?) Pigeon).-Female. Beak, brownish; eyes, orange-yellow; plumage, blue and black chequered; neck much lustred; black-barred tail. Face, 1.25; length, 13.1. Weight, $8.50 \mathrm{z}$.

Sidam Borghul. - Female. Beak, black; eyes, orange; excepting tail, which is dark blue with bar, every feather on this bird is black with a white tip; the head and neck appear as if powdered with white; breast bas a green, bronze lustre. Thighs, ashy and lustrous; shoulders, creamy white, with the black at the roots of the feathers showing in places through the white; flights, black and white, with white tips. Face, 1.23; length, 12. Weight, $8 \cdot 10 \mathrm{oz}$.

Sidam Borghul.-Female. Plumage same as foregoing, but has a peak crest and frontal tuft like the Char Bash. Face, 1.24; length, 12.1. Weight, 8oz.

Kosh Popshak Arghuni (Double Top-knot).-Male. Beak, greyish black; eyes, orange-red; frontal tuft and peak crest; head, neck, and breast, black, richly lustred with green and purple; shoulders, brownish blue, tipped with black; rump, ashy black; flights, bluish brown; tail, blue, with black bars. Face, 1.07 ; length, $13 \cdot 9$. Weight, $12 \cdot 2 \mathrm{oz}$.

Ax Koyrux Bajini (White-tailed Chinese).-Female. Beak, greyish black; eyes, orange; head, black, with white frontal spot; neck and breast, black, lustred with green and bronze; shell crest; thighs, dark ashy black; body feathers, black, with 
white tips, causing the shoulders to appear nearly white; flights, black, with white tips. Face, 93 ; length, 13 . Weight, $10 \mathrm{oz}$.

Siddam Bajini.-Female. Beak, dusky; eyes, orange-yellow; head, neck, and breast, dark, with bronze lustre; shoulders, creamy white, tinged with red, and some feathers ticked with black; rump, ashy black, lustred with green; flights, creamy white and black mixed, darker towards their ends, and having signs of a white tip; tail, blue-black, with dark bar. Face, 1·13; length, 11·6. Weight, 8oz.

BALDAK (a Ladder; in allusion to the marks on the wings).Female. Beak, greyish black; eyes, light pink; small frontal tuft; colour, dusky blue, with white wing bars. Face, 1; length, 12:1. Weight, 8:3oz.

BorghUL.-Female. A great novelty. Mandibles, dusky; eyes, dark straw colour. In each feather of the head there is black, white, and almond-yellow, well broken; the neck feathers show most of the black colour. Breast lustred with purple; the belly a darker shade, but the feathers tricolour, with a bronze lustre; shoulders, white, with ruddy edges and black base; flights, light at base; quills, black, the ends dark, with white and almond tips; rump, black and white, with but little almond colour; tail feathers mostly black. Face, 1.13; length, 11.3. Weight, 8oz.

It will be seen from the foregoing interesting descriptions that there are still many curious pigeons in the possession of Asiatic fanciers that we know very little about. I mentioned, in the first chapter of the first edition of this book, written about 1878 , that we might still expect to get something new from Central Asia and China. 


\section{Appendix.}

\section{$\propto$ PIGEON LITERATURE. $\varnothing$}

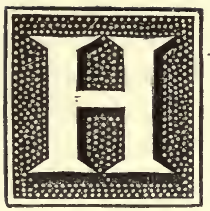

AVING for many years been a collector of books relating to domestic pigeons, I have now a collection of them, in various languages, which it would be difficult to match. Some of the works are of great rarity, and have only been got after years of search. When it is considered that few fanciers consider it necessary to publish their experiences, it is surprising to find how many books have been written on the subject from time to time. It is true that the great proportion of them are merely reprints or abridgments of previous works; but the publication of so many editions of Girton's "Complete Pigeon-Fancier," for instance, shows that the demand for them must have been considerable.

\section{Early Printed Books.}

Pliny's "Naturax History."-The first edition was printed at Venice, by Joannes de Spira, in 1469, and is, I suppose, the first printed book containing any reference to the pigeon fancy. The notices are in Chaps. lii.-liii. of Book X., as already mentioned in Chapter I. of this work. The first edition is 
a rare and expensive book, copies having been sold at from $£ 50$ to $£ 120$, though I was once offered an imperfect one for much less; but many later editions were published before 1550, and these can occasionally be purchased for little money. An English translation of Pliny, by Dr. Philemon Holland, was published in 1601, and another by Bostock, in 6 vols., in late years, by Bohn. Pliny's "History" is a great storehouse of ancient learning, all that is known of the writings of hundreds of lost authors being preserved in it. The author was a man of the most indefatigable industry, and wrote many other works. Being near the Bay of Naples, in command of a Roman fleet, when the eruption of Vesuvius that destroyed Pompeii and Herculaneum (A.D. 79) broke out, he sailed near, and went on shore to observe more closely its effects. A midnight-like darkness coming on, from the quantity of dust and fine ashes in the air, the party hurried back to the shore; but Pliny, then fifty-six years of age, being corpulent, and his breathing becoming affected, was unable to proceed, and soon after lay down and died. These particulars are recorded in the letters of his nephew, Pliny the Younger.

Aldrovand, Ulyssis : "Ornithologia." Bonnoniæ, 15991603, 3 vols.; 2nd Ed., Francofurti, 1610, 2 vols., folio.

Aldrovandi (1522-1607), the Italian naturalist, began the publication of his works on natural history in 1599, and they were continued for many years after his death, the series being concluded in 1668. In the second volume of the Frankfort edition of his "Ornithology" there are sixty closely-printed folio pages containing quotations from ancient authors who have referred in any way to the pigeon, and everything extant on the subject, from Homer to Tasso, seems to have been known to the writer. I find almost everything mentioned about pigeons that I had discovered in my reading of Greek and Roman authors, and much more besides; and I think Aldrovandi's account may be considered an epitome of ancient 
references to them. Several varieties of domestic pigeons, including some malformed ones, are figured in his engravings. The Jacobin and Frizzled breeds are recognisable; also a bird baving a resemblance to the Leghorn Runt as portrayed in the London Treatise on Pigeons of 1765.

WILLUGHBX's "ORNITHOLOGX." London: 1676 and 1678. Folio.

Francis Willughby (1635-1672), according to John Ray (1628-1704), who edited the "Ornithology," was a man of great ability, who, before his death at the age of thirtyseven, had travelled over a great part of the Continent in pursuit of knowledge connected with natural history. Ray writes as follows: "Of his skill in Natural Philosophy, chiefly the History of Animals, I shall say no more at present, but that it hath not yet been my hap to meet with any man, either in England or beyond Seas, of so general and comprehensive knowledge therein." The first description of fancy pigeons published in England, so far as I am aware, is by Willughby, whose book was first published, in 1676, in Latin, and then, in 1678, in English. At pages 181, 182 of the latter edition is an interesting account, so far as it goes, of seventeen varieties of tame pigeons, much of which I have already referred to in the preceding pages. The figures he gives on Plates XXXIII. and XXXIV. are partly copied from Aldrovandi and partly original; but it is impossible to believe that his plates of the Pouter, Carrier, Jacobin, and Fantail, represent the best birds existing in London at the time he wrote. Ray says: "But because $\mathrm{Mr}$. Willughby (though sparing neither pains nor cost) could not procure, and consequently did not describe, all sorts of Birds, to perfect the Work I have added the Descriptions and Histories of those that were wanting out of Gesner, Aldrovandus, Bellonius, Marggravius, Clusius, Hernandez, Bontius, Wormius, and Piso." It may be that additional information on domestic pigeons exists in the writings of these old authors. Gesner is quoted by German writers on pigeons. 


\section{English Books.}

"Columbarium; or, The Pigeon House: being an Introduction to a Natural History of Tame Pigeons. By John Moore. London: Printed for J. Wilford, behind the Chapter House in St. Paul's Churchyard, MDCCXXXV."

"Moore's Columbariom. Reprinted Verbatim et Literatim from the Original Edition of 1735, with a Brief Notice of the Author by W. B. Tegetmeier, F.Z.S. London: The Field Office, 346, Strand, W.C., 1879."

For many years the only known copy of the "Columbarium" among pigeon fanciers was that in the possession of Mr. F. C. Esquilant, from which $\mathrm{Mr}$. Tegetmeier made his reprint, in 1879; but soon afterwards a copy turned up in London, at one of Puttick \& Simpson's sales, which passed into my possession on 5th November, 1879. J. M. Eaton, the writer on pigeons, possessed a copy in 1852, which, there is no doubt, was destroyed. The book is extremely rare. My copy measures $7 \frac{5}{8} \mathrm{in}$. by $4 \frac{5}{8} \mathrm{in}$., and is printed (from the signatures) in quarto. The title-page, dedication, and preface, occupy seven leaves (i.-xiv.), and the body of the book thirty leaves, paged 1-60. There are four copies in the British Museum, according to $\mathrm{Mr}$. Tegetmeier, one of which is paged up to 80 , the additional matter being headed-

An AccodnT of some medecines prepar'd by JOHN MOORE, Apothecary at the Pestle and Mortar, in Lawrence Pountney's Lane, the first great Gates on the left Hand from Cannon Street; who formerly lived at the Pestle \& Mortar in Abchurch Lane, London, with a faithful Narrative of some cures effected by them.

Eaton's copy had these twenty extra pages, to which he refers in his Treatises on Pigeons (1852 and 1858).

Moore was proprietor of a worm powder, and seems, from the references to him in contemporary literature, to have been well known. The Rev. Alex. Headley, rector of Hardenhuish, Wilts, who writes on pigeons under the nom de plume, "Wiltshire Rector," first called attention to Pope's lines entitled- 
To Mr. JOHN MOORE, Author of the celebrated WORM-POWDER,

a witty production of ten verses, that may be found in the poet's works.

I have also discovered that Moore is referred to by Swift in "A Letter from a Gentleman in the Country to his Friend in Town," who compares his existence to that of a tenant of some house, saying :

"At this present time I live in a poor, little, sorry house of clay .... and, what is worst of all, am liable to be turned out at a minute's warning. .... I might have had my tenement (such as it is) upon better terms if it had not been for a fault of my great grand. father; he and his wife together, with the advice of an ill neighbour, were concerned in robbing an orchard belonging to the lord of the manor. . . . . When I am turned out, I understand my lodge, or whatever you please to call it, depends upon a low-spirited, creeping family, remarkable for nothing but being instrumental in advancing the reputation of the Great Moor in Abchurch Lane."

Mr. Tegetmeier says, in the Introduction to his reprint: "Twenty-two years before the issue of the 'Columbarium' he (Moore) published a work with the following title:

"Arcana Mooreana; or a Succinct and Lucid Discourse of the Origine, Essence, Scituation, Symptoms, Causes, and Cure of the Cholick. In all its various Denominations, different Kinds, Degrees and Complications. Done by Mr. John Moore, Apothecary, at the Pestle and Mortar, in Abchurch Lane, near Lumbard Street, London: Printed for the Author 1713."

He also says: "It is probable that the writer must have been in business some time, as he states:

"If ever any person upon the face of the universe who devoted his whole life to the doing good, and rendering himself beneficial to mankind, has reason to complain of the ill and barbarous usage he has encountered .... I am the Man."

Though said to be "Reprinted verbatim et literatim from the original edition of 1735," $\mathrm{Mr}$. Tegetmeier's reprint con- 
tains a few misprints when compared with my copy of the original.

The Gentleman's Magazine for February, 1735, notices the "Columbarium" in a list of lately published books, "price 1s." The author only lived a short time after this, his death being mentioned in the Gentleman's Magazine for 1737, page 252, as follows:-"April 12. Mr. John Moor, of Abchurch Lane, the noted Worm Doctor. He will now shortly verify Mr. Pope's witty Observation, viz.:

"O learned Friend of Abchurch-lane, Who sets our Intrails free,

Vain is thy Art, thy Powder vain,

Since Worms shall eat ev'n thee."

Moore may be called the Father of the pigeon fancy in England; his descriptions are so accurate, concise, and clear, that, generally speaking, they stand good now; and, with the exception of what was written on Short-faced Tumblers, nothing to any great extent original was added on the subject till recent times. From the rarity of the "Columbarium," I should suppose that only a very limited number of copies were printed.

"A Treatise on Domestic Pigeons. London: Printed for and sold by C. Barry, in Ingram Court, Fenchurch Street. MDCCLXV."

This book, the author of which is unknown, is inscribed to John Mayor, Esq. It should contain thirteen full-page copperplate engravings of the principal varieties, and a frontispiece representing the pigeon loft, matching pen, grain hopper, waterfountain, and net for catching the birds. Some copies differ in the plates of the Almond and Mottled Tumblers, two sets of which appear to have been executed. The title-page, dedication, and preface, occupy eight leaves (i.-xvi.), and the remainder of the book seventy-two leaves, paged 1-144, printed in 8vo. It is by no means scarce, at least thirty copies having come under my observation,-some of them containing book- 
plates with coats of arms. They are often very much cut down, but I have one fine uncut copy, which measures $8 \frac{7}{8}$ in. by $5 \frac{5}{8}$ in., illustrated with fifteen plates, those of the Almond and Mottled Tumblers, that differ in some copies, having been added.

The author, who was an experienced pigeon fancier, says in his preface: "In regard to the model of this treatise, we do not offer it to the public as an entire new work, but have proceeded on the plan of Mr. Moore, have corrected some errors, and made many additions. And, as Mr. Moore's essay is very deficient for want of cuts to convey a just idea of the different species, in order to supply that defect we have procured engravings from the best hands, at a very great expence, in order to illustrate this work, all which are done from the life, and very masterly executed, under the inspection of the author, and other fanciers."

He refers to " a kind of standard, calculated for the better judging of Almond Tumblers, lately published by some of the admirers of this fancy, elegantly engraved on copper-plate, at the top of which is an Almond Tumbler, very finely executed from life, the outlines being inimitably well performed, and by much the best I ever saw, and at so reasonable a price as sixpence." A copy of this "standard" is given in Eaton's 1858 book, at page 186 . It is entitled "Ordinances established by the Columbarian Society, at the Globe Tavern, Fleet Street, respecting the perfections and imperfections of Almond or Ermin Tumblers, 1764." Its illustration is the one found in some copies of the Treatise with the words "Simpson, sculpt.," on it. The author also refers to "the standard now published and in use among the Columbarians" for judging Pouters. This is uniform with the "Ordinances" for judging Almond Tumblers. It is a large sheet, headed by the same portrait of a Pouter which the Treatise contains.

The author says, with reference to his own experience in the fancy, that he had kept pigeons for many years, "having been possessed (I believe I may venture to say without vanity, of 
as good, if not the best, in England) of fancy pigeons, besides Toys of all kinds."

The most original part of this book is the long account of the Almond Tumbler, a variety no more than mentioned by Moore, but which had risen, in 1765, to great estimation in London. The Mahomet Pigeon, which Willughby had described, but which Moore had evidently never seen, is also well described; but most of the work is, as the author acknowledges in his preface, "on the plan of Mr. Moore."

(1.) "A Treatise on Domestic Prgeons. London: Printed for the Proprietors, and sold by all the Booksellers in Town and Country. Price only Two Shillings and Six-pence."

(2.) “The New and Complete Pigeon Fancyer; or, Modern Treatise on Domestic Pigeons. By Mr. Daniel Girton, of the County of Bucks. London: Printed for Alex. Hogg, No. 16, Paternoster-Row. Price Two Shillings."

(3.) "The New and Complete Pigeon Fancyer; or, Modern Treatise on Domestic Pigeons. By Daniel Girton, of the County of Bucks. London: Printed for Alex. Hogg, at the King's Arms, No. 16, Pater-noster-Row. Price only One Shilling and Sixpence."

These three books, with the exception of their title-pages, are the same imprint. The second leaf contains a preface (iii., iv.). The remainder of the book consists of sixty-four leaves, paged 13-140. All the copies I have seen are similar, beginning at page 13, though none have more than two leaves of title and preface. They have, when perfect, a folding plate containing the figures of twelve pigeons, copied in reduced size from those in the large Treatise of 1765. Full-sized copies should measure $6 \frac{7}{8} \mathrm{in}$. by $4 \frac{3}{8} \mathrm{in}$. The work is compiled from the large Treatise, from Willughby as regards the Smiter Pigeon, and from writer's such as Worlidge and Lisle, whose agricultural works refer to pigeons as farm stock. Whether the name Girton was a mere nom de plume, taken, as some suppose, from Moore's reference to "one Girton," who had a flight of Turbits 
that would mount almost as high as Tumblers, or the actual name of the compiler, cannot now be determined. The history of the book I imagine to be something like this: The large Treatise was probably too dear for the majority of pigeon fanciers, and the first form, at 2 s. $6 \mathrm{~d}$., was published, to be succeeded by the second, at $2 \mathrm{~s}$. These are both so extremely scarce that not many copies can have been issued. The third form, at 1s. 6 d., seems to have been more successful, as it is not uncommon.

The book was probably printed about 1770 , and issued, with its various title-pages, from that date till about 1780 . Alex. Hogg, the publisher, dealt in remainders, and probably purchased the unsold copies of the first form, issuing them with new title-pages.

(4.) "The Complete Pigeon Fancier; or, a New Treatise on Domestic Pigeons. By Daniel Girton, of the County of Bucks. London: Printed for Alexander Hogg, No. 16, Pater-noster Row. Price only 1s. 6d."

This edition, with the same folding plate of twelve pigeons, is a verbatim reprint of the preceding, page for page, the leaves also being numbered 13-140. The probable date of issue was from 1780-90.

(5.) "The New and Complete Pigeon Fancier; or, Modern Treatise on Domestic Pigeons. By Daniel Girton, Esq., of the County of Bucks. A New Edition, Revised and Improved by Mr. W. Thompson, Author of 'The New and Complete Bird Fancier.' London : Printed by S. Couchman, Throgmorton Street, for Alex. Hogg and Co., at the King's Arms, No. 16, Paternoster Row. Price only One Shilling and Sixpence."

This form, illustrated with the same folding plate of twelve pigeons, is an abridged edition of the preceding, in smaller type. The preface is on the back of the title-page; the second leaf contains a list of "Contents," and the paging is 5-64. The last page contains an advertisement of the "Treatise on the 
Almond Tumbler," by W. P. Windus, which was published in 1802. The date of issue of this edition was probably about 1805 .

T. Ward, a London bird-dealer, "at the Bell and BirdCage, the corner of Silver Street, in Wood Street, near Cripplegate," published early in last century a little book on song birds, which, he says in the preface, is the first of its kind "wholly treating thereof." The copy in my possession is entitled, "THE Bird-Fancier's Recreation: being Curious Remarks on the Nature of Song Birds. Third Edition, London, 1735." Many editions of this little book were published by Hogg towards the end of last century, under the title of the "New and Complete Bird Fancier; or, Bird-Fancier's Recreation and Delight, by Mr. Wm. Thompson, late Gardener to the Duke of Ancaster, and Author of the 'New Gardener's Chronicle."' Although his name is on the title-page of many editions of both "Complete Bird and Pigeon Fanciers," this Thompson had nothing to do in the composition of either.

(6.) "The New and Complete Pigeon-Fancier; or, Modern Treatise on Domestic Pigeons. By Daniel Girton, Esq., of the County of Bucks. A New Edition, Revised and Improved by Mr. W. Thompson. London: Printed by Rider and Weed, Little Britain, for Hogg and Co., No. 16, Paternoster Row. Price only One Shilling and Sixpence."

This contains folding platê, title-page, and preface on first leaf, contents on second, and pages 1-56. It is a reprint of No. 5, and the date may be about 1810 .

(7.) "The New and Complete Pigeon-Fancier; or, Modern Treatise on Domestic Pigeons. By Daniel Girton, Esq., of the County of Bucks. A New Edition, Revised and Improved by Mr. W. Thompson. London: Printed by Weed and Rider, Little Britain, for H. Hogg, No. 16, Paternoster Row. Price only One Shilling and Sixpence."

This contains folding plate (a very worn impression); titlepage; preface, one leaf (iii., iv.); contents, one leaf (v., vi.); and pages 1-66. Descriptions of several foreign wild doves have 
been added to previous editions, and the date, from the type, appears to be 1810-20. While No. 6 was printed by Rider and Weed, this edition was by Weed and Rider.

(8.) “The New and Complete Prgeon-Fancier; or, Modern Treatise on Domestic Pigeons. By Daniel Girton, Esq., of the County of Bucks. A New Edition, Revised and Improved by Mr. W. Thompson. London: Printed for T. Kelly, 17, Paternoster-Row. Price only One Shilling."

This edition was printed at Maidstone, by W. Hill, printer, Bank Street, and has the folding plate of twelve pigeons, which had been re-touched; and it has a second plate of "Improved Pigeon-Houses and Nest Apparatus, by Dr. Dickson, copied by permission from his 'Live Stock and Cattle Management," " a work first published in 1805. It contains title-page ; preface, one leaf (iii., iv.); contents (v., vi.); pages $1-60$, and is a reprint of No. 7, apparently printed about 1820-30.

(9.) "The New and Complete Pigeon-Fancier; or, Modern Treatise on Domestic Pigeons. Printed and Published by J. Bailey, 188, Fleet Street." The probable date of this might be found from an old London Directory. A publisher of same name issued "The Young Sportsman's Pocket Companion," from 116, Chancery Lane.

(10.) "The Pigeon-Fancier. London: Printed and Published by W. Mason, 21, Clerkenwell Green." Plate of six pigeons, copied from Girton. This is Girton cut down to thirty-six pages. About 1820.

(11.) "The Complete Pigeon-Fancier. London: Orlando Hodgson, Cloth Fair." Coloured plate of six pigeons, copied from Girton; twenty-four pages small type. An exact reprint of No. 10. One of a series of sixpenny pamphlets, green paper cover. About 1830.

(12.) “The Pigeon and Bird-Fancier. Derby: Published by Thomas Richardson. Simpkin, Marshall, and Co., London; S. Horsey, Portsea." Twenty-four pages small type, half on 
pigeons, half on cage birds. An abridgment of No. 10. About 1840.

I daresay other editions of this manual, which appears to have been in good demand for three-quarters of a century, may yet be found. Small pamphlets in paper covers are apt to be thrown aside and destroyed; hence their scarcity. The earlier editions are generally found bound, often with other small books, in the same volume, and are not nearly so scarce as the later ones.

Short descriptions of fancy pigeons, taken from authors mentioned, may be found in many works published in the eighteenth century, such as AlBIN's "History of Birds," "The Complete Sportsman," "Dictionary of Country Affairs," "The Country Gentleman's Best Guide," and "The Sportsman's Dictionary." “The New Foundling Hospital FOR WIT," vol. vi., 1784, contains some amusing verses on fancy pigeons.

(1.) "A New and Compleat Treatise on the Art of Breeding and Managing the Almond Tumbler. London: Printed for the Author by W. Williams, No. 35, Chancery Lane. Price Seven Shillings. 1802."

(2.) "A New and Compleat Treatise on the art of Breeding and Managing the Almond Tumbler. London: Printed for the Author by W. Williams, No. 35, Chancery Lane. Price Five Shillings. 1802."

(3.) "A New and Compleat Treatise on the Art of Breeding and Managing the Almond Tumbler. By an Old Fancier, and a Member of the Columbarian Society, held at the Queen's Head Tavern, Holborn. London: Printed for Alex. Hogg and Co., at the King's Arms, No. 16, PaternosterRow. Price 4s., in extra Boards."

These are three forms of the same imprint, full-sized, uncut copies of which should measure $8 \frac{7}{8}$ in. by $5 \frac{5}{8}$ in. Frontispiece of an Almond Tumbler, coloured. Title-page, one leaf. Dedication to the Gentlemen of the Columbarian Society, four 
leaves (i.-viij.), and pages 9-104. No. 3 has an extra leaf following the title-page, containing advertisements of Hogg's "Complete Bird and Pigeon Fanciers" on one side, and "Contents of this Work" on the other. The author was W. P. Windus, a solicitor in London, who says in the book he had been a fancier of Almond Tumblers for ten or twelve. years. He continued in the fancy for some time, for I have a circular letter signed by him in 1813, which I found in a copy of his book which belonged to "Thomas Garle, jun., 1809," who, with his father, was long connected with the Columbarian Society. The circular is partly engraved, the portion I print in italics being in the autograph of $\mathrm{Mr}$. Windus. It is headed by an engraving of an Almond Tumbler, of which I give a copy (Fig. 17).

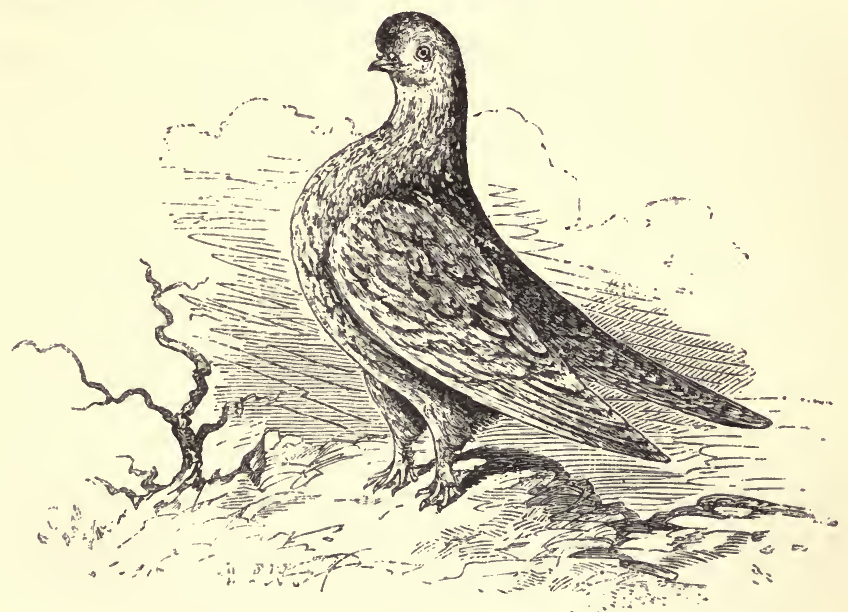

FiG. 17.

Sir,-You are requested to Dine with the Colombarians, on Tuesday next, the 7th of Decr., at four o'clock precisely, to declare Birds, to choose Committee, President, and Deputy, and to audit accounts.

Yours, \&c., W. P. WINDUS, Secy. 
With the above I also found a card, of which the following is a copy:-

\section{Colomberian Society Meetings, Queen's Head Tavern, \\ Holborn,}

The first Wednesday in the following months:

February-Shew Day

April

June

August

October

December

J. BRADSHAW,

President.

The sketch heading the circular was probably etched by Jas. Ward, R.A., himself; it bears his initials. There is a portrait of an Almond Tumbler by him in the Sporting Magazine of the year 1808; and there is another, which I have, in the Sporting Magazine for March, 1825, from a painting by him, the description of which is as follows:

This bird was sister to a famous pigeon called Columbine, and was bred (we believe) from birds of Mr. Parry's, by French Stevens, about the year 1803, who sold her to Richard Latham, Esq., in whose possession she remained some time, during which Edward Whitehead offered him thirty guineas for her. She was one of the most perfect birds of her day, and her family having been successfully continued, has contributed most essentially to the perfection of the present breed; and, notwithstanding the pains that have been taken in the rearing of this breed of pigeons by several amateurs, the feathers of the specimen we lay before our readers have not been surpassed in the present race of Almond Tumblers. We believe she was afterwards in the possession of Sir John Sebright, or Lord Heathfield. The portrait was painted for R. Latham, Esq., by his valued friend, James Ward, R.A.

In the Gentleman's Magazine for 1792, page 1152, there is a notice of the marriage of Mr. W. P. Windus.

There is no edition of the "Treatise on the Almond Tumbler" dated 1804, as stated by Eaton. The edition by Hogg, 
who bought the remainder, is not uncommon. The author's editions, especially the seven-shilling one, are very scarce. He probably disposed of very few copies.

(1.) "A Treatise on Domestic Poultry, Pigeons, and RabBits. By Bonington Moubray, Esq. London, 1815." 12mo. Pages i.-viii., and 1-218.

This was written by John Lawrence, author of veterinary, agricultural, and sporting works, under the assumed name of "Moubray." He was also author of "British Field Sports," and "The Sportsman's Repository," published under the assumed name of "W. H. Scott," as I found in an edition of his "Treatise on Horses," where he lays claim to these works.

He says in the preface: "I may presume to style myself practical, since I have throughout my life been a breeder and keeper, and also an amateur of domestic poultry, pigeons, and rabbits;" also that he had kept a Stud Book for his poultry and pigeons. He gives a very good account of the way to keep and breed pigeons; but, having kept them chiefly for the table, his remarks are of little interest to fanciers. He refers to "The Treatise on Pigeons, 1765," as the best authority he knew of, and says: "The only breeds which I have kept, exclusive of the Common, were Tumblers, Horsemen, Carriers, Turtles, Dragoons (commonly called Dragons), and Runts." Being for some years the only book of its kind, this work had an extensive sale, and went through nine editions, gradually enlarged, before 1850 .

(2.) "Moubray's Treatise on Domestic and Orna. mental Poultry." New Edition (the Tenth), Revised and greatly Enlarged by L. A. Meall. London, 1854." 8vo. Coloured plates. Pages i.-viii., and 1-504. About fifty-five pages are devoted to pigeons, and a good deal of information is given regarding the principal fancy breeds. The compiler was acquainted with Eaton's and Brent's writings. The correct origin of the name "Turbit" is here given for the first time, I believe. 
(1.) “The Boy's Own Book: a Complete Encyclopedia of all the Diversions of Boyhood and Youth. Tenth Edition. Pp. 462. London: Vizetelly, Branston, \& Co., Fleet Street. 1835."

(2.) “The Little Boy's OwN Book of Sports and Pastimes. London : David Bogue, 86, Fleet Street." No date (published 1854).

(3.) “The Boy's Own Book: a Complete Encyclopedia of Sports and Pastimes. A New Edition, Revised and Enlarged. Pp. 696. London: Lockwood \& Co. 1868."

The description of fancy pigeons in the various editions of "The Boy's Own Book" appears to have been edited by a practical fancier, for although evidently inspired by "Daniel Girton, of the County of Bucks," there are a few original observations added. A chapter on pigeon lofts and traps, nicely illustrated, is new, and the pretty woodcuts were in several instances drawn from birds in the possession of London fanciers. All editions are beautifully printed, and illustrated with charming vignettes, and must have been a source of enjoyment to many. I cannot trace the date or publisher of the first edition.

“The Litwle Boy's Own Book. By Augustus Goodfellow. With Sixty Illustrations. London : George Goodfellow, Strand." Small square 8vo, fancy boards. This differs from the previous volume of same title, being printed on 184 pages, in large type. The account of pigeons, taken from Girton, occupies pages 103-140, and the woodcuts of them are the same as those in J. Rogers' “Pigeon Fancier's Guide” (1844), to be afterwards noticed.

"The Poultry and Pigeon Keeper's Companion. London: G. Purkess, 286, Strand, W.C." A small pamphlet of thirty-six pages, in yellow paper covers, published probably about 1855. Small woodcut illustrations. The pigeon part is abridged from Girton.

“The Young Angler, Naturalist, and Pigeon and 
RABbit FANCIER. Ninety-eight illustrations. London: Routledge, Warne, and Routledge. 1860." 12mo. 124 pages, cloth gilt. The description and illustrations of pigeons, occupying pages 69-86, are from "The Boy's Own Book."

"The Natural History of Pigeons. By Prideaux John Selby. Edinburgh, 1835." Thirty-two coloured plates, 8vo, 228 pages. One of the volumes of "Jardine's Naturalist's Library," chiefly on wild pigeons or doves; contains a short account of domestic pigeons, drawn chiefly from Boitard and Corbie's work, published at Paris, 1824. The argument in favour of the Blue Rock being the progenitor of all tame pigeons is clearly stated.

"Bees, Pigeons, Rabbits, and the Canary Bird Familiarly Described. By Peter Boswell, Greenlaw. Glasgow: W. R. McPhun; London: Hall, Arnold, \& Co. 1840. Price One Shilling." The author, who also published a manual on poultry, seems to have had an acquaintance with some previous works on pigeons, but in his brief description there is nothing new on the subject. The book is a small one of 117 pages, in green paper cover, and is now scarce. It was reprinted in America, in 1842, by Wiley \& Putnam, New York; and also in London, in 1852, by Routledge.

(1.) “The Pigeon Fancier's Guide: a Complete Directory for the Proper Treatment and Management of Fancy and other Pigeons. By James Rogers. London: Thomas Dean \& Co., Threadneedle Street. Price One Shilling. "The Second Edition, Enlarged and much Improved." This has a folding plate containing figures of seven pigeons, mostly from Girton, and a pole locker. Other cuts are scattered through the book, which is nicely printed on sixty-eight pages. It may be called a compilation from Girton. Rogers was a pigeon and bird dealer in the City Road, London; and I remember, when on my way from school at Taunton, to Scotland, in the year 1857, standing entranced at Rogers' shop, looking at his pigeons and lockers, of which latter he was a builder. 
I induced my father, who was with me, to buy me a pair of blue Turbits and a pair of black Jacobins. Several hundreds of pairs were descended from the Turbits, which bred in-and-in for fifteen years without any of the bad results which are generally supposed to follow such a course. According to the London Catalogue of Books, Rogers' " Pigeon Fancier's Guide" was published in 1844 .

(2.) “The Pigeon Keeper. By James Rogers. Seventh Edition. London: Dean \& Son, Ludgate Hill." This has no date, but was published in 1860 , at $6 \mathrm{~d}$., in paper covers. It is an exact reprint, on forty-four pages, of "The Pigeon Fancier's Guide," but has no folding plate.

(3.) "Pigeons: How to Rear, Breed, and Keep. By James Rogers. New Edition, Revised by F. Crook, Esq. 32 pages. London: Dean \& Son, E.C." A third form of Rogers' book; no date, but published in 1880, at 6d., in illustrated paper covers. The arrangement slightly altered, and a few additions by $\mathrm{Mr}$. Crook.

(4.) "Poultry and Pigeons. By J. Moffat and J. Rogers. Revised by F. Crook, Esq. With Oil-colour Illustrations. London : Dean \& Son, Ludgate Hill." Two of Dean's pamphlets, issued in one volume, with the oil-colour plates from Meall's 1854 Edition of "Moubray" added. The pigeon part is the same as No. 3. No date, but published in 1880 .

"Our Domestic Fowls and Song Birds. By W. C. L. Martin. London." No date (published 1847). 16mo. The author, who devotes about thirty-eight pages to "The Columbine, or Pigeon Group," acknowledges that he was "not of the fancy;" but he writes in a sensible way of the origin of domestic pigeons, and gives a good account of the uses of Carrier pigeons, from various authentic sources.

“The Pigeon Fancier's Assistant: containing Plain Directions for Breeding and Rearing Every Description of Fancy Pigeon. By G. Bignold, Dog, Rabbit, and Pigeon Breeder and Dealer, Leadenhall Market, London. 
London: 1848." This is another variation of Girton, on thirty-two pages, with a few cuts in the style of those in "The Boy's Own Book." It is paged 33-64, has a yellow paper cover, and was probably the second part of a larger pamphlet which contained information on Dogs or Rabbits.

"Domestic Pets: their Habits and Management. By Mrs. Loudon. London, 1851.” 162 pages. The sixteen pages devoted to pigeons contain nothing of special interest. The book contains four woodcuts by Harrison Weir, in his best style, of Dogs, Cats, Rabbits, and Birds.

(1.) "The Dovecote and the Aviary. By Rev. E. S. Dixon, M.A., Author of 'Ornamental and Domestic Poultry.' Woodcuts. London: John Murray, Albemarle Street. 1851." 8vo. Pages i.-xiv., and 1-458.

(2.) "The Dovecote and the Aviary. By Rev. E. S. Dixon, M.A. London: Wm. S. Orr \& Co."

These are the same impression, No. 2 differing only in titlepage, being issued by Orr \& Co. after purchasing the remainder from Murray. The author, who writes from Cringleford Hall, Norwich, displays great research, and writes in a very entertaining way. He treats pigeons more from a naturalist's than from a critical fancier's point of view; but the book has a charm of its own, and should be in the libraries of all pigeon fanciers.

(3.) "Pigeons and Rabbits in their Wild, Domestic, and Captive States. By E. Sabastian Delamer. Illustrations. London: G. Routledge \& Co., 1854." 8ro. Pages i.-vij., and 1-151.

This book, as regards pigeons, is an abridgment of the account of them in "The Dovecote and the Aviary." The name "Delamer" was a nom de plume assumed by Mr. Dixon when residing on the sea coast. The work must have had a considerable sale, for many editions have been published. I have six of them, all differing slightly, if only in the character of 
the type on title-page. The woodcuts are by Harrison Weir. The first edition, dated 1854-late editions have no datewas my first pigeon book, purchased, as I see from the date on it, in October, 1854. I saw it in a bookseller's window one day when trudging home from school, and began to save up immediately for its acquisition. I soon had it by heart, and such passages as "Tumblers, saith Willughby, are small, and of divers colours; they have strange motions, turning themselves backward over their head, and show like footballs in the air," are indelibly imprinted on my memory.

(4.) "Pigeon Keeping. By E. Sabastian Delamer. London: George Routledge \& Sons. Ninety-four pages." No date (published 1885). This is merely the pigeon part of "Pigeons and Rabbits," printed from the stereotype plates. It has no illustrations.

(1.) "A Treatise on the Art of Breeding and ManagING the Almond Tumbler. By John Matthews Eaton. Published for the Author, 7, Islington Green, London. 1851." Large 8vo. Pages i.-vj., and 7-50. Coloured Plate of Almond Tumbler, by Dean Wolstenholme.

(2.) "A Treatise on the Art of Breeding and Managing Tame, Domestic, and Fancy Pigeons. By John Matthews Eaton. Published for, and to be obtained of, the Author, 7, Islington Green, London. 1852." Large 8vo. Pages i.-xxij., 23-88; i.-vj., 7-50; i.-viij., or 146 in all. Coloured Plate of Almond Tumbler by Dean Wolstenholme.

(3.) "A Set of Six Life-size Coloured Portraits of Pigeons, viz., The Almond, Black-mottred, Baldhead, and Beard Tumblers, Carrier, and Pouter. From Paintings by Dean Wolstenholme. Published by J. M. Eaton, 7, Islington Green, London, Dec. 8, 1852."

(4.) “A Treatise on the Art of Breeding and Managing Tame, Domesticated, Foreign, and Fancy Pigeons. By John Matthews Eaton. Published for, and to be obtained of, the Author, 81, Upper Street, Islington Green, 
London, N. 1858." Large 8vo. Pages i.-xix., 20-200. Thirty coloured Portraits of Pigeons by Dean Wolstenholme.

(5.) "A Set of Six Life-size Coloured Portraits of Pigeons, viz.: The Fantail, Jacobin, OWu, Turbit, TrumPETER, AND BARb. From Paintings by Dean Wolstenholme. Published by J. M. Eaton, 81, Upper Street, Islington, London, Oct. 16, 1860."

(6.) "A New and Improved Coloured Diagram, or a Plan of Building or Fititing up a Pigeonary, Embellished with Tumblers, Pouters, and Carriers. Published by J. M. Eaton, London."

Eaton was an enthusiastic fancier of the Short-faced Tumbler, and the above list of his publications shows how much he contributed to spread knowledge concerning fancy pigeons in general. Dean Wolstenholme, who illustrated these works, was also a fancier; he was born at Waltham Abbey, in 1798, the son of an artist of the same name well known for his pictures of sporting subjects, coloured prints of which may sometimes be found in London print shops. Eaton informs his readers in his work on the Almond that he was indebted to a former work on the subject, but he does not indicate what is his own and what he has copied out of the Treatise by Windus published in 1802, he having reprinted a considerable part of that work. Having obtained a copy of Moore's "Columbarium," after spending pounds and years searching for it, as he informs his readers, Eaton reprinted it in 1852, taking it as the text of his Treatise on Pigeons, and adding footnotes by himself and others. As will be seen from the pagination of No. 2, the latter half of the book is merely made up from the unsold copies of the treatise on the Almond, bound up with the reprint of Moore.

The six life-size portraits of pigeons (No. 3), and the diagram (No. 6) also, were, I believe, originally published by Dean Wolstenholme, on his own account, in 1834. He sold the plates to Eaton, who republished them in $\mathbf{1 8 5 2}$. 
Eaton's 1858 Treatise, containing in all 200 pages, and thirty coloured illustrations of pigeons, two of which (the Almond Tumbler) are identical, includes the whole of his previous writings, together with additional information on the subject, taken chiefly from Brent's articles on pigeons. It is an epitome of what had previously been published in this country on the subject. Eaton sets all rules of grammar and composition at defiance, introduces irrelevant anecdotes, and tells them in a rambling fashion; but there is no doubt his book is a most entertaining and instructive one. I believe the author was once in good business as a tailor at Islington; but his latter days were sadly clouded with misfortune. In 1862, I found him keeping a pigeon shop in the City Road. A circular he used to send to secretaries of shows, to induce them to order copies of his books and pigeon portraits, which were sometimes given as prizes, is a great curiosity. The copy I have is lithographed, from his own peculiar cramped handwriting, on two-and-a-half leaves of paper 15in. by $6 \mathrm{in}$. It is an amusing production, and the space for the date and address is filled up by himself: "Monday, 18th Dec., 1865. To the Right Worshipful the Mayor of Cork. May your Show be crowned with success."

(1.) “The Pigeon Book; WHerein ALL THE KNOWN Varieties of the Domestic Pigeon are Described and Classified. By B. P. Brent. London: Cottage Gardener Office, 162, Fleet Street." Small 8vo, 114 pages. No date (about 1860).

(2.) "The Pigeon Book: containing the Description and Classification of all the KNown Varieties of тhe Domestic Pigeon. By B. P. Brent. Second Edition. London: Journal of Horticulture and Cottage Gardener Office, 171, Fleet Street." 114 pages. No date (about 1865).

(3.) "The Pigeon Book: containing the Description and Classification of all the KNown Varieties of the Domestic Pigeon. By B. P. Brent. Third Edition. 
London: Journal of Horticulture and Cottage Gardener Office." 114 pages. No date (published 1871).

The three editions of Brent's book appear to be printed from the same stereotype plates. Nos. 2 and 3 only differ from No. 1 in having a few lines of additional matter on p. 112, entitled "New Varieties." The author resided for some time on the Continent, and was the first fancier who published good descriptions of French and German varieties, which appeared in the pages of the Poultry Chronicle (1854-5) and Cottage Gardener. Most of the woodcuts in the "Pigeon Book" were first published in the Cottage Gardener, during 1850-2, accompanying a translation of Boitard and Corbie's "Les Pigeons de Volière et de Colombier," Paris, 1824, which was probably done by Brent, and they are copied, though not improved in the process, from those in that book. Brent was not only an ardent pigeon fancier, but had a good knowledge of poultry, cage birds, and all pet stock.

"Home Pers. London: S. O. Beeton, 248, Strand, W.C." This work was first published in fortnightly parts, commencing 1st September, 1861. Parts 12 and 13, issued in 1862, each containing thirty-two pages, treat of pigeons. The name of the compiler is unknown to me, but Brent and Dixon are his chief authorities. The illustrations consist of a coloured plate and various neat vignettes by Harrison Weir. "Our Feathered Families: Game and Water Birds; to which is added a Practical Chapter on Doves and Pigeons. By H. G. Adams. London: James Hogg \& Sons." No date (published 1863).

The appendix to this work (pages $315-340$ ) consists of an account of fancy pigeons gathered from Dixon's "Dovecote and Aviary."

"Pigeons : their Structure, Varieties, Habits, and Management. By W. B. Tegetmeier, F.Z.S. With Coloured Representations of the Different Varieties, Drawn from Life by Harrison Weir. London : George Routledge \& Sons. 1868." 
This work was first issued in eight monthly shilling parts, each containing two coloured plates and woodcuts, and then as above, in one volume, imp. 8vo, pp. 190. The second edition, also in monthly shilling parts, was published from June, 1873, to January, 1874. The book is still being issued by the publishers, but without a date. The author, the wellknown naturalist and pigeon fancier, says in the preface: "In compiling the following pages the Editor has endeavoured to produce a Treatise that should not only furnish the amateur of pigeons with a greater amount of practical information on the different varieties than is to be found in any previous volume, but also to treat the whole subject in a more scientific manner than has hitherto been attempted."

“The Variation of animals and Plants under Domestrcation. By Charles Darwin, M.A., F.R.S., \&c. 2 vols., 8vo. London: John Murray, Albemarle Street. 1868."

The great naturalist refers extensively to domestic pigeons, and explains the experiments he made in breeding different kinds together for the purpose of satisfying himself that they all had a common origin. His book contains a great amount of information most interesting to the pigeon fancier. He refers to a Persian Treatise on Pigeons written by Sayzid Mohammed Musari, who died in 1770, which Sir Walter Elliot discovered when in Madras, and of which he sent him a translation. I applied to Mr. Darwin for leave to copy this Treatise, but he replied that he was unable to find it in his library, and feared that, as it was in loose sheets, it had been mislaid. I then wrote to Sir Walter Elliot, asking him if he still had the original in Persian. He informed me it was lost, with his library, on the voyage home.

(1.) “Pigeons: their Varieties, Management, Breed. ING, and Diseases. By Hugh Piper. London: Groombridge \& Sons, 5, Paternoster Row. 1871." Small 8vo, 64 pages. Coloured plate of seven varieties of pigeons.

(2.) "Pigeons: therr Varieties, Management, Breed- 
ing, and Diseases. By Hugh Piper. London: Groombridge \& Sons." No date. Coloured plate. Blue paper cover. Issued by Wm. F. Clay, 2, Teviot Place, Edinburgh. Published 1881.

(3.) "Poultry and Pigeons : their Varieties, Management, Breeding, and Diseases. By Hugh Piper. London: Groombridge \& Sons, Paternoster Row, 1885." Coloured plate of poultry only. Paged 1-64 and 1-64.

This is a handy little book, compiled from Dixon, Brent, Tegetmeier, and others. The pigeon part in No. 3 is printed. from the same stereotypes as Nos. 1 and 2.

"The Illustrated Book of Pigeons, with Standards For JUdGing. By Robert Fulton. Edited by Lewis Wright. Illustrated with Fifty Coloured Plates from Paintings by J. W. Ludlow. Cassell, Petter, \& Galpin, London, Paris, and New York." No date. 4to. Pages i-viij., and 1-392.

The publication of this fine work commenced in 1874, and extended over two years, being completed in twenty-five monthly shilling parts. It was then issued, as a complete volume, in 1876. It has been re-published, both in parts and in complete form, but the coloured plates of the first edition are much superior to those in later issues. Since the book was written many varieties of domestic pigeons existing in various countries throughout the world have become known which are not mentioned in it; but, so far as it goes, the subject is treated in an exhaustive way.

“The Practical Pigeon Keeper. By Lewis Wright. Cassell, Petter, Galpin, \& Co., London." No date (published 1879). Pages i.-viii., and 1-232, 8vo. This book, by the editor of Fulton's work, is a useful one for the young fancier. It is illustrated by pretty woodcuts, which had previously appeared in a German work by Baldamus. They are mostly copied from Fulton's coloured plates.

"The Pouter Pigeon. By Capt. Norman Hill. Also a Report of the Committee appointed to draw up a Standard of the Pouter. 1882." Octavo, 16 pages. One of the standards 
drawn up by the National Peristeronic Society of London; others already issued include the Carrier, Dragoon, and Eastern Frilled varieties. When completed, these standards might be issued in book form by the Society, but they are not printed uniformly.

"How to Breed, Rear, and Train the Macclesfield Tippler and the High-flying Tumbler Pigeon. By G. Smith, Nottingham. 1883." 58 pages; $4 \frac{1}{4}$ in. by $2 \frac{3}{4} \mathrm{in}$. This little book contains practical information on the subject of High-flying Tumblers, how to train and feed them so that they may fly, as they do, for as long as ten to twelve hours at a stretch. There seems to be nothing new, for I have a copy of a Persian manuscript that was found in Delhi which gives various recipes, such as the following: "To make pigeons soar high and fast, and good tumblers during flight;" "A drink to make pigeons soar high;" "For curing asthma in pigeons," a recipe by Meer Bukar Ali, who was also author of recipes for making Bulbuls and Quails fight well. Had our old friend, "egregious Moore," "author of the celebrated worm-powder," been born a subject of the Great Mogul, he would have been an adept at this kind of thing.

"Prgeons; an Essay delivered before the Tunbridge Wells Ornithological Society by O. E. Cresswell, Esq., on October 3rd, 1883. Tunbridge Wells." Small 8vo, 16 pages.

"Pigeons for Exhibition and Profit. London: J. \& R. Maxwell." 8vo, 32 pages. Woodcuts; coloured wrapper. Published 1884.

"The Management of Pigeons." Small pamphlet, 16 pages; coloured wrapper. Printed by Alex. Boyle, London, 1881.

"Our Fancy Pigeons, and Rambling Notes of a Naturalist. By George Ure, Dundee. 1886." The author repeats, with variations, the accounts of the Pouter and Fantail he wrote for Fulton's "Pigeon Book," and gives a description of his early experience and fancier friends. 
"The Pleasures of a Pigeon Fancier. By the Rev. J. Lucas. London: Sampson Low \& Co., 1886." This work, by a London clergyman, has just been announced. I have not seen it.

To render the foregoing list of books on pigeons as complete as possible, $I$ here give the dates of publication of my own work on the subject.

(1.) "Fancy Pigeons" was originally published in the pages of the Bazaar, Exchange and Mart, from November, 1878, to June, 1881.

(2.) In eleven monthly parts, commencing June, 1880.

(3.) In book form, 8vo, pp. 330. London: The Bazaar Office, 170, Strand, W.C. 1881.

(4.) Second Edition, 8vo, pp. 348. London: L. Upcott Gill, 170, Strand, W.C. 1883.

(5.) Second Edition, in eleven monthly parts, commencing March, 1884.

(6.) Third Edition, in monthly parts, with coloured plates, commencing September, 1885.

\section{Books on Homing Pigeons.}

"The Homing, or Carrier Pigeon (Le Pigeon Voyageur): Its History, General Management, and Method of Training. By W. B. Tegetmeier, F.Z.S. London: George Routledge \& Sons." No date (published 1871). 8vo, 124 pages.

"Carrier Pigeons. By R. W. Alldridge. 1871."

(1.) "Carrier Pigeons. By Hartley and Sons, Woolwich." 8vo, 32 pages. No date (about 1875).

(2.) "Belgran Homing Pigeons. Second Edition (of No. 1). Published by the Authors, Hartley and Sons, Woolwich." 8vo, 32 pages. No date (published 1885).

"On the General Training and Treatment of Carrier Pigeons. By G. Alsteen, Ryde." A pamphlet of 8pp., translated from Dr. Chapuis. (Published 1881.) 
(1.) "The Belgian Homing Pigeon. By J. L. Burgess. 8vo, 52 pages. London: Hamilton, Adams, \& Co. Cirencester : Keyworth \& Everard." No date (published 1881).

(2.) "The Belgian Homing Pigeon. Second Edition. By J. L. Burgess. 8vo, 79 pages. London: Kent \& Co. Cirencester: C. H. Savory." No date (published 1882).

(3.) "The Homing Fancier's Anndal for 1882. Edited by J. L. Burgess." 8vo, 94 pages.

(4.) “The Homing Fancier's Anndal for 1883. Edited by J. L. Burgess." 8vo, 118 pages.

"The Homing Pigeon Fancier's Guide. By John W. Logan. London: The Stock-keeper and Fancier's Chronicle Office." 8vo, 112 pages. Published March, 1885.

This contains "Practical Hints on the Formation of a Loft of Homing Pigeons," well illustrated; Rules of the United Counties' Flying Club; and a List of Races for Season 1885 (should be 1884). The author has been, during the past few years, one of the most prominent and influential fanciers of homing pigeons.

\section{Serial Literature.}

Gardener, Florist, and Agriculturalist. Vol. iii. 1848. This contains four chapters on fancy pigeons, illustrated, on pp. $83,121,324,340$.

The Cottage Gardener, commenced about 1848, now incorporated with the Journal of Horticulture, formerly contained much information on pigeons. A translation of Boitard and Corbie's work on the subject (Paris, 1824) was published during 1850-2. Brent wrote extensively in its pages; and, about 1871, a series of well-written pigeon articles, illustrated by Ludlow, appeared.

The Poultry Chronicle, a weekly periodical, edited by Miss Watts, began on the lst of March, 1854, and was continued for seventy-seren weeks, the last number being published on 15th August, 1855, when it was incorporated with 
the Cottage Gardener. Complete sets of it, in three volumes, small 4to, may occasionally be met with. It is interesting as the first journal devoted entirely to the poultry and pigeon fancy. Under the heading of the "Columbary," the late Mr. Brent contributed to it many papers on fancy pigeons.

The Field newspaper, commenced about 1858, devoted considerable space to poultry and pigeons for many years, but latterly has left these-subjects almost entirely to the various periodicals that cater specially for followers of these fancies.

The Poultry Review, edited by James Long, existed from 21st June, 1873, to 31st December, 1874, and treated of poultry, pigeons, dogs, and pet stock. A complete set consists of eighty-one parts, making three vols. 4to.

The Pigeon, edited by Thomas M. Denne, continued weekly from 19th February, 1876, to 28th December, 1877; in all ninety-eight parts, which make a thick 4 to volume.

THE CoUntry, a weekly periodical for fanciers, was published from May, 1873, to October, 1879, when it was incorporated with The Bazaar, Exchange and Mart.

The Boy's OWN Paper contained, in 1881, a series of illustrated articles on pigeons, entitled, "The Boy's Own Pigeon Loft and Dovecote."

The Bazaar, Exchange and Mart (from 1869), Fanciers' GaZette (1874) (afterwards Live Stock Journal, and again Fanciers' Gazette), Fanciers' Chronicle (1879) (now Stock-Keeper and Fanciers' Chronicle), Poultry (1883), and The Scottish Fancier (1884), are the periodicals presently (October, 1886) being issued in this country for dog, pigeon, poultry, and other pet stock fanciers.

\section{Foreign Literature.}

The quantity of foreign pigeon literature in existence is so extensive that I would not attempt to give a detailed list of 
it. I have in my possession over a hundred books on pigeons in French, German, Dutch, Italian, and Spanish. A considerable number of these have been published since 1870 , and many of them are on Homing or Carrier Pigeons. A number of early essays on pigeons, compiled from Aldrovandi and other sources, and written in mediæval Latin, were published in Germany from 1684 to 1751; but the earliest Continental book on fancy pigeons and poultry was written by M. Buchoz, the French botanist, and published in Paris in 1777. The influence of this book may be traced in many German ones published during the following half-century.

Since Boitard and Corbie's "LeS Pigeons DE Volikire ET DE Colombies" was published in Paris, in 1824, nothing of great interest has appeared in France till Victor La Perre de Roo's recent publications.

The principal pigeon books published in Germany are the "TaUbenbuch," Ulm, 1790; Riedel's Works, 1824; Putsche's “Tauben Katechismus," 1830; Neumeister's “Das Ganze DER TAUBenzucht," 1837 ; and the modern Works by Buhle, Prütz, Baldamus, Durigen, Bungartz, \&c. The "MusterTAUBENBUCH," the latest work by Prütz, now being issued, will be the largest book on pigeons ever published. When complete it will contain about 400 pages, large 4to, and eightyone coloured plates, with about 200 figures of fancy pigeons.

The Italian works by Malmusi, Martinelli, and Bonizzi, are chiefly on the Triganica Pigeons of Modena.

The Dutch pigeon works are few and unimportant, excepting La Perre de Roo's "Postdurf"; and the only Spanish work I know of is a translation of some of La Perre de Roo's writings on homing pigeons.

Many poultry and pigeon journals are published in America; but, with the exception of reprints of Boswell (1842), and Moore's "Columbarium" (1874), the only pigeon book I know of is "The Standard of Excellence for Judging Pigeons," compiled and illustrated with coloured plates by J. W. Ludlow, 
Birmingham, and revised by Wm. Simpson, Jun., New York, 1879.

A Japanese book, in six folio volumes, containing life-size portraits of 150 pigeons, representing each bird on one page facing the right, and on the accompanying page the left, making in all 300 pictures, drawn and coloured by hand, was recently offered to me by a bookseller on the Continent. After seeing one of the volumes, I refused to purchase the work, as the birds represented were merely common pigeons, differing from each other only in colour, but not marked with any degree of regularity. I have no doubt that similar works, representing real fancy breeds, exist in China, Persia, Turkestan, and India, but the difficulty is to get them.

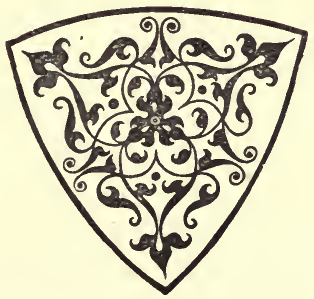




\section{\& Conclusion.}

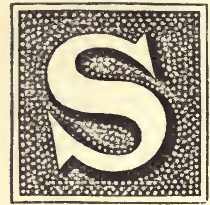

INCE writing about the Persian treatise on pigeons on page 404 I was agreeably surprised to learn that the work was still in existence. Sir Walter Elliot found a translation of it when arranging his papers, and sent it to me. The work is a practical one, treating of the breeding and management, and describing the varieties, of fancy pigeons known to the author. It also contains critical marginal notes by a fancier who had possessed the original. The Preface, written in a conventional style common in the East, interspersed with verses, may interest and amuse the British reader, so $I$ transcribe it. The names Khubin and Wali are short names, such as Jack or Bob. The author gives his proper name at the end of the Preface.

"KABUTAR NAMAH (History of Pigeons).

"In the name of God the Gracious and Merciful.

"Preface.

"When Khubin asked a love-gift from his friend,

Wali this Treatise on the Pigeon penned.

"Boundless praise and infinite Glorification are due to the Creator who hath caused the Pigeon of the human heart in 
this Dovecote (Dhábli) of the bosom to hunger after the delight of seeing Him, that it might gather from the Feedingcourt (Thatar) of his bounty the Grains of grief and care, and might sit in the rapture of love apart from the world on the Perching-place (Addah) of peace and contentment: and who hath then shaken the Disturbing-staff (Chipi-the bamboo rod with flag attached) of desire that the pigeon, urged by the shrill whistle (Zafil) of his prompting may betake itself to flight: and who hath clipt the wings and the tail of the Decoy pigeon (Kutti) of worldly appetite, that sitting on the perch of amazement it may behold from afar the outward show of things.

\section{"Snatch gaily from my bird-like thought, The song-flowers which its sweet note brings; \\ From the soft pigeon's theme is caught \\ Thy poet's joys, thy poet's wings.}

"And abundant praise to that illustrous Syed who hath well ranged the strange pigeons (Parghara) of devious path and erring flight in the bond of the followers of the Law, that they may no more be scattered and distracted: and who hath shewed the lamp of his guidance to them in the dovecote of recklessness and in the darkness of night, that they may become all trained in one system to the Circuit (Khalqa) of obedience; and who hath scattered over the Feeding-ground (Tah) of human helplessness the Grain of high resolve to persevere in the course of duty till they are exercised in the discipline of coming and going (Bhuryan) and abstinence: and at length escaping from the Feeding-tray of weakness, they shall sport at will by the effort of divine grace; and shall finally arrive at the Terrace of proximity to Him and taste the delight of the Sugared rice (chat-used for bringing pigeons down) of Union.

"Whene'er my heart in fairy joys would stray,

With gentle pigeons in rapt thought I play. 
"The following pages on the diversion of Pigeon-flying form a treatise on the various sorts of pigeons, with an account of the color and character of each kind, and the method of training them; being composed by Syed Mohammad Musari, the humble Fakeer, the dust of the feet of the travellers of the region of fancy: and the author hath judged it best to express his ideas on the subject in one introductory chapter and three following sections.

"Of Pigeons Khubin bids me tell, Whose friendship sweetly doth compel.

These artless pages Wali gives, Wherein his soul embodied lives, Along whose descant as it flows, The hue, the fragrance of the rose, As from a hundred bowers is shed : And where the feast of soul is spread, Each eye that scans this rich parterre; Unsated culls the blossoms there."

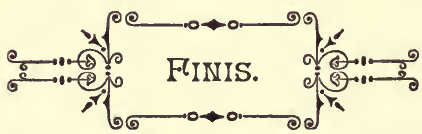




\section{$\propto$ INDEX.}

A. PAGE

$\begin{array}{llllll}\text { African owl } & \ldots & \ldots & \ldots & \ldots & 193\end{array}$

Owl, fancy points of $\quad . .194$

Age of fancy pigeons ... $\quad \ldots \quad 109$

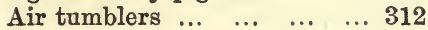

Akbar, Emperor, a pigeon $\begin{array}{lllll}\text { fancier } \ldots & \ldots & \ldots & \ldots & 5\end{array}$

$\begin{array}{lllllll}\text { Albinos } & \ldots & \ldots & \ldots & \ldots & \ldots & 47\end{array}$

Aldrovandi's (Ulysse) "Ornithologia" $\quad \ldots \quad \ldots \quad \ldots 382$

Almond and blue grizzled $\begin{array}{llllll}\text { runts } & \ldots & \ldots & \ldots & \ldots & 142\end{array}$

Fancy points of the $\ldots 343$

History of the... ... ... 335

Treatise on Breeding and

Managing the $\quad . . \quad \ldots 392$

$\begin{array}{lllll}\text { Tumbler ... } & \ldots & \ldots & \ldots & 335\end{array}$

Altenburg trumpeter $\quad \ldots \quad \ldots l 151$

Altstämmer, die $\quad \ldots \quad \ldots \quad \ldots 327$

Ancestor of fancy pigeons ... 9

Ancient, German ... ... ... 327

Annatalozia pigeon $\quad \ldots \quad \ldots 102$

Antiquity of pigeon shows ... 50

Antwerp carrier $\quad . . . \quad \ldots \quad \ldots \quad . \quad 357$

Carrier, how bred ... ... 357

Carrier, Mr. Huie's article

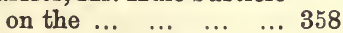

Carriers, homing $\quad \ldots \quad \ldots 365$

Carriers, performances of

$\begin{array}{lllrl} & & & 358, & 362 \\ \text { Long-faced } & \ldots & \ldots & \ldots & 372 \\ \text { Medium-faced } & & \ldots & \ldots & 373 \\ \text { Short-faced } & \ldots & \ldots & \ldots & 370\end{array}$

PAGE

Antwerps as feeders ... 359, 365

$\begin{array}{lllll}\text { Exhibition } & \ldots & \ldots & \ldots & 365\end{array}$

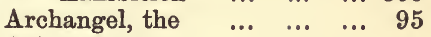

Asian pigeons :

$\begin{array}{lllll}\text { Capuchin ... } & \ldots & \ldots & \ldots & 134\end{array}$

Chinese dewlap $\quad$...

Coral-eyed $\quad \ldots \quad \ldots \quad \ldots \quad \ldots 135$

East Indian flying ... ... 127

Goolèe $\quad . . \quad \ldots \quad \ldots \quad \ldots \quad \ldots 125$

Goolee, mottled ... ... 125

$\begin{array}{llllll}\text { Low tan } & \ldots & \ldots & \ldots & \ldots & 126\end{array}$

$\begin{array}{lllll}\text { Mahomet... } & \text {.. } & \ldots & \ldots & 131\end{array}$

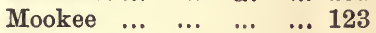

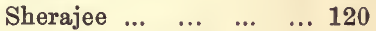

Sherajee, mottled ... ... 121

Austrian klatcher, the $\ldots . \quad \ldots \quad 270$

$\begin{array}{lllllll}\text { Aviary } & \ldots & \ldots & \ldots & \ldots & \ldots & 14\end{array}$

$\begin{array}{lllll}\text { Azure blue pigeon } & \ldots & \ldots & \ldots & 76\end{array}$

B.

Badge of Honour pigeon ... 77

Bagdad carrier $\quad \ldots \quad \ldots \quad \ldots 294$

Bagdads, Batavian _.. ... 305

Batavian, lace-feathered 306

Batavian, little ... ... 306

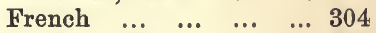

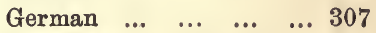

Great wattled ... $\quad$.. $\quad . .304$

Lace-feathered Batavian 306

Little Batavian $\quad$... $\quad \ldots 306$

Mushroomed ... 
PAGE

Bagdads, Nürnberg $\quad \ldots \quad \ldots 307$ Short-faced Turkish $\quad \ldots 307$ $\begin{array}{llllll}\text { Turkish } & \ldots & \ldots & \ldots & \ldots & 307\end{array}$ Baldhead, short-faced ... $\quad . .353$ Tumbler ... $\quad \ldots \quad \ldots \quad \ldots 320$ Baldpate tumbler, Mr. Woodhouse's sport from $\quad . . \quad 12$ $\begin{array}{lllllll}\text { arb } & \ldots & \ldots & \ldots & \ldots & \ldots & 276\end{array}$ Fancy points of $\quad \ldots \quad \ldots 278$ History of $\quad \ldots \quad \ldots \quad \ldots 276$ $\begin{array}{lllll}\text { Barbary pigeon } & \ldots & \ldots & \ldots & 276\end{array}$ $\begin{array}{llllll}\text { Bartige taube } & . . & \ldots & \ldots & \ldots & 79\end{array}$ Baskets, pigeon, plan for $\begin{array}{lllll}\text { dividing } & \ldots & \ldots & \ldots & 53\end{array}$

$\begin{array}{llllll}\text { Show } & \ldots & \ldots & \ldots & \ldots & 52\end{array}$

$\begin{array}{lllll}\text { Bathing water } & \ldots & \ldots & \ldots & 33\end{array}$

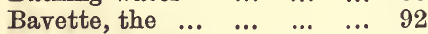

$\begin{array}{lllll}\text { Bearded pigeon } & \ldots & \ldots & \ldots & 79\end{array}$

Beards, Brunswick $\quad$... $\quad \ldots 326$

$\begin{array}{llllll}\text { London } & \ldots & \ldots & \ldots & \ldots & 356\end{array}$

$\begin{array}{lllll}\text { Peppered } & \ldots & \ldots & \ldots & 322\end{array}$

$\begin{array}{lllll}\text { Short-faced } & \ldots & \ldots & \ldots & 353\end{array}$

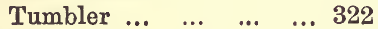

Bengal pouter $\quad \ldots \quad \ldots . \quad \ldots 271$

Birmingham rollers $\quad \ldots \quad \ldots \quad 317$

Blaze face, the $\quad \ldots \quad \ldots \quad \ldots \quad 74$

Blondinettes, black laced $\quad \ldots 217$

$\begin{array}{llllll}\text { Blue ... } & \ldots & \ldots & \ldots & \ldots & 218\end{array}$

$\begin{array}{llllll}\text { Brown } & \ldots & \ldots & \ldots & \ldots & 217\end{array}$

$\begin{array}{llllll}\text { Satin } & \ldots & \ldots & \ldots & \ldots & 217\end{array}$

$\begin{array}{llllll}\text { Silver } & \ldots & \ldots & \ldots & \ldots & 218\end{array}$

Sulphur $\quad \ldots \quad \ldots \quad \ldots \quad \ldots \quad \ldots 217$

Blue Brunswick pigeon $\quad \ldots \quad 86$

$\begin{array}{lllll}\text { Rock } \quad \ldots & \ldots & \ldots & 8,44\end{array}$

Boards, feeding $\quad \ldots \quad \ldots r . \quad \ldots \quad 17$

Bokhara trumpeter $\quad \ldots \quad \ldots 145$

Books on homing pigeons ... 407

On pigeons, early printed 381

On pigeons, English ... 384

$\begin{array}{lllll}\text { Bottle, water ... } & \ldots & \ldots & \ldots & 19\end{array}$

Bowels, inflammation of $\quad \ldots \quad 56$

Boxes, feeding $\quad \ldots \quad \ldots . \quad \ldots \quad 17$

$\begin{array}{lllll}\text { Nesting } & \ldots & \ldots & \ldots & 21,22\end{array}$

$\begin{array}{llllll}\text { Show } & \ldots & \ldots & \ldots & . . & 51\end{array}$

$\begin{array}{llllll}\text { Wall } & \ldots & \ldots & \ldots & \ldots & 14\end{array}$

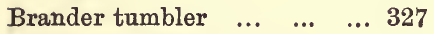

$\begin{array}{lllll}\text { Breaster pigeon } & \ldots & \ldots & \ldots & 75\end{array}$

$\begin{array}{lllll}\text { Breast pigeon ... } & \ldots & \ldots & \ldots & 71\end{array}$

$\begin{array}{llllll}\text { Breeding ... } & \ldots & \ldots & \ldots & \ldots & 35\end{array}$
PAGE

Breeding, elements of success $\begin{array}{llllll}\text { in } \ldots & \ldots & \ldots & \ldots & \ldots & 43\end{array}$

Power, differences in $\quad \ldots \quad 38$

Breeds, characteristics of ... 27

Brent's (B. P.) " Pigeon Book" 402 $\begin{array}{lllll}\text { Breslau pouter } \quad \ldots & \ldots & \ldots & 261\end{array}$ Bristle pigeon $\quad . . \quad \ldots . . .104$ Broad-tailed shakers, Wil-

$\begin{array}{llllll}\text { lughby's } & \ldots & \ldots & \ldots & \ldots & 164\end{array}$

Brünn pigmy pouter $\quad \ldots \quad \ldots 273$

$\begin{array}{lllll}\text { Brunswick beard } & \ldots & \ldots & \ldots & 326\end{array}$

$\begin{array}{llllll}\text { Brusttaube } & \ldots & \ldots & \ldots & \ldots & 75\end{array}$

$\begin{array}{lllll}\text { Bullfinch pigeon } & \ldots & \ldots & \ldots & 95\end{array}$

$\begin{array}{lllll}\text { Burmese pigeon } & \ldots & \ldots & \ldots & 159\end{array}$

C.

Calcutta, pigeon-flying at ... 128

$\begin{array}{lllllll}\text { Canker } & \ldots & \ldots & \ldots & \ldots & \ldots & 57\end{array}$

Captain Hill's black pied pigmy pouter ... $\quad . .254$

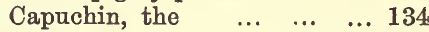

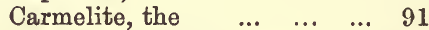

$\begin{array}{lllll}\text { Carp-scale pigeon } & \ldots & \ldots & \ldots & 102\end{array}$

Carriers, absurd stories re-

$\begin{array}{lllll}\text { garding } & \ldots & \ldots & \ldots & 363\end{array}$

Anacreon's ode to ... $\quad . . .355$

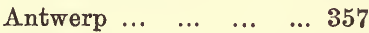

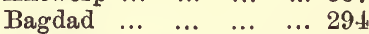

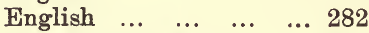

Fancy points of $\quad \ldots . \quad \ldots \quad 285$

$\begin{array}{lllll}\text { Himalayan } & \ldots & \ldots & \ldots & 309\end{array}$

$\begin{array}{lllll}\text { History of } & \ldots & \ldots & \ldots & 282\end{array}$

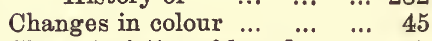

$\begin{array}{lll}\text { Characteristics of breeds } & \ldots & 27\end{array}$

Chinese dewlap pigeon ... $\quad$... $\quad 13$

Gulls $\quad \ldots \quad \ldots \quad \ldots \quad \ldots \quad \ldots 203$

Cleaning pigeon houses $\quad \ldots \quad 23$

Club, Fantail $\quad \ldots \quad \ldots . \quad \ldots \quad \ldots 173$

$\begin{array}{lllllll}\text { Cold } \ldots . & \ldots & \ldots & \ldots & \ldots & \ldots & 59\end{array}$

Joloured breasted pigeon $\quad \ldots \quad 75$

$\begin{array}{llll}\text { Headed pigeon } & \ldots & \ldots & 79\end{array}$

Tailed tumbler $\quad \ldots \quad \ldots 326$

Colours, changes in $\quad \ldots . \quad \ldots \quad 45$

$\begin{array}{llll}\text { Combinations of } & \ldots & \ldots & 48\end{array}$

$\begin{array}{lllll}\text { Of fancy pigeons } & \ldots & \ldots & 44\end{array}$

Of pigeons, general re$\begin{array}{lllll}\text { marks on } & \ldots & \ldots & \ldots & 49\end{array}$ 
PAGE

Colours of Triganica pigeons 118

$\begin{array}{llllll}\text { Whole } & \ldots & \ldots & \ldots & \ldots & 47\end{array}$

$\begin{array}{llll}\text { Columba leuconota } & \ldots & \ldots & 12\end{array}$

$\begin{array}{llllll}\text { Livia } & \ldots & \ldots & \ldots & \ldots & 8\end{array}$

"Columbarium," Moore's 6, 384

Combinations of colour ... ... 48

Common ancestor for fancy $\begin{array}{lllll}\text { pigeons } & \ldots & \ldots & \ldots & 9\end{array}$

$\begin{array}{llllll}\text { Pigeons } & \ldots & \ldots & \ldots & \ldots & 70\end{array}$

Tumblers $\quad \ldots \quad \ldots \quad \ldots 315$

Coral-eyed pigeon ...

Core, the ..

Covering for floors of flights... 24

Crescent pigeon $\quad \ldots \quad \ldots \quad 71,77$

Cropper or pouting pigeons :

Austrian klatcher ... ... 270

$\begin{array}{llllll}\text { Bengal } & \ldots & \ldots & \ldots & \ldots & 271\end{array}$

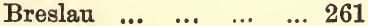

$\begin{array}{llllll}\text { Brünn } & \ldots & \ldots & \ldots & \ldots & 273\end{array}$

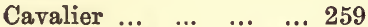

$\begin{array}{llllll}\text { Dutch } & \ldots & \ldots & \ldots & \ldots & 269\end{array}$

Dutch balloon $\quad \ldots \quad$... 275

English pouter $\quad \ldots \quad \ldots 223$

Foreign pigmy $\quad \ldots \quad \ldots 271$

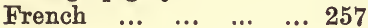

German $\ldots{ }$...

Lille $\ldots \quad \ldots \quad \ldots \quad \ldots \quad \ldots \quad \ldots 258$

Norwich cropper ... ... 241

Old German $\quad$... $\quad \ldots \quad$... 261

$\begin{array}{lllll}\text { Pied pigmy } & \ldots . & \ldots & \ldots & 253\end{array}$

$\begin{array}{lllll}\text { Pomeranian } & \ldots & \ldots & \ldots & 262\end{array}$

Prague magpie $\quad \ldots \quad$... 270

Prague pigmy ... $\quad . . \quad$... 275

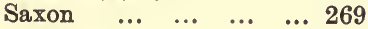

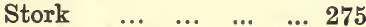

Crossing African owl and

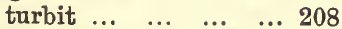

Cumulet, Continental $\ldots . \quad \ldots \quad 357$

Curly Moor head pigeon $\quad \ldots 106$

Cyprus pigeons of Aldro$\begin{array}{lllll}\text { vandus'... } & \ldots & \ldots & \ldots & 175\end{array}$

\section{D.}

Darwin's (Charles) "Variation of Animals and Plants under Domestication" 404 Delhi, pigeon-flying at ... $\quad . .128$
PAGE

Dewlap pigeon, Chinese $\quad \ldots 136$

$\begin{array}{llllll}\text { Diarrhœa } & \ldots & \ldots & \ldots & \ldots & 60\end{array}$

Diseases :

Bowels, inflammation of $\quad 56$

$\begin{array}{llllll}\text { Canker } & \ldots & \ldots & \ldots & \ldots & 57\end{array}$

$\begin{array}{llllll}\text { Cold } \ldots & \ldots & \ldots & \ldots & \ldots & 59\end{array}$

$\begin{array}{llllll}\text { Core } . . . & \ldots & \ldots & \ldots & \ldots & 59\end{array}$

$\begin{array}{lllll}\text { Diarrhœa } & \ldots & \ldots & \ldots & 60\end{array}$

$\begin{array}{lllll}\text { Egg-bound } & \ldots & \ldots & \ldots & 60\end{array}$

Flesh wen $\quad \ldots \quad \ldots \quad \ldots 60$

General remarks on $\quad \ldots \quad 55$

Gizzard fallen... $\quad \ldots \quad \ldots \quad 61$

$\begin{array}{llllll}\text { Gorging } & \ldots & \ldots & \ldots & \ldots & 61\end{array}$

$\begin{array}{llllll}\text { Insects } & \ldots & \ldots & \ldots & \ldots & 62\end{array}$

$\begin{array}{llll}\text { Leg weakness ... } & \ldots & \ldots & 63\end{array}$

$\begin{array}{lllll}\text { Megrims ... } & \ldots & \ldots & \ldots & 65\end{array}$

$\begin{array}{lllll}\text { Moulting ... } & \ldots & \ldots & \ldots & 64\end{array}$

Small-pox $\quad \ldots \quad \ldots 6 \quad \ldots \quad 64$

$\begin{array}{llllll}\text { Spouts } & \ldots & \ldots & \ldots & \ldots & 65\end{array}$

$\begin{array}{llllll}\text { Vertigo } & \ldots & \ldots & \ldots & \ldots & 65\end{array}$

$\begin{array}{llllll}\text { Wing } & \ldots & \ldots & \ldots & \ldots & 65\end{array}$

$\begin{array}{llllll}\text { Dish, water } & \ldots & \ldots & \ldots & \ldots & 19\end{array}$

Dixon's "The Dovecote and

the Aviary" $\quad . . \quad \ldots 399$

Domestication, effects of $\quad \ldots \quad 11$

Domestic pigeons, varieties of $\mathbf{6 7}$

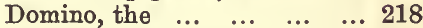

Double-crested tumbler $\quad . .325$

Dovecote, wall $\quad \ldots \quad \ldots \quad \ldots \quad 15$

Dragoons $\quad \ldots \quad \ldots \quad \ldots . . .295$

Fancy points of . . ...297

National Peristeronic

Society's standard of 297

Origin of name "Dragon" 301

Valne of ... $\quad \ldots \quad \ldots \quad \ldots 300$

$\begin{array}{lllll}\text { Drake pigeons ... } & \ldots & \ldots & \ldots & 301\end{array}$

$\begin{array}{lllll}\text { Drummer pigeon } & \ldots & . . & . . & 144\end{array}$

$\begin{array}{lllll}\text { Dundee fantails } & \ldots & \ldots & \ldots & 166\end{array}$

Dutch balloon ponter ... $\quad \ldots 275$

$\begin{array}{llllll}\text { Pouter } & \ldots & \ldots & \ldots & \ldots & 269\end{array}$

$\begin{array}{lllll}\text { Shell pigeon } & \ldots & \ldots & \ldots & 330\end{array}$

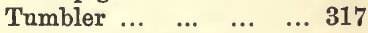

Works on pigeons ... ... 410

E.

Early printed books on pigeons 381 
East Indian pigeons:

Capuchin

Chinese dewlap

Coral-eyed ... $\quad \ldots . \quad \ldots \quad 135$

$\begin{array}{llllll}\text { Flying } & \ldots & \ldots & \ldots & \ldots & 127\end{array}$

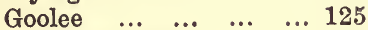

Goolee, mottled $\quad \ldots \quad$... 125

$\begin{array}{llllll}\text { Lowtan } & \ldots & \ldots & \ldots & \ldots & 126\end{array}$

Mahomet $\quad \ldots . \ldots . \quad \ldots l 131$

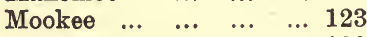

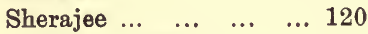

Sherajee, mottled ... ... 121

Eaton's (J. M.) works on pigeons $\quad \ldots \quad \ldots \quad \ldots 400$

Effects of domestication $\quad \ldots \quad 11$

$\begin{array}{llllll}\text { Egg-bound } & \ldots & \ldots & \ldots & \ldots & 60\end{array}$

Eggs, chipped $\quad \ldots \quad \ldots \quad \ldots \quad 39$

Fertility of, determining 38

$\begin{array}{lllll}\text { Thin-shelled } & \ldots & \ldots & \ldots & 39\end{array}$

$\begin{array}{llll}\text { Without shells } & \ldots & \ldots & 39\end{array}$

$\begin{array}{lllll}\text { Egyptian resords } & \ldots & \ldots & \ldots & 1\end{array}$

$\begin{array}{lllll}\text { Swift pigeon } & \ldots & \ldots & \ldots & 107\end{array}$

English books on pigeons ... 384

$\begin{array}{llllll}\text { Carrier } & \ldots & \ldots & \ldots & \ldots & 282\end{array}$

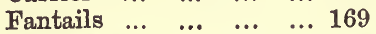

$\begin{array}{lllll}\text { Fire pigeon } & \ldots & \ldots & \ldots & 74\end{array}$

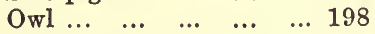

$\begin{array}{llllll}\text { Pouter } & \ldots & \ldots & \ldots & \ldots & 223\end{array}$

$\begin{array}{llll}\text { Exhibiting pigeons } & \ldots & \ldots & 50\end{array}$

Exhibition Antwerps $\quad \ldots \quad \ldots 365$

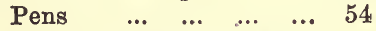

System, value of pigeons enhanced by

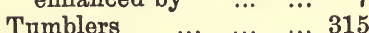

Experience, early, of pigeonkeeping

\section{F.}

$\begin{array}{lllll}\text { Familiar pigeons } & \ldots & \ldots & \ldots & 27\end{array}$

Fanciers, young, pigeons for... 27

Fancy pigeons, colours of ... 44

$\begin{array}{llllll}\text { Fantail Club } & \ldots & \ldots & \ldots & \ldots & 173\end{array}$

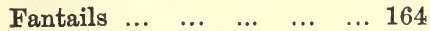

Birthplace of $\ldots . . . . \quad \ldots \quad 164$

$\begin{array}{llllll}\text { Dundee } & \ldots & \ldots & \ldots & \ldots & 166\end{array}$

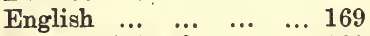

Fancy points of $\quad \ldots \quad \ldots l 169$
PAGE

Fantails, history of $\quad \ldots \quad \ldots 164$

$\begin{array}{lllll}\text { In Calcutta } & \ldots & \ldots & \ldots & 164\end{array}$

$\begin{array}{llllll}\text { Indian } & \ldots & \ldots & \ldots & \ldots & 166\end{array}$

$\begin{array}{llllll}\text { Lace } & \ldots & \ldots & \ldots & \ldots & 173\end{array}$

Literature of $\ldots . \ldots . \quad \ldots \quad 164$

Fattening pigeons in France 71

Feathering, pigeons of peculiar :

Egyptian swift $\quad \ldots \quad \ldots 107$

Frillback $\quad \ldots \quad \ldots \quad \ldots 104$

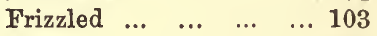

$\begin{array}{llllll}\text { Lace } & \ldots & \ldots & \ldots & \ldots & 105\end{array}$

$\begin{array}{llllll}\text { Mane } & \ldots & \ldots & \ldots & \ldots & 106\end{array}$

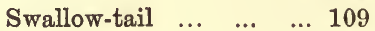

$\begin{array}{lllllll}\text { Feeders } & \ldots & \ldots & \ldots & \ldots & \ldots & 40\end{array}$

$\begin{array}{llllllll}\text { Feeding } & \ldots & \ldots & \ldots & \ldots & \ldots & \ldots & \ldots\end{array}$

$\begin{array}{llllll}\text { Boards } & \ldots & \ldots & \ldots & \ldots & 17\end{array}$

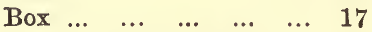

Evils of neglecting ... $\quad \ldots \quad 32$

Grain, how to preserve ... 30

Grain, quality of $\quad \ldots \quad \ldots \quad 30$

$\begin{array}{llll}\text { Grain used in ... } & \ldots & \ldots & 30\end{array}$

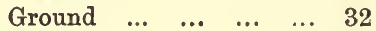

$\begin{array}{llllll}\text { Hoppers } & \ldots & \ldots & \ldots & \ldots & 32\end{array}$

$\begin{array}{llllll}\text { Mode of } & \ldots & \ldots & \ldots & \ldots & 32\end{array}$

$\begin{array}{lllll}\text { Times for } & \ldots & \ldots & \ldots & 32\end{array}$

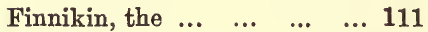

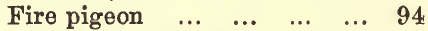

Pigeon, English $\quad \ldots \quad \ldots \quad 74$

$\begin{array}{llllll}\text { Flesh wen } & \ldots & \ldots & \ldots & \ldots & 60\end{array}$

Flights, open-air $\quad \ldots \quad \ldots \quad \ldots \quad \ldots \quad 16$

Floors of flights, covering for 24

Florentine pigeon ... $\quad \ldots \quad \ldots l 160$

Flying pigeons, East Indian... 127

Foods :

$\begin{array}{lccccc}\text { Barley } & \ldots & \ldots & \ldots & \ldots & 31 \\ \text { Beans } & \ldots & \ldots & \ldots & \ldots & 31 \\ \text { Green } & \ldots & \ldots & \ldots & \ldots & 32 \\ \text { Indian corn } & \ldots & \ldots & \ldots & 31 \\ \text { Maize } & \ldots & \ldots & \ldots & \ldots & 31 \\ \text { Mixture of } & \ldots & \ldots & \ldots & 32 \\ \text { Peas } \ldots & \ldots & \ldots & \ldots & \ldots & 31 \\ \text { Seeds } & \ldots & \ldots & \ldots & \ldots & 32 \\ \text { Tares } & \ldots & \ldots & \ldots & \ldots & 31 \\ \text { Wheat } & \ldots & \ldots & & \ldots & 31\end{array}$

Foreign literature on pigeons 409

Pigmy pouters:

$\begin{array}{lllll}\text { Brünn } & \ldots & \ldots & \ldots & 273 \\ \text { Dutch balloon } & . . & \ldots & 275 \\ \text { Prague } & \ldots & \ldots & \ldots & 275\end{array}$


PAGE

Foreign varieties of pigeons... 12

Wattled pigeons $\quad . . . \quad \ldots 304$

Form, variations in $\quad \ldots . \quad \ldots \quad 9$

$\begin{array}{lllll}\text { Fountains, water } & \ldots & \ldots & \ldots & 18\end{array}$

Fowl-like pigeons :

$\begin{array}{llllll}\text { Burmese } & \ldots & \ldots & \ldots & \ldots & 159 \\ \text { Florentine } & \ldots & \ldots & \ldots & 160 \\ \text { Hungarian } & \ldots & \ldots & \ldots & 161 \\ \text { Leghorn runt } & \ldots & \ldots & \ldots & 157 \\ \text { Maltese } & \ldots & \ldots & \ldots & \ldots & 160 \\ \text { Monteneur } & \ldots & \ldots & \ldots & 162 \\ \text { Peculiarities of } & \ldots & \ldots & 157 \\ \text { Speckled hen } & \ldots & \ldots & \ldots & 161 \\ \text { Strasser } & \ldots & \ldots & \ldots & \ldots & 163 \\ \text { nch Bagdads } & \ldots & \ldots & \ldots & 304 \\ \text { Pouters } & \ldots & \ldots & \ldots & \ldots & 257 \\ \text { Works on pigeons } & \ldots & \ldots & 410 \\ \text { esland runt } & \ldots & \ldots & \ldots & 103 \\ \end{array}$

Frillback, the ... $\ldots . . . . . . .104$

Frill - breasted short - faced pigeons:

African owl

Black - laced blondinette 217

Blondinette $\ldots$... $\quad \ldots .216$

Blue blondinette ... $\quad . .2218$

$\begin{array}{llllll}\text { Bluette } & \ldots & \ldots & \ldots & \ldots & 216\end{array}$

Brown blondinette $\quad . .217$

$\begin{array}{lllll}\text { Branette ... } & \ldots & \ldots & \ldots & 215\end{array}$

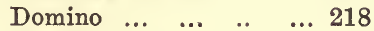

$\begin{array}{lllll}\text { English owl } & \ldots & \ldots & \ldots & 198\end{array}$

History of $\quad \ldots \quad \ldots \quad \ldots 190$

Italian owl $\quad \ldots \quad \ldots . \quad \ldots 203$

Peaked turbit $\quad \ldots . \quad \ldots 211$

Satin blondinette ... ... 217

Satinette... $\quad \ldots \quad$.. $\quad \ldots$ 214

Shell-crested turbit $\ldots 212$

Silver blondinette ... ... 218

$\begin{array}{lllll}\text { Silverette } & \ldots & \ldots & \ldots & 216\end{array}$

Sulphur blondinettes ... 217

$\begin{array}{llllll}\text { Turbit } & \ldots & \ldots & \ldots & \ldots & 205\end{array}$

$\begin{array}{lllll}\text { Turbiteen } & \ldots & \ldots & \ldots & 219\end{array}$

$\begin{array}{llllll}\text { Turkish } & \ldots & \ldots & \ldots & \ldots & 212\end{array}$

Turkish nomenclature of 222

Turkish turbit $\quad \ldots . \quad \ldots 222$

Vizor $\quad \ldots \quad \ldots \quad \ldots \quad \ldots 219$

$\begin{array}{lllll}\text { Whiskered owl } & \ldots & \ldots & 203\end{array}$

Frizzled pigeon $\quad \ldots \quad \ldots \quad \ldots 103$ Frontal - crested tumbler, Russian
Fulton's (Robert) “ Illustrated

Book of Pigeons" ... 405

G.

Gallinaceous pigeon $\quad \ldots \quad \ldots 160$

German ancient $\quad \ldots \quad \ldots . \quad \ldots \quad 327$

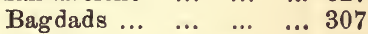

Pouter, old $\quad \ldots . \quad \ldots \quad$... 261

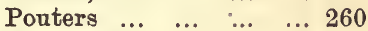

$\begin{array}{lllll}\text { Tumblers } & \ldots & \ldots & \ldots & 326\end{array}$

Works on pigeons ... ... 4110

Girton's "New and Complete

Pigeon Fancyer" $\quad$... 388

$\begin{array}{lllll}\text { Gizzard fallen } & \ldots & \ldots & \ldots & 61\end{array}$

$\begin{array}{lllll}\text { Goolee pigeon } & \ldots & \ldots & \ldots & 125\end{array}$

$\begin{array}{lllllll}\text { Gorging } & . . & \ldots & \ldots & \ldots & \ldots & 61\end{array}$

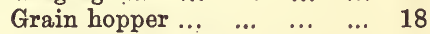

$\begin{array}{lllll}\text { Greasy fairy pigeon } & \ldots & \ldots & 90\end{array}$

Grecian authors, reference by 2

$\begin{array}{llllll}\text { Green foods } & \ldots & \ldots & \ldots & \ldots & 32\end{array}$

Ground tumblers ... $\quad . . \quad \ldots \quad 312$

Gull pigeon, black-backed $\quad \ldots \quad 142$

H.

Handicaps, tippler $\quad$... $\quad$... 314

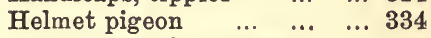

Pigeon of Germany $\quad \ldots \quad 80$

Hevernick, Herr William, on the Pomeranian cropper 263

Hill's, Captain Norman, black pied pigmy pouter ...2 254

Himalayan carrier ... $\quad . . \quad \ldots \quad 309$

Hirondelles fauve etincelé ... 89

$\begin{array}{llllll}\text { Siam } & \ldots & \ldots & \ldots & \ldots & 89\end{array}$

Historical :

Aldrovandi, Ulyssis $\quad \ldots \quad 6$

Almond, the $\quad . .6 \quad \ldots \quad$... 335

Anacreon $\quad \ldots \quad \ldots \quad \ldots \quad 2$

Anacreon's "Ode to the

Carrier Pigeon" ... 355

Annals of Rameses III.... 2

Annals of Thothmes III. 1

$\begin{array}{lllll}\text { Aristotle ... } & \ldots & \ldots & \ldots & 3\end{array}$

Barb, the $\quad \ldots \quad \ldots \quad \ldots 276$

Carrier, the $\quad \ldots \quad \ldots \quad \ldots 282$

Charlemagne's Edicts ... 5

$\begin{array}{llll}\text { Egyptian records } & \ldots & \ldots & 1\end{array}$

$2 \circ 2$ 
Historical :

English pouter $\quad \ldots \quad \ldots 223$

Fantail, the $\quad \ldots \quad \ldots \quad \ldots l 164$

Grecian authors reference

$\begin{array}{llllll}\text { by } & \ldots & \ldots & \ldots & \ldots & 2\end{array}$

$\begin{array}{llllll}\text { Homer } & \ldots & \ldots & \ldots & \ldots & \ldots\end{array}$

$\begin{array}{lllll}\text { Jacobin, the } & \ldots & \ldots & \ldots & 175\end{array}$

$\begin{array}{llllll}\text { Juvenal } & \ldots & \ldots & \ldots & \ldots & 4\end{array}$

Latin authors, reference by 4

Middle Ages, the $\quad . . \quad \ldots \quad$... 6

Moore's" Columbarium " 6, 384

Norwich cropper ... ...242

Pigeon-breeding in Asia, North Africa, and Europe

Picen fl............

$\begin{array}{llllll}\text { Pliny } \quad . . & \ldots & \ldots & \ldots & 4\end{array}$

$\begin{array}{llll}\text { Recent history } & \ldots & \ldots & 6\end{array}$

Short-faced frill-breasted $\begin{array}{lllll}\text { pigeons } & \ldots & \ldots & \ldots & 190\end{array}$

$\begin{array}{llllll}\text { Socrates } & \ldots & \ldots & \ldots & \ldots & 2\end{array}$

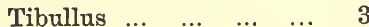

Vataces John Ducas ... 5

Willughby's "Ornithology" $\ldots \quad \ldots \quad \ldots \quad 6,384$

Windsor, pigeons at $\quad \ldots \quad 6$ Homer, show, the ... ... ... 366 Homers, judging, Mr. W. B. Tegetmeier on $\quad \ldots \quad \ldots 366$ Homing pigeons :

Antwerp carrier

Belgian, M. V. la Perre de Roo's account of the origin of

Books on $\quad \ldots . \quad \ldots \quad \ldots 407$

$\begin{array}{llll}\text { Breeds used as } & \ldots & \ldots & 29\end{array}$

Exhibition Antwerps ... 365

London beard ... $\quad . . . \quad \ldots \quad 356$

Long-faced Antwerp ... 372

Medium-faced Antwerp $\quad 373$

Short-faced Antwerp ... 370

$\begin{array}{lllll}\text { Skinnum ... } & \ldots & \ldots & \ldots & 356\end{array}$

$\begin{array}{lllllll}\text { Hoppers } & \ldots & \ldots & . . & \ldots & \ldots & 17\end{array}$

Horseman, Moore's description $\begin{array}{llllll}\text { of } \ldots & \ldots & \ldots & \ldots & \ldots & 295\end{array}$

House, pigeon $\quad \ldots . \quad \ldots \quad \ldots \quad 14$

Tumblers ... $\quad \ldots \quad \ldots \quad \ldots \quad \ldots 312$

Hungarian magpie tumbler ... 327

Pigeon ...
PAGE

$\begin{array}{lllll}\text { Hyacinth pigeon } & \ldots & \ldots & \ldots & 99\end{array}$

Pigeon, speckled ... ... 100

I.

$\begin{array}{llllll}\text { Ice pigeon } & \ldots & \ldots & \ldots & \ldots & 76\end{array}$

Indian fantail $\quad \ldots \quad \ldots \quad \ldots 166$

$\begin{array}{lllllll}\text { Insects } & \ldots & \ldots & \ldots & \ldots & \ldots & 62\end{array}$

Italian owl $\quad \ldots \quad \ldots \quad \ldots \quad \ldots 203$

Works on pigeons ... $\quad \ldots \quad 410$

J.

$\begin{array}{lllllll}\text { Jacobin } & \ldots & \ldots & \ldots & \ldots & \ldots & 175\end{array}$

Fancy points of $\quad \ldots \quad \ldots 180$

$\begin{array}{lllll}\text { History of } & \ldots & \ldots & \ldots & 175\end{array}$

Literature of $\begin{array}{lllll}\ldots & \ldots & \ldots & 175\end{array}$

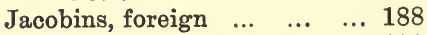

Japanese work on pigeons ... 411

Judging homers, Mr. W. B. Tegetmeier on $\ldots \quad \ldots 366$

\section{K.}

Keeping several varieties of pigeons 28

Kokah pigeon, Akbar's, probable identity of ... $\quad . . \quad 154$

$\begin{array}{llll}\text { Königsber'g Moorhead ... } & \text {... } & 326\end{array}$

\section{L.}

$\begin{array}{llllll}\text { Laced birds } & \ldots & \ldots & \ldots & \ldots & 48\end{array}$

$\begin{array}{llllll}\text { Lace fantail } & \ldots & \ldots & \ldots & \ldots & 173\end{array}$

$\begin{array}{llllll}\text { Pigeon } & \ldots & \ldots & \ldots & \ldots & 105\end{array}$

$\begin{array}{lllll}\text { Lahore pigeon } & \ldots & \ldots & \ldots & 122\end{array}$

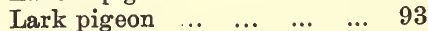

Pigeon, Nürnberg $\quad . . \quad \ldots \quad 94$

Latin authors, reference by ... 4

$\begin{array}{llllll}\text { Latz pigeon } & . . & \ldots & \ldots & \ldots & 80\end{array}$

$\begin{array}{lllll}\text { Shell pigeon } & \ldots & \ldots & \ldots & \\ & \ldots 0\end{array}$

Laugher, the $\quad \ldots \quad \ldots \quad \ldots \quad \ldots \quad \ldots 153$

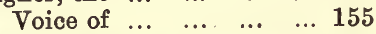

$\begin{array}{llllll}\text { Leghorn runt } \ldots & \ldots & \ldots & \ldots & 157\end{array}$

Runt, Moore's description $\begin{array}{llllll}\text { of } \ldots & \ldots & \ldots & \ldots & \ldots & 157\end{array}$ 
$\begin{array}{llllll}\text { Leg weakness } . . . & \ldots & \ldots & \ldots & 63\end{array}$

Lille pouters $\ldots . \quad \ldots \quad \ldots \quad \ldots 258$

Lime required by pigeons ... 35 Literature :

Adams' (H. G.) "Our Feathered Families"... 403 Aldrovandi's "Ornitho$\begin{array}{lllll}\text { logia } " \ldots & \ldots & \ldots & \ldots & 382\end{array}$

American $\quad \ldots \quad \ldots \quad \ldots 410$

American serial ... $\ldots 4.410$

"A New and Compleat Treatise on the Art of Breeding and Managing the Almond Tumbler" 392

"A Treatise on Domestic Pigeons" $\quad \ldots \quad \ldots \quad \ldots 386$ Bignold's (G.) "Pigeon Fancier's Assistant"... 398 Books on homing pigeons 407 Boswell's (Peter) " Bees, Pigeons, Rabbits, and the Canary Bird Familiarly Described" ... 397 Brent's (B. P.) "Pigeon Book" ... $\ldots$... $\quad \ldots 402$

Cresswell's (O. E.) essay on pigeons $\ldots \quad \ldots \quad \ldots 406$

Darwin's "Variation of Animals and Plants under Domestication" 404

Dixon's (Rev. E. S.) “The Dovecote and the Aviary"... ... $\quad . . \quad \ldots 399$

$\begin{array}{llllll}\text { Dutch } & \ldots & \ldots & \ldots & \ldots & 410\end{array}$

Early printed books ... 381

Eaton's (J. M.) works on pigeons $\quad \ldots \quad \ldots 400$

$\begin{array}{llllll}\text { English } & \ldots & \ldots & \ldots & \ldots & 384\end{array}$

$\begin{array}{llllll}\text { Foreign } & \ldots & \ldots & \ldots & \ldots & 409\end{array}$

French $\quad \ldots \quad \ldots \quad \ldots \quad \ldots 410$

Fulton's (Robert) "Illustrated Book of Pigeons" 405

"Gardener, Florist, and Agriculturalist" ... 408

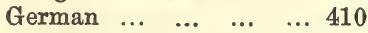

Girton's "New and Complete Pigeon Fancyer" 388 Goodfellow's (A.) "The Little Boy's Own Book" 396
Literature :

Hill's (Capt. Norman) "The Pouter Pigeon" 405 "Home Pets" ... ... 403 Homing pigeons, books on 407 $\begin{array}{llllll}\text { Italian } & \ldots & \ldots & \ldots & \ldots & 410\end{array}$ Japanese ... $\quad \ldots \quad \ldots \quad \ldots 411$

Loudon's (Mrs.) “ Domestic Pets" $\quad \ldots \quad \ldots \quad \ldots 399$

Lucas' (Rev. J.) "The Pleasures of a Pigeon Fancier" $\quad \ldots \quad \ldots \quad \ldots 406$

Lyell's (J. C.) "Fancy Pigeons" $\ldots$... $\ldots 4.407$

Martin's (W. C. L.) " Our Domestic Fowls and Song Birds" $\quad \ldots \quad \ldots 398$

Moore's "Columbarium" 384

Moubray's (Bonington) "Treatise on Domestic Poultry, Pigeons, and Rabbits" $\ldots \quad \ldots \quad \ldots 395$

Musari's (Sayzid Mohammed) History of pigeons 404,412

"Mustertaubenbuch," the 410

"New and Complete Bird

Fancier" ... ... ... 390

Persian treatise on pigeons 404,412

"Pigeons for Exhibition and Profit" ... ...4 406

Piper's (Hugh) " Pigeons : their Varieties, Management, Breeding, and Diseases" ... ... ... 404 Pliny's "Natural History" 381

Prütz's "Mustertauben-

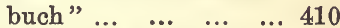

Rogers' "Pigeon Fancier's Guide " $\quad \ldots \quad \ldots \quad \ldots 397$

Selby's (P. J.) "Natural History of Pigeons "... 397

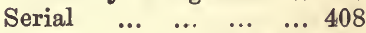
Smith's (G.) "How to Breed, Rear, and Train the Macclesfield Tippler and the High-flying Tumbler Pigeon" ...4 406 
PAGE

Literature :

Spanish

Tegetmeier's (w. "Pigeons: their Structure, Varieties, Habits, and Management" ... 403

"The Bird-fancier's Recreation : being Curious Remarks on the Nature of Song Birds" ... ... 390

"The Boy's Own Paper" 409

"The Cottage Gardener" 408

"The Country" ... ... 409

"The Field" newspaper 409

"The Kabutar Namah" 412

"The Little Boy's Own Book of Sports and Pastimes" $\ldots . . . . \quad \ldots 396$

"The Management of Pigeons" ... ... ...

"The Pigeon" ... ...

"The Poultry and Pigeon Keeper's Companion" 396

"The Poultry Chronicle" 408

"The Poultry Review "... 409

"The Standard of Excellence for Judging Pigeons" ... $\quad \ldots \quad \ldots$

"The Young Angler, Naturalist, and Pigeon and Rabbit Fancier" 396

Ure's (G.) "Our Fancy Pigeons, and Rambling Notes of a Naturalist" 406 Willughby's "Ornithology" $\quad \ldots \quad \ldots \quad \ldots \quad \ldots 384$

Windus' (W. P.) "A New and Compleat Treatise on the Art of Breeding and Managing the Almond Tumbler " ... 392

Wright's (Lewis) " Practical Pigeon Keeper" 405

$\begin{array}{llllll}\text { Loft, pigeon } & \ldots & \ldots & \ldots & \ldots & 14\end{array}$ London beard ... $\quad \ldots \quad \ldots \quad \ldots \quad \ldots 356$ Long-faced Antwerp carrier... 372 $\begin{array}{lllllll}\text { Lowtan } & \ldots & \ldots & \ldots & \ldots & \ldots & 126\end{array}$

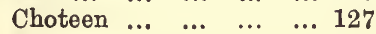
$\begin{array}{llllll}\text { Kulmee } & \ldots & \ldots & \ldots & \ldots & 127\end{array}$
PAGE

Lowtan, sadhee

Lucas' (Rev. J.) “The Pleasures of a Pigeon Fancier" 406

M.

Macclesfield tipplers $\quad \ldots \quad \ldots 317$

Magpie, the $\quad \ldots \quad \ldots \quad \ldots \quad \ldots \quad \ldots 333$

$\begin{array}{lllll}\text { Mahomet pigeon } & \ldots & \ldots & \ldots & 131\end{array}$

Maltese pigeon $\quad \ldots . \quad \ldots \quad \ldots \quad 160$

$\begin{array}{llllll}\text { Management } & . . & \ldots & \ldots & \ldots & 30\end{array}$

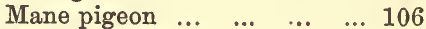

$\begin{array}{lllll}\text { Manure, pigeon } & \ldots & \ldots & \ldots & 72\end{array}$

Market, pigeons for the $\quad \ldots \quad 71$

$\begin{array}{lllll}\text { Martin pigeon } & \ldots & \ldots & \ldots & 122\end{array}$

$\begin{array}{llll}\text { Matching for breeding } & \ldots & \ldots & 36\end{array}$

Mating, how effected $\ldots . \quad \ldots \quad 36$

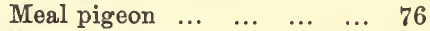

Measuring pouters ...230, 232

Medium-faced Antwerp carrier 373

$\begin{array}{llllll}\text { Megrims ... } & \ldots & \ldots & \ldots & \ldots & 65\end{array}$

$\begin{array}{llllll}\text { Melanoids } & \ldots & \ldots & \ldots & \ldots & 47\end{array}$

Messengers, pigeons formerly $\begin{array}{lllll}\text { used as } & \ldots & \ldots & \ldots & 356\end{array}$

$\begin{array}{llllll}\text { Middle Ages, the } & \ldots & \ldots & \ldots & \ldots & 6\end{array}$

$\begin{array}{llllll}\text { Miroité, the } & \ldots & \ldots & \ldots & \ldots & 98\end{array}$

Modena, pigeon-flying at ... 115

$\begin{array}{llll}\text { Modern show system } & \ldots & \ldots & 50\end{array}$

$\begin{array}{llllll}\text { Monk pigeon } & \ldots & \ldots & \ldots & \ldots & 88\end{array}$

$\begin{array}{lllll}\text { Montauban pigeon } & \ldots & \ldots & 141\end{array}$

$\begin{array}{lllll}\text { Monteneur pigeon ... } & \ldots & \ldots & 162\end{array}$

$\begin{array}{lllll}\text { Mookee pigeon } \quad \ldots & \ldots & \ldots & 123\end{array}$

$\begin{array}{llllll}\text { Moon pigeon } & \ldots & \ldots & \ldots & \ldots & 77\end{array}$

Moore's (John) "Columbarium"

6,384

Mottled tumbler $\quad \ldots \quad \ldots \quad \ldots 318$

Moubray's “Treatise on Domestic Poultry, Pigeons, and Rabbits" ... ... 395

$\begin{array}{lllll}\text { Moulter pigeon } & \ldots & \ldots & \ldots & 87\end{array}$

$\begin{array}{llllll}\text { Moulting } \ldots & \ldots & \ldots & \ldots & \ldots & 64\end{array}$

$\begin{array}{lllll}\text { Mourning pigeon } & \ldots & \ldots & \ldots & 82\end{array}$

Musari's (Sayzid Mohammed)

History of pigeons 404, 412

N.

Narrow-tailed shaker ... $\quad \ldots \quad 167$ 
PAGE

Narrow-tailed shaker, Wil-

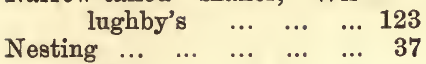

$\begin{array}{lllll}\text { Boxes } & \ldots & \ldots & \ldots & \ldots \\ & & 21,22\end{array}$

Pans, earthenware ... ... 23

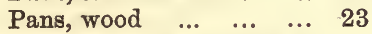

Neumeister and the origin of fancy pigeons $\quad \ldots \quad \ldots 68$

$\begin{array}{lllll}\text { Norwegian pigeon } & \ldots & \ldots & \ldots & 141\end{array}$

Norwich cropper $\quad \ldots \quad \ldots \quad \ldots 241$

Cropper, fancy points of 243

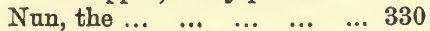

$\begin{array}{llll}\text { Nürnberg lark pigeon } & \ldots & \ldots & 94\end{array}$

Swallow pigeon $\quad \ldots \quad \ldots \quad 90$

o.

$\begin{array}{llllll}\text { Odd birds } & \ldots & \ldots & \ldots & \ldots & 42\end{array}$

$\begin{array}{lllll}\text { Open-air flights } & \ldots & \ldots & \ldots & 16\end{array}$

"Original " pigeons $\quad . .6 \quad \ldots .67$

Origin of fancy pigeons... ...8, 68

Oude's, ex-king of, pigeons ... 128

$\begin{array}{lllll}\text { Overcrowding ... } & \ldots & \ldots & \ldots & 42\end{array}$

$\begin{array}{llllll}\text { Overlaying } & \ldots & \ldots & \ldots & \ldots & 41\end{array}$

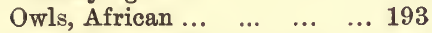

African, fancy points of 194

Description of, by Moore 191

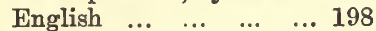

English, fancy points of 199

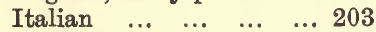

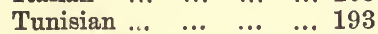

$\begin{array}{lllll}\text { Whiskered } & \ldots & \ldots & \ldots & 203\end{array}$

P.

Pairing

Parisian powter, description of,

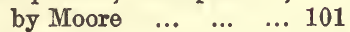

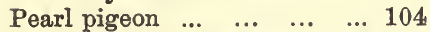

Peculiar feathering, pigeons of 103

Voice, pigeons of ... $\quad . . .144$

$\begin{array}{lllll}\text { Pens, exhibition } & \ldots & \ldots & \ldots & 54\end{array}$

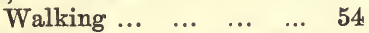

Persian work on pigeons 404, 412

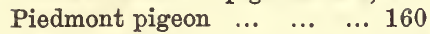

$\begin{array}{llllll}\text { Pigeon aviary } \ldots & \ldots & \ldots & \ldots & 14\end{array}$

$\begin{array}{lllll}\text { Bagadais ... } & \ldots & \ldots & \ldots & 304\end{array}$
PAGE

Pigeon cavalier $\quad$.. $\quad \ldots \quad \ldots 259$

Chanteur du Soudan

$\begin{array}{llll}\text { Coquille barbu } & \text {... } & \text {.. } & 79\end{array}$

$\begin{array}{llll}\text { Coquille étourneau } & \ldots & 82\end{array}$

Coquille Hollondais $\quad$... 330

$\begin{array}{llll}\text { Coquille Souabe } & \ldots & \ldots & 82\end{array}$

Coquille tête de morte ... 80

Flying, antiquity of $\quad . .355$

Flying at Calcutta ... 128

Flying at Delhi . ... ... 128

Flying at Modena, antiquity of $\quad \ldots \quad 5,116,117$

Flying, early $\ldots \quad \ldots \quad \ldots \quad 5$

Flying, modern, at Delhi 5

Flying on the Continent 363

$\begin{array}{lllll}\text { Grosse gorge } & \ldots & \ldots & \ldots & 258\end{array}$

$\begin{array}{llllll}\text { Heurté } & \ldots & \ldots & \ldots & \ldots & 73\end{array}$

$\begin{array}{lllll}\text { Hirondelle } & \ldots & \ldots & \ldots & 89\end{array}$

$\begin{array}{llllll}\text { House } & \ldots & \ldots & \ldots & \ldots & 15\end{array}$

House, sawdust for the $\begin{array}{lllll}\text { floor of } & \ldots & \ldots & \ldots & 23\end{array}$

Houses, cleaning $\ldots{ }^{\prime .} \quad \ldots \quad 23$

Lillois $\quad \ldots \quad \ldots \quad 112,258,259$

Lillois elégant $\quad \ldots \quad \ldots 259$

$\begin{array}{llllll}\text { Loft ... } & \ldots & \ldots & \ldots & \ldots & 14\end{array}$

$\begin{array}{llllll}\text { Maille } & \ldots & \ldots & \ldots & \ldots & 100\end{array}$

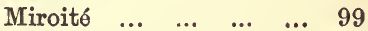

Moine à bavette $\quad \ldots \quad \ldots \quad$.. 93

$\begin{array}{llllll}\text { Nonnain } & \ldots & \ldots & \ldots & \ldots & 188\end{array}$

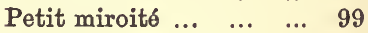

$\begin{array}{llllll}\text { Polonais } & \ldots & \ldots & \ldots & \ldots & 277\end{array}$

$\begin{array}{llllll}\text { Romain } & . . & \ldots & \ldots & \ldots & 139\end{array}$

Shows, antiquity of $\quad \ldots \quad 50$

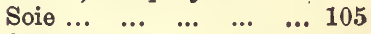

$\begin{array}{lllllll}\text { Suisse } & \ldots & \ldots & \ldots & \ldots & 77\end{array}$

Suisse bai Doré, ou bis

$\begin{array}{llllll}\text { Doré } & \ldots & \ldots & \ldots & \ldots & 79\end{array}$

Tambour glou-glou ... 144:

Tournant... $\quad \ldots \quad \ldots \quad \ldots l 11$

Trembleur de la Guyane 174.

Trembleur paon ... 106, 173

$\begin{array}{llllll}\text { Turc } & \ldots & \ldots & \ldots & \ldots & 307\end{array}$

Volant cou-rouge $\quad . . \quad \ldots 357$

Voyageur de Beyrouth ... 137

Pigeonry, plan of author's 20-23

$\begin{array}{llllll}\text { Small } & \ldots & \ldots & \ldots & \ldots & 19\end{array}$

$\begin{array}{llllll}\text { Pigeons boulans } & \ldots & \ldots & \ldots & 258\end{array}$

For the market $\quad \ldots \quad$... 71

$\begin{array}{llllll}\text { Mailles } & \ldots & \ldots & \ldots & \ldots & 99\end{array}$ 
PAGE

$\begin{array}{lllll}\text { Pigeons mondain } & \ldots & \ldots & \ldots & 71\end{array}$

$\begin{array}{llllll}\text { Patu } & \ldots & \ldots & \ldots & \ldots & 71\end{array}$

$\begin{array}{llllll}\text { Young } & \ldots & \ldots & \ldots & \ldots & 39\end{array}$

Pigmy pouter, pied $\quad \ldots \quad$... 253

pouters, foreign $\quad \ldots \quad$... 271

$\begin{array}{lllll}\text { Pilferer pigeon } & \ldots & \ldots & \ldots & 87\end{array}$

Piper's (Hugh) "Pigeons: their Varieties, Management, Breeding, and Diseases " ... ... 404 Pliny's " Natural History ” ... 381 Plumage, pigeons of varied and $\begin{array}{lllll}\text { striking } & \ldots & \ldots & \ldots & 28\end{array}$

Polish lynx pigeon... $\quad \ldots \quad$... 101

Pomeranian cropper, Herr William Hevernick's

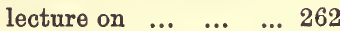

$\begin{array}{llllll}\text { Pouter } & \ldots & \ldots & \ldots & \ldots & 262\end{array}$

Porcelain pigeon $\quad \ldots \quad \ldots \quad 77,100$

Pouters, measuring $\quad$... 230, 232

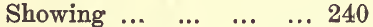

Pouting horseman ... ... 242, 251

Or cropper pigeons:

Austrian klatcher ... 269

Bengal ... $\quad \ldots \quad \ldots 271$

$\begin{array}{lllll}\text { Breslau } & \ldots & \ldots & \ldots & 261\end{array}$

$\begin{array}{lllll}\text { Brünn } \quad \ldots & \ldots & \ldots & 273\end{array}$

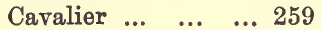

Dutch ...

Dutch balloon ... 275

English pouter $\quad . .2223$

Foreign pigmy $\quad \ldots 271$

French $\ldots . . .2 . .257$

German $\quad \ldots \quad \ldots . \quad \ldots 260$

$\begin{array}{lllll}\text { Lille } & \ldots & \ldots & \ldots & 258\end{array}$

Norwich cropper ... 241

Old German ... ... 261

Pied pigmy $\quad \ldots \quad \ldots 253$

$\begin{array}{llll}\text { Pomeranian } & \ldots & \ldots & 262\end{array}$

Prague magpie ... 270

Prague pigmy $\quad . .2275$

Saxon $\quad \ldots \quad \ldots \quad \ldots 269$

Stork $\quad \ldots \quad \ldots \quad \ldots 275$

Powter, Parisian, Moore's de-

scription of ... $\quad \ldots \quad \ldots \quad 101$

Prague magpie pouter ... ... 270

Pigmy pouter ... $\quad \ldots \quad \ldots 275$

Preparing birds for showing 53

$\begin{array}{lllll}\text { Priests, common } & \ldots & \ldots & \ldots & 85\end{array}$
PAGE

Priests, double-crested ... $\quad \ldots \quad 86$ Starling - barred, white flighted and tailed .. 86

$\begin{array}{llll}\text { White-barred ... } & \ldots & \ldots & 86\end{array}$ White - flighted, barred $\begin{array}{lllll}\text { and tailed } & \ldots & \ldots & \ldots & 86\end{array}$

White-flighted, white$\begin{array}{lllll}\text { barred ... } & \ldots & \ldots & \ldots & 86\end{array}$

$\begin{array}{llll}\text { White-stockinged } & \ldots & \ldots & 86\end{array}$

$\begin{array}{lllll}\text { Printed tippler } & \ldots & \ldots & \ldots & 317\end{array}$

Progenitor, probable, of tame pigeons

Q.

Quarrelsome pigeons $\quad \ldots \quad \ldots \quad 27$

\section{R.}

$\begin{array}{lllll}\text { "Race" pigeons } & \ldots & \ldots & \ldots & 68\end{array}$

$\begin{array}{lllll}\text { Racing pigeons } & \ldots & \ldots & \ldots & 29\end{array}$

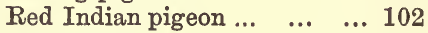

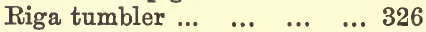

Ringbeater $\quad \ldots \quad \ldots \quad \ldots \quad \ldots l 11$

Neumeister's description $\begin{array}{lllllll}\text { of } \ldots & \ldots & \ldots & \ldots & \ldots & 112\end{array}$

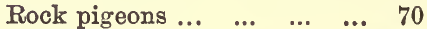

$\begin{array}{lllll}\text { Wild blue } & \ldots & \ldots & \ldots & 44\end{array}$

Rollers, Birmingham $\quad \ldots . \quad \ldots \quad 317$

$\begin{array}{lllll}\text { Colours of } & \ldots & \ldots & \ldots & 318\end{array}$

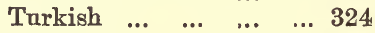

$\begin{array}{lllll}\text { Roman pigeon } & \ldots & \ldots & \ldots & 141\end{array}$

$\begin{array}{llllll}\text { Runt } \quad \ldots & \ldots & \ldots & \ldots & 141\end{array}$

Ruff pigeon of Moore $\quad . . \quad \ldots \quad 176$

Runts, almond and blue$\begin{array}{lllll}\text { grizzled } & \ldots & \ldots & \ldots & 142\end{array}$

$\begin{array}{lllll}\text { Antiquity of } & \ldots & \ldots & \ldots & 138\end{array}$

As table pigeons $\quad \ldots \quad$... 142

Black-backed gull ... $\quad . .142$

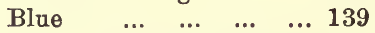

Blue and silver, weight of 139

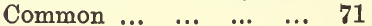

$\begin{array}{llllll}\text { Fancy } \quad \ldots & \ldots & \ldots & \ldots & 139\end{array}$

$\begin{array}{lllll}\text { Friesland } & \ldots & . . & \ldots & 103\end{array}$

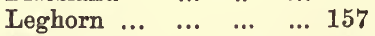

$\begin{array}{lllll}\text { Montauban } & \ldots & \ldots & \ldots & 141\end{array}$

$\begin{array}{lllll}\text { Norwegian } & \ldots & \ldots & \ldots & 141\end{array}$ 
Runts, Roman $\quad \ldots . \quad \ldots \quad \ldots \quad 141$

$\begin{array}{llllll}\text { Silver } & \ldots & \ldots & \ldots & \ldots & 139\end{array}$

$\begin{array}{llllll}\text { Spanish } & \ldots & \ldots & \ldots & \ldots & 138\end{array}$

Russian frontal-crested tum-

$\begin{array}{llllll}\text { bler } & \ldots & \ldots & \ldots & \ldots & 325 \\ & & \end{array}$

$\begin{array}{lllll}\text { Trumpeter } & \ldots & \ldots & \ldots & 145\end{array}$

\section{S.}

Sacred bird, pigeon a $\quad \ldots \quad \ldots \quad 3$

Salt a necessity for pigeons ... 33

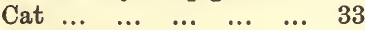

$\begin{array}{lllll}\text { Earth box } \quad \ldots & \ldots & \ldots & 34\end{array}$

Earth mixture $\quad . . \quad \ldots \quad 35$

$\begin{array}{llllll}\text { Satinette ... } & \ldots & \ldots & \ldots & \ldots & 214\end{array}$

$\begin{array}{llllll}\text { Blne } & \ldots & \ldots & \ldots & \ldots & 216\end{array}$

$\begin{array}{lllll}\text { Brunette ... } & \ldots & \ldots & \ldots & 215\end{array}$

$\begin{array}{llllll}\text { Silver } & \ldots & \ldots & \ldots & \ldots & 216\end{array}$

$\begin{array}{llllll}\text { Saxon pigeon } & \ldots & \ldots & \ldots & \ldots & 75\end{array}$

$\begin{array}{llllll}\text { Pouter } & . . & . . & . . & . . & 269\end{array}$

Scanderoon, the $\quad \ldots \quad \ldots \quad \ldots 307$

$\begin{array}{lllll}\text { Scheme of work } & \ldots & \ldots & \ldots & 67\end{array}$

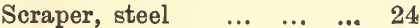

Seeds, pigeons fond of ... $\quad \ldots \quad 32$

$\begin{array}{llll}\text { Selection of stock ... } & \ldots & \ldots & 26\end{array}$

Separating sexes $\ldots . . . . \quad \ldots \quad 42$

Serial literature on the pigeon 408

Sexes, separating $\quad \ldots \quad$...

$\begin{array}{llll}\text { Sex of young pigeons } & \ldots & \ldots & 41\end{array}$

Shaking tumbler $\quad \ldots \quad \ldots \quad \ldots \quad \ldots 327$

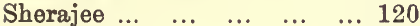

$\begin{array}{llllll}\text { Mottled ... } & \ldots & \ldots & \ldots & 121\end{array}$

Shield pigeon ... $\quad \ldots . \quad \ldots \quad \ldots \quad$...

Short, erect-tailed pigeons:

$\begin{array}{lllll}\text { Burmese ... } & \ldots & \ldots & \ldots & 159\end{array}$

$\begin{array}{lllll}\text { Florentine } & \ldots & \ldots & \ldots & 160\end{array}$

$\begin{array}{lllll}\text { Hungarian } & \ldots & \ldots & \ldots & 161\end{array}$

Leghorn runt ... $\quad \ldots \quad \ldots \quad 157$

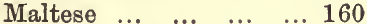

$\begin{array}{lllll}\text { Monteneur } & \text {... } & \ldots & \ldots & 162\end{array}$

Speckled hen ...

$\begin{array}{llllll}\text { Strasser } & \ldots & \ldots & \ldots & \ldots & 163\end{array}$

Short-faced Antwerp ... ... 370

Antwerp, properties of ... 371

Tumbler, history of $\quad . .335$

Tumblers :

Almond ... $\quad \ldots \quad \ldots 335$

$\begin{array}{llll}\text { Baldhead } & \ldots & \ldots & 353\end{array}$
Short-faced tumblers :

$\begin{array}{lllll}\text { Beard } & \ldots & \ldots & \ldots & 353\end{array}$

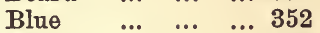

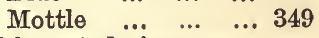

Frill-breasted pigeons:

African owl $\ldots \quad \ldots 193$

Black laced blondi$\begin{array}{lllll}\text { nette } & \ldots & \ldots & \ldots & 217\end{array}$

Blondinette $\ldots . \quad \ldots 216$

Blue blondinette $\quad . .2218$

Bluette ... $\quad . . . \quad \ldots .216$

Brown blondinette... 217

Brunette ... ... ... 215

$\begin{array}{lllll}\text { Domino } & \ldots & \ldots & \ldots & 218\end{array}$

$\begin{array}{llll}\text { English owl } & \ldots & \ldots & 198\end{array}$

History of $\quad \ldots \quad \ldots 190$

Italian owl $\ldots . \quad \ldots 203$

Peaked turbit ...2 211

Satin blondinette ... 217

Satinette... ... ... 214

Shell-crested turbit 212

Silver blondinette ... 218

Silverette $\quad \ldots \quad \ldots 216$

Sulphur blondinette 217

$\begin{array}{lllll}\text { Turbit } & \ldots & \ldots & \ldots & 205\end{array}$

Turbiteen _.. $\quad \ldots 219$

Turkish frilled $\ldots 212$

Turkish nomenclature of $\quad \ldots \quad \ldots 222$

Turkish turbit $\ldots 222$

Vizor $\quad \ldots \quad \ldots \quad \ldots 219$

Whiskered owl ...203

$\begin{array}{lllllll}\text { Shovel } & \ldots & \ldots & \ldots & \ldots & \ldots & 24\end{array}$

$\begin{array}{lllll}\text { Show baskets ... } & \ldots & \ldots & \ldots & 52\end{array}$

$\begin{array}{llllll}\text { Boxes } & \ldots & \ldots & \ldots & \ldots & 51\end{array}$

Homing Antwerp $\ldots . . .6365$

System, modern $\quad \ldots \quad$... 50

$\begin{array}{lllll}\text { Tumblers } & \ldots & \ldots & \ldots & 315\end{array}$

Showing, preparing birds for 53

$\begin{array}{llllll}\text { Shy pigeons } & \ldots & \ldots & \ldots & \ldots & 28\end{array}$

Silesian swallow pigeon $\quad \ldots \quad 90$

Silken-haired pigeon $\quad \ldots \quad \ldots \quad 105$

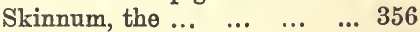

$\begin{array}{llllll}\text { Small-pox } & \ldots & \ldots & \ldots & \ldots & 64\end{array}$

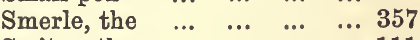

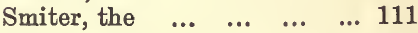

$\begin{array}{llllll}\text { Smyrna runt } & \ldots & \ldots & \ldots & \ldots & 142\end{array}$

Soot pigeon, or russtaube $\quad \ldots \quad 76$

$\begin{array}{lllll}\text { Spangled birds } & \ldots & \ldots & \ldots & 48\end{array}$ 
PAGE

Spanish runt $\ldots \quad \ldots \quad \ldots \quad \ldots 138$

Sparkling fawn-coloured swallow pigeon $\quad \ldots \quad \ldots \quad \ldots \quad \ldots 89$

Speckled hen pigeon $\quad . . . \quad \ldots 161$

Hyacinth pigeon $\quad \ldots \quad \ldots 100$

$\begin{array}{lllll}\text { Spiteful pigeons } & \ldots & \ldots & \ldots & 27\end{array}$

Spot, copper-winged white ... 74

$\begin{array}{llllll}\text { Pigeon } & \ldots & \ldots & \ldots & \ldots & 73\end{array}$

$\begin{array}{llllll}\text { White } & \ldots & \ldots & \ldots & \ldots & 74\end{array}$

$\begin{array}{llll}\text { White-barred ... } & \ldots & \ldots & 74\end{array}$

White, common $\quad \ldots \quad \ldots \quad 73$

$\begin{array}{rrrrrrr}\text { White-scaled } & \ldots & \ldots & \ldots & 74 \\ \text { Spouts } & \ldots & \ldots & \ldots & \ldots & \ldots & 65\end{array}$

Starling pigeon $\quad \ldots \quad \ldots \quad \ldots \quad \ldots \quad 80$

Stock birds, selecting $\quad \ldots \quad 26,36$

$\begin{array}{lllll}\text { Stomacher pigeon } & . . & \ldots & \ldots & 80\end{array}$

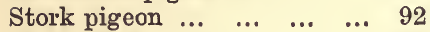

Strasser pigeon $\quad \ldots . \quad \ldots \quad \ldots l 63$

Styles of tumbling $\quad \ldots . \quad \ldots \quad 312$

$\begin{array}{lllll}\text { Suabian pigeon } & \ldots & \ldots & \ldots & 82\end{array}$

$\begin{array}{lllll}\text { Swallow pigeon } & \ldots & \ldots & \ldots & 88\end{array}$

Pigeon, Bohemian ... $\quad \ldots \quad 90$

Pigeon, Nürnberg ... ... 90

Pigeon, Saxon $\quad \ldots \cdot \ldots 90$

Pigeons, varieties in $\begin{array}{llll}\text { colouring of } & \ldots & \ldots & 90\end{array}$

Tail pigeon $\quad \ldots \quad \ldots . \quad \ldots 109$

Swan-necked Egyptian pigeons 306 $\begin{array}{llllll}\text { Swiss pigeon } & \ldots & \ldots & \ldots & \ldots & 77\end{array}$

\section{T.}

Table pigeons, runts as $\quad \ldots 142$

$\begin{array}{lllll}\text { Selecting for } & \ldots & \ldots & \ldots & 72\end{array}$

$\begin{array}{llllll}\text { Tailor pigeon } . . . & \ldots & \ldots & \ldots & 122\end{array}$

Tails, pigeons with short erect :

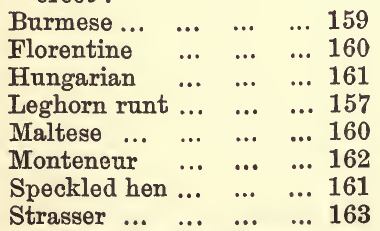

Tame pigeon, probable progenitor of
Tegetmeier's (W. B.) "Pigeons: their Structure, Varieties, Habits, and Man-

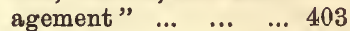

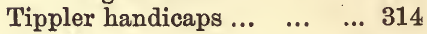

$\begin{array}{lllll}\text { Macclesfield } & \ldots & \ldots & \ldots & 317\end{array}$

$\begin{array}{llllll}\text { Printed .. } & \ldots & \ldots & \ldots & 317\end{array}$

$\begin{array}{lllll}\text { Triganica pigeon } & \ldots & \ldots & \ldots & 115\end{array}$

Pigeons, colours of $\quad$... 118

Triganieri, pigeon-flying by ... 115

$\begin{array}{llll}\text { Terms used by } & \ldots & \ldots & 116\end{array}$

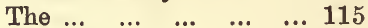

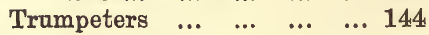

Altenburg $\quad \ldots \quad \ldots \quad \ldots 151$

Altenburg, voice of $\quad$... 153

$\begin{array}{lllll}\text { Bokhara .... } & \ldots & \ldots & \ldots & 145\end{array}$

$\begin{array}{llll}\text { Buff Altenburger } & \ldots & \ldots & 152\end{array}$

Fancy points of $\quad \ldots \quad \ldots l 147$

Lavender Altenburger ... 152

$\begin{array}{llllll}\text { Russian } & \ldots & \ldots & \ldots & \ldots & 145\end{array}$

Sub-varieties of $\quad \ldots \quad \ldots l 151$

$\begin{array}{llllll}\text { Voice of } & \ldots & \ldots & \ldots & \ldots & 149\end{array}$

$\begin{array}{lllllll}\text { Tumblers } & \ldots & \ldots & \ldots & . . & \ldots & 311\end{array}$

$\begin{array}{lllllll}\text { Air } & \ldots & \ldots & \ldots & \ldots & \ldots & 312\end{array}$

Almond ...

Baldhead ......$\quad \ldots 320$

Baldhead, short-faced ... 353

Beard ... $\ldots$... $\quad \ldots \quad 322$

Beard, short-faced _.. 353

Birmingham roller $\quad \ldots 317$

Blne, short-faced ... ... 352

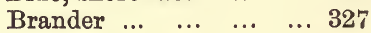

Brunswick beard ... $\quad \ldots \quad 326$

Coloured-tailed $\quad \ldots \quad \ldots 326$

$\begin{array}{lllll}\text { Colours of } & \ldots & \ldots & \ldots & 315\end{array}$

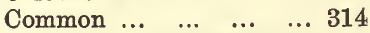

Common, a suitable breed to commence pigeon

$\begin{array}{llll}\text { keeping with } & \ldots & \ldots & 27\end{array}$

Double-crested ... ... 325

$\begin{array}{llllll}\text { Dutch } & \ldots & \ldots & \ldots & \ldots & 317\end{array}$

Exhibition $\quad \ldots . \quad \ldots \quad \ldots 315$

$\begin{array}{llllll}\text { Foreign } & \ldots & \ldots & \ldots & \ldots & 324\end{array}$

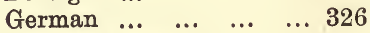

German ancient $\quad \ldots \quad \ldots \quad$.. 327

$\begin{array}{llllll}\text { Ground } & \ldots & \ldots & \ldots & \ldots & 312\end{array}$

$\begin{array}{llllll}\text { House } & \ldots & \ldots & \ldots & \ldots & 312\end{array}$

How and when to fly $\quad . .313$

Hungarian magpie $\quad . .327$ 


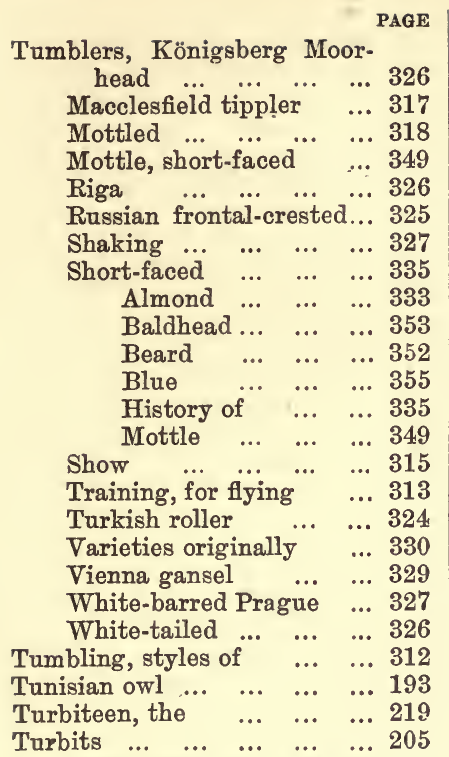

Description of, by Moore 191

Fancy points of ... ... 206

$\begin{array}{llllll}\text { Peaked } \ldots & \ldots & \ldots & \ldots & 211\end{array}$

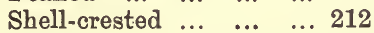

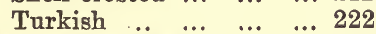

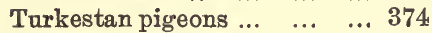

$\begin{array}{lllll}\text { Turkish Bagdads } & \ldots & \ldots & \ldots & 307\end{array}$

Frilled pigeons $\quad \ldots . \quad \ldots 212$

$\begin{array}{llllll}\text { Roller } & \ldots & \ldots & \ldots & \ldots & 324 \\ \end{array}$

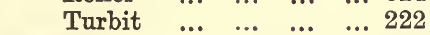

$\begin{array}{lllllll}\text { Turks } & \ldots & \ldots & \ldots & \ldots & \ldots & 304\end{array}$

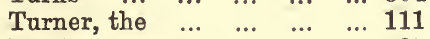

$\begin{array}{lllll}\text { Tyrolese pigeon } & \ldots & \ldots & \ldots & 85\end{array}$

\section{U.}

$\begin{array}{llllll}\text { Uploper, the } & \ldots & \ldots & \ldots & \ldots & 242\end{array}$ $\begin{array}{lllll}\text { Ural ice pigeon } & \ldots & \ldots & \ldots & 77\end{array}$

V.

Vandelli's description of pigeonflying at Modena
Variations in form $\quad \ldots \quad \ldots \quad 9$

Varieties of fancy pigeons :

African owl, the $\quad \ldots \quad \ldots 193$

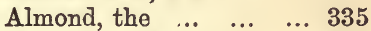

Runt, the... $\quad \ldots \quad \ldots \quad 142$

Altenburg trumpeter, the 151

Ancient, German, the ... 327

Annatalozia, the $\ldots{ }^{\prime} \ldots 102$

Antwerp carrier, the $\quad \ldots 357$

Long-faced, the ... 372

Medium-faced, the ... 373

Short-faced, the $\ldots 370$

Archangel, the $\quad$... $\quad \ldots .95$

Austrian klatcher, the ... 270

Azure blue, the $\quad \ldots \quad \ldots \quad 76$

Badge of Honour, the ... 78

Bagdad, Batavian, the ... 305

Batavian, lace feathered, the ... 306

Batavian, little, the 306

Carrier, the ... ... 294

Great wattled, the... 304

Mushroomed, the ... 304

Nürnberg, the ... ... 307

Short-faced Turkish, $\begin{array}{lllll}\text { the } & \ldots & \ldots & \ldots & 307\end{array}$

Turkish $\ldots \ldots \ldots$... 307

Baldhead tumbler, the ... 320

Tumbler, short-faced,

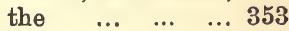

Barb, the $\quad \ldots \quad \ldots \quad \ldots 276$

Bavette, the $\ldots . \quad \ldots \quad \ldots .92$

Beard, Brunswick, the ... 326

London, the $\quad \ldots \quad \ldots 356$

Tumbler, the $\ldots \quad \ldots 322$

Tumbler, short-faced, the $\quad \ldots \quad \ldots \quad \ldots 353$

Bearded pigeon, the $\quad \ldots \quad 79$

Bengal pouter, the $\quad \ldots 271$

Birmingham roller, the ... 317

Blaze face, the $\quad . . \quad \ldots \quad 74$

Blondinette, black-laced, the $\quad \ldots \quad \ldots . \quad \ldots 216$

Blue, the ... $\quad \ldots \quad \ldots 218$

Brown, the $\quad \ldots \quad \ldots 217$

Satin, the $\quad \ldots . \quad \ldots 217$

Silver, the $\quad \ldots .2 . . .218$

Sulphur, the $\ldots$... 217

Blue Brunswick, the $\quad \ldots \quad 86$ 
Varieties of fancy pigeons :

Blue grizzled runt, the ... 142 Rock, the $\quad \ldots \quad 8,44$ Short-faced tumbler,

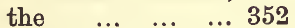

Bluette, the $\quad \ldots \quad \ldots \quad \ldots \quad \ldots 216$

Bohemian swallow, the ... 90

Bokhara trumpeter, the... 145

Brander tumbler, the $\quad . .327$

Breast, the $\quad \ldots \quad \ldots \quad \ldots \quad 75$

Breslau pouter, the $\quad$... 261

Bristle, the $\quad \ldots . \quad \ldots \quad$... 104

Brunette, the ... $\quad \ldots \quad \ldots 215$

Brünn pigmy pouter, the 273

Brunswick beard, the ... 326

Bullfinch, the ... $\quad \ldots \quad \ldots \quad . \quad 95$

Burmese, the ... $\quad \ldots \quad$... 159

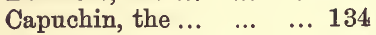

Carmelite, the... $\quad \ldots \quad$... 91

Carp-scale, the $\quad \ldots \quad \ldots 102$

Carrier, Antwerp, the $\ldots 357$

Bagdad, the $\ldots$... $^{294}$

English, the ... ... 282

Himalayan, the ... 309

Chinese dewlap, the $\quad \ldots 136$

Gull, the ... $\quad \ldots \quad \ldots 203$

Coloured breasted pigeon,

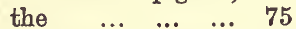

Headed pigeon, the 79

Tailed tumbler, the 326

Coral-eyed, the $\quad \ldots \quad \ldots 135$

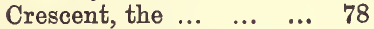

Cropper, Norwich, the ... 241

Pomeranian, the ...2 262

Stork, the $\quad \ldots \quad \ldots 275$

Cumulet, Continental, the 357

Curly Moor head, the ... 106

Dewlap, Chinese, the $\ldots 136$

Domino, the $\ldots$... $\quad \ldots 218$

Double-crested tumbler, the $\quad \ldots \quad \ldots \quad \ldots 325$

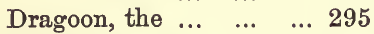

Drummer, the $\quad \ldots \quad \ldots 144$

Dutch balloon pouter, the 275

Pouter, the $\quad$... $\quad$... 269

Shell, the $\quad \ldots \quad \ldots 330$

Egyptian swift, the $\quad \ldots 107$

English carrier, the $\quad \ldots 282$

$\begin{array}{llll}\text { Fantail, the } & . . & \ldots & 164\end{array}$
Varieties of fancy pigeons :

PAGE

English fire pigeon, the ... 94

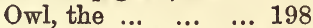

Pouter, the $\quad$... $\quad$... 223

Fantail, the $\quad \ldots \quad \ldots . \quad \ldots \quad 164$

Indian, the $\quad \ldots \quad \ldots 166$

Lace, the $\ldots$... $\quad \ldots \quad 173$

Finnikin, the $\ldots{ } \quad \ldots \quad \ldots 111$

Fire pigeon, the $\quad \ldots \quad \cdot \ldots \quad 94$

Pigeon, English, the 74

Florentine, the $\quad \ldots \quad \ldots 160$

Friesland runt, the $\quad \ldots 103$

Frillback, the ... $\quad \ldots \quad \ldots \quad 104$

Frizzled pigeon, the ... 103

Frontal-crested tumbler,

Russian, the ... ... 325

Gallinaceous pigeon, the 160

Gansel, Vienna, the $\quad . .329$

German ancient, the $\quad \ldots 327$

Pouter, old, the ...2 261

Goolee, the $\quad \ldots \quad$... $\quad \ldots \quad 125$

Mottled, the $\quad . . \quad \ldots \quad 125$

Greasy fairy, the $\ldots . \quad \ldots \quad 90$

Gull, black-backed, the... 142

Helmet, the $\quad$... $\quad$.. $\quad$... 334

Himalayan carrier, the ... 309

Homer, show, the $\ldots . \quad \ldots 366$

Horseman, the $\quad$.. $\quad . .295$

Hungarian magpie tumbler, the $\quad \ldots \quad \ldots 327$

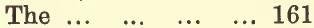

Hyacinth, the $\ldots . \quad \ldots \quad \ldots \quad 99$

Speckled, the $\ldots . . .100$

Ice, the $\ldots \begin{array}{lllll} & \ldots & \ldots & \ldots & 76\end{array}$

Indian fantail, the ... $\quad \ldots \quad 166$

Italian owl, the $\quad . .2 \quad \ldots 203$

Jacobin, the $\quad \ldots \quad \ldots \quad \ldots 175$

Königsberg Moorhead, $\begin{array}{lllll}\text { the } & \ldots & \ldots & \ldots & 326\end{array}$

Lace fantail, the $\ldots . \quad \ldots, 173$

$\begin{array}{llllll}\text { The } & \ldots & \ldots & \ldots & \ldots & 105\end{array}$

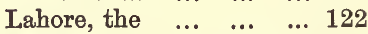

Lark, the $\ldots$...

Nürnberg, the $\quad \ldots .94$

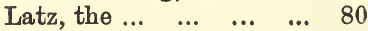

Shell, the $\quad \ldots \quad \ldots 80$

Laugher, the $\quad \ldots \quad \ldots \quad \ldots \quad \ldots 153$

Leghorn runt, the $\ldots . \quad \ldots \quad 157$

Lille pouters $\ldots{ } \ldots$ 
Varieties of fancy pigeons :

London beard, the ... ... 356

Long-faced Antwerp, the 372

Lowtan, the $\quad \ldots \quad \ldots \quad \ldots l 126$

Macclesfield tippler, the 317

Magpie, the $\quad \ldots \quad$...

Mahomet, the $\ldots \quad \ldots \quad \ldots \quad 131$

Maltese, the $\quad \ldots . \quad \ldots \quad \ldots l 160$

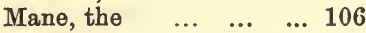

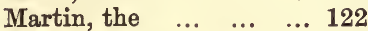

$\begin{array}{lllll}\text { Meal, the } \ldots & \ldots & \ldots & \ldots & 76\end{array}$

Medium-faced Antwerp,

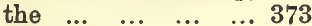

Miroité, the $\quad \ldots \quad \ldots \quad \ldots \quad \ldots 98$

Monk, the $\quad \ldots \quad$...

Montauban, the $\quad \ldots \quad \ldots 141$

Monteneur, the $\quad \ldots . \quad \ldots l 162$

Mookee, the $\quad \ldots \quad \ldots \quad \ldots l 123$

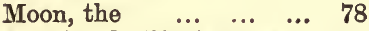

Moorhead, Königsberg, the $\quad \ldots \quad \ldots \quad \ldots 326$

Mottle short-faced tumbler, the $\quad \ldots \quad \ldots 349$

Tumbler, the $\quad \ldots \quad \ldots 318$

$\begin{array}{lllll}\text { Moulter, the } & \ldots & . . & \ldots & 87\end{array}$

Mourning, the... $\quad \ldots \quad$... 82

Norwegian, the $\quad \ldots \quad \ldots 141$

Norwich cropper, the $\ldots 241$

Nun, the $\ldots{ } \quad \ldots \quad \ldots \quad \ldots 330$

Nürnberg lark, the $\quad \ldots \quad 94$

Swallow, the $\quad \ldots \quad \ldots \quad . \quad 90$

Owl, African, the $\quad \ldots \quad \ldots 193$

English, the $\quad \ldots \quad \ldots 198$

Italian, the $\quad \ldots \quad \ldots 293$

Tunisian, the $\ldots{ }^{\prime} \quad \ldots \quad 193$

Whiskered, the $\quad . .203$

Pearl, the $\quad \ldots \quad$... $\quad \ldots$ 104

Piedmont, the $\quad \ldots \quad \ldots 160$

Pigmy pouter, pied, the ... 253

$\begin{array}{lllll}\text { Pilferer, the } & \ldots & \ldots & \ldots & 87\end{array}$

Polish lynx, the $\ldots . \quad \ldots 101$

Pomeranian cropper, the 262

Porcelain, the ... $\quad \ldots \quad 77,100$

Pouter, cavalier, the $\ldots 259$

English, the $\quad \ldots \quad \ldots 223$

Lille, the $\quad \ldots \quad \ldots 258$

Old German, the ...261

Pigmy, pied, the ... 253

Pomeranian, the ...2 262
Varieties of fancy pigeons :

Pouter, Saxon, the _..2 269

Pouting horseman, the 242,251

Prague magpie pouter, the 270

Pigmy pouter, the ... 275

Priest, the $\quad \ldots \quad \ldots \quad \ldots \quad 85$

Printed tippler, the $\quad \ldots 317$

Red Indian, the $\quad \ldots \quad \ldots 102$

Riga tumbler, the ... $\quad \ldots 326$

Ringbeater, the $\quad \ldots \quad \ldots l 11$

Rock, the $\quad \ldots \quad \ldots \quad 44,70$

Roller, Birmingham, the 317

Turkish, the $\quad . . \quad \ldots 324$

Roman runt, the $\ldots . . . .141$

Runt, the $\quad$... $\quad$... $\quad \ldots \quad 138$

Friesland, the ... 103

Leghorn, the ... $\quad . .1157$

Norwegian, the ... 141

Smyrna, the $\quad \ldots \quad$... 142

Spanish, the $\ldots{ }^{\prime} \quad \ldots 138$

Russian frontal - crested tumbler, the $\quad . .325$

Trumpeter, the $\quad \ldots \quad 145$

Satinette, the $\quad \ldots \quad \ldots 214$

Saxon, the $\quad \ldots \quad \ldots \quad \ldots \quad 75$

Pouter, the $\quad . .2 \quad \ldots 269$

Swallow, the $\ldots . . .990$

Scanderoon, the $\quad \ldots \quad \ldots 307$

Shaking tumbler, the ... 327

Sherajee, the ... $\quad \ldots . \quad \ldots \quad 120$

Mottled, the $\quad . . \quad \ldots \quad 121$

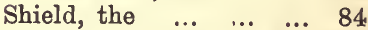

Short-faced Antwerp, the 370

Tumbler, the ... $\quad . .335$

Siberian ice, the $\quad \ldots \quad \ldots \quad 77$

Silesian swallow, the $\quad \ldots \quad 90$

Silken-haired pigeon, the 105

Silverette, the $\quad \ldots \quad \ldots 216$

Skinnum, the ...

Smerle, the $\quad \ldots \quad \ldots \quad \ldots \quad$... 357

Smiter, the $\quad \ldots \quad \ldots . \quad \ldots l 111$

Smyrna runt, the $\quad \ldots \quad \ldots 142$

Soot, the $\ldots \begin{array}{lllll} & \ldots & \ldots & \ldots & 76\end{array}$

Spanish runt, the $\ldots{ }^{\prime} \quad \ldots 138$

Sparkling fawn-coloured swallow, the $\quad$... 89

Speckled hen, the $\ldots . \quad \ldots \quad 161$

Hyacinth, the ... $\quad . .100$

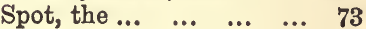


Varieties of fancy pigeons :

Spot, white, the $\quad \ldots \quad$... 74

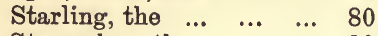

Stomacher, the $\quad \ldots \quad \ldots \quad 80$

Stork, the $\quad \ldots \quad \ldots . \quad \ldots \quad 92$

Cropper, the $\quad \ldots . \quad \ldots 275$

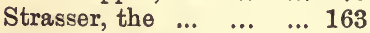

Suabian, the $\quad \ldots \quad$... $\quad \ldots \quad 82$

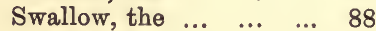

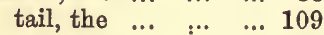

Swiss, the $\quad \ldots \quad$..

Tailor, the $\quad \ldots \quad \ldots \quad \ldots l 122$

Tippler, Macclesfield, the 317 printed, the $\quad \ldots \quad \ldots 317$

Triganica, the $\quad$.. $\quad . .1115$

Trumpeter, the $\quad \ldots \quad \ldots \quad 144$ Altenburg, the ... 151 Bokhara, the ... $\quad \ldots \quad 145$ Russian, the ... ... 145

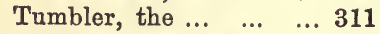
Short-faced, the $\ldots 335$

Tunisian owl, the ... $\ldots 193$

Turbiteen, the $\quad \ldots \quad \ldots 219$

Turbit, the $\quad \ldots \quad \ldots . \quad \ldots 205$

Tures

$\begin{array}{llll}\text { Turkestan pigeons } & \ldots & \mathbf{3 7 4} \\ & & \end{array}$

Turkish Bagdad, the ... 307 Roller, the $\quad . . . \quad \ldots .324$

$\begin{array}{lllll}\text { Turbit } & \ldots & \ldots & \ldots & 222\end{array}$

Turner, the $\quad \ldots \quad$...

Tyrolese, the ... $\quad \ldots . \quad \ldots \quad 85$

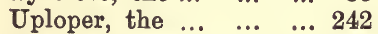

Ural ice, the $\ldots . . . . \quad \ldots .77$

Veiled, the $\quad \ldots \quad \ldots \quad \ldots \quad \ldots \quad 79$

Velvet fairy, the $\ldots . \quad \ldots \quad 90$

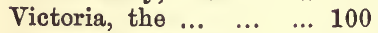

Vienna gansel, the $\ldots 329$

Vizor, the $\quad \ldots \quad \ldots . \quad \ldots 219$

Voyageur, Belgian, the ... 357

Whiskered owl, the $\quad \ldots 203$

White-barred Prague tumbler, the $\quad . .327$

$\begin{array}{llll}\text { Whitehead, the } & \ldots & \ldots & 87\end{array}$

White spot, the $\quad \ldots . \quad \ldots .74$

White-tailed tumbler, the 326

$\begin{array}{lllll}\text { Wing, the } & \ldots & \ldots & \ldots & 92\end{array}$

Yarkand pigeons $\quad . . . \quad \ldots 374$

$\begin{array}{lllll}\text { Veiled pigeon ... } & \ldots & \ldots & \ldots & 79\end{array}$
PAGE

$\begin{array}{llll}\text { Velvet fairy pigeon } & \ldots & \ldots & 90\end{array}$

$\begin{array}{lllllll}\text { Vertigo } & \ldots & \ldots & \ldots & \ldots & \ldots & 65\end{array}$

$\begin{array}{lllll}\text { Vicious pigeons } & \ldots & \ldots & \ldots & 27\end{array}$

Victoria pigeon $\quad \ldots \quad \ldots \quad \ldots 100$

Vienna bodice pigeon $\quad . . . \quad \ldots \quad 80$

Vizor, the $\quad \ldots \quad \ldots \quad \ldots \quad \ldots \quad \ldots 219$

Voice, pigeons of peculiar:

Altenburg trumpeter ... 151

Bokhara trumpeter ... 145

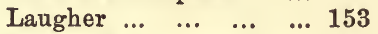

Russian trumpeter ... 145

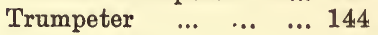

$\begin{array}{llll}\text { Voyageur, Belgian } & \ldots & \ldots & 357\end{array}$

W.

$\begin{array}{lllll}\text { Walking pens } & \ldots & \ldots & \ldots & 54\end{array}$

Wall boxes $\quad \ldots \quad \ldots . \quad \ldots \quad \ldots \quad 14$

Boxes, disadvantage of... 14

$\begin{array}{lllllll}\text { Water } & \ldots & \ldots & \ldots & \ldots & \ldots & 33\end{array}$

$\begin{array}{llllll}\text { Bathing } & \ldots & \ldots & \ldots & \ldots & 33\end{array}$

$\begin{array}{lllllll}\text { Bottle } & \ldots & \ldots & \ldots & \ldots & \ldots & 19\end{array}$

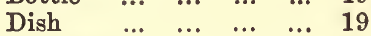

$\begin{array}{lllll}\text { Fountains } & \ldots & \ldots & \ldots & 18\end{array}$

Wattled pigeons :

Bagdad carrier $\quad \ldots \quad \ldots 294$

$\begin{array}{llllll}\text { Barb } \quad \ldots & \ldots & \ldots & \ldots & 276\end{array}$

Batavian Bagdad ... ... 305

Dragoon ... $\quad \ldots \quad \ldots . \quad \ldots 295$

$\begin{array}{llll}\text { English carrier } & \ldots & \ldots & 282\end{array}$

$\begin{array}{llllll}\text { Foreign } & \ldots & \ldots & \ldots & \ldots & 304\end{array}$

French Bagdads ... ... 304

German Bagdads $\ldots . \quad \ldots 307$

Great wattled, or mushroomed Bagdad ... ... 304

Himalayan carrier ... . .. 309

Lace-feathered Batavian $\begin{array}{lllll}\text { Bagdad } \quad \ldots & \ldots & \ldots & 306\end{array}$

Little Batavian Bagdad 306

Nürnberg Bagdad ... ... 307

Short-faced Turkish Bag. $\begin{array}{llllll}\text { dad } & \ldots & \ldots & \ldots & \ldots & 307\end{array}$

$\begin{array}{lllll}\text { Turkish Bagdads } & \ldots & \ldots & \ldots & 307\end{array}$

$\begin{array}{llllll}\text { Turks } & \ldots & \ldots & \ldots & \ldots & 304\end{array}$

$\begin{array}{llllll}\text { Wen, flesh } & \ldots & \ldots & \ldots & \ldots & 60\end{array}$

Whiskered owl $\quad \ldots \quad \ldots . \quad \ldots 203$ 
White-barred Prague tumbler 327

$\begin{array}{llll}\text { Whitehead pigeon ... } & \ldots & \ldots & 87\end{array}$

White-tailed tumbler $\quad$... $\quad . .326$

$\begin{array}{lllll}\text { Whole colours } & \ldots & \ldots & \ldots & 47\end{array}$

Wild blue rock, the $\quad \ldots \quad \ldots \quad 44$

Willughby's "Ornithology" 383

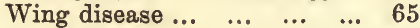

$\begin{array}{llllll}\text { Pigeon } & \ldots & \ldots & \ldots & \ldots & 92\end{array}$

Pigeons that look best on

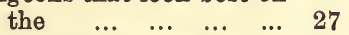

Woodhouse's, $\mathrm{Mr}_{\text {r., baldpate... }} 10$

Works, minor, in which fancy pigeons are mentioned 392

Wright's (Lewis) "Practical

Pigeon Keeper" ... 405

X.

$\begin{array}{llllll}\text { Xenophon } & \ldots & \ldots & \ldots & \ldots & 3\end{array}$

$\mathrm{Y}$.

Yarkand pigeons $\quad \ldots \quad \ldots \quad \ldots 374$

Young fanciers, pigeons for ... 27

$\begin{array}{llllll}\text { Pigeons } & \ldots & \ldots & \ldots & \ldots & 39\end{array}$

$\begin{array}{llll}\text { Pigeons, sex of } & \ldots & \ldots & 41\end{array}$

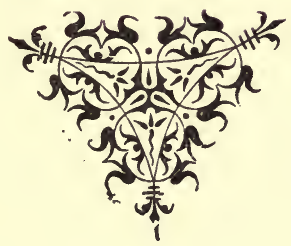




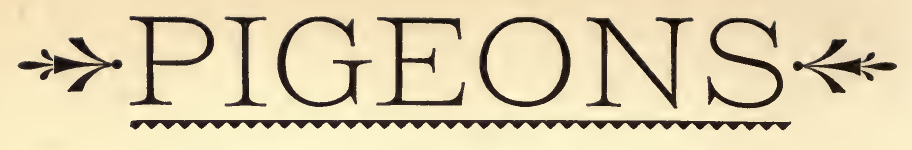

OF EVERY DESCRIPTION, FROM

\section{MOMERS}

TO

\section{GERMAN TOYS,}

Are obtained or disposed of, in the easiest manner, and on the most favourable terms, through the medium of THE BAZAAR, EXCHANGE AND MART, price $2 \mathrm{~d}$. It may be obtained at any Bookseller's or Railway Stall, or from the Office in London.

In addition to the facilities for procuring or disposing of every description of personal property, THE BAZAAR gives a great deal of practical information on a large variety of subjects useful to Amateurs.

GET A COPY AND SEE FOR YOURSELF. 


\section{Catalogue of Practical Handbooks P.ublished ly L. Upcott Gill, I70,
Strand, London, W.C.}

ANGIFR, BOOK OI THE AII-ROUND. A Comprehensive Treatise on Angling in both Fresh and Salt Water. In Four Divisions, as named below. By JонN BICKERDYKE. With over 220 Engravings. In cloth, price 5s. 6d., by post 6s. (A few copies of a LARGE PAPER EDITron, bound in Roxburghe, price 25s.)

Angling for Coarse Fish. Bottom Fishing, according to the Methods in use on the Thames, Trent, Norfolk Broads, and elsewhere. Illustrated. In paper, price 1s., by post 1s. 2d.; cloth, 2s. (uncut), by post $2 s .3 d$.

Angling for Pike. The most Approved Methods of Fishing for Pike or Jack. Profusely Illustrated. In paper, price 1s., by post 1s. $2 d$. ; cloth, $2 s$. (uncut), by post $2 s .3 d$.

Angling for Game Fish. The Various Methods of Fishing for Salmon: Moorland, Chalk-stream, and Thames Trout; Grayling and Char. Well Illustrated. In paper, price 1s. 6d., by post 1s. 9d.; cloth, 2s. 6d. (uncut), by post $2 s 9 d$.

Angling in Salt Water. Sea Fishing with Rod and Line, from the Shore, Piers, Jetties, Rocks, and from Boats; together with Some Account of Hand-Lining. Over 50 Engravings. In paper, price 1s., by post 1s. $2 d$.; cloth, $2 s$. (uncut), by post $2 s .3 d$.

AQUARIA, BOOK OF. A Practical Guide to the Construction, Arrangement, and Management of Fresh-water and Marine Aquaria; containing Full Information as to the Plants, Weeds, Fish, Molluscs, Insects, \&c., How and Where to Obtain Them, and How to Keep Them in Health. Illustrated. By Rev. Gregory C. BatemaN, A.K.C., and Reginald A. R. Bennett, B.A. In cloth gilt, price 5s. 6d., by post 5s. 10d.

AQUARIA, FRFSIW ATIR: Their Construction, Arrangement, Stocking, and Management. Fully Illustrated. By REv. G. C. BATEMAN, A.K.C. In cloth gilt, price 3s. 6d., by post 3s. $10 d$.

AQUARIA, MARINE : Their Construction, Arrangement, and Manage. ment. Fully Illustrated. By R. A. R. BENNETT, B.A. In cloth gilt, price $2 s .6 d$., by post $2 s .9 d$.

AUSTRAIIA, SHAII I TRY ? A Guide to the Australian Colonies for the Emigrant Settler and Business Man. With two Illnstrations. By GEORGE LACON JAMEs. In cloth gilt, price 3s. 6d., by post 3s. $10 d$.

AUTOGRAPH COTIFCTING: A Practical Manual for Amateurs and Historical Students, containing ample information on the Selection and Arrangement of Autographs, the Detection of Forged Specimens, \&c., \&c., to which are added numerous Facsimiles for Study and Reference, and an extensive Valuation Table of Autographs worth Collecting. By HenRY T. ScotT, M.D., L.R.C.P., \&c., Rector of Swettenham, Cheshire. In leatherette gilt, price $7 s$. 6d., by post 7s. 10d.

BFHS AND BEF-TERPING: Scientific and Practical. By F. R. Cheshrre, F.I.S., F.R.M.S., Lecturer on Apiculture at South Kensington. In two vols., cloth gilt, price $168 .$, by post $16 s$. 4 . 
Vol. I., Scientific. A complete Treatise on the Anatomy and Physiology of the Hive Bee. In cloth gilt, price 7s. 6d., by post.7s. $10 d$.

vol. II., Practical Management of Bees. An Exhaustive Treatise on Advanced Bee Culture. In cloth gilt, price 8s. 6d., by post 8s. $10 d$.

BEE-KEEPING, BOOK OF. A very practical and Complete Manual on the Proper Management of Bees, especially written for Beginners and Amatenrs who have but a few Hives. Fully Illustrated. By W. B. Webster, First-class Expert, B.B.K.A. In paper, price 1s., by post $18.2 d$; cloth, $18.6 d$., by post $1 s .8 d$.

BEGONIA CUITURE, for Amateurs and Professionals. Containing Full Directions for the Successful Cultivation of the Begonia, under Glass and in the Open Air. Illustrated. By B. C. RAVEnscroft. In paper, price 1 s., by post $1 s .2 d$.

BENT IRON WORK: A Practical Manual of Instruction for Amateurs in the Art and Craft of Making and Ornamenting Light Articles in imitation of the beautiful Mediæval and Italian Wrought Iron Work. By F. J. Erskine. Illustrated. In paper, price 1s., by post 1s. $2 d$.

BOAT BUILDING AND SAIIING, PRACTICAI. Containing Full Instructions for Designing and Building Punts, Skiffs, Canoes, Sailing Boats, \&c. Particulars of the most suitable Sailing Boats and Yachts for Amateurs, and Instructions for their Proper Handling. Fally Illustrated with Designs and Working Diagrams. By ADRIAN NeIson, C.E., Dixon Krimp, A.I.N.A., and G. Christopher Davies. In one vol., cloth gilt, price 7s. $6 d$., by post 78. $10 d$.

BOAT BUIIDING FOR AMATEURS, PRACTICAL. Contain. ing Full Instructions for Designing and Building Punts, Skiffs, Canoes, Sailing Boats, \&c. Fully Illustrated with Working Diagrams. By Adrian Neison, C.E. Second Edition, Revised and Enlarged by Dixon KEMP, Author of "Yacht Designing," "A Manual of Yacht and Boat Sailing," \&c. In cloth gilt, price 2s. 6d., by post $2 s .9 d$.

BOAT SAIIING FOR AMATEURS. Containing Particulars of the most Suitable Sailing Boats and Yachts for Amateurs, and Instructions for their Proper Handling, \&c. Illustrated with numerous Diagrams. By G. Christopher Davies. Second Edition, Revised and Enlarged, and with several New Plans of Yachts. In cloth gilt, price 5s., by post $5 s .4 d$.

BOOKBINDING FOR AMATEURS: Being Descriptions of the varinus Tools and Appliances Required, and Minute Instructions for their Effective Use. By W. J. E. CRANE. Illustrated with 156 Engrav. ings. In cloth gilt, price 2s. $6 d$., by post $28.9 d$.

BUNKUM FNTERTAINMENTS: A Collection of Original Laughable Skits on Conjuring, Physiognomy, Juggling, Performing Fleas, Waxworks, Panorama, Phrenology, Phonograph, Second Sight; Lightning Calculators, Ventriloquism, Spiritualism, \&c., to which are added Humorous Sketches, Whimsical Recitals, and Drawing-room Comedies. In cloth, price 2s. 6d., by post $2 s .9 d$.

BUTTERFIIES, THE BOOK OF BRITISH: A Practical Manual for Collectors and Naturalists. Splendidly Illustrated through. out with very accurate Engravings of the Caterpillars, Chrysalids, and Butterflies, both upper and under sides, from drawings by the Author or direct from Nature. By W. J. Lucas, B.A. Price 3s.6d., by post 3s. $9 d$. 
BUTTERTY AND MOTH COLLECTING: Where to Search, and What to Do. By G. E. Simms. Illustrated. In paper, price 1s., by post 18. $2 d$.

CACTUS CUITURF FOR AMATrERS: Being Descriptions of the various Cactuses grown in this country; with Full and Practical Instructions for their Successful Cultivation. By W. Watson, Assistant Curator of the Royal Botanic Gardens, Kew. Profusely Illustrated. In cloth gilt, price 58., by post 5s. $3 d$.

CAGP BIRDS, DISEASES OF : Their Causes, Symptoms, and Treatment. A Handbook for everyone who keeps a Bird. By DR. W. T. GREeNE, F.Z.S. In paper, price 1s., by post $18.2 d$.

CAGE BIRDS, BRITISH. Containing Full Directions for Successfully Breeding, Rearing, and Managing the various British Birds that can be kept in Confinement. Illustrated with COLOURED PLATES and numerous finely-cut Wood Engravings.. By R. L. WALlace. In cloth gilt, price 10s. 6d., by post 10s. 10d.

CANARY BOOK. Full Directions for the Breeding, Rearing, and Management of all Varieties of Canaries and Canary Mules, and all other matters connected with this Fancy. By ROBERT L. WALLACE. Third Edition. In cloth gilt, price 5s., by post 5s. 4d.; with COLOURED PLATES, 6s. 6d., by post 6s. 10d.; and in Sections as follows:

General Management of Canaries. Cages and Cage-making, Breeding, Managing, Mule Breeding, Diseases and their Treatment, Moulting, Pests, \&c. Illustrated. In cloth, price 2s. 6d., by post $2 s .9 d$.

Fxhibition Canaries. Full Particulars of all the different Varieties, their Points of Excellence, Preparing Birds for Exhibition, Formation and Management of Canary Societies and Exhibitions. Illustrated. In cloth, price 2s. $6 d$., by post $2 s .9 d$.

CANOE BUILDING FOR AMATEURS: A Practical Manual, with Plans, Working Diagrams, and full Instructions. By Cotrerilu Scholefield. Price $2 s .6 d$., by post $2 s .9 d$.

In the Press.

CARD TRICKS, BOOK OF, for Drawing-room and Stage Entertainments by Amateurs; with an exposure of Tricks as practised by Card Sharpers and Swindlers. Numerous Mlustrations. By PrOF. R. Kunard. In illustrated wrapper, price $2 s .6 d$., by post $2 s .9 d$.

CATS, DOMESTIC OR FANCY: A Practical Treatise on their Antiquity, Domestication, Varieties, Breeding, Management, reases and Remedies, Exhibition and Judging. By Jонn Jennings. Illustrated. In cloth, price $2 s .6 d$., by post $2 s .9 d$.

ChRYSANTHEMUM CUITURE, for Amateurs and Professionals. Containing Full Directions for the Successful Cultivation of the Chrysanthemum for Exhibition and the Market. Illustrated. By B. C. RAVENSCROFT. In paper, price $1 s$., by post $18.2 d$.

COINS, A GUIDE TO ENGIISH PATTERN, in Gold, Silver, Copper, and Pewter, from Edward I. to Victoria, with their Value. By the Rev. G. F. CROwTHer, M.A. Illustrated. In silver cloth, with gilt facsimiles of Coins, price 5s., by post 5s. $3 d$.

COINS OF GREAT BRITAIN AND IRELAND, A GUIDE TO THE, in Gold, Silver and Copper, from the Earliest Period to the Present Time, with their Value. By the late Colonel W. StewakT 
Thorburn. With 27 Plates in Gold, Silver, and Copper, and 8 Plates of Goid and Silver Coins in RAISED FACSIMILE. In cloth, with silver facsimiles of Coins, price 7s. 6d., by post 7s. $10 d$.

COIIIs, THE. Its History, Points, and Breeding. By Hugh Dalzier. Illustrated with Coloured Frontispiece and Plates. In paper, price 1s., by post 1s. $2 d$.; cloth, $2 s$., by post $2 s .3 d$.

COTIIE STUD BOOK. Edited by HUGH Dalzirl. Price $3 s .6 d$. each, by post 3s. $9 d$. each.

Vol. I., containing Pedigrees of 1308 of the best-known Dogs, traced to their most remote known ancestors ; Show Record to Feb., 1890, \&c.

Vol. II. Pedigrees of 795 Dogs, Show Record, \&c.

Vol. III. Pedigrees of 786 Dogs, Show Record, \&c.

COLUMBARIUM, MOORE'S. Reprinted Verbatim from the original Edition of 1735, with a Brief Notice of the Author. By W. B. TEGETMEIER. F.Z.S., Member of the British Ornithologists' Union. Price 1s., by post $1 s .2 d$.

CONJURING, BOOK OF MODERN. A Practical Guide to Drawing. room and Stage Magic for Amateurs. By Profressor R. KUNARD. Illustrated. In illustrated wrapper, price $2 s .6 d$., by post $2 s .9 d$.

COOKFRY FOR AMATEURS; or, Frenoh Dishes for English Homes of all Classes. Includes Simple Cookery, Middle-class Cookery, Superior Cookery, Cookery for Invalids, and Breakfast and Luncheon Cookery. By Madame ValéRIE. Second Edition. In paper, price 1s., by post 1s. 2 d.

CUCUMBER CULTURE FOR AMATEURS. Including also Melons, Vegetable Marrows, and Gourds. Illustrated. By W. J. MAr. In paper, price 1s., by post 1s. $2 d$.

CYCLES OF 1893, with Special Chapters on Tyres and Accessories. By Charles W. Hartung (Stanley Cycling Club). Illustrated. In paper, price 1s., by post 1s. $2 d$.

CYCIIST'S ROUTE MAP of England and Wales. The Third Edition; thoroughly Revised. Shows clearly all the Main, and most of the Cross, Roads, and the Distances between the Chief Towns, as well as the Mileage from London. In addition to this, Routes of Thirty of the most Interesting Tours are printed in red. The map is mounted on linen, and is the fullest, handiest, and best tourist's map in the market. In cloth, price 1s., by post $1 s .2 d$.

DOGS, BREAKING AND TRAINING: Being Concise Directions for the proper education of Dogs, both for the Field and for Companions. Second Edition. By "PATHFinder." With Chapters by HuGH Dalziel. Mlustrated. In cloth gilt, price 6s. 6d., by post 6s. $10 d$.

DOGS, BRITISH, ANCIENT AND MODERN : Their Varieties, History, and Characteristics. By HoGH DALZIEL, assisted by Eminent Fanciers. SECOND EDITION, Revised and Enlarged. Illustrated with First-class COLOURED PLATES and full-page Engravings of Dogs of the Day. This is the fullest work on the various breeds of dogs kept in England. In three volumes, demy $8 v$, cloth gilt, price 10s. 6d. each, by post 11s. 1d. each.

Dogs Used in Field Sports. Containing Particulars of the following among other Breeds: Greyhound, Irish Wolfhound, Bloodhound, Foxhound, Harrier, Basset, Dachshund, Pointer, Setters, Spaniels, and Retrievers. Seven Colodred Plates and 21 full-page Engravings. 
Dogs Useful to Man in other Work than Field Sports; House and Toy Dogs. Containing Particulars of the following, among other Breeds: Collie, Bulldog, Mastiff, St. Bernards, Newfoundland, Great Dane, Fox and all other Terriers, King Charles and Blenheim Spaniels, Pug, Pomeranian, Poodle, Italian Greyhound, Toy Dogs, \&c., \&c. Coloured Plates and full-page Engravings.

Practical Kennel Management: A Complete Treatise on all Matters relating to the Proper Management of Dogs, whether kept for the Show Bench, for the Field, or for Companions. Illustrated with Coloured and numerous other Plates.

[In the Press.

DOGS, DISEASES OF: Their Causes, Symptoms, and Treatment; Modes of Administering Medicines; Treatment in cases of Poisoning, \&c. For the nse of Amateurs. By Hugh Dalzier. Third Edition. In paper, price $1 s$. , by post $1 s .2 d$. ; in cloth gilt, $2 s$. , by post $2 s .3 d$.

FNTERTAINMENTS, AMATEUR, FOR CHARITABIE AND OTHER OBJECTS: How to Organize and Work them with Profit and Success. By RoBert GANTHONY. In coloured cover, price 1s., by post 1 s. $2 d$.

FANCY WORK SERIFS, ARTISTIC. A Series of mlustrated Manuals on Artistic and Popular Fancy Work of various kinds. Each number is complete in itself, and issued at the uniform price of $6 d ., b y$ post $7 d$. Now ready-(1) Macramé Lace (Second Edition); (2) Patchwork; (3) Tatting; (4) Crewel Work; (5) Appliqué; (6) Fancy NetTina.

FERNS, THE BOOK OF CHOICE: for the Garden, Conservatory, and Stove. Describing the best and most striking Ferns and Selaginellas, and giving explicit directions for their Cultivation, the formation of Rockeries, the arrangement of Ferneries, \&c. By GEORGE Schneider. With numerous Coloured Plates and other Illustrations. In 3 vols., large post 4to. Cloth gilt, price $£ 33 s .$, by post $£ 36 s$.

FERIS, CHOICE BRITISH. Descriptive of the most beantiful Variations from the common forms, and their Culture. By C. T. DruerY, F.L.S. Very accurate PLATES, and other Illustrations. In cloth gilt, price $2 s .6 d$., by post $2 s .9 d$.

FERRETS AND FERRETING. Containing Instructions for the Breeding, Management, and Working of Ferrets. Second Edition, Rewritten and greatly Enlarged. Illustrated. In paper, price 6d., by post $7 d$.

FERTIITY OF FGGS CERTIFICATE. These are Forms of Guarantee given by the Sellers to the Buyers of Eggs for Hatehing, undertaking to refund value of any unfertile eggs, or to replace them with good ones. Very valuable to sellers of eggs, as they induce purchases. In books, with counterfoils, price $6 d$., by post $7 d$.

FIREWORK-MAKING FOR AMATEURS. A complete, accurate, and easily-understood work on Making Simple and High-class Fireworks. By Dr. W. H. Browne, M.A. In paper, price $2 s .6 d$., by post $2 s .9 d$.

FOREIGN BIRDS, FAVOURITE, for Cages and Aviaries. How to Keep them in Health. Fully Illustrated. By W. T. Greane, M.A., M.D., F.Z.S., \&c. In cloth, price $2 s .6 d$., by post $2 s .9 d$.

FOX TERRIER, THz. Its History, Points, Breeding, Rearing, Preparing, for Exhibition, and Coursing. By HU⿳H口⺝ Dalziel. Illustrated with Coloured Frontispiece and Plates. In paper, price 18., by post $1 s .2 d$.; cloth, $2 s .$, by post $2 s .3 d$. 
FOX TERRIFR STUD BOOK. Edited by HUGH DalzIel. Price 3s. 6d. each., by post 3s. $9 d$. each.

Vol. I., containing Pedigrees of over 1400 of the best.known Dogs, traced to their most remote known ancestors.

Vol. II. Pedigrees of 1544 Dogs, Show Record, \&c.

Vol. III. Pedigrees of 1214 Dogs, Show Record, \&c.

Vol. IV. Pedigrees of 1168 Dogs, Show Record, \&c.

Vol. V. Pedigrees of 1662 Dogs, Show Record, \&c.

FRETWORK AND MARQUETERIF. A Practical Manual of Instructions in the Art of Fret-cutting and Marqueterie Work. By D. Denning. In paper, price 1s., by post 1s. $2 d$. [In the Press.

FRIFSLAND MERES, A CRUISE ON THE. By ERNest R. SUFFling. Illustrated from Photos and Special Drawings. In paper, price. $1 s$., by post $1 s .2 d$.

GAME AND GAME SHOOTING, NOTES ON. Miscellaneous Observations on Birds and Animals, and on the Sport they afford for the Gun. in Great Britain, including Grouse, Partridges, Pheasants, Hares, Rabbits, Quails, Woodcocks, Snipe, and Rooks. By J. J. MANlex, M.A. Illustrated. In cloth gilt, price 7s. 6d., by post 7s. $10 d$.

GAME PRESFRVING, PRACTICAI. Containing the fullest Directions for Rearing and Preserving both Winged and Ground Game, and Destroying Vermin; with other Information of Value to the Game Preserver. Illustrated. By William Carnegie. In cloth gilt, demy $8 v o$, price 21s., by post $21 s$. $9 d$.

GARDENING, DICTIONARY OF. A Practical Encyclopædia of Horticulture, for Amateurs and Professionals. Illustrated with 2440 Engravings. Edited by G. NICHolson, Curator of the Royal Botanic Gardens, Kew ; assisted by Prof. Trail, M.D., Rev. P. W. Myles, B.A., F.L.S., W. Watson, J. Garrett, and other Specialists. In 4 vols., large post 4to. In cloth gilt, price £3, by post £3 3 s.

GOAT, BOOK OF THE. Containing Full Particulars of the various Breeds of Goats, and their Profitable Management. With many Plates. By H. Stephen Holmes Prgler. Third Edition, with Engravings and Coloured Frontispiece. In cloth gilt, price 4s. 6d., by post 4s. $10 d$.

GOAT-KFEPING FOR AMATEURS: Being the Practical Manage. ment of Goats for Milking Purposes. Abridged from "The Book of the Goat." Illustrated. In paper, price 1s., by post $1 s .2 d$.

GRAPE GROWING FOR AMATEURS. A Thoroughly Practical Book on Successful Vine Culture. By E. Molynedx. Illustrated. In paper, price 18. , by post $1 s .2 d$.

GREFNHOUSE MANAGEMENT FOR AMATEURS. Descriptions of the Best Greenhouses and Frames, with Instructions for Building them, particulars of the various methods of Heating, Illustrated Descriptions of the most. suitable Plants, with general and Special Cultural Directions, and all necessary information for the Guidance of the Amateur. Second Edition, Revised and Enlarged. Magnificently Illustrated. By W. J. MAY. In cloth gilt, price 5s., by post 5s. $4 d$.

GREYHOUND, THE: Its History, Points, Breeding, Rearing, Training, and Running. By Hogr Dalziex. With Coloured Frontispiece. In cloth gilt, demy 8vo, price $2 s .6 d$., by post $2 s .9 d$.

GUINEA PIG, THE, for Food, Fur, and Fancy. Illustrated with Coloured Frontispiece and Engravings. An exhaustive book on the Varieties of the Guinea Pig, and its Management. By C. Comberland, F.Z.S. In cloth gilt, price 2s. $6 d$., by post $2 s .9 d$. 
HAND CAMERA MANUAI, IrI. A Practical Handbook on all Matters connected with the Use of the Hand Camera in Photography. Illastrated. By W. D. Welford. Price 1s., by post $1 s .2 d$.

HANDWRITING, CHARACTER INDICATYD BY. With Illus. trations in Support of the Theories advanced taken from Autograph Letters of Statesmen, Lawyers, Soldiers, Ecclesiastics, Anthors, Poets, Musicians, Actors, and other persons. Second Edition. By R. BAUghan. In cloth gilt, price 2s. 6d., by post 2s. $9 d$.

FARDT PERENTIAIS and Old-fashioned Garden Flowers. Descriptions, alphabetically arranged, of the most desirable Plants for Borders, Rockeries, and Shrubberies, including Foliage as well as Flowering Plants. Profusely Illustrated. By J. WooD. In cloth, price 5s., by post 5s. $4 d$.

HOMF MFDICINY AND SURGFRY: A Dictionary of Diseases and Accidents, and their proper Home Treatment. For Family Use. By W. J. Mackenzie, M.D., Medical Officer for Lower Holloway, Medical Referee for North London of the Scottish Provincial Assurance Company, late Lecturer to the St. John's Ambulance Association, Author of the "Medical Management of Children," \&c. Illustrated. In cloth, price $2 s .6 d$., by post $2 s .9 d$.

HORSE-KFEP ER, THE PRACTICAI. By George Flemina, C.B., LL.D., F.R.C.V.S., late Principal Veterinary Surgeon to the British Army, and Ex-President of the Royal College of Veterinary Surgeons. In cloth, price $3 s, 6 d$., by post $3 s, 10 d$.

HORSE-KEFPING FOR AMATEURS. A Practical Manual on the Management of Horses, for the guidance of those who keep one or two for their personal nse. By Fox Russelu. In paper, price 1s., by post 1s. $2 d$.; cloth, $2 s .$, by post $2 s .3 d$.

HORSFS, DISFASFS OF: Their Causes, Symptoms, and Treatment. For the use of Amateurs. By HuGH Dalziel. In paper, price 1s., by post $1 s .2 d$. ; cloth $2 s$., by post $2 s .3 d$.

INTAND WATERING PIACES. A Description of the Spas of Great Britain and Ireland, their Mineral Waters, and their Medicinal Valne, and the attractions which they offer to Invalids and other Visitors. Profusely illustrated. A Companion Volume to "Seaside Watering Places.' In cloth, price $2 s .6$., by post $2 s .10 d$.

JOURNATISM, PRACIICAI : How to Enter Thereon and Succeed. A book for all who think of "writing for the Press." Ву Јонм DAwson. In cloth gilt, price $2 s .6 d$., by post $2 s .9 d$.

IAYING HENS, HOW TO KIFP and to Rear Chickens in Large or Small Numbers, in Absolnte Confinement, with Perfect Success. By MAJoR G. F. MoRANT. In paper, price $6 d$., by post $7 d$.

IFGAI PROFESSION, A GUIDE TO THE. A Practical Treatise on the various Methods of Entering either Branch of the Legal Profession; also a Course of Study for each of the Examinations, and selected Papers of Questions ; forming a Complete Gaide to every Department of Legal Preparation. By J. H. Sistrer, Barrister-at-Law, of the Middle Temple. In cloth, price 7s. 6d., by post 7s. $10 d$.

IIBRARY MANUAI, IHE. A Guide to the Formation of a Library, and the Values of Rare and Standard Books. By J. H. Suater: Barrister-at-Law. Third Edition. Revised and Greatly Enlarged. In cloth gilt, price 7s. 6d., by post 7s. 10d.

MICI, FANCY : Their Varieties, Management, and Breeding. Re-issue, with Criticisms and Notes by Dr. CARTER BLAKE. Mlastrated. In paper, price $6 d$., by post $7 d$. 
MODEL YACHTS AND BOATS: Their Designing, Making, and Sailing. Illustrated with 118 Designs and Working Diagrams. A splendid book for boys and others interested in making and rigging toy boats for sailing. It is the best book on the subject now published. By J. DU V. Grosvenor. In leatherette, price 5s., by post $5 s .3 d$.

MONKFYS, PFT, and How to Manage Them. Illustrated. By ARTHUR Patterson. In cloth gilt, price 2s. $6 d$., by post $2 s .9 d$.

MUSHROOM CUITURE FOR AMATFURS. With Full Directions for Successful Growth in Houses, Sheds, Cellars, and Pots, on Shelves, and Out of Doors. Illustrated. By W. J. MAY. In paper, price $1 s$, by post 1 s. $2 d$.

NATURAI HISTORY SKETCHES among the Carnivora-Wild and Domesticated; with Observations on their Habits and Mental Faculties. By ARTHUR Nicols, F.G.S., F.R.G.S. Illustrated. In cloth gilt, price 58 ., by post $5 s$. $4 d$.

NEEDLEWORK, DICTIONARY OF. An Encyclopædia of Artistic, Plain, and Fancy Needlework; Plain, practical, complete, and magnificently Ilustrated. By S. F. A. CAULFEILd and B. C. SAWARd. Accepted by H.M. the Queen, H.R.H. the Princess of Wales, H.R.H. the Duchess of Edinburgh, H.R.H. the Duchess of Connanght, and H.R.H. the Duchess of Albany. Dedicated by special permission to H.R.H. Princess Louise, Marchioness of Lorne. In demy 4to, 528pp., 829 Ilustrations, extra cloth gilt, plain edges, cushioned bevelled boards, price 21s., by post 22s.; with COLOURED PLATES, elegant satin brocade cloth binding, and coloured edges, 31s. 6d., by post 32s. 6 d.

ORCHIDS : Their Culture and Management, with Descriptions of all the Kinds in General Cultivation. Illustrated by Coloured Plates and Engravings. By W. WATson, Assistant-Curator, Royal Botanic Gardens, Kew ; Assisted by W. BeAN, Foreman, Royal Gardens, Kew. Second Edition, Revised and with Extra Plates. In cloth gilt and gilt edges, price $£ 11$ s., by post $£ 12 s$.

PAINTING, DECORATIVE. A practical Handbook on Painting and Etching upon Textiles, Pottery, Porcelain, Paper, Vellum, Leather, Glass, Wood, Stone, Metals, and Plaster, for the Decoration of our Homes. By B. C. SAWARD. In cloth, price 5s., by post 5s. $4 d$.

PARCEI POST DISPATCH BOOK (registered). An invaluable book for all who send parcels by post. Provides Address Labels, Certificate of Posting, and Record of Parcels Dispatched. By the use of this book parcels are insured against loss or damage to the extent of $£ 2$. Authorized by the Post Office. Price 1s., by post 1s. 2d., for 100 parcels; larger sizes if required.

PARROT, THE GREY, and How to Treat it. By W. T. GREene, M.D., M.A., F.Z.S., \&c. Price 1 s., by post $1 s .2 d$.

PARROTS, THE SPEAKING. The Art of Keeping and Breeding the principal Talking Parrots in Confinement. By DR. KarL Russ. Illustrated with COLOURED PLATES and Engravings. In cloth gilt, price $5 s$. by post $5 s .4 d$.

PATIENCE. GAMrs OF, for one or more Players. A very clearlywritten and well-illustrated Book of Instructions on How to play 106 different Games of Patience. By Miss Whitmore Jones. Illustrated. Series I., thirty-nine games, $1 s$. , by post $1 s$. $2 d$.; Series II., thirty-four games, $1 s .$, by post $1 s .2 d$. ; Series III., thirty-three games, $1 s .$, by post 1s. 2d. The three bound together in cloth, price 3s. 6d., by post 3s. 10d. (A copy has been graciously accepted by H.M. the Queen). 
PEN PICTURES AND HOW TO DRAW THEM. A Practical

Handbook on the various Methods of Illustrating in Black and White for "Process" Engraving, with numerous Design», Diagrams, and Sketches. By ErIC Meade. In cloth gilt, price 2s. 6d., by post 2s. $9 d$.

PERSPECTIVE, THE ESSENTIAIS OF. With numerous Illustrations drawn by the Author. By L. W. MILLER, Principal of the School of Industrial Art of the Pennsylvania Museum, Philadelphia. This book is such a manual as has long been desired for the guidance of art students and for self-instruction. The instructions are clearly set forth, and the principles are vividly enforced by a large number of attractive drawings. Price $6 s .6 d$., by post $6 s .10 d$.

PHEASANT-KEEPING FOR AMATEURS. A Practical Handbook on the Breeding, Rearing, and General Management of Fancy Pheasants in Confinement. By GEO. HorNe. Illustrated with Diagrams of the necessary Pens, Aviaries, \&c., and a COLOURED FRONTISPIECE and many full-page Engravings of the chief Varieties of Pheasants, drawn from life by A. F. LYDoN. In cloth gilt, price 3s. $6 d$., by post $3 s .9 d$.

PHOTOGRAPHY (MODERN) FOR AMATEURS. By J. EATON FEARN. In paper, price 1 s., by post $1 s .2 d$.

PICTURE-TRAME MAKING FOR AMATEURS. Being Practical Instructions in the Making of various kinds of Frames for Paintings, Drawings, Photographs, and Engravings. Illustrated. By the REv. J. LUKIN. Cheap Edition, in paper, price 18., by post 1s. $2 d$.

PIG, BOOK OF THE. The Selection, Breeding, Feeding, and Management of the Pig; the Treatment of its Diseases; the Curing and Preserving of Hams, Bacon, and other Pork Foods; and other information appertaining to Pork Farming. By Professor James Long. Fully Illustrated with Portraits of Prize Pigs, Plans of Model Piggeries, \&c. In cloth gilt, price 108. 6d., by post 11s. 1 d.

PIG-KFEPING, PRACTICAI: A Manual for Amateurs, based on Personal Experience in Breeding, Feeding, and Fattening; also in Buying and Selling Pigs at Market Prices. By R. D. Garratr. In paper, price 1s., by post 1 s. 2 d.

PIGEONS, FANCY. Containing Full Directions for the Breeding and Management of Fancy Pigeons, and Descriptions of every known Variety, together with all other information of interest or use to Pigeon Fanciers. Third Edition, bringing the subject down to the present time. 18 COLOURED PLATES, and 22 other full-page Illustrations. By J. C. LYELL. In cloth gilt, price 10s. 6d., by post 10s. $10 d$.

PIGEON-KEEPING FOR AMATEURS. A complete Guide to the Amateur Breeder of Domestic and Fancy Pigeons. By J. C. LYELL. Illustrated. In cloth, price 2s. 6d., by post $2 s .9 d$.

POKER BOOK, THE. How to Play Poker with Successs. By R. GUERNDALE. In paper, price $1 s$., by post $1 s .2 d$.

POIISHES AND STAINS FOR WOODS : A Complete Guide to Polishing Woodwork, with Directions for Staining, and Full Information for making the Stains, Polishes, \&c., in the simplest and most satisfactory manner. By David Denning. In paper, price 1s., by post 18. $2 d$.

POOI, GAMES OF. Describing Various English and American Pool Games, and giving the Rules in full. Illustrated. In paper, price 1s., by post 1s. $2 d$. 
POUITRY-KEEPING, POPUIAR. A Practical and Complete Guide to Breeding and Keeping Poultry for Eggs or for the Table. By F. A. Mackenzie. Illustrated. In paper, price 1 s., by post $1 s .2 d$.

POULTRY AND PIGEON DISFASES: Their Canses, Symptoms, and Treatment. A Practical Manual for all Fanciers. By QUINTIN CRAIG and JAmes Lrell. In paper, price 1 s., by post $18.2 d$.

POUITRY FOR PRIZIS AND PROFIT. Contains: Breeding Poultry for Prizes, Exhibition Poultry and Management of the Poultry Yard. Handsomely Illustrated. Second Edition. By ProF. JAMES LONG. In cloth gilt, price $2 s$. 6 d., by post $2 s .9 d$.

PYROGRAPHY OR POKER WORK. By MRS. MaUd MAUDE. With Fifty-two Original Illustrations and Designs by Wm. Frememan. In paper, price 1s. 6d., by post 1s. 8d.; cloth, 2s.6d., by post $2 s .9 d$.

RABBIT, BOOK OF THE. A Complete Work on Breeding and Rearing all Varieties of Fancy Rabbits, giving their History, Variations, Uses, Points, Selection, Mating, Management, \&c., \&c. SECOND EDITION. Edited by KeMPSTer W. KNIGHT. Illustrated with Coloured and other Plates. In cloth gilt, price 10s. 6d., by post 11 s.

RABBITS, DISEASES OF: Their Canses, Symptoms, and Cure. With a Chapter on The Diseasms of Cavies. Reprinted from "The Book of the Rabbit" and "The Guinea Pig for Food, Fur, and Fancy." In paper, price 1s., by post $1 s .2 d$.

RABBIT-FARMING, PROFITABIE. A Practical Manual, show. ing how Hutch Rabbit-farming in the Open can be made to Pay Well. By MaJor G. F. Morant. In paper, price 18. , by post $1 s .2 d$.

RABBITS FOR PRIZES AND PROFIT. Containing Full Directions for the Proper Management of Fancy Rabbits in Health and Disease, for Pets or the Market, and Descriptions of every known Variety, with Instructions for Breeding Good Specimens. Illustrated. By Charles Rayson. In cloth gilt, price $2 s .6 d$., by post $2 s .9 d$. Also in Sections, as follows:-

General Management of Rabbits. Including Hutches, Breeding, Feeding, Diseases and their Treatment. Rabbit Courts, \&c. Fully Illustrated. In paper, price 1s., by post $1 s .2 d$.

Exhibition Rabbits. Being descriptions of all Varieties of Fancy Rabbits, their Points of Excellence, and how to obtain them. Illustrated. In paper, price 1s., by post 1 s. $2 d$.

REPOUSSE WORK FOR AMATEURS: Being the Art of Ornamenting Thin Metal with Raised Figures. By L. L. HASLOPE. Illustrated. In cloth gilt, price $2 s .6 d$., by post $2 s .9 d$.

ROSES FOR AMATEURS. A Practical Guide to the Selection and Cultivation of the best Roses, either for Exhibition or mere Pleasure, by that large section of the Gardening World, the Amateur Lover of Roses. Illustrated. By the Rev. J. Honywood D Ombrarn, Hon. Sec. of the National Rose Society. In paper, price 1s., by post 1 s. $2 d$.

SAIIING GUIDE TO THE SOIENT AND POOLE HARBOUR, with Practical Hints as to Living and Cooking on, and Working a Small Yacht. By Lieut.-Coloner T. G. Cuthell. Illustrated with Coloured Charts. In cloth, price $2 s .6 d$., by post $2 s .9 d$.

SAIIING TOURS. The Yachtman's Guide to the Cruising Waters of the English and Adjacent Coasts. By Frank CowPER, B.A. 
Vol. I., the Coasts of Essex and Suffolk, containing Descriptions of every Creek from the Thames to Aldborough. Numerous Charts and Illustrations. In cloth, price 5s., by post 5s. $3 d$.

Vol. II. The South Coast, from the Thames to the Scilly Islands. with twenty-five Charts printed in Colours. In cloth, price 7s. 6d., by post 7s. $10 d$.

Vol. III. The Coast of Brittany, including the Departments of Finisterre, the Morbihan, and the Lower Loire. Containivg Descriptions of every Creek, Harbour, and Roadstead from L'Abervrach to St. Nazaire, with an Account of the Loire and its celebrated Castl+s. With twelve Charts, printed in Colours. In crown $8 v 0$, cloth gilt, prire 7s. 6d., by post 7s. 10d. With larger Charts, mounted on linen $10 s .6 d$., by post $11 s$. Charts separately $3 s .$, by post $3 s .3 d$.

ST. BERNARD, THE. Its History, Points, Breeding, and Rearing. By HUGH Dalziel. Illustrated with Coloured Frontispiece and Plates. In cloth, price $2 s .6 d$., by post $2 s .9 d$.

ST. BERNARD STUD BOOK. Edited by Hugh Dalziel. Price 3s. 6d. each., by post 3s. 9d. each.

Vol. I. Pedigrees of 1278 of the best known Dogs, traced to their most remote known ancestors, Show Record, \&c.

Vol. II. Pedigrees of 564 Dogs, Show Record, \&c.

SEA-FISHING FOR AMATEURS. Practical Instructions to Visitors at Seaside Places for Catching Sea-Fish from Pier-heads, Shore, or Boats, principally by means of Hand Lines, with a very useful List of Fishing Stations, the Fish to be caught there, and the Best Seasons. By Frank Hudson. Illustrated. In paper, price 1s., by post $18,2 d$. SEA-FISHING ON THE ENGIISH COAST. A Manual of Practical Instruction on the Art of Making and Using Sea-Tackle. With a full account of the methods in vogue during each month of the year, and a Detailed Guide for Sea-Fishermen to all the most Popular Watering Places on the English Coast. By FredericK G. Aflalo. Illustrated. In cloth, price $2 s .6 d$., by post $2 s$. $9 d$.

SFASIDE WATERING PIACES. A Description of nearly 200 Holiday Resorts on the Coasts of England and Wales, the Channel Islands, and the Isle of Man, including the gayest and most quiet places, giving full particulars of them and their attractions, and all other information likely to assist persons in selecting places in which to spend their Holidays according to their individual tastes; with BUSINESS DIREC. TORY of Tradesmen, arranged in order of the Towns. Illustrated. In cloth, price 2s. 6d., by post 2s. 10d. [7th Edition in the Press.

SHAVE, AN EASY: The Mysteries, Secrets, and Whole Art of, laid bare for $1 s$., by post $1 s .2 d$. Edited by Joseph Morton.

SHFET METAL, WORKING IN : Being Practical Instructions for Making and Mending Small Articles in Tin, Copper, Iron, Zinc, and Brass. Illustrated. Third Edition. By the Rev. J. LukIN, B.A. In paper, price 1s., by post 1s. 1 d.

SHORTHAND, ON GURNIY'S SYSTEM (IMPROVED), LESSONS IN : Being Instructions in the Art of Shorthand Writing as used in the Service of the two Houses of Parliament. By R. E. Milier. In paper, price $1 s$. by post $1 s .2 d$.

SHORTHAND, EXERCISES IN, for Daily Half Hours, on a Nowlydevised and Simple Method, free from the Labour of Learning. Illustrated step by step. Being Part II. of "Lessons in Shorthand on Gurney's System (Improved)." By R. E. Mrller. In paper, price $9 d$., by post $10 d$. 
SHORTHAND SYSTEMS; WHICH IS THE BEST? Being a Discussion, by various Experts, on the Merits and Demerits of all the principal Systems, with Mlustrative Examples. Edited by Tномаs ANDERSON. In paper, price 1s., by post 1s. $2 d$.

SICK NURSING AT HOME: Being Plain Directions and Hints for the Proper Nursing of Sick Persons, and the Home Treatment of Diseases and Accidents in cases of Sudden Emergencies. By S. F. A. CAULFEILD. In paper, price 1s., by post 1s. 2d.; cloth, 1s. 6d., by post 1.. $8 d$.

SKATING CARDS : An Easy Method of Learning Figure Skating, as the Cards can be used on the Ice. In cloth case, $2 s .6 d$., by post $2 s .9 d$.: leather, 3s. 6d., by post 3s. 9d. A cheap form is issued printed on paper and made up as a small book, 1 s., by post 1 s. $1 d$.

SIEIGHT OF HAND. A Practical Manual of Legerdemain for Amateurs and Others. New Edition, Revised and Enlarged. Profusely Illustrated. By E. SACHs. In cloth gilt, price 6s. $6 d$., by post $6 s .10 d$.

SNAKES, MARSUPIAIS, AND BIRDS. A Charming Book of Anecdotes, Adventures, and Zoological Notes relating to Snakes, Marsupials, and Birds. A capital Book for Boys, and all interested in Popular Natural History. By ArThur Nicols, F.G.S., F.R.G.S., \&c. Mllustrated. In cloth gilt, price 5s., by post 5s. $4 d$.

TAXIDFRMY, RRACTICAL. A Manual of Instruction to the Amateur in Collecting, Preserving, and Setting-up Natural History Specimens of all kinds. Fully Illustrated with Examples and Working Diagrams. By MoNTAGU Browne, F.Z.S., Curator of Leicester Museum. Second Edition. In cloth gilt, price 7s. 6d., by post 7s. 10d.

THAMES GUIDE BOOK. From Lechlade to Richmond. For Boating Men, Anglers, Picnic Parties, and all Pleasure-seekers on the River. Arranged on an entirely new plan. Second Edition, profusely illustrated. In paper, price 1 s., by post 1 s. $3 d$.; cloth, 1 s. $6 d$., by post 1 s. $9 d$.

TOMATO AND FRUIT GROWING as an Industry for Women. Lectures given at the Forestry Exhibition, Earl's Court, during July and August, 1893. By Grace Harriman, Practical Fruit Grower and County Council Lecturer. In paper, price 1s., by post 1s. $1 d$.

TOMATO CULTURE FOR AMATEURS. A Practical and very Complete Manual on the Subject. By B. C. Ravenscroft. Illustrated. In paper, price 1 s., by post 1 s. $3 d$.

TRAPPING, PRACTICAI: Being some Papers on Traps and Trapping for Vermin, with a Chapter on General Bird Trapping and Snaring. By W. CARNegIe. In paper, price 1s., by post $1 s .2 d$.

TURNING FOR AMATFURS : Being Descriptions of the Lathe and its Attachments and Tools, with Minute Instructions for their Effective Use on Wood, Metal, Ivory, and other Materials. Second Edition, Revised and Enlarged. By JAMEs Lukin, B.A. Illustrated with 144 Engravings. In cloth gilt, price $2 s .6 d$., by post $2 s .9 d$.

TURNING IATHES. A Manual for Technical Schools and Apprentices. A guide to Turning, Screw-cutting, Metal-spinning, \&c. Edited by JAMEs LukIN, B.A. Third Edition. With 194 Illustrations. In cloth gilt, price $3 s$., by post $3 s .3 d$.

VAMPING. A Practical Guide to the Accompaniment of Songs by the Unskilled Musician. With Examples. In paper, price $9 d$., by post $11 d$. 


\section{SIXPENNY PRACTICAL GUIDE BOOKS.}

Dean's Champion Hand Boolis.

OIROUIN 8VO. IIIUSTIRATID.

Series 64.

1-Football, Lawn Tennis, Golf, and other Sports and Games; Rounders, La Crosse, Hurling, Trap-Ball, Skittles, Bowls, Racquets, \&c. By Capt. WilsoN.

2-Billiards, with its Rules. With Diagrams, New and Revised Edition.

4-Cricket, and How to Play. Edited by ROBERT ABEL.

5-Draughts, and How to Play. By W. PATTERSON.

6-Fishing (Handbook of the Art of). For River and Sea. By G. C. Davies.

8-Indian Clubs, Dumb-bells, and Sword Exerclses. With Diagrams. By the late Professor HARRISON.

9-Magic Lantern. By J. ALLEN.
10-Stuffing and Preserving Animals, Birds, Fishes, Reptiles, \&c. By JAS. Gardner.

11-Rowing, Sculling, Canoeing, and Yachting. By a Member of the Thames Yacht Club.

13-Art of Attack and Defence; Fencing, Sword and Bayonet Exercise, Singlestick, Boxing. By Major ELLIOTr.

14-The Handbook of Boxing. With the Marquis of Queensberry and Amateur Boxing Association Rules for the Regulation of Contests with the Gloves. By JohN C. EARL, Ex-Champion of Heavy Weights, Ireland.

16-The Art of Swimming. By HARRY GURR, ex-champion Swimmer of England.

Sixth Edition.

By GORDON STABLES, M.D., R.N.

Handsomely Bound, Cloth Gilt, 6/6, Post Free 7/-, and Richly Illustrated.
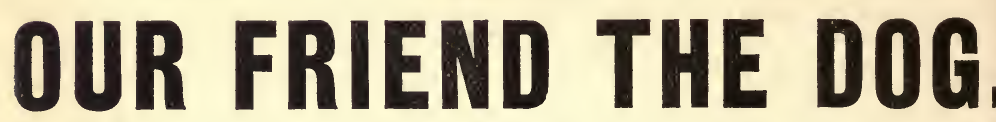

\section{CONTAINING :}

(a) All that is known about every breed of Dog in the World, and the show-points, properties, uses, and peculiarities of each.

(b) A complete digest of the diseases from which Dogs are apt to suffer, and plain advice for the treatment.

(c) Important information on the Rearing of the Puppy and the treatment of the Dam.

(d) The approved methods of Kenneling, Grooming, Feeding, and Preparing for bringing Dogs to the Show Bençes.

(e) Valuable hints about Buying and Selling.

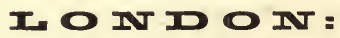

DEAN \& SON, Ltd, I60a, Fleet Street, 

RETURN TO the circulation desk of any University of California Library or to the

NORTHERN REGIONAL LIBRARY FACILITY

Bldg. 400, Richmond Field Station

University of California

Richmond, CA 94804-4698

\section{ALL BOOKS MAY BE RECALLED AFTER 7 DAYS}

- 2-month loans may be renewed by calling (510) 642-6753

- 1-year loans may be recharged by bringing books to NRLF

- Renewals and recharges may be made 4 days prior to due date.

DUE AS STAMPED BELOW

\section{JUN 301997}




\section{U.C. BERKELEY LIBRARIES}

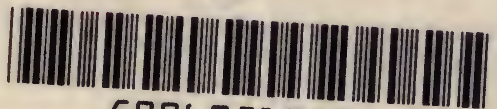
C006051350 
